\title{
SURFACE ELECTROCHEMICAL CONTROL FOR FINE COAL AND PYRITE SEPARATION
}

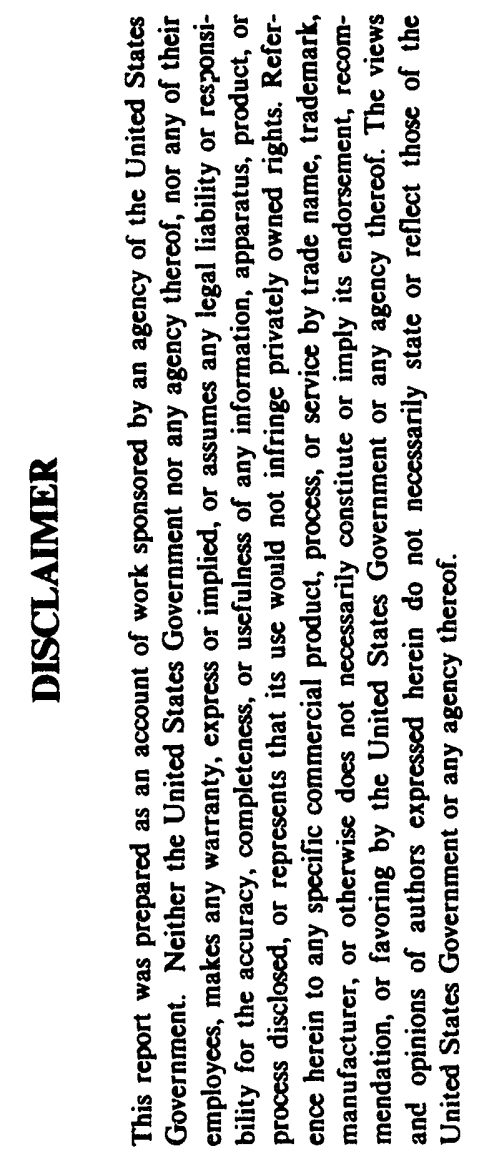

DOE Project No. DE-AC22-89PC89758

$\mathrm{DOE} / \mathrm{PC} / 89758--\mathrm{T} 15$

Final Report

January 20, 1993

DE93 008539

\author{
Prepared for \\ U.S. Department of Energy \\ Pittsburgh Energy Technology Center \\ Pittsburgh, Pennsylvania
}

by

Milton E. Wadsworth, Principal Investigator

David M. Bodily and Weibai $\mathrm{Hu}$, Co-principal Investigator Wanxiong Chen, Qinping Huang, Jun Liang, Andrew M. Riley

Jun Li, Jyi-Perng Wann, Tingke Zhong, and Ximeng Zhu

College of Mines and Earth Sciences

University of Utah

Salt Lake City, Utah

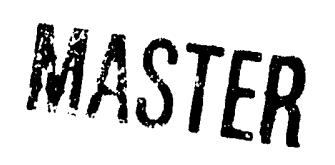

OISTHEUTION OF THIS DOCUAENT IS UNLIMITED 


\section{CONTENTS}

LIST OF FIGURES $\ldots \ldots \ldots \ldots \ldots \ldots \ldots \ldots \ldots \ldots \ldots \ldots$

LIST OF TABLES $\ldots \ldots \ldots \ldots \ldots \ldots \ldots \ldots \ldots \ldots \ldots \ldots \ldots \ldots \ldots \ldots$

EXECUTIVE SUMMARY $\ldots \ldots \ldots \ldots \ldots \ldots \ldots \ldots \ldots \ldots \ldots \ldots \ldots \ldots \ldots$ xiii

I. CHARACTERIZATION $\ldots \ldots \ldots \ldots \ldots \ldots \ldots \ldots \ldots \ldots$

INTRODUCTION $\ldots \ldots \ldots \ldots \ldots \ldots \ldots \ldots \ldots \ldots \ldots \ldots \ldots$

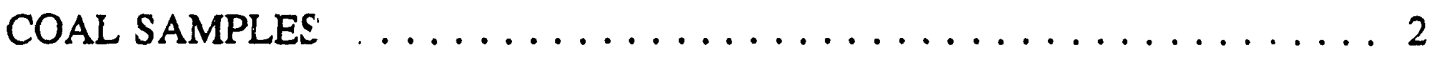

SCANNING ELECTRON MICROSCOPY $\ldots \ldots \ldots \ldots \ldots \ldots \ldots \ldots 4$

ELECTRON MICROPROBE ANALYSIS $\ldots \ldots \ldots \ldots \ldots \ldots \ldots \ldots 10$

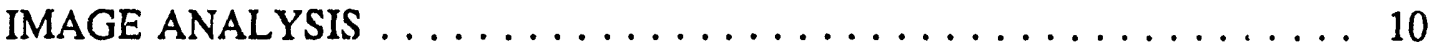

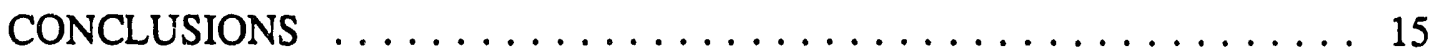

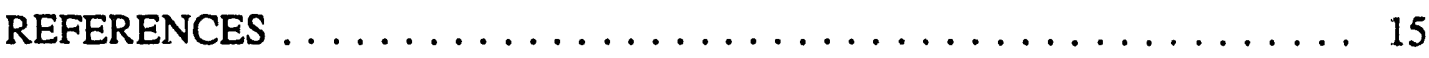

II. ELECTROCHEMISTRY $\ldots \ldots \ldots \ldots \ldots \ldots \ldots \ldots \ldots \ldots \ldots$

INTRODUCTION $\ldots \ldots \ldots \ldots \ldots \ldots \ldots \ldots \ldots \ldots \ldots \ldots \ldots \ldots$

EXPERIMENTAL ....................... 20

Electrode and Solution Preparation $\ldots \ldots \ldots \ldots \ldots \ldots \ldots 20$

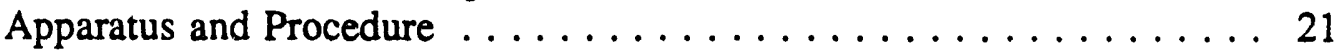

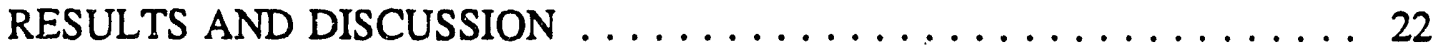

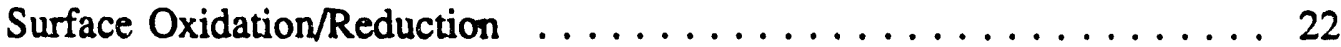

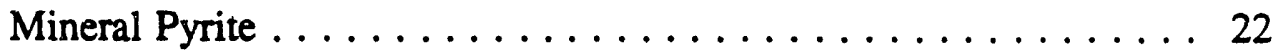

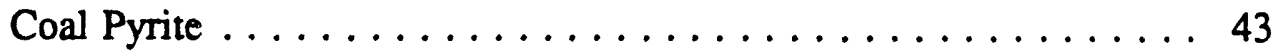

Comparison of Mineral and Coal Pyrites ........... 58

Conditions Affecting Peak 1a ................ 58

Transpassive Oxidation ....................... 69

Electrode Rotation Speed . . . . . . . . . . . . . . 78

Anodic Reversal Potential . . . . . . . . . . . . . . . . 78

Electrode Pre-Condition Time ................... 93

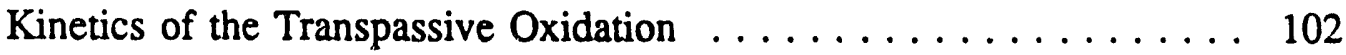

Effect of Applied Potential . . . . . . . . . . . . . . . . 105

Effect of Electrode Rotation Speed . . . . . . . . . . . . 112

Effect of Electrolyte pH . . . . . . . . . . . . . . . 112

Effect of Temperature .................... 119

AC Impedance Measurement $\ldots \ldots \ldots \ldots \ldots \ldots \ldots \ldots \ldots . \ldots \ldots$

SUMMARY AND CONCLUSIONS $\ldots \ldots \ldots \ldots \ldots \ldots \ldots \ldots \ldots \ldots$

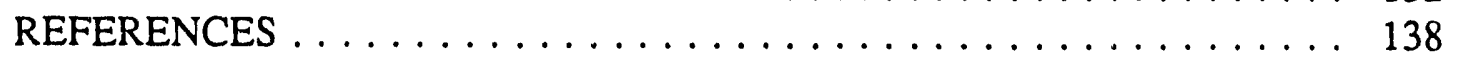

III. IN-SITU SPECTROSCOPIC CHARACTERIZATION

OF ELECTROCHEMICALLY MODIFIED PYRITE $\ldots \ldots \ldots \ldots \ldots 141$ 
INTRODUCTION $\ldots \ldots \ldots \ldots \ldots \ldots \ldots \ldots \ldots \ldots \ldots \ldots \ldots \ldots \ldots \ldots$

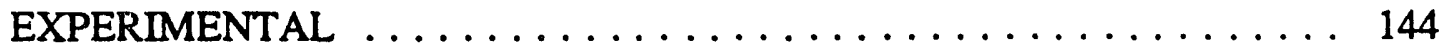

Outline of the Experimental Work . . . . . . . . . . . . . . 144

Equipment and Procedures for Raman Experiments .......... 145

Experiments to Obtain Reference Spectra . . . . . . . . . . . . . 148

Equipment and Procedures for Phctocurrent Experiments . . . . . . . 149

Particle Bed Experiments . . . . . . . . . . . . . . . . . . . 149

RESULTS AND DISCUSSION $\ldots \ldots \ldots \ldots \ldots \ldots \ldots \ldots \ldots \ldots \ldots$

Reference Spectra ....................... 151

Raman Spectra of Pyrite $\ldots \ldots \ldots \ldots \ldots \ldots \ldots \ldots \ldots \ldots 151$

Raman Spectra of Elemental Sulfur ................ 151

Raman Spectra of Electrodeposited Sulfur ............ 155

Raman Spectra of Precipitated Iron Hydroxides . . . . . . . . 164

Effect of Solution pH on Oxidation of Pyrite . . . . . . . . . 164

Acid Conditions ........................... 164

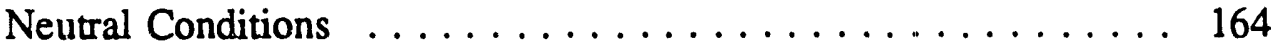

Weak Alkaline Conditions . . . . . . . . . . . . . . . 172

Strong Alkaline Conditions . . . . . . . . . . . . . . 172

Conditions of Potential and $\mathrm{pH}$ for Sulfur Formation . . . . . . . 193

Intermediates of Pyrite Oxidation: Polysulfides . . . . . . . . . . 193

Detection of Oxy-Sulfur Compounds . . . . . . . . . . . . . . . . . 199

Optimum Potential for Sulfur Formation . . . . . . . . . . . . 202

Rate of Sulfur Formation and Sensitivity Analysis . . . . . . . 204

Cathodic Reduction of Electrochemically Formed Sulfur . . . . . . . 204

Detection of Iron Hydroxides . . . . . . . . . . . . . . . . 206

Raman Spectra of Coal Pyrite . . . . . . . . . . . . . . . . . . 209

Electrochemical Oxidation of Galena . . . . . . . . . . . . . . 209

Raman Spectra of Other Mineral Sulfides ............ 220

Particle Bed Experiments . . . . . . . . . . . . . . . 232

Photocurrent Experiments . . . . . . . . . . . . . . 232

Pyrite .......................... 232

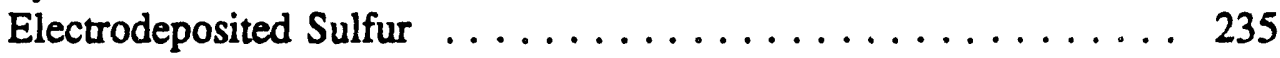

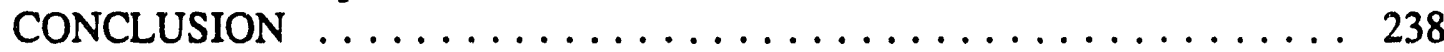

ACKNOWLEDGEMENT $\ldots \ldots \ldots \ldots \ldots \ldots \ldots \ldots \ldots \ldots \ldots \ldots \ldots$

REFERENCES . . . . . . . . . . . . . . . . . . . . 239

IV. FLOATABILITY OF COAL AND COAL PYRITE $\ldots \ldots \ldots \ldots \ldots . \ldots 243$

INTRODUCTION $\ldots \ldots \ldots \ldots \ldots \ldots \ldots \ldots \ldots \ldots \ldots \ldots \ldots \ldots \ldots$

EXPERIMENTAL ........................ 244

Sample Characteristics ..................... 244

Hallimond Tube Floatability Tests . . . . . . . . . . . . 246

Sample Preparation ...................... 246

Equipment and Experimental Procedures . . . . . . . . 246 
Floatability Measurements Using a Laboratory Flotation Cell . . . . . 246

Sample Preparation ...................... 246

Equipment and Experimental Procedures ............ 246

Electrochemical Hallimond Mini-flotation Cell Test . . . . . . . . 247

Sample Preparation ...................... 247

Solutions ......................... 248

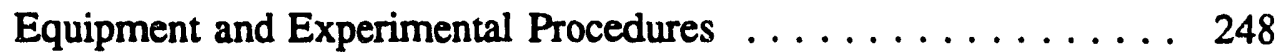

RESULTS AND DISCUSSION .................. 250

Floatability Measurements Using the Hallimond Tube . . . . . 250

Flotation Using Amyl Xanthate as a Collector .......... 250

Flotation Using Dodecane as a Collector ............ 255

Flotation Using Butyl Alcohol as a Collector . . . . . . . 255

Pretreatment of the Pyrite Surface . . . . . . . . . . . 255

$\mathrm{Cu}_{2} \mathrm{SO}_{4}$ and $\mathrm{Na}_{2} \mathrm{~S}$ as Modifiers ................. 262

$\mathrm{CO}_{2}$ as a Modifier ..................... 270

EDTA as a Modifiers ................... 270

Flotation Using Lime as a Modifier . . . . . . . . . . . . . . 270

Pyrite Rejection From Raw Coal . . . . . . . . . . . . . 276

Floatability Measured in a Laboratory Flotation Cell . . . . . . . . 276

Natural Floatability and Selectivity . . . . . . . . . . 276

Floatability with Frother Only ................. 282

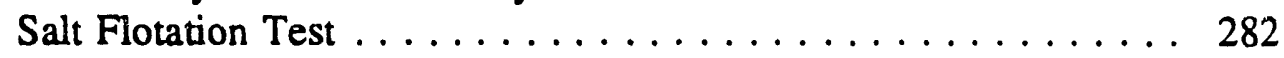

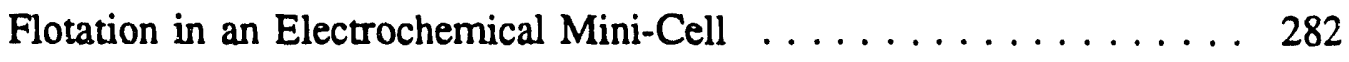

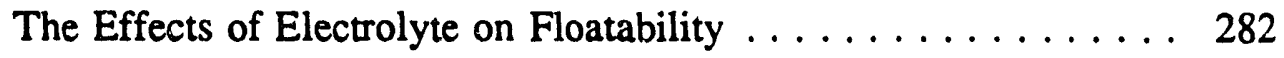

Electrochemical Pretreatment of Coal Pyrite . . . . . . . . . . 296

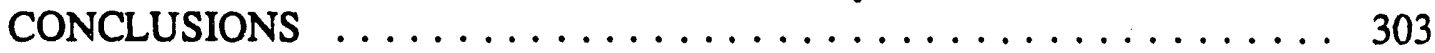

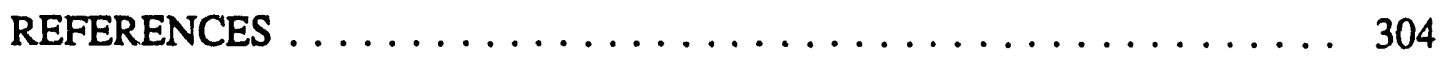

V. FLOTATION KINETICS $\ldots \ldots \ldots \ldots \ldots \ldots \ldots \ldots \ldots \ldots \ldots$

INTRODUCTION ........................ 305

MATERIALS AND EXPERIMENTAL PROCEDURES . . . . . . . 307

EXPERIMENTAL RESULTS AND DISCUSSION $\ldots \ldots \ldots \ldots \ldots \ldots 308$

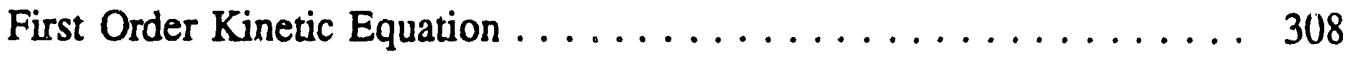

Proportional Law . .................... 308

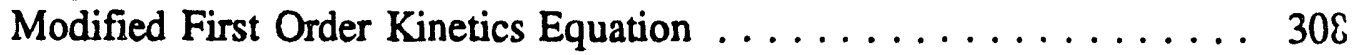

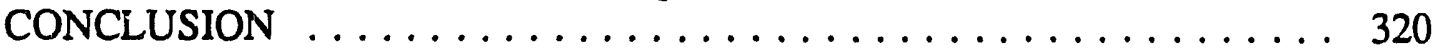

REFERENCES ........................ 320

- iii - 


\section{LIST OF FIGURES}

Figure 1.1. Scanning electron micrographs of Ward's mineral pyrite

a. $1440 \mathrm{X}$; b. $2520 \mathrm{X}$; c. $14400 \mathrm{X} \ldots \ldots \ldots \ldots \ldots \ldots \ldots \ldots$

Figure 1.2. Scanning electron micrographs of Colorado mineral pyrite

a. $1440 \mathrm{X}$; b. $2520 \mathrm{X} ;$ c. $14400 \mathrm{X} \ldots \ldots \ldots \ldots \ldots \ldots \ldots \ldots 6$

Figure 1.3. Scanning electron micrographs of Upper Freeport coal pyrite

a. $1440 \mathrm{X}$; b. $2520 \mathrm{X}$; c. $14400 \mathrm{X} \ldots \ldots \ldots \ldots \ldots \ldots \ldots$

Figure 1.4. Scanning electron micrographs of Pittsburgh No. 8 coal pyrite

a. $1440 \mathrm{X} ;$ b. $2520 \mathrm{X} ;$ c. $14400 \mathrm{X} \ldots \ldots \ldots \ldots \ldots \ldots \ldots \ldots$

Figure 1.5. Scanning electron micrographs of Illinois No. 6 coal pyrite

a. $1440 \mathrm{X}$; b. $2520 \mathrm{X}$; c. $14400 \mathrm{X} \ldots \ldots \ldots \ldots \ldots \ldots . \ldots 9$

Figure 1.6. Images of Upper Freeport coal $\ldots \ldots \ldots \ldots \ldots \ldots \ldots \ldots \ldots$

Figure 1.7. Images of Pittsburgh No. 8 coal $\ldots \ldots \ldots \ldots \ldots \ldots$

Figure 1.8. Images of Illinois No. 6 coal $\ldots \ldots \ldots \ldots \ldots \ldots \ldots \ldots$

Figure 2.1. Experimental setup $\ldots \ldots \ldots \ldots \ldots \ldots \ldots \ldots \ldots \ldots$

Figure 2.2. Mineral pyrite in quiescent solutions at $\mathrm{pH} 9.2$, scan from $0.0 \mathrm{~V}$ towards anodic, scan rate $50 \mathrm{mV} / \mathrm{s} \ldots \ldots \ldots 24$

Figure 2.3. Mineral pyrite in quiescent solutions at $\mathrm{pH} 9.2$, scan from $0.0 \mathrm{~V}$ towards cathodic, scan rate $50 \mathrm{mV} / \mathrm{s} \ldots \ldots \ldots 25$

Figure 2.4. Mineral pyrite in quiescent solutions at $\mathrm{pH} 9.2$, scan from $-0.5 \mathrm{~V}$ towards anodic, scan rate $50 \mathrm{mV} / \mathrm{s} \ldots \ldots \ldots 26$

Figure 2.5. Mineral pyrite in quiescent solutions at $\mathrm{pH} 9.2$, scan from $-0.5 \mathrm{~V}$ towards cathodic, scan rate $50 \mathrm{mV} / \mathrm{s} \ldots \ldots \ldots .27$

Figure 2.6. Mineral pyrite in stirred solution at $\mathrm{pH} 9.2$, scan rate $100 \mathrm{mV} / \mathrm{s}$

Figure 2.7. Mineral pyrite in quiescent solutions at $\mathrm{pH} 9.2$ for various scan rates $(\mathrm{mV} / \mathrm{s}) \ldots \ldots \ldots \ldots \ldots \ldots \ldots \ldots \ldots \ldots$

Figure 2.8. Mineral pyrive in stirred solutions at $\mathrm{pH} 9.2$ for various scan rates $(\mathrm{mV} / \mathrm{s}) \ldots \ldots \ldots \ldots \ldots \ldots \ldots \ldots \ldots$ 
Figure 2.9. Effect of solution stirring, mineral pyrite in solutions at $\mathrm{pH} 9.2$, scan rate $100 \mathrm{mV} / \mathrm{s} \ldots \ldots \ldots \ldots \ldots \ldots 32$

Figure 2.10. Mineral pyrite in stirred solutions at $\mathrm{pH} 9.2$, anodic scan reversed at $0.8 \mathrm{~V}$, scan rate $100 \mathrm{mV} / \mathrm{s} \ldots \ldots \ldots . \ldots 34$

Figure 2.11. Effect of scan rate $(\mathrm{mV} / \mathrm{s})$ on peak 1 and peak 1a, mineral pyrite in stirred solutions at $\mathrm{pH} 9.2$, electrode pre-conditioned at $0.4 \mathrm{~V}$ for 1 minute $\ldots \ldots \ldots \ldots 35$

Figure 2.12. Effect of electrode pre-condition time on peak 1 and peak 1a, mineral pyrite in stirred solutions at $\mathrm{pH} 9.2$, scan rate $50 \mathrm{mV} / \mathrm{s} \ldots \ldots \ldots \ldots \ldots \ldots \ldots \ldots$

Figure 2.13. Mineral pyrite in quiescent solutions at $\mathrm{pH} 9.2$, scan reversed at various anodic limits, scan rate $100 \mathrm{mV} / \mathrm{s} \ldots \ldots .38$

Figure 2.14. Mineral pyrite in quiescent solutions at $\mathrm{pH} 9.2$ with or without $\mathrm{NaHS}$, scan rate $50 \mathrm{mV} / \mathrm{s}$

Figure 2.15. Effect of solution $\mathrm{pH}$, mineral pyrite in quiescent solutions, scan rate $50 \mathrm{mV} / \mathrm{s}$

Figure 2.16. Effect of solution $\mathrm{pH}$, mineral pyrite in quiescent solutions, scan rate $200 \mathrm{mV} / \mathrm{s}$

Figure 2.17. Effect of solution stirring, mineral pyrite in solutions at $\mathrm{pH} 2.6$, scan rate $400 \mathrm{mV} / \mathrm{s} \ldots \ldots \ldots \ldots \ldots \ldots 44$

Figure 2.18. Mineral pyrite (Colorado) in solutions at $\mathrm{pH} 9.2$, anodic scan reversed at $0.8 \mathrm{~V}$, scan rate $50 \mathrm{mV} / \mathrm{s}$

Figure 2.19. Mineral pyrite in $\mathrm{NaHCO}_{3} / \mathrm{Na}_{2} \mathrm{CO}_{3}$ solutions at $\mathrm{pH} 9.28$, anodic scan reversed at $0.8 \mathrm{~V}$, scan rate $50 \mathrm{mV} / \mathrm{s}$

Figure 2.20. Pittsburgh coal pyrite in quiescent solutions at $\mathrm{pH} 9.2$ for various scan rates $(\mathrm{mV} / \mathrm{s})$

Figure 2.21. Upper Freeport coal pyrite in quiescent solutions at $\mathrm{pH} 9.2$ for various scan rates $(\mathrm{mV} / \mathrm{s})$

Figure 2.22. Illinois coal pyrite in quiescent solutions at $\mathrm{pH} 9.2$ for various scan rates $(\mathrm{mV} / \mathrm{s})$ 
Figure 2.23. Pittsburgh coal pyrite in quiescent solutions at $\mathrm{pH} 9.2$, scan reversed at various anodic limits, scan rate $100 \mathrm{mV} / \mathrm{s} \ldots \ldots .51$

Figure 2.24. Upper Freeport coal pyrite in quiescent solutions at $\mathrm{pH}$ 9.2, scan reversed at various anodic limits, scan rate $100 \mathrm{mV} / \mathrm{s} \ldots \ldots .52$

Figure 2.25. Illinois coal pyrite in quiescent solutions at $\mathrm{pH} 9.2$, scan reversed at various anodic limits, scan rate $100 \mathrm{mV} / \mathrm{s} \ldots \ldots . .53$

Figure 2.26. Pittsburgh coal pyrite in quiescent solutions at pH 9.2, electrode pre-conditioned at $1.0 \mathrm{~V}$ for 1.5 minutes, scan rate $100 \mathrm{mV} / \mathrm{s} \ldots .54$

Figure 2.27. Effect of solution stirring, Pittsburgh coal pyrite in solutions at $\mathrm{pH} 9.2$, scan rate $50 \mathrm{mV} / \mathrm{s} \ldots \ldots \ldots \ldots \ldots \ldots 5$

Figure 2.28. Effect of solution stiring, Upper Freeport coal pyrite in solutions at $\mathrm{pH} 9.2$, scan rate $50 \mathrm{mV} / \mathrm{s} \ldots \ldots \ldots \ldots 6$

Figure 2.29. Effect of solution stirring, lllinois coal pyrite in solutions at $\mathrm{pH} 9.2$, scan rate $50 \mathrm{mV} / \mathrm{s} \ldots \ldots \ldots \ldots \ldots . \ldots 57$

Figure 2.30. Effect of solution pH, Pittsburgh coal pyrite in quiescent solutions, scan rate $50 \mathrm{mV} / \mathrm{s} \ldots \ldots \ldots \ldots \ldots \ldots 9$

Figure 2.31. Effect of solution $\mathrm{pH}$, Upper Freeport coal pyrite in quiescent solutions, scan rate $50 \mathrm{mV} / \mathrm{s} \ldots \ldots \ldots \ldots \ldots 60$

Figure 2.32. Effect of solution $\mathrm{pH}$, lllinois coal pyrite in quiescent solutions, scan rate $50 \mathrm{mV} / \mathrm{s} \ldots \ldots \ldots \ldots \ldots \ldots 61$

Figure 2.33. Comparison of mineral pyrite and Pittsburgh coal pyrite in quiescent solutions at $\mathrm{pH} 9.2$, scan rate $100 \mathrm{mV} / \mathrm{s} \ldots \ldots \ldots 62$

Figure 2.34. Comparison of Pittsburgh and Upper Freeport coal pyrites in quiescent solutions at $\mathrm{pH} 9.2$, scan rate $100 \mathrm{mV} / \mathrm{s} \ldots \ldots \ldots 63$

Figure 2.35. Comparison of Illinois and Pittsburgh coal pyrites in quiescent solutions at $\mathrm{pH} 9.2$, scan rate $100 \mathrm{mV} / \mathrm{s} \ldots \ldots \ldots .64$

Figure 2.36. Effect of solution stirring on peak 1a, mineral pyrite in solutions at $\mathrm{pH} 9.2$, scan initiated at $0.0 \mathrm{~V}$, scan rate $50 \mathrm{mV} / \mathrm{s} \ldots 65$

Figure 2.37. Mineral pyrite in solutions at $\mathrm{pH} 9.2$, electrode pre-conditioned at $0.4 \mathrm{~V}$ for 3 minutes, scan rate $50 \mathrm{mV} / \mathrm{s} \ldots \ldots \ldots \ldots \ldots 66$ 
Figure 2.38. Pittsburgh coal pyrite in solutions at $\mathrm{pH} 9.2$, electrode pre-conditioned at $0.4 \mathrm{~V}$ for 3 minutes, scan rate $50 \mathrm{mV} / \mathrm{s} \ldots \ldots 67$

Figure 2.39. Illinois coal pyrite in solutions at $\mathrm{pH} 9.2$, electrode pre-conditioned at $0.4 \mathrm{~V}$ for 3 minutes, scan rate $50 \mathrm{mV} / \mathrm{s} \ldots \ldots 68$

Figure 2.40. Effect of electrode pre-condition time at $0.4 \mathrm{~V}$, mineral pyrite in stirred solutions of $\mathrm{pH} 9.2$, scan rate $50 \mathrm{mV} / \mathrm{s} \ldots \ldots \ldots \ldots 70$

Figure 2.41. Effect of electrode pre-condition time at $0.4 \mathrm{~V}$, Pittsburgh coal pyrite in stirred solutions of $\mathrm{pH} 9.2$, scan rate $50 \mathrm{mV} / \mathrm{s} \ldots \ldots .71$

Figure 2.42. Effect of electrode pre-conditioning potential after 3 minutes, mineral pyrite in stirred solutions of $\mathrm{pH} 9.2$, scan rate $50 \mathrm{mV} / \mathrm{s} \quad \ldots 72$

Figure 2.43. Mineral pyrite in quiescent solutions at $\mathrm{pH} 9.2$, scan reversed at various cathodic limits, scan rate $100 \mathrm{mV} / \mathrm{s} \ldots \ldots \ldots \ldots .73$

Figure 2.44a. Mineral pyrite in solutions at $\mathrm{pH} 9.2$ for various electrode rotation speeds $(\mathrm{rpm})$, scan rate $50 \mathrm{mV} / \mathrm{s} \ldots \ldots \ldots \ldots \ldots . \ldots 79$

Figure 2.44b. Mineral pyrite in solutions at $\mathrm{pH} 9.2$ for various electrode rotation speeds $(\mathrm{rpm})$, scan rate $50 \mathrm{mV} / \mathrm{s} \ldots \ldots \ldots \ldots \ldots$

Figure 2.45a. Illinois coal pyrite in solutions at $\mathrm{pH} 9.2$ for various electrude rotation speeds $(\mathrm{rpm})$, scan rate $50 \mathrm{mV} / \mathrm{s} \ldots \ldots \ldots . .81$

Figure 2.45b. Illinois coal pyrite in solutions at $\mathrm{pH} 9.2$ for various electrode rotation speeds $(\mathrm{rpm})$, scan rate $50 \mathrm{mV} / \mathrm{s}$

Figure 2.46. Effect of electrode rotation speed on peak current for mineral pyrite $\ldots \ldots \ldots \ldots \ldots \ldots \ldots \ldots \ldots . \ldots 3$

Figure 2.47. Effect of electrode rotation speed on peak current for Illinois coal pyrite $\ldots \ldots \ldots \ldots \ldots \ldots \ldots \ldots \ldots . \ldots$

Figure 2.48a. Pittsburgh coal pyrite in solutions at $\mathrm{pH} 9.2$, for various electrode rotation speeds $(\mathrm{rpm})$, scan rate $50 \mathrm{mV} / \mathrm{s} \ldots \ldots \ldots 85$

Figure 2.48b. Pittsburgh coal pyrite in solutions at $\mathrm{pH} 9.2$, for various electrode rotation speeds $(\mathrm{rpm})$, scan rate $50 \mathrm{mV} / \mathrm{s} \ldots \ldots \ldots 86$

Figure 2.49. Effect of electrode rotation speed on peak current for Pittsburgh coal pyrite . . . . . . . . . . . . . . . 
Figure 2.50a. Mineral pyrite in solutions at $\mathrm{pH} 9.2$, scan reversed

at various anodic limits, scan rate $50 \mathrm{mV} / \mathrm{s}, \mathrm{rpm}=200$

Figure 2.50b. Mineral pyrite in solutions at $\mathrm{pH} 9.2$, scan reversed

at various anodic limits, scan rate $50 \mathrm{mV} / \mathrm{s}, \mathrm{rpm}=200 \ldots \ldots .90$

Figure 2.51. Effect of anodic reversal potential on charge of peak 1a for mineral pyrite, scan rate $50 \mathrm{mV} / \mathrm{s} \ldots \ldots \ldots \ldots . . .91$

Figure 2.52. Mineral pyrite in stirred solutions at $\mathrm{pH} 9.2$, electrode pre-conditioned at $0.4 \mathrm{~V}$ for 3 minutes, scan reversed at various anodic limits, scan rate $50 \mathrm{mV} / \mathrm{s} \ldots \ldots \ldots \ldots . \ldots 92$

Figure 2.53. Illinois coal pyrite in solutions at $\mathrm{rH} 9.2$, scan reversed at various anodic limits, scan rate $50 \mathrm{mV} / \mathrm{s}, \mathrm{rpm}=2000 \ldots \ldots . .94$

Figure 2.54. Effect of anodic reversal potential on charge of peak 1a for Illinois coal pyrite, scan rate $50 \mathrm{mV} / \mathrm{s} \ldots \ldots \ldots \ldots 95$

Figure 2.55. Mineral pyrite in solutions at $\mathrm{pH} 9.2$, electrode pre-conditioned at $0.6 \mathrm{~V}$ for various times, scan

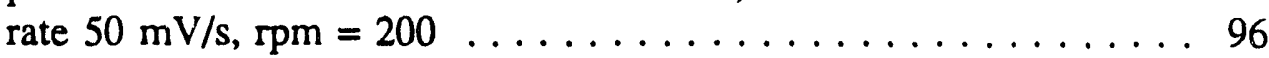

Figure 2.56. Integrated charge of peak 1 and peak 1a, scan rate $50 \mathrm{mV} / \mathrm{s}, \mathrm{rpm}=200$

Figure 2.57. Integrated charge of peak 1 and peak 2, scan rate $50 \mathrm{mV} / \mathrm{s}, \mathrm{rpm}=200$

Figure 2.58. Effect of electrode pre-condition time on charge of peak 1a for mineral pyrite, scan rate $50 \mathrm{mV} / \mathrm{s}$

Figure 2.59. Illinois coal pyrite in solutions at $\mathrm{pH} 9.2$, electrode pre-conditioned at $0.4 \mathrm{~V}$ for various times, scan rate $50 \mathrm{mV} / \mathrm{s}, \mathrm{rpm}=1000 \ldots \ldots \ldots \ldots \ldots \ldots . \ldots \ldots \ldots$

Figure 2.60. Effect of electrode pre-condition time on charge of peak 1a for Illinois coal pyrite, scan rate $50 \mathrm{mV} / \mathrm{s}$

Figure 2.61. Comparison of mineral pyrite (a) and Illinois coal pyrite (b) . . 104

Figure 2.62. Current vs time curves for pyrite in stirred solutions of $\mathrm{pH} 9.2$ at various potentials 106 
Figure 2.63. Charge vs time curves for pyrite in stirred solutions of $\mathrm{pH} 9.2$ at various potentials . . . . . . . . . . . 107

Figure 2.64. Correlation of charge vs time curves at various potentials with paralinear equation . . . . . . . . . . . . . 110

Figure 2.65. Effect of applied potential on rate constants $k_{p}$ and $k_{1} \ldots \ldots 111$

Figure 2.66. Current vs time curves for pyrite in solutions of $\mathrm{pH} 9.2$ at various rpms, applied potential $0.6 \mathrm{~V}$

Figure 2.67. Current vs time curves for pyrite in solutions of $\mathrm{pH} 9.2$ at various upms, applied potential $0.5 \mathrm{~V} \ldots \ldots \ldots \ldots 114$

Figure 2.68. Current vs time curves for pyrite in solutions of $\mathrm{pH} 8.07$ at various rpms, applied potential $0.6 \mathrm{~V} \ldots \ldots \ldots \ldots 115$

Figure 2.69. Current vs time curves for pyrite in solutions of $\mathrm{pH} 10.27$ at various rpms, applied potential $0.6 \mathrm{~V} \ldots \ldots \ldots \ldots 116$

Figure 2.70. Correlation of charge vs time curves at various $\mathrm{pHs}$ with paralinear equation $(0.6 \mathrm{~V}, 700 \mathrm{rpm}) \ldots \ldots \ldots \ldots \ldots 117$

Figure 2.71. Effect of solution $\mathrm{pH}$ on $\log$ rate constants, $\mathrm{k}_{\mathrm{p}}$ and $\mathrm{k}_{1} \ldots \ldots \ldots 118$

Figure 2.72. Current vs time curves for pyrite in solutions of $\mathrm{pH} 9.2$ at various temperatures $(0.6 \mathrm{~V}, 700 \mathrm{rpm}) \ldots \ldots \ldots \ldots .120$

Figure 2.73. Correlation of sharge vs time curves at various temperatures with paralinear equation $(0.6 \mathrm{~V}, 700 \mathrm{rpm}) \ldots \ldots .121$

Figure 2.74. Current vs time curves for pyrite in solutions of $\mathrm{pH} 9.2$ at various temperatures $(0.5 \mathrm{~V}, 700 \mathrm{rpm}) \ldots \ldots \ldots \ldots 122$

Figure 2.75. Correlation of charge vs time curves at various temperatures with paralinear equation $(0.5 \mathrm{~V}, 700 \mathrm{rpm}) \ldots \ldots \ldots 123$

Figure 2.76. Arrhenius plot based on parabolic constant, $\mathrm{k}_{\mathrm{p}}$ in temperature range $23.4^{\circ} \mathrm{C}-59.5^{\circ} \mathrm{C} \ldots \ldots \ldots \ldots \ldots . \ldots 124$

Figure 2.77. Arrhenius plot based on linear rate constant, $\mathrm{k}_{1}$ in temperature range $23.4{ }^{\circ} \mathrm{C}-49.9^{\circ} \mathrm{C} \ldots \ldots \ldots \ldots \ldots \ldots 125$ 
Figure 2.78. Correlation of calculated data using $\mathrm{k}_{\mathrm{p}}$ and $\mathrm{k}_{\mathrm{l}}$ estimated from Eqs. (2.59) and (2.60) with paralinear equation . . . . . . 128

Figure 2.79. Correlation of calculated data using $\mathrm{k}_{\mathrm{p}}$ and $\mathrm{k}_{1}$ estimated from Eqs. (2.62) and (2.63) with paralinear equation for various temperatures ................. 12

Figure 2.80. Correlation of calculated data using $\mathrm{k}_{\mathrm{p}}$ and $\mathrm{k}_{1}$ estimated from Eqs. (2.62) and (2.63) with paralinear equation for various $\mathrm{pHs} \ldots \ldots \ldots \ldots \ldots \ldots \ldots \ldots \ldots \ldots$

Figure 2.81. Correlation of calculated data using $\mathrm{k}_{\mathrm{p}}$ and $\mathrm{k}_{1}$ estimated from Eqs. (2.62) and (2.63) with paralinear equation for various potentials $\ldots \ldots \ldots \ldots \ldots \ldots \ldots \ldots \ldots \ldots \ldots$

Figure 2.82. Impedance of mineral pyrite at various potentials in solutions of $\mathrm{pH} 9.2, \mathrm{rpm}=700 \ldots \ldots \ldots \ldots \ldots \ldots$

Figure 2.83. Impedance of Pittsburgh coal pyrite at various potentials in solutions of $\mathrm{pH} 9.2, \mathrm{rpm}=700 \ldots \ldots \ldots \ldots 134$

Figure 2.84. Effect of electrode pre-conditioning on impedance of mineral pyrite in solutions of $\mathrm{pH} 9.2$ at open circuit potential, $\mathrm{rpm}=700 \ldots \ldots \ldots \ldots \ldots \ldots \ldots \ldots \ldots \ldots \ldots$

Figure 2.85. Comparison of impedance of Pittsburgh coal pyrite and mineral pyrite in solutions of $\mathrm{pH} 9.2$ at open circuit potential, $\mathrm{rpm}=700 \ldots \ldots \ldots \ldots \ldots \ldots \ldots \ldots \ldots \ldots$

Figure 3.1. Electrochemical cell for Raman and photocurrent experiments . . 146

Figure 3.2. Schematic diagram of apparatus for Raman spectroscopy . . . . . 147

Figure 3.3. Apparatus used for photocurrent spectroscopy $\ldots \ldots \ldots \ldots \ldots 150$

Figure 3.4. Raman spectrum of mineral pyrite in $0.5 \mathrm{M} \mathrm{NaCl}$ at rest potential ................... 152

Figure 3.5. Raman spectrum of elemental sulfur in air $\left(100-700 \mathrm{~cm}^{-1}\right) \ldots \ldots 153$

Figure 3.6. Raman spectrum of elemental sulfur in air $\left(700-1400 \mathrm{~cm}^{-1}\right) \ldots 154$

Figure 3.7. Voltammogram of platinum in $0.001 \mathrm{M} \mathrm{Na}_{2} \mathrm{~S}$ and $0.5 \mathrm{M}$ $\mathrm{NaCl}$ solution of $\mathrm{pH} 12.5$, scan rate $50 \mathrm{mV} / \mathrm{sec} \ldots \ldots \ldots \ldots 156$

$$
-\mathbf{x i}-
$$


Figure 3.8. Raman spectra of electrodeposited sulfur on platinum at

$-0.10 \mathrm{~V}$ (solution: $0.001 \mathrm{M} \mathrm{Na}_{2} \mathrm{~S}, 0.5 \mathrm{M} \mathrm{NaCl}, \mathrm{pH} 12.5$ )

Figure 3.9. Raman spectra of electrodeposited sulfur on platinum at $0.38 \mathrm{~V}$ (solution: $0.001 \mathrm{M} \mathrm{Na} 2 \mathrm{~S}, 0.5 \mathrm{M} \mathrm{NaCl}, \mathrm{pH} \mathrm{12.5)} \mathrm{\ldots} \mathrm{.} \mathrm{.} \mathrm{.} 158$

Figure 3.10. Raman spectra of electrodeposited sulfur on platinum at $0.80 \mathrm{~V}$ (solution: $0.001 \mathrm{M} \mathrm{Na}_{2} \mathrm{~S}, 0.5 \mathrm{M} \mathrm{NaCl}, \mathrm{pH} 12.5$ ) . . . . . 159

Figure 3.11. Raman spectra of electrodeposited sulfur on platinum at $1.20 \mathrm{~V}$ (solution: $0.001 \mathrm{M} \mathrm{Na}_{2} \mathrm{~S}, 0.5 \mathrm{M} \mathrm{NaCl}, \mathrm{pH} \mathrm{12.5)} \ldots \ldots . . .160$

Figure 3.12. Amount of charge passed during 20 minutes of sulfur deposition experiments as a function of potential $\ldots \ldots \ldots \ldots 16$

Figure 3.13. Relative height of sulfur peak at $470 \mathrm{~cm}^{-1}$ as a function of applied potential after 20 minutes $\ldots \ldots \ldots 162$

Figure 3.14. Raman spectra of electrodeposited sulfur on platinum at $1.0 \mathrm{~V}$ (solution: $0.001 \mathrm{M} \mathrm{Na}_{2} \mathrm{~S}, 0.5 \mathrm{M} \mathrm{NaCl}, \mathrm{pH} 6.5$ ) . . . . . 163

Figure 3.15. Voltammogram of mineral pyrite in a $0.5 \mathrm{M} \mathrm{NaCl}$ solution of $\mathrm{pH} 2.7$, scan rate $50 \mathrm{mV} / \mathrm{sec} \ldots \ldots \ldots \ldots \ldots$

Figure 3.16. Raman spectra of electrochemic aridized pyrite at $-0.87 \mathrm{~V}$ (solution: $0.5 \mathrm{M} \mathrm{NaCl}, \mathrm{pH}$ 2.7) . . . . . . . . . 166

Figure 3.17. Raman spectra of electrochemically oxidized pyrite at $-0.63 \mathrm{~V}$ (solution: $0.5 \mathrm{M} \mathrm{NaCl}, \mathrm{pH} 2.7$ ) . . . . . . . . . . 167

Figure 3.18. Raman spectra of electrochemically oxidized pyrite at $0.06 \mathrm{~V}$ (solution: $0.5 \mathrm{M} \mathrm{NaCl}, \mathrm{pH} 2.7$ )

Figure 3.19. Raman spectra of electrochemically oxidized pyrite at $0.57 \mathrm{~V}$ (solution: $0.5 \mathrm{M} \mathrm{NaCl}, \mathrm{pH} 2.7$ )

Figure 3.20. Raman spectra of electrochemically oxidized pyrite at $0.80 \mathrm{~V}$ (solution: $0.5 \mathrm{M} \mathrm{NaCl}, \mathrm{pH} 2.7$ )

Figure 3.21. Raman spectra of electrochemically oxirized pyrite at $1.0 \mathrm{~V}$ (solution: $0.5 \mathrm{M} \mathrm{NaCl}, \mathrm{pH} 2.7$ )

Figure 3.22. Voltammogram of mineral pyrite in a $0.5 \mathrm{M} \mathrm{NaCl}$ solution of $\mathrm{pH} 6.5$, scan rate $50 \mathrm{mV} / \mathrm{sec}$ 
Figure 3.23. Raman spectra of electrochemically oxidized pyrite at $-0.76 \mathrm{~V}$ (solution: $0.5 \mathrm{M} \mathrm{NaCl}, \mathrm{pH} 6.5$ ) . . . . . . . . . . 174

Figure 3.24. Raman spectra of electrochemically oxidized pyrite at $-0.40 \mathrm{~V}$ (solution: $0.5 \mathrm{M} \mathrm{NaCl}, \mathrm{pH} 6.5) \ldots \ldots \ldots \ldots \ldots \ldots .175$

Figure 3.25. Raman spectra of electrochemically oxidized pyrite at $-0.15 \mathrm{~V}$ (solution: $0.5 \mathrm{M} \mathrm{NaCl}, \mathrm{pH} 6.5) \ldots \ldots \ldots \ldots \ldots \ldots 176$

Figure 3.26. Raman spectra of electrochemically oxidized pyrite at $0.30 \mathrm{~V}$ (solution: $0.5 \mathrm{M} \mathrm{NaCl}, \mathrm{pH} 6.5$ )

Figure 3.27. Raman spectra of electrochenically oxidized pyrite at $0.42 \mathrm{~V}$ (solution: $0.5 \mathrm{M} \mathrm{NaCl}, \mathrm{pH} 6.5$ ) 178

Figure 3.28. Raman spectra of electrochemically oxidized pyrite at $0.62 \mathrm{~V}$ (solution: $0.5 \mathrm{M} \mathrm{NaCl}, \mathrm{pH} 6.5$ ) . . . . . . . . . . 179

Figure 3.29. Raman spectra of electrochemically oxidized pyrite at $0.80 \mathrm{~V}$ (solution: $0.5 \mathrm{M} \mathrm{NaCl}, \mathrm{pH} 6.5$ ) $\ldots \ldots \ldots \ldots \ldots \ldots .180$

Figure 3.30. Raman spectra of electrochemically oxidized pyrite at $1.0 \mathrm{~V}$ (solution: $0.5 \mathrm{M} \mathrm{NaCl}, \mathrm{pH} 6.5$ )

Figure 3.31. Voltammogram of mineral pyrite in a $0.5 \mathrm{M} \mathrm{NaCl}$ solution of $\mathrm{pH} 9.2$, scan rate $50 \mathrm{mV} / \mathrm{sec} \ldots \ldots \ldots \ldots \ldots \ldots \ldots . \ldots 182$

Figure 3.32. Raman spectra of electrochemically oxidized pyrite at $0.60 \mathrm{~V}$ (solution: $0.5 \mathrm{M} \mathrm{NaCl}, \mathrm{pH} 9.2$ ) . . . . . . . . . . 183

Figure 3.33. Raman spectra of electrochemically oxidized pyrite at $0.80 \mathrm{~V}$ (solution: $0.5 \mathrm{M} \mathrm{NaCl}, \mathrm{pH}$ 9.2) . . . . . . . . . . . . 184

Figure 3.34. Raman spectra of electrochemically oxidized pyrite at $1.0 \mathrm{~V}$ (solution: $0.5 \mathrm{M} \mathrm{NaCl}, \mathrm{pH} 9.2$ ) . . . . . . . . . . . 185

Figure 3.35. Raman spectra of electrochemically oxidized pyrite at $1.2 \mathrm{~V}$ (solution: $0.5 \mathrm{M} \mathrm{NaCl}, \mathrm{pH} 9.2) \ldots \ldots \ldots \ldots \ldots \ldots 186$

Figure 3.36. Voltammogram of mineral pyrite in a $0.5 \mathrm{M} \mathrm{NaCl}$ solution of $\mathrm{pH} 12.5$, scan rate $50 \mathrm{mV} / \mathrm{sec} \ldots \ldots \ldots \ldots \ldots . \ldots . . . .187$

Figure 3.37. Raman spectra of electrochemically oxidized pyrite at $-0.40 \mathrm{~V}$ (solution: $0.5 \mathrm{M} \mathrm{NaCl}, \mathrm{pH} 12.5$ ) 
Figure 3.38. Raman srectra of electrochemically oxidized pyrite at $0.0 \mathrm{~V}$ (sniction: $0.5 \mathrm{M} \mathrm{NaCl}, \mathrm{pH} 12.5) \ldots \ldots \ldots \ldots \ldots \ldots$

Figure 3.39. Raman spe: ira of electrochemically oxidized pyrite at $0.35 \mathrm{~V}$ (solution: $0.5 \mathrm{M} \mathrm{NaCl}, \mathrm{pH} 12.5) \ldots \ldots \ldots \ldots \ldots \ldots 190$

Figure 3.40. Raman spectra of electrochemically oxidized pyrite at $0.62 \mathrm{~V}$ (solution: $0.5 \mathrm{M} \mathrm{NaCl}, \mathrm{pH} 12.5) \ldots \ldots \ldots \ldots \ldots \ldots 191$

Figure 3.41. Raman spectra of electrochemically oxidized pyrite at $1.0 \mathrm{~V}$ (solution: $0.5 \mathrm{M} \mathrm{NaCl}, \mathrm{pH} 12.5) \ldots \ldots \ldots \ldots \ldots \ldots 2$

Figure 3.42. Conditions for sulfur detection from oxidation of pyrite with Raman spectroscopy . . . . . . . . . . . . . . . . 194

Figure 3.43. Expanded frequency shift scale for Figure $3.21(\mathrm{pH} 2.7) \ldots \ldots 196$

Figure 3.44. Expanded frequency shift scale for Figure $3.30(\mathrm{pH} 6.5) \ldots \ldots 197$

Figure 3.45. Expanded frequency shift scale for Figure $3.34(\mathrm{pH} \mathrm{9.2)} \ldots \ldots 198$

Figure 3.46. Raman spectra of pyrite during a cyclic voltammetry experiment (solution: $0.5 \mathrm{M} \mathrm{NaCl}$, pH 6.5 ; scan rate: $0.02 \mathrm{mV} / \mathrm{sec}$ ) . . . . . . 200

Figure 3.47. Detection of sulfate with Raman spectroscopy (a) sulfur in air; (b) $\mathrm{Na}_{2} \mathrm{SO}_{4}$ in air, (c) mineral pyrite oxidized at $1.0 \mathrm{~V} / \mathrm{SCE}$ for 1 hour ( $\mathrm{pH}$ 6.5); (d) adding $\mathrm{Na}_{2} \mathrm{SO}_{4}$ to solution after (c) . . . . 201

Figure 3.48. Effect of charge on sulfur formation by mineral pyrite oxidation at different potentials: (a) 0.80 , (b) 1.0 , and (c) $1.20 \mathrm{~V} / \mathrm{SCE}$ (solution $0.5 \mathrm{M} \mathrm{NaCl}, \mathrm{pH}$ 9.2) $\ldots \ldots \ldots \ldots \ldots \ldots \ldots . \ldots 203$

Figure 3.49. Raman intensity of sulfur peak at $470 \mathrm{~cm}^{-1}$ as a function of time: data fit with exponential equation (data from Figure 3.48 for the potential of $0.80 \mathrm{~V} / \mathrm{SCE}$, mineral pyrite, $0.5 \mathrm{M} \mathrm{NaCl}, \mathrm{pH} 9.2) \ldots 205$

Figure 3.50. Raman spectra of mineral pyrite in $0.5 \mathrm{M} \mathrm{NaCl}$ solution (pH 9.2). Experimental sequence: (a) $10 \mathrm{~min}$ at +1.0 ; (b) $20 \mathrm{sec}$ at -1.0 ; (c) $3 \mathrm{~min}$ at -1.0 ; (d) $8 \mathrm{~min}$ at -1.0 ; (e) $2 \mathrm{~min}$ at $1.0 \mathrm{~V} / \mathrm{SCE} \ldots . .207$

Figure 3.51. Raman spectra of electrodeposited sulfur on platinum. Experimental sequence: (a) $25 \mathrm{~min}$ at +1.0 ; (b) $30 \mathrm{sec}$ at -0.93 ; and (c) $2 \mathrm{~min}$ at $-0.93 \mathrm{~V} / \mathrm{SCE}$ (solution: $0.002 \mathrm{M} \mathrm{Na}_{2} \mathrm{~S}, 0.5 \mathrm{M} \mathrm{NaCl}, \mathrm{pH} 6.5$ ) . 208 
Figure 3.52. Raman spectrum of pyrite in air after being oxidized at $1.0 \mathrm{~V} / \mathrm{SCE}$ for 1 hour in $0.5 \mathrm{M} \mathrm{NaCl}(\mathrm{pH} 6.5)$ and polarized at $-0.6 \mathrm{~V} / \mathrm{SCE}$ in $0.001 \mathrm{M} \mathrm{AgNO}_{3}$ and $0.5 \mathrm{M} \mathrm{KNO}_{3}$ for passage of $5 \mathrm{mC} \ldots \ldots 210$

Figure 3.53. Reduction of $\mathrm{Fe}(\mathrm{OH})_{3}$ in $0.5 \mathrm{M} \mathrm{NaCl}$ solution of $\mathrm{pH} 6.5 \ldots \ldots 211$

Figure 3.54. Raman spectra of electrochemically oxidized Illinois coal pyrite at $1.0 \mathrm{~V} / \mathrm{SCE}$ (solution: $0.5 \mathrm{M} \mathrm{NaCl}, \mathrm{pH} 6.5$ ) . . . . 212

Figure 3.55. Raman spectra of electrochemically oxidized Upper Freeport coal pyrite at $0.8 \mathrm{~V} / \mathrm{SCE}$ (solution: $0.5 \mathrm{M} \mathrm{NaCl}, \mathrm{pH} 6.5$ ) . . . . 213

Figure 3.56. Raman spectra of electrochemically oxidized Pittsburgh coal pyrite at $0.7 \mathrm{~V} / \mathrm{SCE}$ (solution: $0.5 \mathrm{M} \mathrm{NaCl}, \mathrm{pH} 6.5$ ) $\ldots \ldots \ldots 214$

Figure 3.57. Raman sperta of electrochemically oxidized galena at $-0.32 \mathrm{~V}$ (soiution: $0.5 \mathrm{M} \mathrm{NaCl}, \mathrm{pH} 6.5$ ) . . . . . . . . . 215

Figure 3.58. Raman spectra of electrochemically oxidized galena at $0.13 \mathrm{~V}$ (solution: $0.5 \mathrm{M} \mathrm{NaCl}, \mathrm{pH} 6.5$ ) $\ldots \ldots \ldots \ldots \ldots \ldots 216$

Figure 3.59. Raman spectra of electrochemically oxidized galena at $0.32 \mathrm{~V}$ (solution: $0.5 \mathrm{M} \mathrm{NaCl}, \mathrm{pH} 6.5$ ) $\ldots \ldots \ldots \ldots \ldots \ldots 217$

Figure 3.60. Raman spectra of electrochemically oxidized galena at $0.57 \mathrm{~V}$ (solution: $0.5 \mathrm{M} \mathrm{NaCl}, \mathrm{pH} 6.5$ ) $\ldots \ldots \ldots \ldots \ldots \ldots 218$

Figure 3.61. Raman spectra of electrochemically oxidized galena at $1.0 \mathrm{~V}$ (solution: $0.5 \mathrm{M} \mathrm{NaCl}, \mathrm{pH} 6.5$ ) $\ldots \ldots \ldots \ldots \ldots \ldots .219$

Figure 3.62. Raman spectrum of pyrrhotite in air $\ldots \ldots \ldots \ldots \ldots \ldots 221$

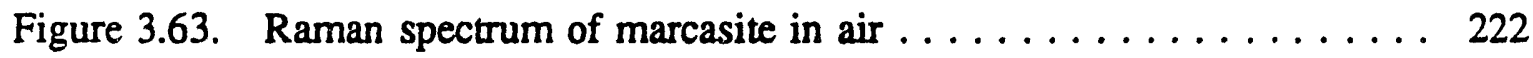

Figure 3.64. Raman spectrum of chalcopyrite in air ............ 223

Figure 3.65. Raman spectrum of chalcocite in air . . . . . . . . . 224

Figure 3.66. Raman spectrum of covellite in air $\ldots \ldots \ldots \ldots \ldots \ldots 225$

Figure 3.67. Raman spectra of electrochemically oxidized pyrrhotite at $1.0 \mathrm{~V}$ (solution: $0.5 \mathrm{M} \mathrm{NaCl}, \mathrm{pH} 6.5$ ) $\ldots \ldots \ldots \ldots \ldots 227$ 
Figure 3.68. Raman spectra of electrochemically oxidized chalcopyrite at $1.0 \mathrm{~V}$ (solution: $0.5 \mathrm{M} \mathrm{NaCl}, \mathrm{pH} 9.2) \ldots \ldots \ldots \ldots \ldots 228$

Figure 3.69. Raman spectra of electrochemically oxidized covellite at $0.4 \mathrm{~V}$ (solution: $0.5 \mathrm{M} \mathrm{NaCl}, \mathrm{pH} 6.5$ ) . . . . . . . . . 229

Figure 3.70. Raman spectra of electrochemically oxidized chalcocite at $0.3 \mathrm{~V}$ (solution: $0.5 \mathrm{M} \mathrm{NaCl}, \mathrm{pH} 6.5$ ) $\ldots \ldots \ldots \ldots \ldots \ldots 230$

Figure 3.71. Raman spectrum of mineral pyrite particles at (a) rest potential; (b) $1.5 \mathrm{~V} / \mathrm{SCE}$ (solution: $0.5 \mathrm{M} \mathrm{NaCl}$, pH 6.5) . . . . . 233

Figure 3.72. Raman spectrum of mineral pyrite particles at (a) the beginning; (b) the end of experiment in $\mathrm{KClO}$ solution

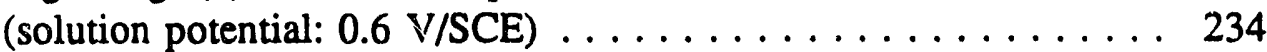

Figure 3.73. In-phase photocurrent for pyrite in a $0.5 \mathrm{M} \mathrm{NaCl}$ solution

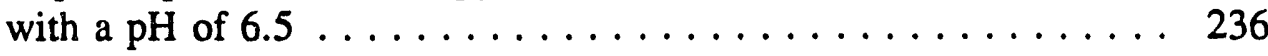

Figure 3.74. Out-of-phase photocurrent for pyrite in a $0.5 \mathrm{M} \mathrm{NaCl}$ solution with a $\mathrm{pH}$ of $6.5 \ldots \ldots \ldots \ldots \ldots \ldots \ldots \ldots \ldots \ldots \ldots \ldots$

Figure 4.1. Electrochemical flotation mini-cell . . . . . . . . . . . . 249

Figure 4.2. Floatability of mineral pyrite for various xanthate concentrations . . . . . . . . . . . 251

Figure 4.3. Floatability of coal pyrite for various xanthate concentrations . . . . . . . . . . . . . 252

Figure 4.4. Floatability of Pittsburgh coal and coal pyrite with xanthate as a collector . . . . . . . . . . . . . 253

Figure 4.5. Floatability of Pittsburgh coal and coal pyrite as a function of $\mathrm{pH} \ldots \ldots \ldots \ldots \ldots \ldots \ldots \ldots \ldots \ldots$

Figure 4.6. Floatability of Pittsburgh coal and coal pyrite as a function of $\mathrm{pH}$ in dodecane electrolyte $\ldots \ldots \ldots \ldots \ldots 256$

Figure 4.7. Floatability of Pittsburgh coal and coal pyrite in dodecane-electrolyte $(\mathrm{pH}=6)$

Figure 4.8. Floatability of Pittsburgh coal and coal pyrite in dodecane-electrolyte $(\mathrm{pH}=9.21)$. 
Figure 4.9. Floatability of Pittsburgh coal and coal pyrite as a function of $\mathrm{pH}$ in butyl alcohol electrolyte solution . . . . . . 259

Figure 4.10. Floatability of Pittsburgh coal in butyl alcohol electrolyte solution $(\mathrm{pH}=4.0) \ldots \ldots \ldots \ldots \ldots \ldots 260$

Figure 4.11. Floatabiity of Pittsburgh coal in butyl alcohol electrolyte solution $(\mathrm{pH}=9.21) \ldots \ldots \ldots \ldots \ldots 261$

Figure 4.12. Floatability of Pittsburgh coal pyrite after pretreatment with $\mathrm{H}_{2} \mathrm{SO}_{4} \ldots \ldots \ldots \ldots \ldots \ldots \ldots \ldots$

Figure 4.13. Floatability of Pittsburgh coal pyrite after pretreatment with $\mathrm{HCl} \ldots \ldots \ldots \ldots \ldots \ldots \ldots . \ldots \ldots$

Figure 4.14. Floatability of Pittsburgh coal pyrite after pretreatment with $\mathrm{H}_{2} \mathrm{SO}_{4} \ldots \ldots \ldots \ldots \ldots \ldots \ldots \ldots$

Figure 4.15. Floatability of Pittsburgh coal pyrite after pretreatment with $\mathrm{H}_{2} \mathrm{SO}_{4} \ldots \ldots \ldots \ldots \ldots \ldots \ldots \ldots$

Figure 4.16. Floatability of Pittsburgh coal pyrite activated by $\mathrm{CuSO}_{4} \ldots \ldots 267$

Figure 4.17. Floatability of Colorado mineral pyrite activated by $\mathrm{Na}_{2} \mathrm{~S} \ldots 268$

Figure 4.18. Floatability of Pittsburg coal pyrite activated by $\mathrm{Na}_{2} \mathrm{~S} \ldots \ldots 269$

Figure 4.19. Floatability of Colorado mineral pyrite

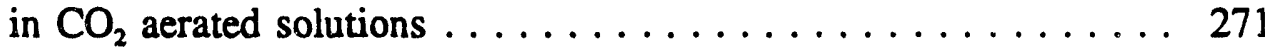

Figure 4.20. Floatability coal pyrite in $\mathrm{CO}_{2}$ aerated solutions $\ldots \ldots \ldots \ldots 272$

Figure 4.21. Floatability of Pittsburgh coal pyrite in EDTA tetrasodium solution . . . . . . . . . . . . . 273

Figure 4.22. Floatability of Pittsburgh coal and coal pyrite as a function of $\mathrm{pH}$ with lime as a modifier . . . . . . . . . 274

Figure 4.23. Floatability of Pittsburgh coal pyrite in xanthate with and without lime as a modifier ............. 275

Figure 4.24. Floatability of Pittsburgh coal in xanthate-lime solution . . . . . 277 
Figure 4.25. Floatability of Pittsburgh coal and coal pyrite in xanthate-lime solution $(\mathrm{pH}=9) \ldots \ldots \ldots \ldots \ldots \ldots .278$

Figure 4.26. Pyrite rejection as a function of yield for Pittsburgh coal in xanthate-lime solution . . . . . . . . . . . . . . . . 279

Figure 4.27. Ash rejection as a function of yield for Pittsburgh coal in xanthate-lime solution . . . . . . . . . . . . . . . . 280

Figure 4.28. Pyrite rejection as a function of yield for Pittsburgh coal in dodecane-electrolyte . . . . . . . . . . . . . . 281

Figure 4.29. Natural floatability of coal samples and effect of MIBC on flotation ................ 283

Figure 4.30. Natural floatability of coal samples and effect of MIBC on flotation ................ 284

Figure 4.31. Natural floatability of coal samples and effect of MIBC on flotation . . . . . . . . . . . 285

Figure 4.32. Flotation kinetics using MIBC only (MIBC $1000 \mathrm{~g} / \mathrm{Mt}) \ldots \ldots 286$

Figure 4.33. Flciation kinetics using MIBC only (MIBC $1000 \mathrm{~g} / \mathrm{Mt})$. . . . 287

Figure 4.34. Flotation kinetics using MIBC only (MIBC $1000 \mathrm{~g} / \mathrm{Mt}) \ldots \ldots 288$

Figure 4.35. The effect of salt $(\mathrm{NaCl})$ on floatability of coal (no frother or collector) . . . . . . . . . . . . . . . . . . 289

Figure 4.36. The effect of salt $(\mathrm{NaCl})$ on the combustible material recovery of coal (no frother or collector) . . . . . . . . . . . 290

Figure 4.37. The effect of salt $(\mathrm{NaCl})$ on the separation efficiency of pyritic sulfur (no frother or collector) . . . . . . . . . 291

Figure 4.38. Relation between the yield of salt flotation and the flotation time (salt concentration: $3 \%$, no frother or collector) . . . . . 292

Figure 4.39. Relation between the yield of salt flotation and the flotation time (salt concentration: 3\%, no frother or collector) . . . . . . 293

Figure 4.40. Relation between the yield of salt flotation and the flotation time (salt concentration: 3\%, no frother or collector) . . . . . . 294 
Figure 4.41. Floatability of mineral and coal pyrite as a function of $\mathrm{pH} \ldots \ldots 295$

Figure 4.42. Floatability of Pittsburgh coal and coal pyrite as a function of $\mathrm{pH} \ldots \ldots \ldots \ldots \ldots$. . . . . . . . . . 297

Figure 4.43. Floatability of Pittsburgh coal pyrite in xanthate-electrolyte . . . . . . . . . . . . . . . . 298

Figure 4.44. The effect of potential on floatability of coal pyrite . . . . . . . 299

Figure 4.45. The effect of electrochemical pretreatment on floatability of coal pyrite $\ldots \ldots \ldots \ldots \ldots$

Figure 4.46. The effect of Electrochemical pretreatment on floatability of coal pyrite in xanthate-lime solution $(\mathrm{pH}=10.0) \ldots \ldots 1$

Figure 4.47 The effect of electrochemical pretreatment on floatability of coal pyrite in xanthate solution $(\mathrm{pH}=12.3) \ldots \ldots 2$

Figure 5.1. Flotation kinetics of pittsburgh no $8 \mathrm{coal}$ and coal pyrite without frother or collector . . . . . . . . . . . . . . 309

Figure 5.2. Flotation kinetics of pittsburgh no 8 coal and coal pyrite

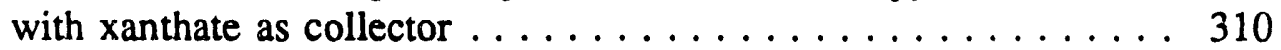

Figure 5.3. The kinetics evaluation using the first order kinetics and without dodecane $\ldots \ldots \ldots \ldots \ldots \ldots \ldots \ldots \ldots$

Figure 5.4. The kinetics evaluation using the first order kinetics and with dodecane .................. 314

Figure 5.5. The log-log plot of flotation kinetics of Upper Freeport coal

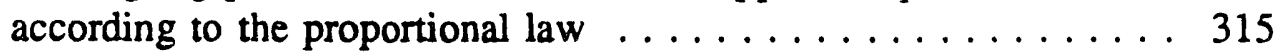

Figure 5.6. The log-log plot of flotation kinetics of Pittsburgh No. 8 coal according to the proportional law ............ 316

Figure 5.7. The log-log plot of flotation kinetics of Illinois No. 6 coal according to the proportional law .............. 317

Figure 5.8. The kinetics evaluation using the proportional law and without dodecane ................. 318 
Figure 5.9. The kinetics evaluation using the proportional law and with dodecane ..................... 319

Figure 5.10. The kinetics evaluation using the modified first order kinetics equation and without dodecane $\ldots \ldots \ldots \ldots \ldots \ldots 321$

Figure 5.11. The kinetics evaluation using the modified first order kinetics equation and with dodecane $\ldots \ldots \ldots \ldots \ldots \ldots \ldots 322$ 


\section{LIST OF TABLES}

Table 1.1 Properties of coal samples $\ldots \ldots \ldots \ldots \ldots \ldots \ldots \ldots$

Table 1.2 Properties of Argonne Premium Coal Bank samples . . . . . . . . . 3

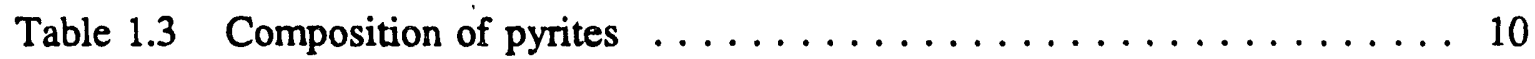

Table 2.1. Effect of scan rate on charge of peaks 1 and 1a

(Electrode pre-conditioned at $0.4 \mathrm{~V}$ for $1 \mathrm{~min}$. ) $\ldots \ldots \ldots 33$

Table 2.2. Effect of electrode pre-conditioning time on charge of peaks

1 and 1 a (scan rate: $50 \mathrm{mV} / \mathrm{s}$, applied potential: $0.4 \mathrm{~V}$ ) . . . . . . 37

Table 2.3. Parabolic and linear rate constants $\left(k_{p}\right.$ and $\left.k_{1}\right)$ for various applied potentials . . . . . . . . . . . . . . . . 109

Table 2.4. Parabolic and linear rate constants $\left(k_{p}\right.$ and $\left.k_{1}\right)$ for various electrolyte $\mathrm{pH}$ (Electrode rotation speed: $700 \mathrm{rpm}$ ) . . . . . . . . . 119

Table 2.5. Parabolic and linear rate constants $\left(k_{p}\right.$ and $\left.k_{1}\right)$ for various temperatures (Electrode rotation speed: $700 \mathrm{rpm}$ ) . . . . . . . 126

Table 4.1. Proximate analysis of three coal samples . . . . . . . . . . . 245

Table 4.2. Ultimate analysis and heat value of three coal samples . . . . . . 245

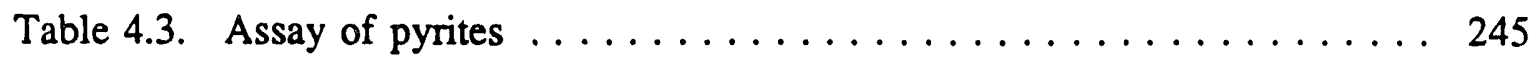

Table 5.1. Kinetics data for fine coal flotation $\ldots \ldots \ldots \ldots \ldots \ldots \ldots$

Table 5.2. The kinetics parameter of the fine coal flotation . . . . . . . . . 312 


\section{EXECUTIVE SUMMARY}

Research results included in this final report are presented under five major headings. Each represents a separate research effort presented under sub-headings Introduction, Experimental, Results and Discussion, and Conclusions. The conclusions are summarized below:

\section{CHARACTERIZATION}

The surfaces of coal pyrite and mineral pyrite were characterized by electron microprobe and scanning electron microscopic analyses. Mineral distribution was demonstrated using image analysis. Mineral pyrite was observed to have a smoother surface morphology than the coal pyrites. Surface roughness of the coal pyrites increased in the order

Upper Freeport < Pittsburgh \#8 < Illinois \#6.

The atomic ratio of sulfur to iron in all samples was found to be 2.0 and there was little association of pyrite with other minerals.

\section{ELECTROCHEMISTRY}

Voltammograms were obtained under variable conditions of agitation and sweep rates for mineral pyrite and Upper Freeport, Pittsburgh \#8, and Illinois \#6 coal pyrites. Continuous as well as interrupted sweeps were obtained to identify the various surface layers formed under oxidizing and reducing conditions. Potentiostatic-current measurement were made to determine the kinetics of surface product film growth.

Three anodic peaks were observed for mineral pyrite. Two corresponded to the oxidation of surface products forming $\mathrm{Fe}$ (II) and Fe(III) surface oxides. The third anodic peak corresponded to the oxidation of the $\mathrm{FeS}_{2}$ itself. Conjugate cathodic peaks of surface product layers were also clearly discernable. For Pittsburgh and Upper Freeport coal pyrite, fewer anodic/cathodic conjugate peaks were in evidence and they were much broader and more diffuse than for mineral pyrite. The current densities observed for the coal pyrites were much greater than for mineral pyrite, indicating higher reactivity. Illinois 
pyrite was similar to mineral pyrite in character but had a higher intrinsic current density. Coal pyrite was less sensitive to $\mathrm{pH}$ and degree of agitation than was mineral pyrite. The relative reactivity of coal and mineral pyrites were in the order

Upper Freeport > Pittsburgh \#8 $\approx$ Illinois \#6 > mineral.

Under acid conditions $(\mathrm{pH}<2.6)$, cathodic reduction of pyrite was a major reaction. For anodic potentials in the range of 0.4 to $0.8 \mathrm{~V}$ (SCE), aggressive oxidation of pyrite occurred. The reaction products were Fe(III) oxides, sulfate ion and partially oxidized sulfur intermediates. These sulfur intermediates significantly affected the subsequent oxidation/reduction reactions in the lower potential region and were sensitive to the character and degree of solution agitation. For higher potentials $(\mathrm{V}>1.0 \mathrm{~V}, \mathrm{SCE})$, complete oxida'ion of pyritic lattice sulfur $\left(\mathrm{S}_{2}{ }^{2-}\right)$ to sulfate ion occurred.

The kinetics of film growth on mineral pyrite were obtained from potentiostaticcurrent decay curves using rotation disk electrodes. Sulfur intermediates in the form of polysulfides (metal deficient sulfides) and elemental sulfur were observed to form a continuous adherent protective layer. Fe(III) oxides formed at the same time were loosely held on the surface and were readily removed by agitation. The kinetics obeyed the paralinear rate law with associated parabolic $\left(k_{p}\right)$ and linear $\left(k_{1}\right)$ rate constants. The kinetics were consistent with diffusion of charged iron species through the film followed by oxidation of the sulfur and formation of Fe(III) oxides at the outer layer. The effects of voltage, $\mathrm{pH}$, temperature and rotation speed were determined for both $\mathrm{k}_{\mathrm{p}}$ and $\mathrm{k}_{1}$. The kinetics provided a model for pyrite oxidation which explained all of the observed results. This study was discontinued before similar kinetics could be measured for the several coal pyrite samples.

\section{IN-SITU SPECTROSCOPIC CHARACTERIZATION OF ELECTROCHEMICALLY MODIFIED PYRITE}

Raman spectroscopy was used successfully to characterize anodic and cathodic surface product layers in situ while being formed. This was done at fixed potentials and during slow voltage sweeps. Strong spectra were observed in relatively short periods of time making it possible to characterize surface reactions and to follow their formation and 
subsequent changes in real time.

Potential and $\mathrm{pH}$ conditions were identified which promote sulfur formation during the anodic oxidation of pyrite. Initial surface products were polysulfides and elemental sulfur. Similar surface products were formed chemically in the presence of a suitable oxidizing agent. In this way hydrophobic surface layers of sulfur could be formed either electrochemically or by adjusting the solution potential.

Alternate oxidation and reduction cycles demonstrated the sulfur layers formed on the pyrite surface were readily reducible, indicating appreciable electrical conductivity. This was reinforced by the existence of a photocurrent, providing further evidence of the semiconducting nature of these surface layers.

Coulombic measurements showed that the formation of surface sulfur layers constituted only a very small fraction of the coslombic production. Most of the current went to the formation of sulfate ion. While polysulfides and elemental sulfur were observed, no oxy-sulfur species were observed by Raman spectroscopy. The SERS spectroscopy technique was successful in detecting the presence ferric hydroxide films which also gave strong photocurrent response.

\section{FLOATABILITY OF COAL AND COAL PYRITE}

Laboratory flotation tests were carried out on three coals and on coal pyrite. Floatability measurements included natural floatability, flotation with a xanthate collector and salt flotation. The ranking of the floatability of the three coals were:

\section{Upper Freeport $>$ Pittsburgh $>$ Illinois.}

The floatability of mineral pyrite and coal pyrite increased markedly with xanthate concentration, but decreased with increased $\mathrm{pH}$. In general, coal pyrite was more difficult to float than mineral pyrite. This was attributed to the presence of surface carbonaceous and mineral matter, since floatability of coal pyrite improved by acid pretreatment.

Flotation tests demonstrated that the floatability of coal and mineral pyrite was greatly enhanced by the presence of an electrolyte. Flotation was also enhanced by the addition of modifiers such as $\mathrm{CuSO}_{4}, \mathrm{Na}_{2} \mathrm{~S}, \mathrm{CO}_{2}$ and EDTA. Lime additions markedly reduced the floatability of coal pyrite. 
Enhanced floatability of coal pyrite resulter when the pyrite was anodically oxidized in a specially constructed electrochemical flotation cell. Pretreatment in potential ranges previously observed for polysulfide and sulfur film formation resulted in the enhanced floatability.

While interesting trends and influences, both chemical and electrochemical, markedly improved the floatability of coal, there is little hope for reverse flotation as an effective technology for coal/coal-pyrite separations. The effects of poor liberation and entrainment appear overriding.

\section{FLOTATION KINETICS}

Flotation kinetics were measured for the three coals considered in this study. The results may be explained by either a first order kinetics model or by a proportional rate law. The first order kinetics required a model which considered two mixed fractions of coal having respectively rapid and slow kinetics. Both models fit the kinetic data and provided similar conclusions regarding relative flotation behavior. Based on the calculated rate constants the three coals decrease in rate according to the ranking:

Upper Freeport > Pittsburgh \#8 > Illinois \#6. 


\section{ChaRaCterization}

\section{INTRODUCTION}

Sulfur is found in coals as organic sulfur and as inorganic sulfur-containing minerals. The relative abundance of both organic and pyritic sulfur show a similar behavior with changes in total sulfur concentration in coal samples. The sulfur comes from plant (mostly bacteria) or animal protein deposited with the coal or from sulfate ions in associated waters [1.1]. Coals formed in marine environments show higher sulfur content than fresh-water coals due to the higher sulfate concentrations in the waters. The sulfate ion is reduced to sulfur by the action of bacteria and $\mathrm{H}_{2} \mathrm{~S}$ is formed. Iron is present in solution due to the weathering of silicate minerals. This occurs most readily in calcium rich swamps, where the $\mathrm{pH}$ is neutral to slightly basic.

Pyrite is formed from the hydrogen sulfide and iron. Most inorganic sulfur is found in the form of pyrite, with smaller amounts of marcasite and traces of galena, sphalerite, and chalcopyrite $[1.1,1.2]$. In oxidized coals, the sulfides may be oxidized to sulfates. Most iron is in the form of sulfides, with some carbonate (siderite) and silicate (chlorite, illite). Syngenetic deposition of pyrite occurs during digenesis of coal material. Such material can be of sinall particle size and highly dispersed in the organic matrix of the coal. Deposition also occurs by epigenetic precipitation of sulfides in fissures and cleats from percolating water solutions. This material will generally be of larger particle size. Although the particle size distribution of pyrites in coals is broad and depends on the mechanism of formation, most pyrite falls in the range of 10-45 $\mu \mathrm{m}$ in diameter [1.2].

Pyrite has a density of about $5,000 \mathrm{~kg} / \mathrm{m}^{3}$, compared to $1,340 \mathrm{~kg} / \mathrm{m}^{3}$ for the organic portion of coal and an average of about $2,850 \mathrm{~kg} / \mathrm{m}^{3}$ for the average mineral content of typical coals. Gravity processes should be effective in the separation of pyrite from coals if the pyrite can be liberated from the organic matter. However, the small particle size and the dispersion of the pyrite through the coal matrix require fine grinding for effective pyrite liberation. Under such conditions, surface properties become important in separating the coal and the pyrite and gravitational techniques must be replaced or augmented by surface techniques for separation. 
Organic sulfur occurs in thiophenes (including benzologs of thiophene), aromatic and aliphatic sulfides, thiols and thiophenols [1.3]. Thiophenes and aromatic sulfides are particularly stable and require intense thermal or chemical treatment to remove them from the coal.

\section{COAL SAMPLES}

Three coal samples that have been widely sudied were selected for this study. Samples were obtained from those collected and characterized on is previous research project [1.4]. The ultimate and proximate analysis of the samples is shown in Table 1.1. The analysis of samples obiained from the same seams by the Argonne Premium Coal Sample Bank are shown in Table 1.2 for comparison and to provide additional information on the coals [1.5].

Table 1.1 Properties of coal samples

\begin{tabular}{lccc}
\hline \multicolumn{1}{c}{ Property } & Upper Freeport & Pittsburgh No. 8 & Illinois No. 6 \\
\hline Volatile matter, \% & & & \\
AR & 25.03 & 34.34 & 32.40 \\
MAF & 29.14 & 40.52 & 43.46 \\
Moisture, \% AR & 2.23 & 3.63 & 11.05 \\
Ash, \% dry & 12.14 & 12.06 & 16.19 \\
Carbon, \% MAF & 87.92 & 81.94 & 79.32 \\
Hydrogen, \% MAF & 5.28 & 5.52 & 5.44 \\
Nitrogen, \% MAF & 1.50 & 1.50 & 1.34 \\
Sulfur, \% dry & 2.24 & 3.95 & 5.19 \\
Oxygen, \% dry & 2.41 & 5.76 & 6.46 \\
by difference & & 14572 & 14096 \\
Heating value, & 15480 & & high volatile C \\
Btu/b MAF & & bituminous & bituminous \\
Rank & medium volatile & & \\
\hline
\end{tabular}

$\mathrm{AR}=$ as received; $\mathrm{MAF}=$ moisture, ash-free. 
Table 1.2 Properties of Argonne Premium Coal Bank samples

\begin{tabular}{|c|c|c|c|}
\hline Property & Upper Freeport & Pittsburgh No. 8 & Illinois No. 6 \\
\hline \multicolumn{4}{|l|}{ Volatile matter, $\%$} \\
\hline AR & 27.14 & 37.20 & 36.86 \\
\hline MAF & 31.62 & 41.67 & 47.39 \\
\hline Moisture, \% AR & 1.13 & 1.65 & 7.97 \\
\hline Ash, \% dry & 13.18 & 9.10 & 15.48 \\
\hline Carbon, \% MAF & 85.50 & 83.20 & 77.67 \\
\hline Hydrogen, \% MAF & 4.70 & 5.32 & 5.00 \\
\hline Nitrogen, \% MAF & 1.55 & 1.64 & 1.37 \\
\hline Sulfur, \% dry & 2.32 & 2.19 & 4.83 \\
\hline pyritic & 1.77 & 1.37 & 2.81 \\
\hline sulfate & 0.01 & 0.01 & 0.01 \\
\hline organic & 0.54 & 0.81 & 2.01 \\
\hline $\begin{array}{l}\text { Oxygen, \% MAF } \\
\text { by difference }\end{array}$ & 7.51 & 8.83 & 13.51 \\
\hline $\begin{array}{l}\text { Heating value, } \\
\text { Btu/lb MAF }\end{array}$ & 15511 & 15018 & 14140 \\
\hline \multicolumn{4}{|l|}{ Mineral matter, $\%$} \\
\hline dry LTA & 15.3 & 10.9 & 18.1 \\
\hline quartz & 1.5 . & 1.7 & 3.4 \\
\hline pyrite & 3.4 & 2.4 & 5.5 \\
\hline calcite & 1.0 & 0.5 & 1.9 \\
\hline total clay, (dif.) & 9.4 & 6.3 & 7.3 \\
\hline \multicolumn{4}{|l|}{ Maceral, \% } \\
\hline liptinite & 1 & 7 & 5 \\
\hline vitrinite & 91 & 85 & 85 \\
\hline inertinite & 8 & 8 & 10 \\
\hline
\end{tabular}


Fine sized liberated coal pyrite samples were obtained by gravity separation from the coals samples on a shaking table. Larger chunks of Upper Freeport coal pyrite from Coshocton County, Ohio were obtained from the Pittsburgh Energy Technology Center. Pyrite chunks and table reject from the Pittsburgh seam in Pennsylvania were obtained from the preparation plant of the Consolidation Coal Company. Larger pyrite chunks and gob samples of pyrite from the Illinois No. 5 seam at the Kerr-McGee's Galatia mine in Saline County, Illinois were received from the Illinois State Geological Survey.

A mineral pyrite sampie from Colorado and a second mineral pyrite sample obtained from Ward's Natural Science Establishment were used for comparison with the coal pyrite samples.

\section{SCANNING ELECTRON MICROSCOPY}

Pyrite is found in coal as highly-dispersed fine fractions and as larger agglomerates in cleats and fissures. During grinding, larger agglomerates are ground along with the coal and fracture products may report to the fine fractions, but the dispersed pyrite is only liberated by very fine grinding and may remain in the courser fractions, combined with the coal. Samples of pyrite from the three coal pyrites and the two mineral pyrites were crushed and mounted with epoxy cement on aluminum stubs. The samples were coated with gold and examined with a Hitachi S-500 scanning electron microscope.

Examples of the electron micrographs for the 5 pyrite samples are shown in Figures 1.1-1.5 at three different magnifications, 1440X, 2520X, and 14400X. The micrographs are representative of a larger number of observations. Some conclusions may be drawn based on the qualitative observations. At low magnification, the mineral pyrite samples show smoother surfaces, fewer tiny particles on the surfaces, and sharper edges. The mineral pyrites show relatively smooth surfaces even at higher magnification, although small particles are observed on the surfaces. The Pittsburgh No. 8 and Ilinois No. 6 coal pyrites exhibit a high degree of surface roughness, while the Upper Freeport coal pyrite in intermediate between these samples and the mineral pyrite. The order of surface roughness for the pyrite samples is Illinois No. $6>$ Pittsburgh No. $8>$ Upper Freeport > mineral. No pores were observed in these samples. Higher BET surface areas 


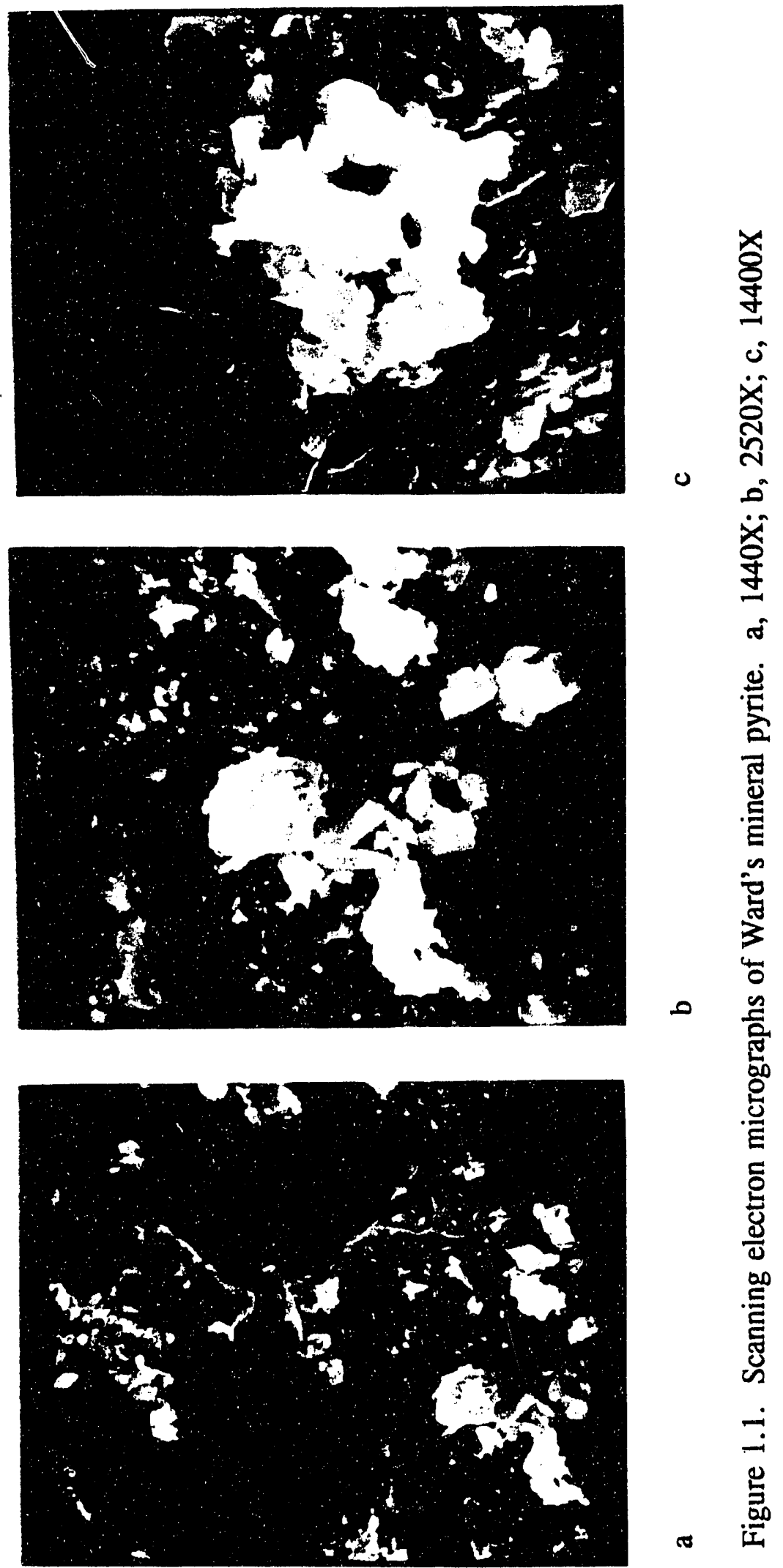




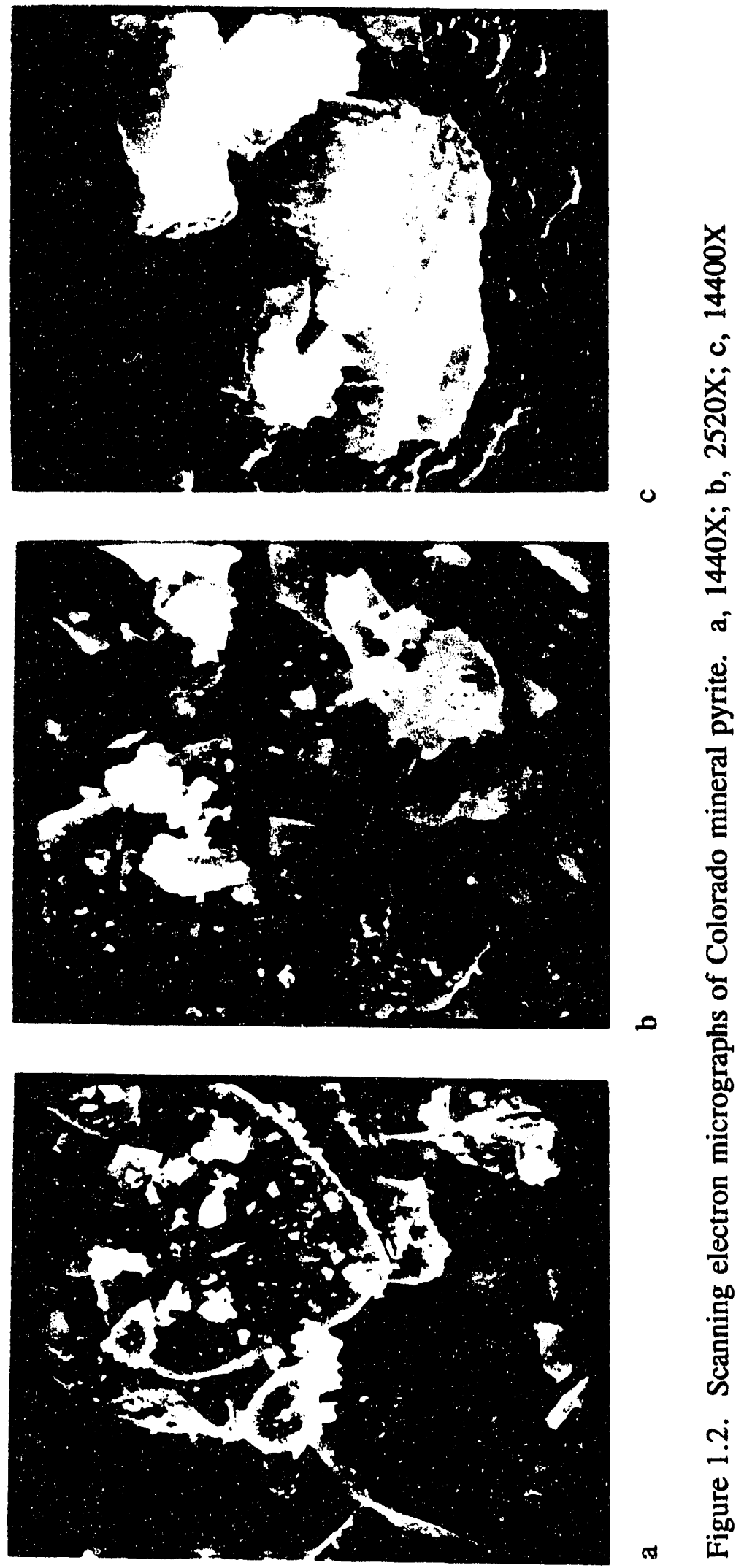




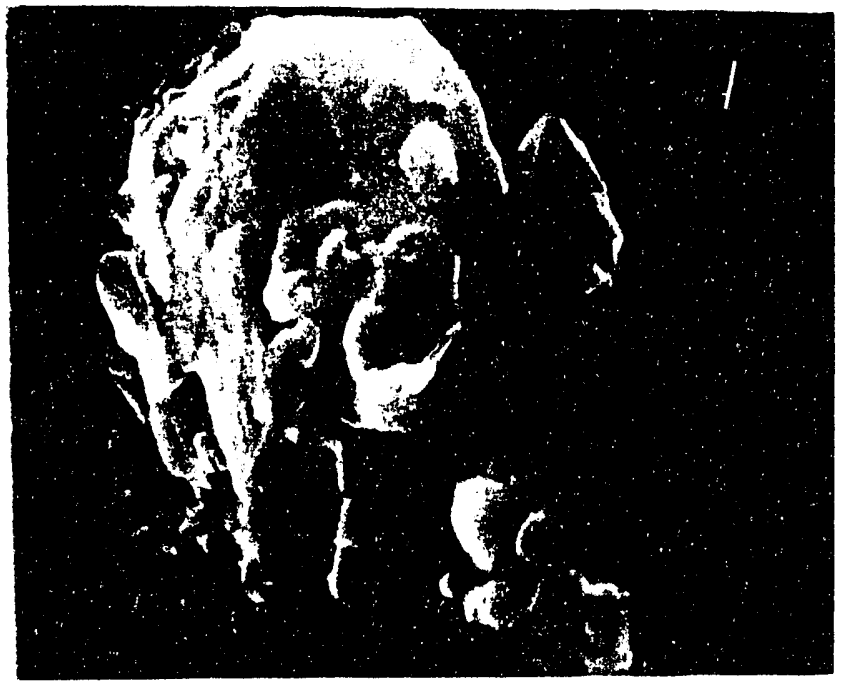

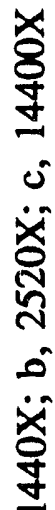

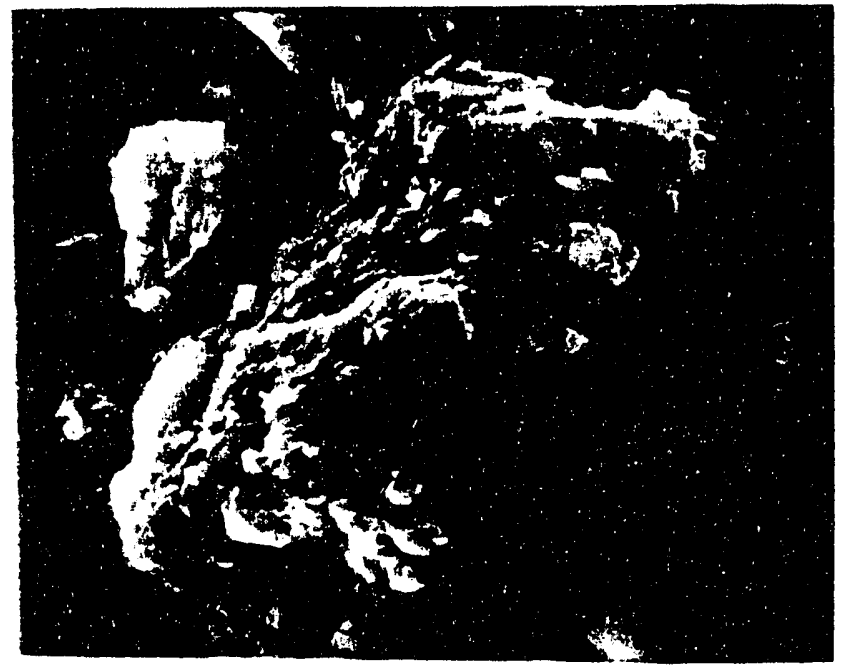

os

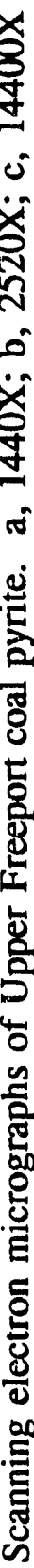

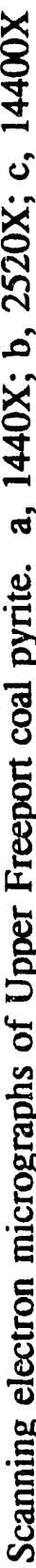

总

- $\frac{\text { ก }}{2}$

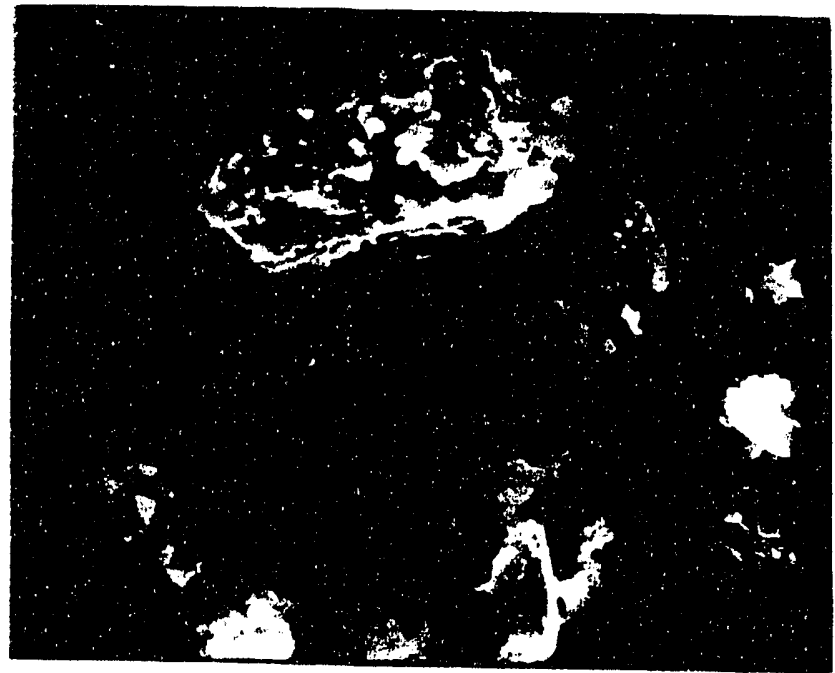

- 


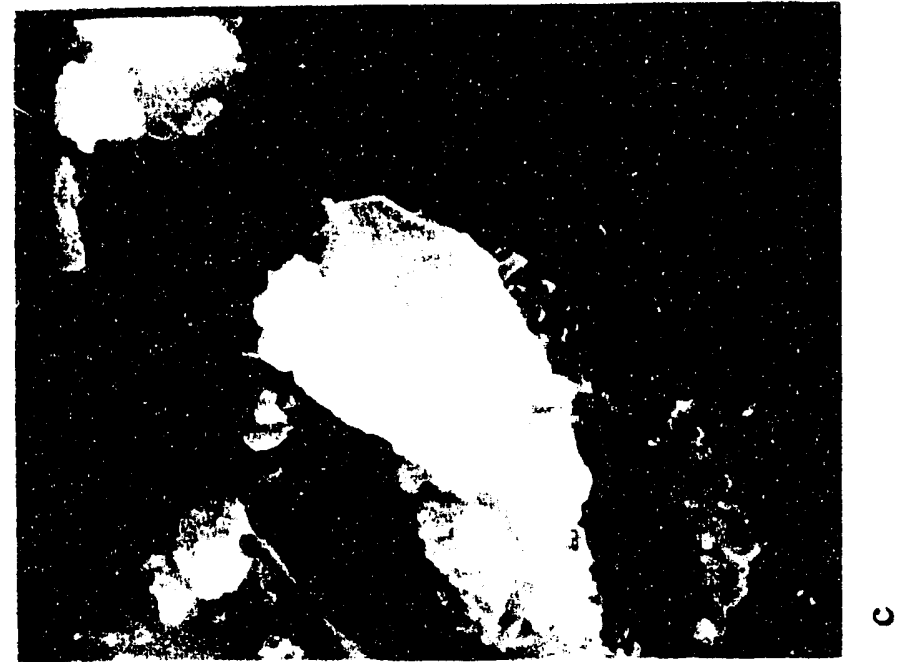

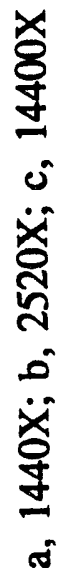

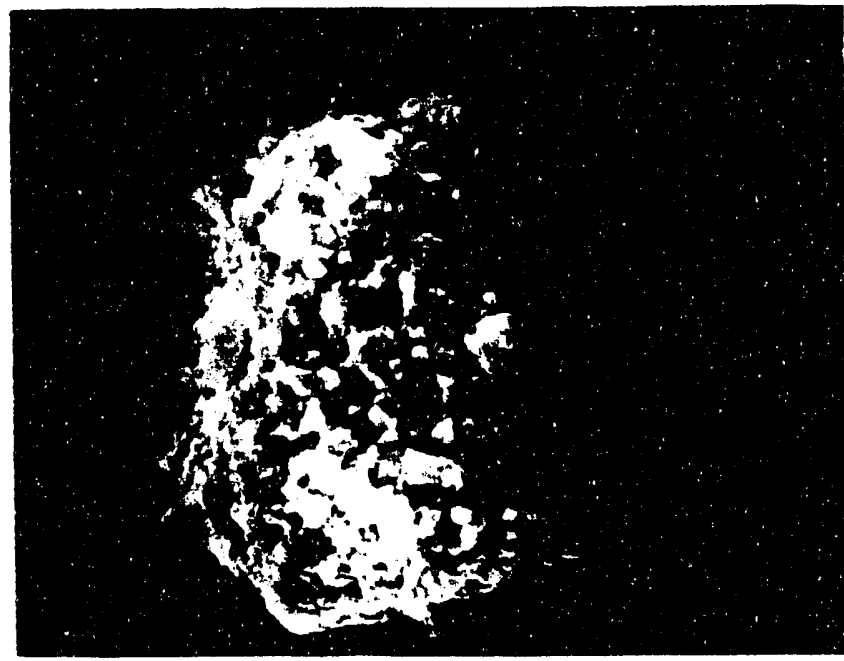

莡

$\infty$

운

包

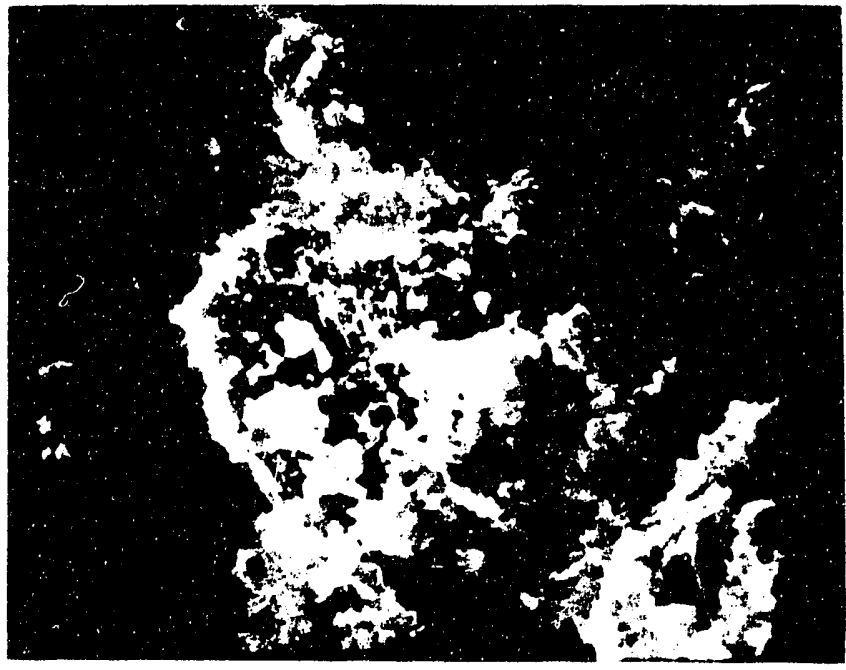

8

을

농

를

i

늘

$\pi \quad$ 的 


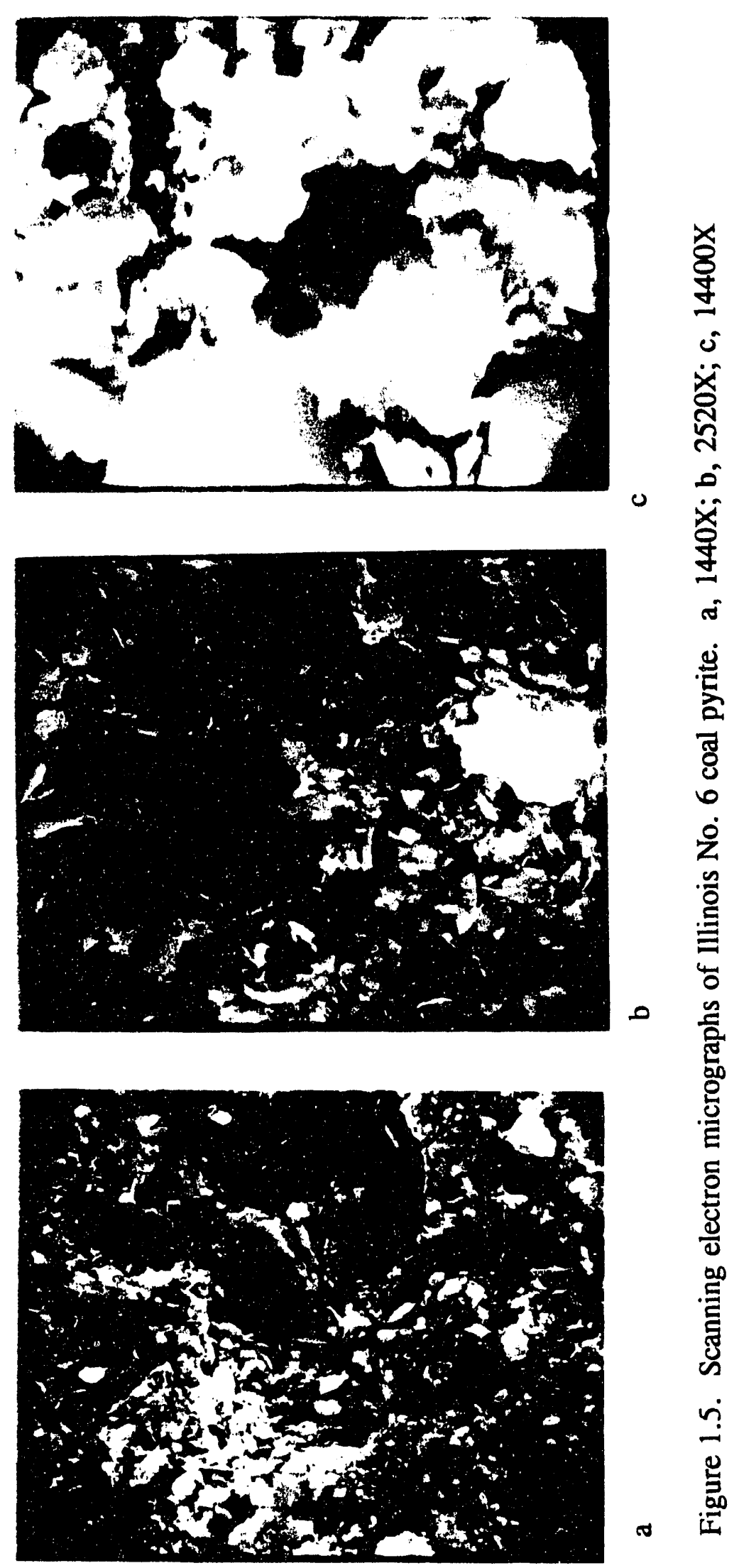


reported for coal pyrites as compared with mineral pyrites may be due in part to the surface roughness of the coal pyrites [1.6].

\section{ELECTRON MICROPROBE ANALYSIS}

Powdered pyrite samples where imbedded in epoxy resin, polished to expose a cross-section of the particles, coated with carbon, and examined in a Cameca SX-50 electron microprobe. The samples were examined for $\mathrm{Si}, \mathrm{Ca}, \mathrm{Fe}, \mathrm{S}$, and $\mathrm{O}$ by mapping the distribution of the elements using fluorescent $\mathrm{X}$-rays and by measurements of composition using an EDX spectrometer. The selection of particles for analysis is arbitrary and nonpyritic particles were not analyzed, but the results are representative of the samples.

The average composition and iron to sulfur ratios are shown in Table 1.3. Small amounts of $\mathrm{Ca}$ and $\mathrm{Si}$ are found associated with the pyrites. The mapping results show that these elements are found on the surfaces of the pyrites and are not intimately mixed with the pyrites. The iron to sulfur ratios measured in these experiments are all very close to 2.00 .

Table 1.3 Composition of pyrites

\begin{tabular}{lcccc}
\hline Element & $\begin{array}{c}\text { Colorado } \\
\text { pyrite }\end{array}$ & $\begin{array}{c}\text { Ward's } \\
\text { pyrite }\end{array}$ & $\begin{array}{c}\text { Upper Freeport } \\
\text { coal pyrite }\end{array}$ & $\begin{array}{c}\text { Pittsburgh No.8 } \\
\text { coal pyrite }\end{array}$ \\
\hline $\mathrm{Si}, \%$ & 0.05 & 0.02 & 0.19 & 0.05 \\
$\mathrm{Ca}, \%$ & 0.00 & 0.00 & 0.01 & 0.21 \\
$\mathrm{Fe}, \%$ & 45.73 & 45.99 & 43.57 & 44.95 \\
$\mathrm{~S}, \%$ & 52.48 & 52.59 & 49.61 & 51.07 \\
$\mathrm{O}, \%$ & 1.46 & 0.49 & 3.04 & 2.96 \\
$\mathrm{Fe} / \mathrm{S}$, range & 2.00 & $1.97-2.01$ & $1.97-2.02$ & $1.92-2.04$ \\
\hline
\end{tabular}

\section{IMAGE ANALYSIS}

Examination of coal samples in the optical microscope with automated image 
analysis has the potential to provide much useful information about coals. Conventional coal petrography requires examination of 500 points on each of two polished pellets of coal embedded in epoxy. Each point is classified by reflectance and shape and sometimes fluorescence behavior. In image analysis, an area is viewed and the reflectance for each square pixel is measured and stored as a digital image. The field of view may be automatically moved to acquire high degree of coverage of the entire coal pellet. Computer programs must then be developed to identify each individual particle.

Image analysis was used to examine the three coal samples used in this study. Epoxy grain mounts of the coals were prepared and polished according to standard procedures. A Zeiss Vidas system was used for the analysis. The grey values for each of the main maceral groups and pyrite were determined. Exinite values were in the range 117 to 140 , with 255 being the maximum grey value possible. Vitrinites covered the range 122 to 167 and inertinites 166 to 253. Pyrite particles had grey values of from 253 to 255. Mineral matter other than pyrite was not observed separately and would be included with one of the maceral groups. These results indicate that reflectance alone is not sufficient to identify maceral and mineral groups in coal.

Optical images of the three coal samples are shown as the images on the left in Figures 1.6-1.8. The horizontal field of view is $500 \mu \mathrm{m}$ and the size of a pixel is $25 \mathrm{~nm}$ square. A grey value is assigned to each pixel and the intensity of each region is a measure of reflectance for that maceral or mineral. The bright particles are pyrite and the lighter grey areas are the epoxy mounting medium. A grey value of 253 was used to discriminate between the pyrite and the coal. Areas with grey values between 253 and 255 are shown as white portions in the binary images on the right hand side of Figures 1.61.8. The remaining material is dark. In theory, the binary images could be used to determine size, shape, and volume percent of pyrite particles. Attempts to calculate these parameters were unsuccessful. One hundred images for each coal were summed to calculate the percent composition. The area for the coal was calculated by determining the area of epoxy resin using the fluorescence mode. Some difficulty was experienced in discriminating between the epoxy and the exinite macerals. The results of the measurements showed variation, depending on the number of images included in the 

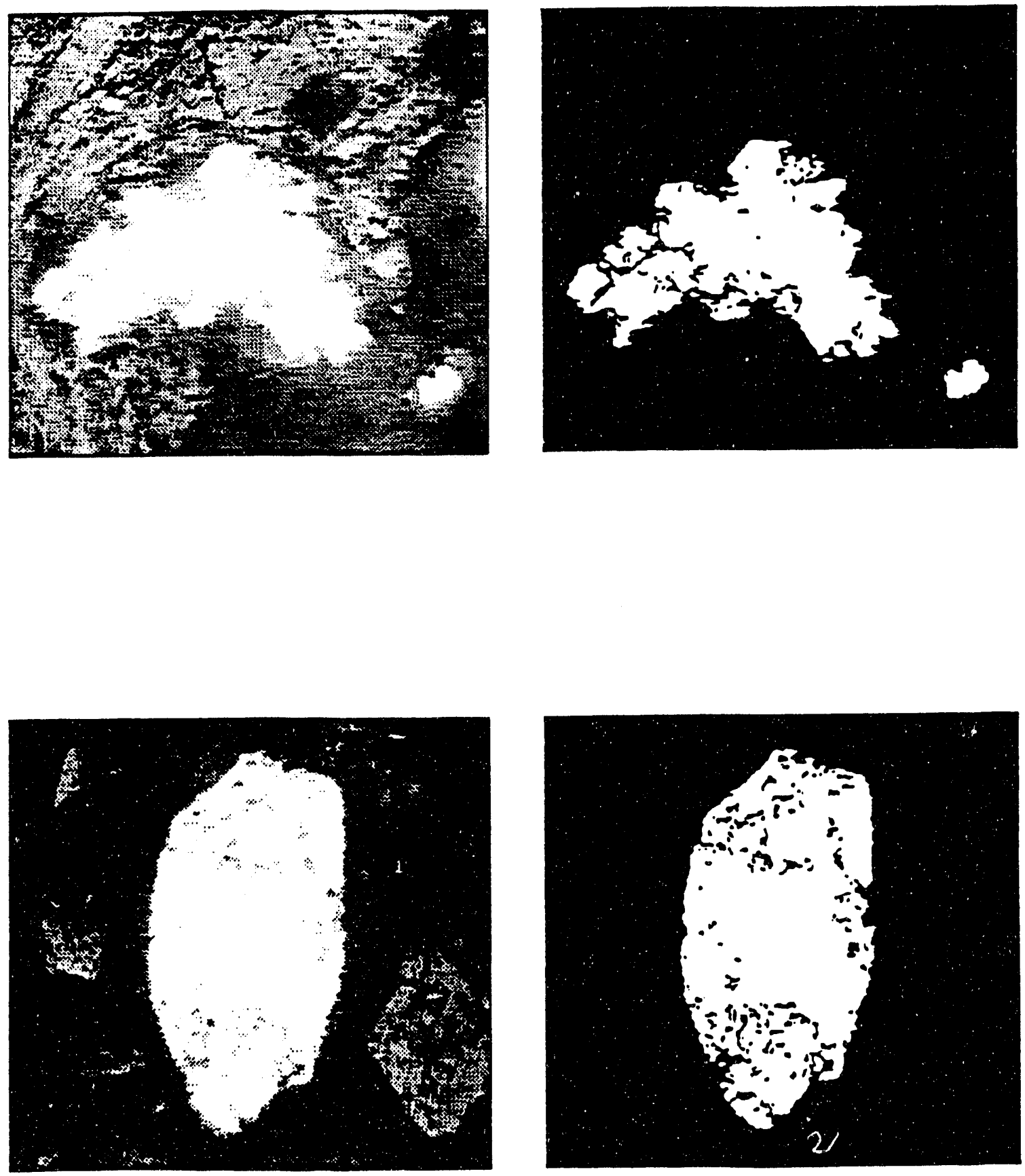

Figure 1.6. Optical microscope image (left) and binary image of pyrite with grey scale of 253-255 (right) for Upper Freeport coal 

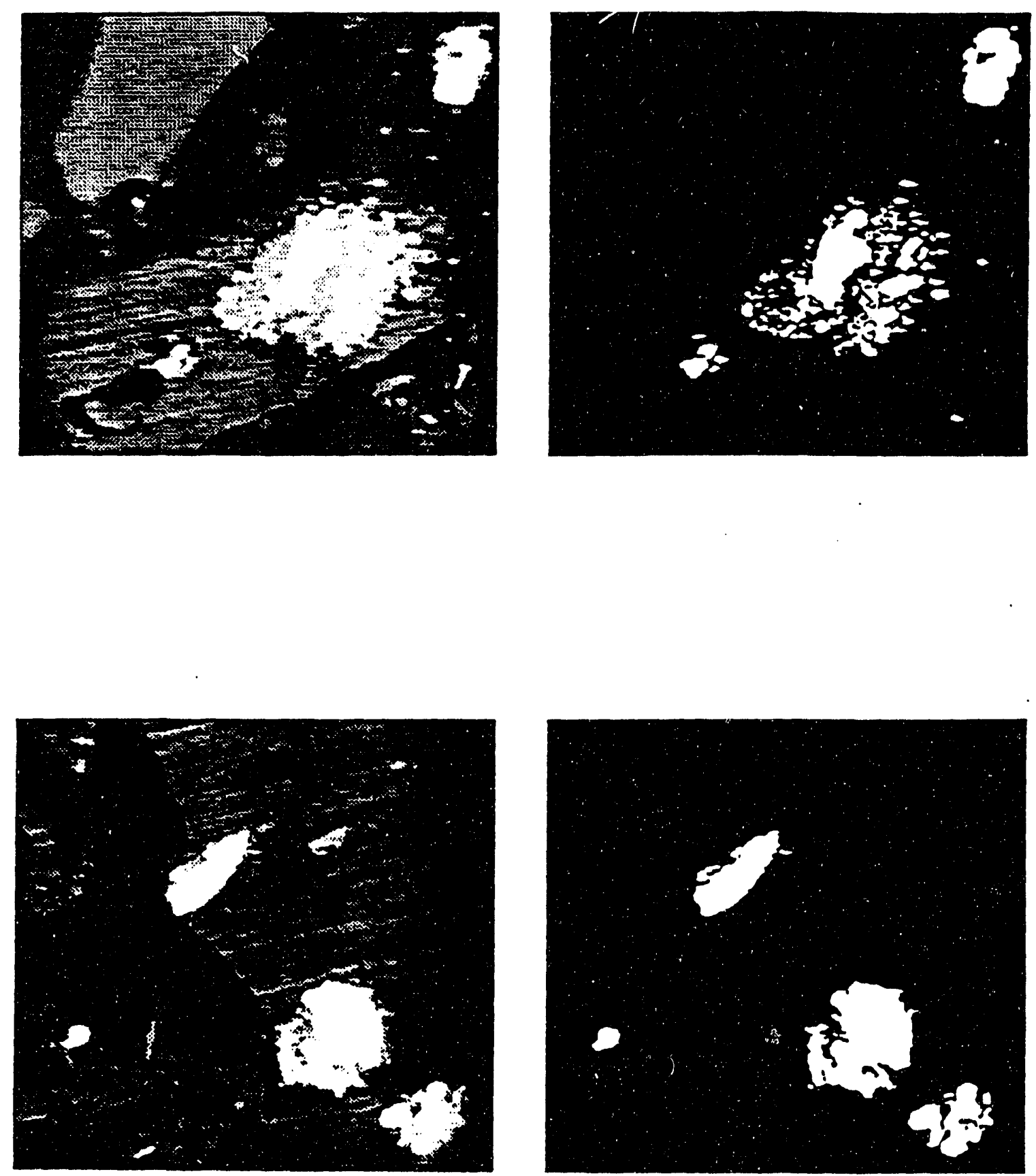

Figure 1.7. Optical microscope image (left) and binary image of pyrite with grey scale of 253-255 (right) for Pittsburgh No. 8 coal 

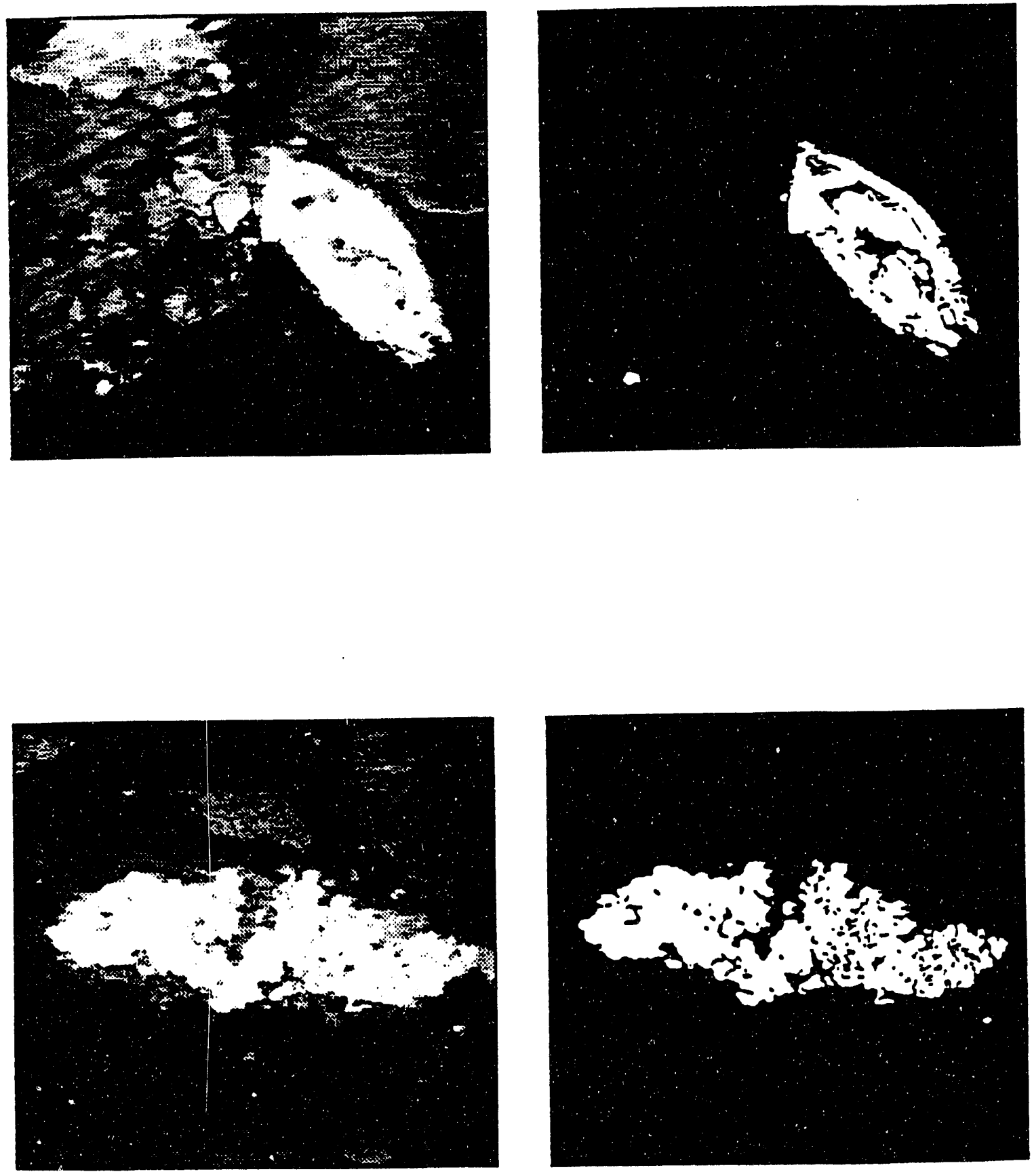

Figure 1.8. Optical microscope image (left) and binary image of pyrite with grey scale of 253-255 (right) for Illinois No. 6 coal 
calculation and were not in agreement with chemical measurements of the pyrite content. The error is attributed to the intense reflectance of the pyrite, which creates a "halo" effect around pyrite particles and distorts their size and shape. If these difficulties can be overcome by modified procedures, image analysis could provide much useful information on pyrite properties and changes occurring during processing.

\section{CONCLUSIONS}

1. Electron microprobe and scanning electron microscopic analysis of mineral pyrite and coal pyrite samples demonstrates that mineral pyrite has a smoother surface morphology than coal pyrites. Among coal pyrite samples, surface roughness increases in the order: Upper Freeport coal pyrite < Pittsburgh No. 8 coal pyrite < Illinois No. 6 pyrite. The atomic ratio of sulfur to iron in all pyrite samples was found to be 2.0. There is little association of pyrite with other minerals and few inclusions.

2. Image analysis of polished coal samples demonstrates the distribution of the pyrite, but quantitative analysis of the pyrite concentration was not achieved.

\section{REFERENCES}

[1.1] E. Stach, M. -Th Mackowsky, M. Teichmüller, G. H. Taylor, D. Chandra, and R. Teichmüller, Stach's Textbook of Coal Petrology, 3rd edition (Berlin; Gebrüder Bottraeger, 1982).

[1.2] Erich Raask, Mineral Impurities in Coal Combustion (Washington; Hemisphere Publishing Corporation, 1985).

[1.3] A. Attar, "Sulfur Groups in Coal and Their Determinations," Analytical Methods for Coal and Coal Products; C. Karr, Jr., ed., Vol. III (New York, N.Y.; Academic Press, 1979), Chap. 56.

[1.4] Coal Surface Control for Advanced Fine Coal Flotation; U. S. Department of Energy Contract Number DE-AC-88PC88878; Fuerstenau, D.W., Principal Investigator. 
16

[1.5] Karl S. Vorres. Users Handbook for the Argonne Premium Coal Sample Program (Argonne, Ilinois; Argonne National Laboratory, 1989); Energy \& Fuels, 4 (1990) 426.

[1.6] M. C. Esposite, S. Chander, and F. F. Aplan, "Characterization of Pyrite from Coal Sources," Process Mineralogy; A. H. Vassiliou, ed., (TMS/AIME, 1987), 23. 


\section{ELECTROCHEMISTRY}

\section{INTRODUCTION}

Pyrite is the most widespread and abundant of naturally occurring metal sulfides. It is commonly present in base metal sulfides and is frequently the major sulfur containing constituent in coal. Combustion of high-sulfur coal presents an important environmental problem due to the sulfur oxide emissions. A knowledge of the surface electrochemical properties of pyrite is important in better understanding methods for the modification : nd control of surface properties, hopefully to improve its separation from coal.

Numerous investigations have addressed the anodic oxidation response of pyrite in acid solutions. Only limited attention has been directed to the anodic behavior of pyrite in alkaline solutions, especially in the anodic transpassive region. There has been little work done on the kinetics and mechanism of surface film formation resulting from pyrite transpassive oxidation.

Hamilton and Woods [2.1] studied the surface oxidation of pyrite and pyrrhotite in $0.05 \mathrm{M} \mathrm{Na}_{2} \mathrm{~B}_{4} \mathrm{O}_{7}$ solutions ( $\mathrm{pH} 9.2$ ) and $0.1 \mathrm{M} \mathrm{NaOH}$ solutions $(\mathrm{pH} 13.0$ ) by linear puter.jal sweep voltammetry. The potential scan range used was about -0.8 to $+0.8 \mathrm{~V}$ (SHE). In solutions at pH 9.2, an anodic peak at about $0.0 \mathrm{~V}$ (SHE) was observed. The proposed oxidation reactions were

$$
\begin{gathered}
\mathrm{FeS}_{2}+3 \mathrm{H}_{2} \mathrm{O}=\mathrm{Fe}(\mathrm{OH})_{3}+2 \mathrm{~S}^{0}+3 \mathrm{H}^{+}+3 e^{-} \\
\mathrm{FeS}_{2}+11 \mathrm{H}_{2} \mathrm{O}=\mathrm{Fe}(\mathrm{OH})_{3}+2 \mathrm{SO}_{4}^{2-}+19 \mathrm{H}^{+}+15 e^{-}
\end{gathered}
$$

The proportion of sulfate formed was found to increase with an increase in the upper potential limit of the sweep. The reduction of both $\mathrm{Fe}(\mathrm{OH})_{3}$ and $\mathrm{S}^{\circ}$ occurs in a similar potential range and hence a single cathodic peak appeared at about $-0.3 \mathrm{~V}$ (SHE) on the voltammogram. It was concluded that HS- would not be released to the solution since iron oxides are presented on the mineral surface and would react directly with any HS' formed. The proposed reduction reactions are

$$
\mathrm{Fe}(\mathrm{OH})_{3}+\mathrm{S}^{0}+3 e^{-}=\mathrm{FeS}+3 \mathrm{OH}^{-}
$$




$$
\mathrm{Fe}(\mathrm{OH})_{3}+\mathrm{H}^{+}+e^{-}=\mathrm{Fe}(\mathrm{OH})_{2}+\mathrm{H}_{2} \mathrm{O}
$$

Janetski, Woodburn and Woods [2.2] also concluded that these peaks involve predominantly the oxidation and reduction of $\mathrm{Fe}$ (II) and Fe(iil) hydirated oxides on the sulfide mineral surface.

Chander and Briceno [2.3] studied the properties of surface films formed during pyrite oxidation in unstirred $0.1 \mathrm{M}$ sodium borate solution at $\mathrm{pH} 9.3$ using $\mathrm{AC}$ impedance and cyclic voltammetry with a scan range of $-0.8 \mathrm{~V}$ to $0.0 \mathrm{~V}$ (SHE). Similar peaks as indicated by Janetski et al. [2.2] were observed in cyclic voltammetry measurements. These authors also postulated that the observed peaks resulted from the oxidation of $\mathrm{Fe}(\mathrm{OH})_{2}$ to $\mathrm{Fe}(\mathrm{OH})_{3}$ during the anodic scan and reduction of $\mathrm{Fe}(\mathrm{OH})_{3}$ to $\mathrm{Fe}(\mathrm{OH})_{2}$ in the subsequent sweep. An almost linear increase of polarization resistance, $R_{p}$ with time resulting from AC impedance measurements, showed that the film growth is likely to be responsible for the increase. If it is assumed that the film characteristics do not change with time, the linear increase in $R_{p}$ may be taken as a measure of the thickness of the film.

Franklin, Nnodimele and Adeniyi [2.4] proposed that, for the anodic oxidation of pyrite in alkaline solutions, there are three reactions producing sulfur, ferric oxide and sulfate. However, experimentally only one voltammetric oxidation peak was observed. These investigators used a surfactant which served to form a film on the electrode. Without a film, only one voltammetry wave was observed and was associated with a one electron oxidation of $S_{2}{ }^{2-}$ to $S_{2}$. In the filmed system three waves and a sharp rise in current before oxygen evolution were observed indicating the presence of three reactions associated with the pyrite surface,

$$
\begin{aligned}
S_{2}^{2-} & =S_{2}^{-}+e^{-} \\
F e^{2+} & =F e^{3+}+e^{-} \\
S_{2}^{2-} & =S_{2}^{0}+2 e^{-}
\end{aligned}
$$

Ahlberg et al. [2.5] studied the surface oxidation of pyrite in $1 \mathrm{M} \mathrm{NaClO}_{4}$ solutions ( $\mathrm{pH} 11)$. In the high potential region the anodic dissolution of pyrite was 
proposed to be diffusion controlled and charge transfer in this region to be a single electron process. It was concluded that the initial oxidation of pyrite produces a hydrophobic sulfur rich surface together with hydrophilic iron hydroxide species. These investigators demonstrated that removal of surface iron oxidation products by EDTA produce natural floatability. This was attributed to the presence of sulfur rich layers formed below the hydrophilic iron hydroxide surface at high voltages.

Wheelock et al. [2.6] performed potentiometric and voltammetric measurements on pyrite electrodes in solutions of different $\mathrm{pH}$ values (2.0, 4.6 and 9.3). A reversed anodic scan to $+0.3 \mathrm{~V}$ resulted in the appearance of two cathodic peaks at about $-0.5 \mathrm{~V}$ and $-0.95 \mathrm{~V}$. These were attributed to the presence of elemental sulfur and iron oxidation products, respectively. The authors proposed that $\mathrm{Fe}(\mathrm{OH})_{2}$ and $\mathrm{HS}^{-}$ions are expected to form during cathodic polarization of $\mathrm{FeS}_{2}$ at $\mathrm{pH}$ 9.3. In the following anodic scan these two products undergo oxidation to $\mathrm{Fe}(\mathrm{OH})_{3}$ and $\mathrm{S}^{\circ}$, respectively. Moreover, the ratio of hydrophilic iron oxidation products to hydrophobic elemental sulfur was found to increase with increasing anodic potential.

Mycroft et al. [2.7] investigated the electrochemical oxidation of pyrite surfaces in near-neutral aqueous chloride solutions using Raman spectroscopy. The surface oxidation products of pyrite between 600 and $700 \mathrm{mV}$ (SCE) were identified as polysulfides and elemental sulfur.

Many authors have studied the electrodissolution and passivation of iron in basic solutions. Iron oxide layers on the surface of pyrite when exposed to sufficiently negative cathodic potentials would be expected to form metallic iron and thus show some similarities in electrochemical response. Armstrong and Coates [2.8] reported that two anodic peaks were observed before passivation on a rotating iron disk electrode in a $\mathrm{NaHCO}_{3} / \mathrm{Na}_{2} \mathrm{CO}_{3}$ solution of $\mathrm{pH}$ 8.7. The $\mathrm{Fe}(\mathrm{II})$ species resulting from iron dissolution was mainly $\mathrm{Fe}(\mathrm{OH})^{+}$. Rangel et al. $[2.9,2.10]$ and Beck et al. [2.11] detected an additional anodic peak, at 0.65-0.85 V (SHE), besides the two anodic peaks in the prepassivation region, in unstirred $600 \mathrm{ppm}$ sodium carbonate/bicarbonate solution $(\mathrm{pH}$ 10.05). The additional peak was proposed to have resulted from the transpassive anodic dissolution of $\mathrm{Fe}$ (III)-oxide layers to $\mathrm{Fe}(\mathrm{VI})$-species, $\mathrm{FeO}_{3}$, and hydrolysis to yield 
ferrate(VI) ion, $\mathrm{FeO}_{4}{ }^{2-}$. The conjugate cathodic reaction was the reduction of ferrate(VI) ion, $\mathrm{FeO}_{4}{ }^{2}$, to ferrate(III) ion, $\mathrm{FeO}_{2}$. Valentini et al. $[2.12,2.13]$ studied the electrochemical behavior of iron in potassium carbonate/bicarbonate using rotating iron disc electrodes. Peaks similar to those detected by Rangel et al. were observed as well as a double peak, which was stirring velocity dependent, at about -0.6 to $-0.4 \mathrm{~V}$ (SHE).

Pyrite in coal has been observed to behave differently from pyrite in mineral samples. As early as 1938, Burke and Downs [2.14] noted that coal pyrite was 10 times as reactive as either synthetic or naturally occurring marcasite and pyrite. Other authors similarly have made comparative studies of coal pyrite and mineral pyrite. Lai et al. [2.15] used cyclic voltammetry, flotation response, evolved-gas analysis and X-ray photoelectron spectroscopy to evaluate the major differences in surface properties and reactivity. They demonstrated that the oxidation rate of Ohio coal pyrite is higher than that of Colorado mineral pyrite under identical conditions used in their study. Briceno and chander [2.16] used three different electrochemical methods: steady state polarization, cyclic voltammetry and AC impedance measurements, to characterize coal and mineral pyrite in $0.1 \mathrm{M}$ unstirred borate solution (pH 9.3). The results showed that the corrosion potential of coal pyrite is $0.45 \mathrm{~V}$ more negative than that of mineral pyrite. The current densities for the coal pyrites were always higher than that of mineral pyrite and the charge transfer resistance of coal pyrite was much lower.

In this study, cyclic voltammetry was used to determine oxidation/reduction reactions occurring at mineral and coal pyrite surfaces. Chronoamperometry and AC impedance measurements were used to study the surface film growth kinetics. The objective was to develop methods to control the conditions: oxidation/reduction potential and time, as well as solution $\mathrm{pH}$ in electro-flotation processes and ultimately to modify surface properties for the optimum separation of pyrite from fine coal.

\section{EXPERIMENTAL}

\section{Electrode and Solution Preparation}

For each experiment, a selected pyrite sample was used as the working electrode. Mineral pyrite and coal pyrite electrodes were prepared from sections of natural crystals. 
The mineral pyrite was obtained from Ward's National Science Establishment and the three coal pyrites were from sulfur refuses obtained from the Pittsburgh No.8 seam of the Cumberland Mine, Greene County, PA, the Upper Freeport seam, Coshocton County, $\mathrm{OH}$, and the Illinois No.5 seam, Saline County, IL. For stationary electrodes, the samples were cut to size, avoiding inclusions, cracks and voids and encapsulated in epoxy cement. For rotating disk electrodes, the samples were cut with a diamond core drill of $1.1 \mathrm{~cm}$ diameter and tightly fitted into a teflon disk holder. The electrical contact between the disk electrode and the rotator was through a spring connected to the contact stud of the rotator. This made the disk electrode readily changeable. The electrode surfaces were ground on 180 and 600 grit silicon carbide paper and polished sequentially using 1.0, 0.3 and 0.05 micron alumina before each measurement. The exposed surfaces of both stationary and rotating disk electrodes were $1 \mathrm{~cm}^{2}$, except that of Upper Freeport coal pyrite sample, which was $0.3 \mathrm{~cm}^{2}$. A $12 \mathrm{~cm}^{2}$ platinum sheet was used as the counter electrode and a saturated calomel electrode was used as the reference electrode.

An electrolyte solution of $0.01 \mathrm{M}$ sodium borate in $0.49 \mathrm{M}$ sodium sulfate was prepared from reagent grade chemicals and deionized distilled water. The resulting $\mathrm{pH}$ of the solution is 9.2 . Higher and lower $\mathrm{pH}$ values were obtained by addition of $\mathrm{NaOH}$ or $\mathrm{HCl}$ solutions.

\section{Apparatus and Procedure}

Cyclic voltammetry, AC impedance and chronoamperometry measurements, except those for evaluation of the temperature effect, were conducted at room temperature in a three-compartment Pyrex cell. Both the saturated calomel reference electrode and the platinum counter electrode were kept in separate compartments. The solution was purged with bubbling argon for about two hours prior to insertion of the sample electrode. The flow of argon at the surface of the solution was continued during measurements to prevent diffusion of atmospheric oxygen to the solution surface. For experiments using a stationary electrode, stirring was provided by a magnetic stirrer in the working electrode compartment. For experiments using a rotating disk electrode, the rotation speed was controlled by a model 616 rotating disk electrode manufactured by EG\&G PARC, capable 
of rotating an electrode at speeds from 100 to $8000 \mathrm{rpm}$ with a speed accuracy of better than $\pm 3 \%$ for the entire range. For temperature effect tests, the three-compartment cell was clamped into place in a water bath, set to the desired temperature using a Haake constant temperature controller, with temperature stability of $\pm 0.1^{\circ} \mathrm{C}$. An EG\&G PARK Model 273 Potentiostat/Galvanostat was used for the dc electrochemical experiments. Coupled with a Model 5208 EC lock-in amplifier, it was used for ac impedance measurements. The frequency range of the configuration was $5 \times 10^{-5}$ to $1 \times 10^{5} \mathrm{~Hz}$. An IBM PC-XT computer was utilized to control the potentiostat and the lock in amplifier. For cyclic voltammetry study, the scanning potential covered the range from hydrogen to oxygen evolution $(-1.3$ to $+0.8 \mathrm{~V}$, vs SCE), unless otherwise specified. Scan rates were varied between 20 to $400 \mathrm{mV} / \mathrm{s}$. Most scans were at $50 \mathrm{mV} / \mathrm{s}$. Because the electrode surface was oxidized very easily during polishing, the first one or two cycles were not reproducible, but reproducible results were obtained after approximately three cycles. The voltammograms presented are for fifth cycle sweeps, unless otherwise indicated, and the potentials are recorded versus SCE. During chronoamperometry experiments, cell current was measured as a function of time and then the current versus time data were integrated numerically to determine the accumulated charge versus time. A schematic diagram of apparatus used for dc and ac electrochemical experiments is shown in Figure 2.1.

\section{RESULTS AND DISCUSSION}

\section{Surface Oxidation/Reduction}

The oxidation/reduction reactions occurring on pyrite surfaces were studied in sodium borate/sodium sulfate solutions using cyclic voltammetry with stationary electrodes.

Mineral Pyrite. The effects of the initial potential at the beginning of the scan and the direction of the scan were examined. See Figures 2.2 to 2.5. Regardless of the initial potential and direction of scan, after three cycles the cyclic voltammograms all coincided with one another. It is evident that the cathodic peaks in the $-1.3 \mathrm{~V}$ to $-0.4 \mathrm{~V}$ range result from prior anodic surface products. The peaks in this range are missing when the initial scan is in the cathodic direction. Subsequent voltammograms were scanned from $-1.3 \mathrm{~V}$ 

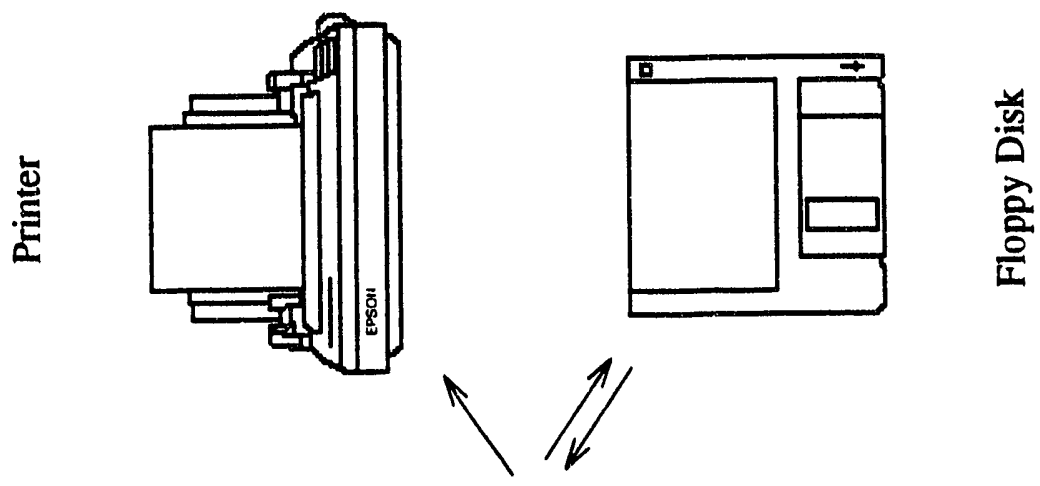

$\frac{2}{2}$

总

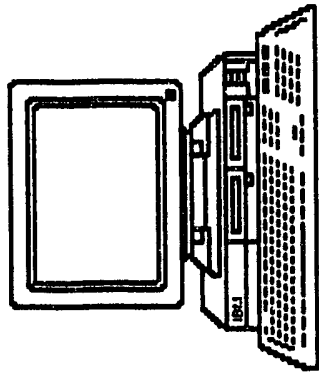

产
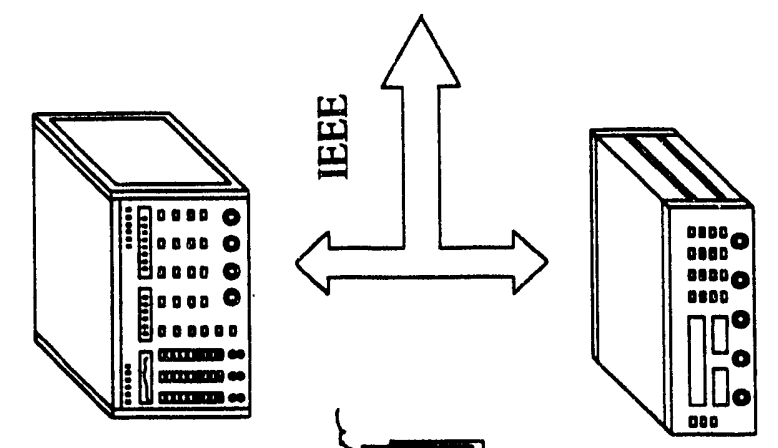

递

言

总
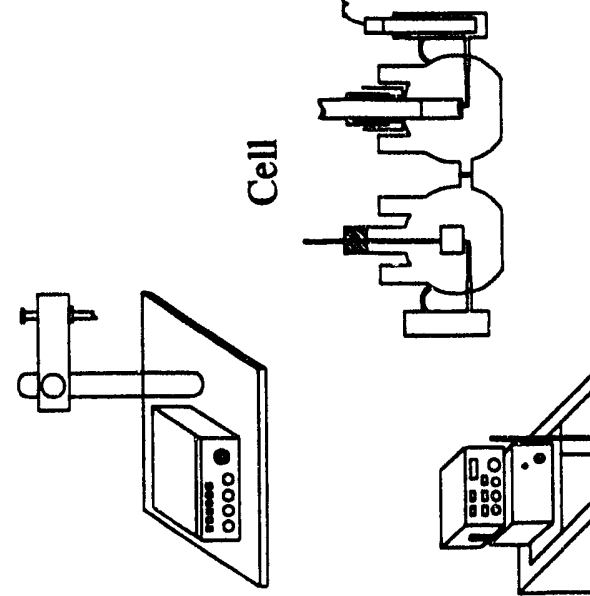

吾 


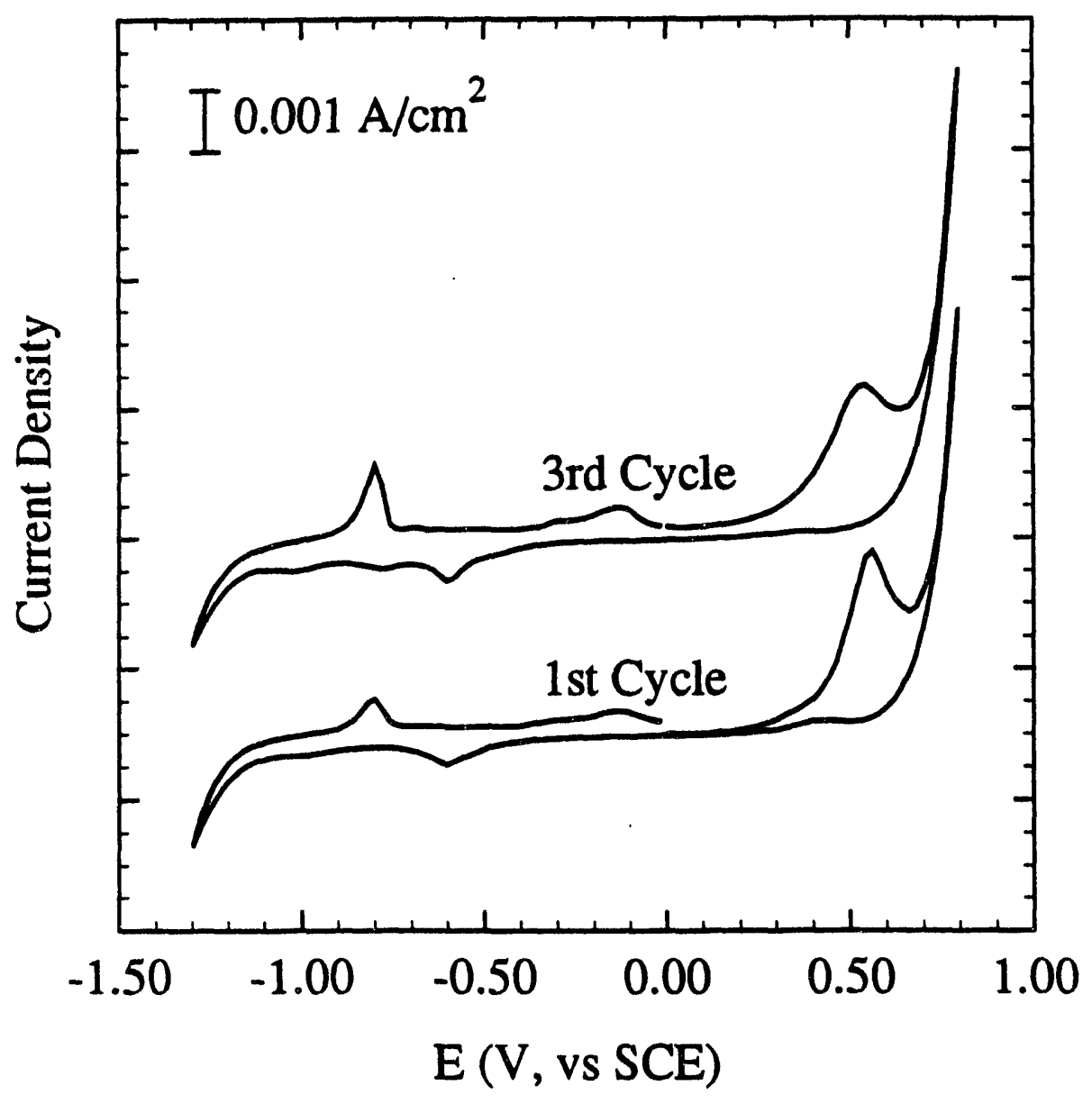

Figure 2.2. Mineral Pyrite in Quiescent Solutions at pH 9.2 Scan from $0.0 \mathrm{~V}$ towards Anodic, Scan Rates, $50 \mathrm{mV} / \mathrm{s}$ 


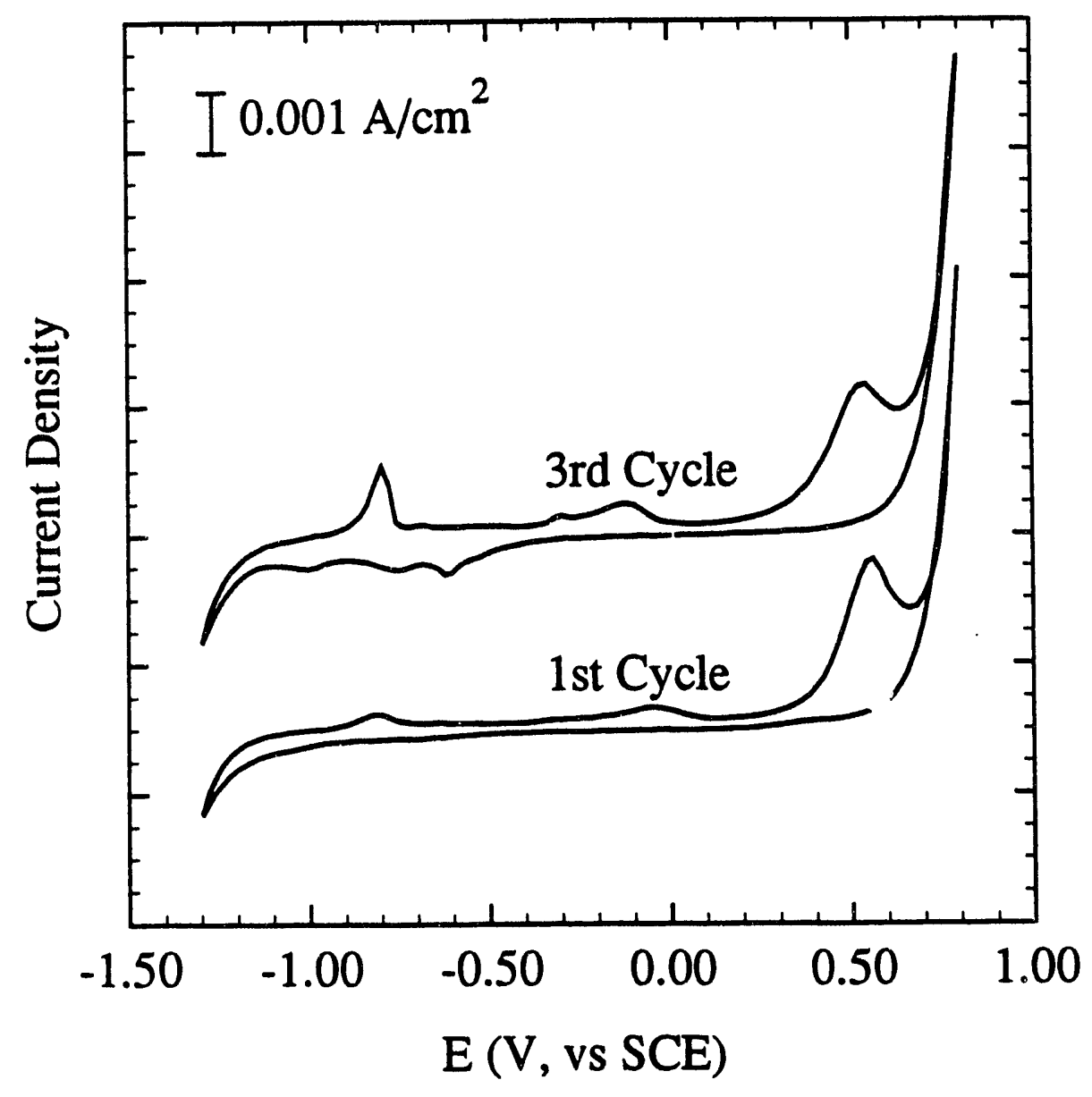

Figure 2.3. Mineral Pyrite in Quiescent Solutions at $\mathrm{pH} 9.2$ Scan from $0.0 \mathrm{~V}$ towards Cathodic, Scan Rates, $50 \mathrm{mV} / \mathrm{s}$ 


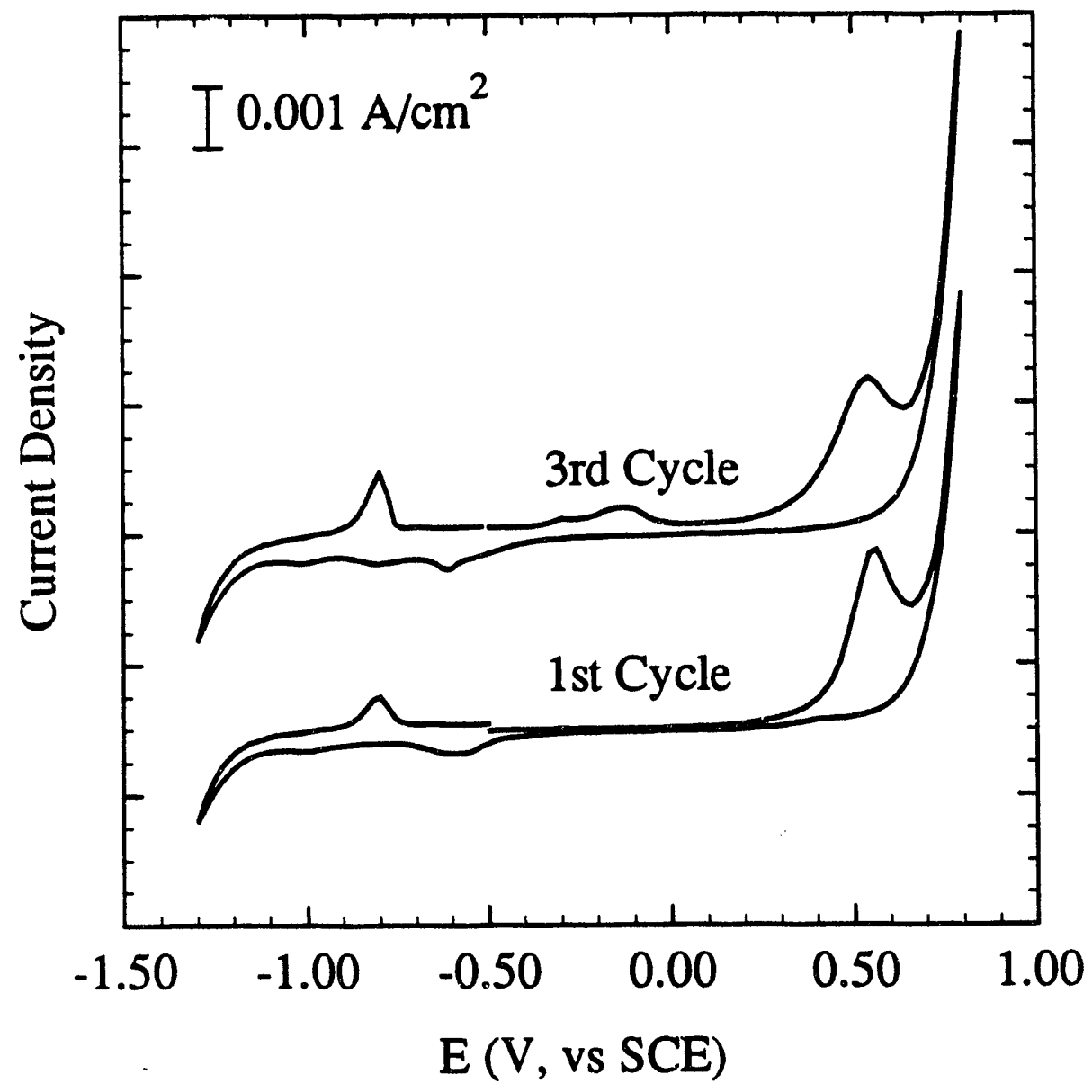

Figure 2.4. Mineral Pyrite in Quiescent Solutions at pH 9.2 Scan from $-0.5 \mathrm{~V}$ towards Anodic, Scan Rates, $50 \mathrm{mV} / \mathrm{s}$ 


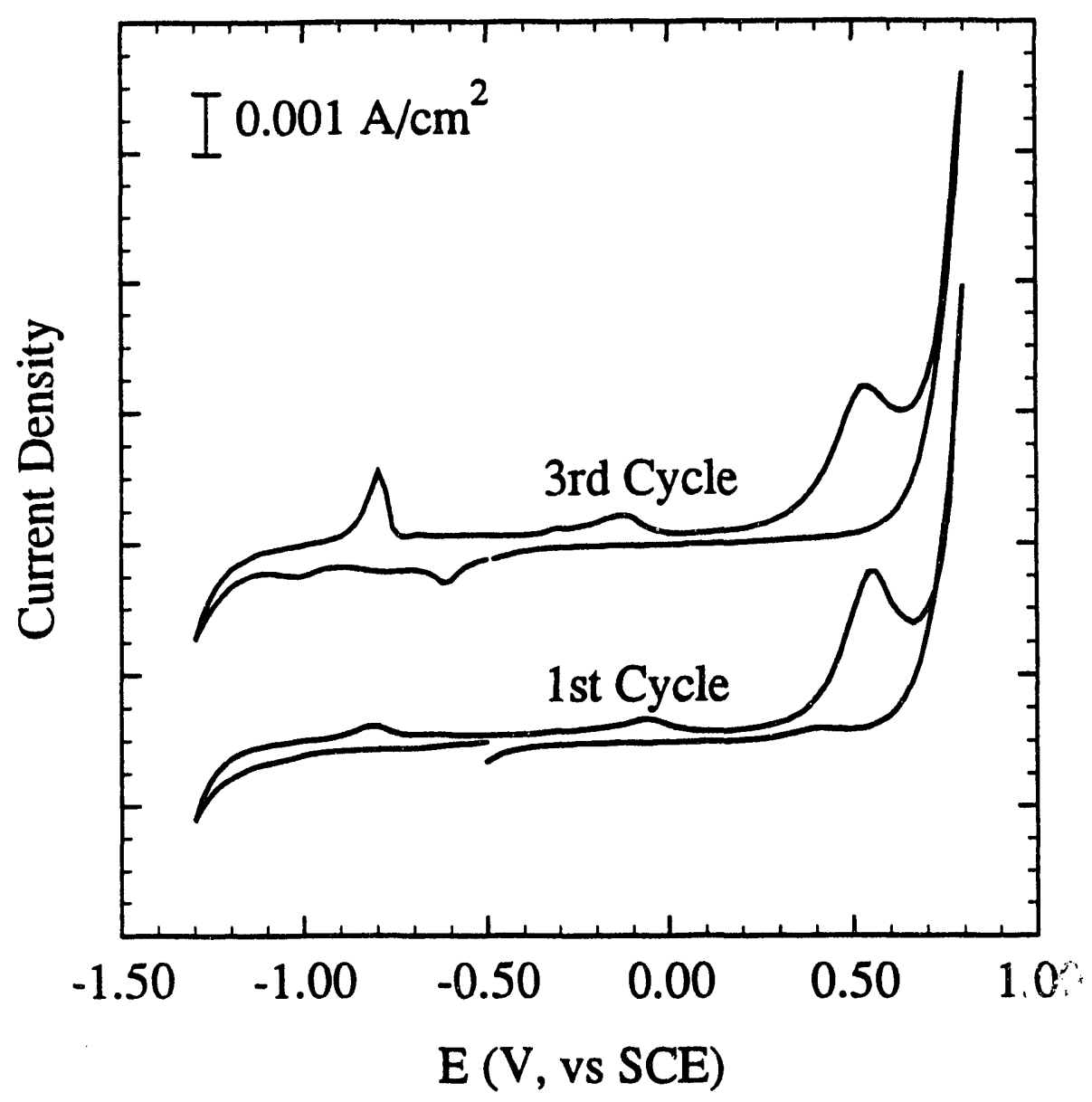

Figure 2.5. Mineral Pyrite in Quiescent Solutions at pH 9.2 Scan from $-0.5 \mathrm{~V}$ towards Cathodic, Scan Rates, $50 \mathrm{mV} / \mathrm{s}$ 
in the anodic direction unless otherwise indicated.

Cathodic/anodic pairs of peaks (Figure 2.6) were observed at potentials of about $1.0 /-0.8 \mathrm{~V}$ (peaks $6 / 1$ ) and $-0.5 /-0.15 \mathrm{~V}$ (peaks $5 / 2$ ) for $\mathrm{pH} 9.2$, a scan rate of $100 \mathrm{mV} / \mathrm{s}$ and stirred electrolyte. The maximum potential of the scan was $+0.6 \mathrm{~V}$. A series of runs at various scan rates is shown in Figure 2.7 for quiescent conditions and a maximum scan potential of $0 . \mathrm{V}$. Surface oxide layers exposed to cathodic potentials more negative than $\approx-0.83 \mathrm{~V}(\mathrm{SCE})($ at $\mathrm{pH}=9.2)$ would be expected to form metallic iron $[2.17,2.18]$,

$$
\begin{gathered}
\mathrm{Fe}(\mathrm{OH})_{2}+2 \mathrm{H}^{+}+2 e^{-}-\mathrm{Fe}^{\circ}+2 \mathrm{H}_{2} \mathrm{O} \\
E_{h}=-0.0475-0.059 \mathrm{pH}
\end{gathered}
$$

At $\mathrm{pH}=9.2, \mathrm{E}_{\mathrm{h}}=-0.59 \mathrm{~V}$ and $\mathrm{E}_{\mathrm{SCE}}=-0.832 \mathrm{~V}$. The cathodic partial reaction of Eq. 8 would account for peak 6 ( $\mathrm{Fe}^{\circ}$ formation) and the anodic partial reaction peak $1\left(\mathrm{Fe}(\mathrm{OH})_{2}\right.$ formation). Ferrous hydroxide present on the surface would be expected to oxidized to ferric hydroxide at higher potentials [2.1-2.3] according to the reaction

$$
\begin{gathered}
\mathrm{Fe}(\mathrm{OH})_{2}+\mathrm{H}_{2} \mathrm{O}=\mathrm{Fe}(\mathrm{OH})_{3}+\mathrm{H}^{+}+e^{-} \\
E_{h}=0.271-0.059 \mathrm{pH}
\end{gathered}
$$

At $\mathrm{pH} 9.2, \mathrm{Eh}=-0.272 \mathrm{~V}$ and $\mathrm{E}_{\mathrm{SCE}}=-0.514 \mathrm{~V}$.

The anodic and cathodic peaks increase with scan rate. The total coulombs of current associated with the various scans for each of the peaks 1,2,5 and 6 are about the same. This would be expected for rapid complete reaction of previously formed surface products and is consistent with the reaction of surface film as proposed by other investigators [2.12.3].

An additional peak (peak 3 ) was observed at about +0.5 V. For sweep rates over the range of 20 to $200 \mathrm{mV} / \mathrm{s}$, peak 3 is only present under quiescent conditions as shown in Figure 2.7. Figure 2.8 illustrates a similar series of voltammograms obtained with stirred electrolyte. The upper voltage in this series was $+0.8 \mathrm{~V}$ (SCE). Peak 3 is now missing and there is a great increase in current in the high potential region and for the other peaks at lower potentials. The effect of agitation is illustrated in Figure 2.9 where 


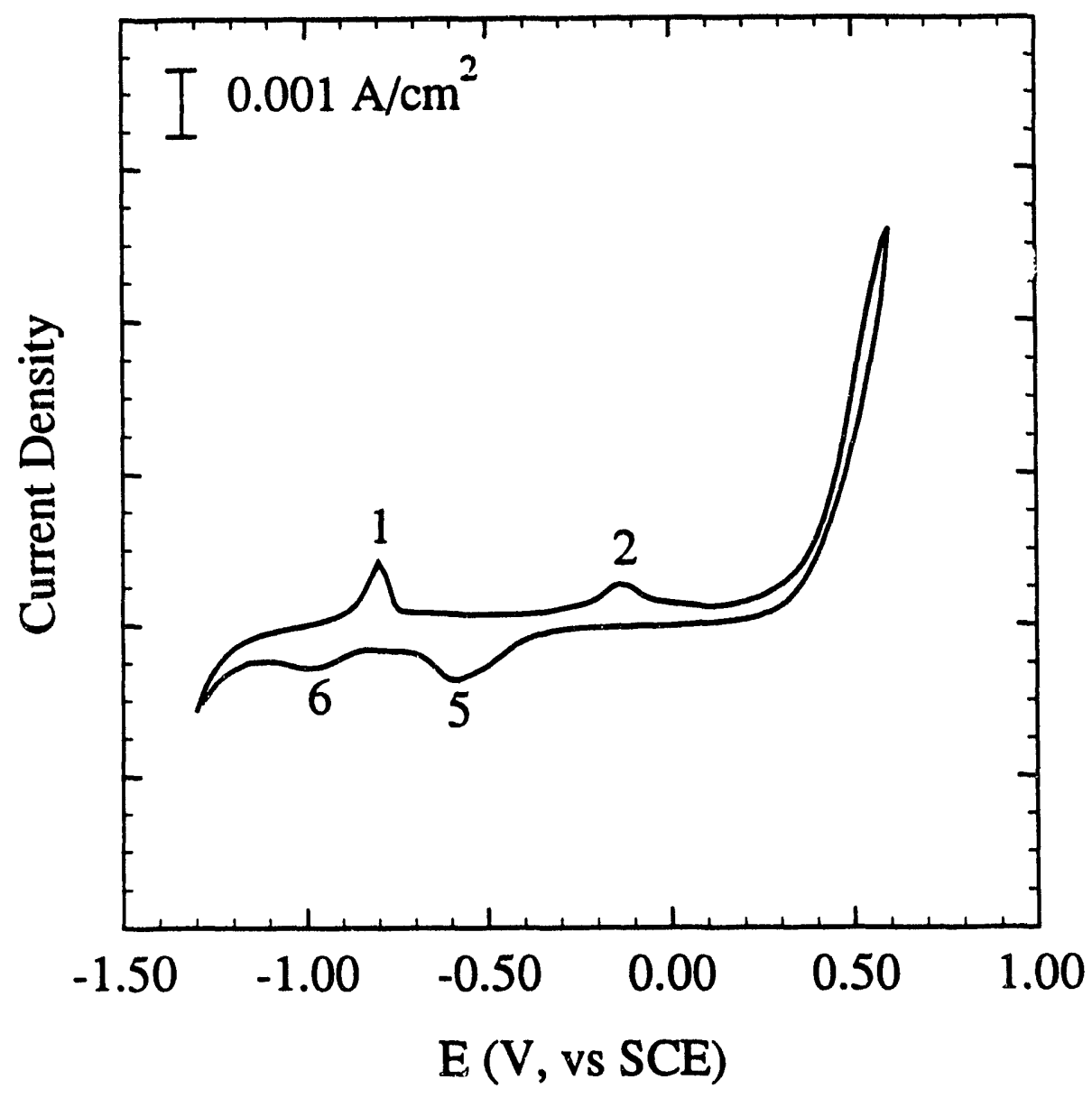

Figure 2.6. Mineral Pyrite in Stirred Borate Solution at $\mathrm{pH} 9.2$, Scan Rates, $100 \mathrm{mV} / \mathrm{s}$ 


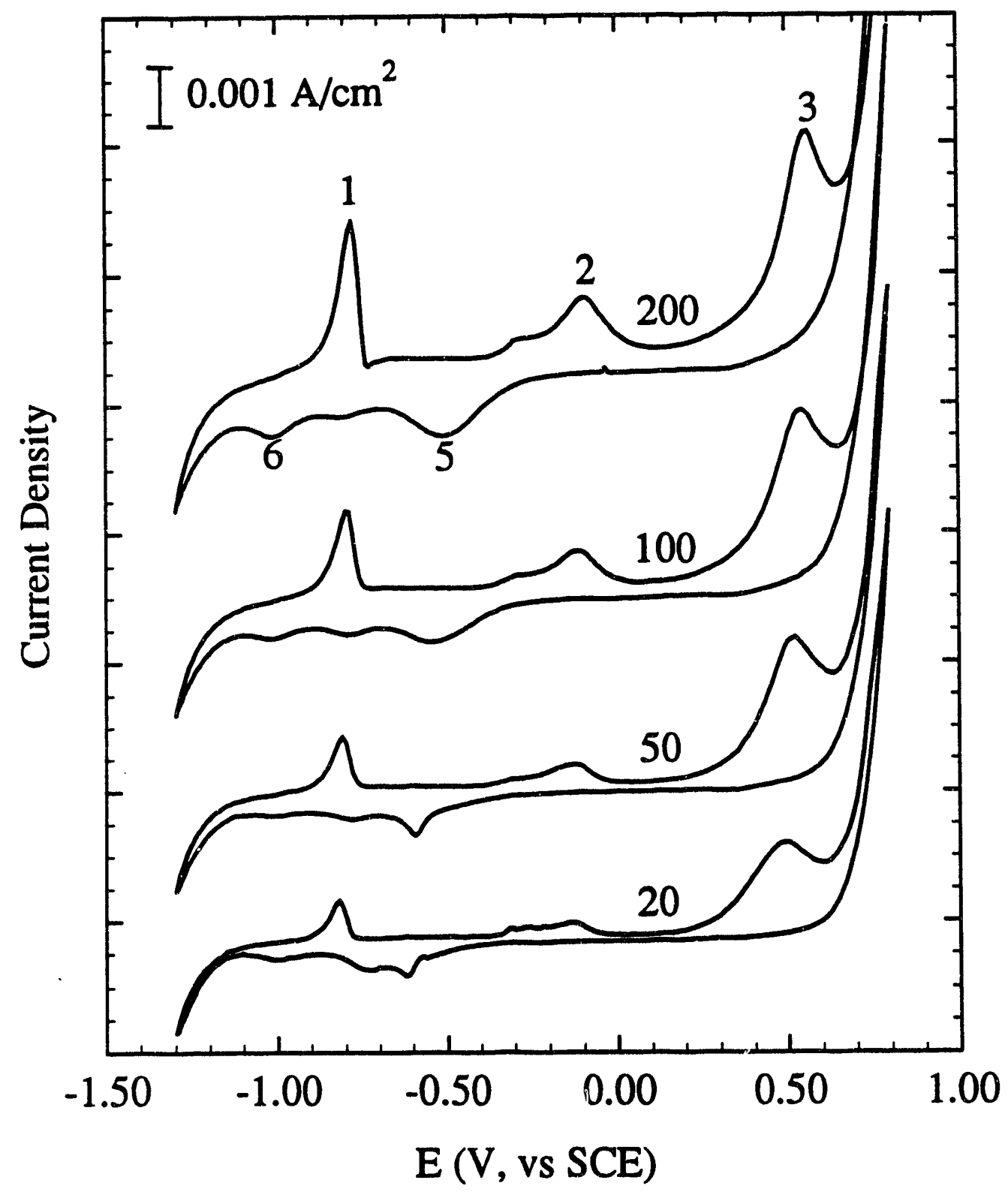

Figure 2.7. Mineral Pyrite in Quiescent Solutions at $\mathrm{pH} 9.2$ for Various Scan Rates, (mV/s) 


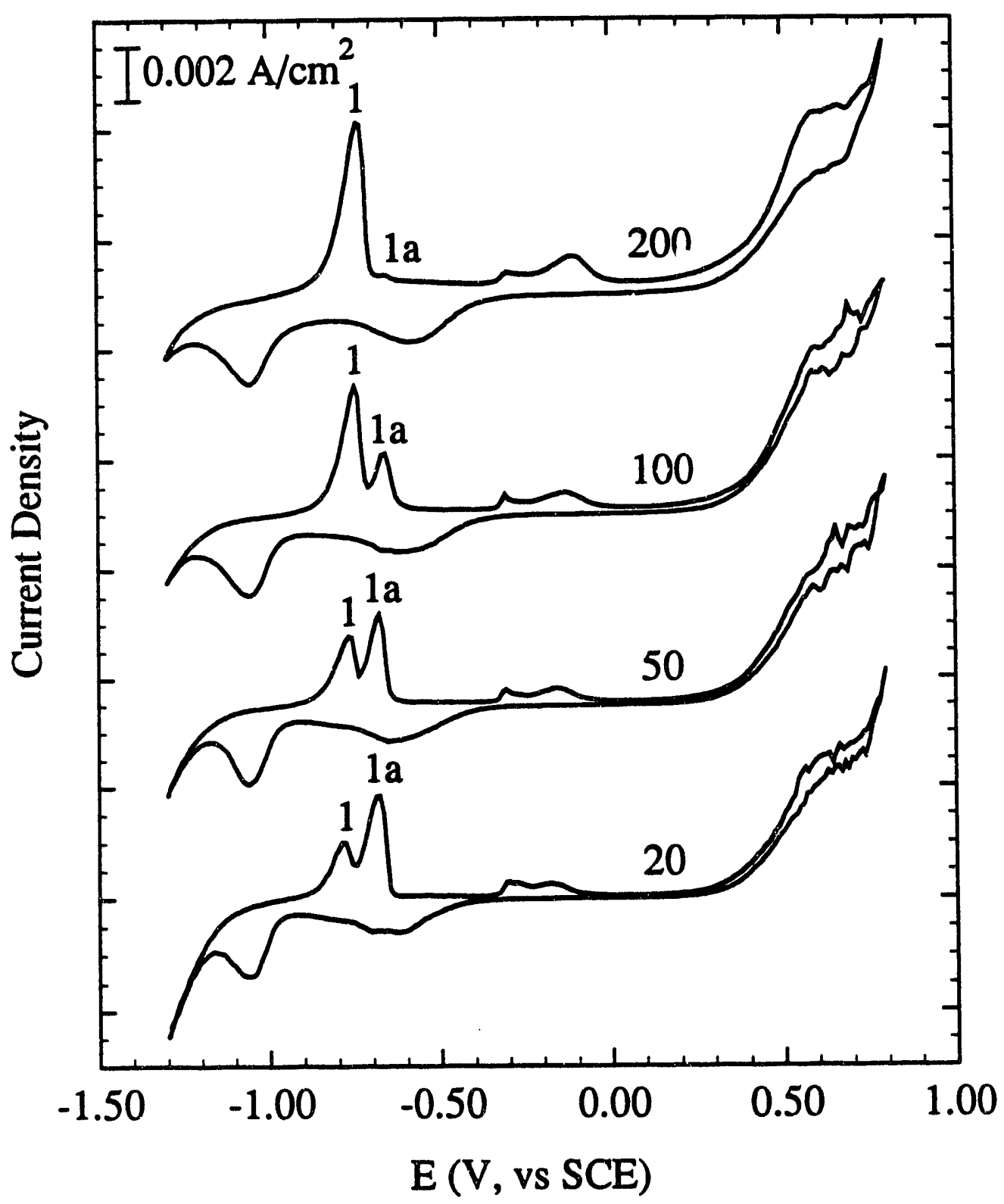

Figure 2.8. Mineral Pyrite in Stirred Solutions at pH 9.2 for Various Scan Rates, (mV/s) 


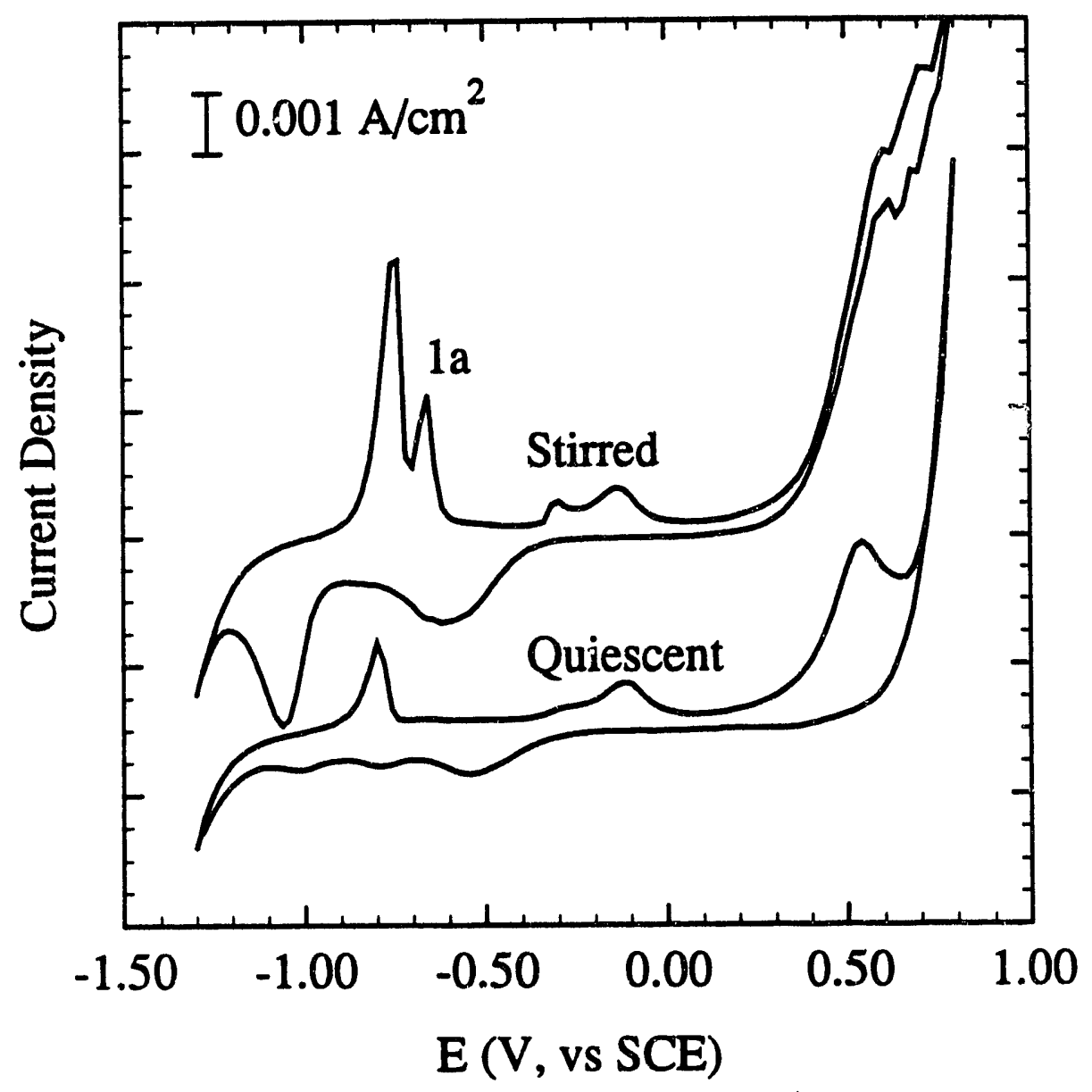

Figure 2.9. Effect of Solution Stirring, Mineral Pyrite in Solutions at pH 9.2, Scan Rate, $100 \mathrm{mV} / \mathrm{s}$ 
quiescent and stirred runs are compared for a scan rate of $100 \mathrm{mV} / \mathrm{s}$. All peak currents increase with stirring. A new peak, 1a, is now apparent and only occurred when the upper potential approached $+0.8 \mathrm{~V}$. Peak 1a first appeared at the second cycle and increased in intensity with cycling as shown in Figure 2.10, indicating peak 1a is time dependent. Figure 2.8 also illustrates the relative change of peaks 1 and 1 a for various sweep rates. As the sweep rate increased, peak 1 increased. Peak 1a decreased and was almost absent at the highest scan rate $(200 \mathrm{mV} / \mathrm{s})$. The effects of scan rate and electrode preconditioning time on peaks 1 and 1a are shown in Figures 2.11 and 2.12. The electrode in each case was pre-conditioned at $+0.4 \mathrm{~V}$, switch to $-1.1 \mathrm{~V}$ for equilibration for 30 seconds and then scanned from $-1.1 \mathrm{~V}$ to $-0.5 \mathrm{~V}$ immediately. Figure 2.11 illustrates results for a pre-conditioning time of 1 minute followed by various scan rates and Figure 2.12 compares pre-conditioning time of 1 and 3 minutes at a single scan rate. The integrated charge associated with peaks 1 and 1a is summarized in Tables 2.1 and 2.2. The total number of coulombs associated with the sum of both peaks remains about the same indicating both peaks are associated with the same reactants produced during the previous cathodic reduction cycle. The charge ratios(peak 1/peak 1a) appear to be essentially independent of scan rate in the range of $20-200 \mathrm{mV} / \mathrm{s}$. and near 0.75 . The charge of peak 1a is electrode pre-conditioning time dependent. If the pre-conditioning time is increased from 1 to 3 minutes, the total charge associated with peak $1 \mathrm{a}$ is almost tripled and the charge ratio of peak 1/peak 1a, for a scan rate of $50 \mathrm{mV} / \mathrm{s}$., is decreased from 0.72 to 0.54 .

Table 2.1. Effect of scan rate on charge of peaks 1 and 1a (Electrode pre-conditioned at $0.4 \mathrm{~V}$ for $1 \mathrm{~min}$.)

\begin{tabular}{ccccc}
\hline $\begin{array}{c}\text { Scan Rate } \\
\mathrm{mV} / \mathrm{sec}\end{array}$ & Total & Peak 1 & Peak 1a & Peak 1/1a \\
\hline 20 & 6.37 & 2.69 & 3.18 & 0.731 \\
50 & 6.33 & 2.64 & 3.69 & 0.715 \\
100 & 6.64 & 2.78 & 3.86 & 0.720 \\
200 & 6.30 & 3.06 & 3.24 & 0.944 \\
\hline
\end{tabular}




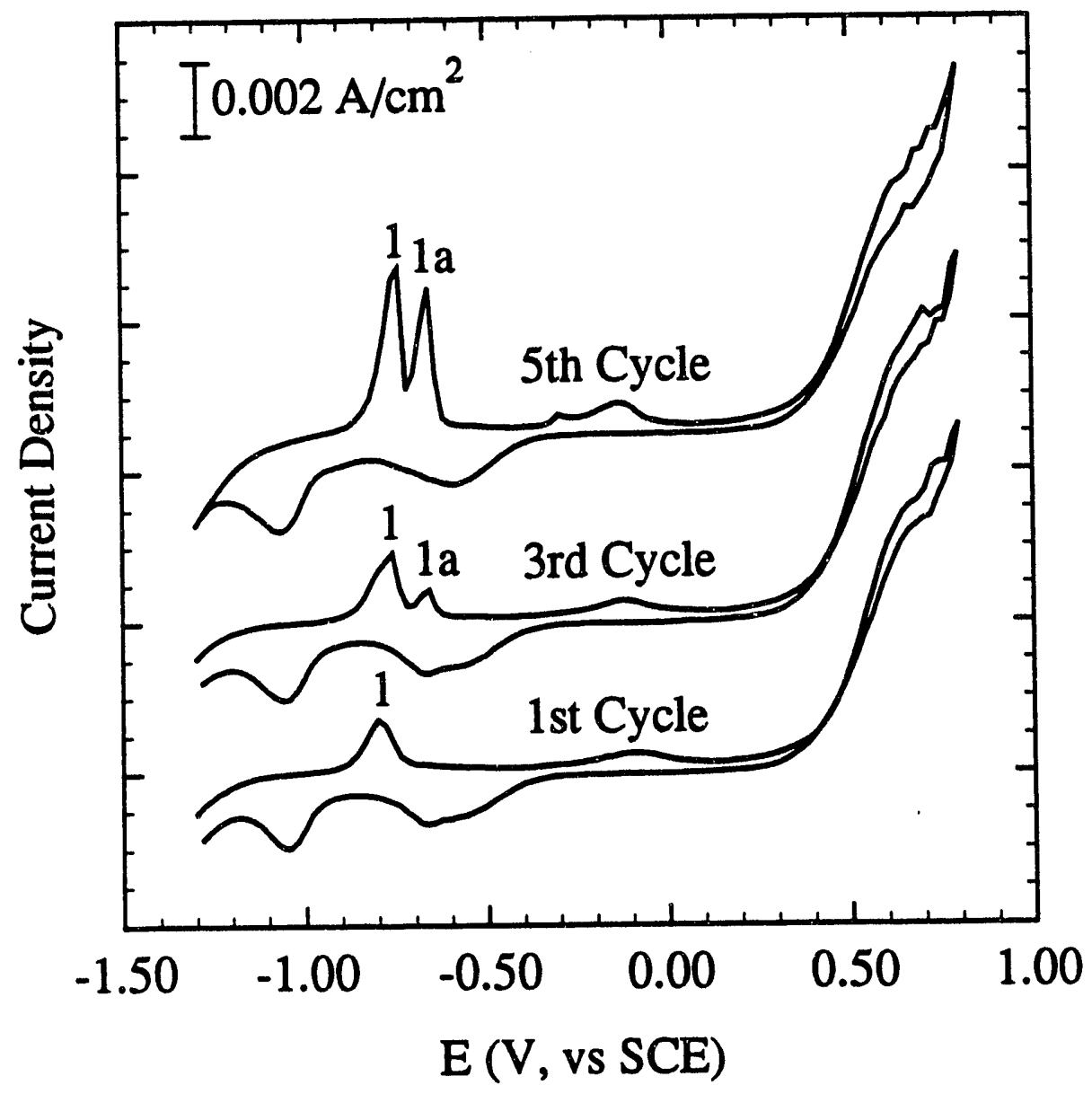

Figure 2.10. Mineral Pyrite in Stirred Solutions at pH 9.2, Anodic Scan Reversed at $0.8 \mathrm{~V}$, Scan Rates, $100 \mathrm{mV} / \mathrm{s}$ 


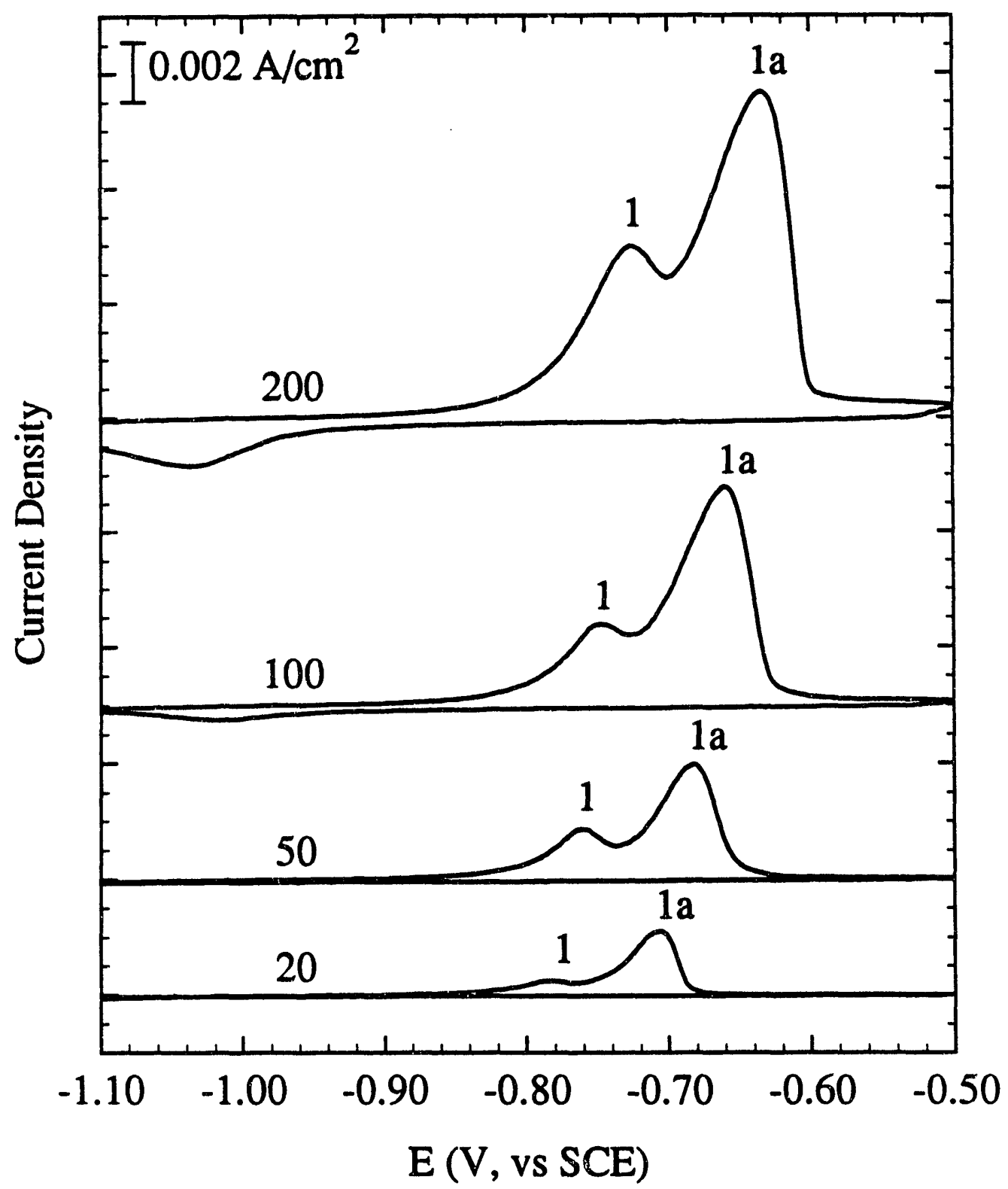

Figure 2.11. Effect of Scan Rate (mV/s) on Peaks 1 and 1a. Mineral Pyrite in Stirred Solutions at pH 9.2, Electrode Pre-conditioned at $0.4 \mathrm{~V}$ for 1 Minute 


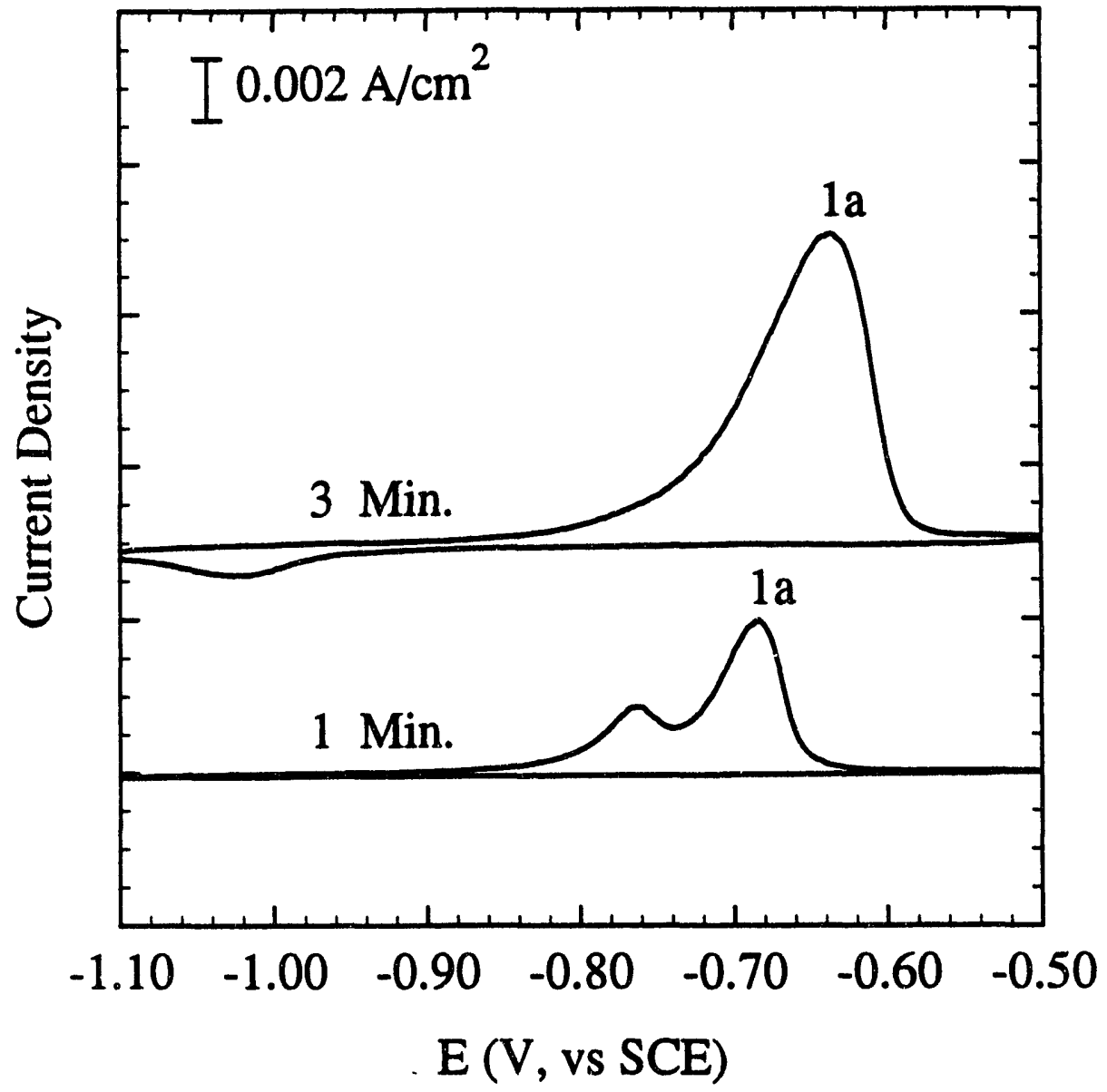

Figure 2.12. Effect of Electrode Pre-condition Time (at 0.4 V) on Peaks 1 and 1a, Mineral Pyrite in Stirred Solutions at pH 9.2, Scan Rates, $50 \mathrm{mV} / \mathrm{s}$. 
Table 2.2. Effect of electrode pre-conditioning time on charge of peaks 1 and $1 \mathrm{a}$

(scan rate: $50 \mathrm{mV} / \mathrm{s}$, applied potential: $0.4 \mathrm{~V}$ )

\begin{tabular}{ccccc}
\hline Time & \multicolumn{5}{c}{ Number of Coulombs x 10 } \\
Minute & Total & Peak 1 & Peak 1a & Peak 1/1a \\
\hline 1 & 6.33 & 2.64 & 3.69 & 0.715 \\
3 & 16.04 & 5.63 & 10.41 & 0.541 \\
\hline
\end{tabular}

The voltammograms in Figures 2.7, 2.8 and 2.9 also provide evidence of elemental sulfur formation. After reaction in the high potential region, a new cathodic/anodic pair is present at approximately $-0.75 \mathrm{~V} /-0.25 \mathrm{~V}$. This pair may be attributed to the $\mathrm{S}^{\circ} / \mathrm{HS}^{-}$ reaction

$$
\begin{gathered}
S^{0}+H^{+}+2 e^{-}=H S^{-} \\
E_{h}=-0.0653-0.0295 p H-0.0295 \log \left[H S^{-}\right]
\end{gathered}
$$

At $\mathrm{pH} 9.2$ and for [HS] concentrations between $10^{-2}$ to $10^{-6} \mathrm{M}, \mathrm{E}_{\mathrm{h}}$ would fall in the range of -0.28 to $-0.16 \mathrm{~V}$ and $E_{S C E}$ in the range -0.52 to $-0.4 \mathrm{~V}$. These results indicate that the high potential oxidation of pyrite produced some elemental sulfur and increased the quantity of iron oxides formed as evidenced by the associated cathodic and anodic reactions at lower potentials. A series of tests were carried out under quiescent conditions where the potential was reversed at different anodic limits. The results are shown in Figure 2.13. The sulfur peaks appeared for the upper limits of $0.2 \mathrm{~V}$ and up. In comparing Figure 2.8 with Figure 2.6, for the $100 \mathrm{mV} / \mathrm{s}$ scan rates, it is evident that peaks 5 and 6 are greatly enhanced by prior treatment in the high potential region. This can be explained if the high potential reactions produced some elemental sulfur and $\mathrm{Fe}$ (III) oxides. Hamilton and Woods [2.1] indicated some elemental sulfur is formed (approximately a monolayer at $\mathrm{pH}$ 9.2) at high anodic potentials but that the majority of the pyrite sulfur forms sulfate ion. Also, the cathodic currents preceding hydrogen evolution are greatly enhanced. Voltammograms were performed in borate solution without and with $0.005 \mathrm{M}$ 


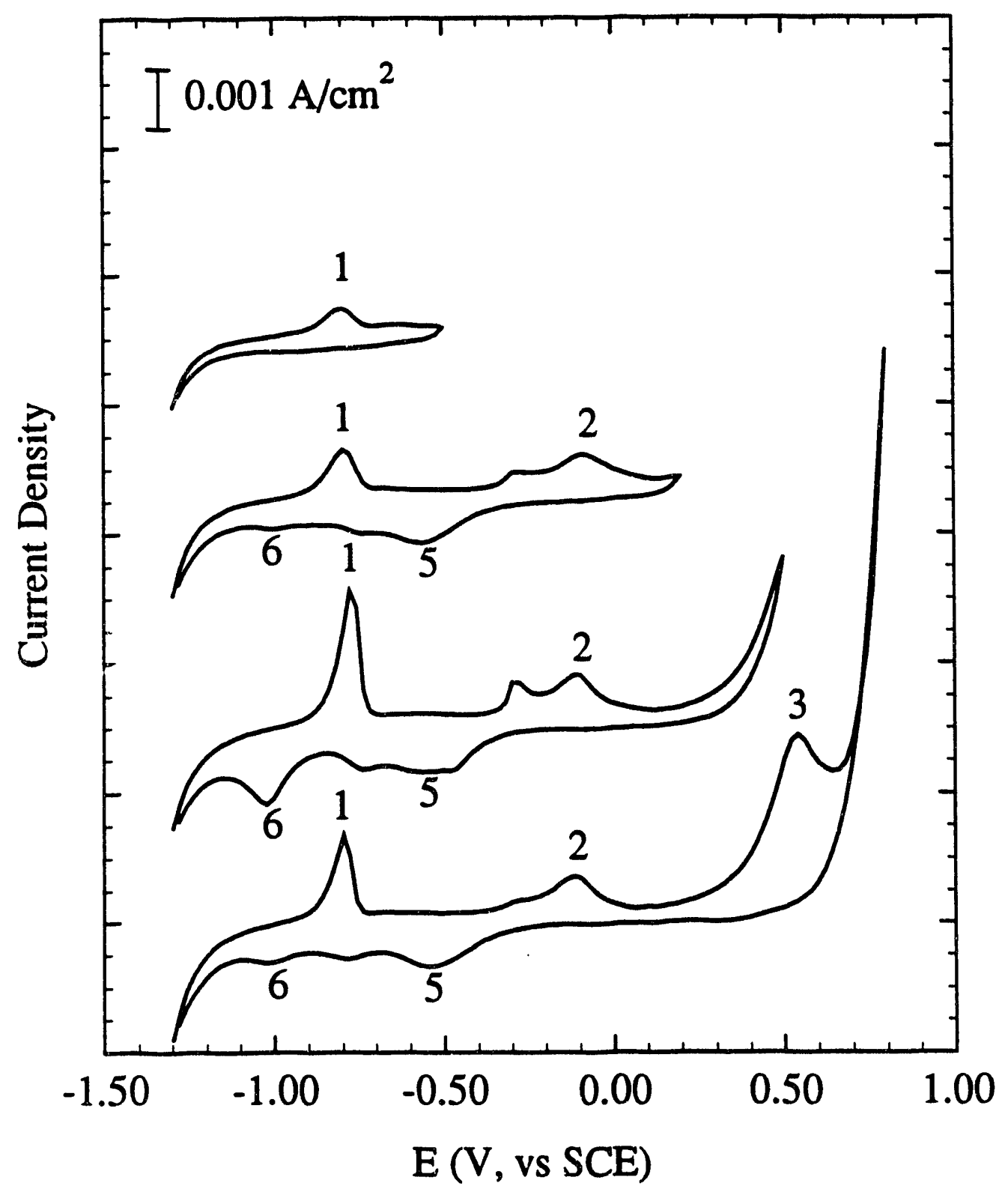

Figure 2.13. Mineral Pyrite in Quiescent Solutions at $\mathrm{pH}$ 9.2, Scan Reversed at Various Anodic Limits, Scan Rates, $100 \mathrm{mV} / \mathrm{s}$ 
NaHS. The results presented in Figure 2.14, showing a greatly enhanced $S^{\circ} / \mathrm{HS}^{-}$peak pair (at $-0.25 \mathrm{~V} /-0.75 \mathrm{~V}$ ), when NaHS was added, support the previous assignment.

The effect of $\mathrm{pH}$ in the basic region is shown in Figure 2.15 for unstirred electrolyte. The intensity of all peak currents increased with increasing solution $\mathrm{pH}$. Peak 1a was observed at $\mathrm{pH} 10.5$ even in quiescent solution. The potential of peak 1 was not affected by the solution pH. This suggests the reaction (Eq. 2.8) leading to the formation of $\mathrm{Fe}(\mathrm{OH})_{2}$ occurs in a series of steps. Rangle et al. [2.9] proposed the following sequence of reactions

$$
\begin{gathered}
\mathrm{Fe}^{\circ}+\mathrm{H}_{2} \mathrm{O} \rightarrow \mathrm{Fe}(\mathrm{OH})_{a d s}+\mathrm{H}^{+}+e^{-} \\
\mathrm{Fe}(\mathrm{OH})_{a d s} \rightarrow \mathrm{FeOH}^{+}+e^{-} \\
\mathrm{FeOH}^{+}+\mathrm{OH}^{-} \rightarrow \mathrm{Fe}(\mathrm{OH})_{2} \rightarrow \mathrm{Fe}(\mathrm{OH})_{2} \text { (hydrated) }
\end{gathered}
$$

Because of the large overpotential, the back reaction, Eq. (2.14), would have little influence and the potential would not reflect the solution $\mathrm{pH}$. The precipitation reaction, Eq. (2.16), would be sensitive to [OH'] explaining the increase in peak 1 current with increased $\mathrm{pH}$. The potential of peak 2 shifted to more negative values with increased $\mathrm{pH}$ as required by Eq. (2.4). An additional cathodic peak, peak 4, is evident in Figure 2.15 for $\mathrm{pH}$ 7.9. Peak 4 may be considered a cathodic conjugate to one of the higher potential oxidation reactions. Emphasis is given here to peak 4 because, as will be noted later, it is a prominent cathodic peak for coal pyrites.

The preceding cyclic voltammetry measurements were limited to alkaline media. Considering that the subsequent flotation process may be conducted in acid media, the study of solution $\mathrm{pH}$ has been extended from the alkaline to the acidic region. The results are summarized and compared with the previous result at a pH of 9.2 in Figure 2.16. When solution $\mathrm{pH}$ decreased from 9.2 to 4.2 , the peaks remained essentially the same, consistent with other author's conclusion [2.1], that between $\mathrm{pH} 4.6$ and 13, there are no significant changes in the oxidation mechanism. At a solution $\mathrm{pH}$ of 2.6 , there is a very strong cathodic peak at about $-0.82 \mathrm{~V}$ (SCE). This peak can be assigned to the direct reduction of pyrite, 


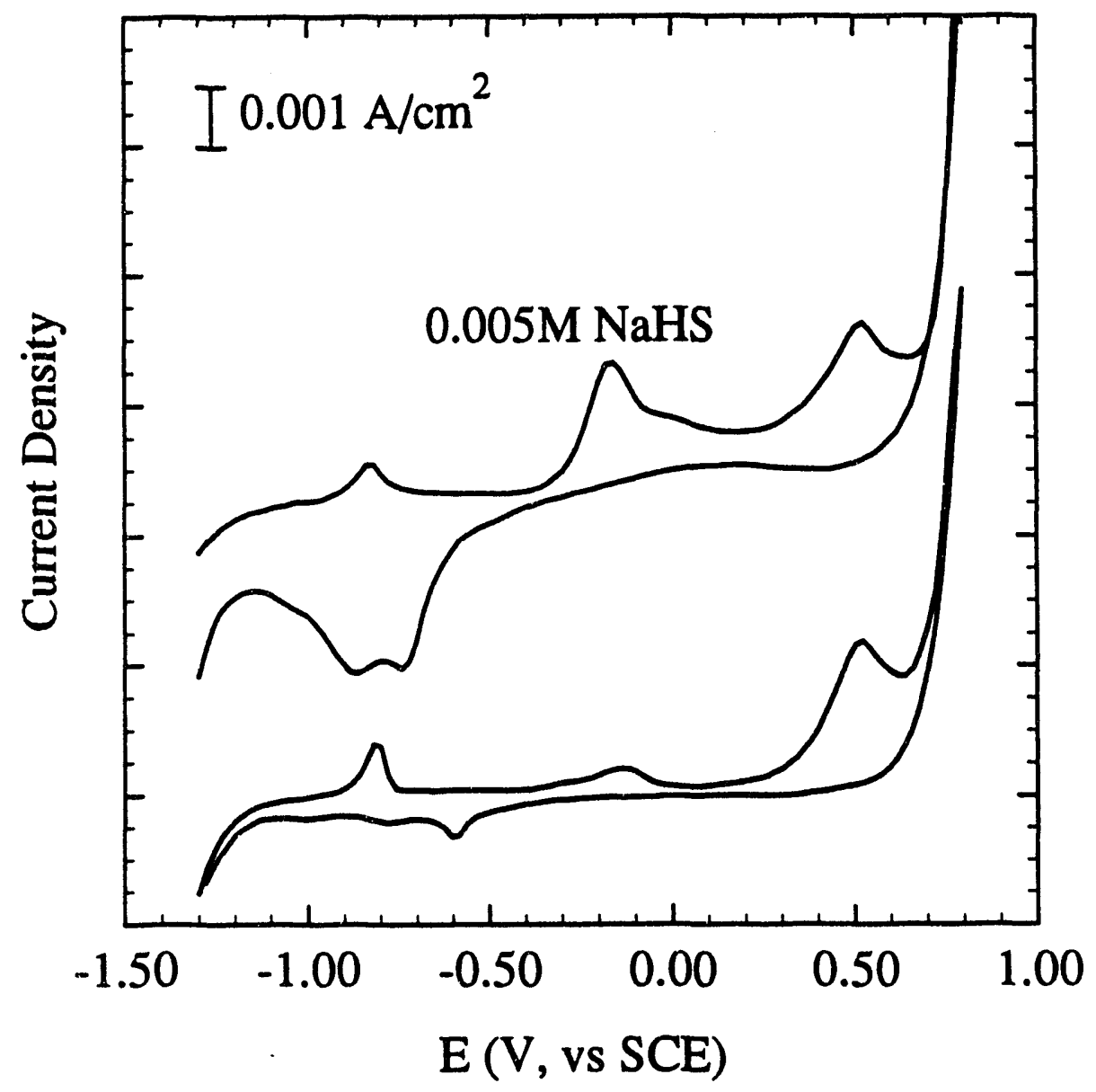

Figure 2.14. Mineral Pyrit in Quiescent Solutions at $\mathrm{pH}$ 9.2, with or without NaHS. Scan Rate, $50 \mathrm{mV} / \mathrm{s}$ 


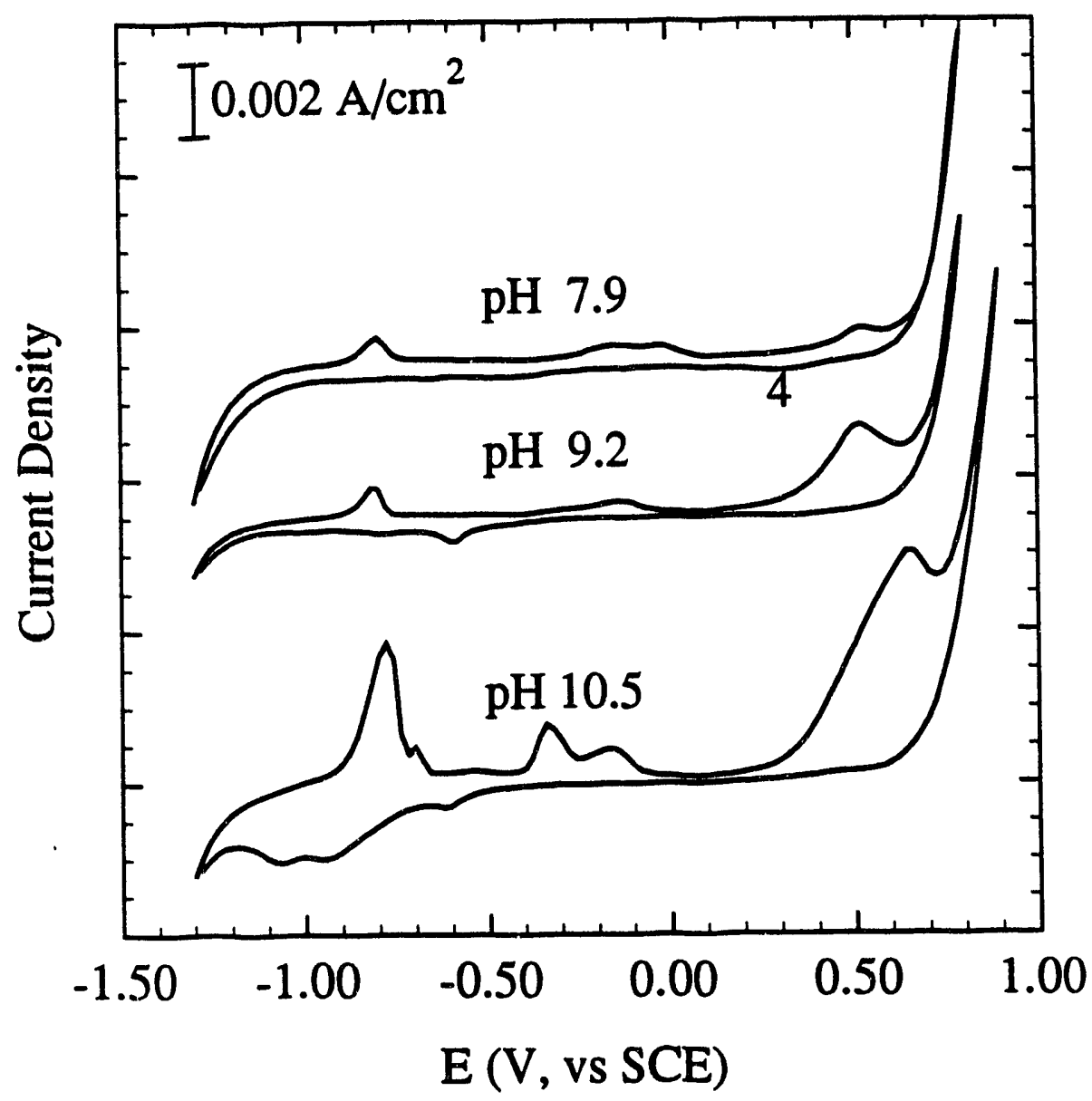

Figure 2.15. Effect of Solution pH, Mineral Pyrite in Quiescent Solutions Scan Rates, $50 \mathrm{mV} / \mathrm{s}$ 


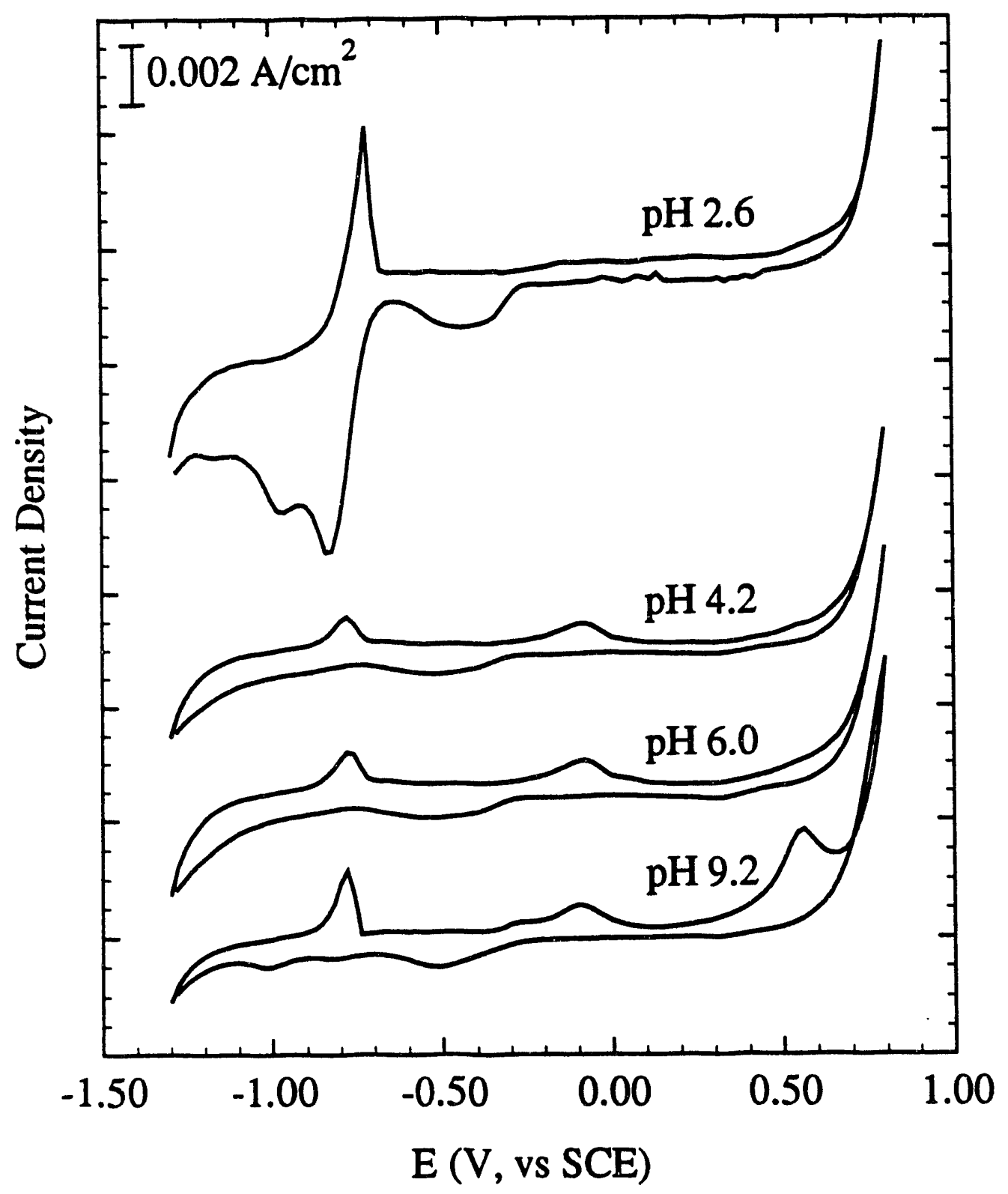

Figure 2.16. Effect of Solution pH. Mineral Pyrite in Quiescent Solutions Scan Rates, $200 \mathrm{mV} / \mathrm{s}$ 


$$
\begin{gathered}
\mathrm{FeS}_{2}+2 \mathrm{H}^{+}+2 e^{-}=\mathrm{FeS}+\mathrm{H}_{2} \mathrm{~S} \\
\mathrm{FeS}+2 \mathrm{H}^{+}=\mathrm{Fe}^{2+}+\mathrm{H}_{2} \mathrm{~S} \\
\mathrm{Fe}^{2+}+2 e^{-}=\mathrm{Fe}^{0}
\end{gathered}
$$

Stirring in acid solutions has an effect opposite to that observed in alkaline solutions. Figure 2.17 illustrate results obtained at $\mathrm{pH}$ 2.6. When the solution is stirred, almost no distinct peak can be observed for this formation. In stirred solutions the oxidation /reduction peaks can be observed only when the scan rate is very rapid, such as $400 \mathrm{mV} / \mathrm{s}$ used to obtain Figure 2.17. It is not unexpected, considering that in acid medium, $\mathrm{Fe}(\mathrm{II})$ and $\mathrm{Fe}(\mathrm{III})$ will exist as soluble $\mathrm{Fe}^{2+}$ and $\mathrm{Fe}^{3+}$ and diffuse away from electrode under solution agitation.

Peaks $3 / 4$, and the unique properties of the double peak 1 and $1 \mathrm{a}$, have not been reported in previous studies. In order to rule out any accidental phenomena, such as unknown inclusions in the electrode or the peculiarity of the electrolyte used, cyclic voltammetry measurements were repeated with a mineral pyrite electrode from another source (Rico, Colorado) in the same solution $\left(\mathrm{Na}_{2} \mathrm{~B}_{4} \mathrm{O}_{7} / \mathrm{Na}_{2} \mathrm{SO}_{4}\right)$ and with the original mineral pyrite electrode in $0.1 \mathrm{M} \mathrm{NaHCO} / \mathrm{Na}_{2} \mathrm{CO}_{3}$ solution. The results are shown in Figures 2.18 and 2.19 respectively. By comparison with Figures 2.7 and 2.8, it is evident that in both quiescent and stirred solutions, the same peaks are observed and the shapes of the voltammograms are very similar. In $\mathrm{NaHCO}_{3} / \mathrm{Na}_{2} \mathrm{CO}_{3}$ solution peak la appears even in quiescent solution (Figure 2.19), and the current density is higher but less affected by solution stirring than in borate solutions.

Coal Pyrite. The effect of scan rate on peak current and potential for Pittsburgh No.8 coal pyrite for quiescent solutions is shown in Figure 2.20. The upper anodic limit was $0.8 \mathrm{~V}$. Compared to mineral pyrite, the peaks are more diffuse and display much higher currents over a broad potential range. The high voltage peak, peak 3 , is not well defined, but its conjugate, peak 4 , is clearly discernable at $\mathrm{pH} 9.2$, particularly for the higher scan rates. The iron peak, peak 6, is not clearly discernable although its anodic conjugate, peak 1 , 


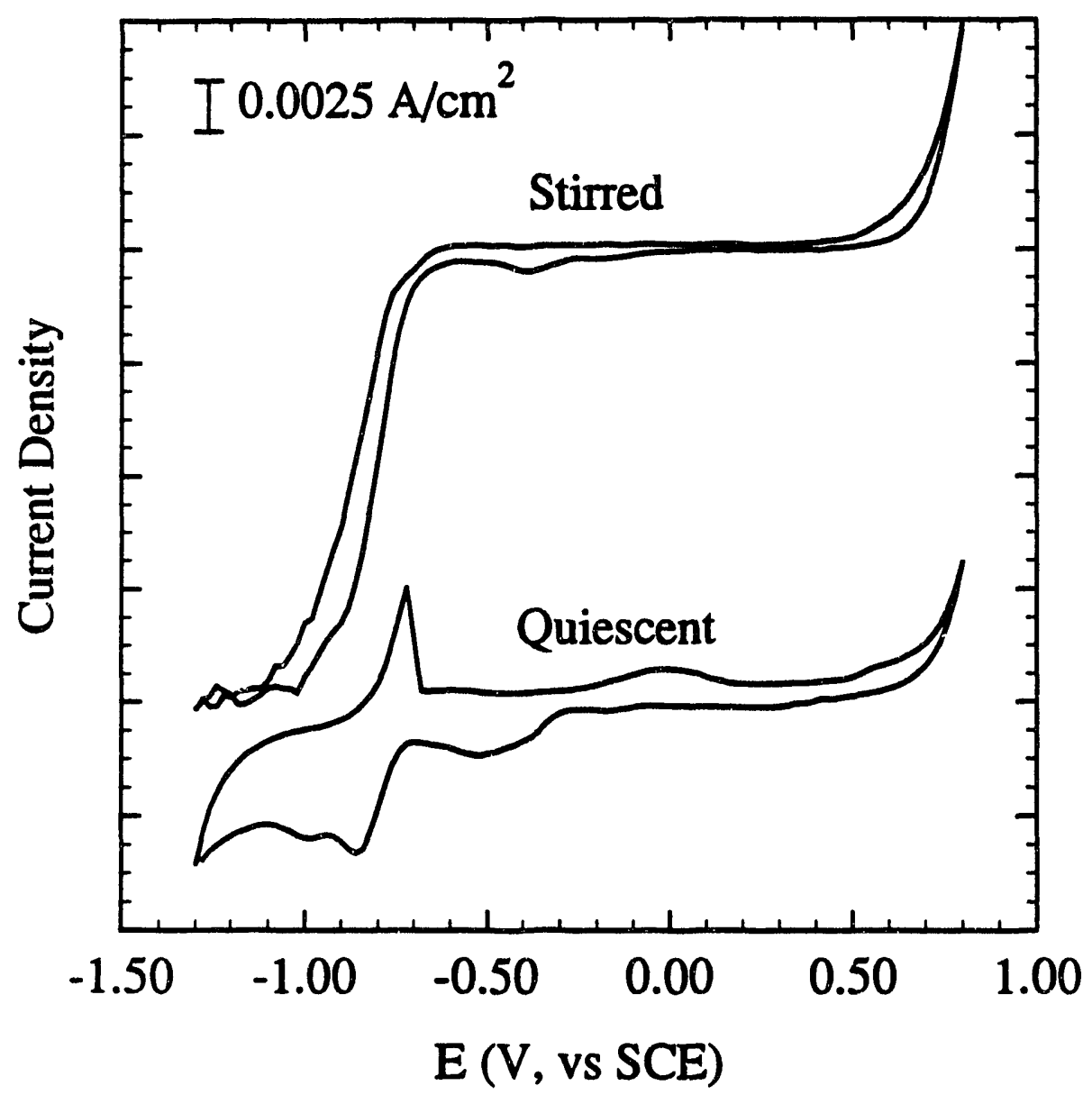

Figu" 2.17. Effect of Solution Stirring, Mineral Pyrite in Solutions at pH 2.6. Scan Rate, $400 \mathrm{mV} / \mathrm{s}$ 


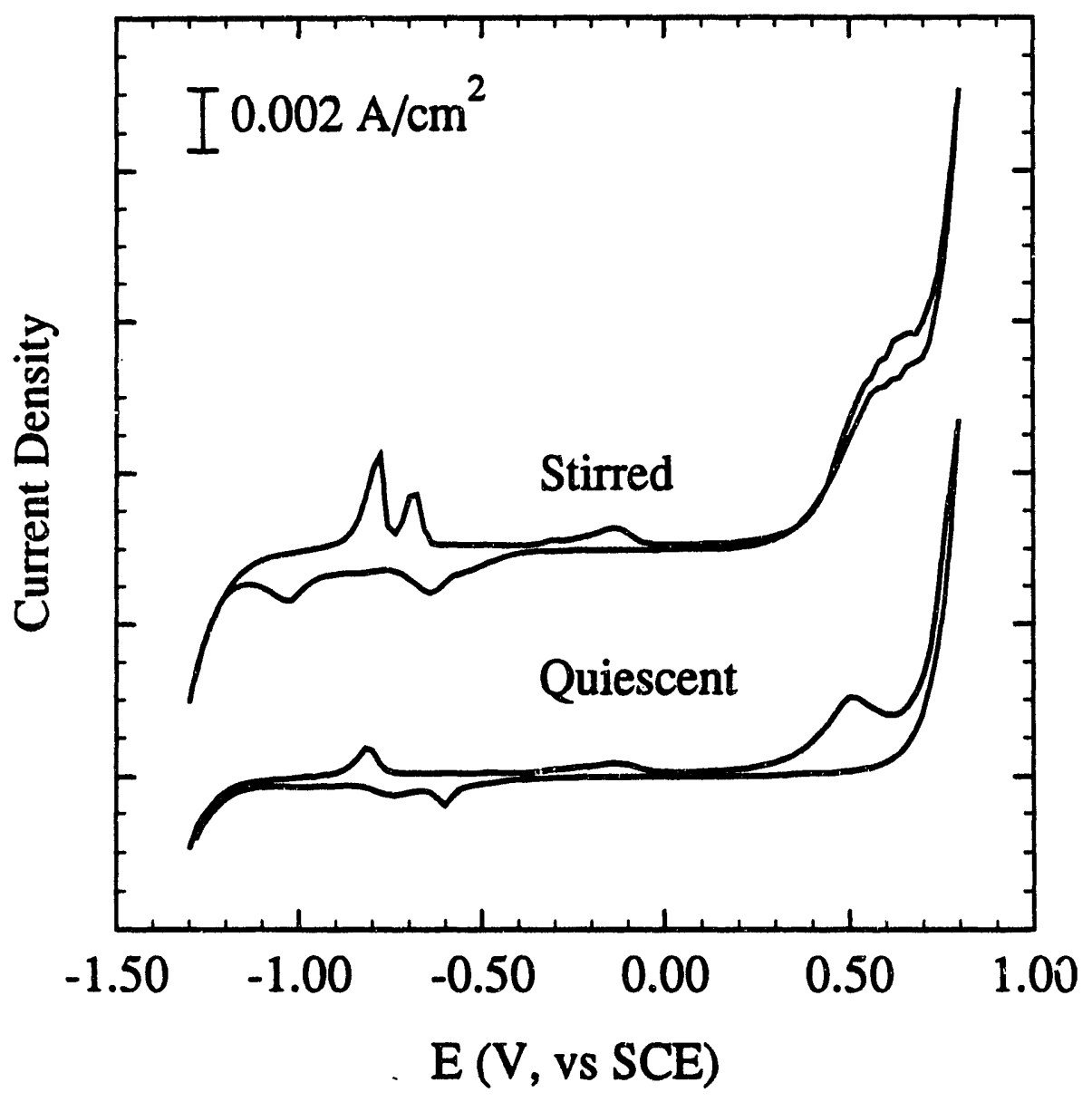

Figure 2.18. Mineral Pyrite (Colorado) in Solutions at pH 9.2, Anodic Scan Reversed at 0.8 V. Scan Rates, $50 \mathrm{mV} / \mathrm{s}$ 


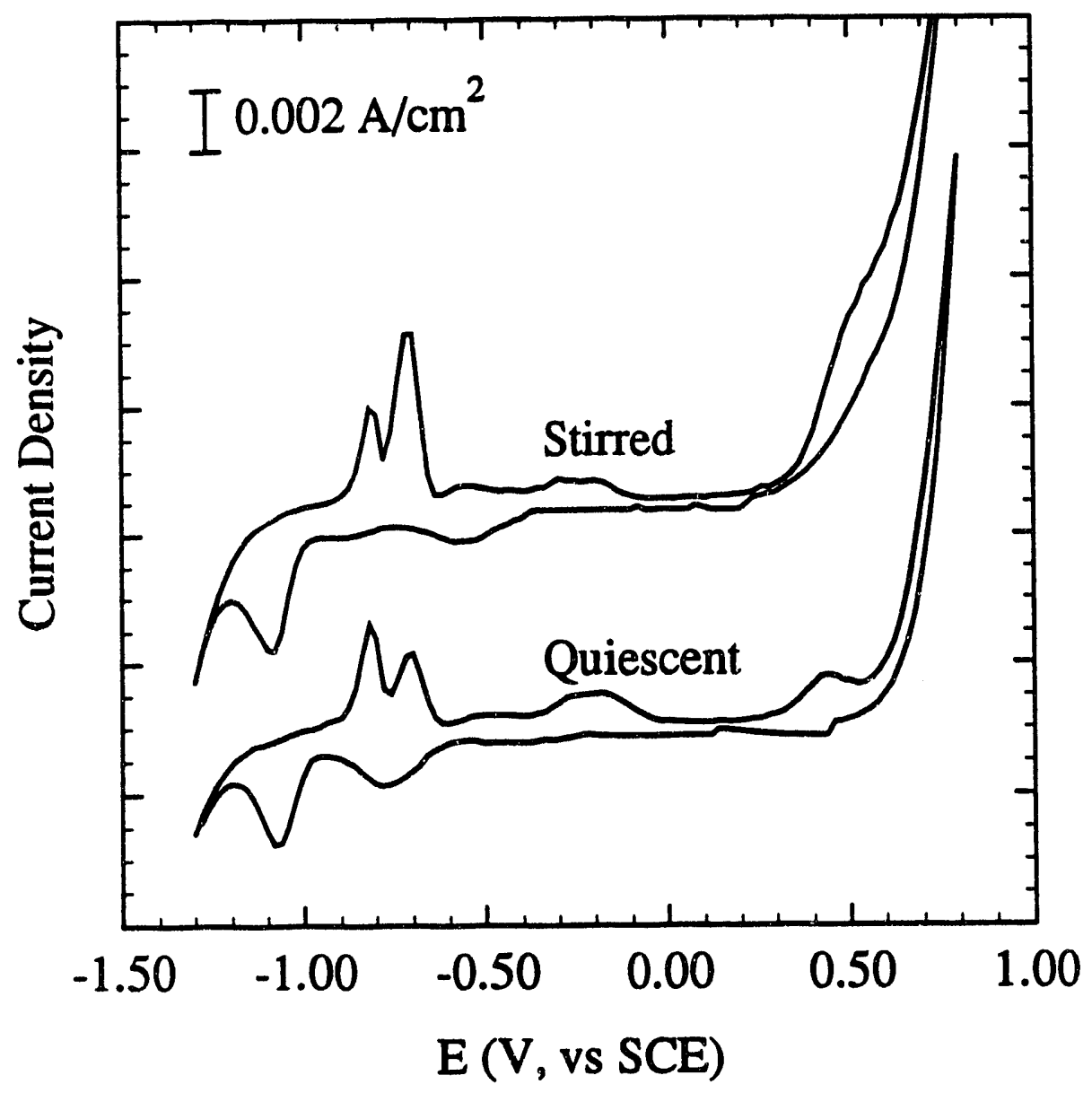

Figure 2.19. Mineral Pyrite in $\mathrm{NaHCO}_{3} / \mathrm{Na}_{2} \mathrm{CO}_{3}$ Solutions at $\mathrm{pH} 9.28$, Anodic Scan Reversed at $0.8 \mathrm{~V}$. Scan Rates, $50 \mathrm{mV} / \mathrm{s}$ 


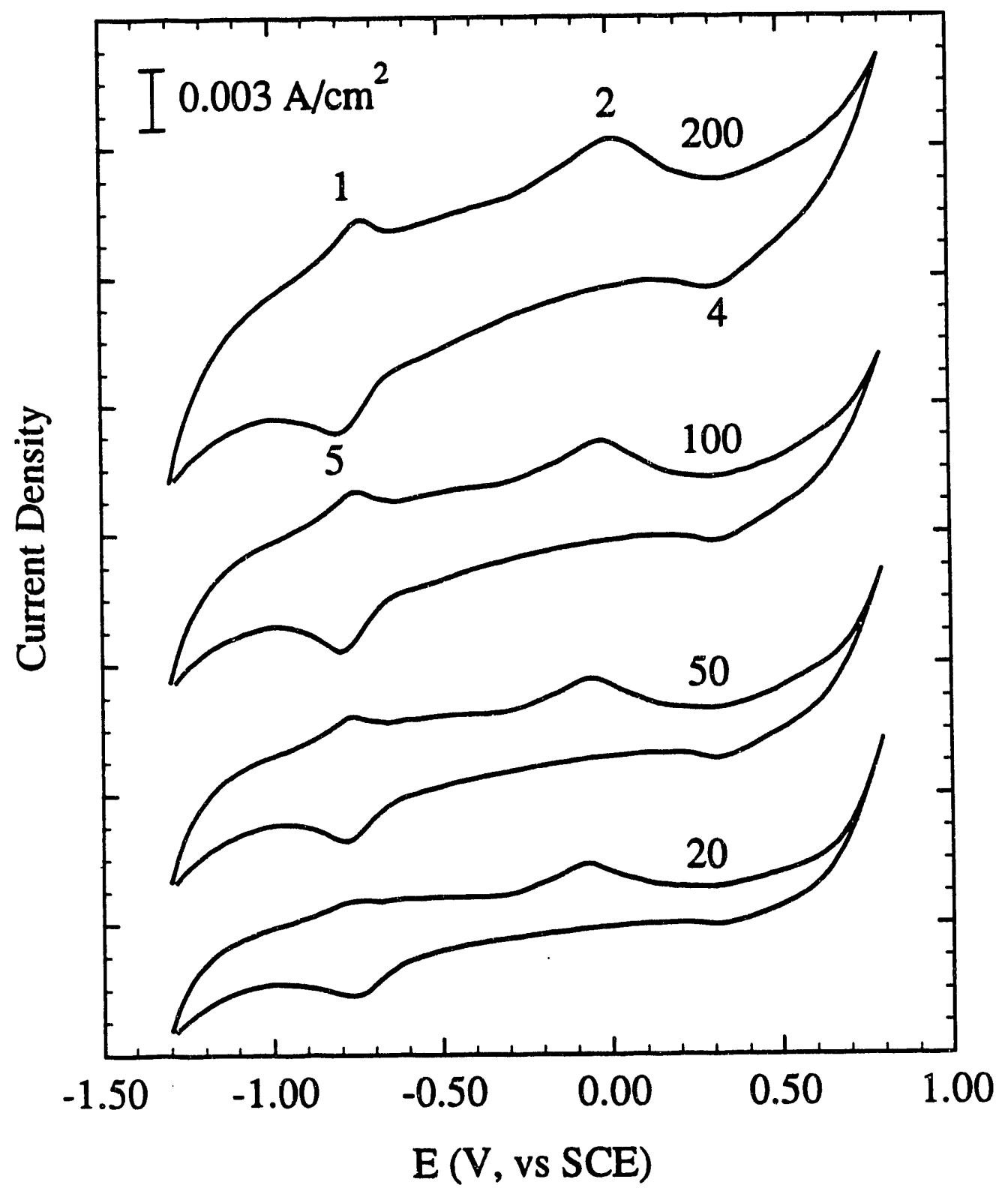

Figure 2.20. Pittsburgh Coal Pyrite in Quiescent Solutions at $\mathrm{pH} 9.2$ for Various Scan Rates, (mV/s) 
is. Similar results are shown for Upper Freeport coal pyrite in Figure 2.21. Peak 3 is slightly apparent as a shoulder at $0.5 \mathrm{~V}$, and peak 4 is very pronounced. Neither peak 1 or peak 6 are discernable, however, the presence of peak 2 indicates these precursor reactions are occurring but are apparently very broad and poorly resolved. The potential difference between peaks 2 and 5 was larger than that observed for the same peaks in mineral pyrite, indicating that the degree of irreversibility is greater in coal pyrites. This effect was more pronounced at higher scan rates. The effect of scan rate on peak current and potential for Illinois coal pyrite is shown in Figure 2.22. Compared to Pittsburgh No. 8 and Upper Freeport coal pyrites, the voltammograms are more like those of mineral pyrite. Peak la was detected even in quiescent solution at high scan rates. The high voltage peak, peak 3, was observed for the first cycle, but weakened with repeated cycling. Similar to the former two coal pyrites, peak 4 , the conjugate cathodic peak of peak 3 at about $0.3 \mathrm{~V}$, is clearly discernable.

The effect of reversing the potential at different anodic limits is shown for Pittsburgh, Upper Freeport and Illinois coal pyrite respectively in Figures 2.23, 2.24 and 2.25. Peak 4 and the $S^{\circ} / H^{-}$peaks are discernable in all three coal pyrite voltammograms, if the upper anodic potential limit is $0.8 \mathrm{~V}$ or greater. Peak 4, a prominent cathodic peak for coal pyrites, may be attributed to the reduction of $\mathrm{Fe}(\mathrm{VI})$ oxide, $\mathrm{FeO}_{3}$, to ferrate(III) ion, $\mathrm{FeO}_{2}$. $\mathrm{Fe}$ (III)-oxides, formed at high anodic potentials, continue to oxidize to $\mathrm{Fe}(\mathrm{VI})$ species, $\mathrm{FeO}_{3}$, due to the higher reactivity of coal pyrite compared to mineral pyrite, and split $\mathrm{O}_{2}$ in cathodic scan to yield soluable ferrate(VI) ion, $\mathrm{FeO}_{4}{ }^{2-}[2.9-2.11]$. If the electrode is held at $1.0 \mathrm{~V}$ for 1.5 minutes and then swept cathodically, a large cathodic peak was observed at $-0.1 \mathrm{~V}$, similar to that (peak 6) observed in the case of mineral pyrite. The intensity of the peak decreased with cycling and remained constant after the fifth cycle, as shown in Figure 2.26 for Pittsburgh coal pyrite.

The effect of solution stirring is shown for Pittsburgh, Upper Freeport and Ilinois coal pyrite respectively in Figures 2.27, 2.28 and 2.29. For Pittsburgh coal pyrite, contrary to the results observed for mineral pyrit peak currents for stirred electrolyte decreased, except for peaks $1 / 6$. Similar to mineral pyrite, peaks 1 and 1a appeared. For Upper Freeport and Illinois coal pyrites the effect of solution stirring was less pronounced than 


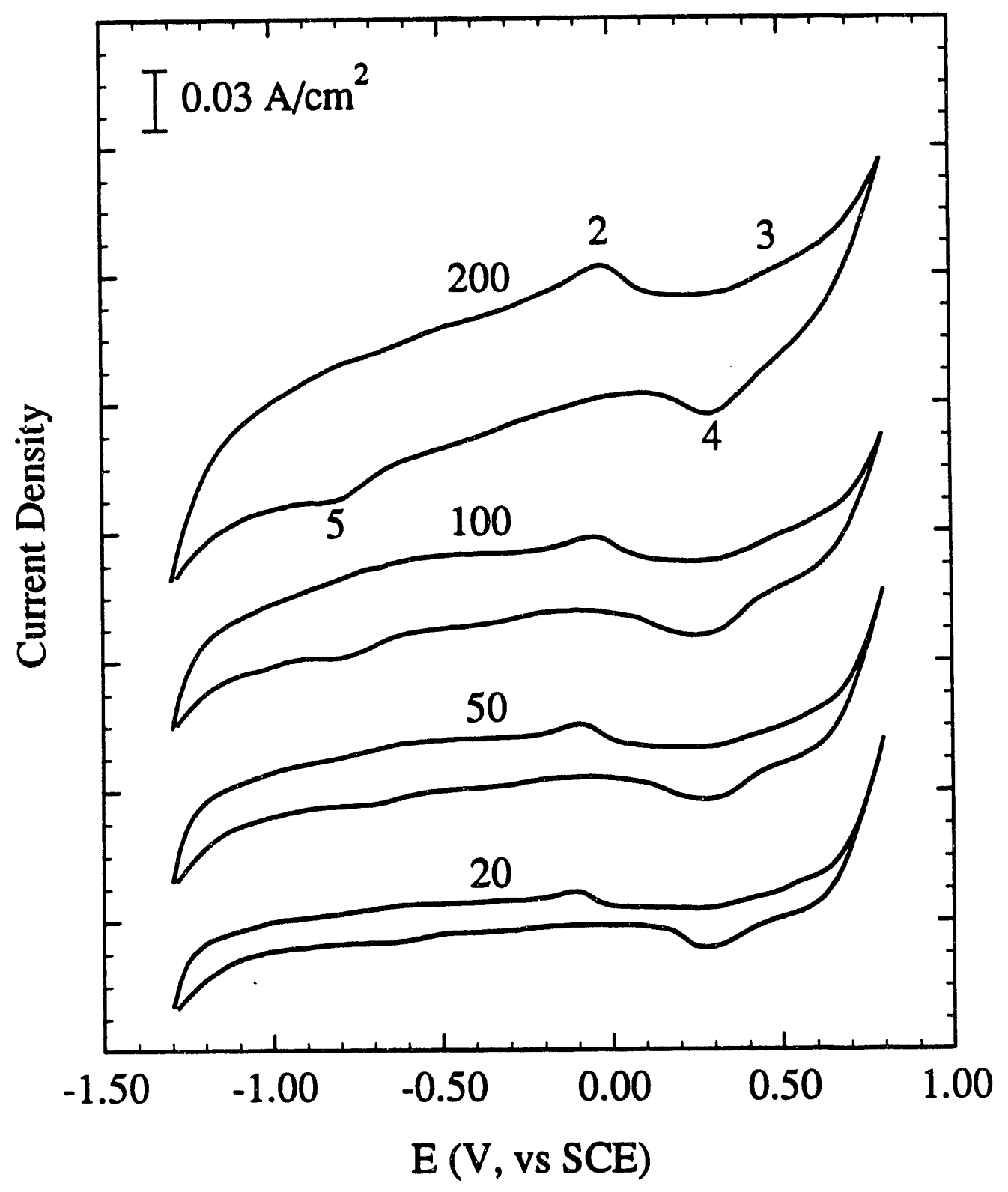

Figure 2.21. Upper Freeport Coal Pyrite in Quiescent Solutions at pH 9.2 for Various Scan Rates, $(\mathrm{mV} / \mathrm{s})$ 


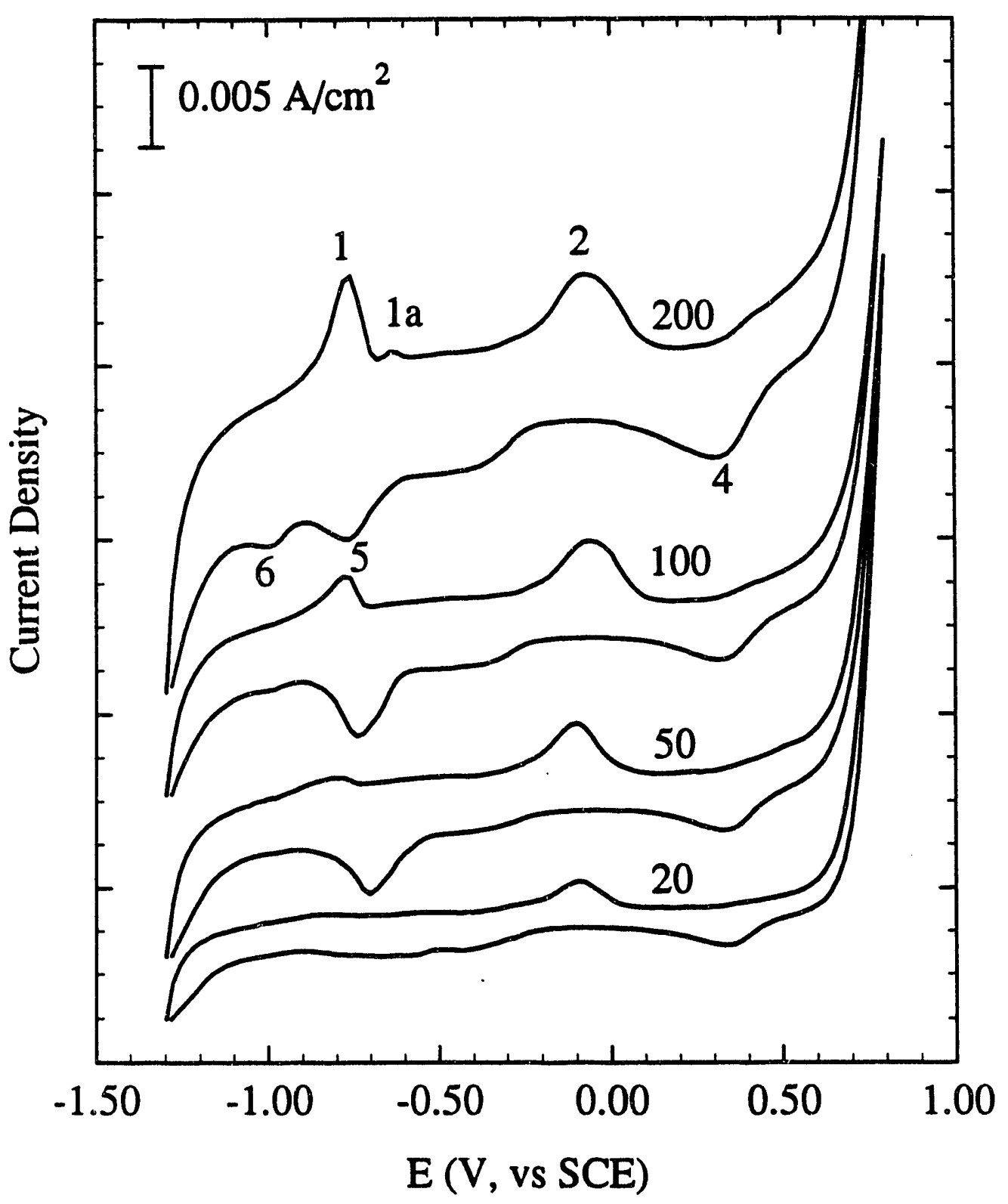

Figure 2.22. Illinois Coal Pyrite in Quiescent Solutions at pH 9.2 for Various Scan Rates, (mV/s) 


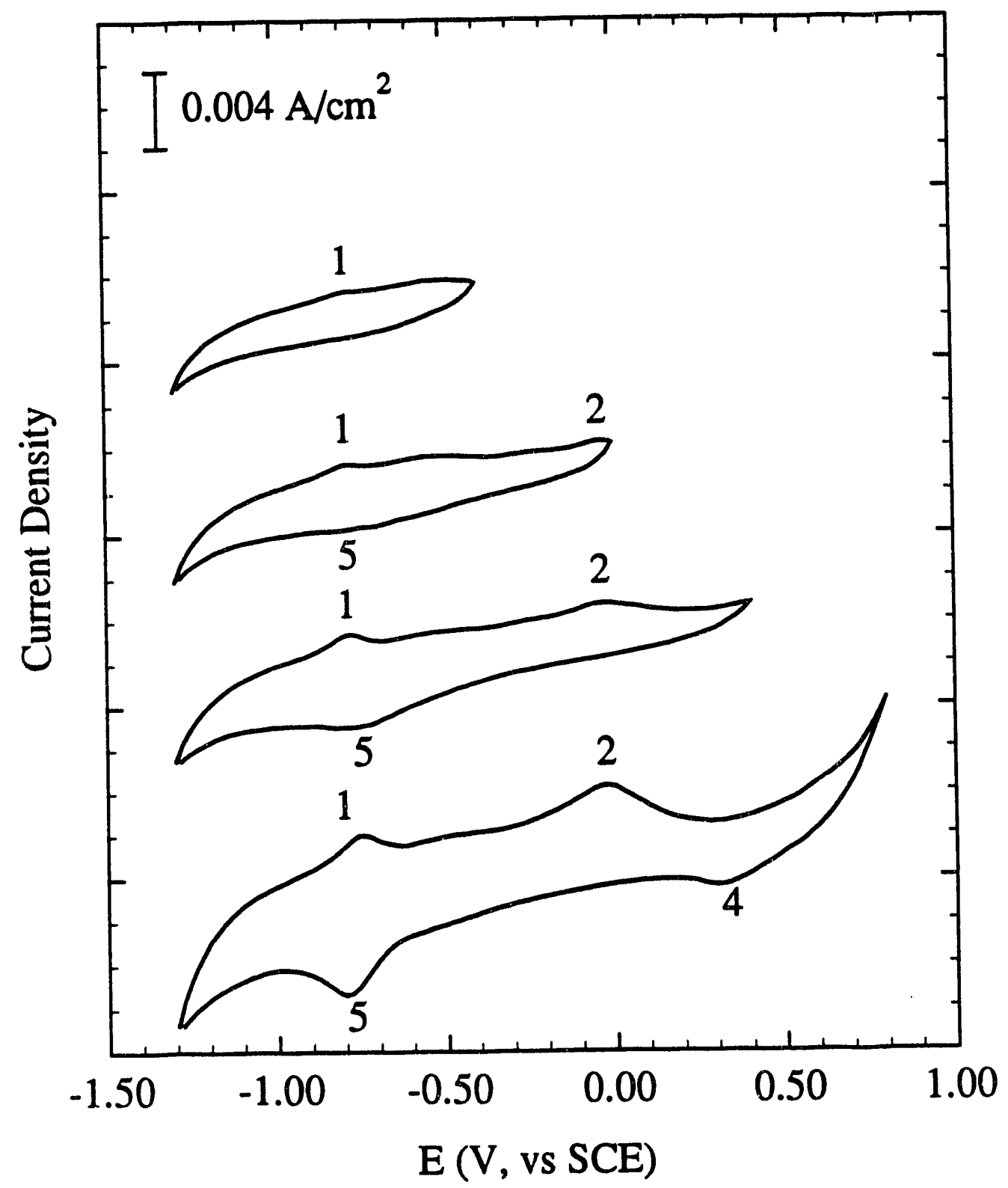

Figure 2.23. Pittsburgh Coal Pyrite in Quiescent Solutions at pH 9.2, Scan Reversed at Various Anodic Limits, Scan Rates, $100 \mathrm{mV} / \mathrm{s}$ 


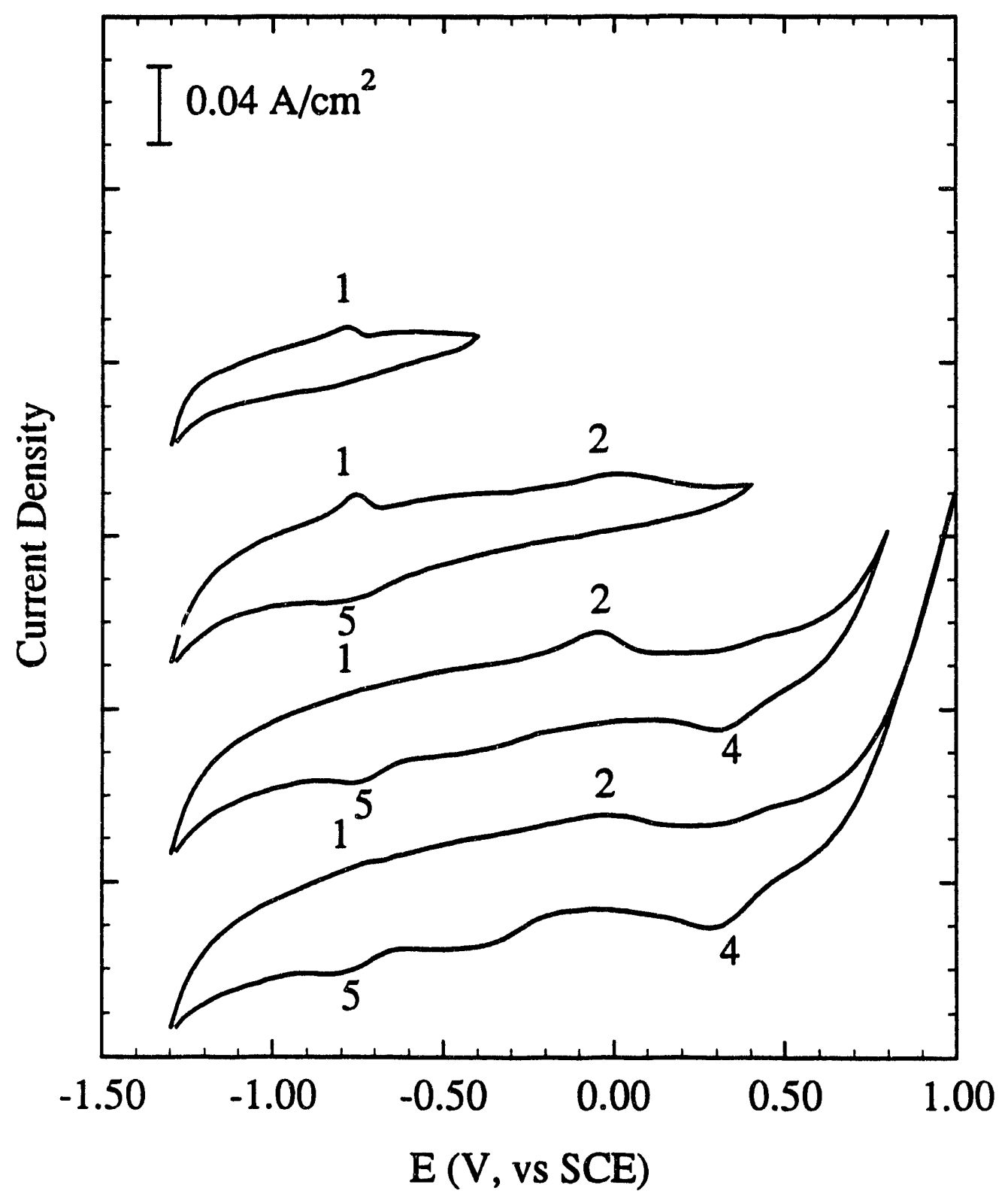

Figure 2.24. Upper Freeport Coal Pyrite in Quiescent Solutions at pH 9.2, Scan Reversed at Various Anodic Limits, Scan Rates, $100 \mathrm{mV} / \mathrm{s}$ 


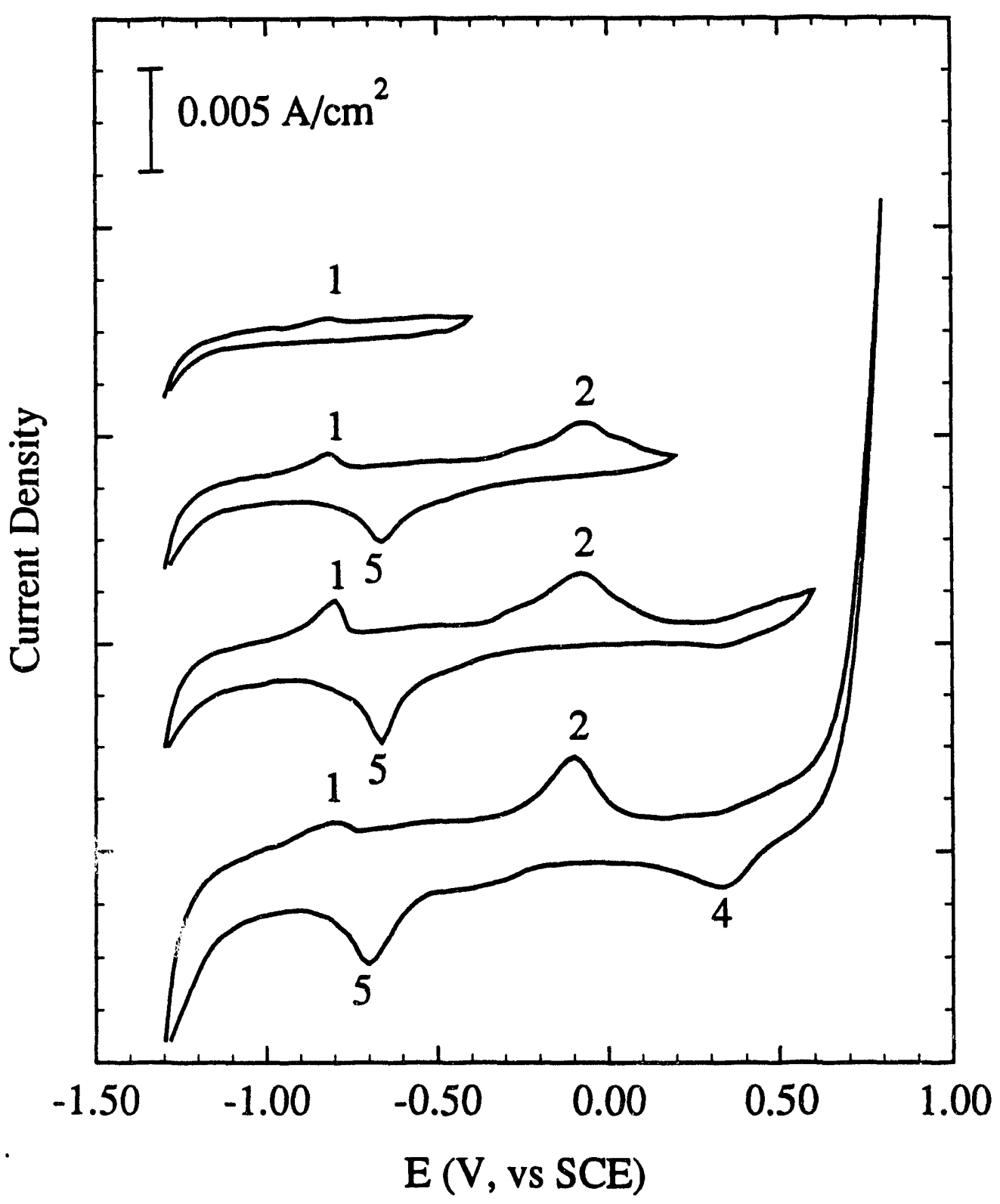

Figure 2.25. Illinois Coal Pyrite in Quiescent Solutions at pH 9.2, Scan Reversed at Various Anodic Limits, Scan Rates, $50 \mathrm{mV} / \mathrm{s}$ 


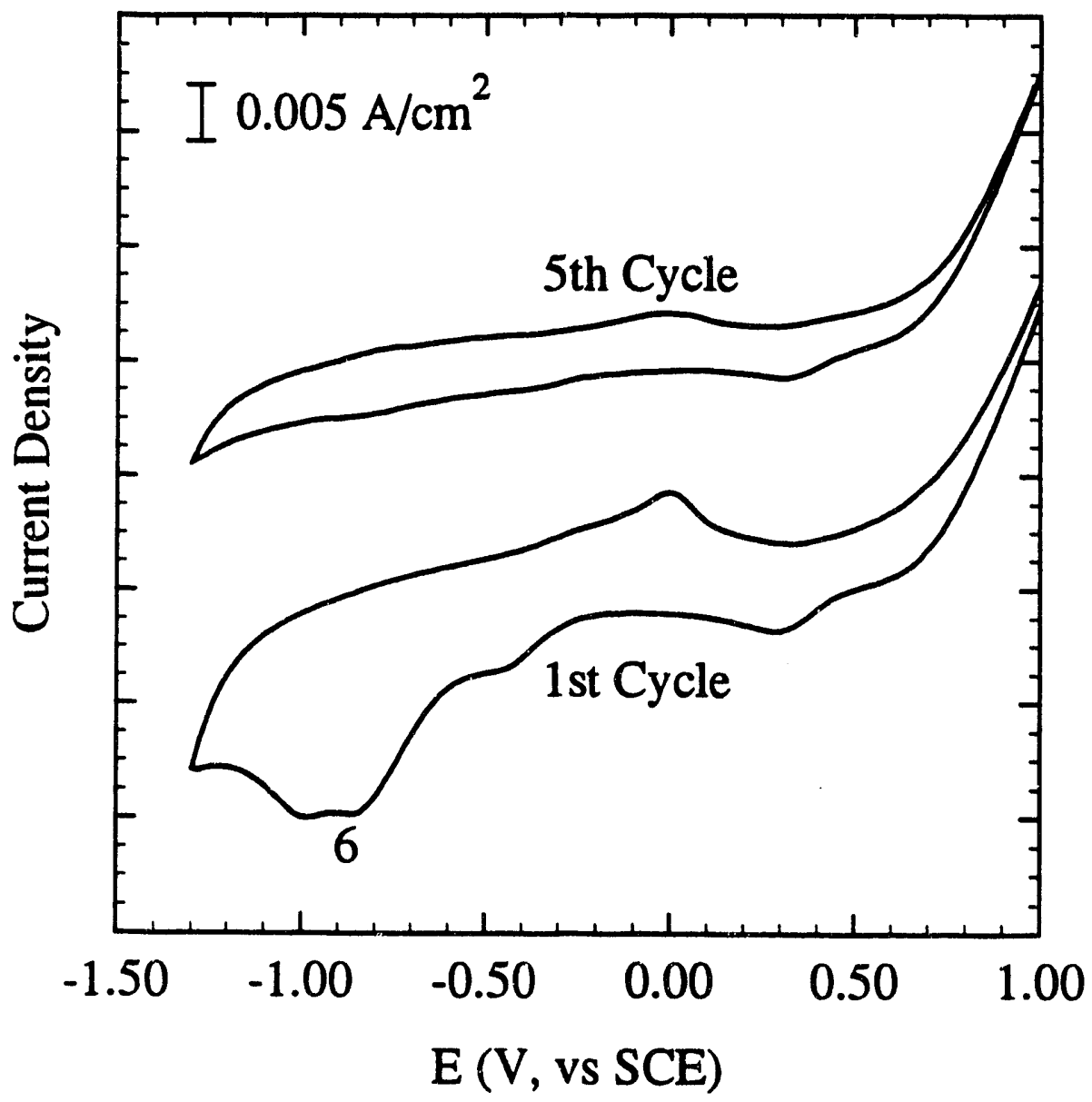

Figure 2.26. Pittsburgh Coal Pyrite in Quiescent Solutions at pH 9.2, Electrode Pre-Conditioned at $1.0 \mathrm{~V}$ for $1.5 \mathrm{~min}$. Scan Rates, $100 \mathrm{mV} / \mathrm{s}$ 


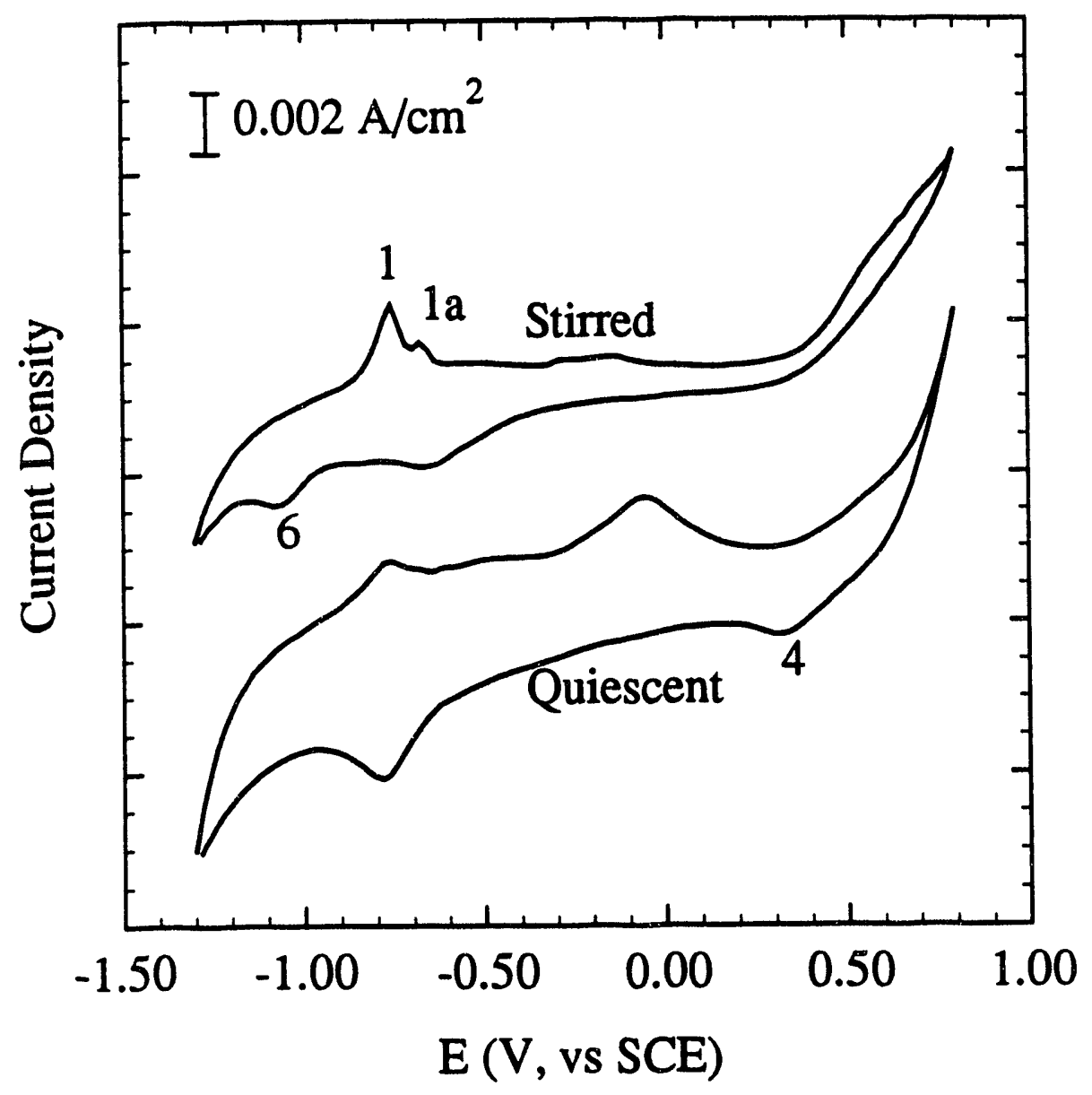

Figure 2.27. Effect of Solution Stirring, Pittsburgh Coal Pyrite in Solutions at pH 9.2, Scan Rate, $50 \mathrm{mV} / \mathrm{s}$ 


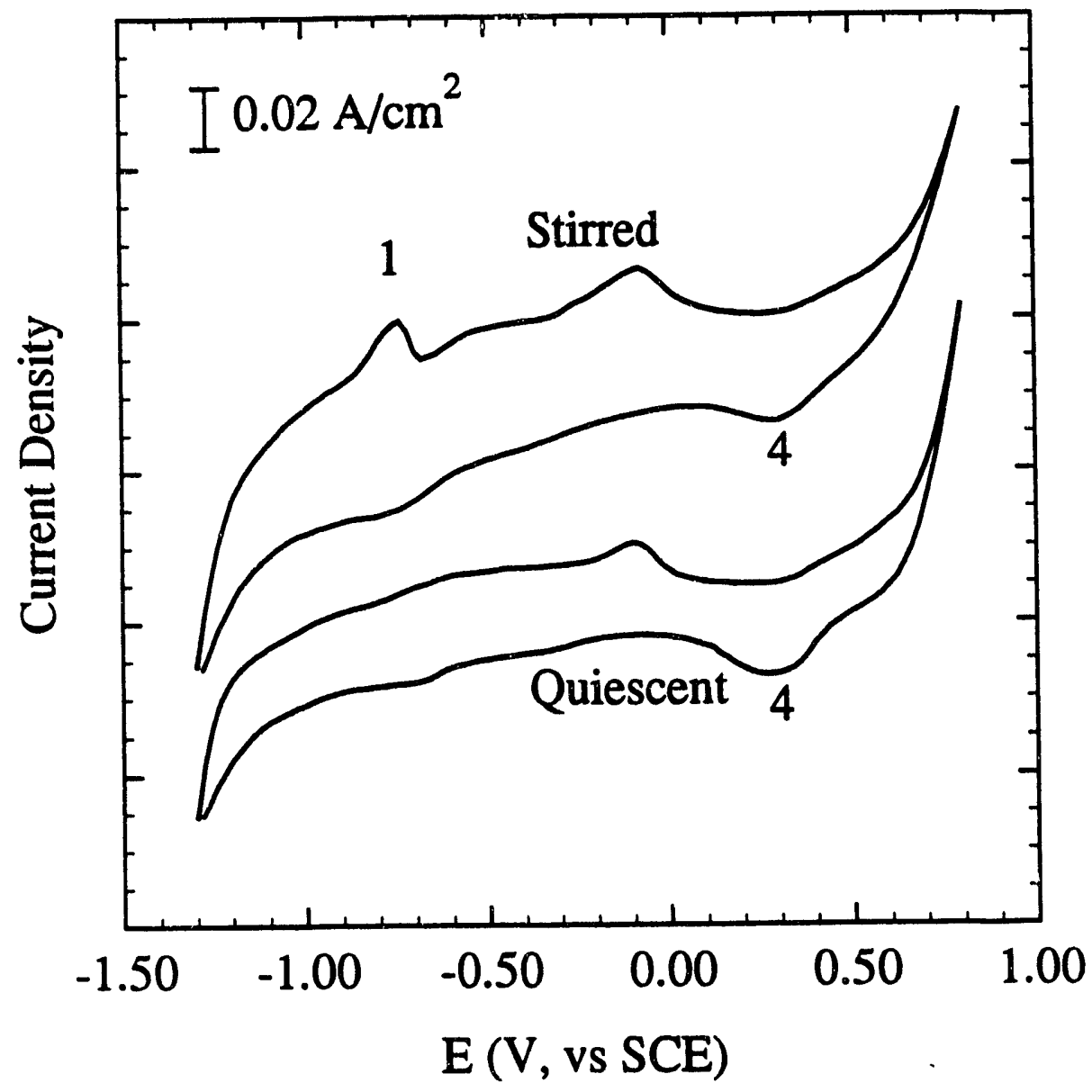

Figure 2.28. Effect of Solution Stirring, Upper Freeport Coal Pyrite in Solutions at pH 9.2, Scan Rate, $50 \mathrm{mV} / \mathrm{s}$ 


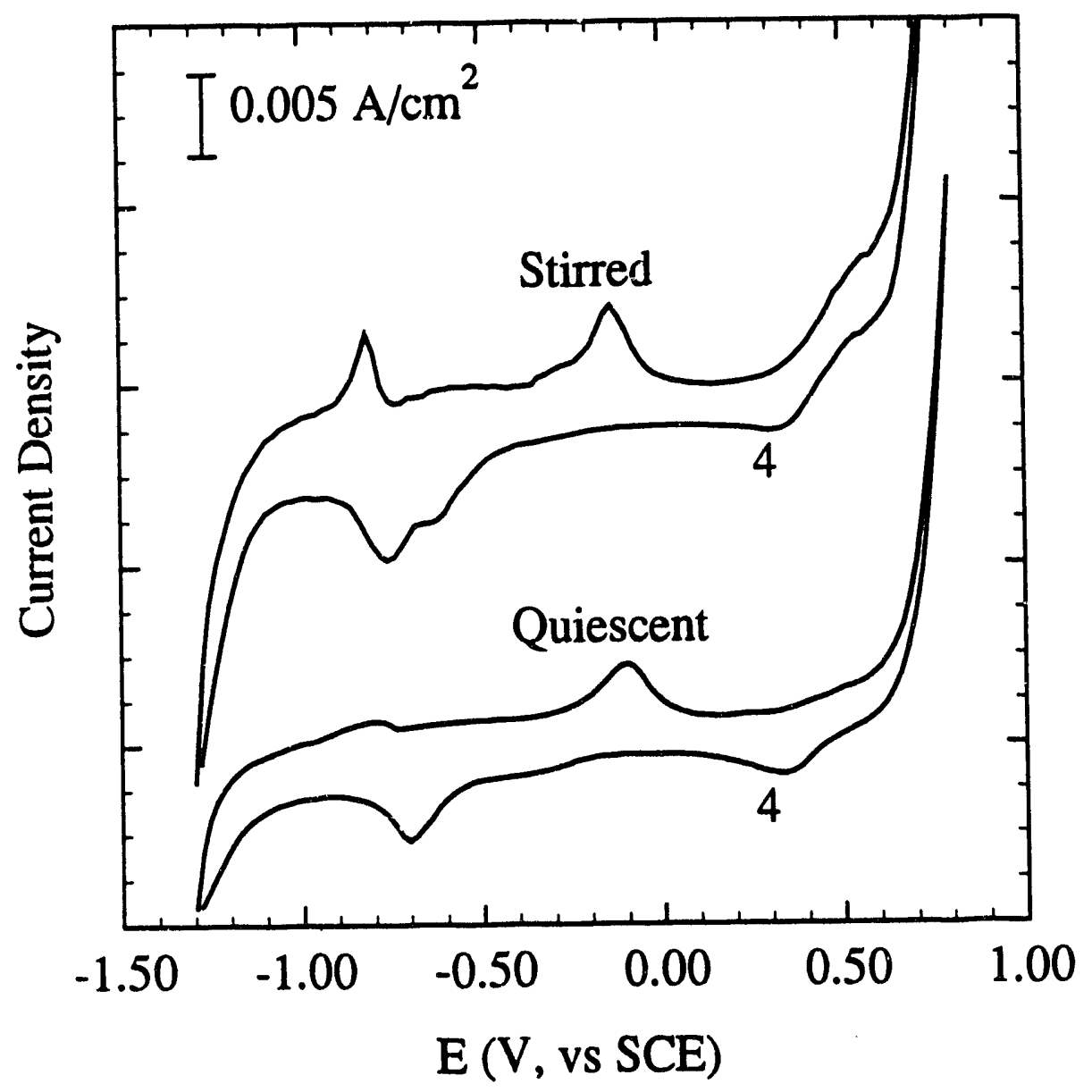

Figure 2.29. Effect of Solution Stirring, Illinois Coal Pyrite in Solutions at pH 9.2. Scan Rate, $50 \mathrm{mV} / \mathrm{s}$ 
that for mineral pyrite but with the exception of peak 4, stirring increased the current.

The effect of solution $\mathrm{pH}$ for three coal pyrites is illustrated in Figures 2.30, 2.31 and 2.32, and is less pronounced or height and position than for mineral pyrite.

Comparison of Mineral and Coal Pyrites. Figure 2.33 illustrates differences between mineral pyrite and Pittsburgh coal pyrite in the absence of stirring. The much greater reactivity of the coal pyrite is evident. Figure 2.34 compares Pittsburgh and Upper Freeport coal pyrites and illustrates the much greater reactivity of Upper Freeport coal pyrite over Pitisburgh coal pyrite. Figure 2.35 compares Pittsburgh and Illinois coal pyrites. The peaks for Pittsburgh coal pyrite are much broader but the current is about the same, indicating similar reactivity. Based on current densities, the increasing reactivity follows in the order:

Upper Freeport coal pyrite $>$ Pittsburgh No.8 coal pyrite $\approx$ Illinois coal pyrite $>$ mineral pyrite.

Conditions Affecting Peak 1a. As described above, peak 1a appears in cyclic voltammograms only under conditions of solution stirring, providing the electrode had been subjected to anodic potentials as high as $+0.8 \mathrm{~V}$. Under these conditions, a unique double peak 1/1a is apparent (Figure 2.8). Peak 1a did not appear in the voltammograms for quiescent conditions even for scan rate as low as $20 \mathrm{mV} / \mathrm{s}$ (Figure 2.7). Additional experiments were carried out to elucidate conditions which lead to the formation of peak 1a. In the latter experiments, voltammograms were obtained with stirring present for only a portion of the scan. Quiescent conditions were maintained for the remainder of the scan. The effects of stirring in the potential regions of 0.0 to $+0.8 \mathrm{~V}$ and -1.3 to $0.0 \mathrm{~V}$ for mineral pyrite in solutions at $\mathrm{pH} 9.2$ are shown in Figure 2.36. The results further indicate that peak $1 \mathrm{a}$ is dependent on solution stirring only in the high potential region $(0.0$ to $+0.8 \mathrm{~V}$ ). Stirring in the low potential region had no influence on peak la formation. When the electrode was pre-conditioned at +0.4 or $+0.5 \mathrm{~V}$ for 3 minutes, peak 1a was greatly enhanced and appeared for both stirred and quiescent solutions as shown in Figures 2.37, 2.38 and 2.39 for mineral pyrite, Pittsburgh and Illinois coal pyrites respectively. These 


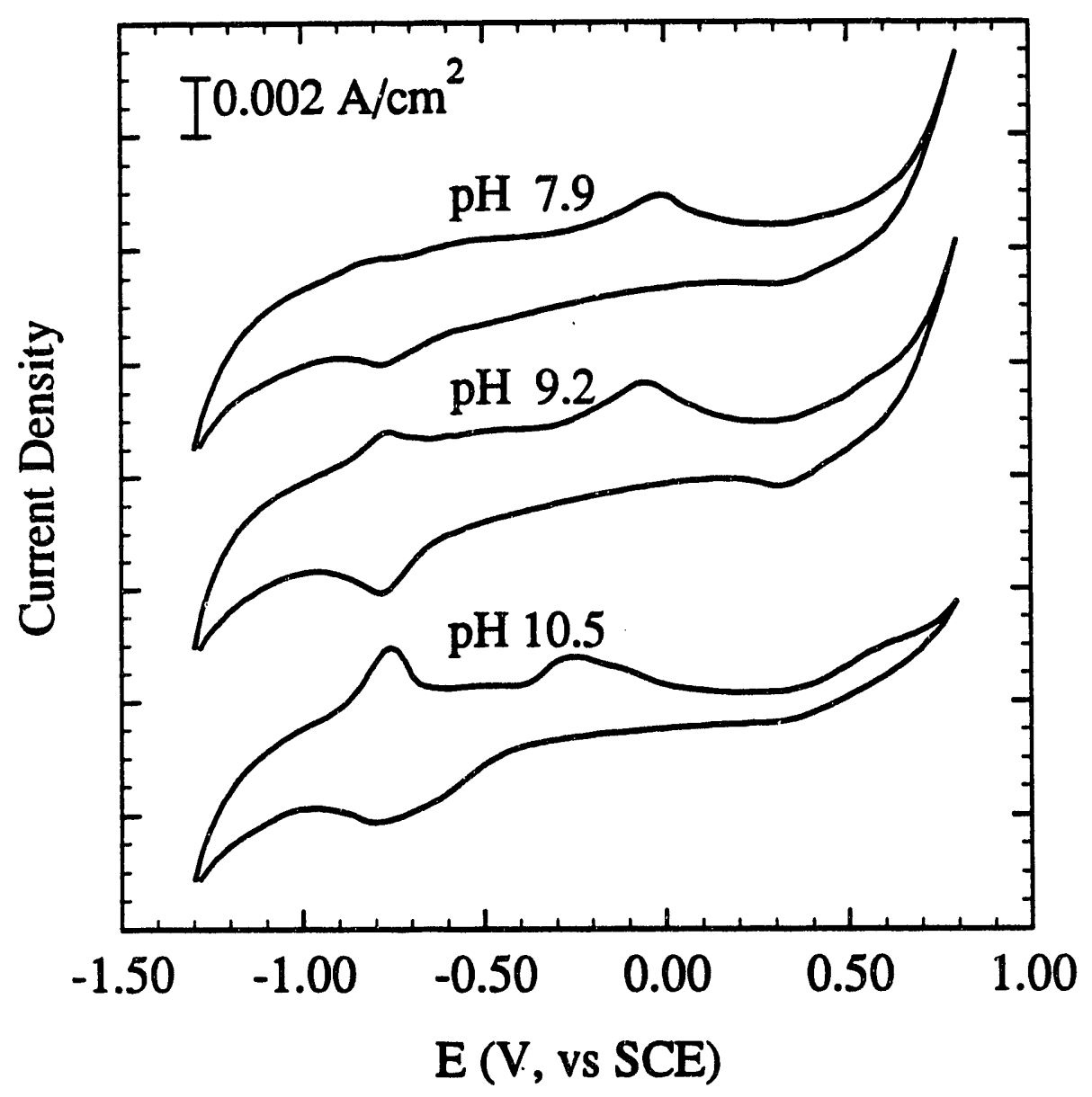

Figure 2.30. Effect of Solution pH, Pittsburgh Coal Pyrite in Quiescent Solutions, Scan Rates, $50 \mathrm{mV} / \mathrm{s}$ 


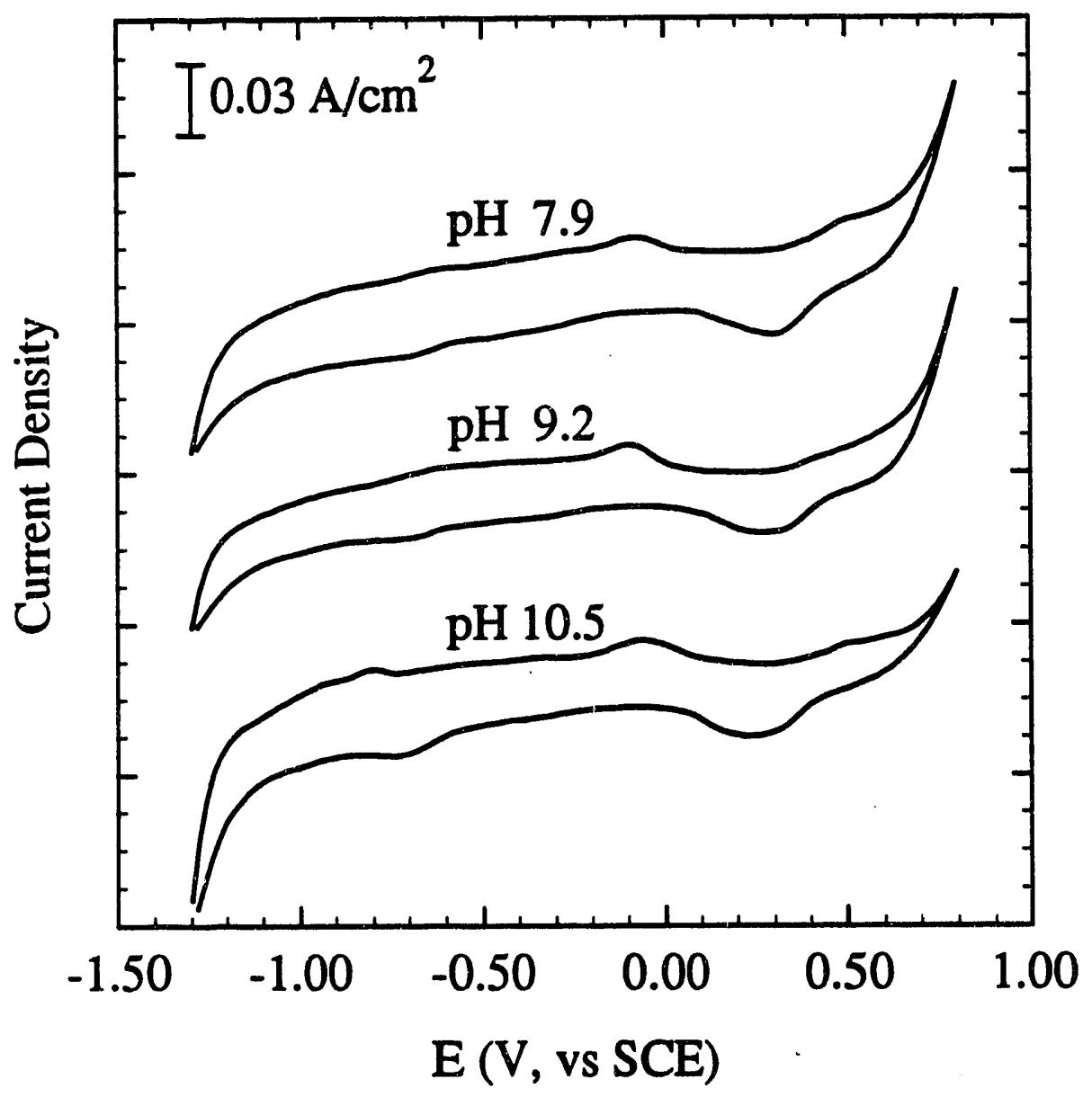

Figure 2.31. Effect of Solution pH, Upper Freeport Coal Pyrite in Quiescent Solutions, Scan Rates, $50 \mathrm{mV} / \mathrm{s}$ 


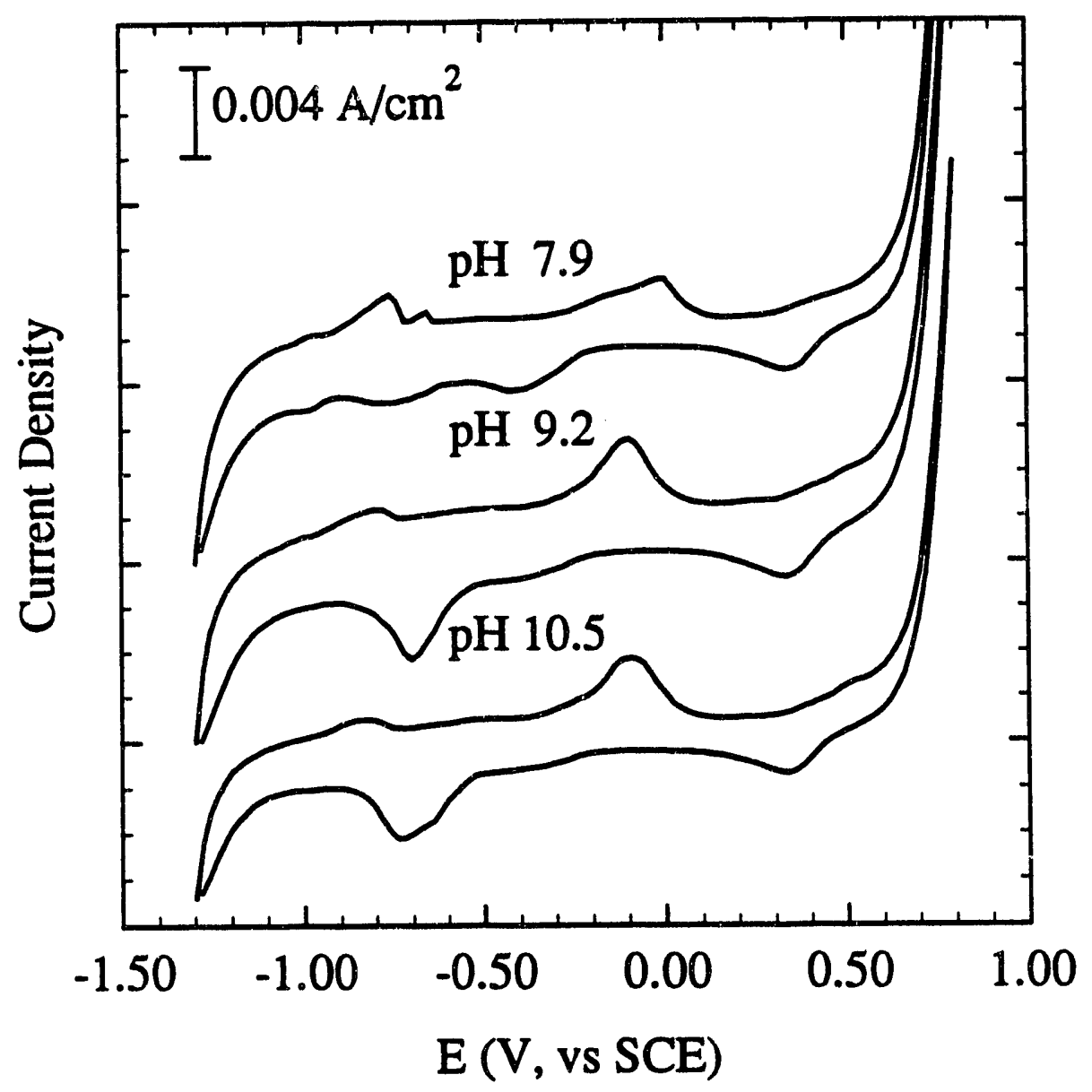

Figure 2.32. Effect of Solution pH, Illinois Coal Pyrite in Quiescent Solutions, Scan Rates, $50 \mathrm{mV} / \mathrm{s}$ 


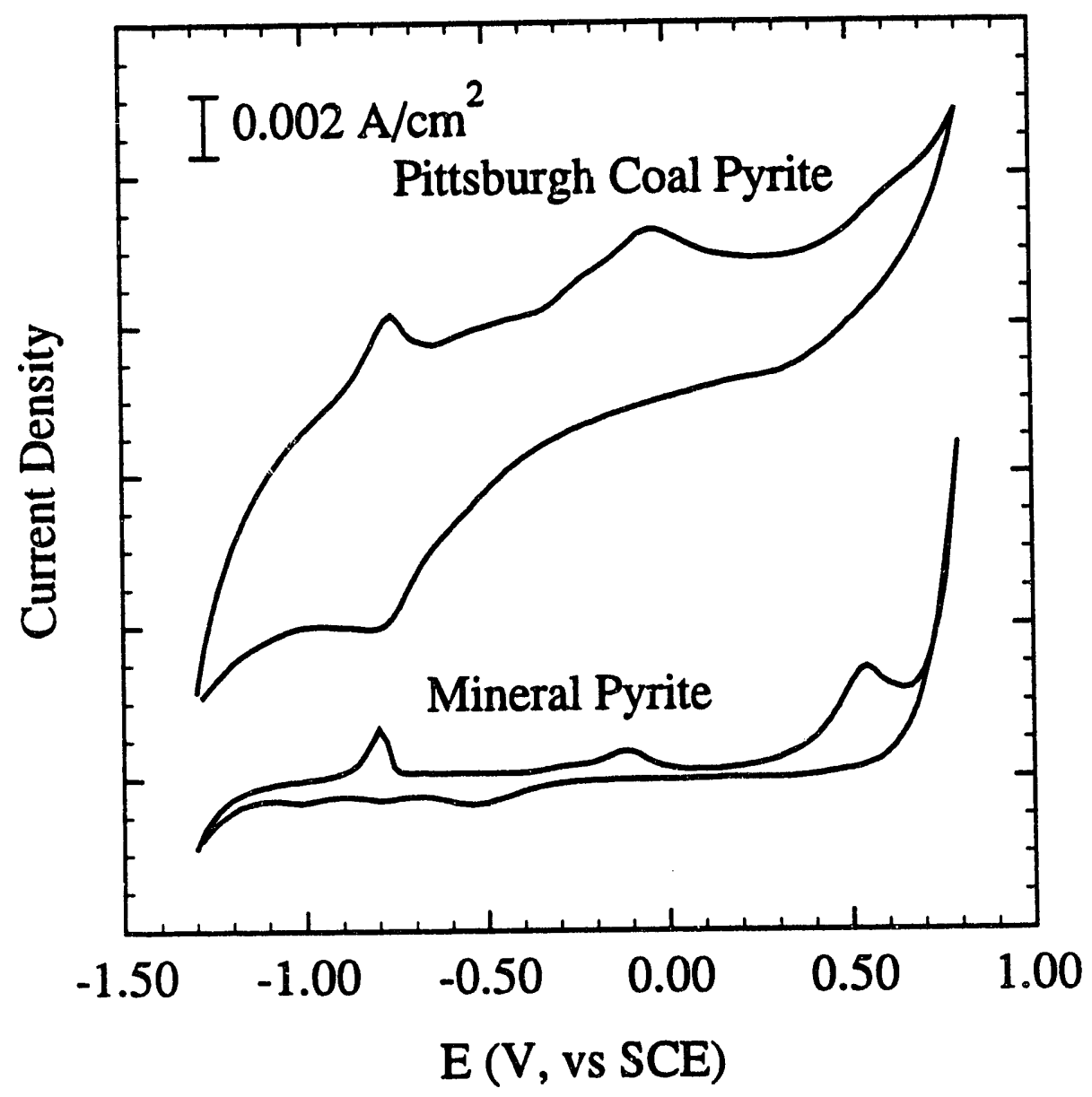

Figure 2.33. Comparison of Mineral Pyrite and Pittsburgh Coal Pyrite in Quiescent Solutions at pH 9.2, Scan Rate, $100 \mathrm{mV} / \mathrm{s}$ 


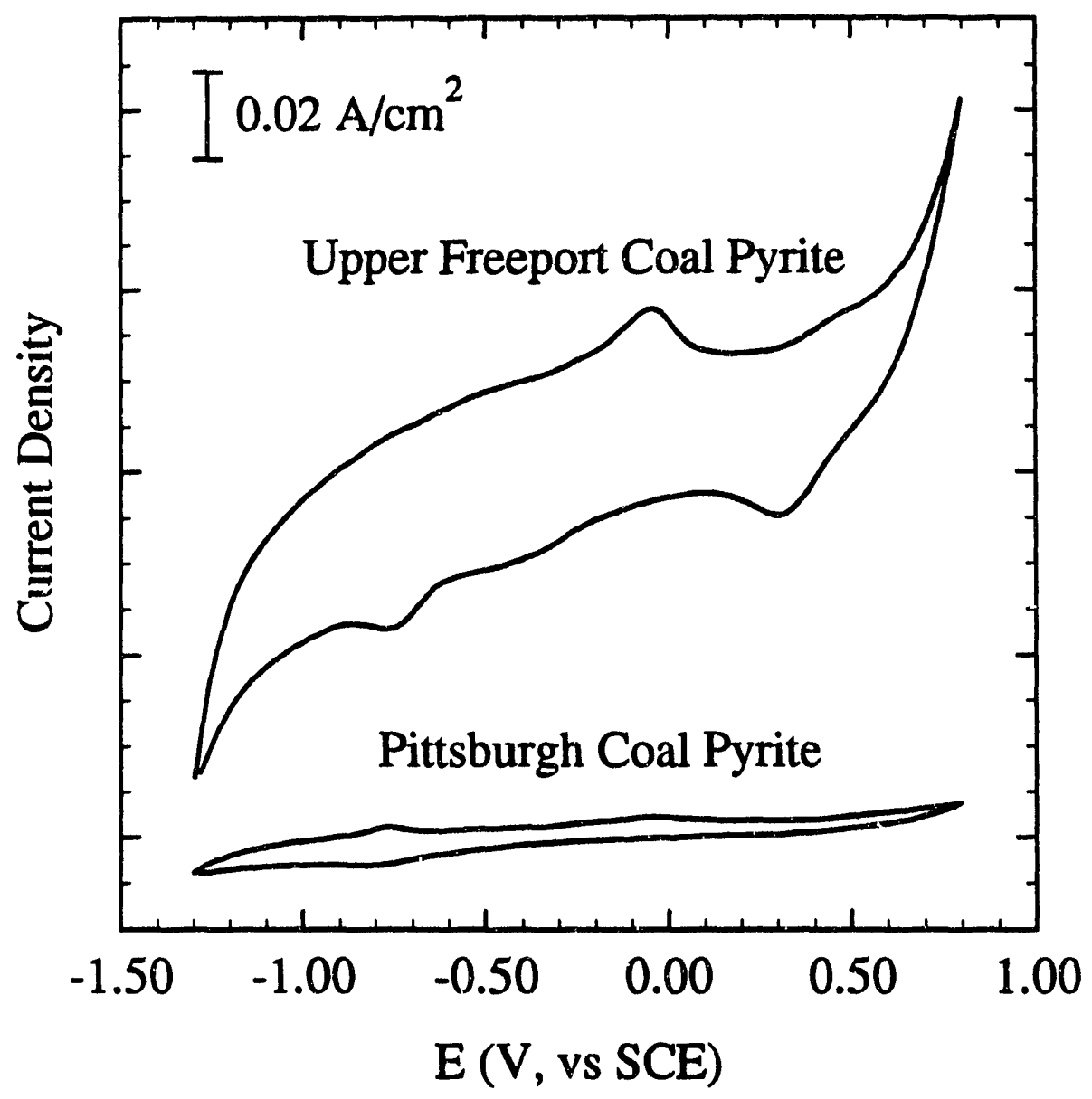

Figure 2.34. Comparison of Pittsburgh and Upper Freeport Coal Pyrites in Quiescent Solutions at pH 9.2, Scan Rate, $100 \mathrm{mV} / \mathrm{s}$ 


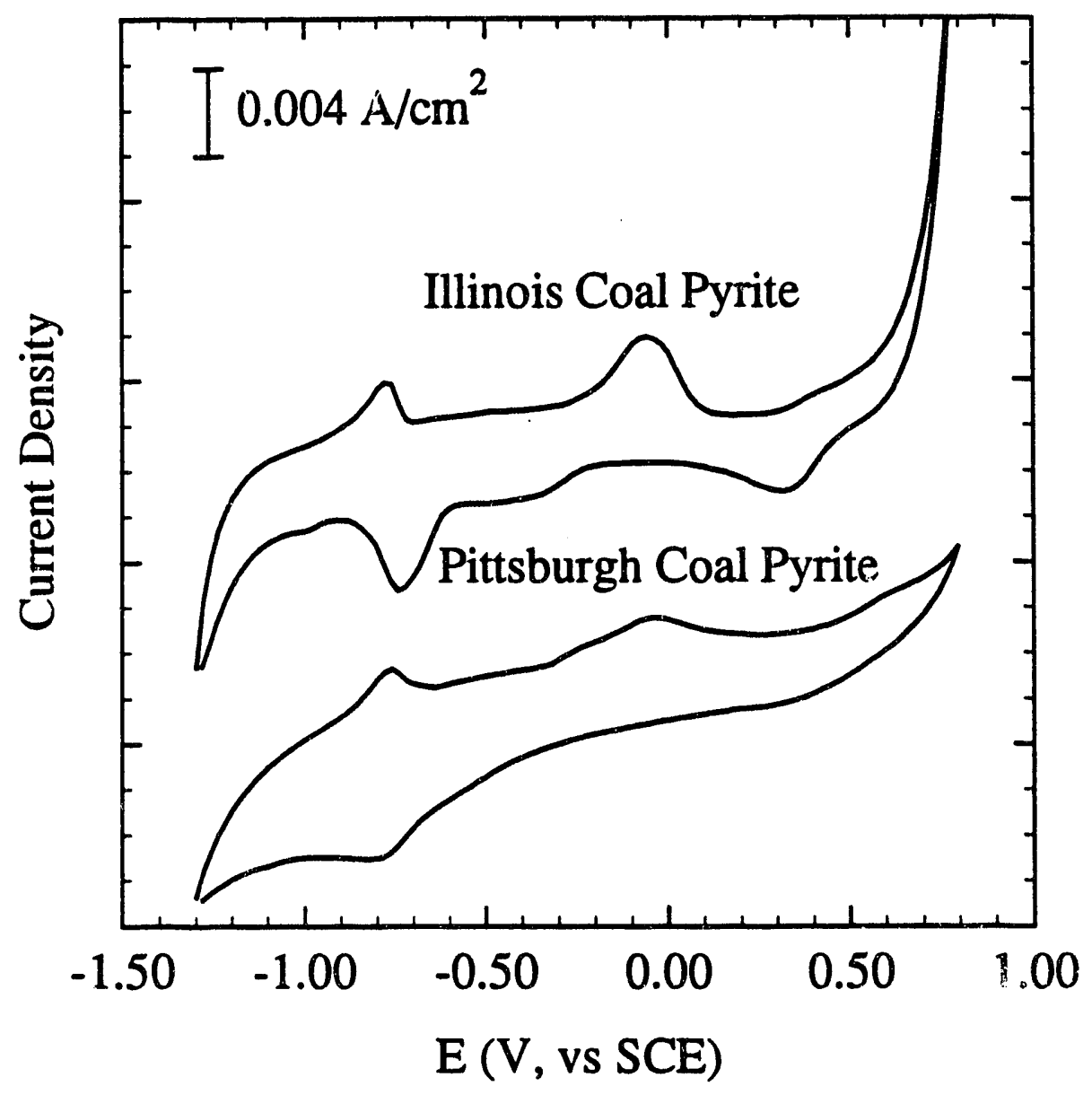

Figure 2.35. Comparison of Illinois Coal Pyrite and Pittsburgh Coal Pyrite in Quiescent Solutions at pH 9.2, Scar Rater, $100 \times 1 \%$ \%/s 


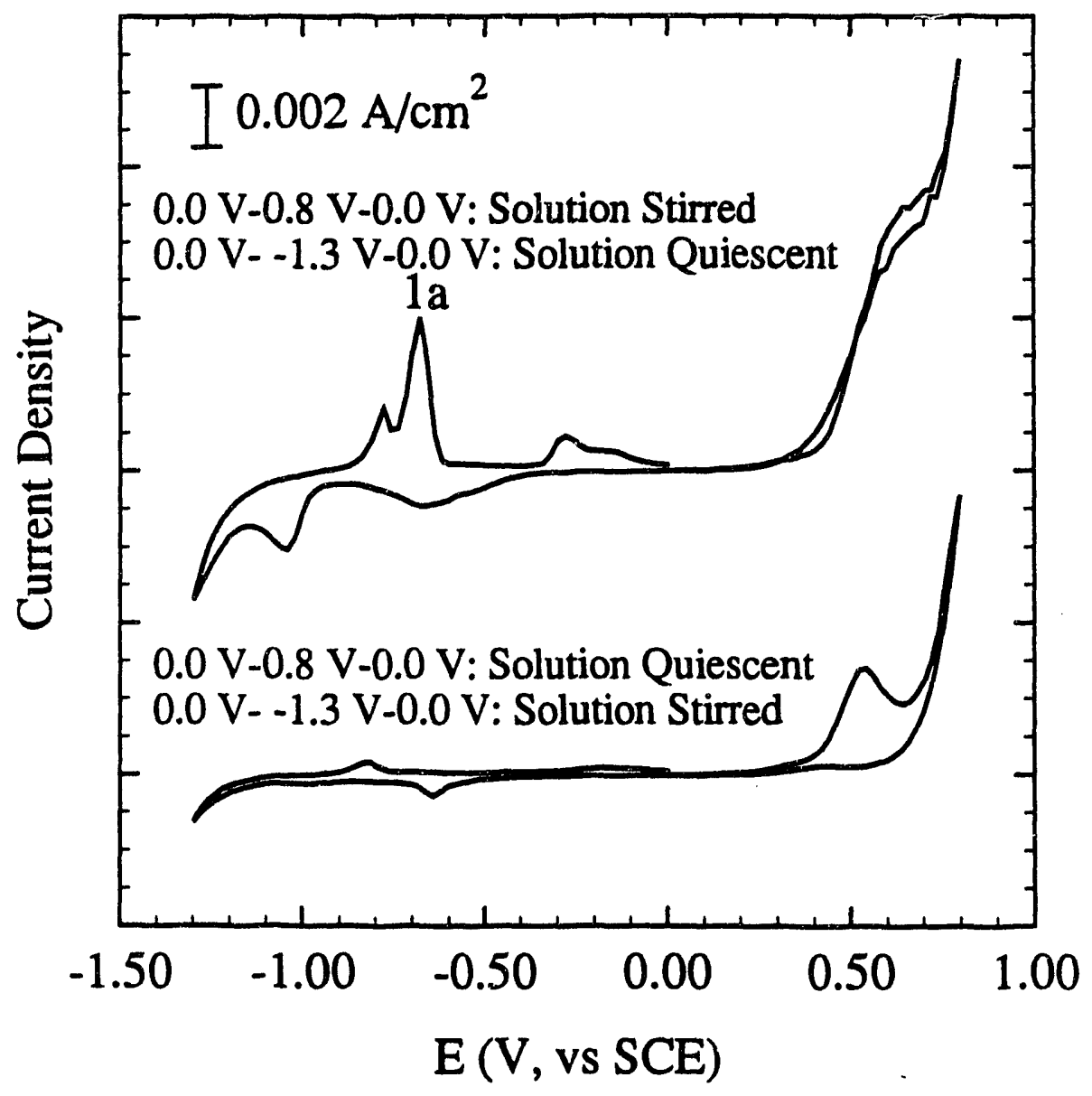

Figure 2.36. Effect of Solution Stirring on Peak 1a, Mineral Pyrite in Solutions at $\mathrm{pH} 9.2, \mathrm{Scan}$ Initiated at $0.0 \mathrm{~V}$, Scan Rates, $50 \mathrm{mV} / \mathrm{s}$ 


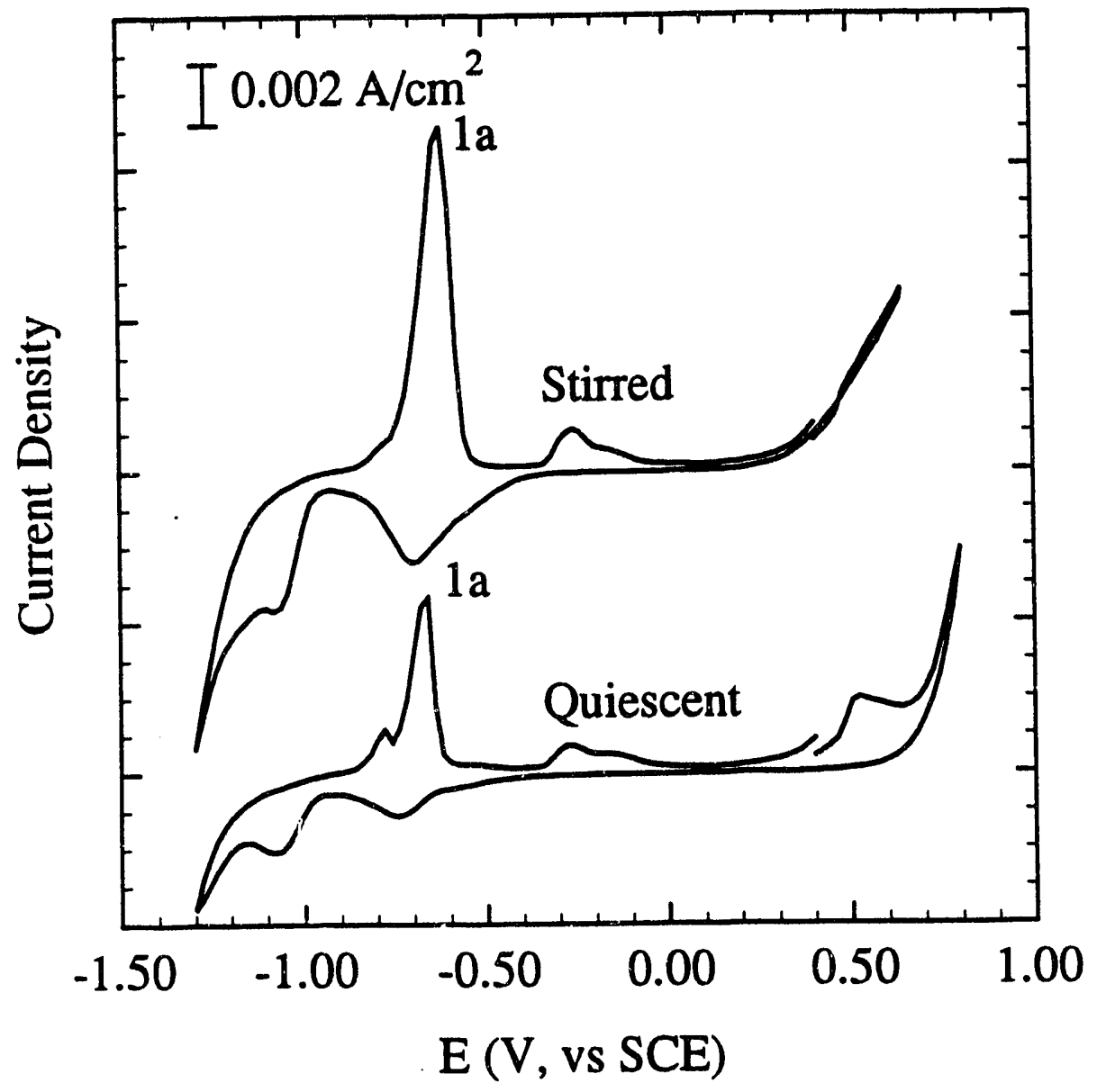

Figure 2.37. Mineral Pyrite in Solutions at pH 9.2, Electrode Pre-conditioned at $0.4 \mathrm{~V}$ for 3 Mirutes, Scan Rates, $50 \mathrm{mV} / \mathrm{s}$ 


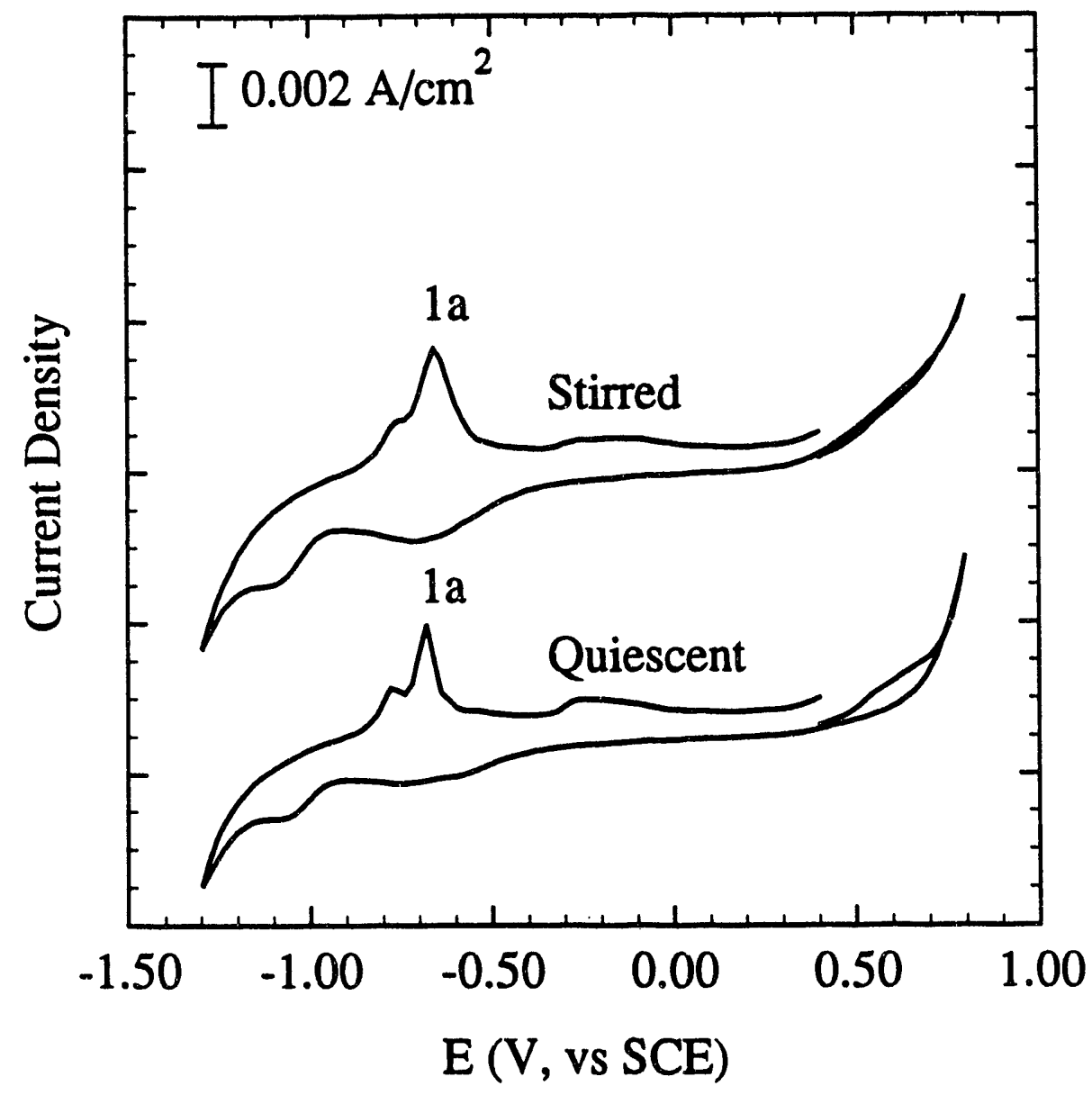

Figure 2.38. Pittsburgh Coal Pyrite in Solutions at pH 9.2, Electrode Preconditioned at $0.4 \mathrm{~V}$ for 3 Minutes, Scan Rates, $50 \mathrm{mV}$ is 


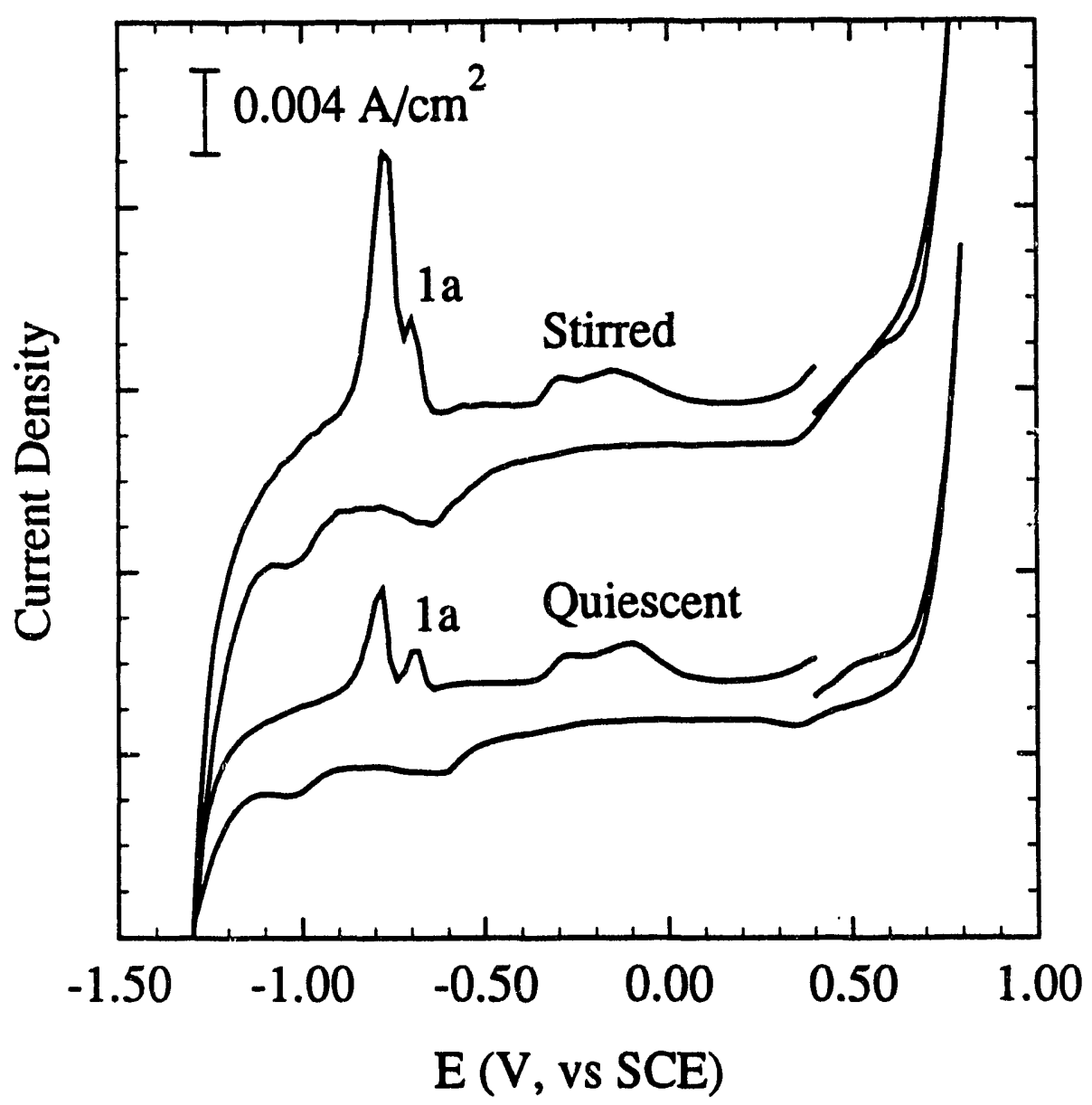

Figure 2.39. Illinois Coal Pyrite in Solutions at pH 9.2, Electrode Preconditioned at $0.4 \mathrm{~V}$ for 3 Minutes, Scan Rates, $50 \mathrm{mV} / \mathrm{s}$ 
results indicate that peak 1a must be related to the formation of oxidation products in the higher potential region. The high voltage reaction leading to peak $1 \mathrm{a}$ is evident for unstirred electrolyte only after long exposure at the higher voltages.

The effect of variable electrode pre-conditioning time on peak 1a is shown in Figures 2.40 and 2.41 for mineral pyrite and Pittsburgh coal pyrite respectively. The intensity of peak 1a increases regularly with electrode pre-condition time, indicating a build-up of reaction products during the pre-conditioning period.

Figure 2.42 demonstrates the effect of electrode pre-condition potential. The highest peak intensity was obtained when the electrode had been pre-conditioned at 0.4 $\mathrm{V}$ under solution stirring. This result infers that there is an optimum potential for the reaction forming oxidation products which lead to peak 1a.

\section{Transpassive Oxidation}

As described above, at the mineral pyrite surface, three anodic peaks at about -0.8 $\mathrm{V},-0.1 \mathrm{~V}$ and $+0.5 \mathrm{~V}$ were detected along with their corresponding reduction peaks, as shown in Figures 2.7 and 2.8, for quiescent and stirred solutions respectively with stationary electrodes, at various scan rates (mV/s.). The first two peaks (peaks $1 / 6$ and 2/5) correspond to $\mathrm{Fe} / \mathrm{Fe}$ (II) and $\mathrm{Fe}(\mathrm{II}) / \mathrm{Fe}$ (III) oxidation (Eqs. 2.8 and 2.10), $\mathrm{Fe}^{\circ}$ having been formed on a prior cathodic scan. A third peak at a higher oxidation potential $(+0.5$ $\mathrm{V}$, peak 3) is present for quiescent conditions (Figure 2.7) but disappears as a distinct peak when the electrolyte is stirred (Figure 2.8). A series of voltammograms were performed for mineral pyrite in quiescent solutions at various cathodic starting/reversal potentials. The results are summarized in Figure 2.43. Peak 1 is related to peak 6 and appeared only when the potential scan was reversed after peak 6. Peak 2 is related to peak 5 and is weakened significantly if peak 1 does not appear. When the potential scan is reversed before peak $5(-0.4 \mathrm{~V}, \mathrm{SCE})$, a strong peak 3 is observed while the other peaks are not seen, indicating that peak 3 is related to the direct oxidation of pyrite in the transpassive region. The expected reactions in this region may be:

$$
\mathrm{FeS}_{2}+3 \mathrm{H}_{2} \mathrm{O} \rightarrow \mathrm{Fe}(\mathrm{OH})_{3}+2 \mathrm{~S}^{\circ}+3 \mathrm{H}^{+}+3 e^{-}
$$




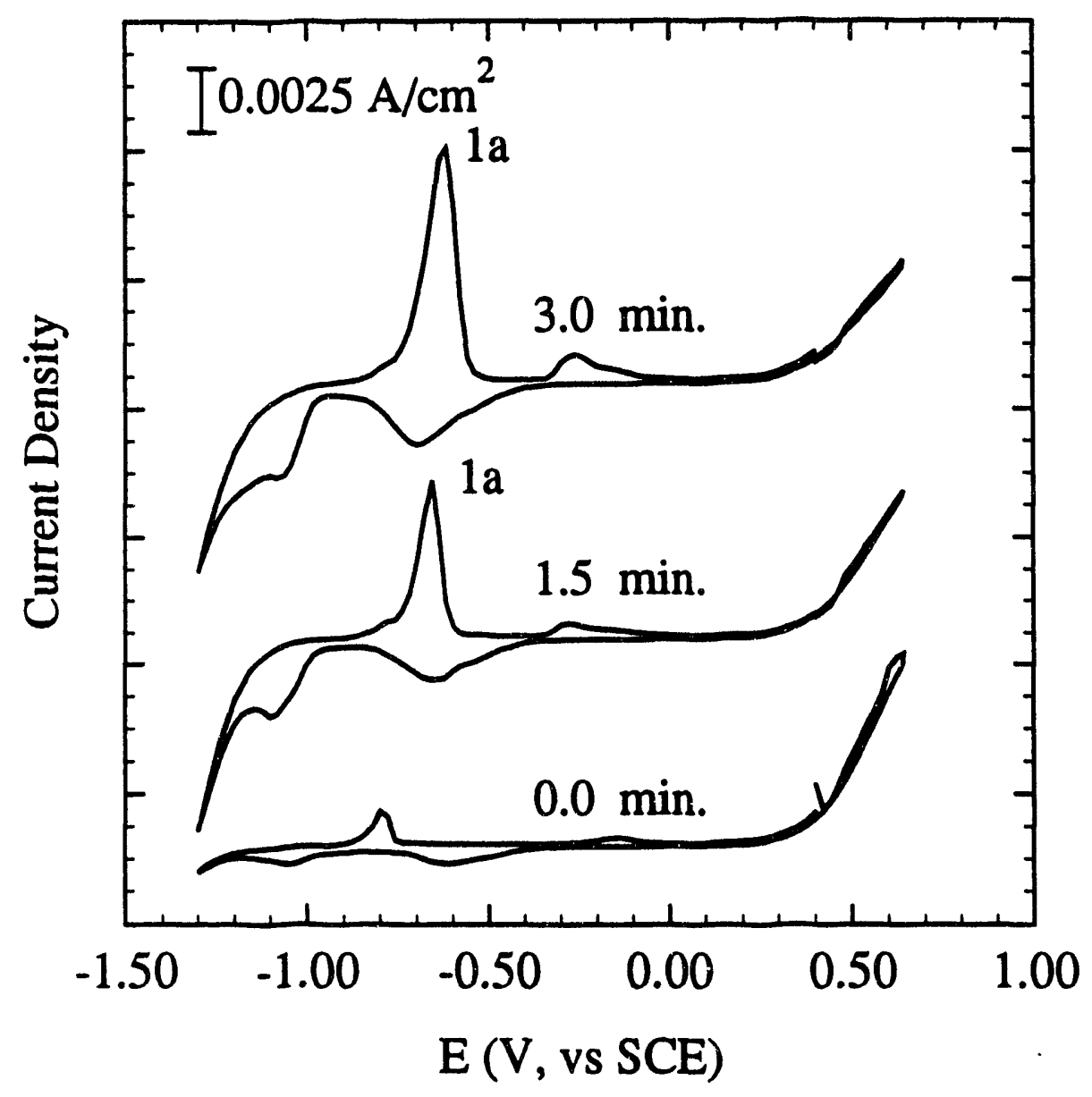

Figure 2.40. Effect of Electrode Pre-conditioning Time at 0.4 V, Mineral Pyrite in Stirred Solutions of pH 9.2, Scan Rate, $50 \mathrm{mV} / \mathrm{s}$ 


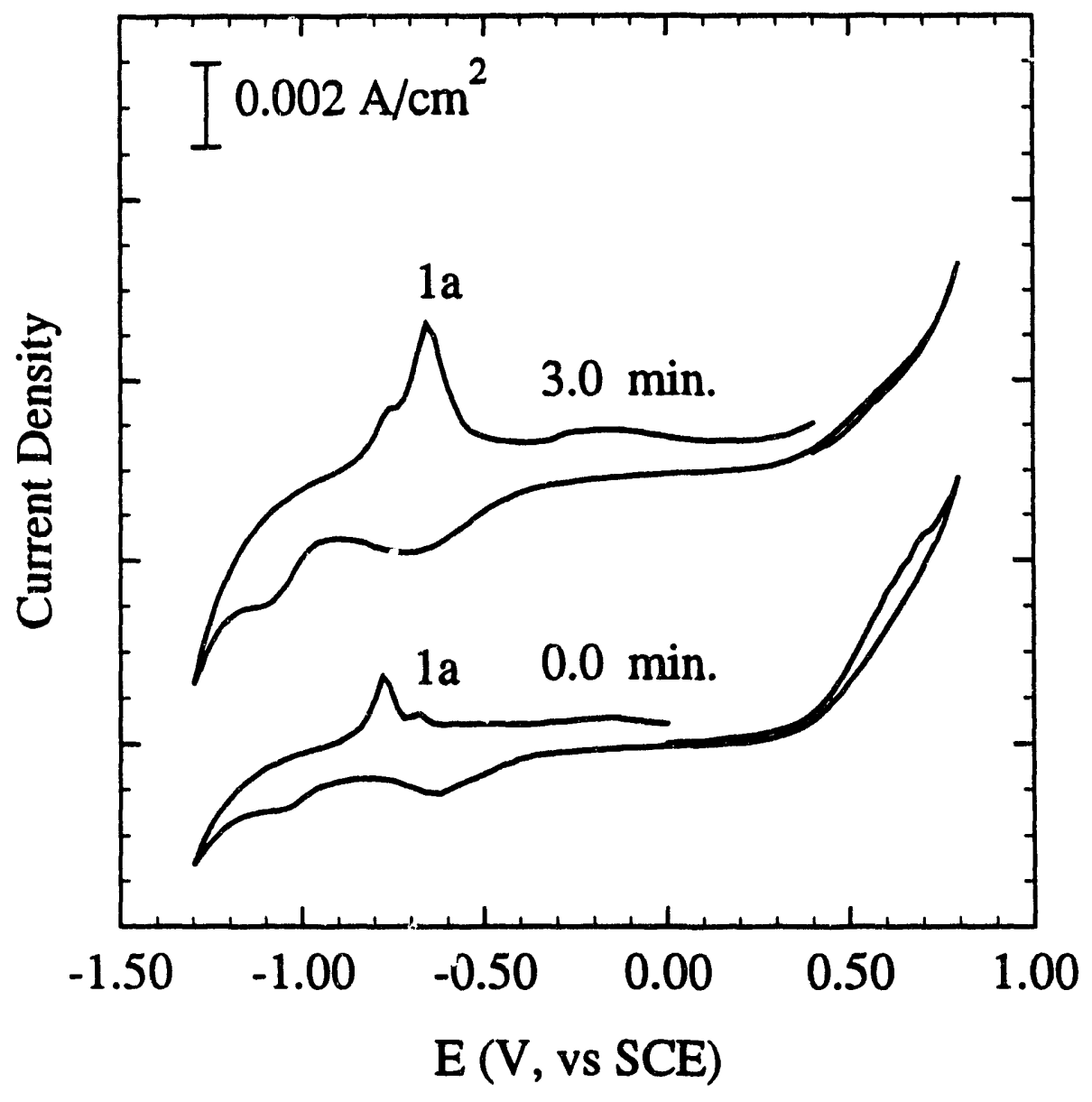

Figure 2.41. Effect of Electrode Pre-conditioning Time at 0.4 V, Pittsburgh Coal Pyrite in Stirred Solutions of $\mathrm{pH}$ 9.2, Scan Rate, $50 \mathrm{mV} / \mathrm{s}$ 


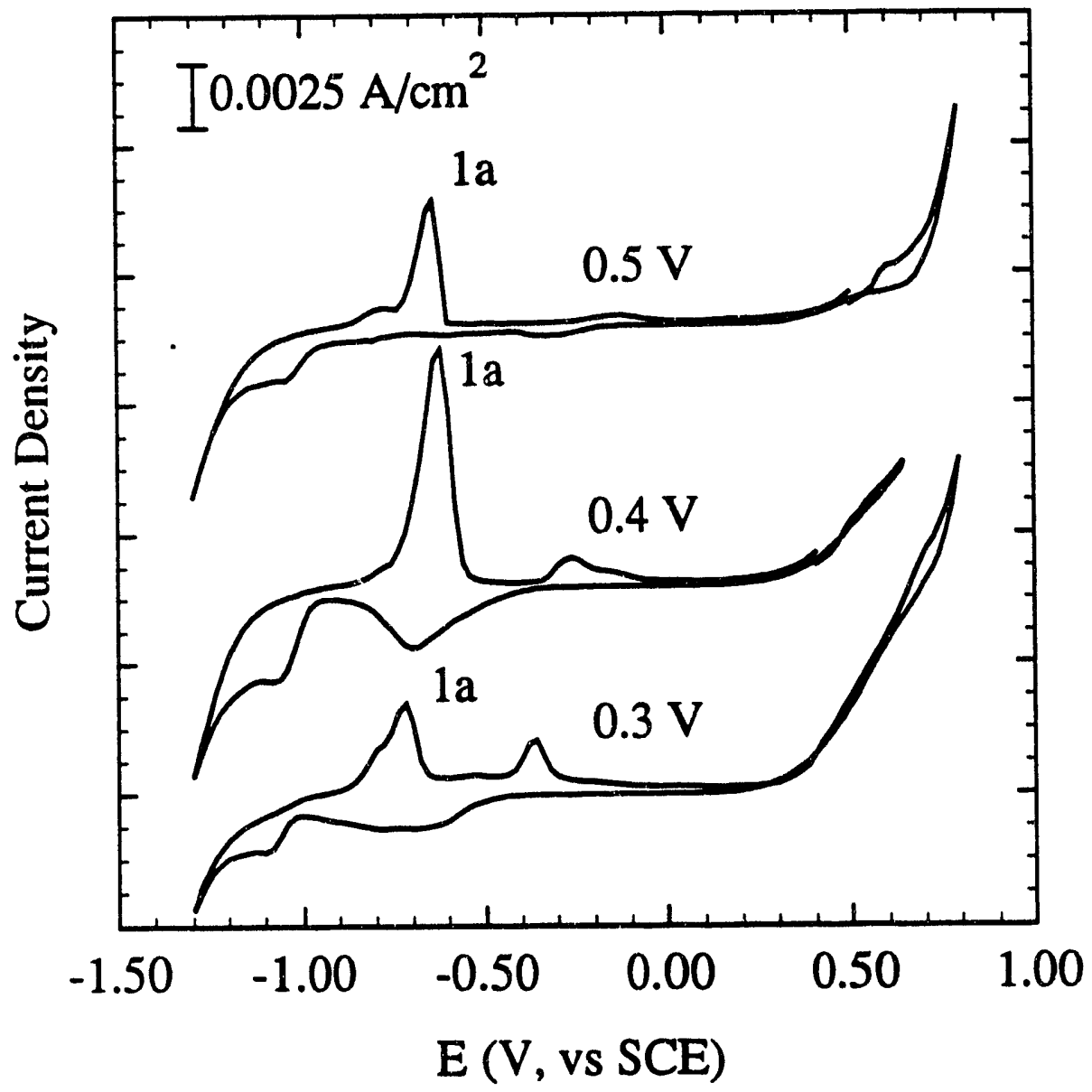

Figure 2.42. Effect of Electrode Pre-conditioning Potential after $3 \mathrm{~min}$., Mineral Pyrite in Stirred Solutions of $\mathrm{pH}$ 9.2, Scan Rate, $50 \mathrm{mV} / \mathrm{s}$ 


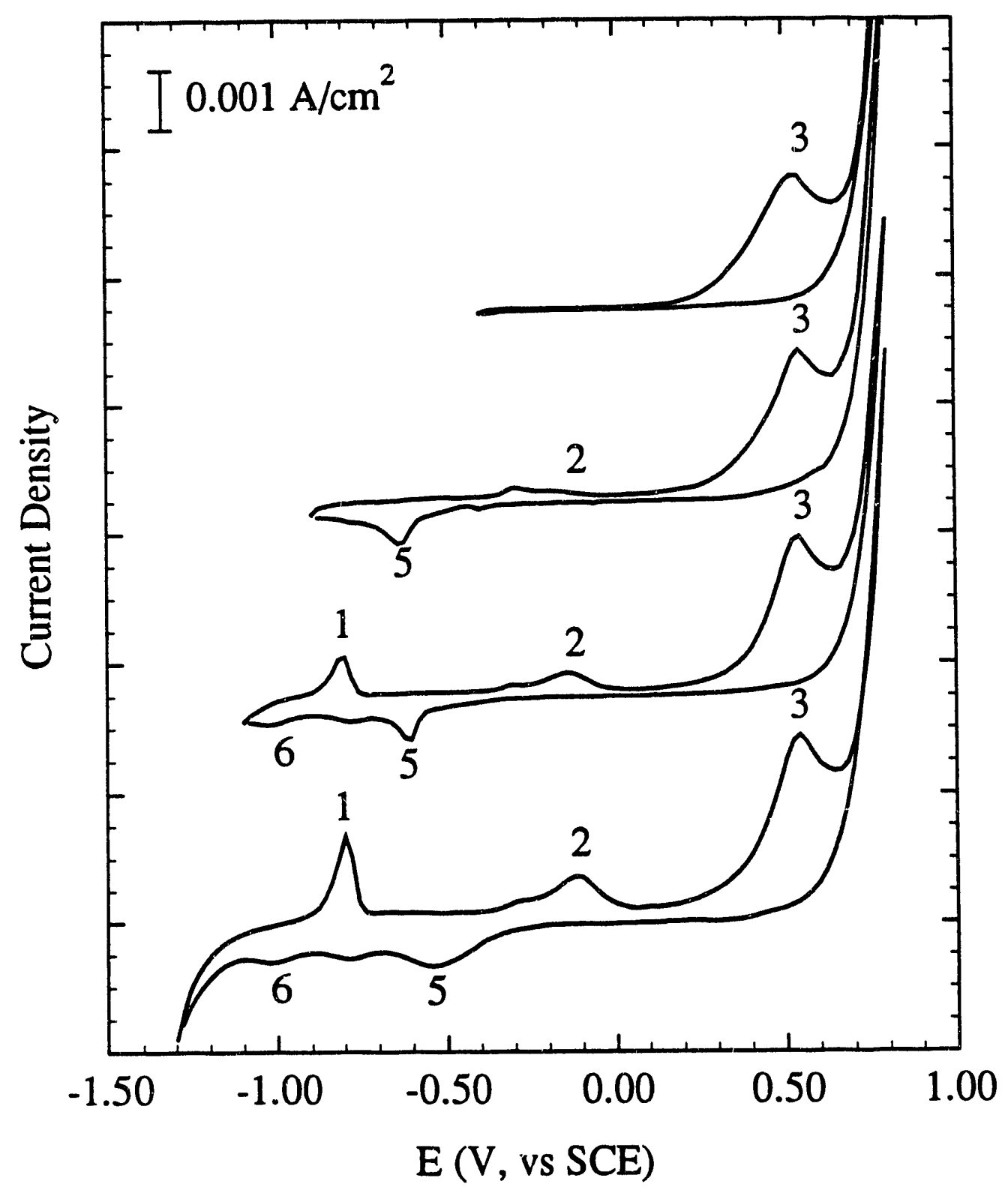

Figure 2.43. Mineral Pyrite in Quiescent Solutions at pH 9.2, Scan Reversed at Various Cathodic Limits, Scan Rates, $100 \mathrm{mV} / \mathrm{s}$ 


$$
E_{h}=0.58-0.059 p H
$$

At $\mathrm{pH}=9.2, \mathrm{E}_{\mathrm{h}}=0.037 \mathrm{~V}$ and $\mathrm{E}_{\mathrm{SCE}}=-0.203 \mathrm{~V}$.

$$
\begin{gathered}
\mathrm{FeS}_{2}+11 \mathrm{H}_{2} \mathrm{O} \rightarrow \mathrm{Fe}(\mathrm{OH})_{3}+2 \mathrm{SO}_{4}^{*}+19 \mathrm{H}^{+}+15 e^{-} \\
E_{h}=0.4-0.075 \mathrm{pH}+0.008 \log \left[\mathrm{SO}_{4}^{2-}\right]
\end{gathered}
$$

At $\mathrm{pH}=9.2$ and neglect the last term, $\mathrm{E}_{\mathrm{h}}=-0.29 \mathrm{~V}$ and $\mathrm{E}_{\mathrm{SCE}}=-0.53 \mathrm{~V}$.

It would be expected that the surface iron oxide product would likely be goethite, $\mathrm{FeOOH}$.

$$
\begin{aligned}
\mathrm{FeS}_{2}+2 \mathrm{H}_{2} \mathrm{O} & =\mathrm{FeOOH}+2 S^{\circ}+3 H^{+}+3 e^{-} \\
E_{h} & =0.472-0.059 p H
\end{aligned}
$$

At $p H=9.2 E_{h}=-0.07 V$ and $E_{S C E}=-0.31 \mathrm{~V}$.

$$
\begin{gathered}
\mathrm{FeS}_{2}+10 \mathrm{H}_{2} \mathrm{O}=\mathrm{FeOOH}+2 \mathrm{SO}_{4}^{2-}+19 \mathrm{H}^{+}+15 e^{-} \\
E_{h}=0.38-0.075 \mathrm{pH}+0.008 \log \left[\mathrm{SO}_{4}^{2-}\right]
\end{gathered}
$$

At $\mathrm{pH}=9.2$ and neglect the last term, $\mathrm{E}_{\mathrm{h}}=-0.31 \mathrm{~V}$ and $\mathrm{E}_{\mathrm{SCE}}=-0.55 \mathrm{~V}$.

These calculated values are quite low suggesting the observed voltage for the transpassive region respond to the formation of intermediates. It is noted that a brown precipitate of ferric hydroxide forms in the electrochemical cell. This is most pronounced for stirred cell. One possible ferric-oxy cation intermediate is $\mathrm{Fe}(\mathrm{OH})_{2}{ }^{+}$.

$$
\begin{aligned}
& \mathrm{FeS}_{2}+2 \mathrm{H}_{2} \mathrm{O}=\mathrm{Fe}(\mathrm{OH})_{2}^{+}+2 \mathrm{~S}^{\circ}+2 \mathrm{H}^{+}+3 e^{-} \\
& E_{h}=0.624-0.039 \mathrm{pH}+0.02 \log \left[\mathrm{Fe}(\mathrm{OH})_{2}^{+}\right]
\end{aligned}
$$

At $\mathrm{pH}=9.2$ and for $\left[\mathrm{Fe}(\mathrm{OH})_{2}^{+}\right]=10^{-4}, \mathrm{E}_{\mathrm{b}}=0.185 \mathrm{~V}$ and $\mathrm{E}_{\mathrm{SCE}}=-0.055 \mathrm{~V}$.

$$
\begin{aligned}
& \mathrm{FeS}_{2}+10 \mathrm{H}_{2} \mathrm{O}=\mathrm{Fe}(\mathrm{OH})_{2}^{+}+2 \mathrm{SO}_{4}^{2-}+18 \mathrm{H}^{+}+15 e^{-} \\
& E_{h}=0.411-0.071 \mathrm{pH}+0.004 \log \left[\mathrm{SO}_{4}^{2-}\right]^{2}\left[\mathrm{Fe}(\mathrm{OH})_{2}^{+}\right]
\end{aligned}
$$


At $\mathrm{pH}=9.2$ and neglect the last term, $\mathrm{E}_{\mathrm{b}}=-0.242 \mathrm{~V}$ and $\mathrm{E}_{\mathrm{SCE}}=-0.482 \mathrm{~V}$.

It may be that soluble intermediates of sulfur formed. It has been noted polysulfide formation prior to elemental sulfur in Raman spectroscopical study (see Chapter 3). Also sulfoxy anion would be expected to form in basic solutions. For example dithionate ion is often found in metal sulfide leach solutions. Considering dithionate, $\mathrm{S}_{3} \mathrm{O}_{6}{ }^{2-}$, as an intermediate,

$$
\begin{aligned}
& 3 \mathrm{FeS}_{2}+18 \mathrm{H}_{2} \mathrm{O}=3 \mathrm{Fe}(\mathrm{OH})_{2}^{+}+2 \mathrm{~S}_{3} \mathrm{O}_{6}^{2-}+30 \mathrm{H}^{+}+29 e^{-} \\
& E_{h}=0.565-0.066 \mathrm{pH}+0.002 \log \left[\mathrm{S}_{3} \mathrm{O}_{6}^{2-}\right]^{2}\left[\mathrm{Fe}(\mathrm{OH})_{2}^{+}\right]^{3}
\end{aligned}
$$

At $\mathrm{pH}=9.2$ and neglect the last term, $\mathrm{E}_{\mathrm{b}}=-0.042 \mathrm{~V}$ and $\mathrm{E}_{\mathrm{SCE}}=-0.282 \mathrm{~V}$.

There is no direct evidence of the formation of polythionate ions during anodic oxidation of pyrite. For all of the above reactions, large overpotentials are required for the transpassive region, $E_{S C E}>0.4 \mathrm{~V}$. These reactions thus appear highly irreversible making it difficult to ascertain what intermediates form. The observation of Raman spectroscopical study (see Chapter 3) confirming the formation of polysulfide intermediates suggests the reaction,

$$
x \mathrm{FeS}_{2}+2 x \mathrm{H}_{2} \mathrm{O}=x \mathrm{Fe}(\mathrm{OH})_{2}^{+}+2 \mathrm{~S}_{x}^{2-}+2 x \mathrm{H}^{+}+(3 x-4) e^{-}
$$

and for $\mathrm{x}=3$,

$$
\begin{aligned}
& 3 \mathrm{FeS}_{2}+6 \mathrm{H}_{2} \mathrm{O}=3 \mathrm{Fe}(\mathrm{OH})_{2}^{+}+2 \mathrm{~S}_{3}^{2-}+6 \mathrm{H}^{+}+5 e^{-} \\
& E_{h}=1.435-0.071 p H+0.012 \log \left[\mathrm{S}_{3}^{2-}\right]^{2}\left[\mathrm{Fe}(\mathrm{OH})_{2}^{+}\right]^{3}
\end{aligned}
$$

At $\mathrm{pH}=9.2$, for $\left[\mathrm{S}_{3}{ }^{2-}\right]$ and $\left[\mathrm{Fe}(\mathrm{OH})_{2}{ }^{+}\right]=10-4, \mathrm{E}_{\mathrm{h}}=0.542 \mathrm{~V}$ and $\mathrm{E}_{\mathrm{SCE}}=0.3 \mathrm{~V}$.

This is much more reasonable. Additional reactions for $3<\mathrm{x}<6$ give similar results. If goethite forms directly on the surface, then,

$$
x \mathrm{FeS}_{2}+2 x \mathrm{H}_{2} \mathrm{O}=x \mathrm{FeOOH}+2 \mathrm{~S}_{x}^{2-}+3 x \mathrm{H}^{+}+(3 x-4) e^{-}
$$

and for $x=3$,

$$
3 \mathrm{FeS}_{2}+6 \mathrm{H}_{2} \mathrm{O}=3 \mathrm{FeOOH}+2 \mathrm{~S}_{3}^{2-}+9 \mathrm{H}^{+}+5 e^{-}
$$




$$
E_{h}=1.16-0.106 p H+0.012 \log \left[S_{3}^{2-}\right]^{2}
$$

At $\mathrm{pH}=9.2$ and for $\left[\mathrm{S}_{3}{ }^{2-}\right]=10^{-4}, \mathrm{E}_{\mathrm{h}}=0.089 \mathrm{~V}$ and $\mathrm{E}_{\mathrm{SCE}}=-0.151 \mathrm{~V}$.

The confirmation of the presence of a solid layer of polysulfide $\left(\mathrm{FeS}_{\mathrm{x}}\right)$ in the transpassive region (see Chapter 3 ) suggests the following reaction sequence for $x>2$ :

$$
\begin{gathered}
x \mathrm{FeS}_{2}+(2 x-4) \mathrm{H}_{2} \mathrm{O}=2 \mathrm{FeS}_{x}+(x-2) \mathrm{Fe}(\mathrm{OH})_{2}^{+}+(2 x-4) \mathrm{H}^{+}+(3 x-6) e^{-} \\
\mathrm{FeS}_{x}+2 \mathrm{H}_{2} \mathrm{O}=\mathrm{Fe}(\mathrm{OH})_{2}^{+}+\mathrm{S}_{x}^{2-}+2 \mathrm{H}^{+}+e^{-}
\end{gathered}
$$

An expected sequence for the oxidation of the polysulfide to sulfate is through the formation of polythionate oxyanions, although the presence of polythionates in solution has not been observed.

$$
\begin{gathered}
S_{x}^{2-}+4 x \mathrm{H}_{2} \mathrm{O}=x \mathrm{SO}_{4}^{2-}+8 x \mathrm{H}^{+}+(6 x+2) e^{-} \\
S_{x}^{2-}=x S^{0}+2 e^{-} \\
\mathrm{Fe}(\mathrm{OH})_{2}^{+}=\mathrm{FeOOH}+\mathrm{H}^{+} \\
\mathrm{FeOOH}+\mathrm{H}_{2} \mathrm{O}=\mathrm{Fe}(\mathrm{OH})_{3}
\end{gathered}
$$

The reactions Eqs. 2.41, 2.42 and 2.43 account for the transpassive anodic peak 3 in quiescent solutions, where passivation is related to $\mathrm{FeOOH}, \mathrm{Fe}(\mathrm{OH})_{3}$ and $\mathrm{S}^{\circ}$ formation on the surface. Reactions Eq. 2.39 and Eq. 2.40 would explain the loss of passivation for stirred solutions. The majority of the polysulfide and sulfoxy anions would continue to oxidize to sulfate (Eq. 2.40) but those on or near the surface would be reduced to HS or elemental sulfur on the return cathodic cycle.

$$
S_{x}^{2-}+x H^{+}+(2 x-2) e^{-}=x H S^{-}
$$

and,

$$
S_{x} \mathrm{O}_{6}^{2-}+12 \mathrm{H}^{+}+10 e^{-}=x S^{0}+6 \mathrm{H}_{2} \mathrm{O}
$$

As noted earlier, under conditions of solution stiring, peak 1 appeared actually 
as a double peak including peaks 1 and 1a (Figure 2.8). Peak 1a is apparent only for scans reversed at anodic potentials higher than $0.8 \mathrm{~V}$. The products (partially oxidized sulfur intermediates and iron hydroxide) formed in the transpassive region are reduced to metallic iron (Eqs. 2.8 and 2.10) and hydrogen sulfide ion during the cathodic scan

$$
S^{0}+H^{+}+2 e^{-} \rightarrow H S_{a d s}^{-}
$$

and during the next anodic scan the metallic iron and the surface adsorbed hydrogen sulfide ion react preferentially forming iron sulfide.

$$
F e^{0}+x H S_{a d s}^{-}=F e S_{x}+x H^{+}+2 x e^{-}
$$

Reduced iron, without adsorbed HS, oxidizes to ferrous hydroxide (Eq. 2.8). These reactions (Eqs. 2.8 and 2.47) are characterized by two dominant oxidation peaks, corresponding to ferrous hydroxide and iron sulfide, observed in the region $-0.8 \mathrm{~V}$ to $0.65 \mathrm{~V}$ (SCE). Peak intensity was directly related to the amount of partially oxidized intermediates of pyritic disulfide ion formed in the transpassive region. Arico et al. [2.19] studied the electrochemical mechanism of iron sulfide deposition on a Pt substrate in organic solutions (diethyleneglycol) containing $\mathrm{FeCl}_{2}$ and $\mathrm{S}_{8}$ by means of cyclic voltammetry, chronopotentiometry and coulometry. The potential region suitable for deposition of iron sulfide films was identified as lying between -0.45 to $-0.65 \mathrm{~V}$ (SCE).

The exact intermediates formed during pyrite oxidation have not been determined. Reported intermediates of sulfur are the polysulfides [2.20]. Further oxidation may then form sulfur oxygen intermediates (polythionates) [2.20] leading to the final formation of sulfate ion. This sequence may include some of the following: $S_{3}{ }^{2-}, S_{4}{ }^{2-}, S_{5}{ }^{2-}, S_{6}{ }^{2-}, \ldots S^{0}$, ... $\mathrm{S}_{\mathrm{n}} \mathrm{O}_{6}{ }^{2-}, \ldots \mathrm{SO}_{4}{ }^{2-}$. A knowledge of the formation of sulfur intermediates in the transpassive region is important in that it may lead to methods for the modification and control of pyrite surfaces, and hopefully improve coal/pyrite sepirations. With this objective, a detailed study of the transpassive oxidation of mineral and coal pyrite was conducted with rotating disk electrodes to elucidate the conditions (oxidation potential, electrode pre-condition time and rotation speed) which lead to enhanced formation of sulfur products, and to show the difference in response between mineral and coal pyrite. 
Electrode Rotation Speed. The effect of electrode rotation speed on intensity of peak 1 and peak $1 \mathrm{a}$ in solutions at $\mathrm{pH} 9.2$ is shown in Figures $2.44 \mathrm{a}$ and $2.44 \mathrm{~b}$ for mineral pyrite and $45 \mathrm{a}$ and $45 \mathrm{~b}$ for Illinois coal pyrite. Based on these results, plots of peak current density versus the electrode rotation speed for mineral pyrite and Ilinois coal pyrite were obtained and are illustrated in Figures 2.46 and 2.47 respectively. The effect of rotation speed was markedly different for mineral pyrite compared to Illinois coal pyrite. For mineral pyrite, at lower rotation speeds, peak 1 (the ferrous hydroxide peak) was predominant and peak 1a (the iron sulfide peak) was relatively insignificant (Figure 2.44a). As rotation speed increased, peak 1a increased, becoming predominant at $700 \mathrm{rpm}$ (Figures 2.44a and 2.46) and continue to increase with further increase in electrode rotation speed (Figure 2.44b). For Illinois coal pyrite, peak 1a did not appear until 700 rpm had been attained (Figure 2.45a). Above $700 \mathrm{rpm}$, it increased slowly with increasing rotation speed (Figure 2.45b), but was always much smaller than peak 1 (Figure 2.47). The same measurements were performed for Pittsburgh coal pyrite. The effect of electrode rotation speed on intensity of peaks 1 and $1 \mathrm{a}$ in solutions at $\mathrm{pH} 9.2$ is shown in Figures $2.48 \mathrm{a}$ and $2.48 \mathrm{~b}$. The plot of peak current density versus the electrode rotation speed is illustrated in Figure 2.49. The results were similar to Illinois coal pyrite, except above $1000 \mathrm{rpm}$, intensity of peaks 1 and la decreased with increasing electrode rotation speed.

The formation of peak $1 \mathrm{a}$ is directly related to the oxidation products, iron hydroxide and sulfur intermediates formed in the transpassive region. The greater the intensity of peak 1a, the greater the tendency for oxidation of pyritic disulfide ion $\left(\mathrm{S}_{2}{ }^{*}\right)$ to partially oxidized intermediates $\left(\mathrm{S}_{\mathrm{x}}{ }^{2}, \mathrm{~S}^{\circ}, \mathrm{S}_{\mathrm{x}} \mathrm{O}_{6}{ }^{2-}\right.$, etc.). Further, the greater the amount of reaction forming peak 1a, the greater the expected hydrophobicity and floatability of pyrite particle. Results obtained for Illinois coal pyrite (also for Pittsburgh coal pyrite) show that peak 1 (ferrous hydroxide formation) is favored over peak 1a (ferrous sulfide formation). This result infers that enhanced floatability for mineral pyrite may be greater than that expected for coal pyrites following electrochemical alteration.

Anodic Reversal Potential. In preceding voltammograms, using stationary electrodes, the iron sulfide peak (peak 1a) is apparent only for scans reversed at anodic potential higher 


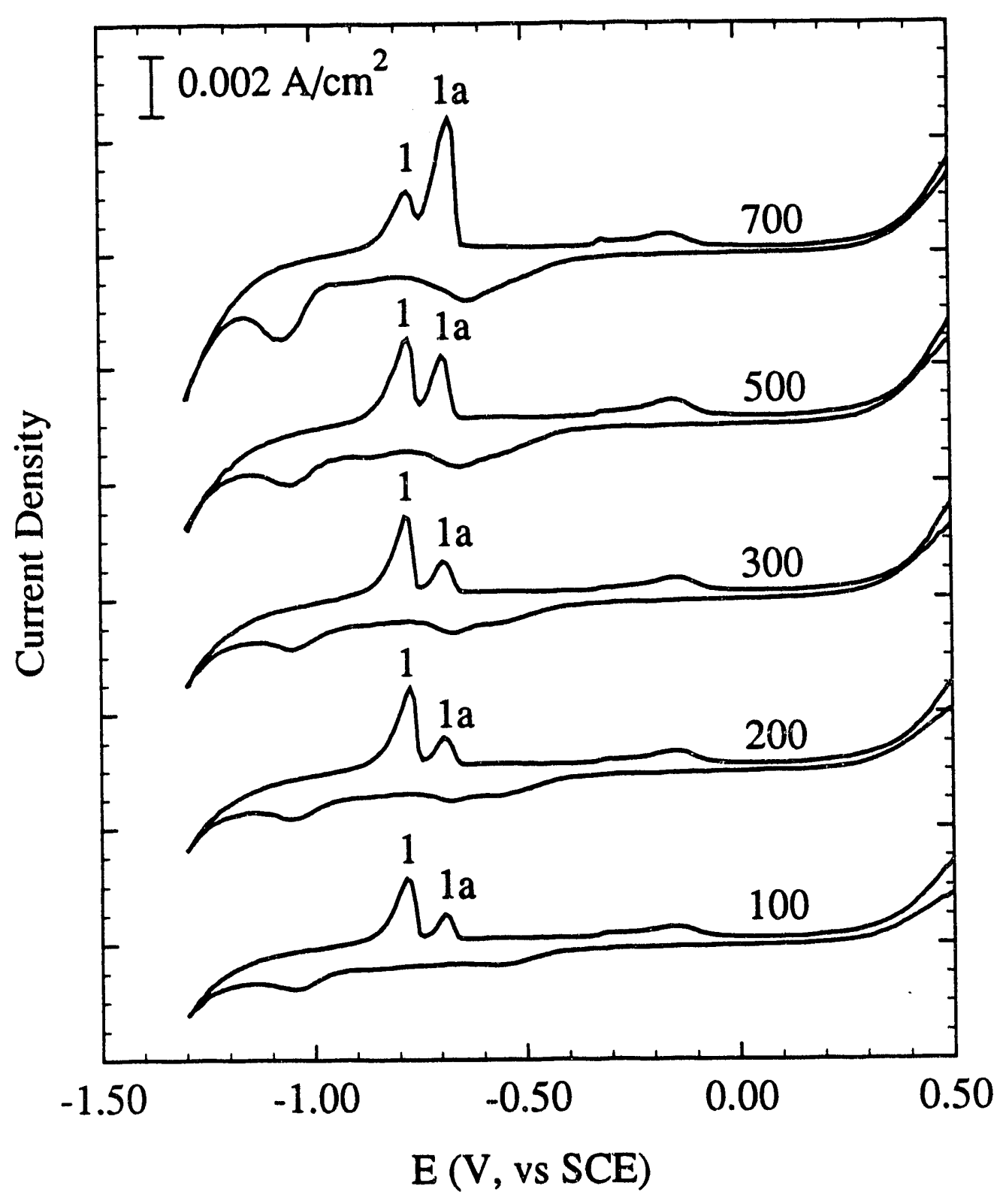

Figure 2.44a. Mineral Pyrite in Solutions at $\mathrm{pH}$ 9.2. for Various Electrode Rotation Speeds (rpm). Scan Rate, $50 \mathrm{mV} / \mathrm{s}$. 


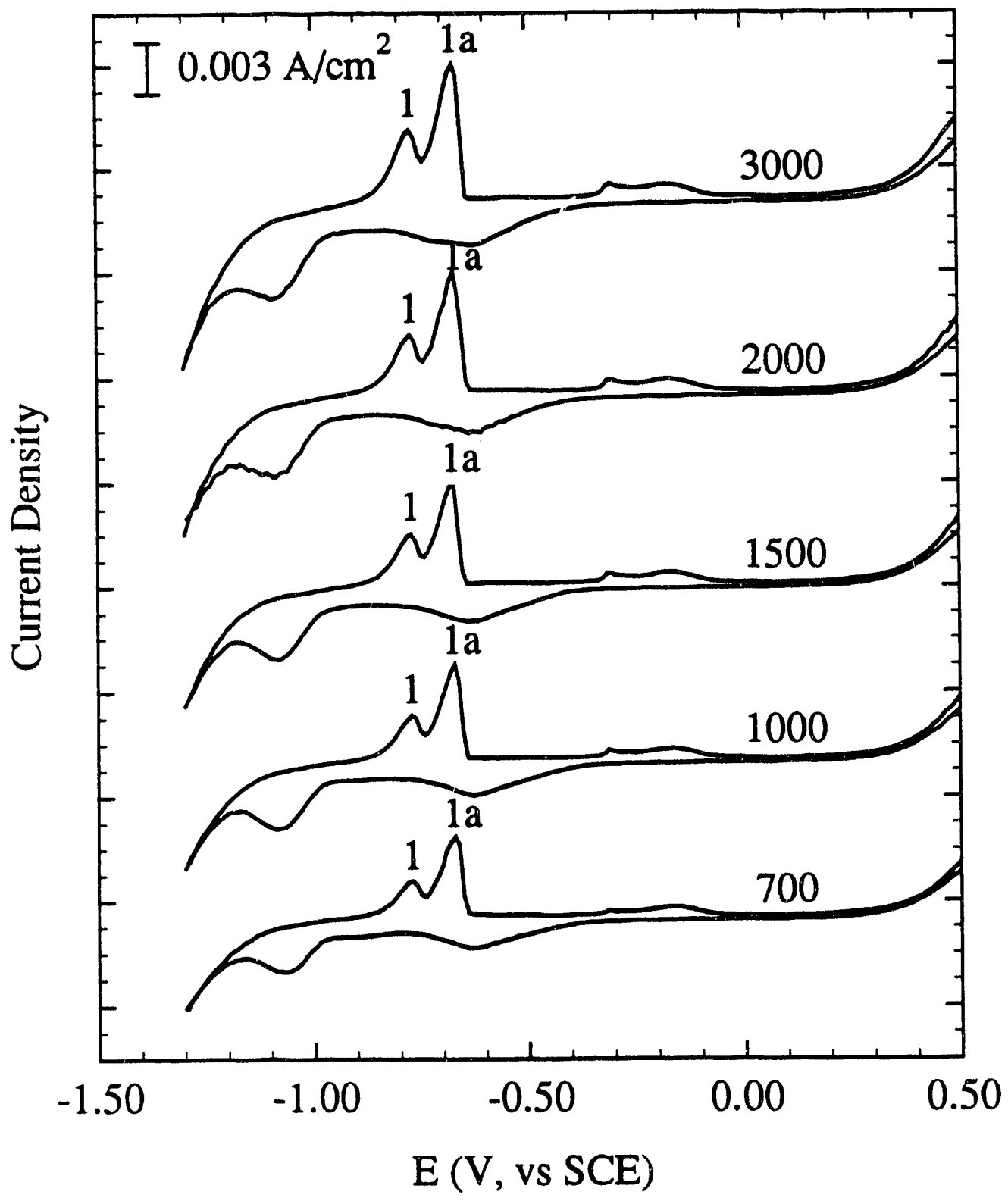

Figure 2.44b. Mineral Pyrite in Solutions at $\mathrm{pH}$ 9.2. for Various Electrode Rotation Speeds (rpm). Scan Rate, $50 \mathrm{mV} / \mathrm{s}$. 


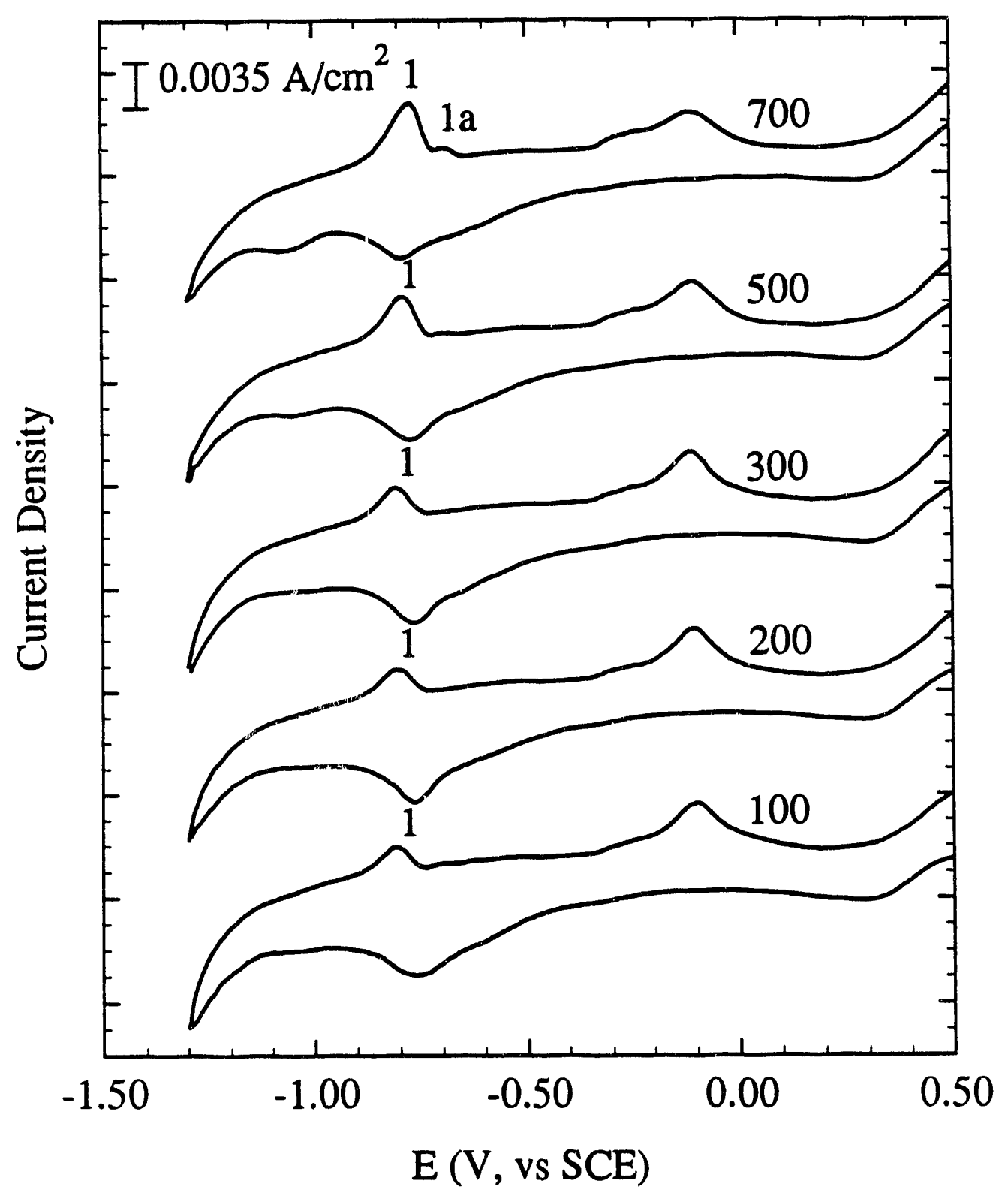

Figure 2.45a. Illinois Coal Pyrite in Solutions at $\mathrm{pH}$ 9.2. for Various Electrode Rotation Speeds (rpm). Scan Rate, $50 \mathrm{mV} / \mathrm{s}$. 


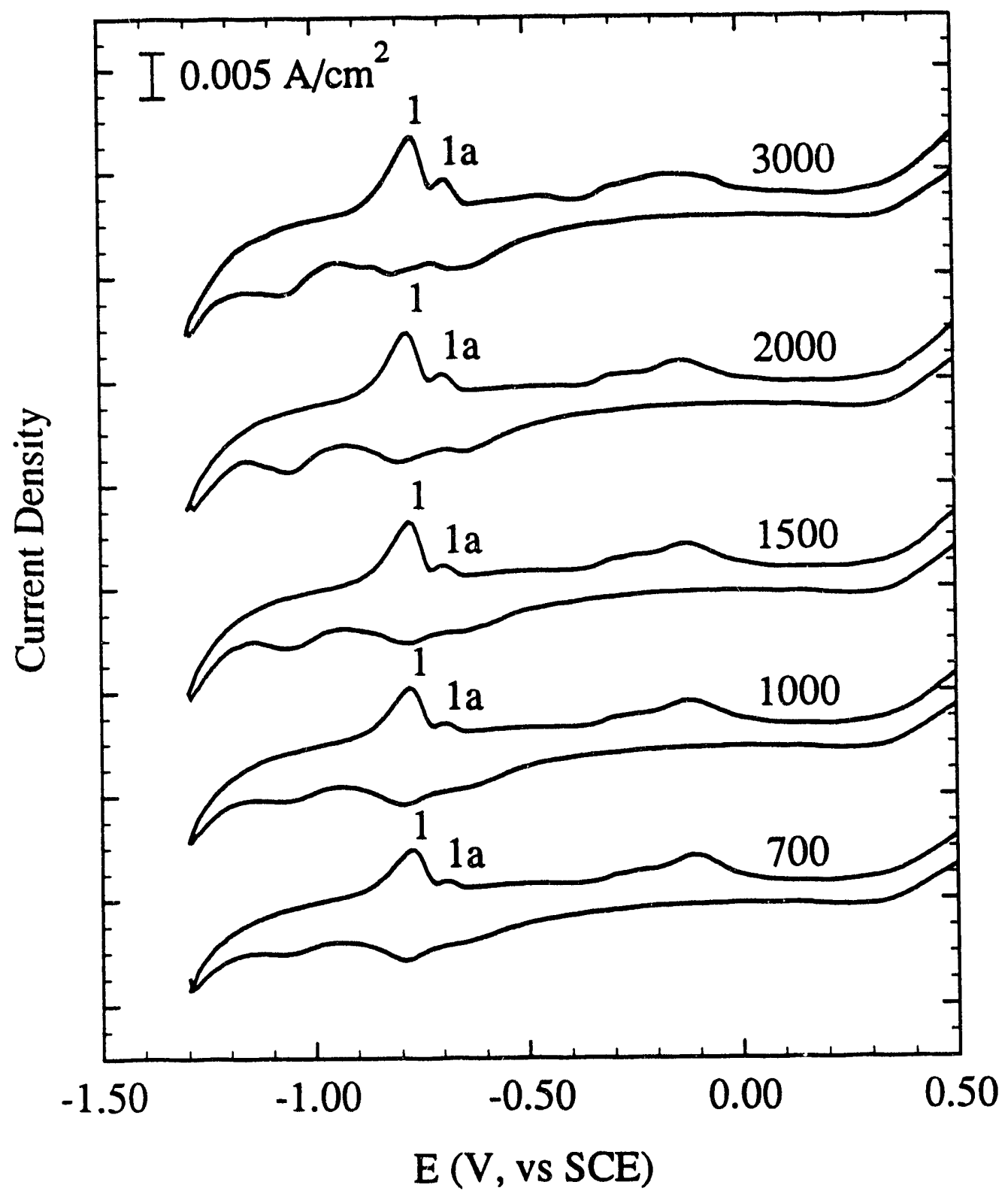

Figure 2.45b. Illinois Coal Pyrite in Solutions at $\mathrm{pH}$ 9.2. for Various Electrode Rotation Speeds (rpm). Scan Rate, $50 \mathrm{mV} / \mathrm{s}$. 


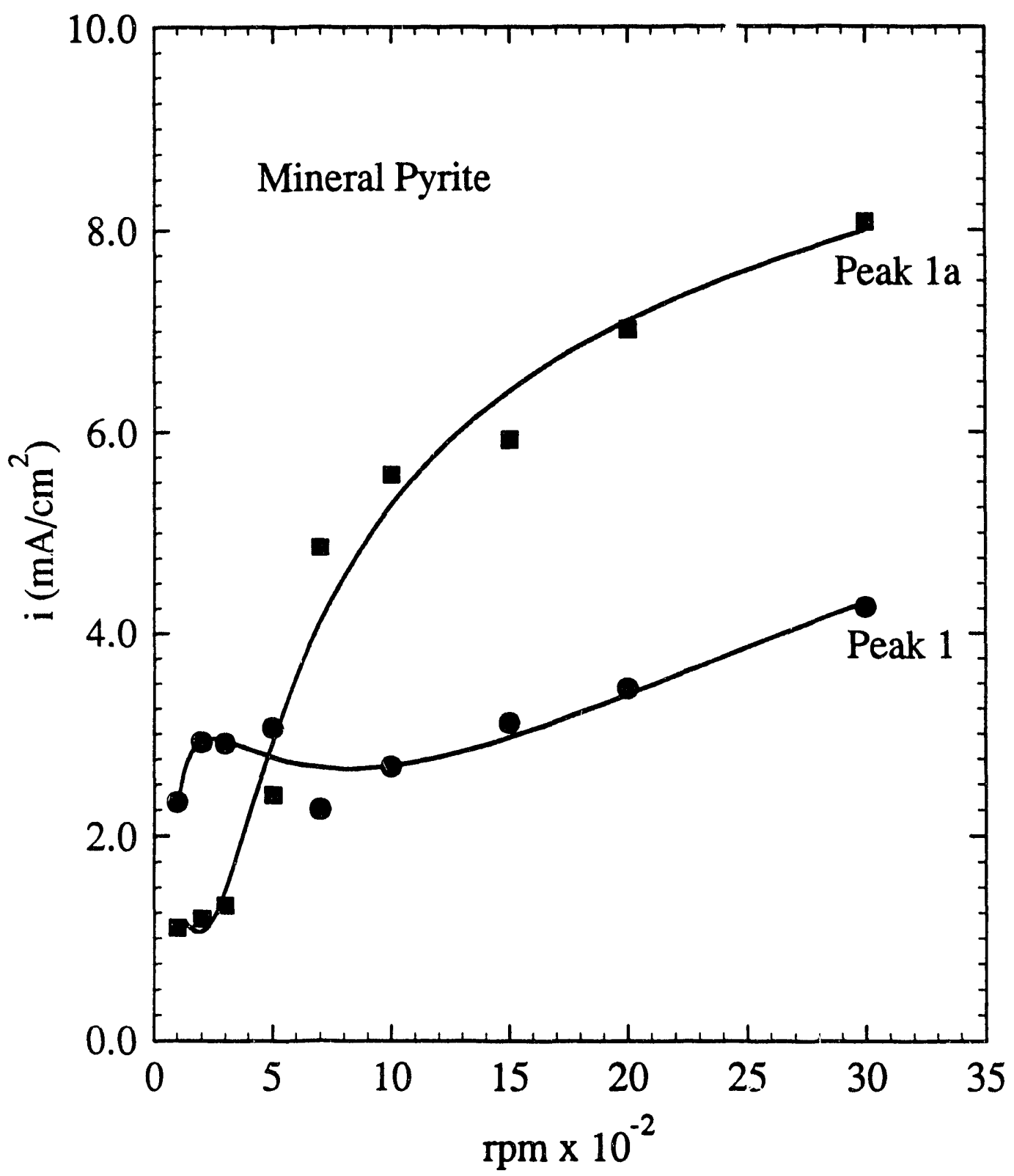

Figure 2.46. Effect of Electrode Rotation Speed on Peak Current 


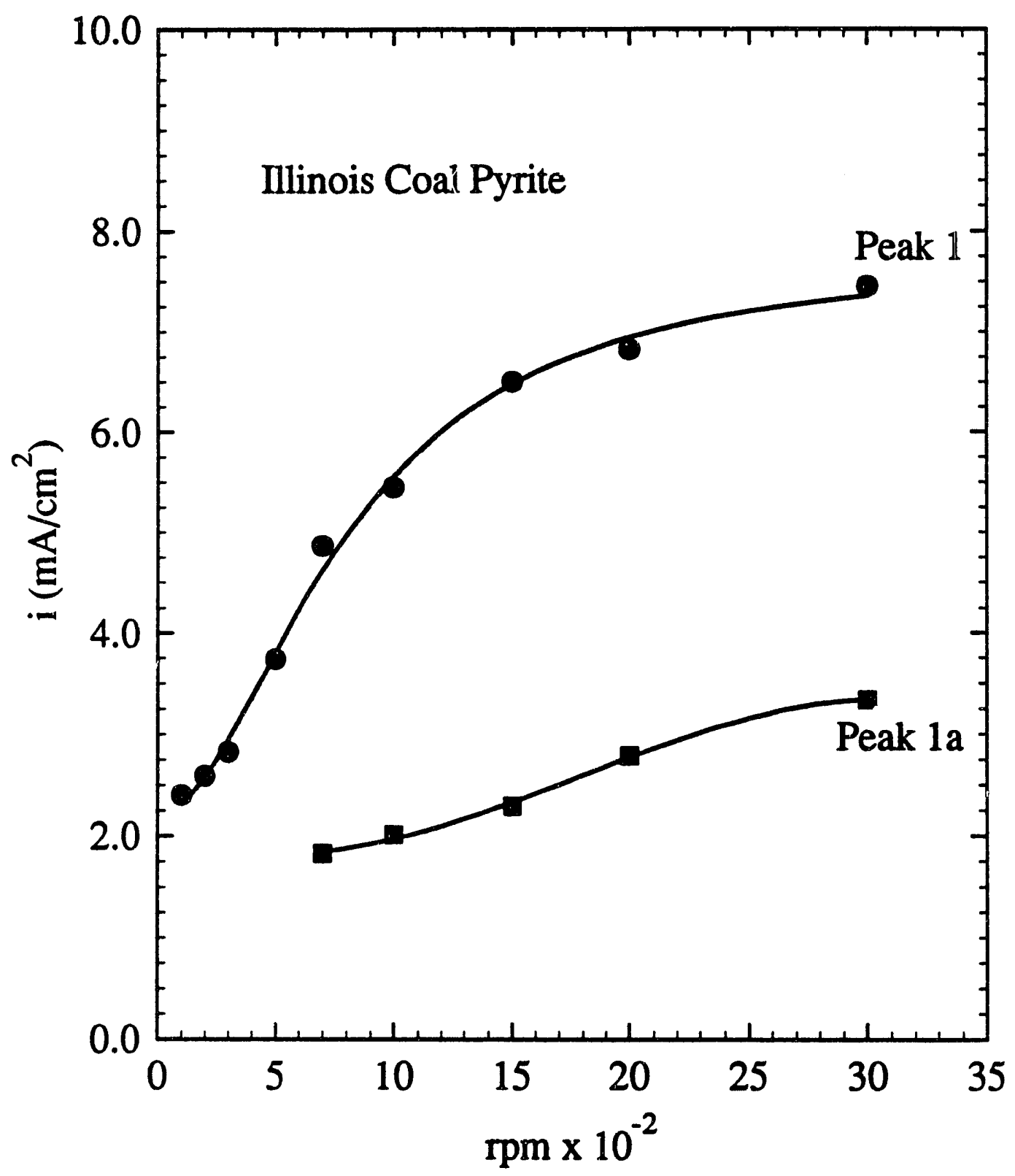

Figure 2.47. Effect of Electrode Rotation Speed on Peak Current 


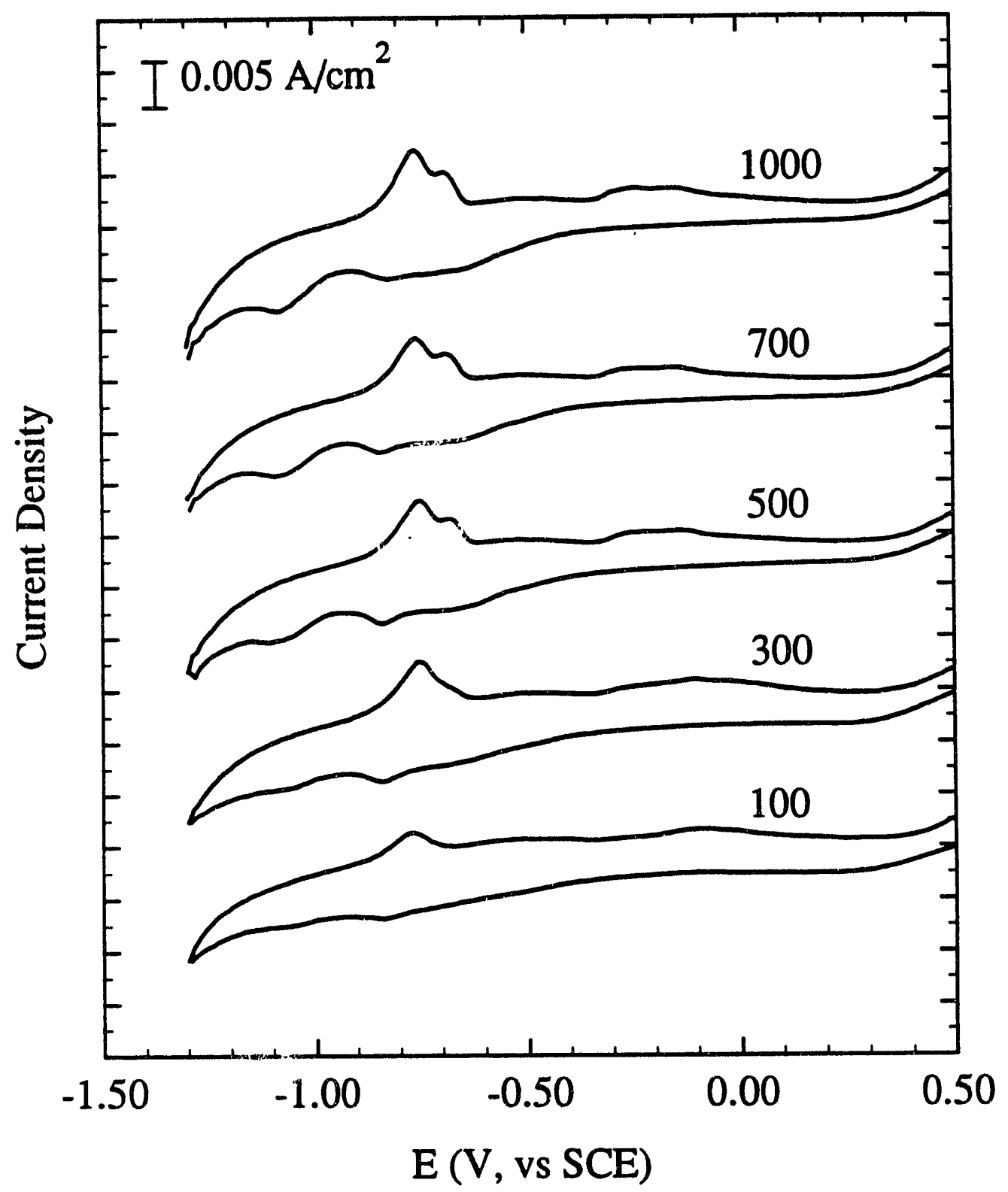

Figure 2.48a. Pittsburgh Coal Pyrite in Borate Solutions at pH 9.2. for Various Electrode Rotation Speeds (rpm). Scan Rate, $50 \mathrm{mV} / \mathrm{s}$. 


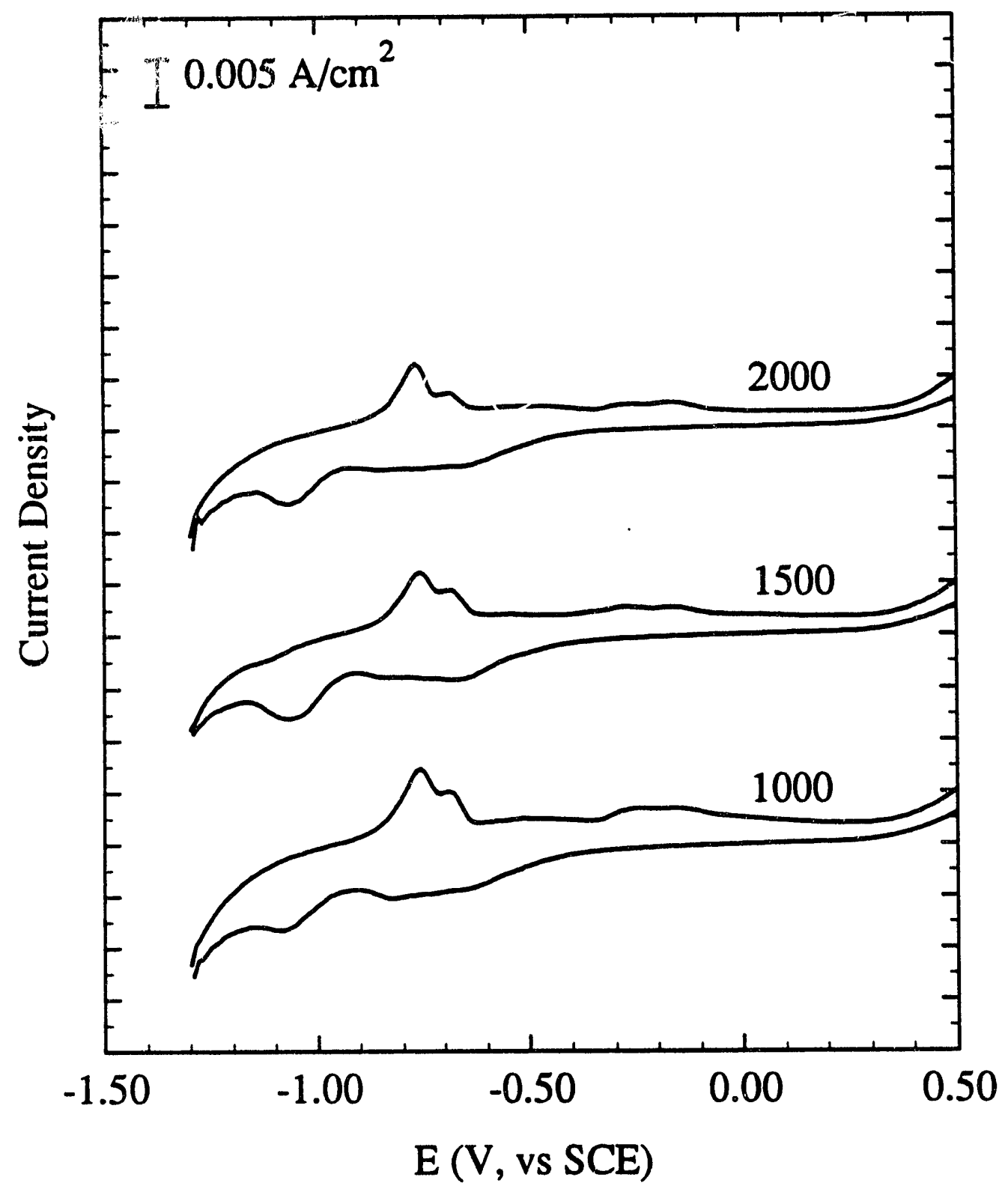

Figure 2.48b. Pittsburgh Coal Pyrite in Borate Solutions at pH 9.2. for Various Electrode Rotation Speeds (rpm). Scan Rate, $50 \mathrm{mV} / \mathrm{s}$. 


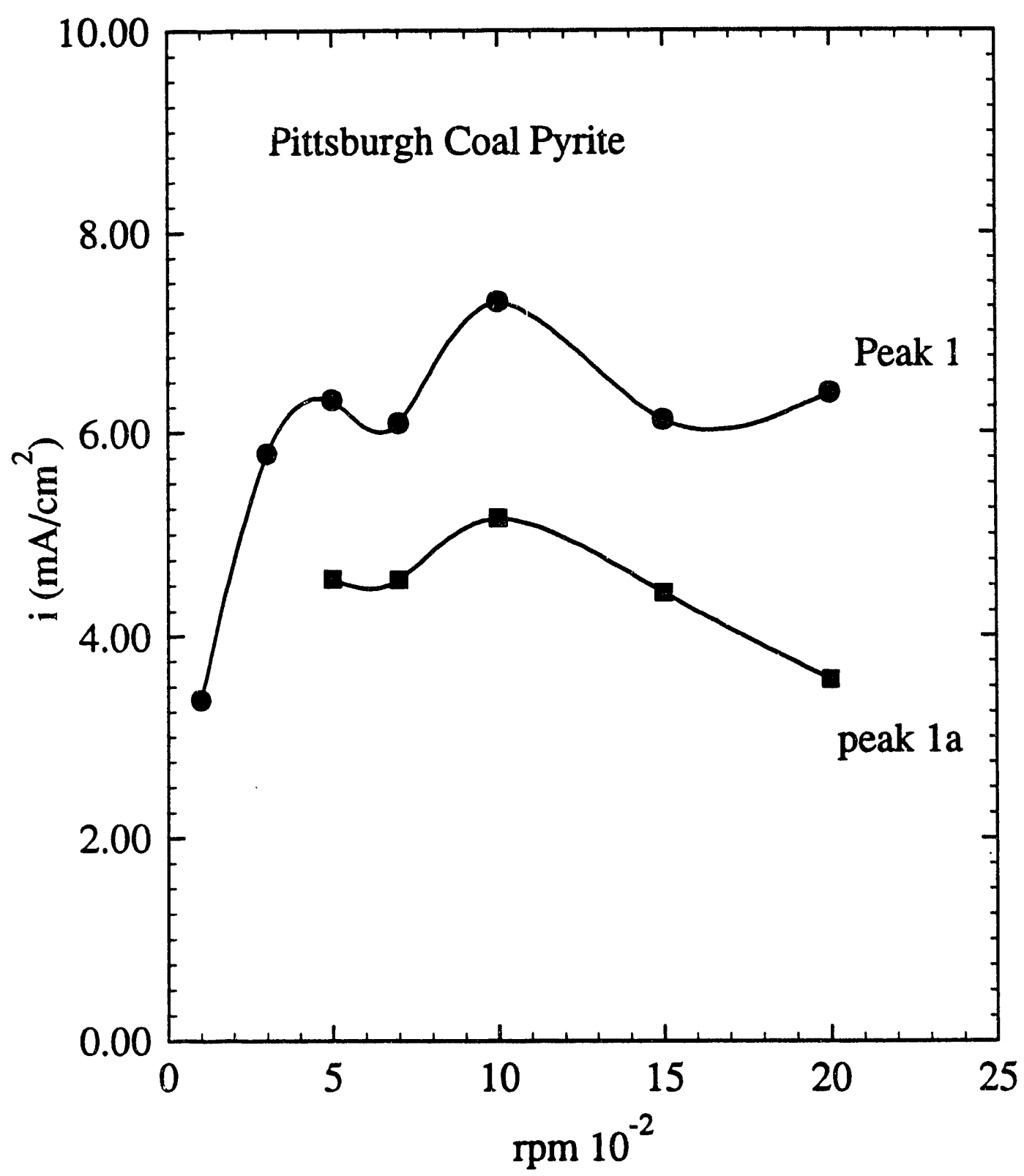

Figure 2.49. Effect of Electrode Rotation Speed on Peak Current 
than $0.6 \mathrm{~V}$. A series of voltammograms at various anodic reversal potentials in solutions of $\mathrm{pH} 9.2$ for mineral pyrite were scanned at $50 \mathrm{mV} / \mathrm{s}$, with rotating disk electrode rpm $-200,700$ and 1000. The results for $200 \mathrm{rpm}$ are shown in Figures 2.50a and 2.50b. As the anodic reversal potential increased from $0.65 \mathrm{~V}$ to $0.85 \mathrm{~V}$, the intensity of peak $1 \mathrm{a}$ increased (Figure 2.50a). Further increase of anodic reversal potential resulted in gradually decreasing peak 1a intensity (Figure 2.50b). Peak 1a disappeared for anodic reversal potential above $1.1 \mathrm{~V}$. This result clearly indicates that, at potentials higher than certain limits, the partially oxidized sulfur intermediates oxidize rapidly to sulfate ion. For electrode $\mathrm{rpm}=700$ and 1000 , similar voltammograms were obtained, except the current densities were higher than that observed for lower rpm.

The integrated charge associated with peak la versus the anodic reversal potential for various electrode rotation speeds is shown in Figure 2.51. For each electrode rotation speed, the intensity of peak 1a increased with increasing anodic reversal potential and reached a maximum value at about 0.85 to $0.9 \mathrm{~V}$ (depending on electrode rotation speed). These results identify the potential range where the reaction forming partially oxidized sulfur intermediates predominate.

Additional information to suppori wie discriminating influence of potential is shown in Figure 2.52. Voltammogram (A) corresponds to a stationary electrode of mineral pyrite in stirred solution at $\mathrm{pH}$ 9.2. The electrode was pre-conditioned at $0.4 \mathrm{~V}$ for $3 \mathrm{~min}$., then scanned cathodically at $50 \mathrm{mV} / \mathrm{s}$. Voltammogram (B) is of the same electrode after being pre-conditioned at $0.4 \mathrm{~V}$ for $3 \mathrm{~min}$., scanned anodically at the same scan rate to $0.75 \mathrm{~V}$ then reversed. The intensity of peak $1 \mathrm{a}$ increased, compare to that in $(\mathrm{A})$. Voltammogram (C) is same as $(B)$, but the electrode, after being pre-conditioned at 0.4 $\mathrm{V}$ for $3 \mathrm{~min}$., was scanned anodically to $1.0 \mathrm{~V}$, then reversed. In contrast, the intensity of peak 1a decreased, compared to that in (A), and peak 1 increased greatly. The integrated charge associated with peak 1a increased significantly as rotation speed was increased from $200 \mathrm{rpm}$ to $700 \mathrm{rpm}$, but continued to increase only slightly as rotation speed was raised from $700 \mathrm{rpm}$ to $1000 \mathrm{rpm}$. The anodic reversal potential corresponding to maximum charge of peak la tended to increase as electrode rotation speed increased (Figure 2.51). 


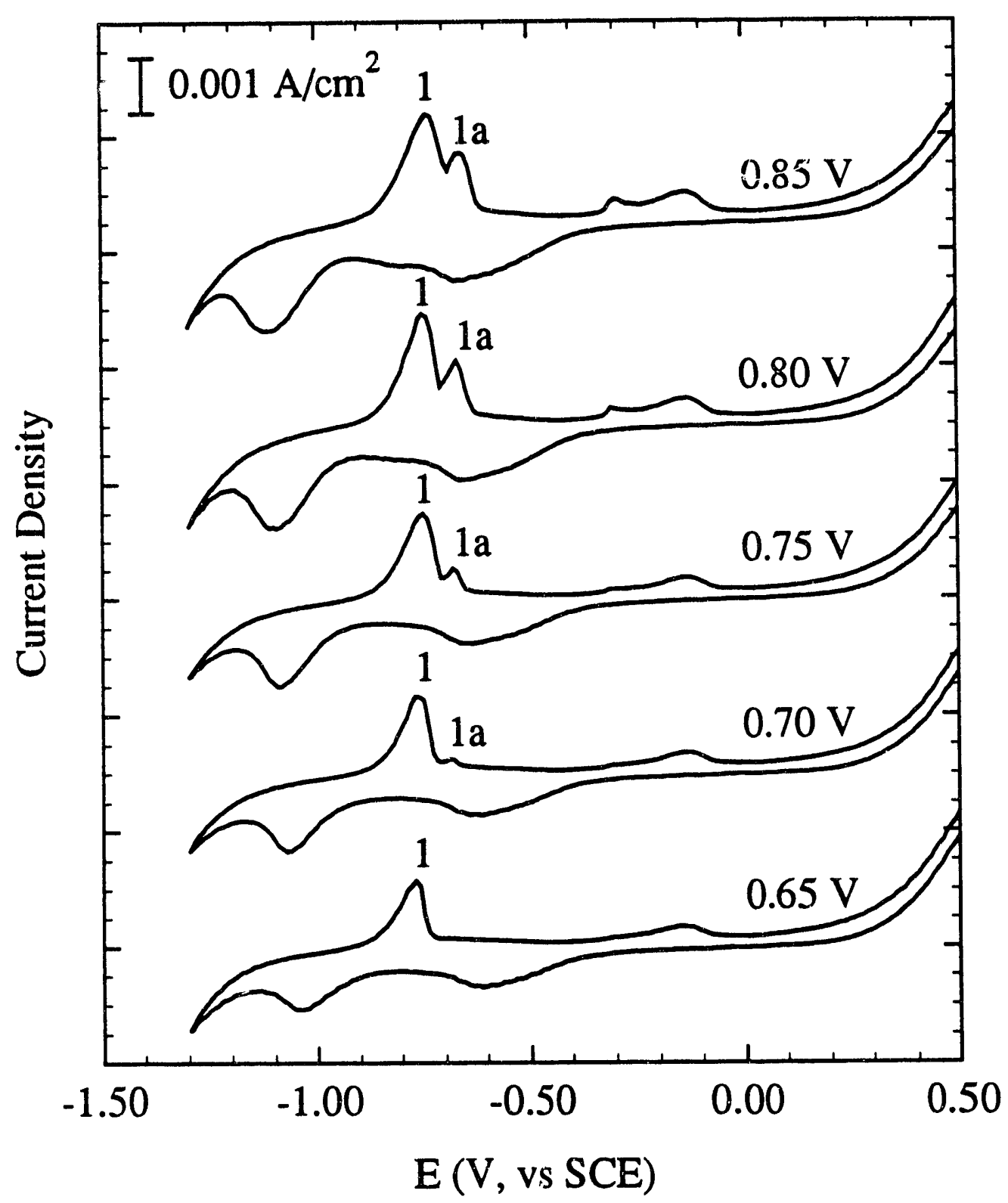

Figure 2.50a. Mineral Pyrite in Solutions at $\mathrm{pH}$ 9.2. Scan Reversed at Various Anodic Limits, Scan Rate, $50 \mathrm{mV} / \mathrm{s}$. rpm $=200$ 


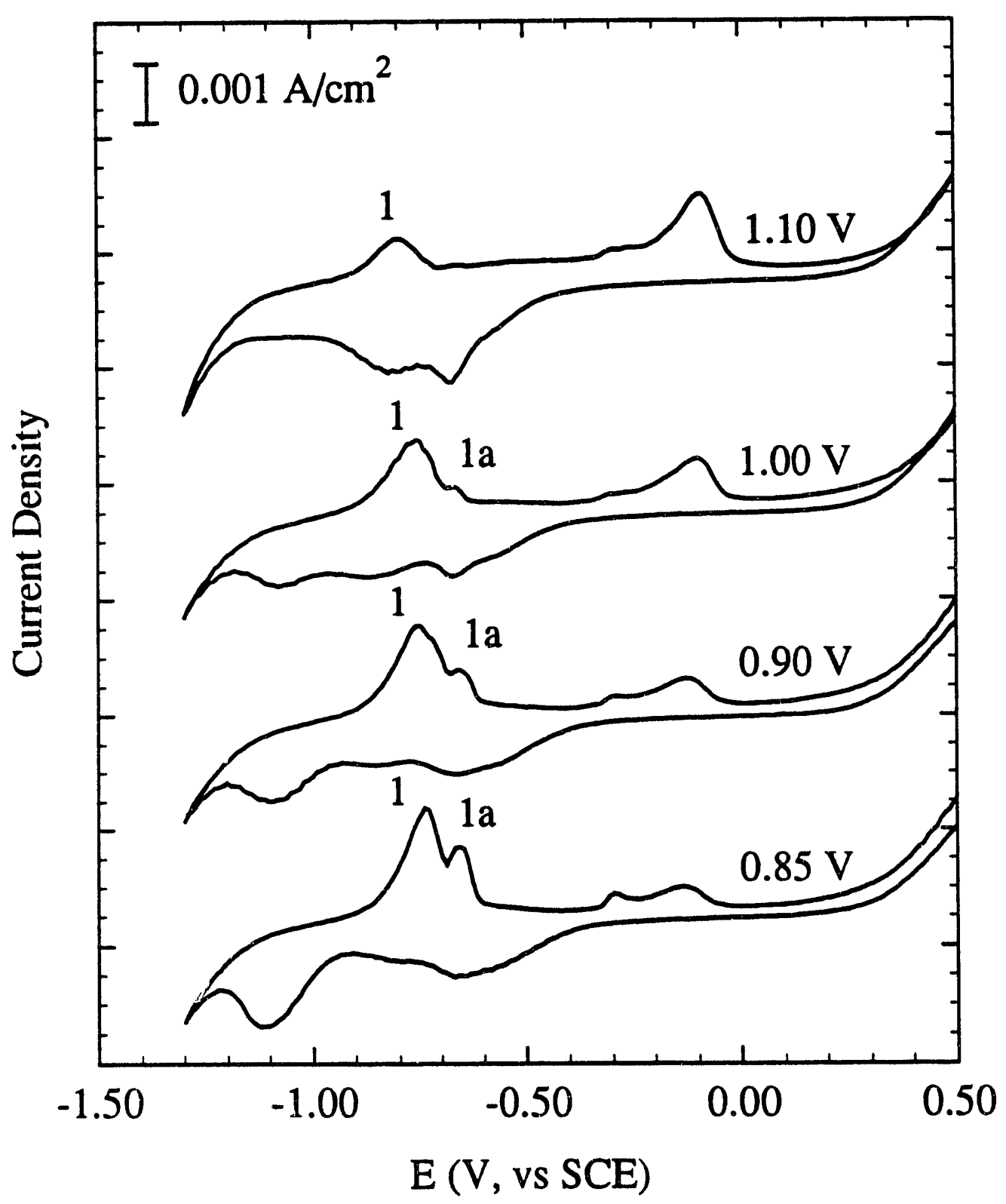

Figure 2.50b. Mineral Pyrite in Solutions at pH 9.2. Scan Reversed at Various Anodic Limits, Scan Rate, $50 \mathrm{mV} / \mathrm{s} . \mathrm{rpm}=200$ 


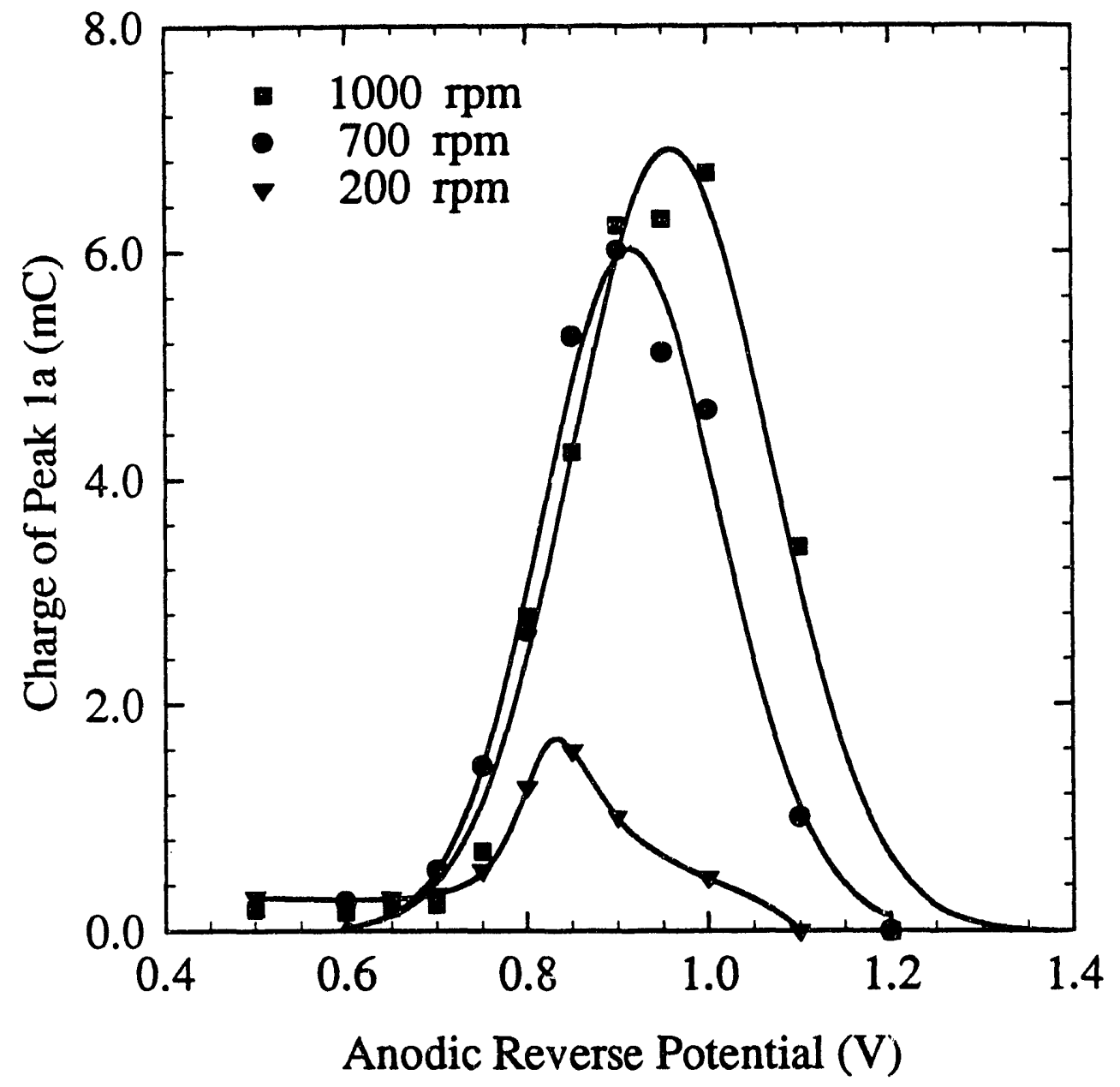

Figure 2.51. Effect of Anodic Reversal Potential on Charge of Peak 1a for Mineral Pyrite. Scan Rate, $50 \mathrm{mV} / \mathrm{s}$. 


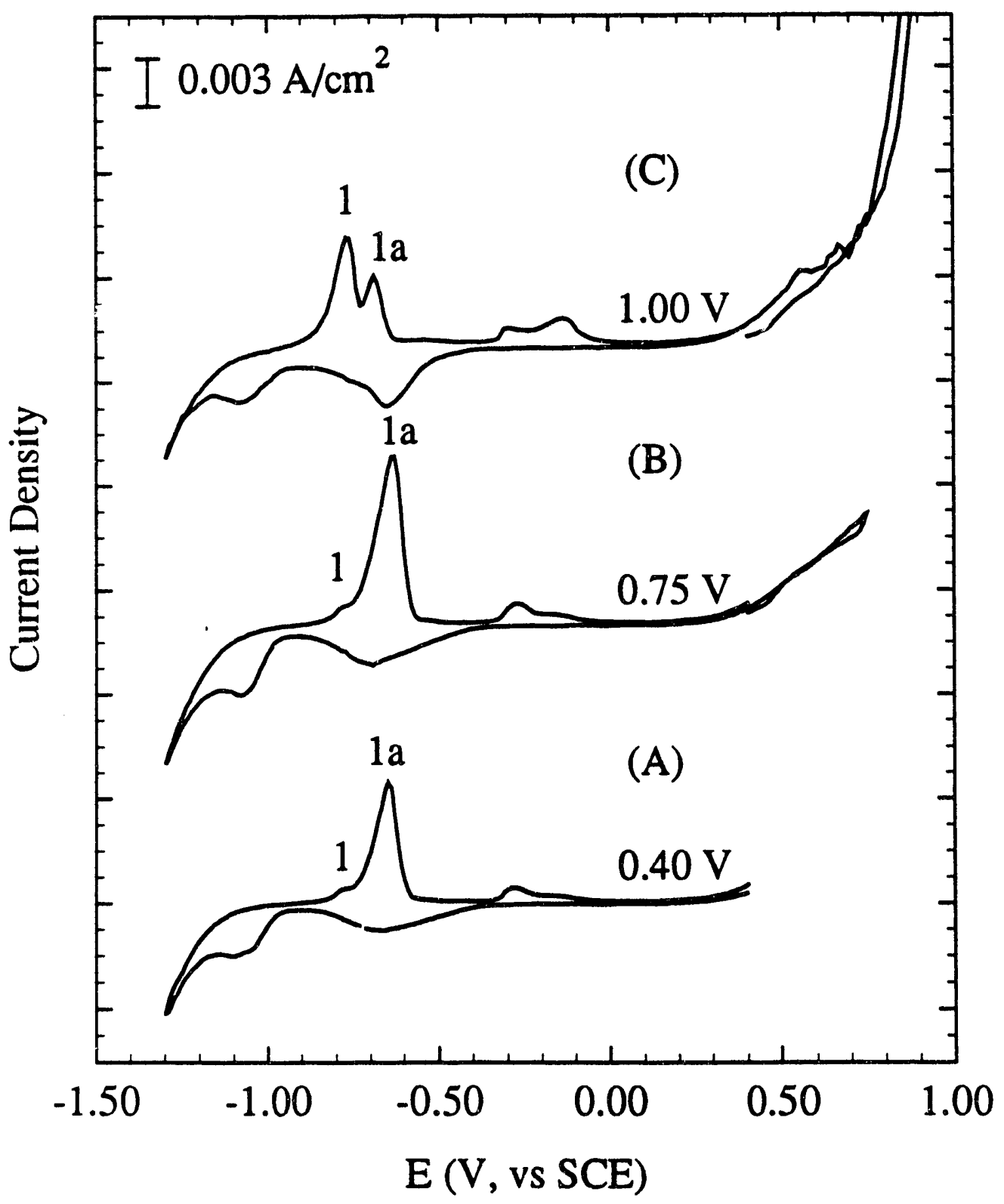

Figure 2.52. Mineral Pyrite in Stirred Solutions at pH 9.2. Electrode Pre-conditioned at $0.4 \mathrm{~V}$ for $3 \mathrm{~min}$. Scan Reversed at Various Anodic Limits. Scan Rate, $50 \mathrm{mV} / \mathrm{s}$ 
A similar series of voltammograms at various anodic reversal potentials was obtained for Illinois coal pyrite for electrode $\mathrm{rpm}=200,700$ and 2000 . The results for $2000 \mathrm{rpm}$ are shown in Figure 2.53. The integrated charge associated with peak 1a versus anodic reversal potential for various electrode rotation speeds is shown in Figure 2.54. The intensity of peak 1a increased slowly with increasing anodic reversal potential and reached the maximum value at about $0.75 \mathrm{~V}$, which is lower than that for mineral pyrite. The charge associated with peak $1 a$ is much less than for mineral pyrite. Also, the effect of electrode rotation speed is less pronounced compared to mineral s'yrite.

Electrode Pre-Condition Time. When the electrode was pre-conditioned at a threshold potential of $0.6 \mathrm{~V}$ for increasing time periods, peak 1a was continuously enhanced. Figure 2.55 illustrates the relative magnitudes of peak 1 and peak $1 \mathrm{a}$ of mineral pyrite, for various pre-conditioning times at a threshold potential of $0.6 \mathrm{~V}$, scanned cathodically at $50 \mathrm{mV} / \mathrm{s}$ for a electrode rotation speed of $200 \mathrm{rpm}$. The threshold potential of $0.6 \mathrm{~V}$ was selected for the longer time experiments because this potential discriminated most clearly the reaction leading to the formation of peak 1 and peak 1a. Based on the results of Figure 2.55, a plot of integrated charge associated with peak 1 and peak 1a versus electrode pre-conditioning time is shown in Figure 2.56. These results show clearly the change of the relative magnitudes of peak 1 and peak 1a with electrode pre-conditioning time. As electrode pre-conditioning time increased, more sulfur intermediates formed, hence peak 1a increased and peak 1 decreased gradually. After 30 sec., peak 1 disappeared as a distinct peak.

Figure 2.55 also provides clear evidence that the sulfur peak $(\sim-0.3 \mathrm{~V})$ increased as the electrode pre-conditioning time was increased. These results may be attributed to the reduction of sulfur intermediates to HS during the cathodic scan with subsequent reoxidation to $S^{\circ}$ during anodic scan. Thus, as more sulfur intermediates are formed in the transpassive region, the greater the amount of elemental sulfur produced during the following anodic scan.

Peaks 1 and 2 have been proposed to correspond to $\mathrm{Fe} / \mathrm{Fe}(\mathrm{II})$ and $\mathrm{Fe}(\mathrm{II}) / \mathrm{Fe}(\mathrm{III})$ oxidation (Eqs. 2.8 and 2.10). Thus, the magnitude of peak 2 should decrease as the 


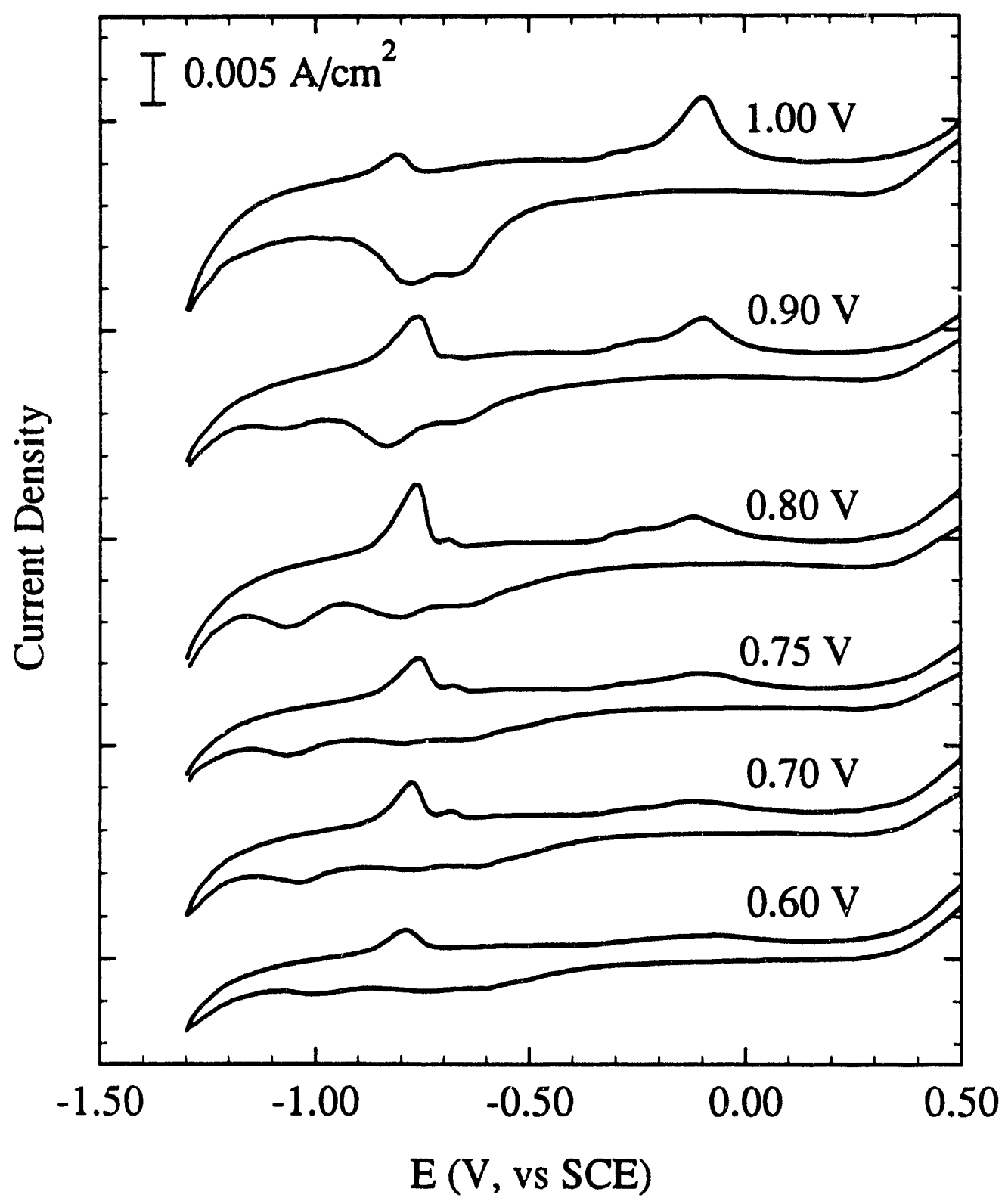

Figure 2.53. Illinois Coal Pyrite in Borate Solutions at $\mathrm{pH}$ 9.2. Scan Reversed at Various Anodic Limits, Scan Rate, $50 \mathrm{mV} / \mathrm{s} . \mathrm{rpm}=2000$ 


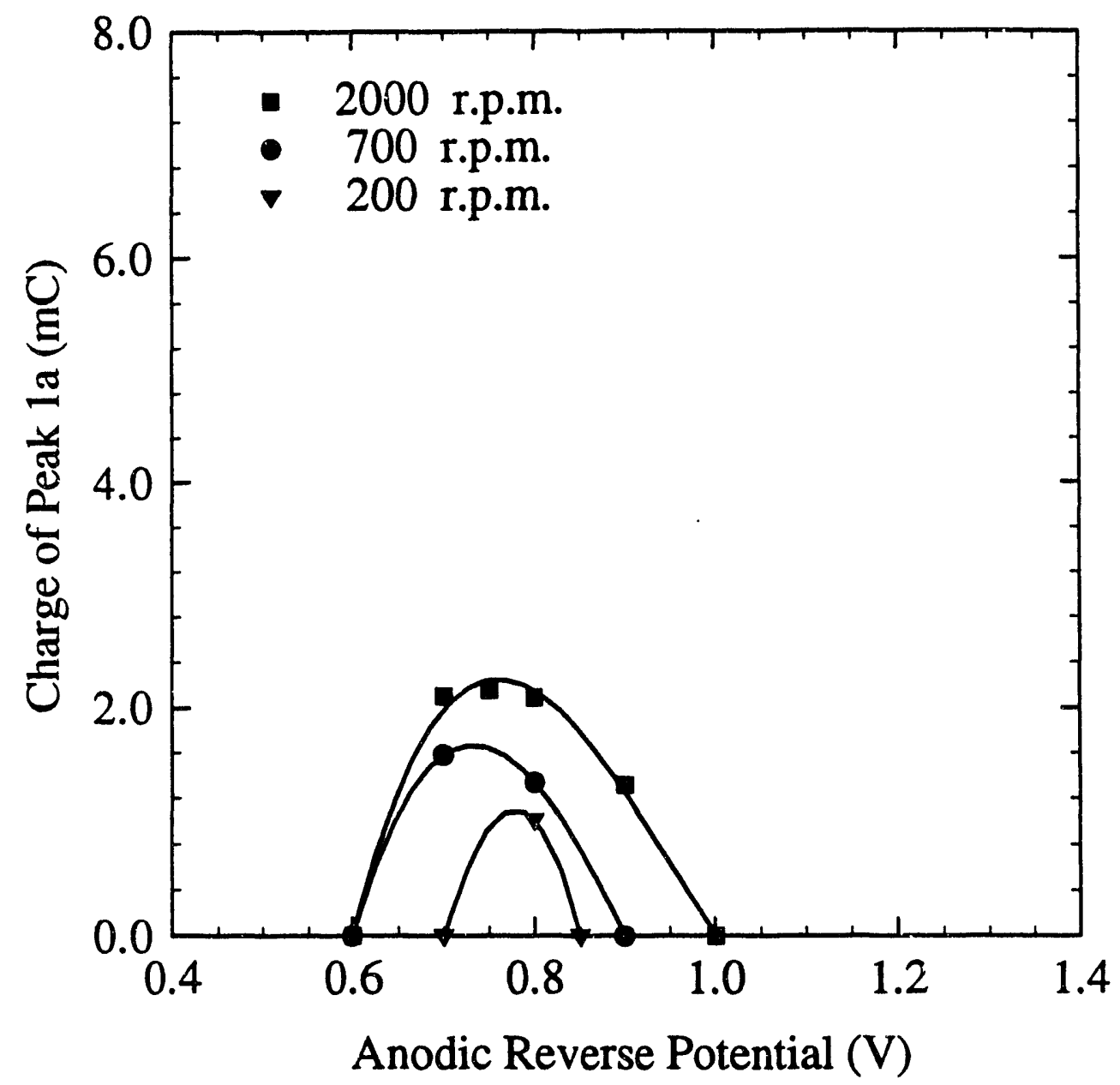

Figure 2.54. Effect of Anodic Reversal Potential on Charge of Peak 1a for Illinois Coal Pyrite. Scan Rate, $50 \mathrm{mV} / \mathrm{s}$ 


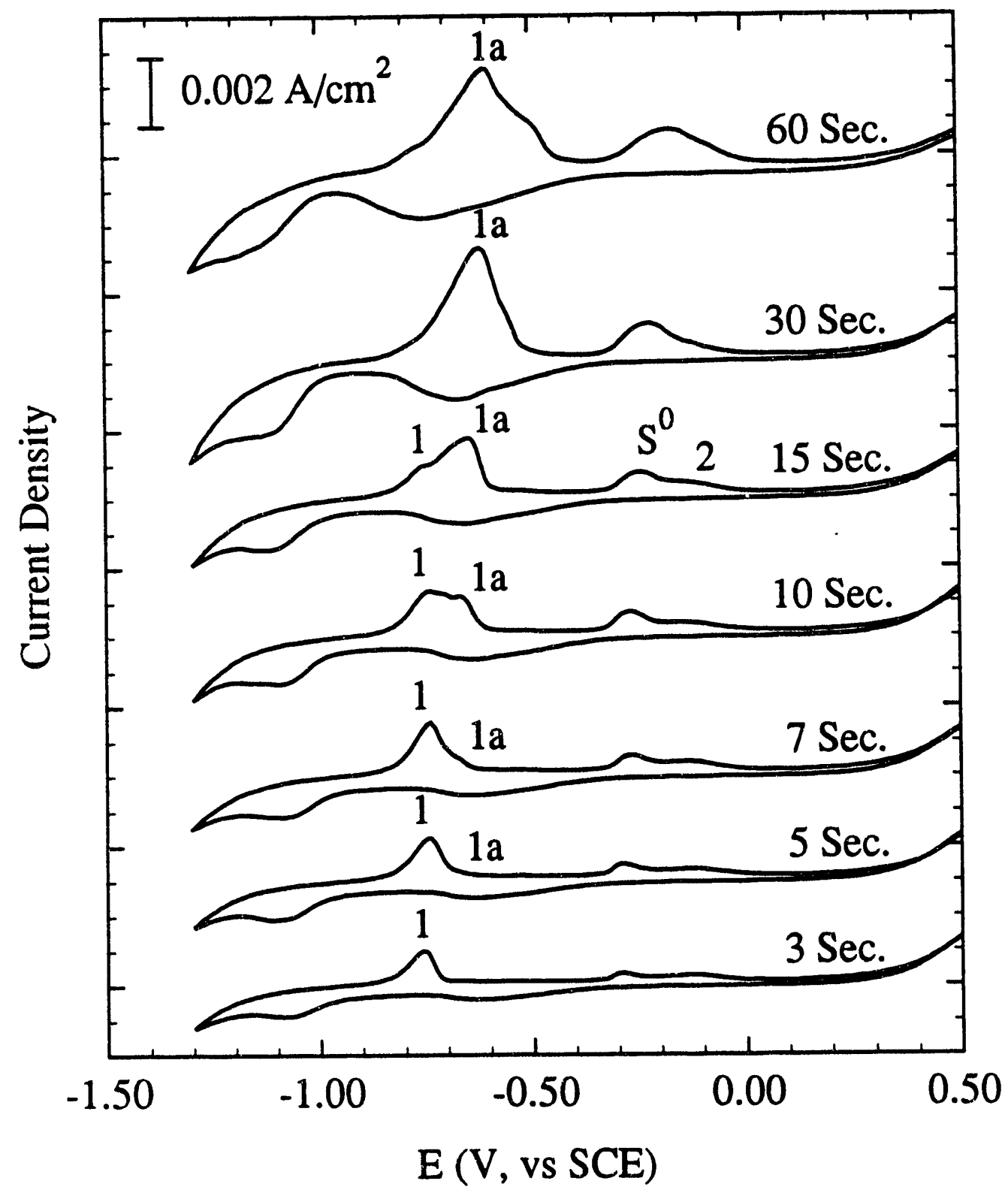

Figure 2.55. Mineral Pyrite in Solutions at pH 9.2. Electrode Pre-conditioned at $0.6 \mathrm{~V}$ for Various Times. Scan Rate, $50 \mathrm{mV} / \mathrm{s}$. $\mathrm{rpm}=200$ 


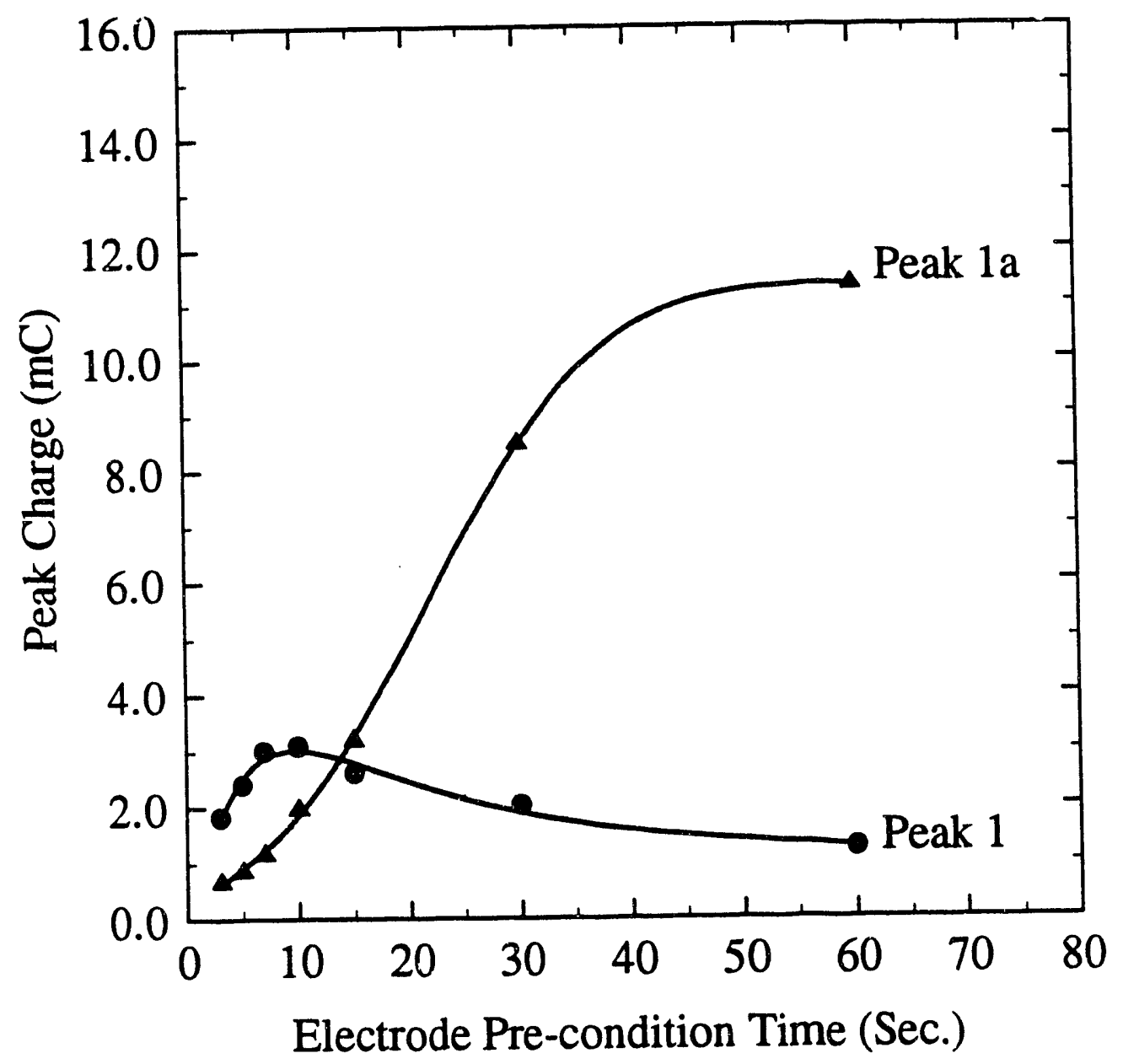

Figure 2.56. Integrated Charge of Peak 1 and Peak 1a, rpm $=200$ Scan Rate, $50 \mathrm{mV} / \mathrm{s}$ 
magnitude of peak 1 decreases. Based on the results of Figure 2.55 (expanded figures were used), the charges associated with peak 1 and peak 2 were integrated and plotted versus electrode pre-condition times in Figure 2.57. After $10 \mathrm{sec}$., the magnitude of peak 1 decreased, but peak 2 remained almost constant. As the magnitude of peak 1a, the iron sulfide peak, increased, the magritude of peak 1 , the ferrous hydroxide peak, decreased and less ferrous hydroxide was produced. This suggests the iron sulfide formed at peak la oxidized according to the reaction

$$
\mathrm{FeS}+2 \mathrm{H}_{2} \mathrm{O}=\mathrm{Fe}(\mathrm{OH})_{2}+\mathrm{S}^{0}+2 \mathrm{H}^{+}+2 e^{-}
$$

For which, at $\mathrm{pH} 9.2, \mathrm{E}_{\mathrm{SCE}}=-0.05 \mathrm{~V}$. Ferrous hydroxide, resulting from the oxidation of iron sulfide, appears to compensate for the decrease of ferrous hydroxide formed at peak 1 , which is expected to continue to oxidize to ferric nydroxide at peak 2 . This would explain why the magnitude of peak 2 remained almost the same while peak 1 decreased.

Three series of scaris for various electrode pre-conditioning times at $0.6 \mathrm{~V}$ were obrained for electrode rotation speeds of 0 (quiescent), 200 and $1000 \mathrm{rpm}$. The integrated charge measurements associated with peak 1a versus electrode pre-conditioning times for electrode rotation speeds of 0,200 and $1000 \mathrm{rpm}$ are shown in Figure 2.58. The charge increased with increasing electrode pre-condition time and tended to level off after 30 sec., probably indicating saturation of the surface. The maximum charge associated with peak 1a is about $10 \mathrm{mC}$, the estimated film thickness is 27 monolayers. Again, the effect of electrode rotation speed was distinct only at low rpm. For speeds higher than $200 \mathrm{rpm}$, enhancement of the effect was almost negligible. For example, a similar test at $700 \mathrm{rpm}$, was essentially the same as for the 200 and $1000 \mathrm{rpm}$ test results.

The effect of electrode pre-conditioning time on peak la for various electrode rotation speeds was also examined for Illinois coal pyrite. Figure 2.59 illustrates the relative magnitudes of peak 1 and peak 1a, for various pre-conditioning times at a threshold potential of $0.4 \mathrm{~V}$, scanned cathodically at $50 \mathrm{mV} / \mathrm{s}$ for a electrode rotation speed of $1000 \mathrm{rpm}$. The magnitude of peak 1a increased when the electrode preconditioning time was increased from 1 to 5 minutes, at its threshold potential. This threshold was $0.4 \mathrm{~V}$ compared to $0.6 \mathrm{~V}$ for mineral pyrite. The integrated charges 


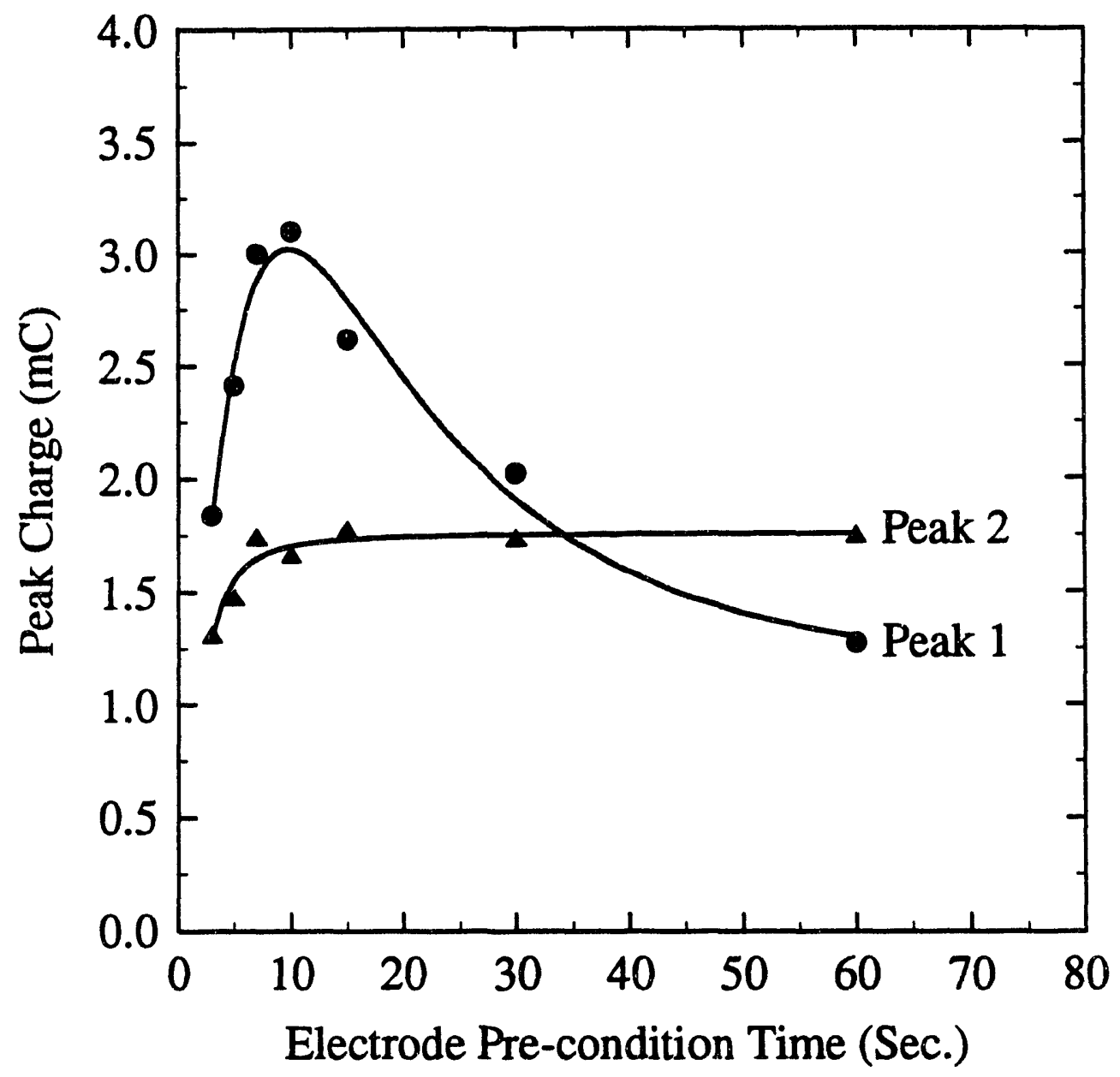

Figure 2.57. Integrated Charge of Peak 1 and Peak 2, $\mathrm{rpm}=200$ Scan Rate, $50 \mathrm{mV} / \mathrm{s}$ 


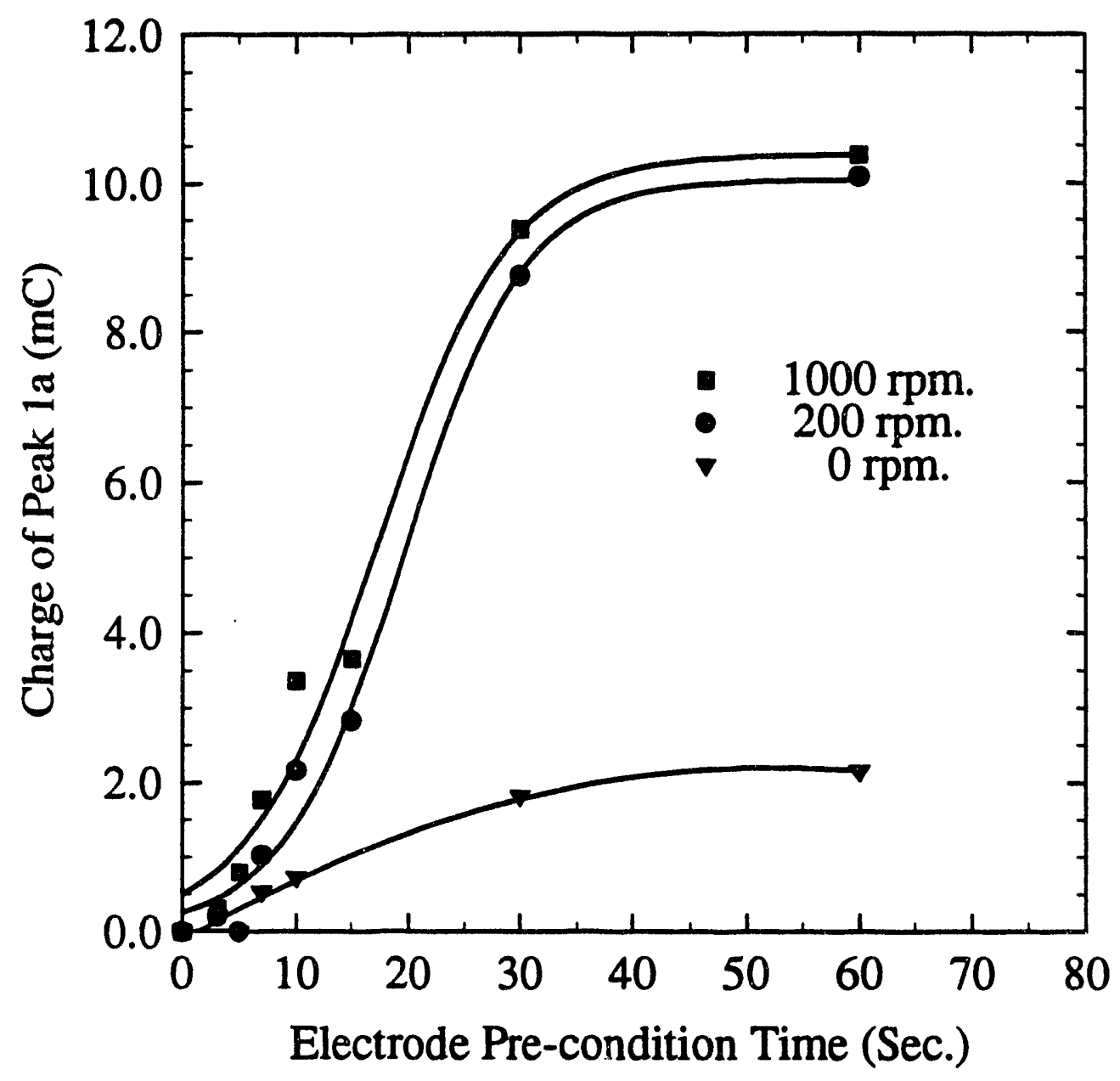

Figure 2.58. Effect of Electrode Pre-condition Time on Charge of Peak 1a for Mineral Pyrite. Scan Rate, $50 \mathrm{mV} / \mathrm{s}$ 


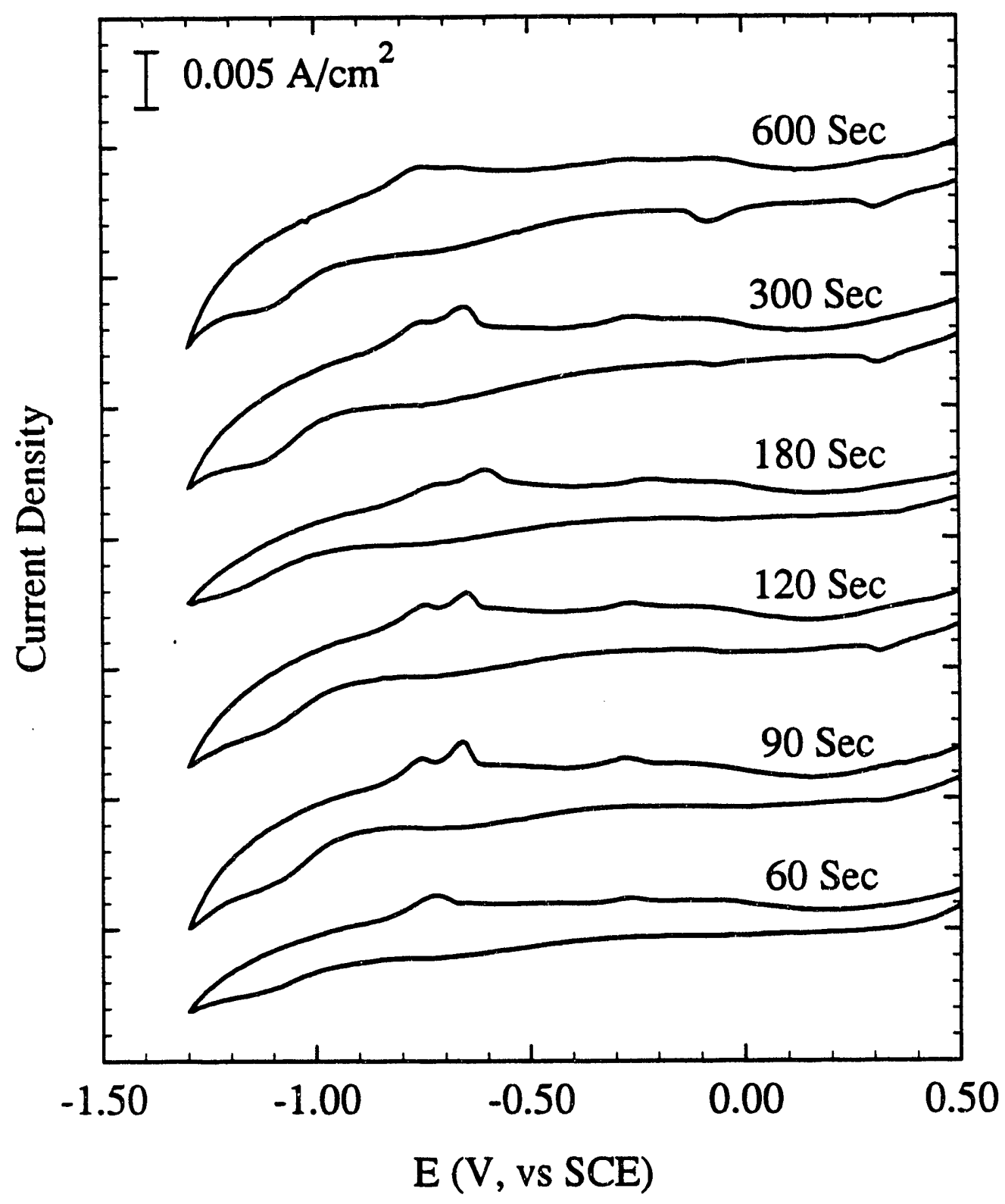

Figure 2.59. Illinois Coal Pyrite in Borate Solutions at $\mathrm{pH}$ 9.2. Electrode Preconditioned at $0.4 \mathrm{~V}$ for Various Times. Scan Rate, $50 \mathrm{mV} / \mathrm{s}$ $\mathrm{rpm}=1000$ 
associated with peak 1a versus electrode pre-conditioning time for electrode rotation speeds of 0,200 and $1000 \mathrm{rpm}$ are shown in Figure 2.60. The electrode pre-conditioning time required to obtain the same magnitude of peak 1a is much greater than that for mineral pyrite. For rotation speeds greater than $200 \mathrm{rpm}$, the charge associated with peak 1a increased with increasing electrode pre-condition time and reached a maximum value (about $8 \mathrm{mC}$ compared to $10 \mathrm{mC}$ for mineral pyrite) in about 4 to $5 \mathrm{~min}$. The total peak charge was observed to decrease when the pre-conditioning time was prolonged. Under quiescent conditions (electrode $\mathrm{rpm}=0$ ) no maximum was found within a $10 \mathrm{~min}$. period.

A comparison of mineral pyrite and Illinois coal pyrite is shown in Figure 2.61. The effect of electrode rotation speed and anodic scan reversal potential on the magnitude of peak 1 and peak 1a for mineral pyrite and Illinois coal pyrite is markedly different. For minesal pyrite (Figure 2.61a), at lower rotation speed and anodic scan reversal potential, peak 1, the ferrous hydroxide peak was predominant and peak 1a, the iron sulfide peak, was relatively insignificant. As rotation speed and/or anodic scan reversal potential increased, the iron sulfide peak increased, becoming predominant at $700 \mathrm{rpm}$, when the anodic scan was reversed at $0.8 \mathrm{~V}$. For Illinois coal pyrite (Figure 2.61b), the iron sulfide peak also increased slowly with increasing electrode rotation speed and/or anodic scan reversal potential, but the ferrous hydroxide peak remained predominant up to $2000 \mathrm{rpm}$. The vertical scale is expanded five times for Figure 2.61a compared to Figure 2.61b. These results are consistent with the enhanced reactivity observed for coal pyrite in the transpassive region compared to mineral pyrite, here approximately five to one. The disulfide ion in coal pyrite is oxidized more readily all the way to sulfate with fewer partially oxidized sulfur intermediates.

\section{Kinetics of the Transpassive Oxidation}

Previous studies of the transpassive oxidation of pyrite demonstrated that, in the transpassive region, $0.4 \mathrm{~V}$ to $0.8 \mathrm{~V}$ (SCE), aggressive electrochemical oxidation of pyrite occurs. The reaction products in this region are Fe(III) oxides, sulfate ion and partially oxidize. i sulfur intermediates. Exposure of pyrite to anodic potentials higher than the trans ${ }^{\prime}$ assive region resulted in rapid oxidation of sulfur intermediates to sulfate ion. The 


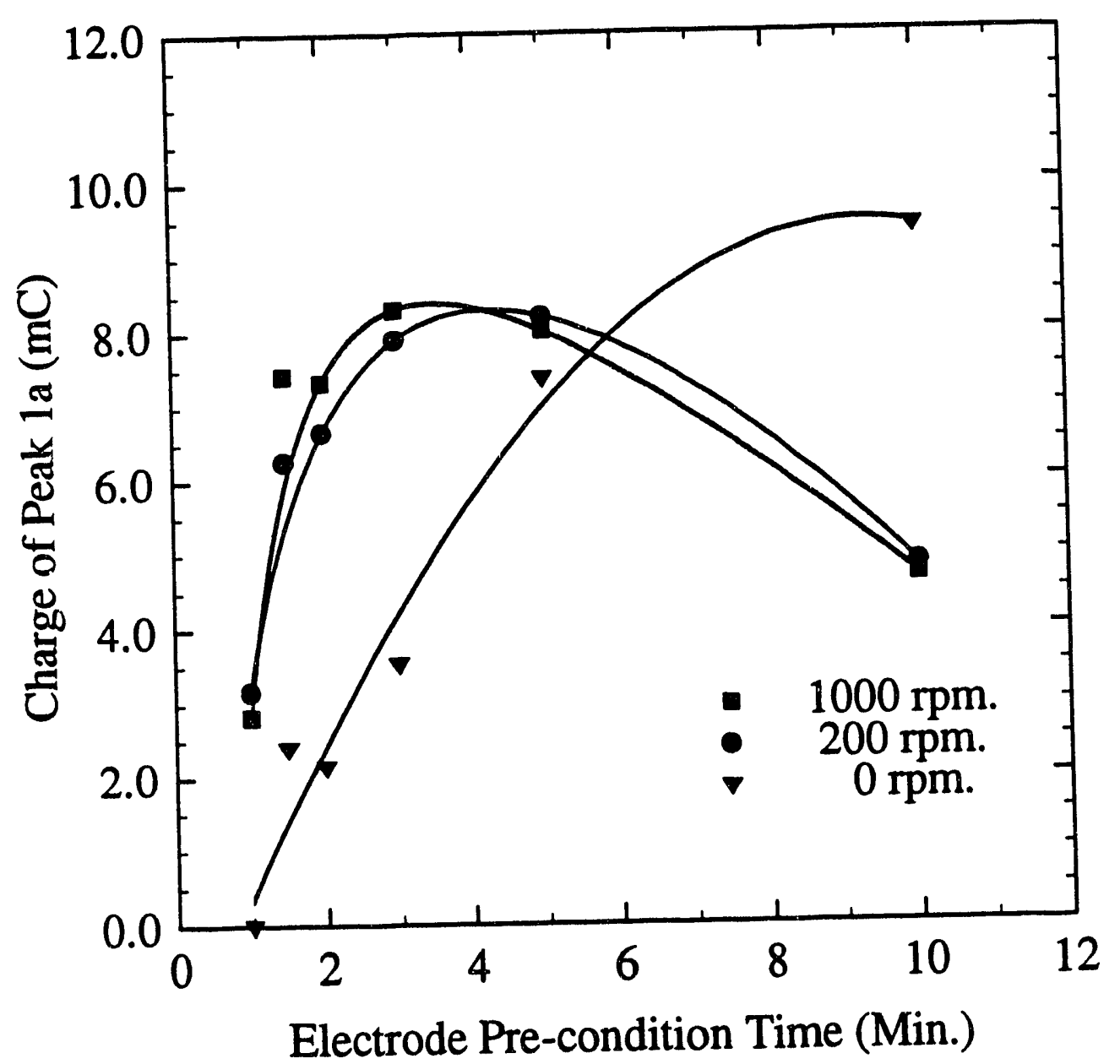

Figure 2.60. Effect of Electrode Pre-condition Time on Charge of Peak 1a for Illinois Coal Pyrite. Scan Rate, $50 \mathrm{mV} / \mathrm{s}$ 


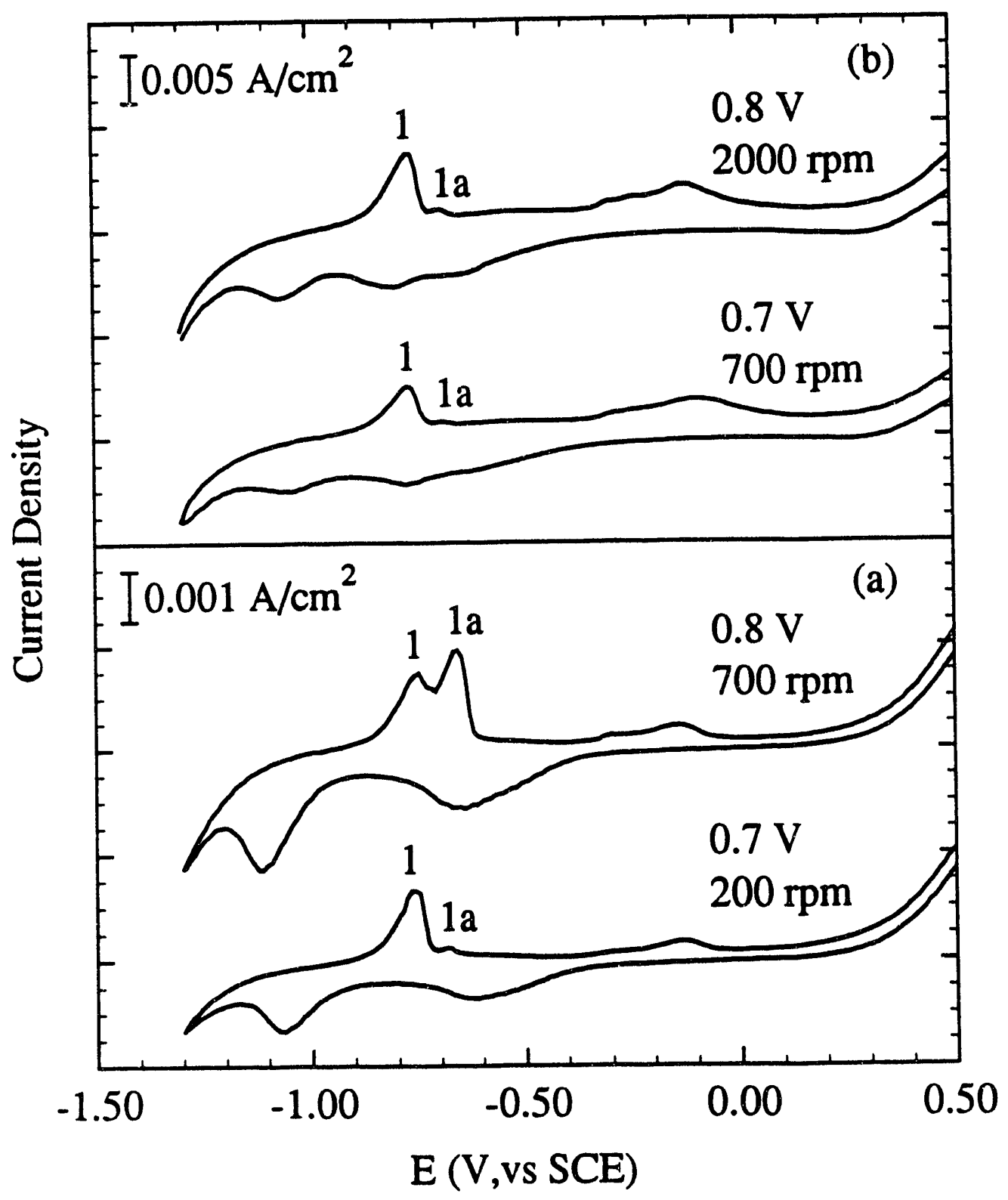

Figure 2.61. Comparison of Mineral Pyrite (a) and Illinois Coal Pyrite (b) 
formation of sulfur intermediates (elemental sulfur and polysulfides) was identified by in situ Raman spectroscopy (see next chapter). The results correlated findings from the electrochemical studies very well.

There has been little work done on the kinetics and mechanism of surface film formation resulting from pyrite transpassive oxidation. As noted above, a knowledge of the formation of sulfur rich films on pyrite surfaces is important in that it may lead to methods for the modification and control of pyrite surfaces, and hopefully improve pyrite separation. With this objective, an investigation with chronoamperometry was undertaken to study the growth kinetics of surface film formation as pyrite was oxidized in the transpassive region.

Effect of Applied Potential. Figure 2.62 illustrates the current density, i, as a function of time for various applied potentials, in well stirred solutions $(\mathrm{pH} 9.2)$, with stationary mineral pyrite electrodes. As applied potential was increased from 0.4 to $0.65 \mathrm{~V}$, the current density increased systematically. For applied potentials higher than $0.65 \mathrm{~V}$, oxygen evolution started, and the current density increased irregularly. Figure 2.63 illustrates the accumulation of charge passed, $Q$, as a function of time at different applied potentials. Charge $\mathrm{Q}$ increased with increasing applied potential. Consistent with previous results for the transpassive oxidation experiments, increased anodic oxidation potential increased the amount of sulfur intermediates formed.

During the initial stage, (Figure 2.62) currents decreased quickly, indicating the build up of a passivation film, and then became almost constant. This situation may arise if a compact film, growing at a parabolic rate in the initial stage transforms to a linear rate in later stage [2.21]. As the film increases in thickness, the reaction rate decreases, and approaches the rate of dissolution of the outer surface of the film, corresponding to the corrosion current, $i_{\text {cor. }}$. The passive film thickness thus becomes essentially constant, leading to the linear kinetic region observed for longer periods of time (Figure 2.62). The reaction rate is controlled by solid state diffusion. A schmatic diagram is shown on page 108. 


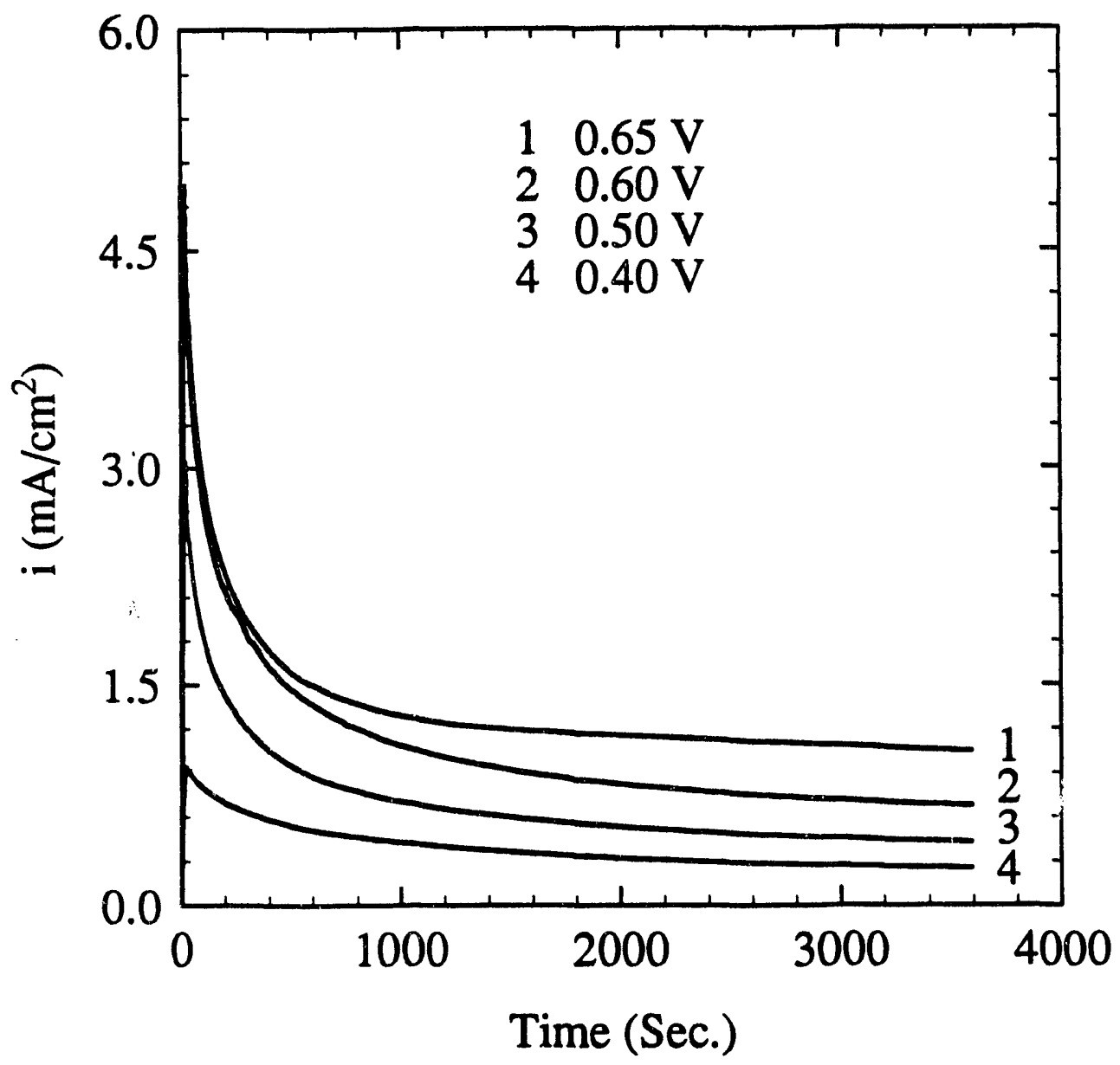

Figure 2.62. Current vs Time Curves for Pyrite in Stirred Solution of $\mathrm{pH} 9.2$ at Various Pctentials 


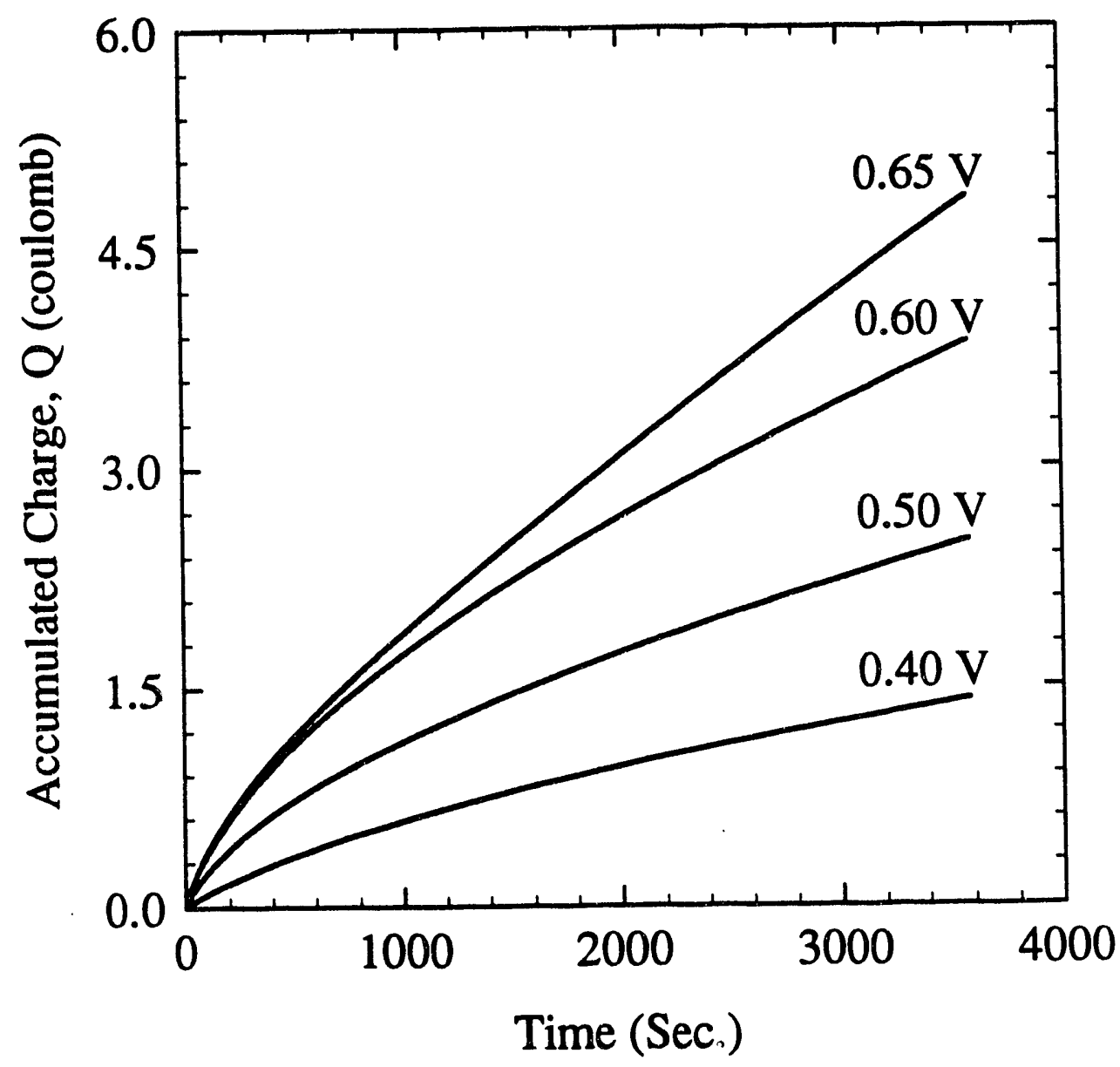

Figure 2.63. Charge vs Time Curves for Pyrite in Stirred Solution of p.H 9.2 at Various Potentials 


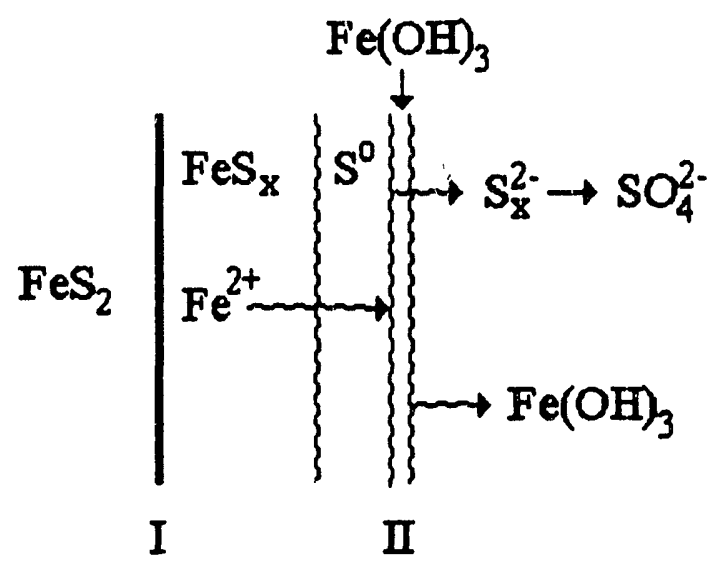

The formation of an intermediate passivation film may be explained by the equation

$$
\frac{1}{A} \frac{d m}{d t}=\frac{1}{n F}\left(i-i_{\text {corn }}\right)
$$

where $m=A \delta \rho / M$, and $m, \delta, \rho$ and $M$ are respectively, the passive film mass, thickness, density and molecular weight. The electrode area is $A, i$ is the current density, $n$ is the number of electrons per mole of product and $F$ the Faraday number. Equaticn (2.49) may be expressed in terms of film thickness $\delta$

$$
\frac{d \delta}{d t}=\frac{M}{n F p}\left(i-i_{\text {com }}\right)
$$

The rate of passive film formation is given by the parabolic rate equation

$$
i=\frac{d Q}{d t}=\frac{k}{8}
$$

$\mathrm{k}$ is a constant. The thickness of the passive film, $\delta$, may be estimated by integration of equation (2.50) assuming $i_{\text {cor }}$ is constant with respect to time

$$
\delta=\frac{M}{n F_{p}} \int\left(i-i_{\text {corr }}\right) d t=\frac{M}{n F_{p}}\left(Q-k_{l} t\right)
$$


and equation (2.50) becomes

$$
\frac{d Q}{d t}=\frac{k_{p}}{Q-k_{i} i}
$$

where the parabolic rate constant, $k_{p}=n F p k / M$ and $k_{1}$ is the linear rate constant corresponding to the corrosion current. Integration of equation (2.53) gives the paralinear rate equation,

$$
Q=\frac{k_{p}}{k_{l}} \ln \frac{k_{p}}{k_{p}-k_{l}\left(Q-k_{l} t\right)}
$$

Figure 2.64 demonstrates the correlation of the experimental data with the paralinear rate law, equation (2.54). The parabolic and linear rate constants, $\mathrm{k}_{\mathrm{p}}$ (millicoulomb $\mathrm{sec}^{-1}$ ) and $\mathrm{k}_{1}$ (millicoulomb $\mathrm{sec}^{-1}$ ) for various applied potentials, calculated by equation (2.54), are listed in Table 2.3 and plotted in Figure 2.65.

Table 2.3. Parabolic and linear rate constants $\left(k_{p}, k_{l}\right)$ for various applied potentials

\begin{tabular}{ccc}
\hline $\begin{array}{c}\text { Applied Potential } \\
(\mathrm{V})\end{array}$ & $\begin{array}{c}\mathrm{k}_{\mathrm{p}} \\
\mathrm{m} \mathrm{coul.}{ }^{2} / \mathrm{sec}\end{array}$ & $\begin{array}{c}\mathrm{k}_{\mathrm{l}} \\
\mathrm{m} \mathrm{coul./sec}\end{array}$ \\
\hline 0.40 & 113 & 0.299 \\
0.45 & 345 & 0.399 \\
0.50 & 482 & 0.416 \\
0.55 & 898 & 0.588 \\
0.60 & 1111 & 0.655 \\
\hline
\end{tabular}

Both $k_{p}$ and $k_{1}$ increased linearly with increasing applied potential.

$$
\begin{aligned}
& k_{p}=-1960+5.1(\mathrm{mV}) \\
& k_{l}=-43+0.18(\mathrm{mV})
\end{aligned}
$$




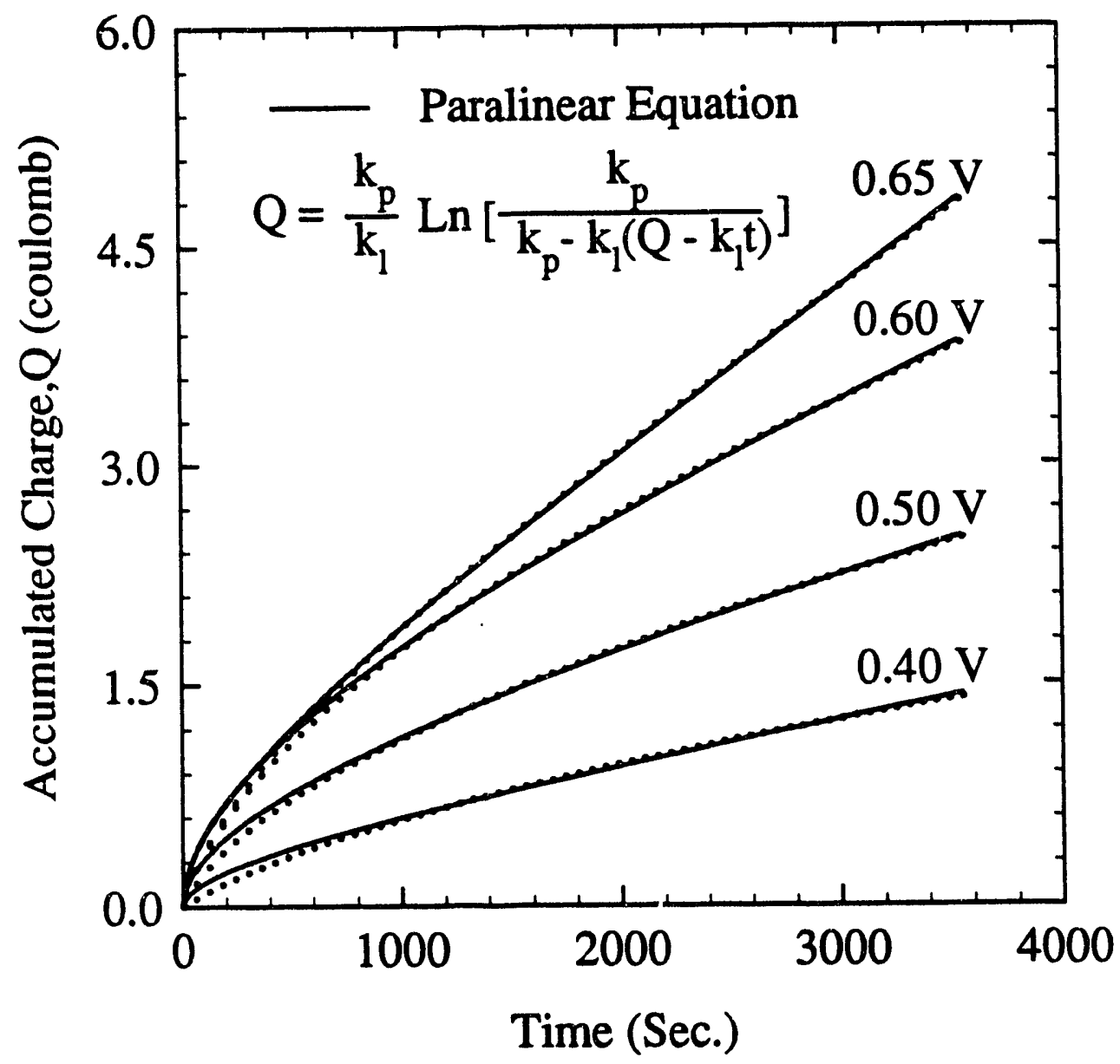

Figure 2.64. Correlation of Charge vs Time Curves at Various Potentials with Paralinear Equation 


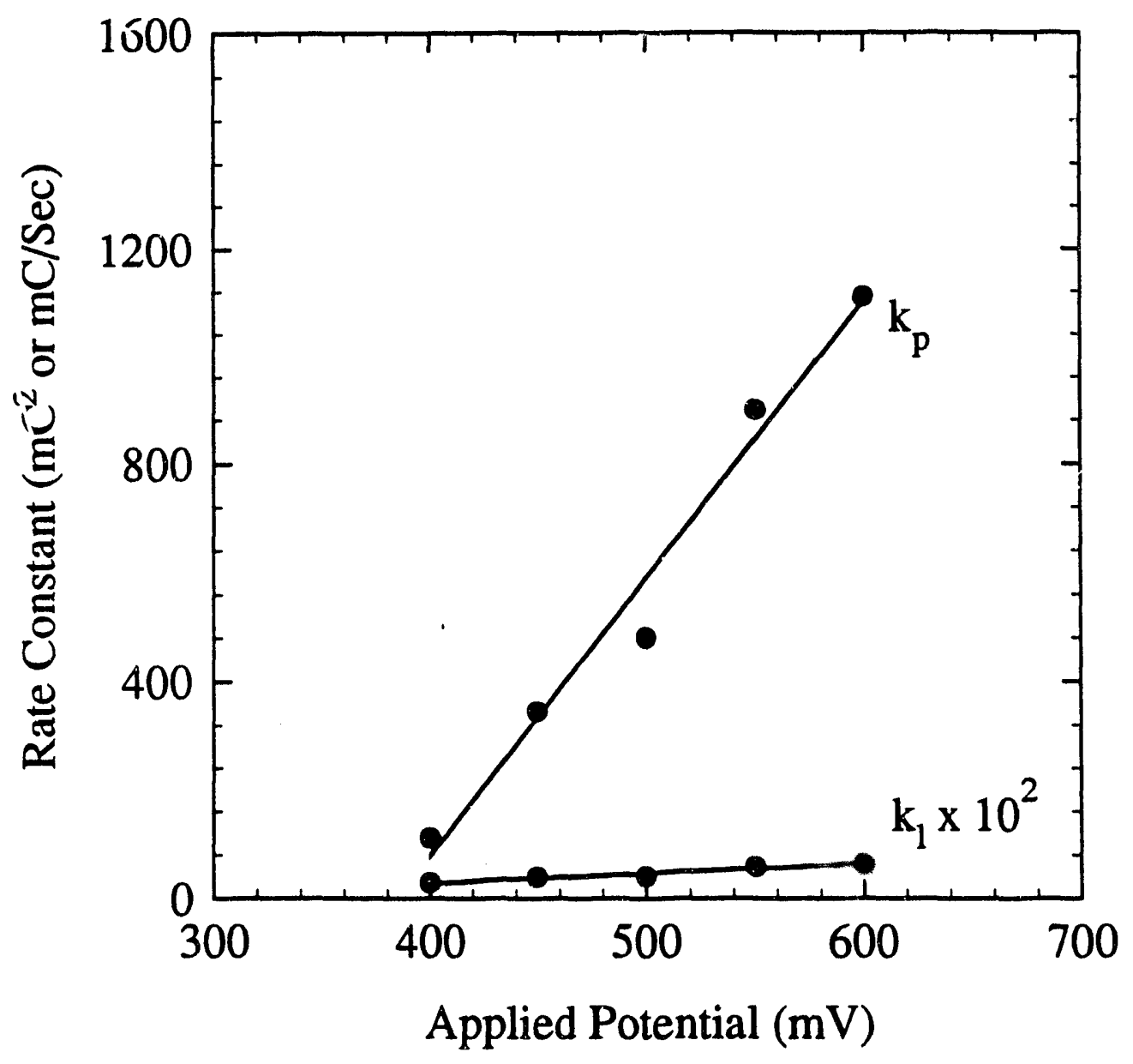

Figure 2.65. Effect of Applied Potential on Rate Constants, $k_{p}, k_{1}$ 
The parabolic constant is much more sensitive to the applied potential than is the linear rate constant. According to the above derivation $k_{p}$ includes the factor, $n F p / M$, which is about 8000 for pyrite.

Effect of Electrode Rotation Speed. The effect of electrode rotation speed on reaction rate was examined at different applied potentials and solution $\mathrm{pH}$ using rotating disk electrodes. A set of typical current-time curves, obtained using the potentiostatic rechnique at an applied potential of $0.6 \mathrm{~V}$ in a solution of $\mathrm{pH} 9.2$ for electrode rotation speeds from 0 to $700 \mathrm{rpm}$, is shown in Figure 2.66. The current increased notably as electrode rotation speed increased from 0 to $100 \mathrm{rpm}$. Further increase in electrode rotation speed, increased the initial current only slightly, while the steady state current remained alms st constant. Similar results were obtained at an applied potential of $0.5 \mathrm{~V}$ as shown Figure 2.67 and for solutions of pH 8.07 and 10.27 as shown in Figures 258 and 2.69 respectively. All subsequent tests using rotating disk electrodes were run at $700 \mathrm{rpm}$. It was noticed that, the parabolic and linear rate constants obtained using station?ry electrode in well stirred solution are greater than those obtained using rotating disk electrodes at $700 \mathrm{rpm}$. This difference resulted from different hydrodynamic flow patterns for the two systems.

Effect of Electrolyte $\mathrm{pH}$. The effect of electrolyte $\mathrm{pH}$ on reaction rates was examined at applied potentials of $0.5 \mathrm{~V}$ and $0.6 \mathrm{~V}$ for an electrode rotation speed of $700 \mathrm{rpm}$. Figure 2.70 demonstrates the charge-time curves at $0.6 \mathrm{~V}$ and their correlation with the paralinear rate equation. The parabolic and linear rate constants at applied potentials of $0.5 \mathrm{~V}$ and $0.6 \mathrm{~V}$ in solutions of $\mathrm{pH}, 8.07,9.20$ and 10.27 calculated with equation (2.54) were listed in Table 2.4 and plotted in Figure 2.71. The parabolic rate constant, $k_{p}$, increased with increasing electrolyte $\mathrm{pH}$ as expected from equations (2.38) and (2.39), during the initial parabolic kinetic region.

$$
\begin{array}{ll}
\log k_{p}=0.136+0.29(p H) & \text { at } 0.6 V \\
\log k_{p}=-1.035+0.38(p H) & \text { at } 0.5 V
\end{array}
$$




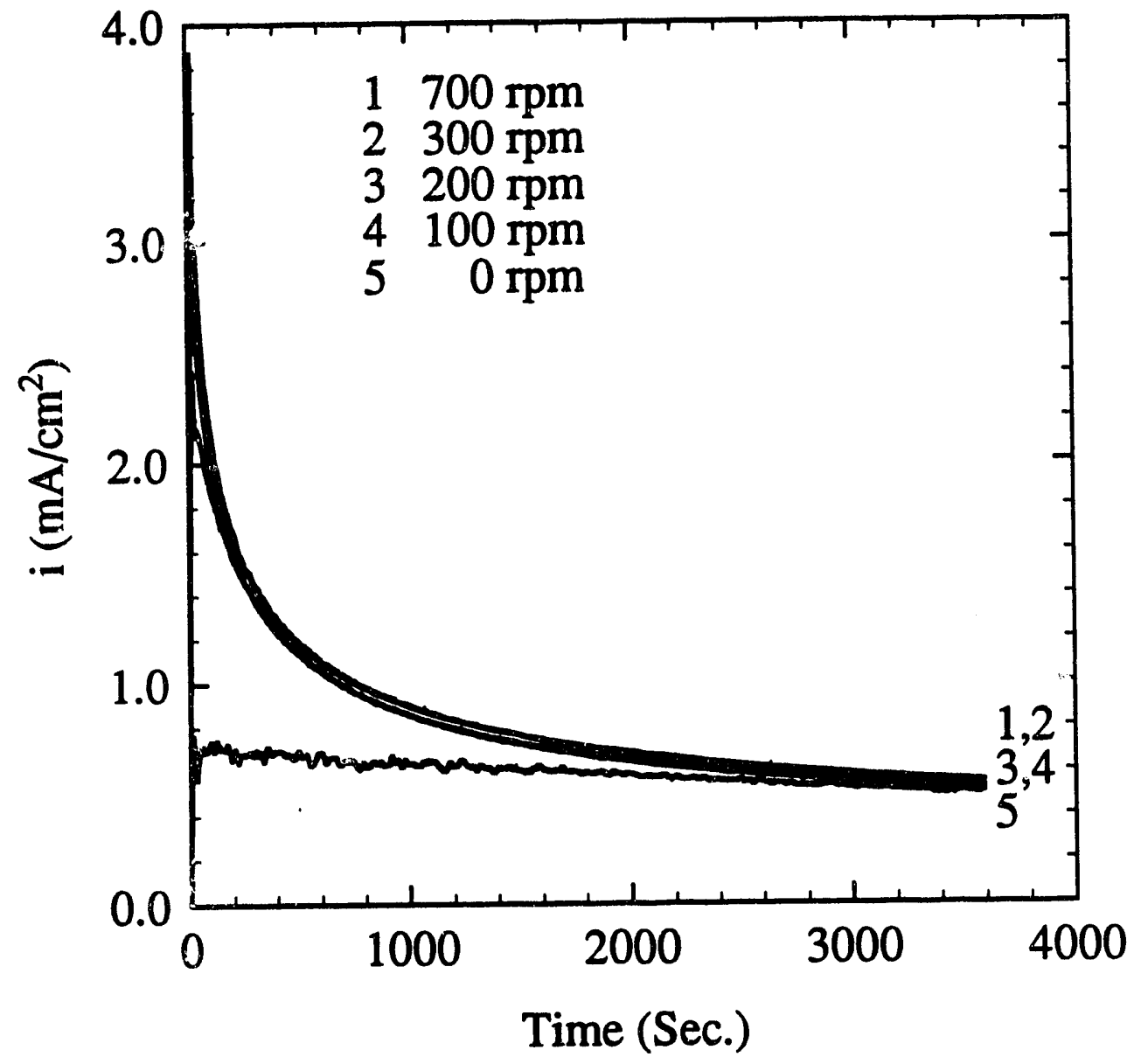

Figure 2.66. Current vs Time Curves for Pyrite in Solutions of $\mathrm{pH} 9.2$ at Various Electrode Rotation Speeds, Applied Potential, $0.6 \mathrm{~V}$ 


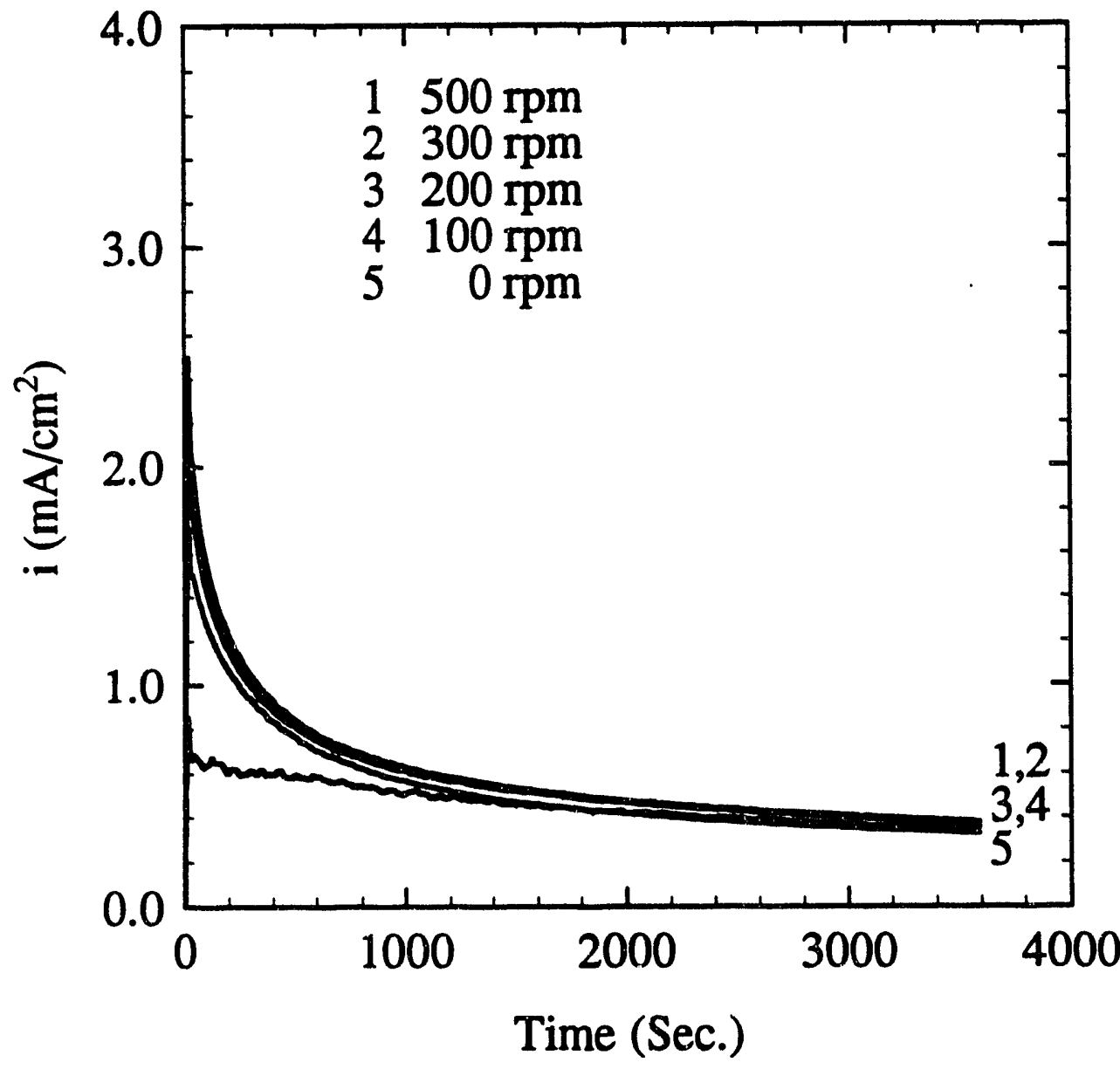

Figure 2.67. Current vs Time Curves for Pyrite in Solutions of $\mathrm{pH} 9.2$ at Various Electrode Rotation Speeds, Applied Potential, $0.5 \mathrm{~V}$ 


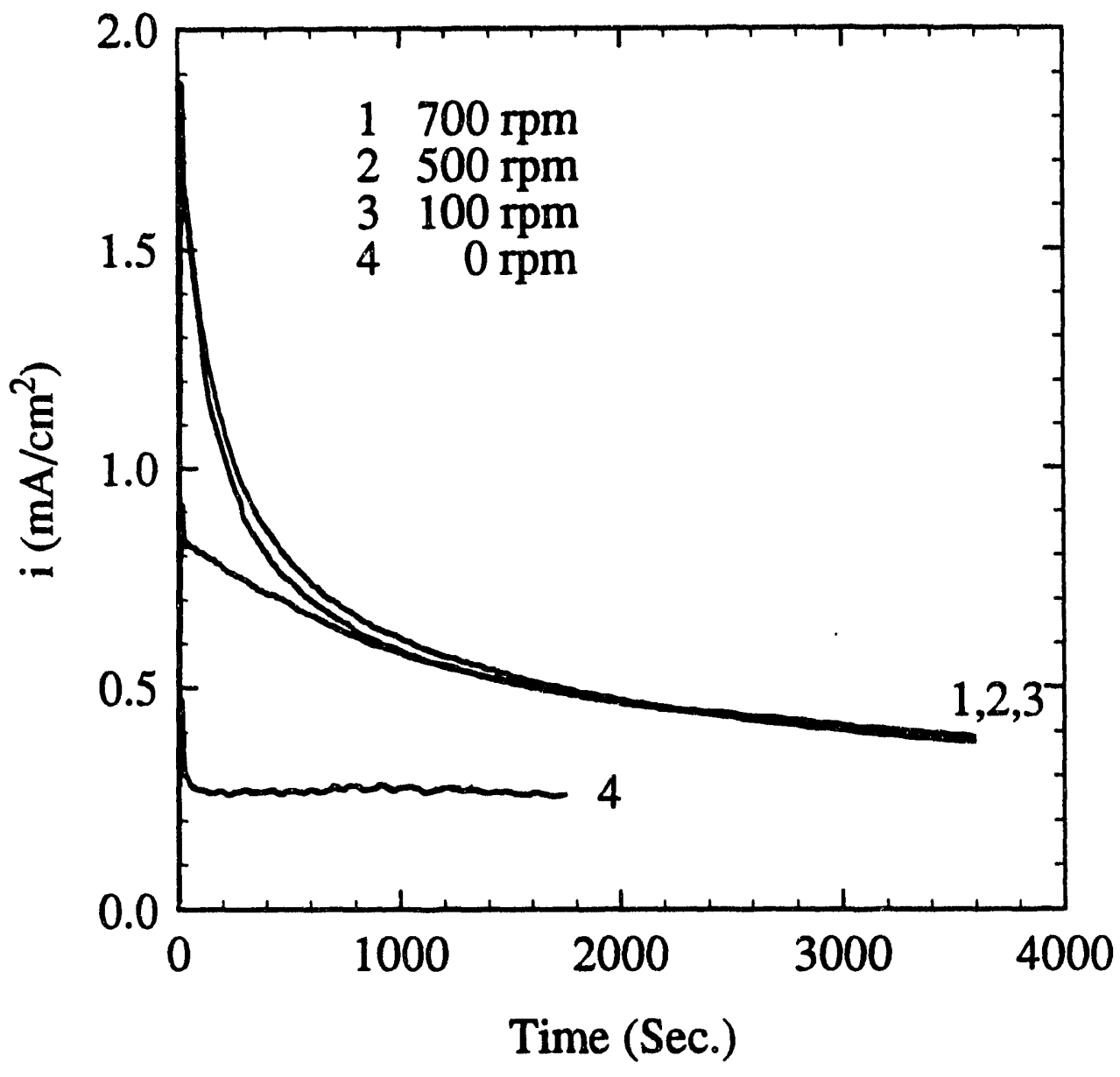

Figure 2.68. Current vs Time Curves for Pyrite in Solutions of pH 8.07 at Various Electrode Rotation Speeds, Applied Potential, $0.6 \mathrm{~V}$ 


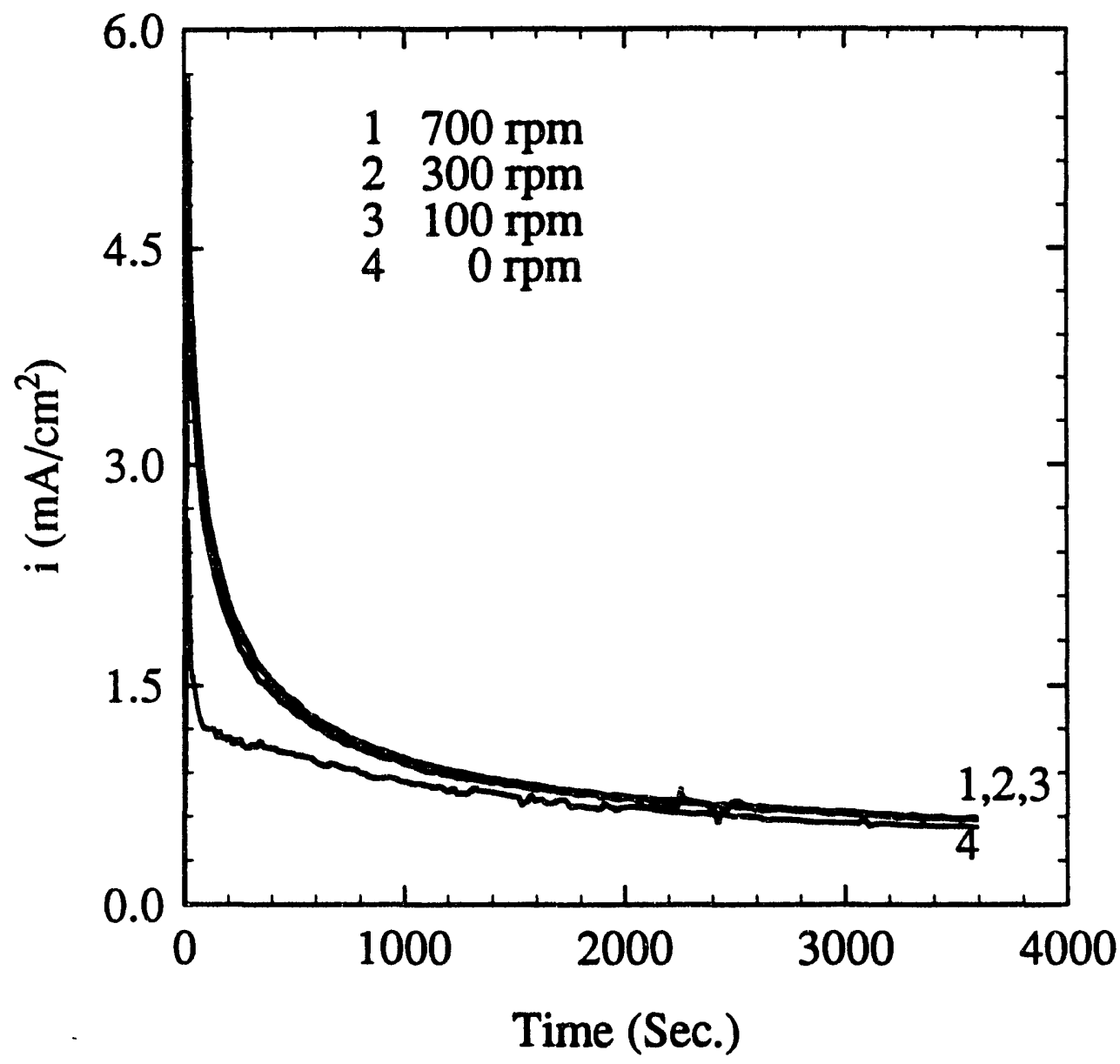

Figure 2.69. Current vs Time Curves for Pyrite in Solutions of $\mathrm{pH} 10.27$ at Various Electrode Rotation Speeds, Applied Potential, $0.6 \mathrm{~V}$ 


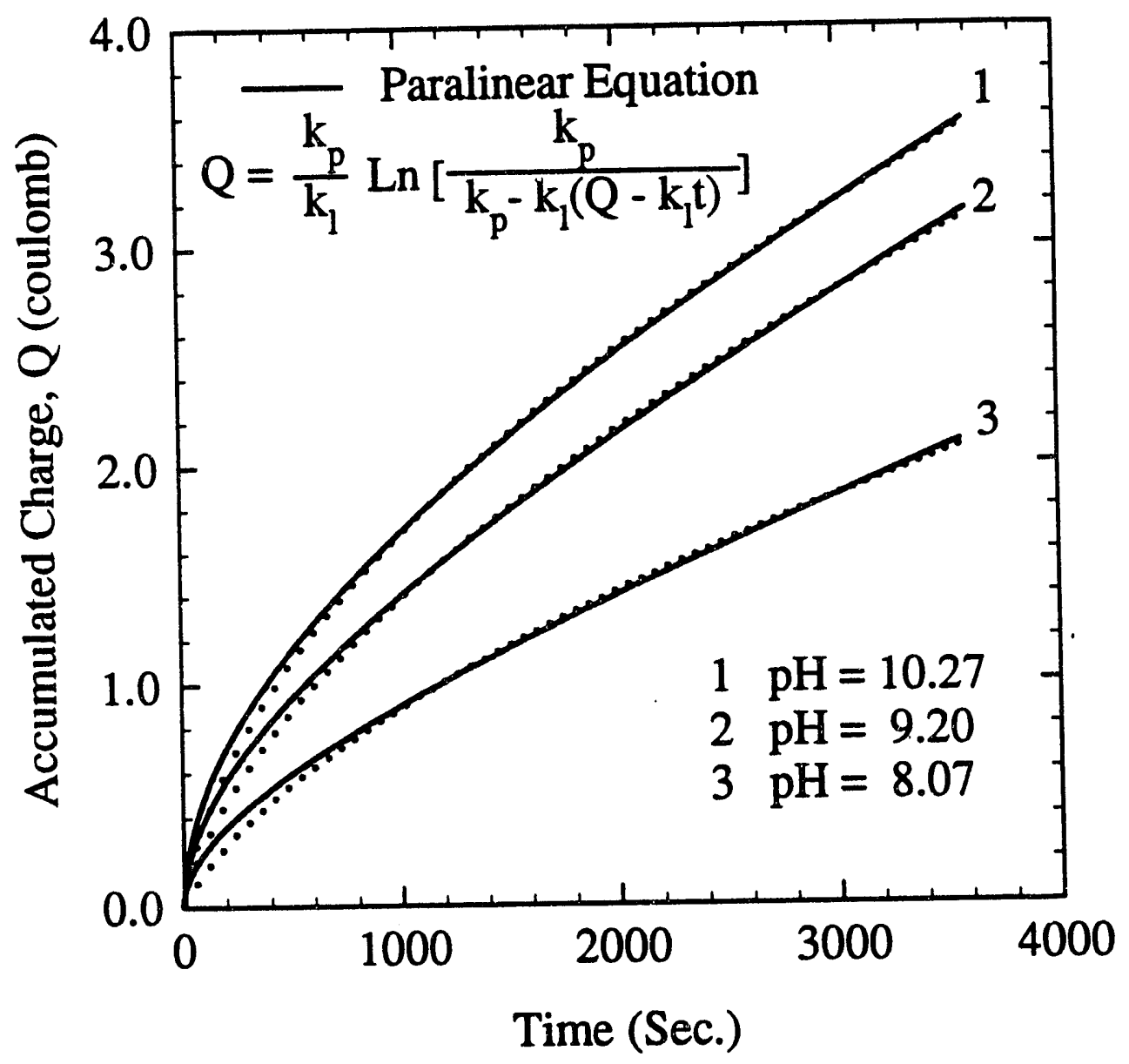

Figure 2.70. Correlation of Charge vs Time Curves at Various pH with Paralinear Equation ( $0.6 \mathrm{~V}, 700 \mathrm{rpm}$ ) 


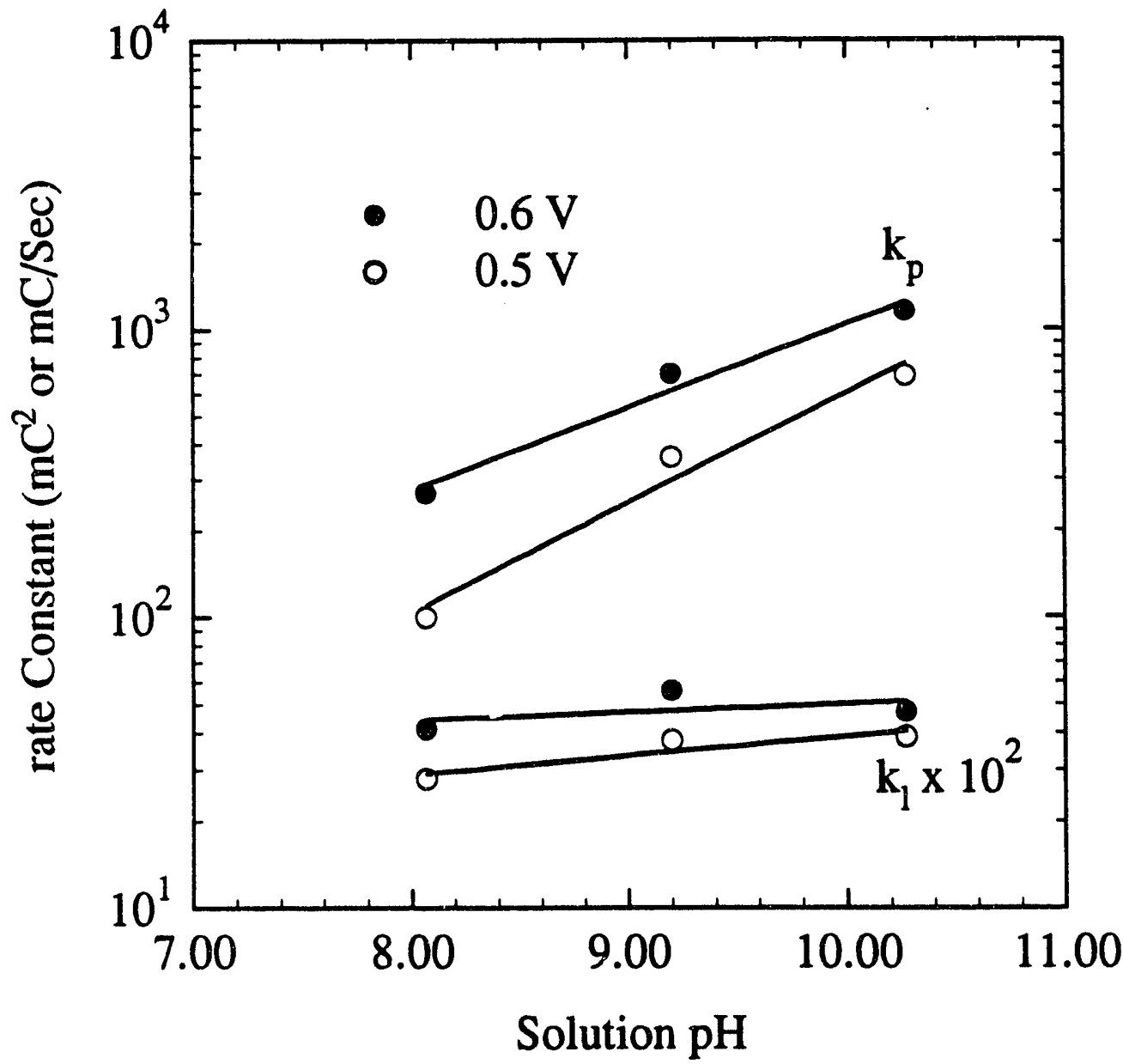

Figure 2.71. Effect of Solution $\mathrm{pH}$ on $\log$ Rate Constants, $\mathrm{k}_{\mathrm{p}}, \mathrm{k}_{\mathrm{l}}$ 
Table 2.4. Parabolic and linear rate constants $\left(k_{p}, k_{1}\right)$ for various electrolyte $\mathrm{pH}$ (Electrode rotation speed: $700 \mathrm{rpm}$ )

\begin{tabular}{ccc}
\hline $\begin{array}{c}\text { Electrolyte } \\
\mathrm{pH}\end{array}$ & $\begin{array}{c}\mathrm{k}_{\mathrm{p}} \\
\mathrm{m} \text { coul. }{ }^{2} / \mathrm{sec}\end{array}$ & $\begin{array}{c}\mathrm{k}_{1} \\
\mathrm{~m} \text { coul./sec }\end{array}$ \\
\hline \multicolumn{3}{c}{ Applied Potential, 0.6 V } \\
8.07 & 270 & 0.415 \\
9.20 & 700 & 0.559 \\
10.27 & 1154 & 0.473 \\
& Applied Potential, 0.5 V \\
8.07 & 78 & 0.281 \\
9.20 & 359 & 0.377 \\
10.27 & 689 & 0.390 \\
\hline
\end{tabular}

This can be explained if the surface $\mathrm{Fe}^{3+}$ (lattice) concentration decreased with increasing $\mathrm{pH}$, thus increasing the diffusion gradient and the rate of $\mathrm{Fe}^{3+}$ (lattice) diffusion through the passivation film. No significant change of $\mathrm{k}_{1}$ with $\mathrm{pH}$ was observed.

Effect of Temperature. The effect of electrolyte temperature on reaction rate was investigated at $0.5 \mathrm{~V}$ and $0.6 \mathrm{~V}$ in a solution of $\mathrm{pH} 9.2$ for the temperature range $23.4^{\circ} \mathrm{C}$ to $59.5^{\circ} \mathrm{C}$. The current-time and charge-time curves, for $0.6 \mathrm{~V}$ are shown in Figures 2.72 and 2.73 along with calculated curves using the paralinear rate equation. The accumulated charge, $Q$, increased systematically with increasing solution temperature. Similar results were obtained for an applied potential of $0.5 \mathrm{~V}$, as shown in Figures 2.74 and 2.75. The calculated parabolic and linear rate constants are listed in Table 2.5 for various temperatures at $0.5 \mathrm{~V}$ and $0.6 \mathrm{~V}$. Arrhenius plots of the parabolic and linear rate constants are illustrated in Figures 2.76 and 2.77 respectively. The activation energies were calculated by linear regression, and found to be $66.17 \mathrm{~kJ} / \mathrm{mole}(15.83 \mathrm{kcal} / \mathrm{mole})$ at 0.6 $\mathrm{V}$ and $68.34 \mathrm{~kJ} / \mathrm{mole}(16.35 \mathrm{kcal} / \mathrm{mole})$ at $0.5 \mathrm{~V}$ for the parabolic rate process and 38.67 


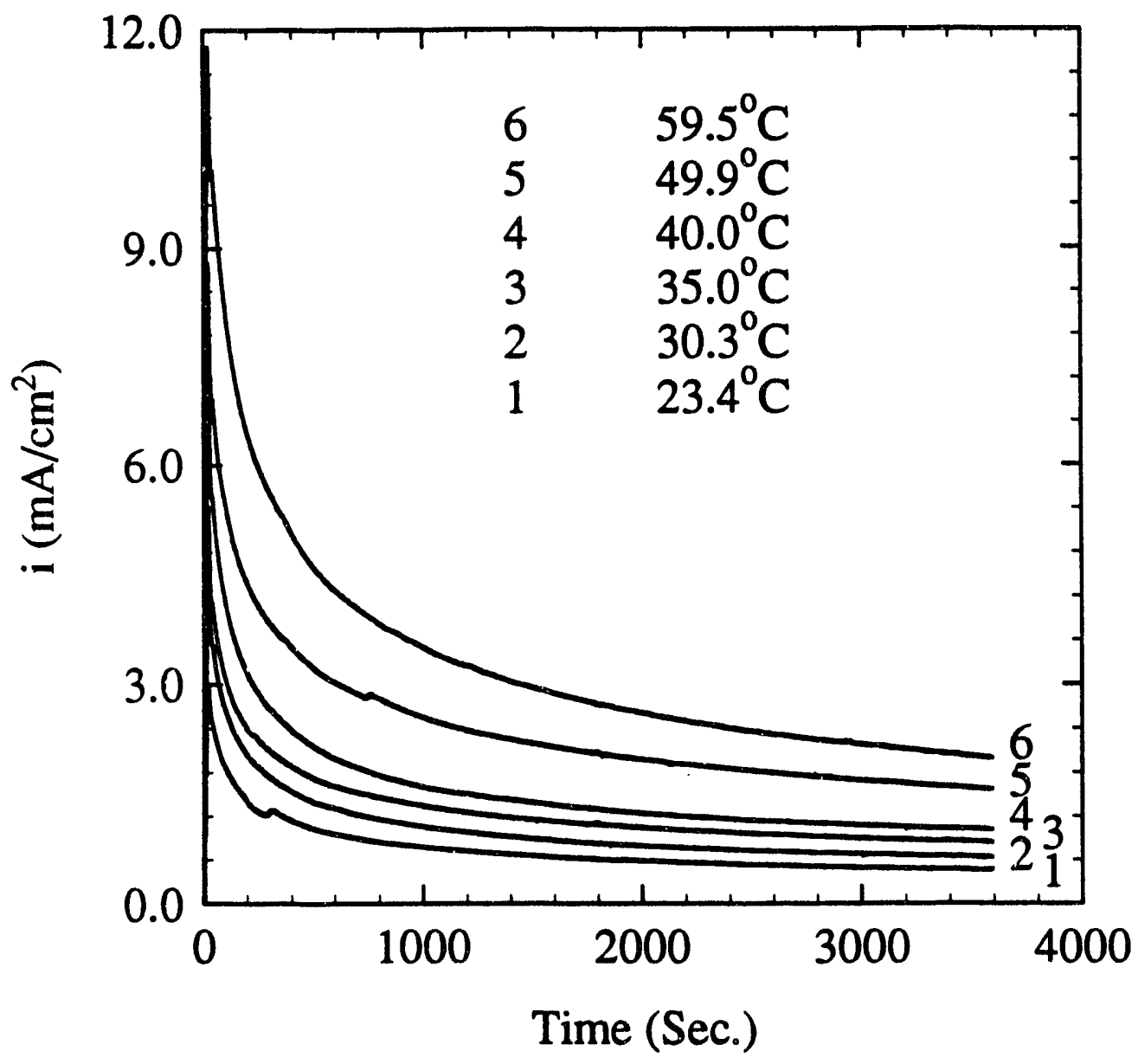

Figure 2.72. Current vs Time Curves for Pyrite in Solutions of $\mathrm{pH} 9.2$ at Various Temperatures, Applied Potential, $0.6 \mathrm{~V}, \mathrm{rpm}=700$ 


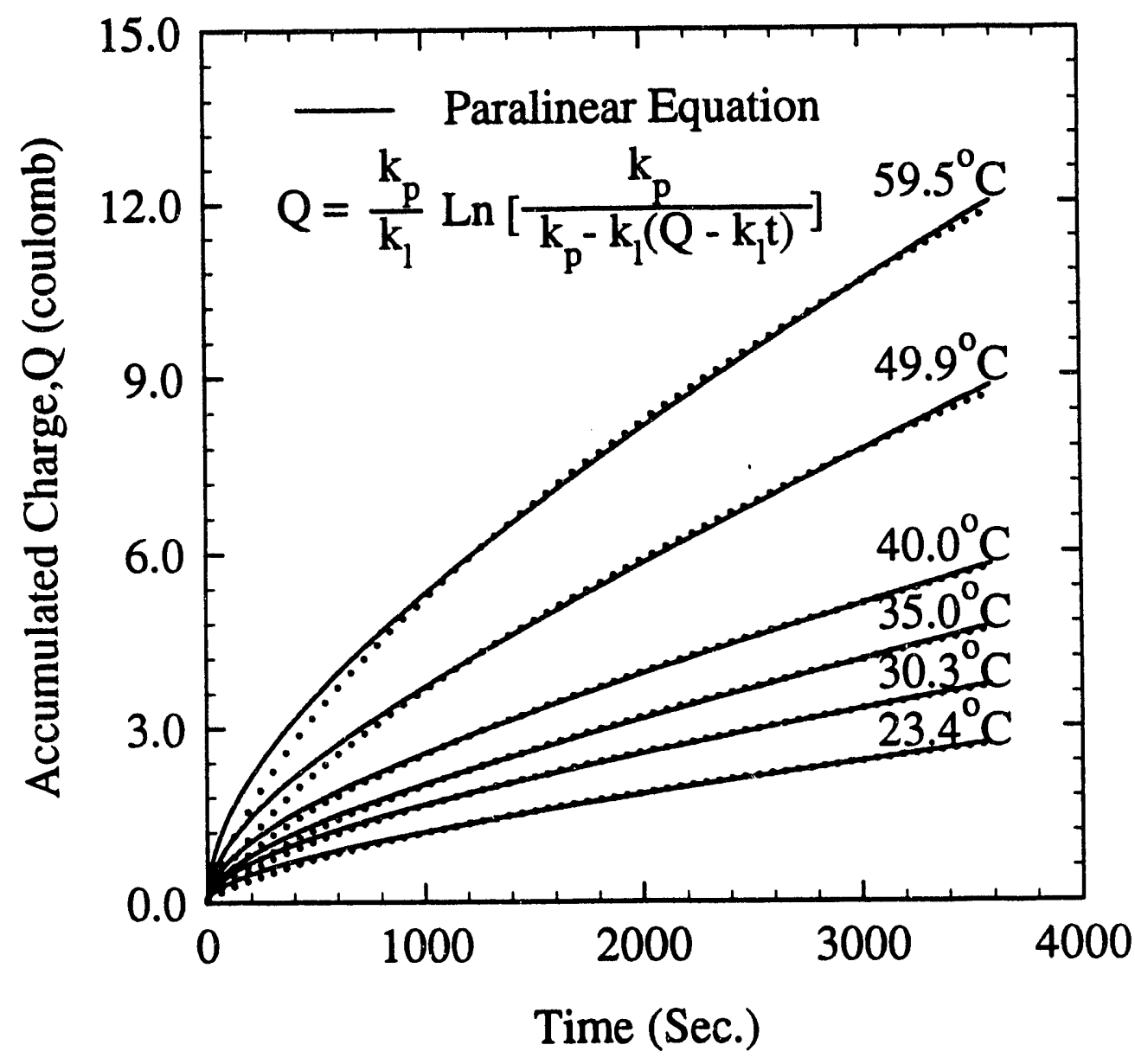

Figure 2.73. Correlation of Charge vs Time Curves at Various Temperatures with Paralinear Equations. Applied Potential, $0.6 \mathrm{~V}$ 


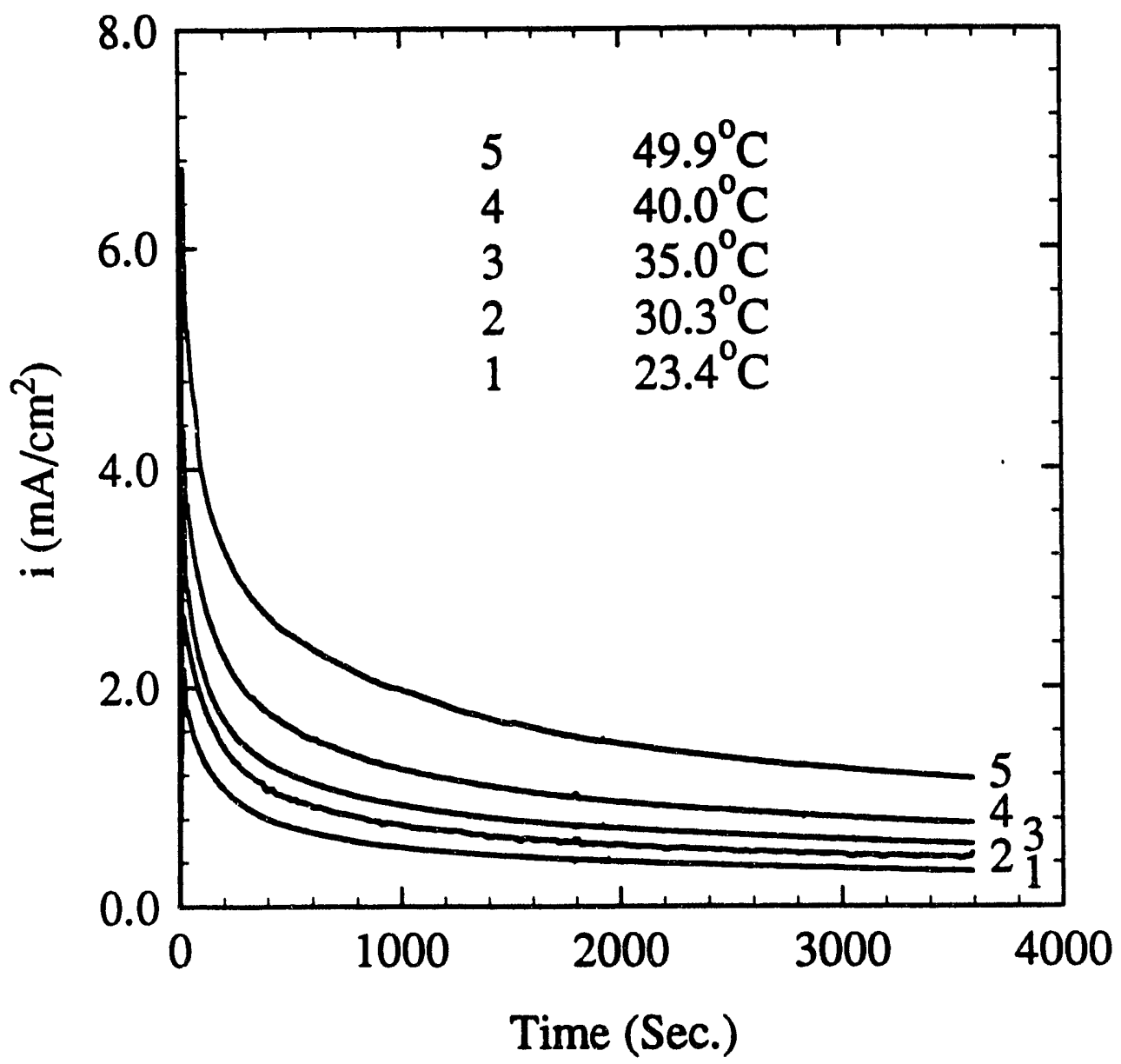

Figure 2.74. Current vs Time Curves for Pyrite in Solutions of $\mathrm{pH} 9.2$ at Various Temperatures, Applied Potential, $0.5 \mathrm{~V}, \mathrm{rpm}=700$ 


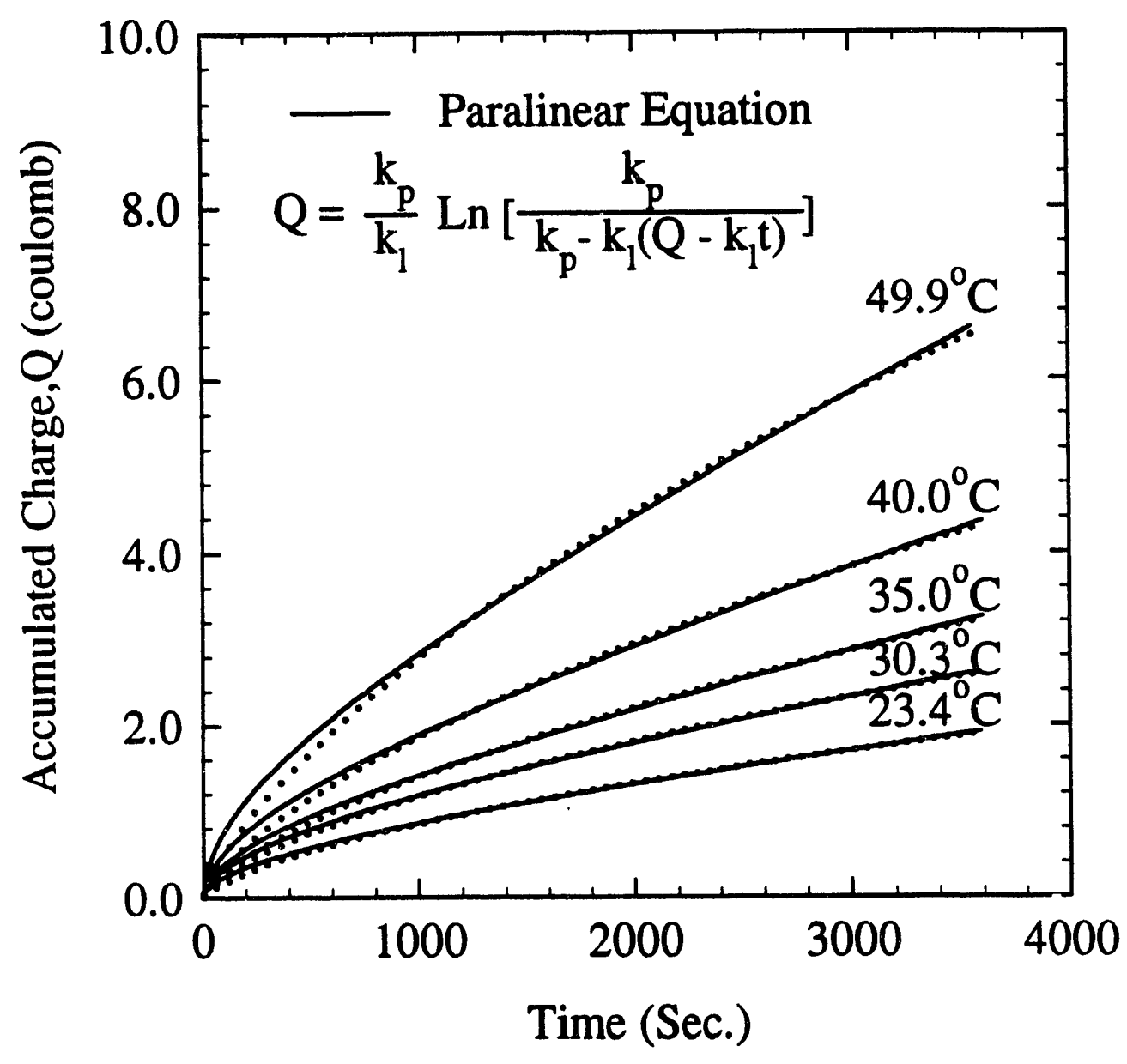

Figure 2.75. Correlation of Charge vs Time Curves at Various Temperatures with Paralinear Equation. Applied Potential, $0.5 \mathrm{~V}$ 


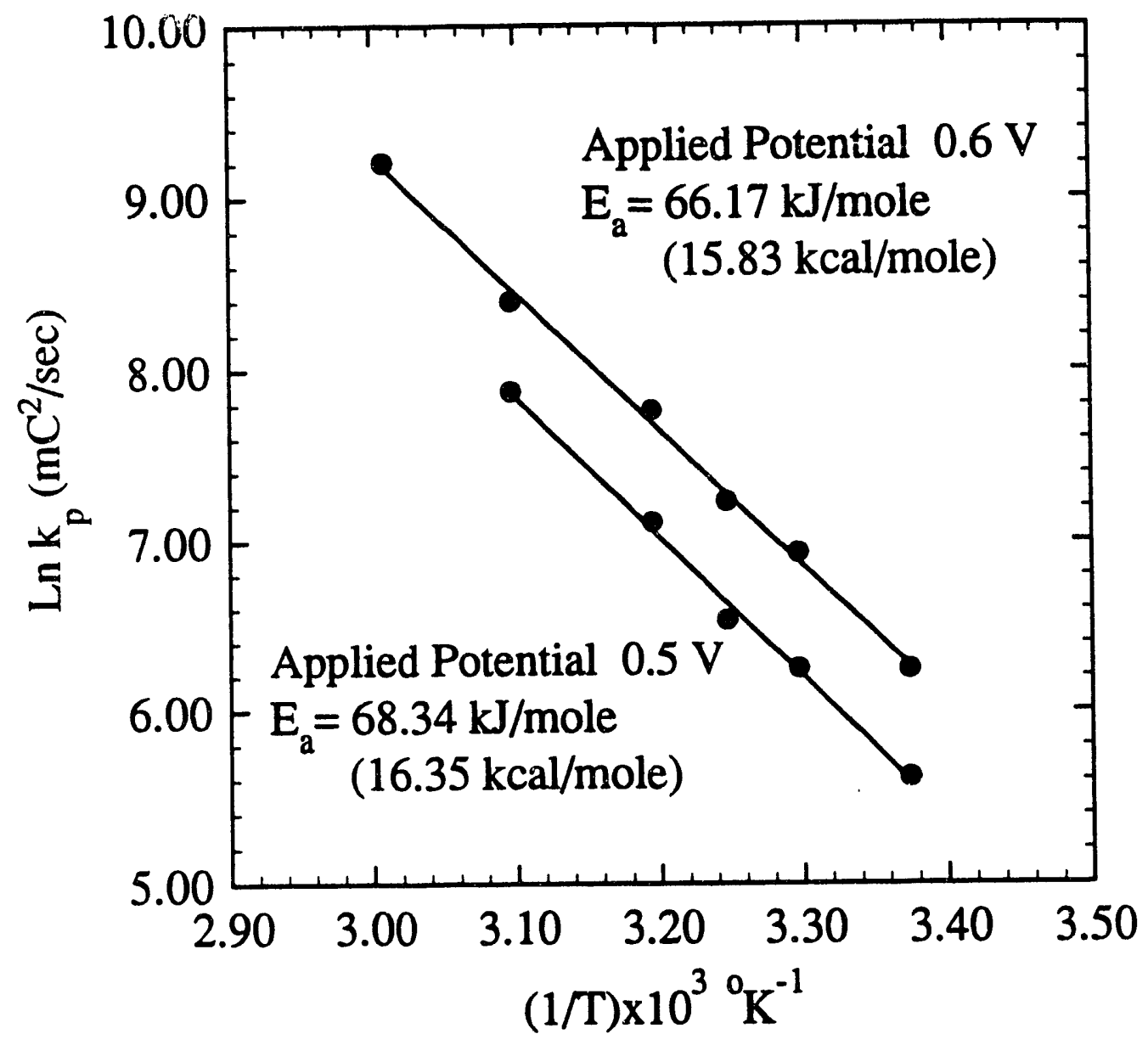

Figure 2.76. Arrhenius Plot Based on Parabolic Rate Constant, $\mathrm{k}_{\mathrm{p}}$ in Temperature range $23.4^{\circ} \mathrm{C}-59.5^{\circ} \mathrm{C}$ 


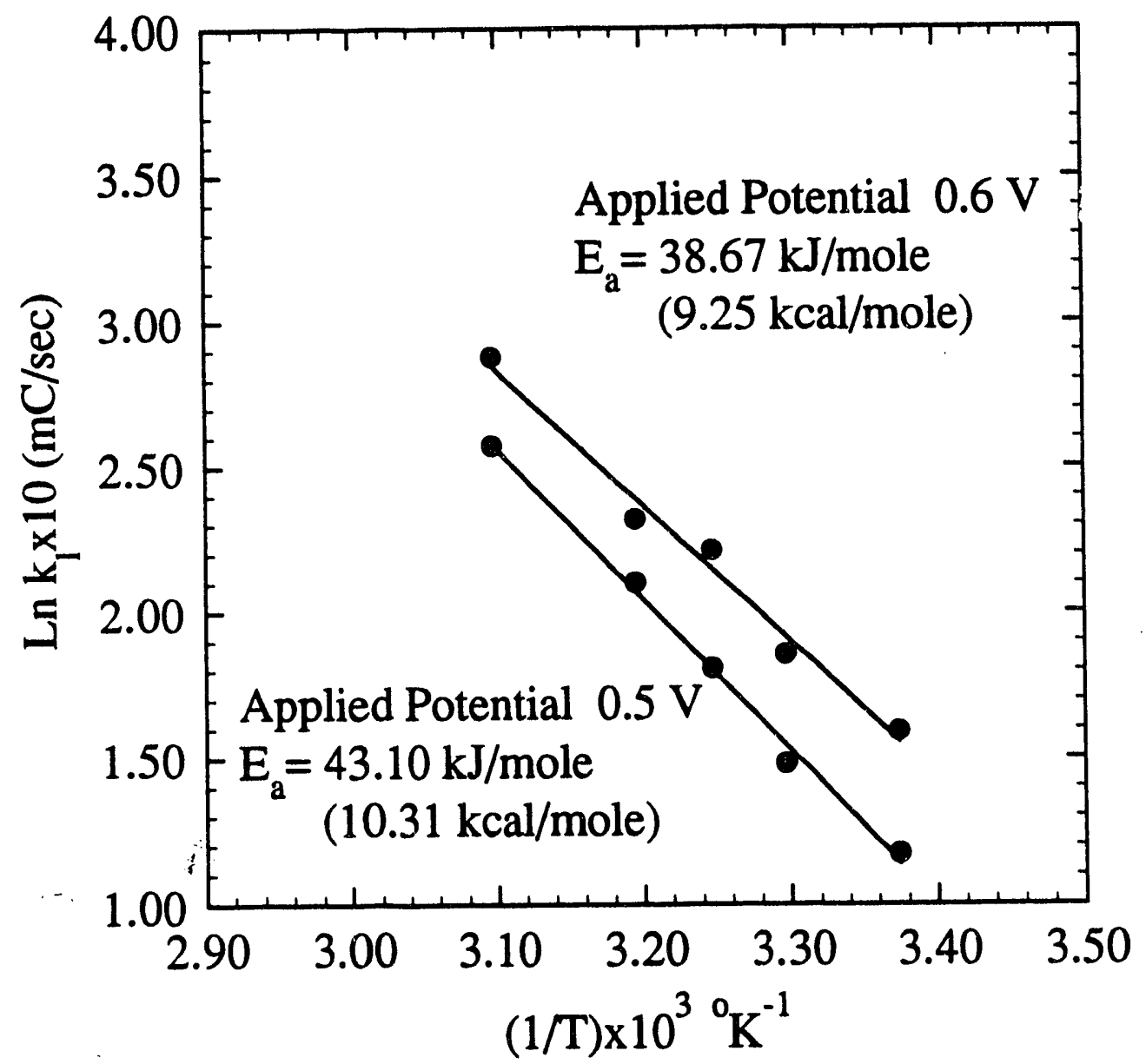

Figure 2.77. Arrhenius Plot Based on Linear Rate Constant, $\mathrm{k}_{1}$ in Temperature range $23.4^{\circ} \mathrm{C}-49.9^{\circ} \mathrm{C}$ 
Table 2.5. Parabolic and linear rate constants $\left(k_{p}, k_{1}\right)$ for various temperatures

(Electrode rotation speed: $700 \mathrm{rpm}$ )

\begin{tabular}{ccc}
$\begin{array}{c}\text { Temperature } \\
{ }^{\circ} \mathrm{C}\end{array}$ & $\begin{array}{c}\mathrm{k}_{\mathrm{p}} \\
\mathrm{m} \text { coul. }{ }^{2} / \mathrm{sec}\end{array}$ & $\begin{array}{c}\mathrm{k}_{\mathrm{l}} \\
\mathrm{m} \mathrm{coul} . / \mathrm{sec}\end{array}$ \\
\hline 23.4 & Applied Potential, 0.6 V & \\
30.3 & 513 & 0.491 \\
35.0 & 1020 & 0.640 \\
40.0 & 1382 & 0.915 \\
49.9 & 2356 & 1.019 \\
59.5 & 4443 & 1.781 \\
& 9983 & 2.137 \\
23.4 & Applied Potential, $0.5 \mathrm{~V}$ & \\
30.3 & 274 & 0.323 \\
35.0 & 515 & 0.431 \\
40.0 & 688 & 0.609 \\
49.9 & 1225 & 0.818 \\
& 2640 & 1.313 \\
\hline
\end{tabular}

$\mathrm{kJ} / \mathrm{mole}(9.25 \mathrm{kcal} / \mathrm{mole})$ at $0.6 \mathrm{~V}$ and $43.10 \mathrm{~kJ} / \mathrm{mole}(10.31 \mathrm{kcal} / \mathrm{mole})$ at $0.5 \mathrm{~V}$ for the linear rate process, in the temperature range $23.4^{\circ} \mathrm{C}$ to $59.5^{\circ} \mathrm{C}$.

Using the activation energies of $15.83 \mathrm{kcal} / \mathrm{mole}$ and $9.25 \mathrm{kcal} / \mathrm{mole}$, the parabolic and linear rate constants $k_{p}$ and $k_{1}$ at certain temperature can be calculated according to Arrhenius equation

$$
\begin{aligned}
& k_{p}=2.46 \times 10^{14} \exp \left(\frac{-7966}{T}\right) \\
& k_{l}=7.57 \times 10^{5} \exp \left(\frac{-4220}{T}\right)
\end{aligned}
$$


Substituting these $k_{p}, k_{1}$ to paralinear equation (2.54), a series of charge vs time data were obtained. Figure 2.78 illustrates the good correlation of calculated charge-time data using $k_{p}, k_{1}$ estimated from activation energies with the paralinear equation.

As discussed above, the parabolic rate constant, $k_{p}$ is temperature, applied potential and electrolyte $\mathrm{pH}$ dependent, thus, a general equation may be developed:

$$
k_{p}=a \exp \left(-\frac{E_{a}}{T}\right) \exp \left(\frac{b V}{T}\right) 10^{\mathrm{cpH}}
$$

Using the value of $k_{p}$ listed in Tables 2.3, 2.4 and 2.5 and by regression

$$
\begin{aligned}
& a=4.87 \times 10^{11} \\
& b=1938.7 \\
& c=0.3122 \\
& E_{a}=9253.3
\end{aligned}
$$

Substituting in Eq.(2.61), then

$$
k_{p}=4.87 \times 10^{11} \exp \left(\frac{1939 V-9253}{T}\right) 10^{0.31 p H}
$$

The linear rate constant, $\mathrm{k}_{1}$, is independent of electrolyte $\mathrm{pH}$, thus, the $\mathrm{pH}$ term in Eq. (2.61) can be neglected $(c=0)$, then by regression

$$
\begin{aligned}
& a=8.77 \times 10^{5} \\
& b=809.9 \\
& E_{a}=4760.2
\end{aligned}
$$

Substituting in Eq.(2.61), then

$$
k_{l}=8.77 \times 10^{5} \exp \left(\frac{810 V-4760}{T}\right)
$$

The parabolic and linear rate constants $k_{p}$ and $k_{1}$ at certain temperature, applied potential and electrolyte $\mathrm{pH}$ can be calculated according to Eqs. 2.62 and 2.63. Substituting these $k_{p}, k_{1}$ to paralinear equation (2.54), a series of charge vs time data were obtained. Figures $2.79,2.80$ and 2.81 illustrate the good correlation of calculated charge- 


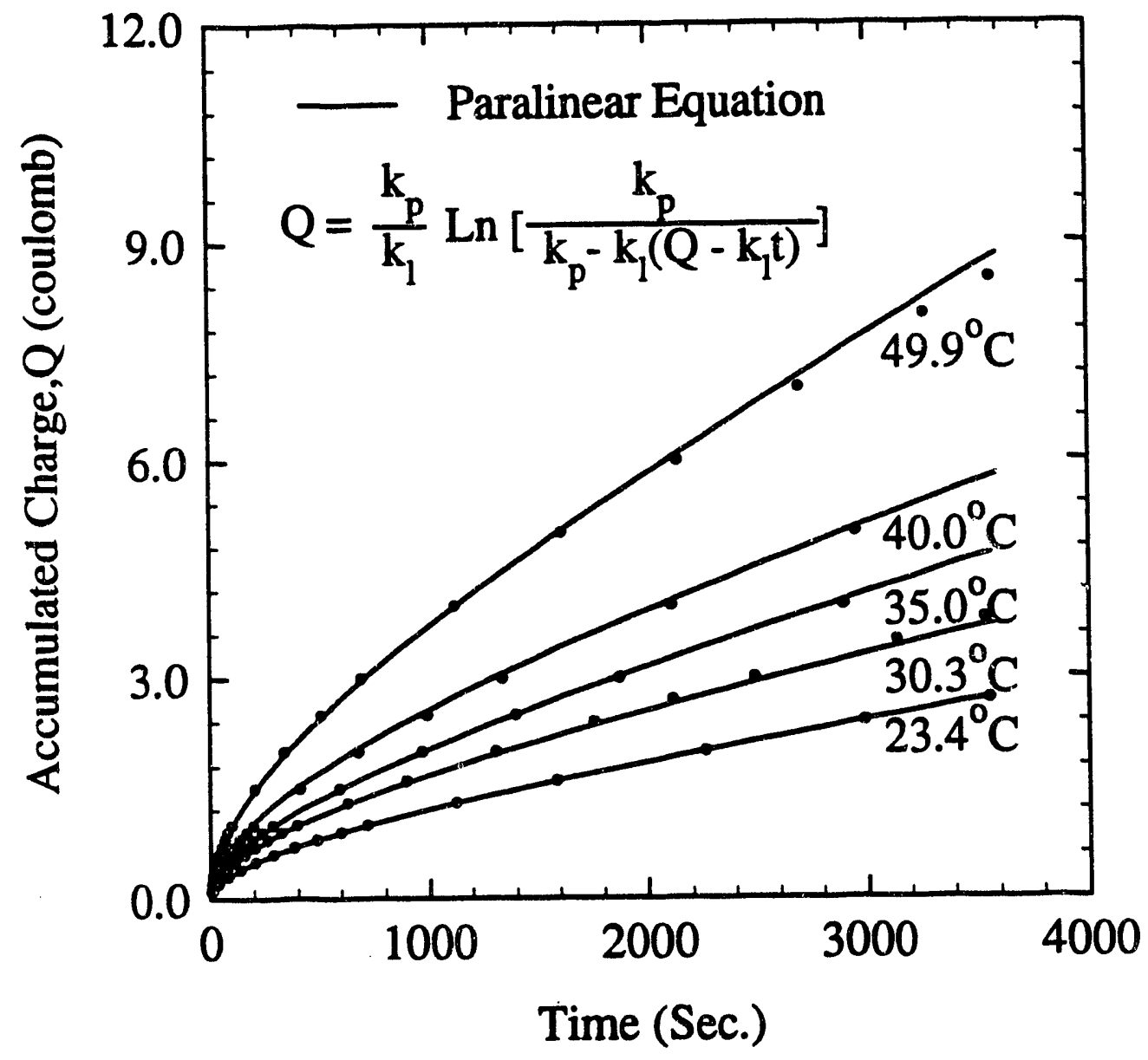

Figure 2.78. Correlation of Calculated Data using $\mathbf{k}_{\mathrm{p}}, \mathrm{k}_{1}$ Estimated from Eqs. $(2.59,2.60)$ with Paralinear Equation 


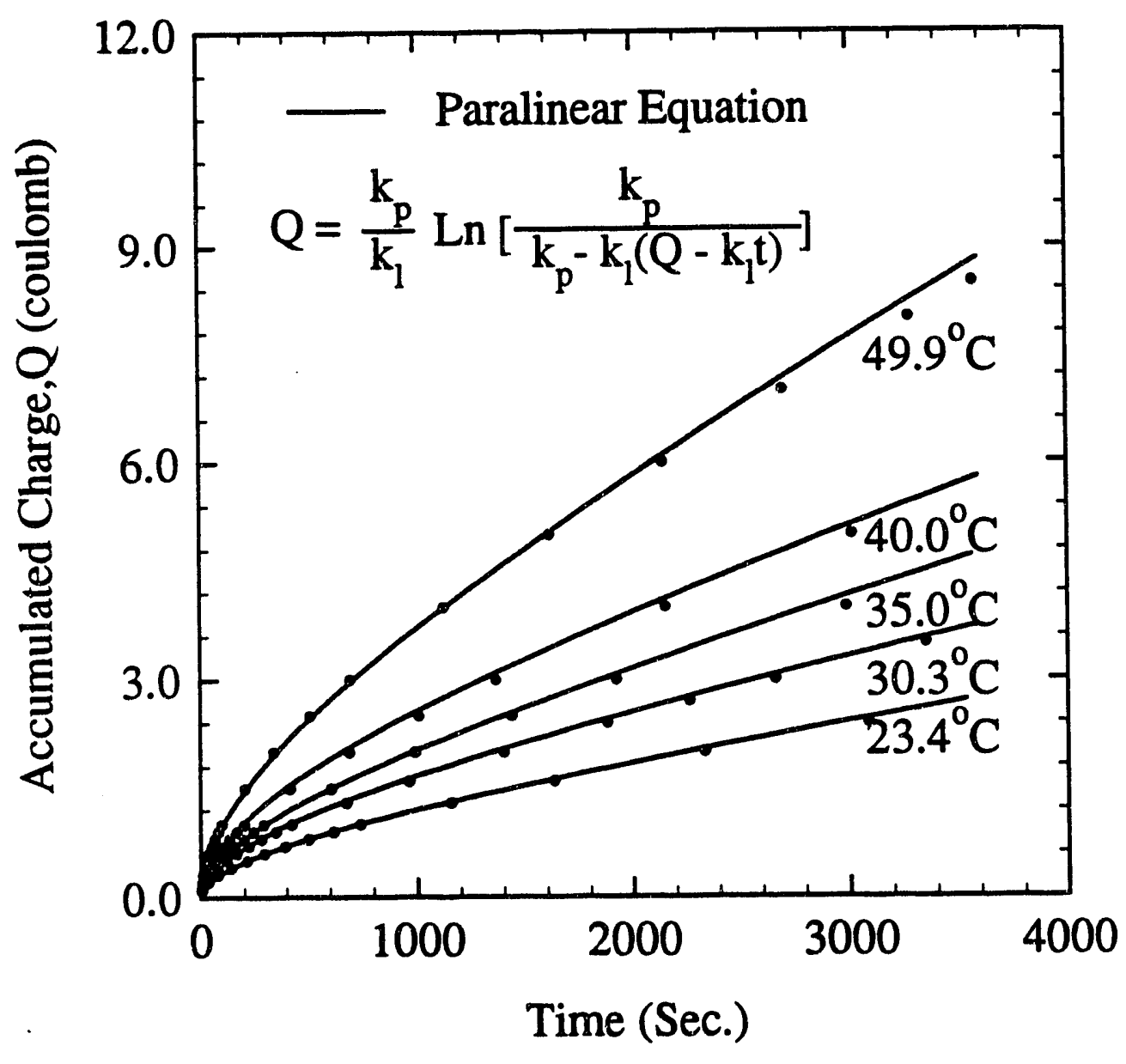

Figure 2.79. Correlation of Calculated Data using $k_{p}, k_{1}$ Estimated from Eqs. $(2.62,2.63)$ with Paralinear Equation for Various Temperatures 


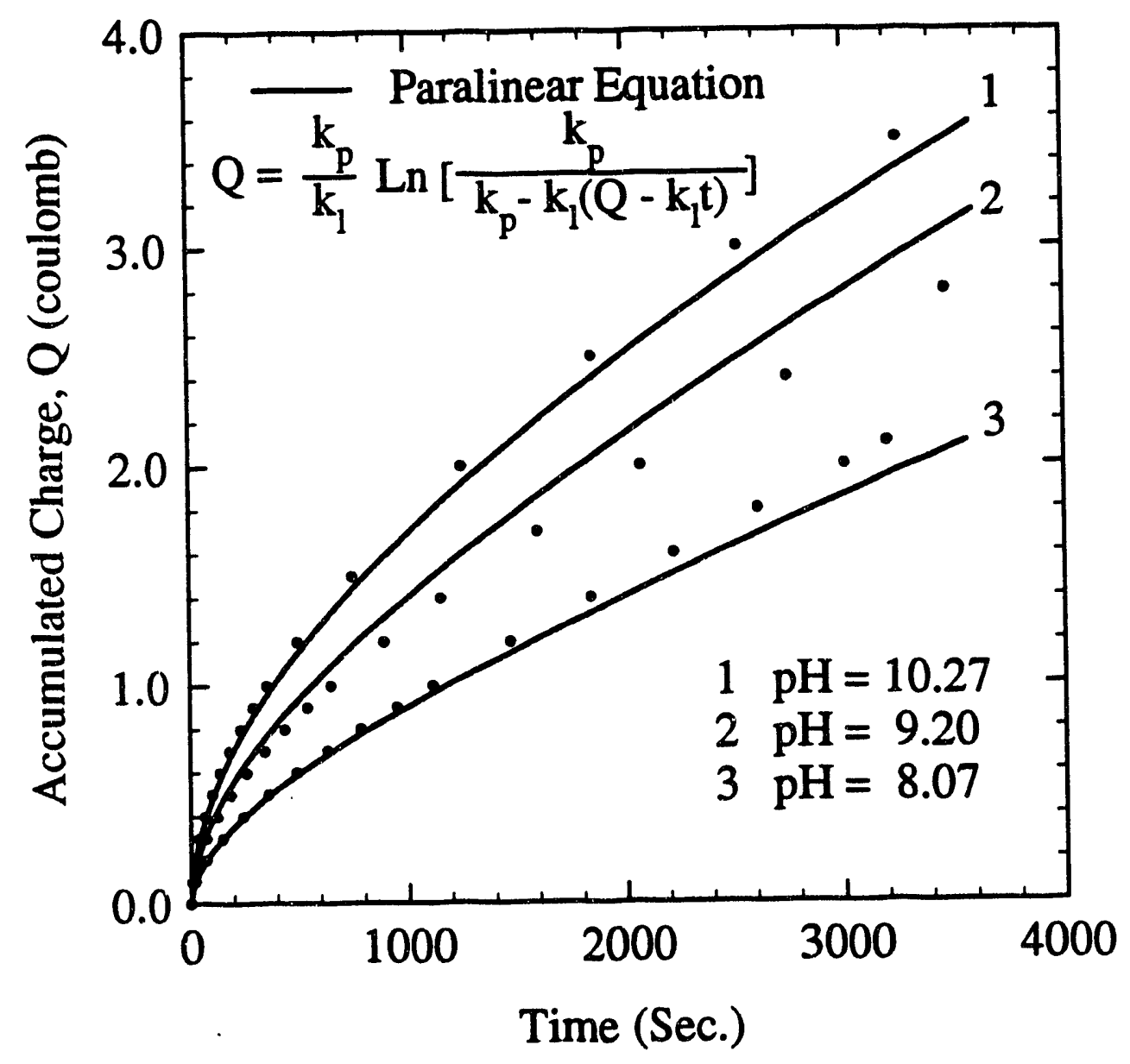

Figure 2.80. Correlation of Calculated Data using $k_{p}, k_{1}$ Estimated from Eqs. $(2.62,2.63)$ with Paralinear Equation for Various pH. 


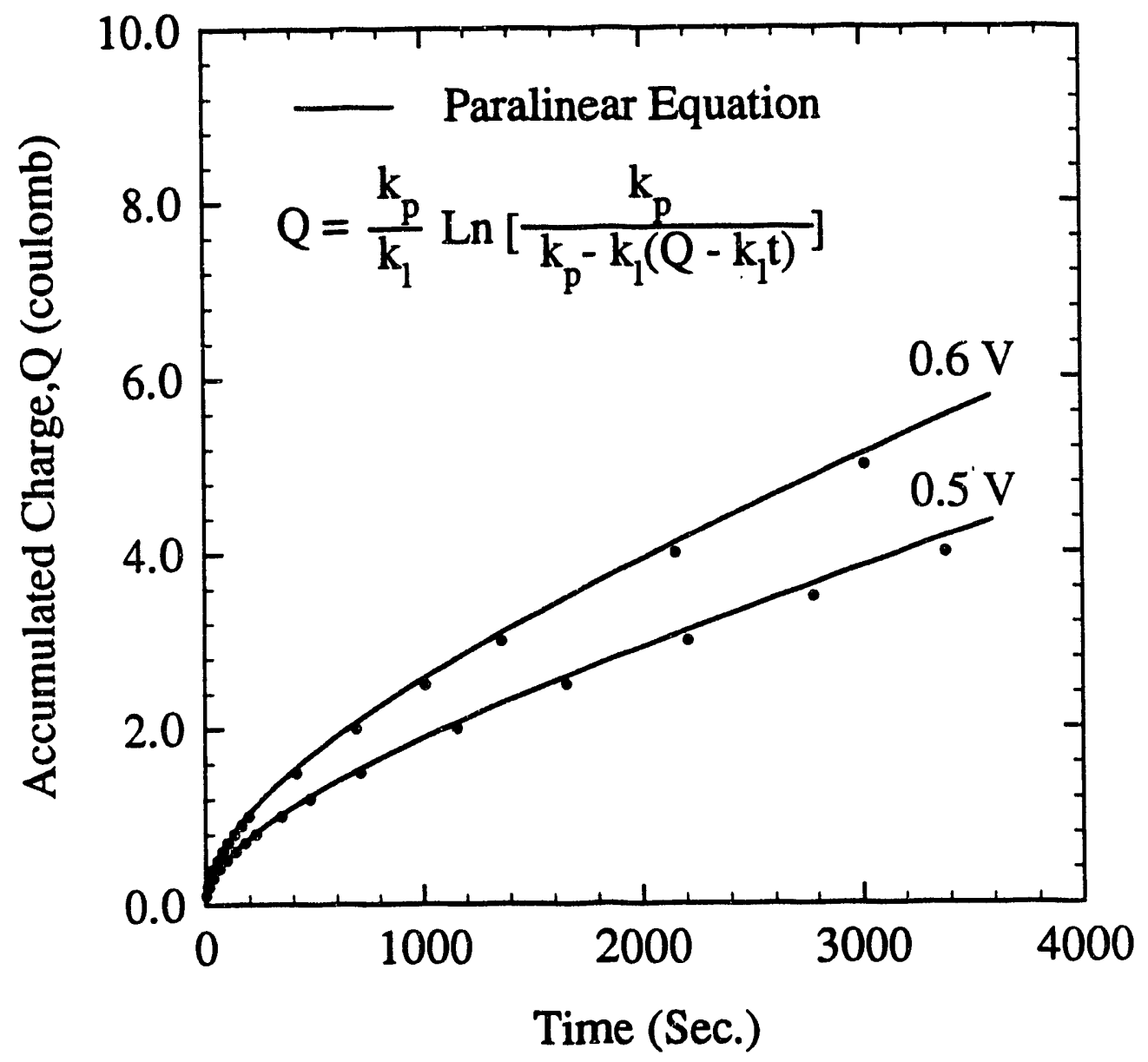

Figure 2.81. Correlation of Calculated Data using $\mathrm{k}_{\mathrm{p}}, \mathrm{k}_{\mathrm{l}}$ Estimated from Eqs. $(2.62,2.63)$ with Paralinear Equation for Various Potentials 
time data using $k_{p}, k_{1}$ estimated from Eqs. $(2.62,2.63)$ with the paralinear equation for various temperatures, electrolyte $\mathrm{pHs}$ and applied potentials respectively.

\section{AC Impedance Measurement}

AC impedance spectroscopy, which measures frequency dispersion, has been recognized as a valuable tool in the study of electrochemical systems. It can provide a wealth of kinetic and mechanistic information. To confirm preceding results from transpassive oxidation and kinetics studies, impedance measurements were performed with rotating disk electrode on the pyrite system under various conditions. The results are shown in the following figures in the Nyquist plot form.

The effect of applied potential on impedance is shown for mineral pyrite and Pittsburgh coal pyrite respectively in Figures 2.82 and 2.83. For both mineral and coal pyrites, the resistances decreased with increased applied potential from $0.4 \mathrm{~V}$ to $0.6 \mathrm{~V}$. The evidence of diffusion control kinetics, indicated by the straight line regions, is consistent with the results from DC measurements. In this potential region sulfur intermediates and surface iron oxides for a diffusion barrier. Figure 2.84 shows results with and without pre-conditioning at $0.4 \mathrm{~V}$. Surface film formation is clearly evident. The resistance increased as expected if the electrode was pre-conditioned at $0.4 \mathrm{~V}$ for 30 minutes. A comparison of impedance measurements for mineral and coal pyrites is shown in Figure 2.85. Under the same conditions, the resistance of mineral pyrite is much greater than that of coal pyrite, and consequently as noted by DC measurements, the current density of mineral pyrite is much smaller than that of coal pyrite.

\section{SUMMARY AND CONCLUSIONS}

The following conclusions can be made on the basis of this investigation.

1. For mineral pyrite, three anodic peaks at about $-0.8 \mathrm{~V},-0.1 \mathrm{~V}$ and $+0.5 \mathrm{~V}$ were detected along with their corresponding reduction peaks. These peaks are proposed to be related to the formation of $\mathrm{Fe}(\mathrm{II}), \mathrm{Fe}(\mathrm{III})$ and $\mathrm{FeS}_{2}$ oxidation respectively.

2. For Pittsburgh and Upper Freeport coal pyrite surfaces, fewer anodic/cathodic 


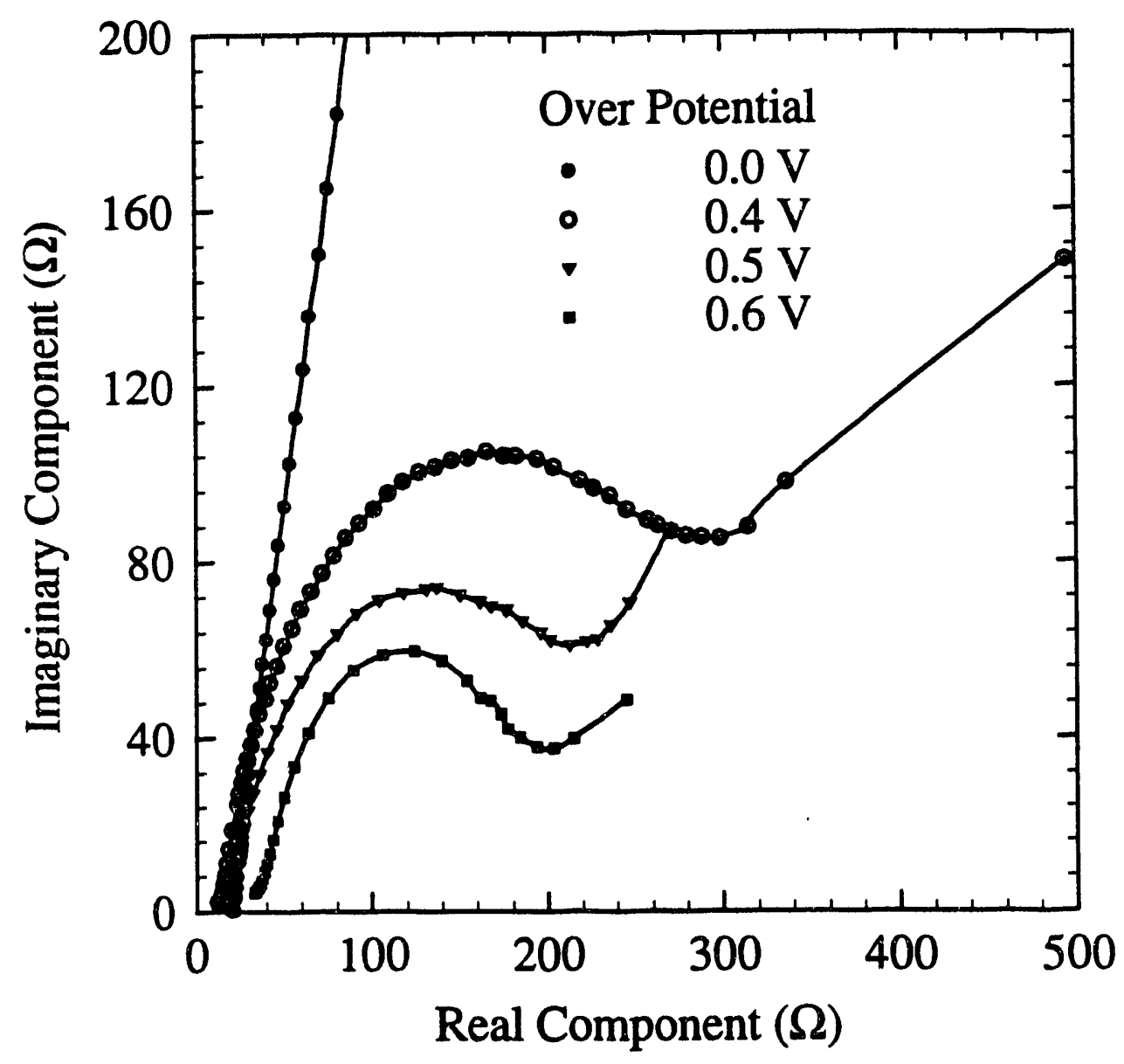

Figure 2.82. Impedance of Mineral Pyrite at Various Potentials in Solutions of $\mathrm{pH} 9.2, \mathrm{rpm}=700$ 


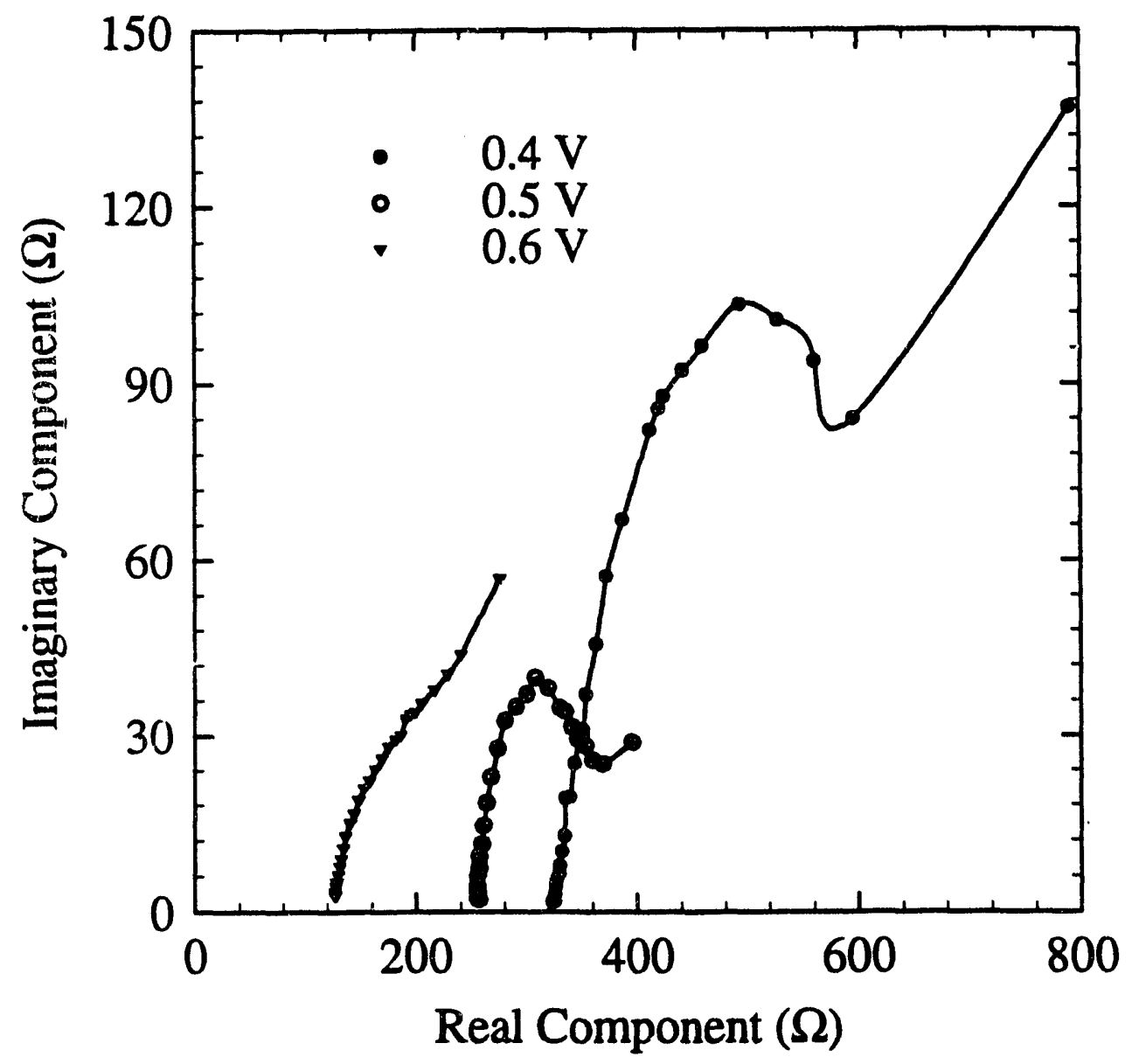

Figure 2.83. Impedance of Pittsburgh Coal Pyrite at Various Potentials in Solutions of $\mathrm{pH} 9.2, \mathrm{rpm}=700$ 


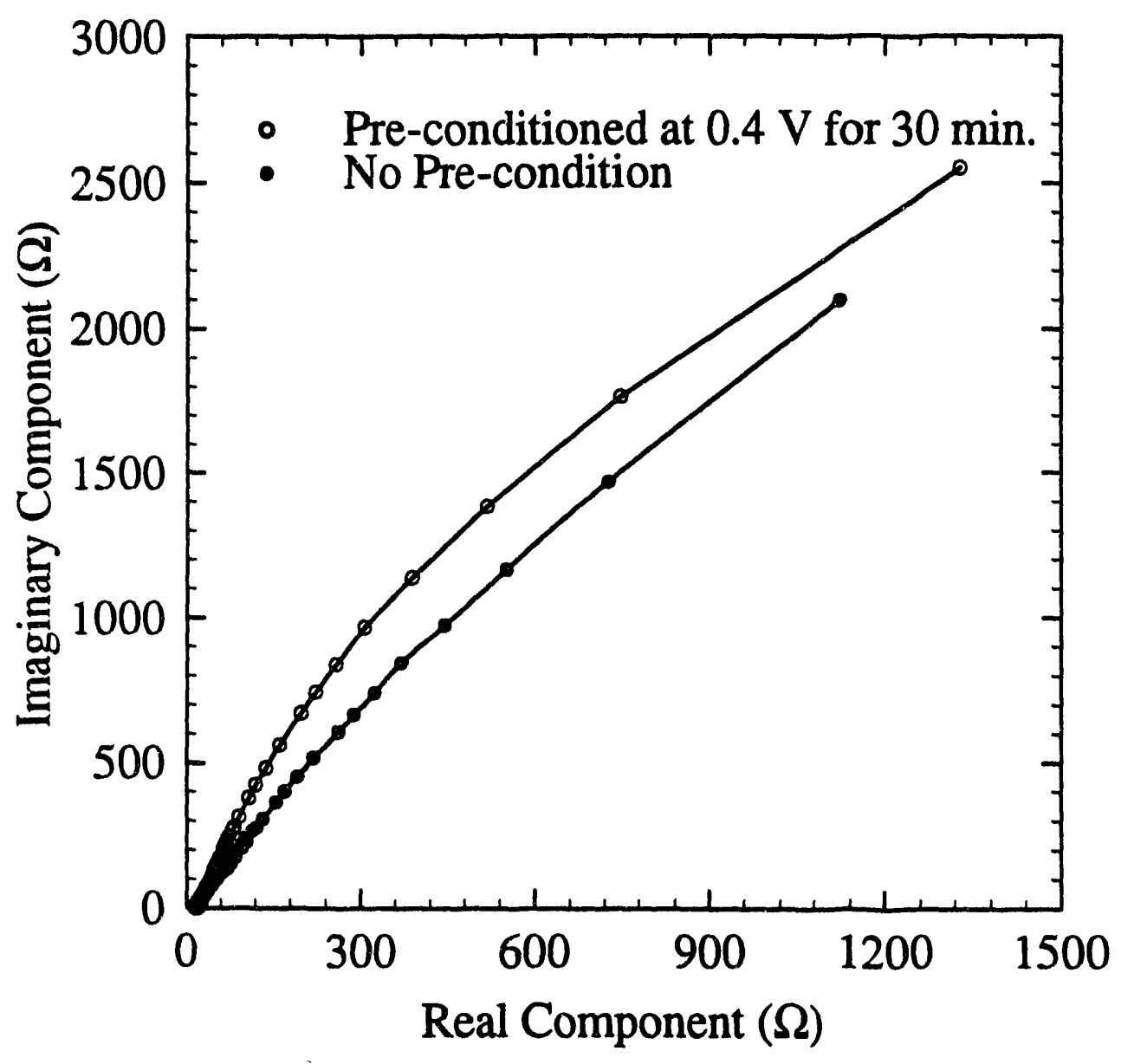

Figure 2.84. Effect of Electrode Pre-condition on Impedance of Mineral Pyrite in Solutions of pH 9.2. at Open Circuit Potential, $\mathrm{rpm}=700$ 


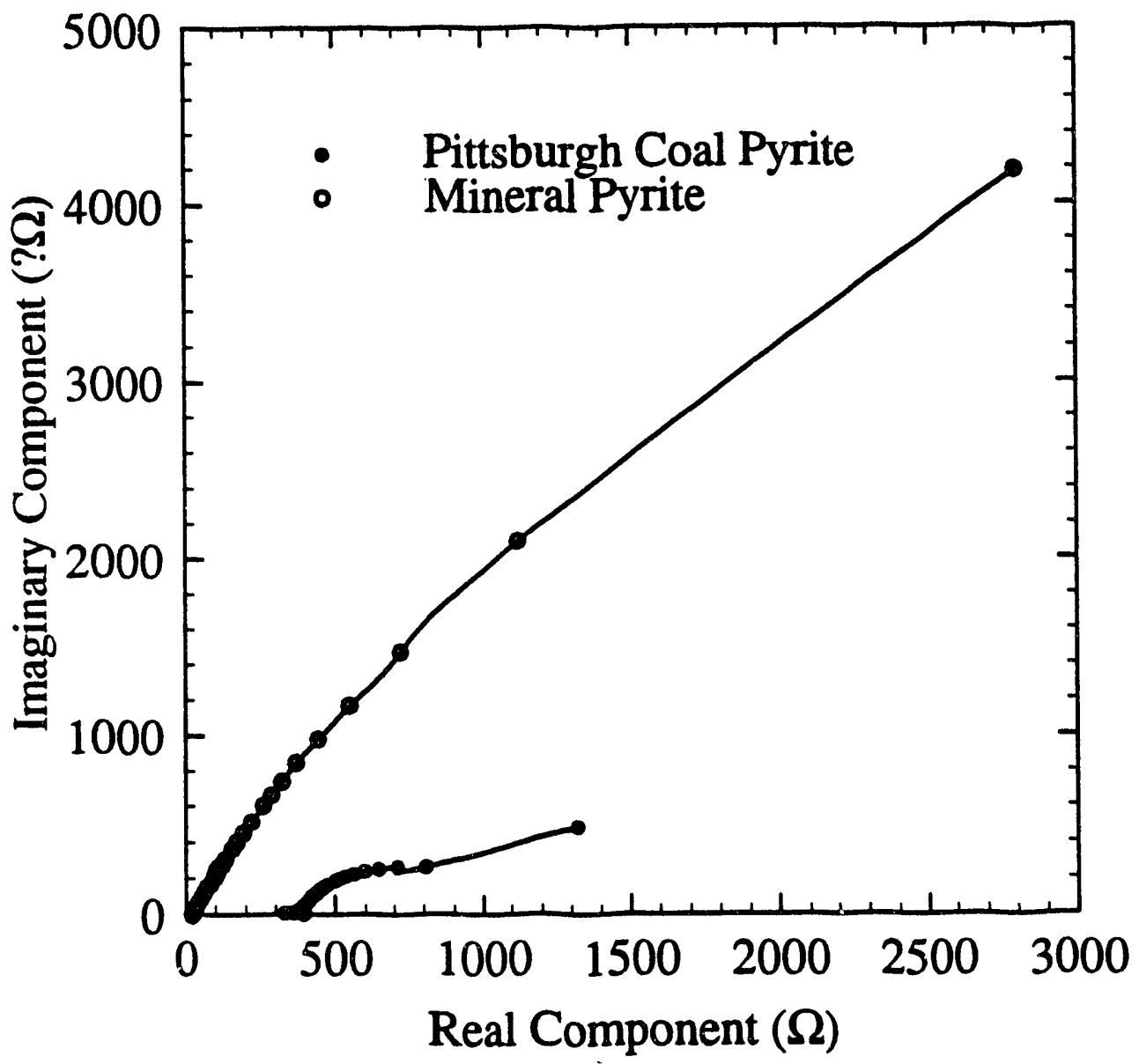

Figure 2.85. Comparison of Impedance of Pittsburgh Coal Pyrite and Mineral Pyrite in Solutions of pH 9.2 at Open Circuit Potential, rpm $=700$ 
conjugated peaks were cbserved for the same conditions. The peaks were broad and much more diffuse than for mineral pyrite. In general, evidence was clear that very similar reactions occur with coal pyrite as with mineral pyrite but at much higher current density. The electrochemical response of Illinois coal pyrite was similar to mineral pyrite, but its current density was close to that of Pittsburgh coal pyrite.

3. Based on current densities, the reactivity sequence is: Upper Freeport coal pyrite $>$ Pittsburgh No.8 coal pyrite $\approx$ Illinois coal pyrite $>$ mineral pyrite.

4. Mineral pyrite is more sensitive to solution $\mathrm{pH}$ and the effect of stirring than were the coal samples examined in this study. For electrolytes with $\mathrm{pH}$ values between 10.5 and 4.6, no significant changes in the oxidation/reduction results were observed. Under more acidic conditions ( $\mathrm{pH} 2.6$ ) cathodic reduction of pyrite becomes a major reaction.

5. In the transpassive region, about 0.4 to $0.8 \mathrm{~V}$ (SCE), aggressive oxidation of pyrite occurred. The reaction products in this region were Fe(III) oxides, sulfate ion and partially oxidized sulfur intermediates. The sulfur intermediates, formed in the transpassive region, affected significantly the subsequent oxidation/reduction reactions occurring in the lower potential region. Exposure of pyrite to anodic potentials higher than the transpassive region resulted in rapid and essentially complete oxidation of sulfur to sulfate ion.

6. The effect of electrode rotation speed, electrode pre-conditioning time and anodic scan reversal potential in the transpassive region was observed to be critical to the formation of sulfur intermediates. This effect was less pronounced for coal pyrite compared to mineral pyrite.

7. Potentiostatic-current decay curves for mineral pyrite, measured in the transpassive region, demonstrated the formation of a protective surface film. This film consists of polysulfides (metal-deficient sulfides) and sulfur plus some iron oxides. Iron oxide was observed to be loose dispersive, and readily removed by agitation. 
8. The rate of transpassive oxidation of mineral pyrite, was well correlated by a paralinear rate equation. The kinetic results are consistent with the formation of an intermediate passive layer by diffusion of charged species, $\mathrm{Fe}^{3+}$ explaining the parabolic kinetic region with a rate constant, $\mathrm{k}_{\mathrm{p}}$. Simultaneous dissolution of the outer layer of the film, resulting from sulfur and polysulfides oxidation to sulfate ions explains the linear kinetic region with a rate constant, $\mathbf{k}_{\mathbf{1}}$.

9. Reaction rates in both the parabolic and linear kinetics regions were affected by applied potential and solution temperature. Increases in both potential or temperature increased the reaction rate. The activation energies were found to be $66.17 \mathrm{~kJ} / \mathrm{mole}(15.83 \mathrm{kcal} / \mathrm{mole})$ at $0.6 \mathrm{~V}$ and $68.34 \mathrm{~kJ} / \mathrm{mole}(16.35$ $\mathrm{kcal} / \mathrm{mole})$ at $0.5 \mathrm{~V}$ for the parabolic rate process and $38.67 \mathrm{~kJ} / \mathrm{mole}(9.25$ $\mathrm{kcal} / \mathrm{mole})$ at $0.6 \mathrm{~V}$ and $43.10 \mathrm{~kJ} / \mathrm{mole}(10.31 \mathrm{kcal} / \mathrm{mole})$ at $0.5 \mathrm{~V}$ for the linear rate process, in the temperature range $23.4^{\circ} \mathrm{C}$ to $59.5^{\circ} \mathrm{C}$.

10. Reaction rates were independent of electrode rotation speed. The solution $\mathrm{pH}$ affected the parabolic reaction rate significantly, increasing with increasing solution $\mathrm{pH}$. The linear rate constant was $\mathrm{pH}$ independent.

11. AC impedance measurements agree well with the results of DC measurements and confirmed surface film formation as pyrite is oxidized in the transpassive region.

\section{REFERENCES}

[2.1] I.C. Hamilton and R. Woods, "An Investigation of Surface Oxidation of Pyrite and Pyrrhotite by Linear Potential Sweep Voltammetry," J. Electroanal. Chem., 118, (1981), 327.

[2.2] N.D. Janetski, S.I. Woodburn, and R. Woods, "An Electrochemical Investigation of Pyrite Flotation and Depression," Int. J. Min. Proc., 4, (1977), 227.

[2.3] S. Chander and A. Briceno, "Kinetics of Pyrite Oxidation," Minerals Metal. Proc., 8, (1987), 171. 
[2.4] T.C. Franklin, R. Nnodimele and W.K. Andeniyi, "The Anodic Oxidation of Iron Pyrite Powder in a cationic Surfactant-Styrene-Aqueous Sodium Hydroxide Emulsion," J. Electrochem. Soc., 134(9) (1987), 2150.

[2.5] E. Ahlberg, K.S.E. Forssberg and X. Wang, "The Surface Oxidation of Pyrite in Alkaline Solution," J. Appl. Electrochem., 20, (1990), 1033.

[2.6] T. Chmielewski and T.D. Wheelock, "Some Electrochemical Aspect of Pyrite Hydrophobicity - Investigations on Cleaved Electrodes," J. Mining \& Metall., 26, (1990), 133.

[2.7] J.R. Mycroft et al., "Detection of Sulfur and Polysulfides on Electrochemically Oxidized Pyrite Surfaces by X-ray Photoelectron Spectroscopy and Raman Spectroscopy," J. Electroanal. Chem., 292, (1990), 139.

[2.8] R.D. Armstrong and A.C. Coates, "The Passivation of Iron in Carbonate/Bicarbonate Solutions," J. Electroanal. Chem., 50(1974), 303.

[2.9] C.M. Rangel and R.A. Leitao, "Voltammetric Studies of the Transpassive Dissolution of Mild Steel in Carbonate/Bicarbonate solutions," Electrochim. Acta., 34(2) (1989), 255.

[2.10] C.M. Rangel, I.R. Fonseca and R.A. Leitao, "Some Aspect of the Electrochemical Behavior of Mild Steel in Carbonate/Bicarbonate Solutions," ibid, 31(12) (1986), 1659.

[2.11] R. Beck, R. Kaus and M. Oberst, "Transpassive Dissolution of Iron to Ferrate(VI) in Concerntrated Alkali Hydroxide Snlutions," ibid, 30(2) (1985), 173.

[2.12] C.R. Valentini and C.A. Moina,"The Electrochemical Behavior of Iron in Stagnant and Stirred Potassium Carbonate-Bicarbonate Solutions in the $0-75^{\circ} \mathrm{C}$ Temperature Range," Corros. Sci., 25(11) (1985), 985.

[2.13] E.B. Castro et al., "The Influence of Ionic Composition on the Electrodissolution and Passivation of Iron Electrodes in Potassium Carbonate-Bicarbonate Solutions in the 8.4-10.5 pH Range at $25^{\circ} \mathrm{C}$." ibid, 26(10) (1986), 781.

[2.14] S.P. Burke and R. Downs, "Oxidation of Pyritic Sulfur in Coal Mines," Trans. AIME, 130 (1938), 425. 
[2.15] R.W. Lai et al., "Comparative Study of the Surface Properties and the Reactivity of Coal Pyrite and Mineral pyrite," Preprint, SEM Annual Meeting, Las Vegas, NV, Preprint number 89-6 (1989).

[2.16] A. Briceno and S. Chander, "An Electrochemical Characterization of Pyrites from Coal and Ore Sources," Int. J. Min. Proc., 24 (1988), 73.

[2.17] R.M. Garrels and C.L. Christ, Solutions, Minerals and Equilibria, (San Francisco, CA: Freeman, Cooper and company, 1965), 183,221.

[2.18] G. Milazzo and S. Caroli, Tables of Standard Electrode Potentials, (New York, NY: Wiley 1978), 320.

[2.19] A.S. Arico et al., "A Voltammetric Study of the Electrodeposition Chemistry in the Fe-S System," Electrochimica Acta, 36 (1991), 581.

[2.20] F.A. Cotton and L. Wilkinson, in "Advanced Inorganic Chemistry," P. 431;452, John Wiley and Sons Interscience Publishers, (1972).

[2.21] J.H. Ahn and M.E. Wadsworth, "The Electrochemical Reaction Kinetics of Molybdenite in Aqueous Acid Solution," Proceedings of the International Symposium on Electrochemistry in Mineral and Metal Processing II, ed. P.E. Richardson and R. Woods (Pennington, NJ: The Electrochemical Society, Inc. 1988), 280. 


\section{IN-SITU SPECTROSCOPIC CHARACTERIZATION OF ELECTROCHEMICALLY MODIFIED PYRITE}

\section{INTRODUCTION}

Iron pyrite is a common constituent of coal and its presence during combustion leads to the production of sulfur dioxide and acid rain. Consequently, there is great interest in and support for research dedicated to improving the methods of separating pyrite from coal.

One of the principal methods of separation is froth flotation. Under suitable conditions the sulfide minerals are sufficiently hydrophobic that their floatability is greatly enhanced. Many studies have attributed this to the formation of elemental sulfur on the surface of the sulfide minerals. In some studies, sulfur has been dissolved from the mineral surface using carbon disulfide and the presence of sulfur detected using calorimetric techniques [3.1]. Electrochemical studies using cyclic voltammetry have suggested that sulfur may be formed by the direct oxidation of pyrite to sulfur [3.2]:

$$
\mathrm{FeS}_{2}+3 \mathrm{H}_{2} \mathrm{O}=\mathrm{Fe}(\mathrm{OH})_{3}+2 \mathrm{~S}^{\circ}+3 \mathrm{H}^{+}+3 e^{-}
$$

Alternatively, the floatability of sulfide minerals may be depressed by forming a hydrophilic surface. At high anodic potentials the sulfide surface can be oxidized to sulfates and metal hydroxides (which are hydrophilic in nature) by the following reaction [3.2]:

$$
\mathrm{FeS}_{2}+11 \mathrm{H}_{2} \mathrm{O}=\mathrm{Fe}(\mathrm{OH})_{3}+2 \mathrm{SO}_{4}^{2-}+19 \mathrm{H}^{+}+15 \mathrm{e}^{-}
$$

ESCA studies have been carried out to directly confirm the presence of sulfur on the surface [3.3]. However, the results have not been conclusive. The primary disadvantage with ESCA is that it is an ex-situ technique and requires that the sulfide mineral be removed from solution and placed in a vacuum. This loss of electrochemical potential control can severely modify the surface. The use of a cold stage has proven necessary to prevent the sublimation of the elemental sulfur in the vacuum. 
The floatability of pyrite has been investigated using micro-floatation cells in which the pyrite can be electrochemically modified [3.4]. This is the most direct way to investigate whether the electrochemical formation of sulfur films can enhance the hydrophobicity of the surface of sulfide minerals. However, cyclic voltammograms of particulate pyrite are not identical to those obtained from single specimens which have been mounted and polished [3.5]. The peaks from particulate pyrite are shifted in a way which is suggestive of the presence of resistive potential drops in the particulate bed. The resistance may be attributable to oxidation products on the surface of the pyrite produced during grinding or during electrochemical pretreatment. It is difficult to interpret these voltammograms and establish whether the pyrite has been conditioned at a potential suitable for the growth of a hydrophobic sulfur layer.

Preliminary experiments using micro-flotation cells revealed little or no increase in floatability over a range of preconditioning potentials and $\mathrm{pH}$. The lack of success may be attributable to the inability to polarize the pyrite at the correct potential to develop the desired hydrophobic surface. One of the objects for developing Raman spectroelectrochemistry was to observe directly the electrochemical formation of sulfur with an in-situ spectroscopic method. The method has been developed using large single specimens of pyrite to characterize the surface and obtain Raman spectra in the absence of resistive potential drops. Subsequently, the technique has been used to study the surface chemistry in a modified electrochemical micro-floatation cell equipped with an optical window to allow observation of the particulate pyrite.

Recent developments in instrumentation have made it possible to conduct in-situ studies of surface electrochemistry. In particular, there has been much work using infrared spectroscopy in conjunction with Fourier transform techniques. However, there are some serious disadvantages with in-situ infrared spectroscopy techniques. The aqueous medium used in most hydrometallurgical studies is highly absorbing in the important region of the infrared spectrum. This requires the mineral surface to be extremely close to the observation window to minimize the attenuation. As a consequence, the geometry of the electrochemical cell is highly compromised. There is an uneven current distribution in the vicinity of the specimen and a large ohmic resistance causing a loss of potential control. 
Raman spectroscopy offers a solution to some of the problems associated with insitu infrared spectroscopy. The ability to obtain spectra using visible light eliminates the constraints on cell design posed by infrared spectroscopy. The experimental arrangement is greatly simplified and electrochemical studies are free from the complications of ohmic potential drop. The relatively small size of the Raman effect has hindered its use in in-situ electrochemical studies. However, the development of lasers and highly sensitive CCD arrays has increased the magnitude of the Raman signal to the point that it can now be successfully used in in-situ electrochemical studies [3.6, 3.7]. Mycroft et al. have recently reported preliminary studies on mineral pyrite using Raman spectroscopy [3.8]. Campion has demonstrated that it is possible to obtain Raman spectra from monolayers of adsorbed material under suitable conditions [3.9]. Other improvements such as resonant Raman and SERS (Surface Enhanced Raman Scattering) have also increased the sensitivity of Raman spectroscopy to the point that in-situ studies are feasible [3.10, 3.11]. Raman studies have also recently been performed on metal surfaces in-situ. Of particular interest are studies of the corrosion of iron based alloys [3.12].

Photocurrent measurement is a well established and powerful method of studying the electronic properties of surface films [3.13-3.16]. In particular, it provides detailed information concerning the electronic properties and structure of the surface. It is simple to carry out photocurrent and Raman spectroscopy simultaneously at a surface as the basic equipment required for them is almost identical. There have been some studies of the photoelectrochemistry of pyrite [3.17-3.20]. However, these studies have mainly concentrated on the semiconducting properties of bulk pyrite and little attention was paid to the existence and nature of surface films. In particular, little work has been done to characterize the oxidation products of pyrite. In studies of this kind, careful attention must be paid to making good ohmic contacts to the metal sulfides as the metal-semiconductor contact is akin to a Schottky barrier and can have appreciable resistance [3.21].

In this part of the study, Raman spectroscopy was the main tool for the investigation. The object was to characterize the surfaces of various pyrite samples modified electrochemically in solutions of different $\mathrm{pH}$ values. Preliminary photoelectrochemistry experiments were also conducted on pyrite samples. 


\section{EXPERIMENTAL}

\section{Outline of the Experimental Work}

A cell was specially designed to study the surface of pyrite with Raman spectroscopy during the course of an electrochemical experiment. These studies were carried out to provide additional information to aid in the analysis of previously reported cyclic voltammetric experiments.

Initial experiments used large single specimens of mineral pyrite to characterize the surface during cyclic voltammetric experiments under ideal electrochemical conditions with negligible resistive potential drop. Raman spectra were obtained at potentials of interest over the potential range covered during the cyclic voltammetry experiments. Four pH values have been investigated, 2.7 (acid), 6.5 (neutral), 9.2 (weak alkaline) and 12.5 (strong alkaline). In each case the electrolyte was $0.5 \mathrm{M} \mathrm{NaCl}$. This solution was selected as the ions gave the least interference with the Raman spectra. Anions such as sulfate (also borate, silicate, carbonate and nitrate) have Raman peaks in potential regions of interest $\left(1000 \mathrm{~cm}^{-1}\right)$.

As an aid to the interpretation of the pyrite electrochemistry, an attempt was made to establish a set of suitable Raman reference spectra. In particular, a study was made of the electrodeposition of sulfur onto platinum from sulfide solutions. It was hoped that sulfur formed by this method would be similar in both character and mode of formation to sulfur films on metal sulfides.

Raman spectra were also taken from a wide range of metal sulfides to help identify the products of the electrochemical oxidation and reduction of the pyrite. Some specimens of naturally occurring iron oxides were obtained and characterized. However, most of these minerals are partially hydrated and crystalline and may not be typical of the iron oxides formed in solution on the surface of the pyrite. Ferrous and ferric hydroxides were synthesized by precipitation from saturated solutions. It was hoped that these extensively hydrated and non-crystalline materials would be more representative of the products of the aqueous oxidation of pyrice.

The equipment already in place for the Raman experiments also permitted the characterization of the photoelectrochemical behavior of the surface films. The results 
presented here are preliminary and demonstrate the potential of the technique. The photocurrents were measured at one incident wavelength during the course of cyclic voltammetry experiments.

\section{Equipment and Procedures for Raman Experiments}

The spectroelectrochemical cell designed for this study is shown in Figure 3.1. The main sample was a piece of mineral pyrite (Wards) which was glued with epoxy resin into the plunger of a ground glass syringe. Electrical contact to the pyrite was made with silver impregnated epoxy resin. The barrel of the syringe was connected to the rear of the cell opposite a quartz window. This arrangement enabled the distance between the sample and the window to be accurately controlled. A similar electrode was made using a disc of platinum ( $5 \mathrm{~mm}$ diameter) instead of pyrite. Provision was also made for a spiral platinum wire counter electrode and a saturated calomel reference electrode. A Luggin capillary was placed as close to the observation window as possible to minimize any resistance drop. Prior to the experiments, the pyrite surface was polished with 400 grit sand paper and $0.3 \mathrm{~mm}$ alumina and washed in deionized water.

A schematic diagram of the Raman spectrometer is shown in Figure 3.2. The laser line used in this work was from an Argon ion laser (Spectra Physics) at $514.5 \mathrm{~nm}$ and the incident power was set at $20-50 \mathrm{~mW}$. The cell was arranged such that the incident laser light was at a grazing angle of approximately 70 degrees to the sample. The collection lens was placed normal to the sample to minimize the collection of light from the incident laser beam. The distance between the sample and the window was kept less than $2 \mathrm{~mm}$. The laser beam was focussed to a spot of approximately $150 \mu \mathrm{m}$ in diameter. In addition there was scattered light from the window which enlarged the probed area to an uncertain extent. The optics of the spectrometer required a narrow focused beam and hence there was a very small area of the specimen that was probed during each experiment. It was possible to achieve a certain degree of spatial resolution by using a cylindrical lens and the spatial second dimension of the CCD array. Alternatively, selected areas could be individually probed in conjunction with an optical microscope.

The spectrometer (Spex Triplemate 1877) consisted of a triple spectrograph and 


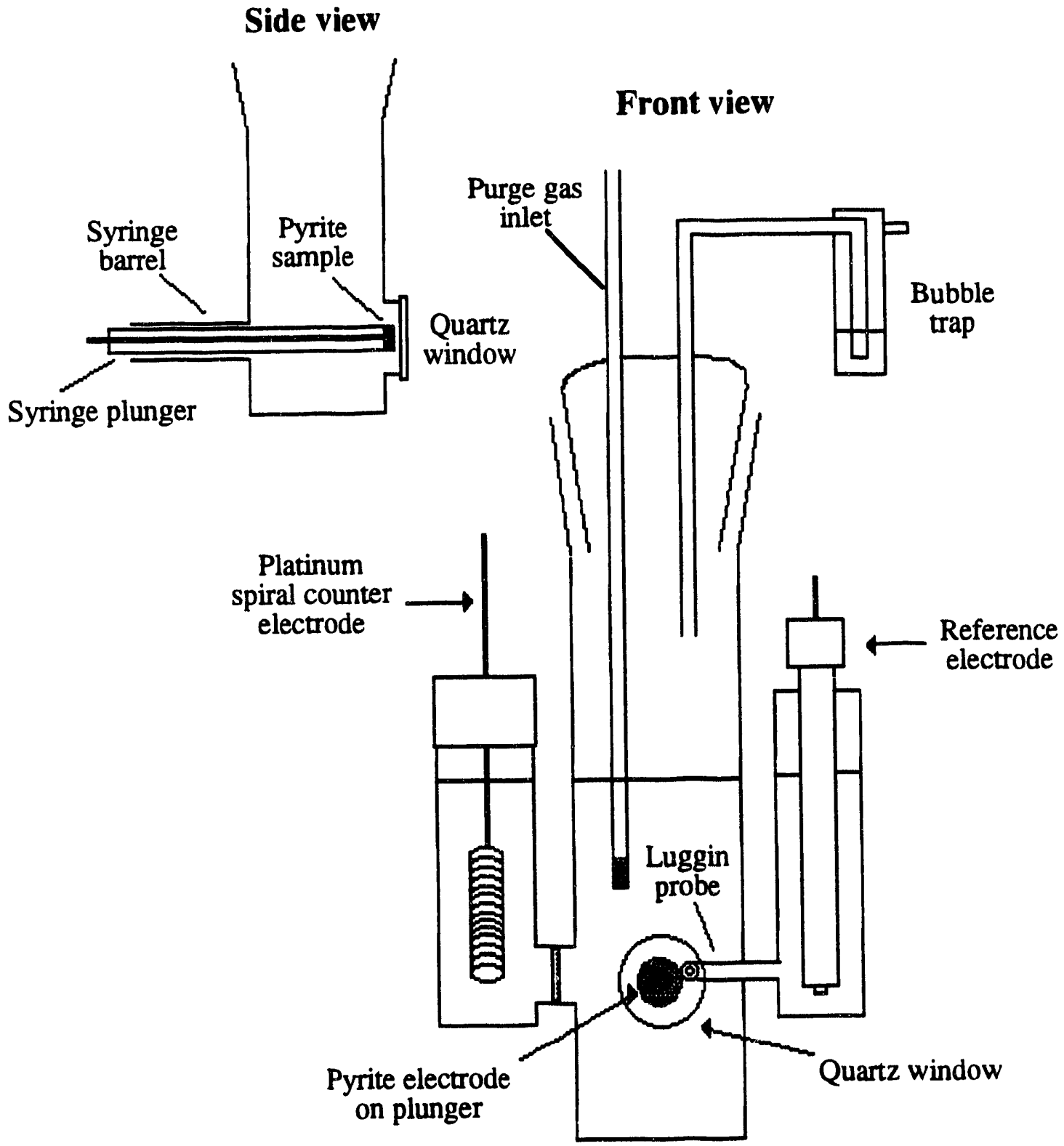

Figure 3.1. Electrochemical cell for Raman and photocurrent experiments. 


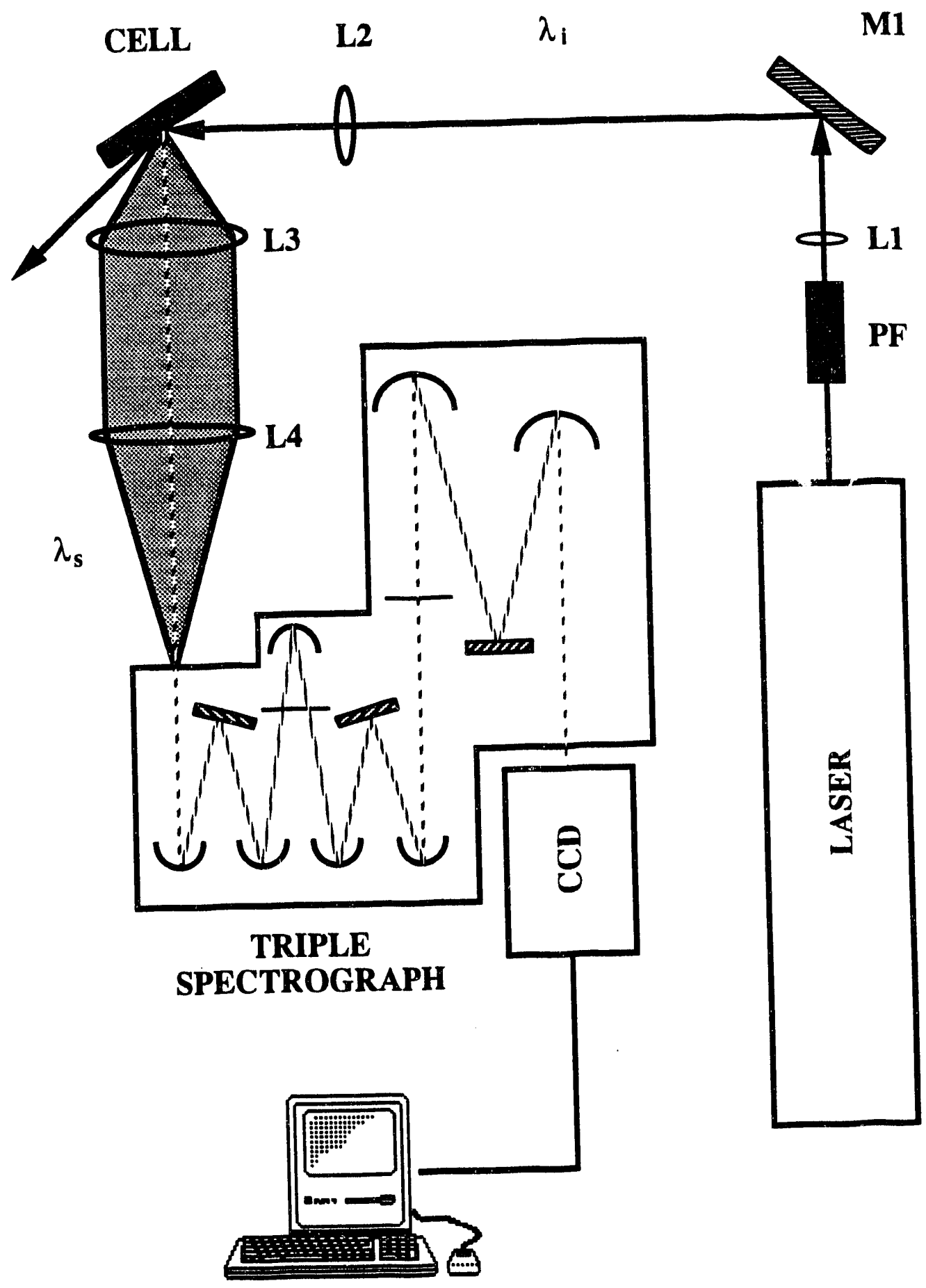

Figure 3.2. Schematic diagram of apparatus used for Raman spectroscopy. L1-LA are lenses, M1 is a mirror, and PF a plasma line filter. 
a two-dimension CCD array (Photometrics). Two CCD arrays were used. One had 576 by 354 pixels and the binning was set at 24 by 2 while another had 512 by 512 pixels with the binning at 32 by 2 . In this work the gratings were 1200 grooves $/ \mathrm{mm}$ and the final slit width was $100 \mathrm{~mm}$.

In early experiments a fixed amount of charge was passed through the cell with the laser beam not directed onto the specimen. After conditioning, the electrode was made open circuit, the laser beam was directed onto the surface and the Raman spectrum was measured immediately. However, problems were experienced with this method. The films dissolyed or were modified when potential control was lost. In all subsequent experiments the potential was continuously applied and the laser beam was incident on the surface during the entire experiment. Spectra were taken after various intervals of time. These results illustrate the added importance of an in-situ method which can obtain spectra while the specimen voltage is closely controlled.

The solutions used contained $0.5 \mathrm{M} \mathrm{NaCl}$ as the electrolyte. The acid solution was prepared by the addition of concentrated $\mathrm{HCl}$ to attain a $\mathrm{pH}$ of about 2.7. The alkaline solutions ( $\mathrm{pH} 9.2$ and 12.5) were prepared in a similar fashion by the addition of concentrated sodium hydroxide.

The position of the Raman peaks was calibrated by a combination of two methods. A reference spectrum of tungsten oxide was taken under identical equipment settings. The peaks of the various tungsten oxides are well characterized and were used as a standard. In addition there are good fundamental studies available in the literature which provide exact identification for the major peaks for pyrite and elemental sulfur [3.22, 3.23].

\section{Experiments to Obtain Reference Spectra}

A Raman spectrum in air was made from sublimed elemental sulfur obtained from Aldrich (purity above 99.9999\%). The sulfur was held between two glass slides. Sulfur was also electrodeposited onto a platinum electrode from a solution of about $0.001 \mathrm{M}$ sodium sulfide in $0.5 \mathrm{M} \mathrm{NaCl}$.

Reference spectra of ferric and ferrous hydroxide were taken from samples prepared by precipitation from a solution of ferric and ferrous chloride by the addition of 
sodium hydroxide. The precipitates were washed with deionized water and then placed between glass slides. No attempt was made to dry the precipitates and they were examined immediately after being made.

\section{Equipment and Procedures for Photocurrent Experiments}

The electrochemical cell for photocurrent spectroscopy was identical to that used in the Raman experiments. A laser beam was directed onto the surface of the working electrode (incident angle is unimportant). It was modulated at a fixed frequency with a mechanical chopper or eletroacoustic modulator. The specimen was potentiostated at either a fixed potential or the potential was slowly scanned as in cyclic voltammetry. A voltage signal, proportional to the electrochemical current, was fed to a lock-in amplifier. This signal was compared to a reference signal produced by the modulator which was synchronous with the light pulses. The lock-in amplifier was programmed to detect current pulses in phase with the reference signal producing an output signal whose magnitude was proportional to the size of the in-phase photocurrent. The in-phase photocurrent signal was sent to the $\mathrm{Y}$ axis of a chart recorder and was recorded as a function of the applied potential ( $\mathrm{X}$ axis). In addition, an oscilloscope directly monitored the electrochemical current to record to shape of the photocurrent pulse produced by the chopped laser beam. A schematic diagram of the equipment is shown in Figure 3.3.

The photocurrent was measured over a wide potential range as used in the cyclic voltammetry experiments using one wavelength of light $(514.5 \mathrm{~nm})$. Additional information can be obtained at a single potential by scanning with incident light of variable frequency. This could be achieved using white light source and monochromator.

\section{Particle Bed Experiments}

The original objective of this work was to develop an in-situ tool to determine whether electrochemical modification was able to create a sulfur rich, hydrophobic surface on mineral and coal pyrite. It was hoped to extend this work to a particulate bed of pyrite. The existence of electrical resistance between the particles and in the solution due to a poor current distribution can greatly affect the electrochemistry. The potential of the pyrite 


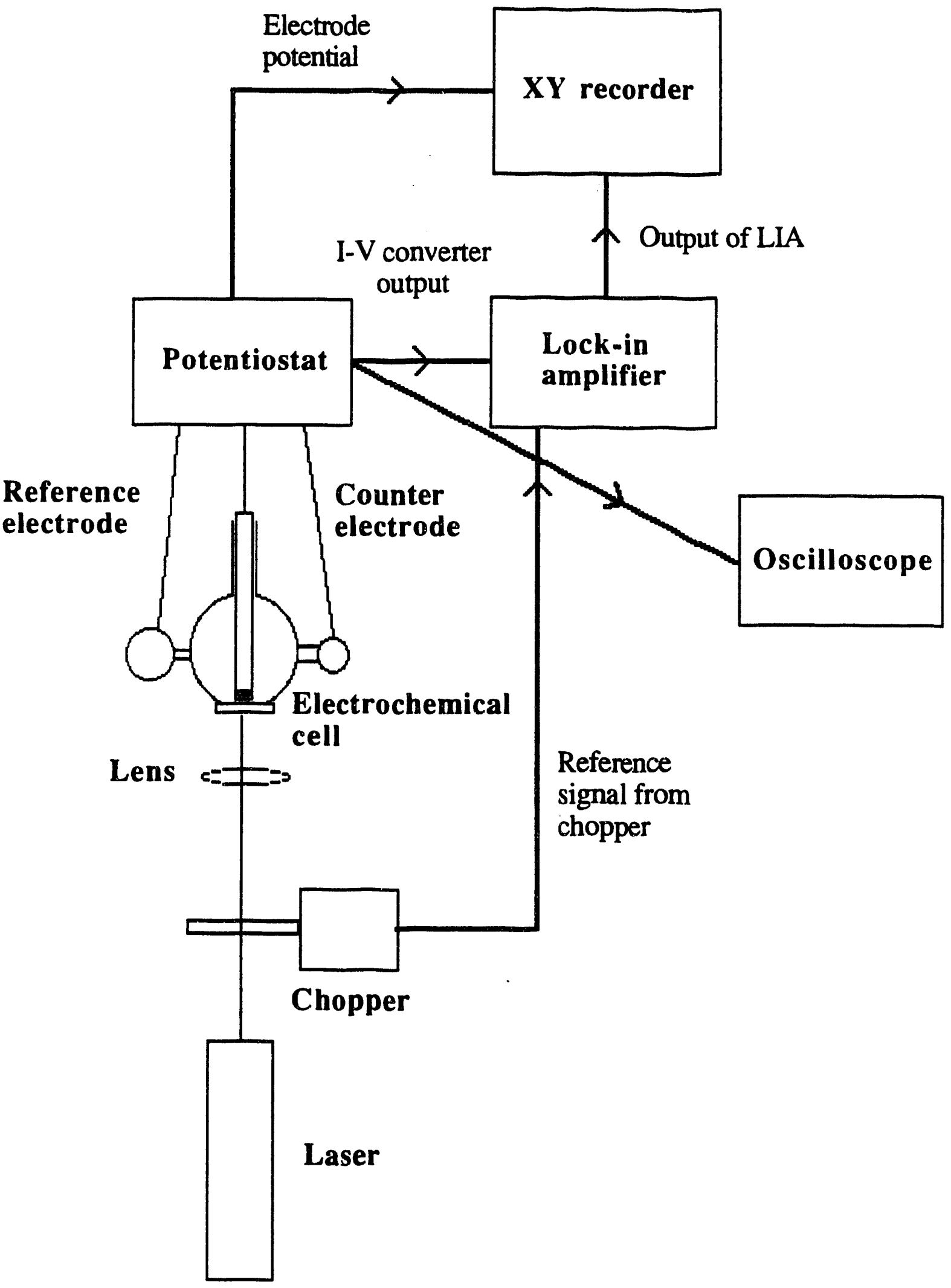

Figure 3.3. Apparatus used for photocurrent spectroscopy. 
bed may not be at the desired potential to produce sulfur.

Some preliminary experiments were carried out to determine whether sulfur could be detected on an electrochemically modified bed electrode. Mineral pyrite (75-106 $\mu \mathrm{m})$ was placed in the spectroelectrochemical cell and electrical contact was made with a piece of platinum mesh. The bed was polarized at several potentials at which sulfur was detected on single piece macro-electrodes. The laser beam was focused onto the pyrite through the optical window and the Raman spectra measured in an identical manner.

\section{RESULTS AND DISCUSSION}

\section{Reference Spectra}

Raman Spectra of Pyrite. The Raman spectrum of mineral pyrite at its open circuit potential in a solution of $0.5 \mathrm{M} \mathrm{NaCl}$ is shown in Figure 3.4. The rising background at lower wave numbers is due to solution fluorescence or enhanced collection of Rayleigh elastically scattered light. There are two distinct peaks at about 345 and $380 \mathrm{~cm}^{-1}$. This spectrum is very similar to those reported in other work. A third peak is observed at about $430 \mathrm{~cm}^{-1}$ but is much weaker than either of the other two. The spectrum of pyrite obtained in this study was similar to that observed by Vogt et al. [3.22] and Ushioda [3.24]. The two large peaks are located at 343 and $379 \mathrm{~cm}^{-1}$ respectively. The peak at $379 \mathrm{~cm}^{-1}$ is for stretching vibrations of the $S_{2}$ dumb-bells in phase throughout the crystal. The peat at 343 $\mathrm{cm}^{-1}$ results from displacement of the $S$ atoms perpendicular to the dumb-bell axis. 'The smaller feature at $430 \mathrm{~cm}^{-1}$ is a combination of various stretching and vibrational motions and is weaker than either of the fundamental modes. The spectrum was obtained with an integration time of 100 seconds.

Raman Spectra of Elemental Sulfur. The spectra of pure elemental sulfur, taken in air, are shown in Figures 3.5 and 3.6. The peaks present are in good agreement with previously published studies. In particular the paper of Harvey and Butler [3.23] is important as it presents a detailed description of the origin of the peaks in the sulfur spectrum. The fundamental vibrations are very strong. There are two fundamental vibration modes for elemental sulfur. The $S-S$ stretch produces a Raman peak at $470 \mathrm{~cm}^{-1}$. Two strong peaks 


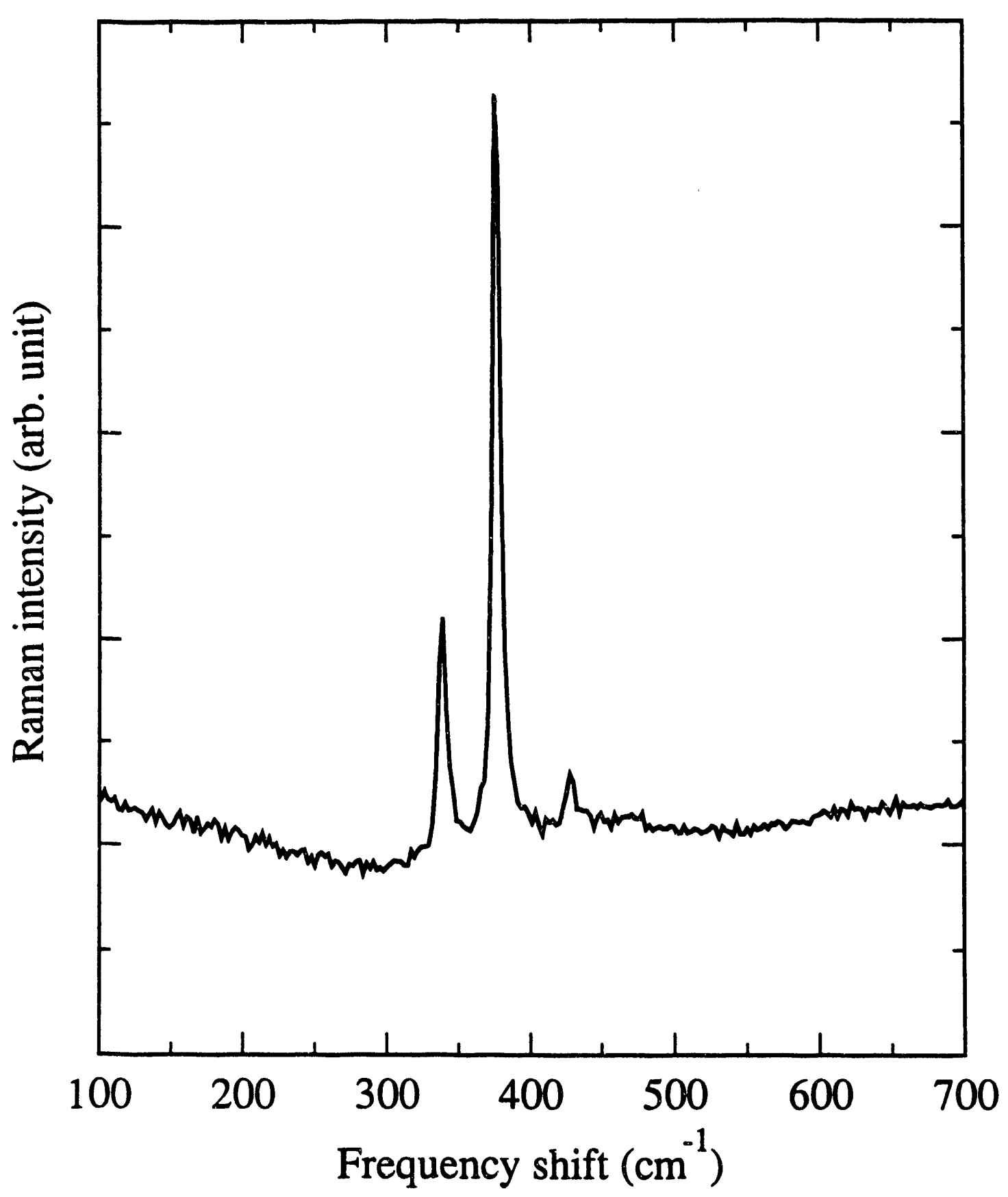

Figure 3.4. Raman spectrum of mineral pyrite in $0.5 \mathrm{M} \mathrm{NaCl}$ at rest potential. 


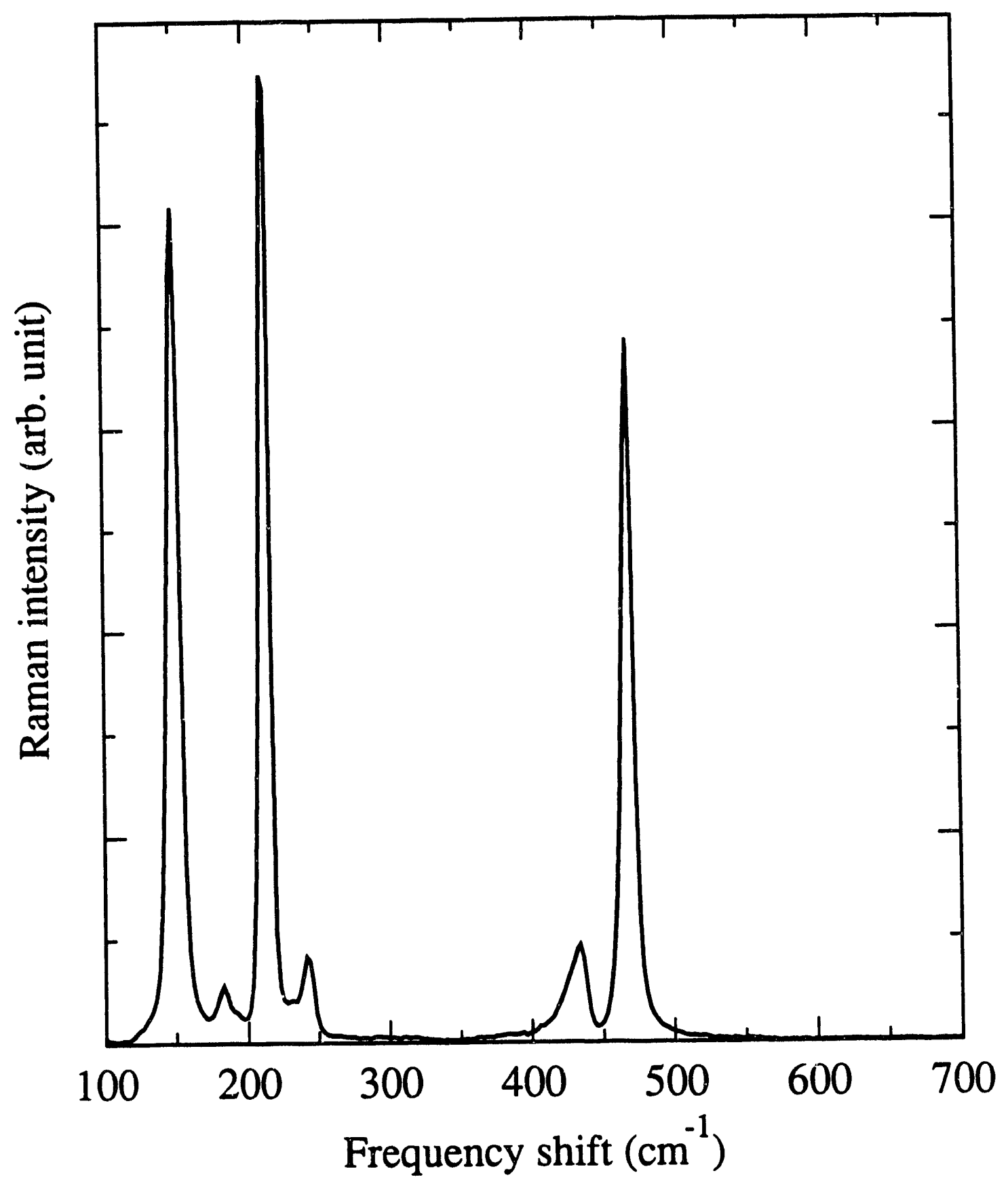

Figure 3.5. Raman spectrum of elemental sulfur in air $\left(100-700 \mathrm{~cm}^{-1}\right)$. 


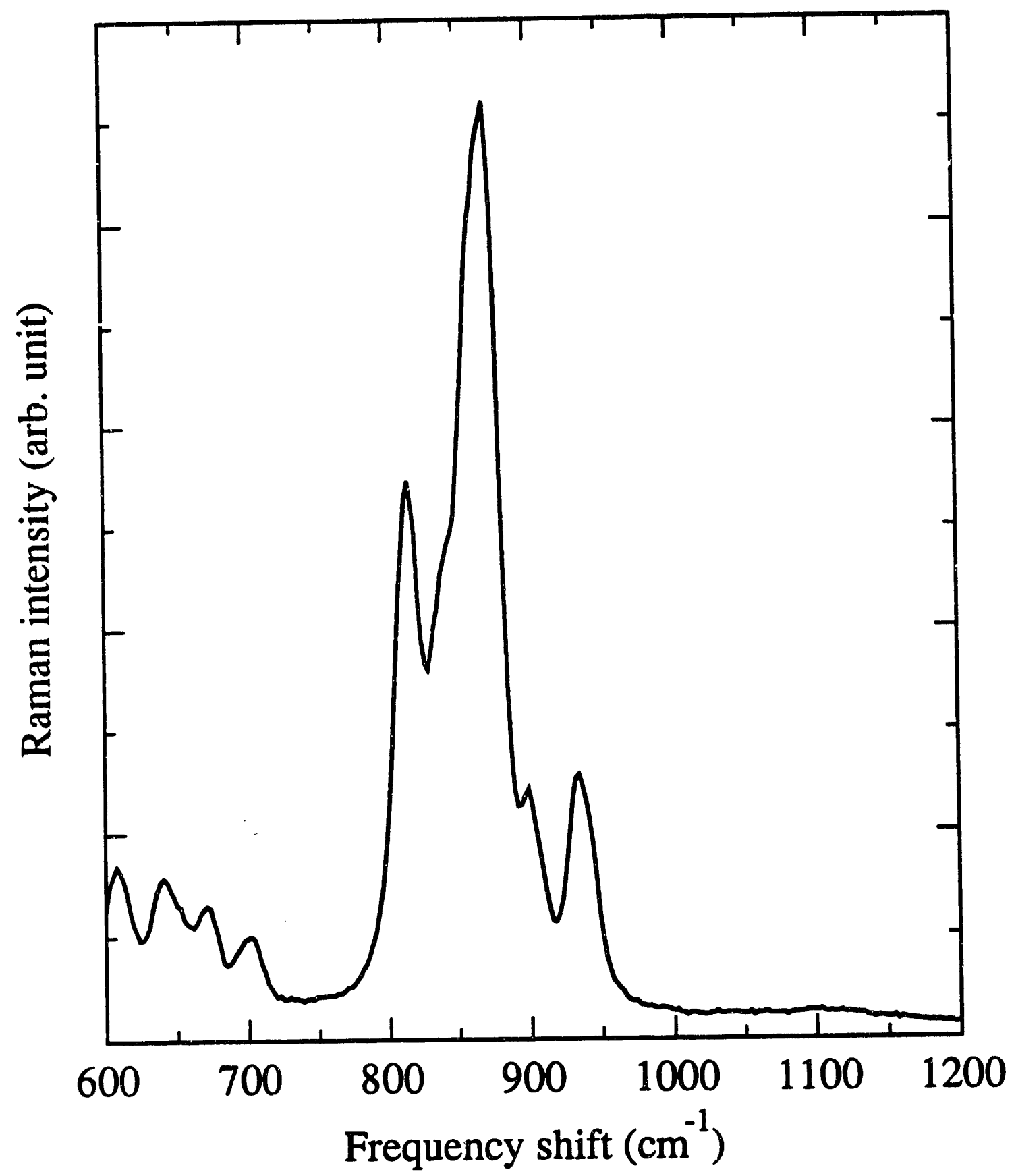

Figure 3.6. Raman spectrum of elemental sulfur in air $\left(700-1400 \mathrm{~cm}^{-1}\right)$. 
at 150 and $215 \mathrm{~cm}^{-1}$ are produced due to bending of the S-S-S chain. All the other peaks in the range from 100 to $1200 \mathrm{~cm}^{-1}$ are overtones and combinations of these various modes and are much weaker. Sulfur is a very strong Raman scatterer and sufficient counts were obtained to provide good spectra in 0.1 second of integration.

Raman Spectra of Electrodeposited Sulfur. For comparison with anodically oxidized pyrite, sulfur was electrodeposited onto a platinum electrode. The cyclic voltammogram for platinum in a $0.5 \mathrm{M} \mathrm{NaCl}$ and $0.001 \mathrm{M} \mathrm{Na}_{2} \mathrm{~S}$ solution with a $\mathrm{pH}$ of 12.5 is shown in Figure 3.7. Raman spectra were taken at the following potentials: $-0.10,+0.38,+0.80$, and $+1.20 \mathrm{~V} / \mathrm{SCE}$. The spectra are shown in Figures 3.8-3.11. Raman peaks characteristic of elemental sulfur were observed at all of these potentials. Significantly more charge was passed as the oxidation potential was made more anodic (see Figure 3.12). The height of the sulfur peak at $470 \mathrm{~cm}^{-1}$ was plotted as a function of potential after 20 minutes (Figure 3.13). The peak height reached a maximum then decreased. If the peak height is proportional to the quantity of sulfur produced then the coulombic efficiency of elemental sulfur production also passed through a maximum. If these results are compared to the charge passed in the same time (Figure 3.12) then it may be concluded that sulfur is being converted to solution soluble species.

It has been observed that the presence of sulfide ions in solution can attenuate the Raman signal. When sulfur was electrodeposited on the platinum electrode and observed in deionized water, strong spectral bands were observed. However, the addition of a small amount of sodium sulfide greatly diminished the size of the sulfur peaks. This is probably due to the chemical dissolution of the sulfur by reaction with bisulfide ions to form soluble polysulfide ions as discussed by Buckley et al. [3.3]:

$$
S^{2-}+(x-1) S=S_{x}^{2-}
$$

The sulfur spectra were also obtained with the platinum electrode immersed in a neutral solution of sodium sulfide. Results were similar to those for alkaline solutions. The spectra at $+1.0 \mathrm{~V} / \mathrm{SCE}$ for various times are shown in Figure 3.14. 


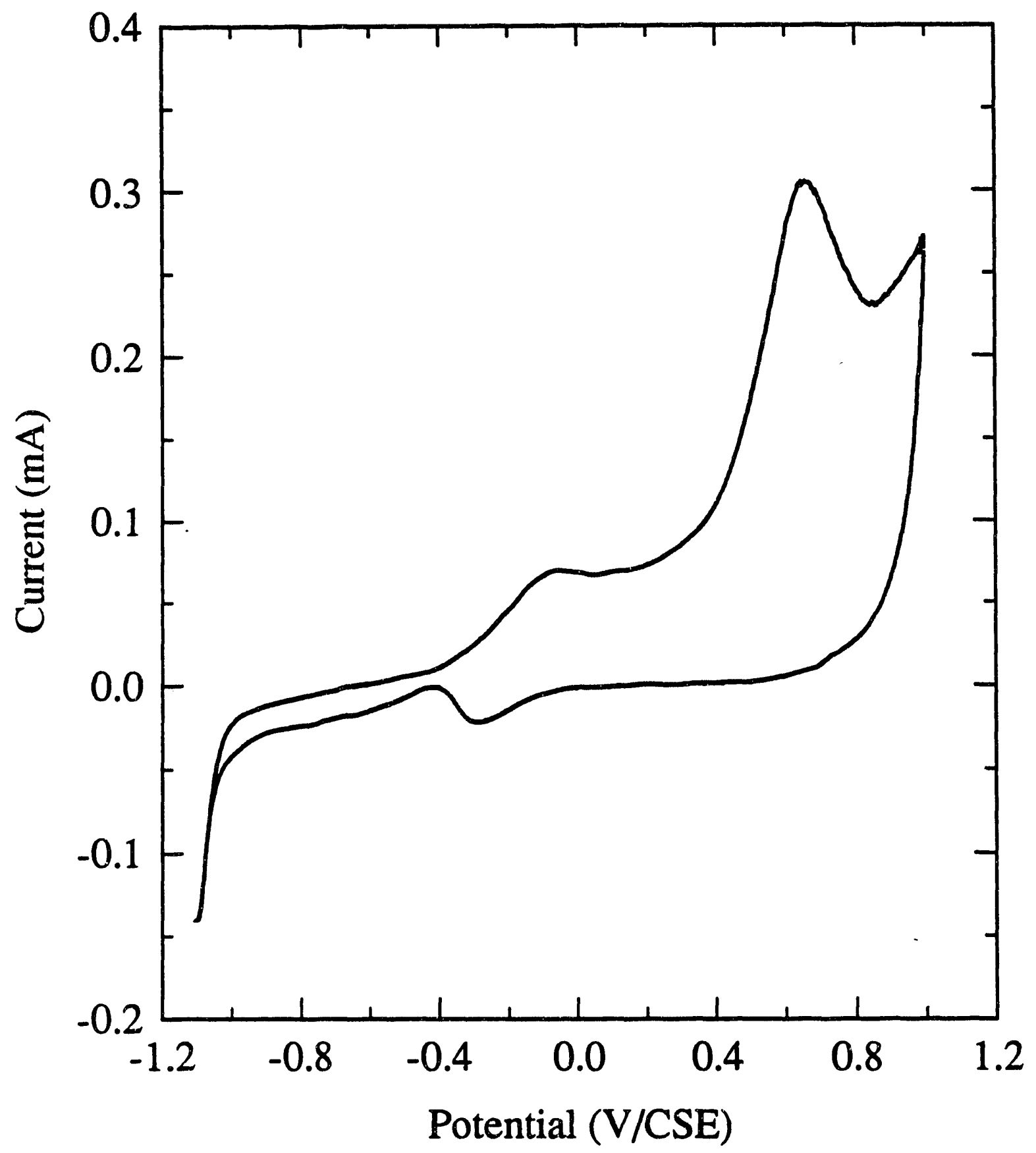

Figure 3.7. Voltammogram of platinum in $0.001 \mathrm{M} \mathrm{Na}_{2} \mathrm{~S}$ and $0.5 \mathrm{M} \mathrm{NaCl}$ solution of $\mathrm{pH} 12.5$, scan rate $50 \mathrm{mV} / \mathrm{sec}$. 


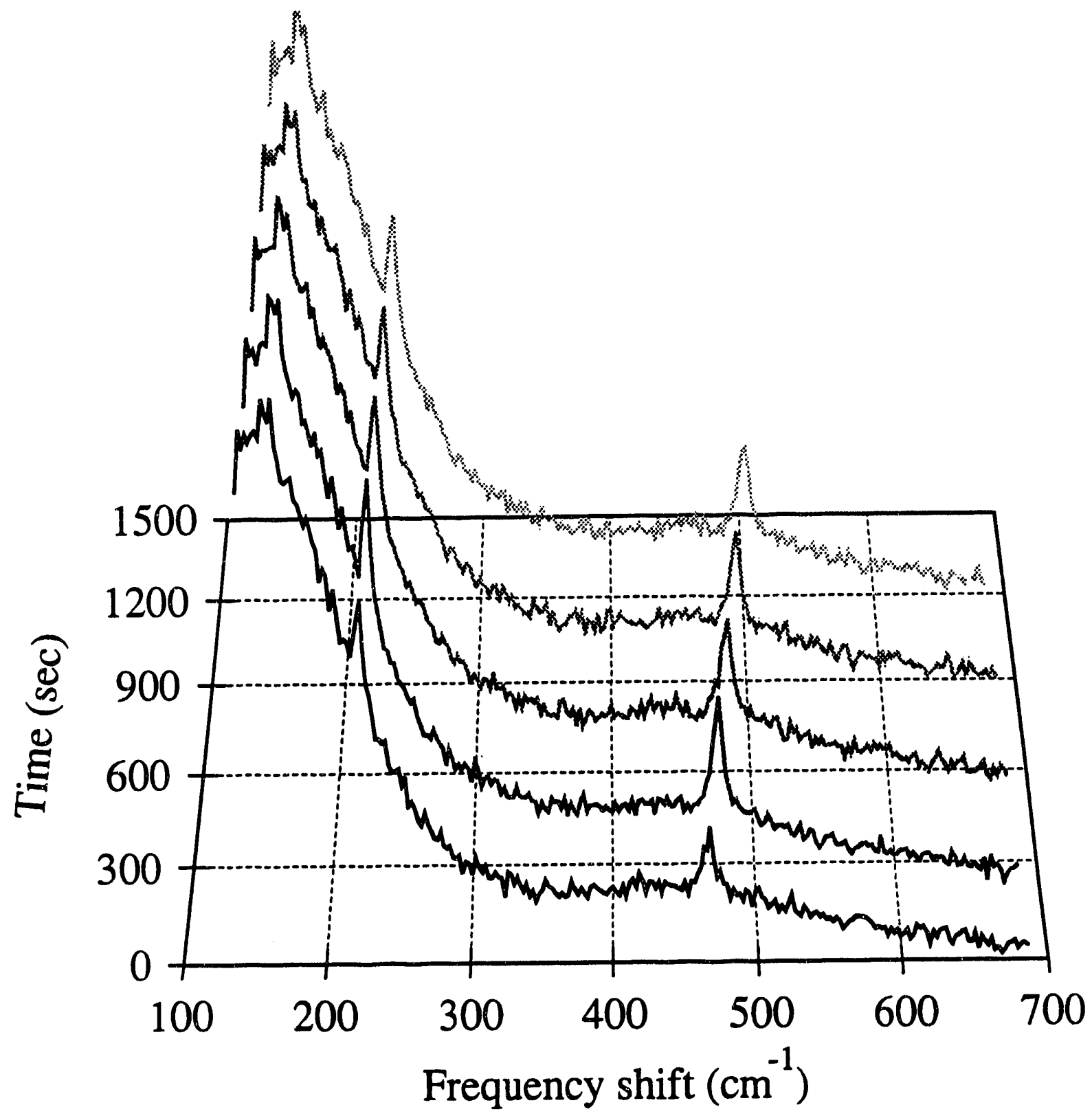

Figure 3.8. Raman spectra of electrodeposited sulfur on platinum at $-0.10 \mathrm{~V}$ (solution: $0.001 \mathrm{M} \mathrm{Na}_{2} \mathrm{~S}, 0.5 \mathrm{M} \mathrm{NaCl}, \mathrm{pH}$ 12.5). 


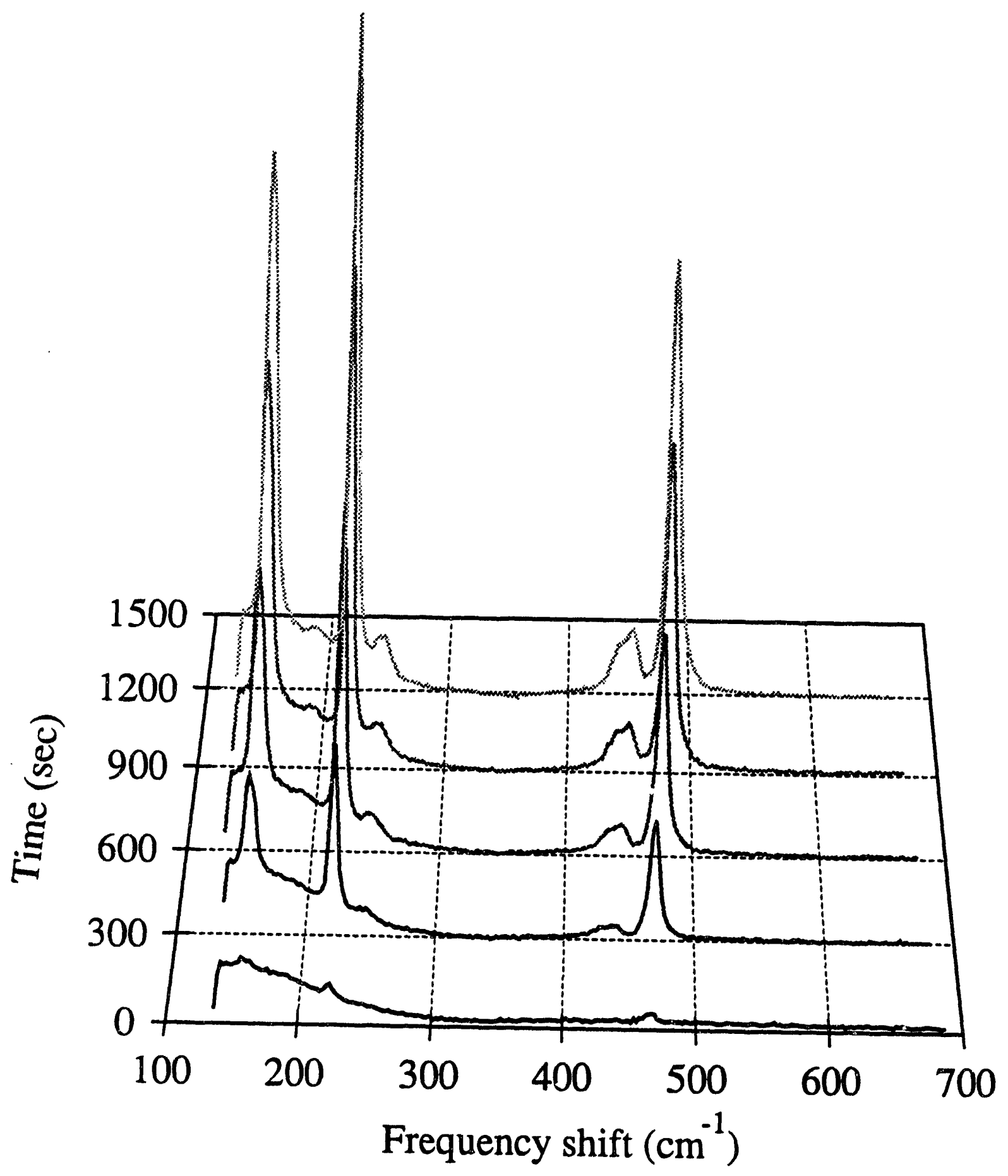

Figure 3.9. Raman spectra of electrodeposited sulfur on platinum at $0.38 \mathrm{~V}$ (solution: $0.001 \mathrm{M} \mathrm{Na}_{2} \mathrm{~S}, 0.5 \mathrm{M} \mathrm{NaCl}, \mathrm{pH} 12.5$ ). 


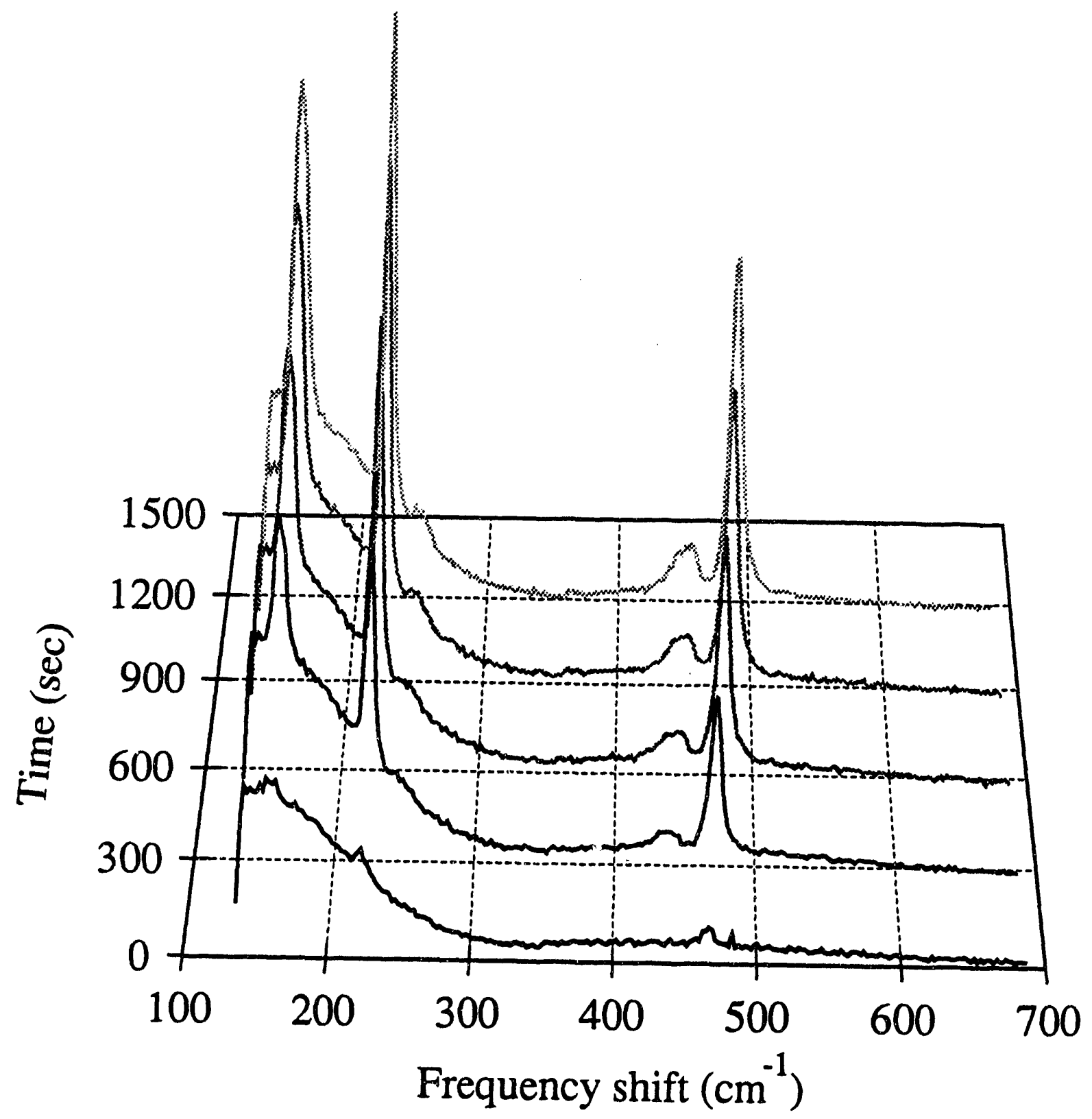

Figure 3.10. Raman spectra of electrodeposited sulfur on platinum at $0.80 \mathrm{~V}$ (solution: $0.001 \mathrm{M} \mathrm{Na}_{2} \mathrm{~S}, 0.5 \mathrm{M} \mathrm{NaCl}, \mathrm{pH} 12.5$ ). 


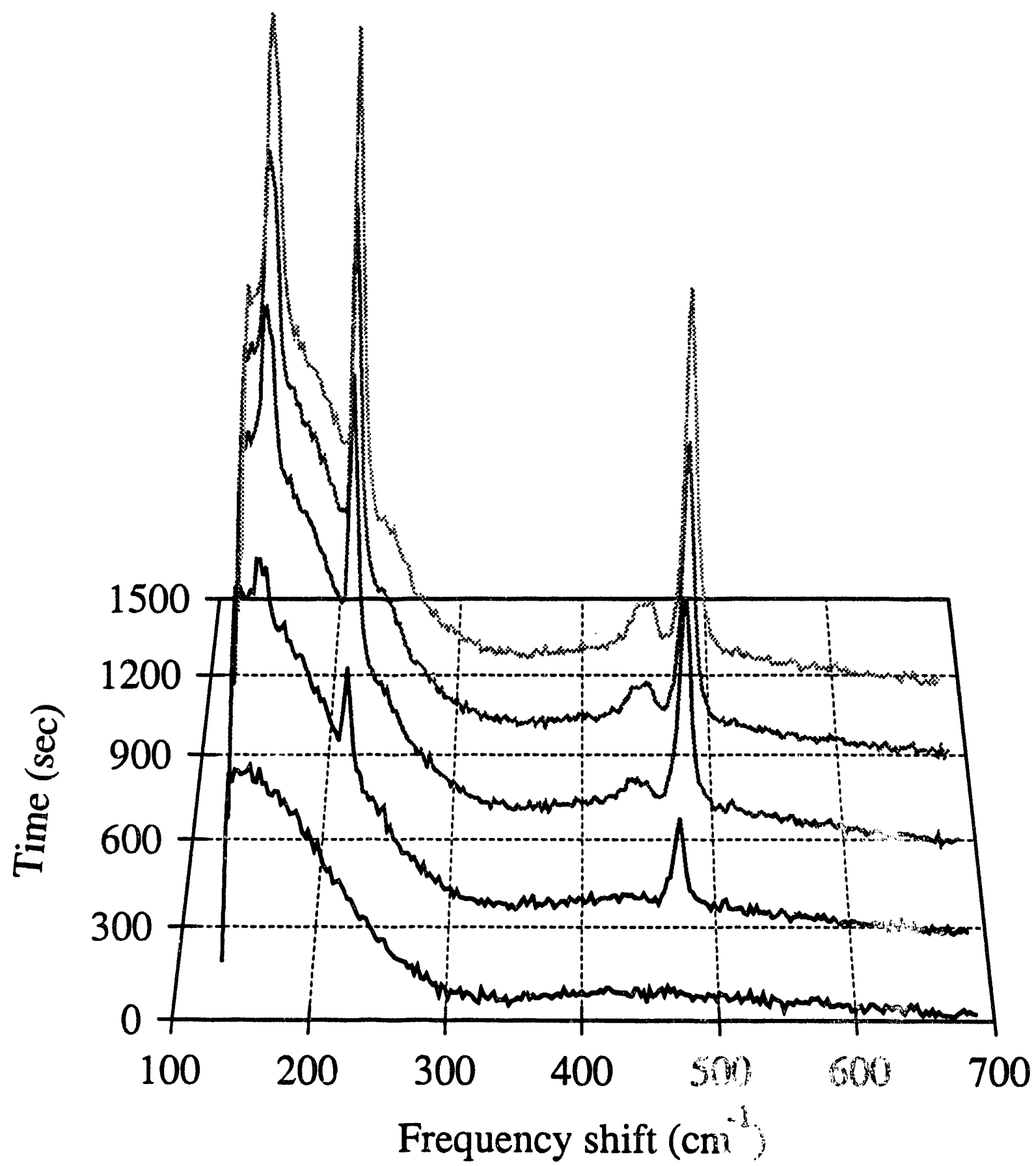

Figure 3.11. Raman spectra of electrodeposited sulfur on platinum at $1.20 \mathrm{~V}$ (solution: $0.001 \mathrm{M} \mathrm{Na}_{2} \mathrm{~S}, 0.5 \mathrm{M} \mathrm{NaCl}, \mathrm{pH} 12.5$ ). 


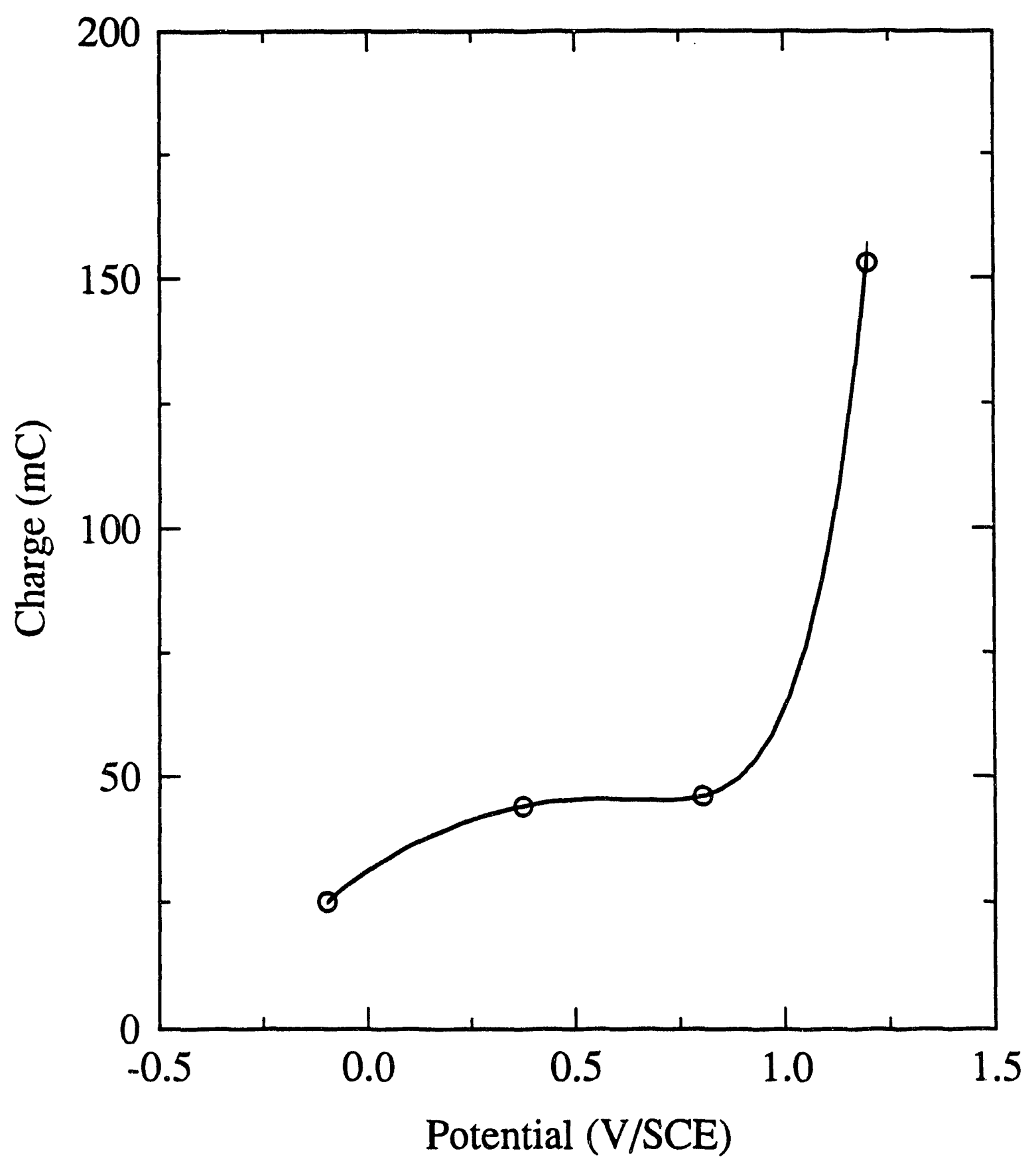

Figure 3.12. Amount of charge passed during 20 minutes of sulfur deposition expriments as a function of potential. 


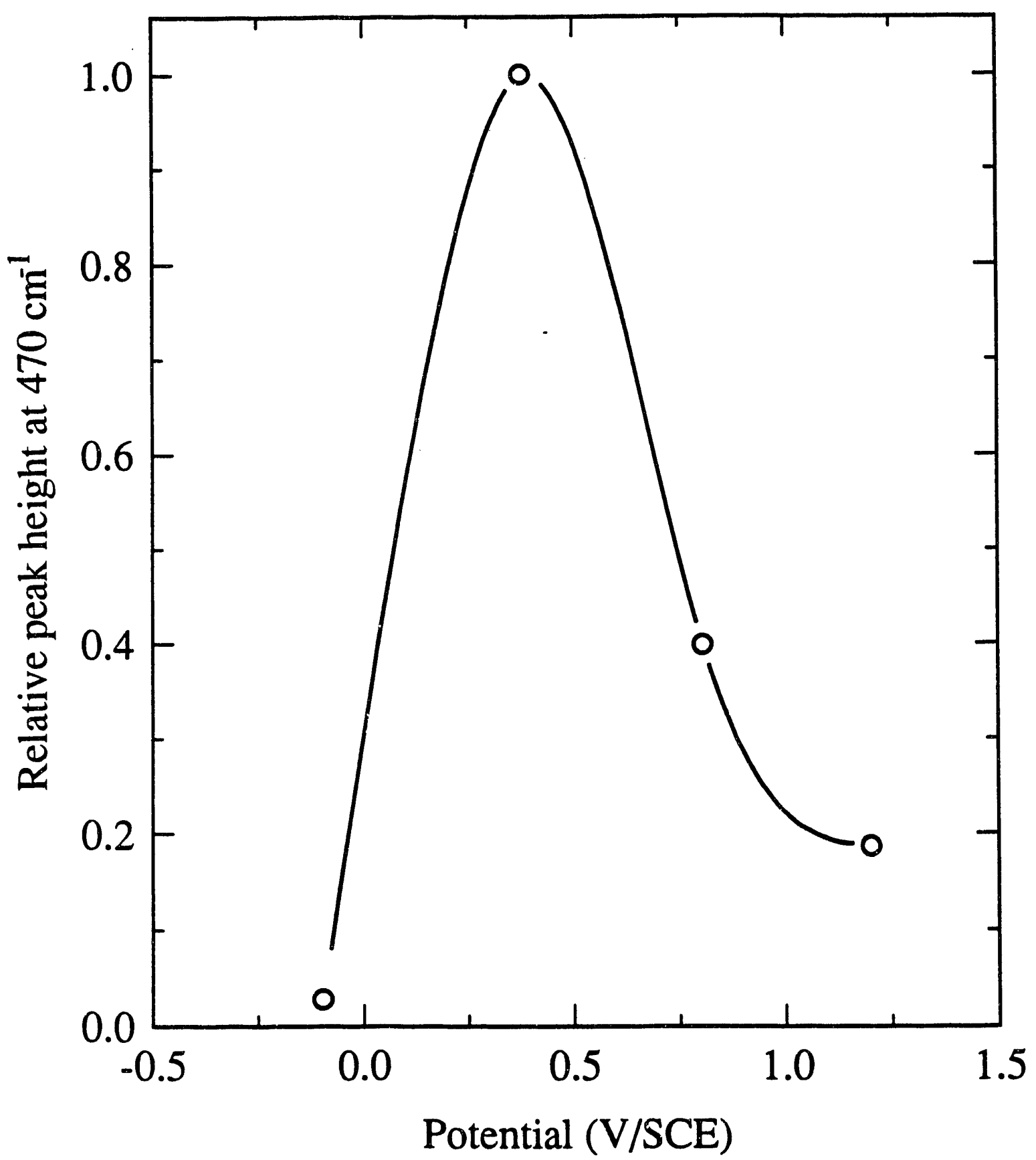

Figure 3.13. Relative height of sulfur peak at $470 \mathrm{~cm}^{-1}$ as a function of applied potential after 20 minutes. 


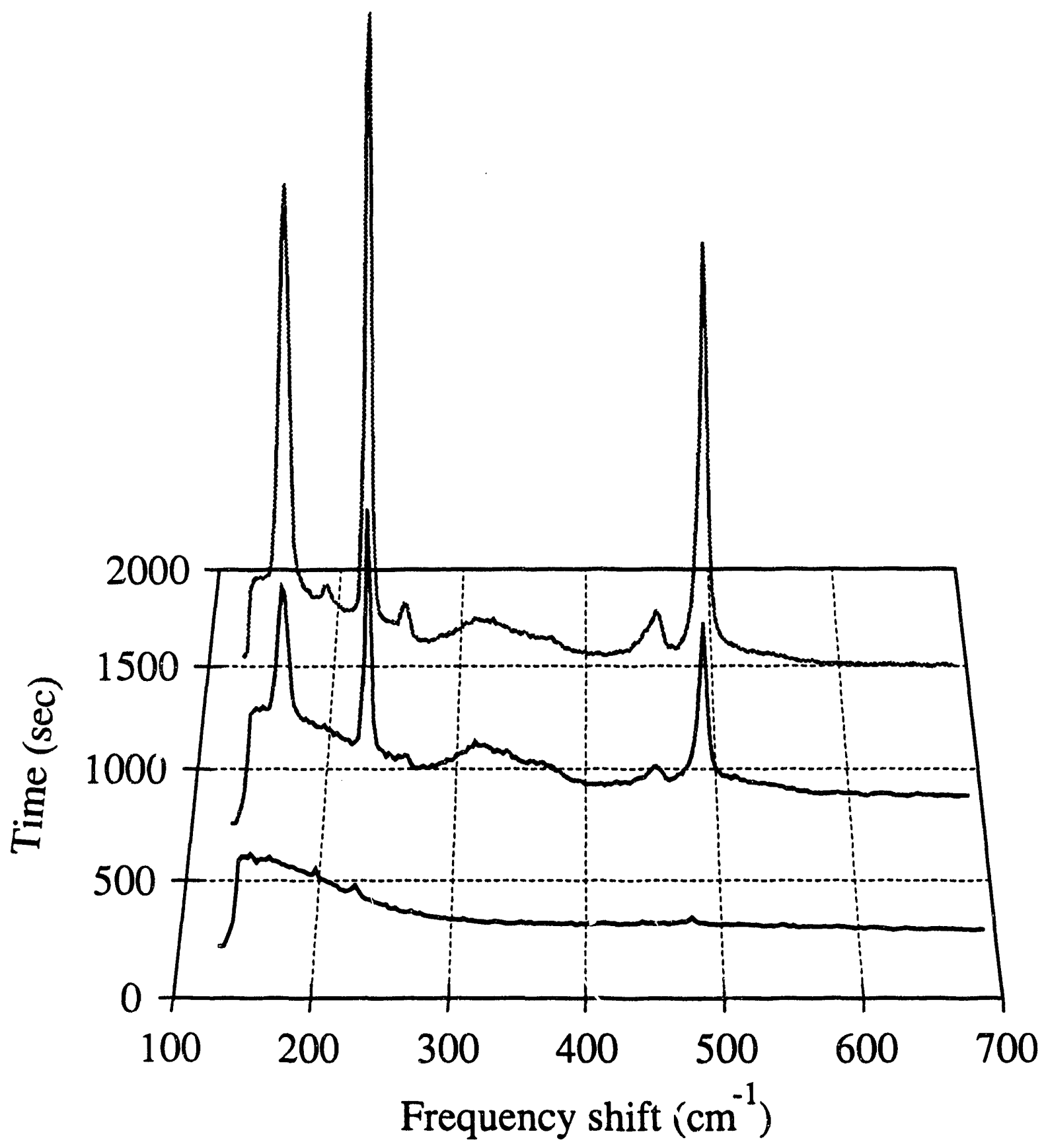

Figure 3.14. Raman spectra of electrodeposited sulfur on platinum at $1.0 \mathrm{~V}$ (solution: $0.001 \mathrm{M} \mathrm{Na}_{2} \mathrm{~S}, 0.5 \mathrm{M} \mathrm{NaCl}, \mathrm{pH} 6.5$ ). 
Raman Spectra of Precipitated Iron Hydroxides. Iron(II) and iron(III) hydroxides should also be formed on the pyrite surface at certain anodic potentials. The hydroxides of iron are known to be weak Raman scatterers and the use of SERS has been necessary to obtain useful spectra [3.25-3.27]. There are reference spectra available in the literature. Dünnwald and Otto present a series of reference spectra of iron hydroxides [3.12]. They show that $\mathrm{Fe}(\mathrm{OH})_{3}$ also has a small broad Raman peak centered at $696 \mathrm{~cm}^{-1}$.

\section{Effect of Solution pH on Oxidation of Pyrite}

Acid Conditions. The cyclic voltammogram for pyrite in an acidic electrolyte (pH 2.7) is shown in Figure 3.15. Anodic peaks were identified at the following potentials: -0.63 , $-0.1,+0.06,+0.57 \mathrm{~V} / \mathrm{SCE}$. Raman spectra were taken as a function of time at each of the above potentials plus potentials of $-0.87,+0.80$ and $+1.0 \mathrm{~V} / \mathrm{SCE}$ and are shown in Figures 3.16-3.21. The potential was applied for more than 30 minures in each case and the current was measured continuously during the experiment. At potentials of -0.87 (Figure 3.16 ) and $-0.63 \mathrm{~V} / \mathrm{SCE}$ (Figure 3.17) there was a noticeable increase in the intensity of the pyrite peaks as a function of time. This is attributed to the reduction of a surface film (possibly an oxide) formed on the pyrite electrode. At $+0.06 \mathrm{~V} / \mathrm{SCE}$ (Figure 3.18) the intensity of the pyrite Raman peaks was constant, indicating little reaction. The pyrite electrode is close to its rest of potential about $0.1 \mathrm{~V} / \mathrm{SCE}$. For potentials from -0.87 to +0.57 V/SCE Raman peaks, characteristic of sulfur, did not appear.

At +0.80 and $+1.0 \mathrm{~V} / \mathrm{SCE}$ pyrite peaks were observed together with peaks centered at 150,215 , and approximately $470 \mathrm{~cm}^{-1}$. The peaks at 150 and $215 \mathrm{~cm}^{-1}$ are characteristic of elemental sulfur (see Figure 3.5) and are attributed to the S-S-S bending mode. The peak at $470 \mathrm{~cm}^{-1}$ is characteristic of elemental sulfur. At $0.8 \mathrm{~V} / \mathrm{SCE}$, a shoulder at $\sim 460$ $\mathrm{cm}^{-1}$ is in evidence. Two distinct peaks are resolved at $1.0 \mathrm{~V} / \mathrm{SCE}$. Because of time limitations it was decided to obtain spectra predominantly in the range $100-700 \mathrm{~cm}^{-1}$ where important sulfur peaks are located. It has been known that pyrite does not have Raman peaks at wavenumbers greater than $700 \mathrm{~cm}^{-1}[3.22,3.24]$.

Neutral Conditions. The cyclic voltammogram for pyrite in neutral conditions (pH 6.5) 


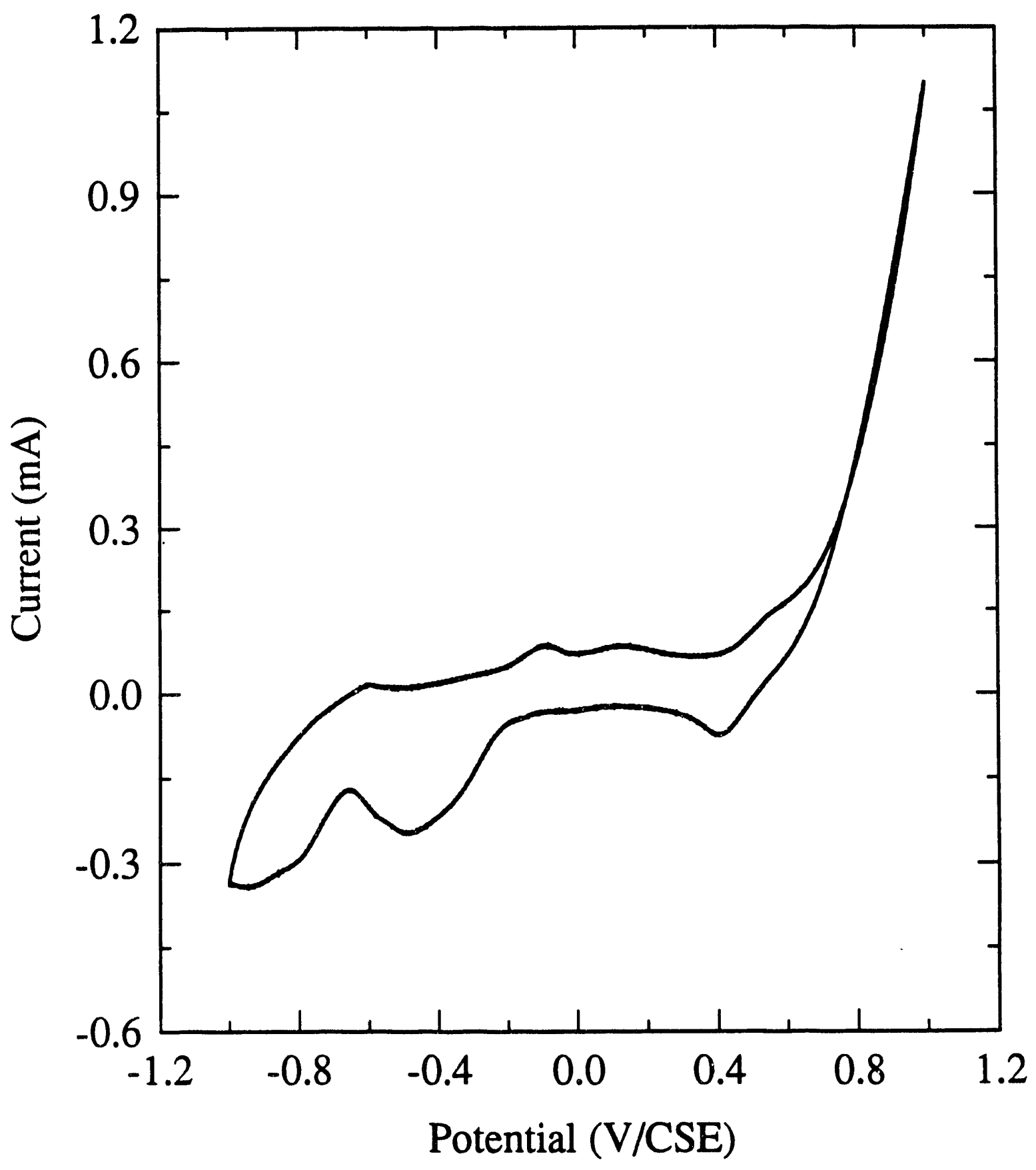

Figure 3.15. Voltammogram of mineral pyrite in a $0.5 \mathrm{M} \mathrm{NaCl}$ solution of $\mathrm{pH} 2.7$, scan rate $50 \mathrm{mV} / \mathrm{sec}$. 


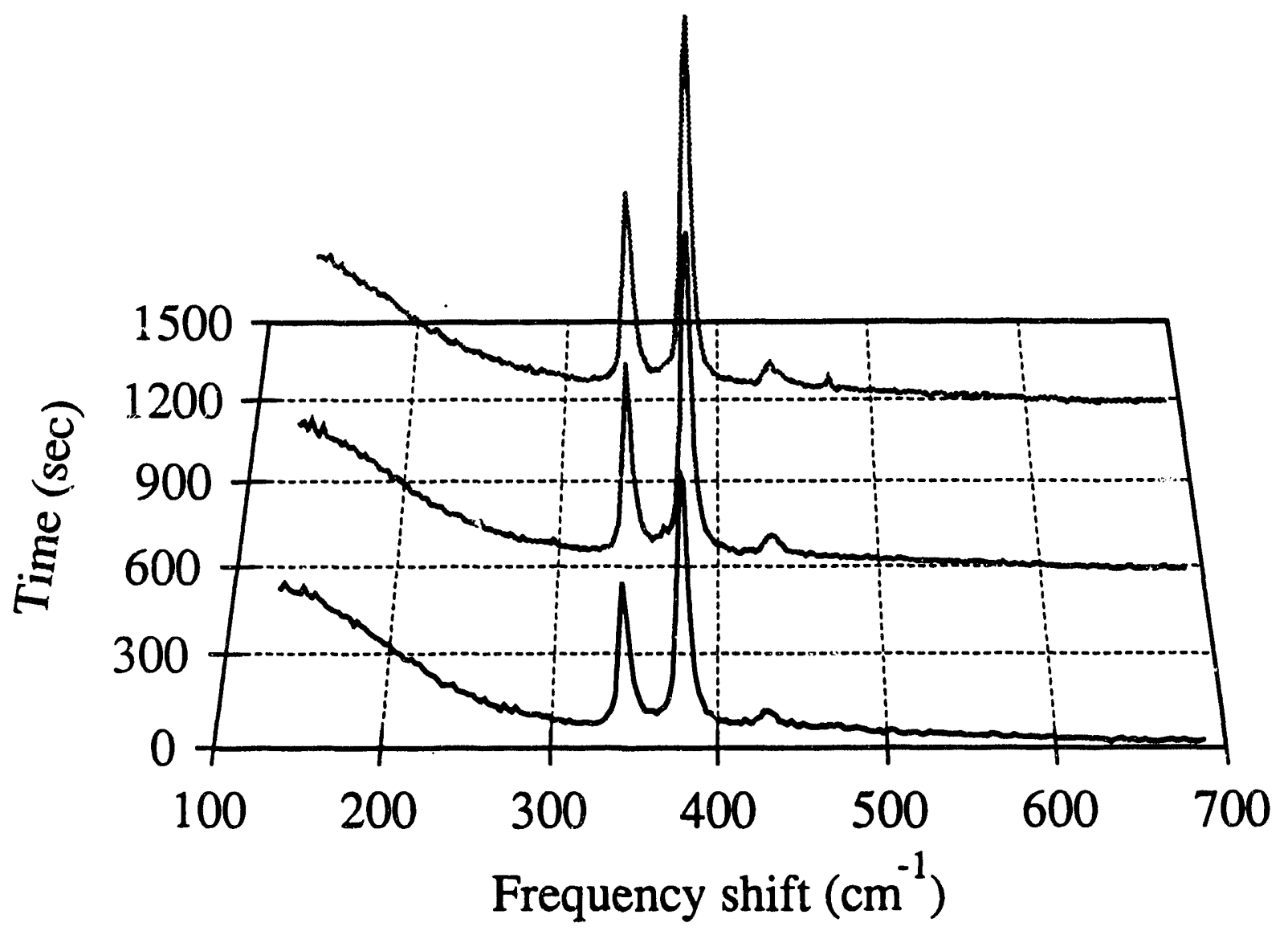

Figure 3.16. Raman spectra of electrochemically oxidized pyrite at $-0.87 \mathrm{~V}$ (solution: $0.5 \mathrm{M} \mathrm{NaCl}, \mathrm{pH} 2.7$ ). 


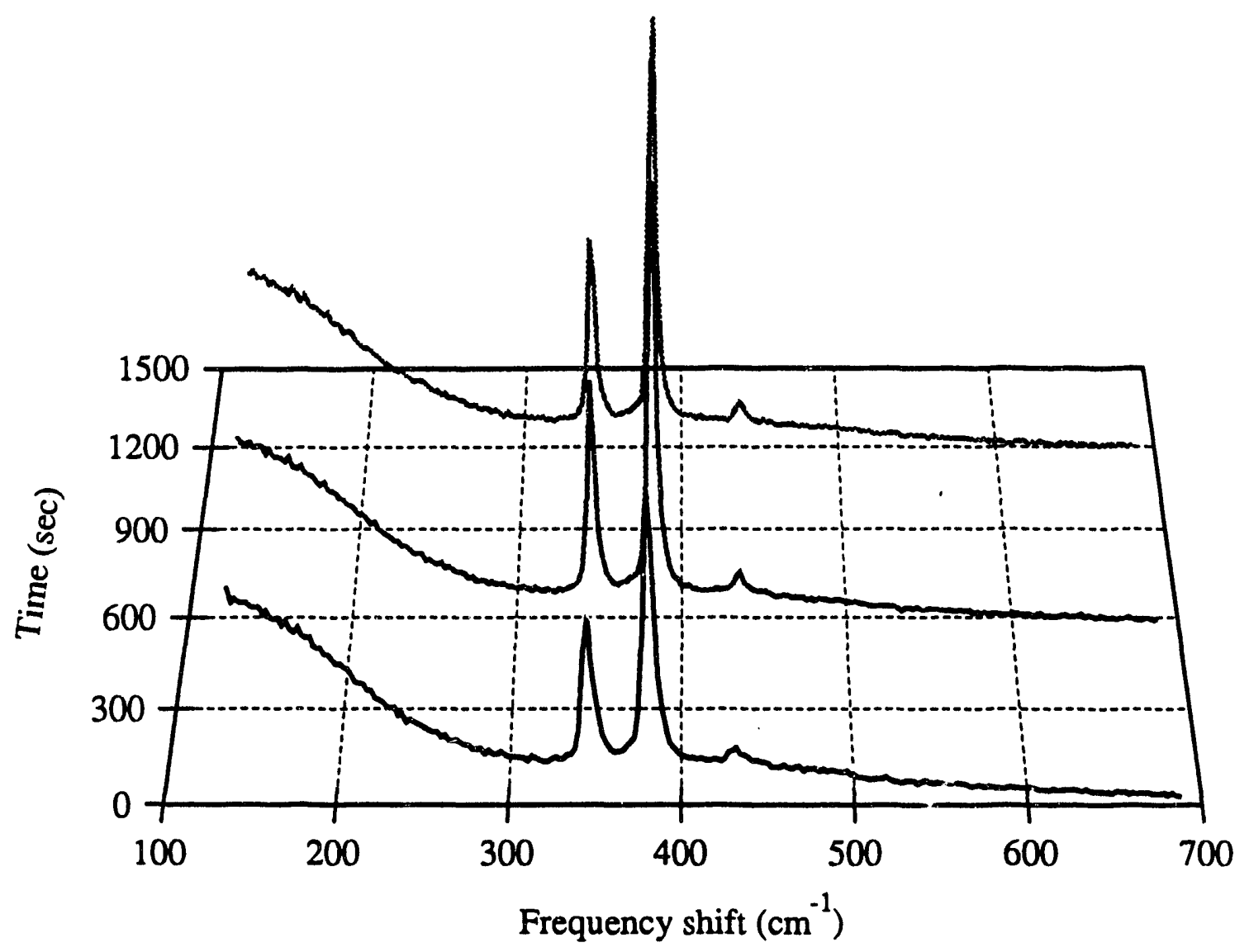

Figure 3.17. Ramans ctra of electrochemically oxidized pyrite at $-0.63 \mathrm{~V}$ (solution: $0.5 \mathrm{M} \mathrm{NaCl}, \mathrm{pH} 2.7$ ). 


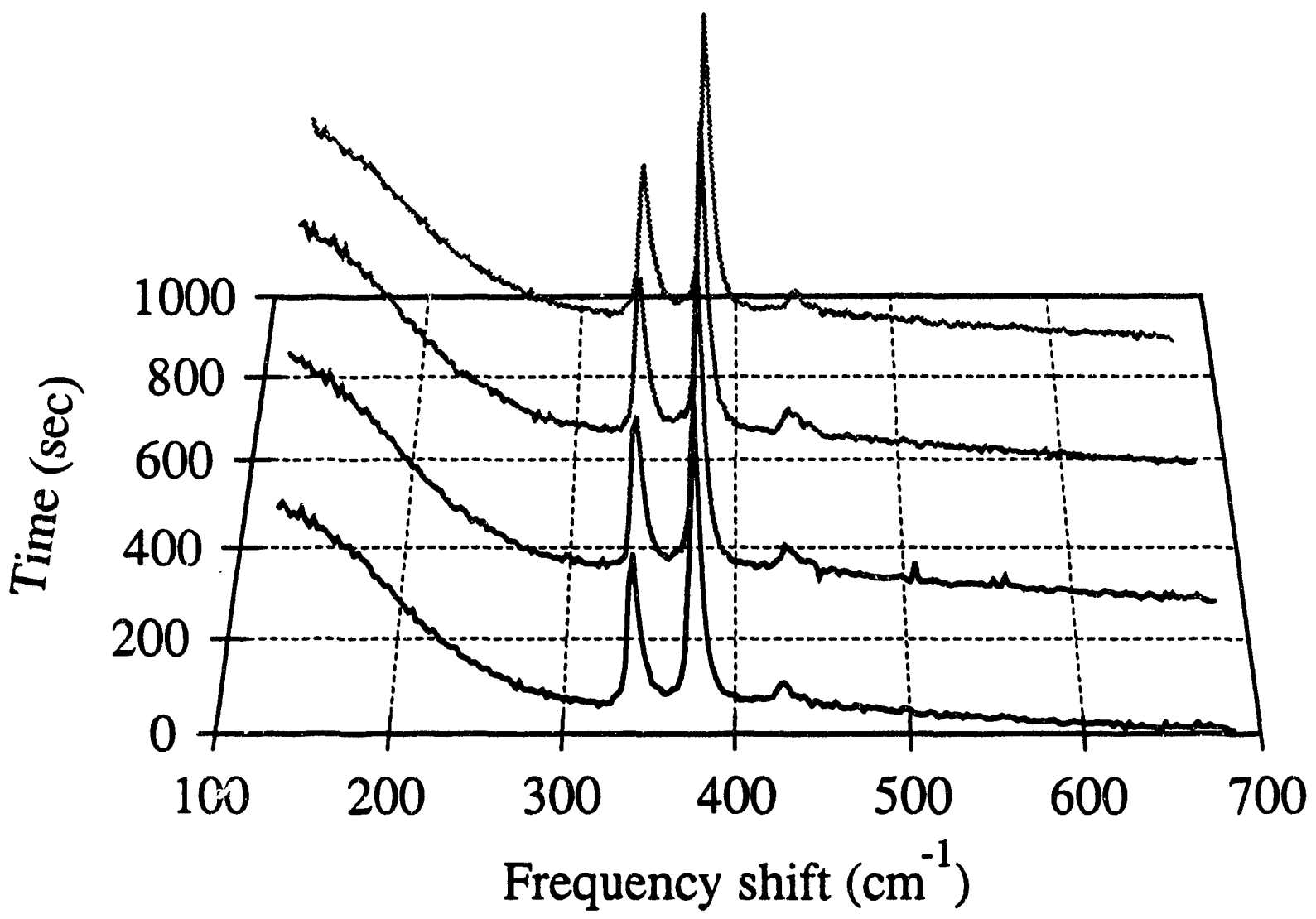

Figure 3.18. Raman spectra of electrochemically oxidized pyrite at $0.06 \mathrm{~V}$ (solution: $0.5 \mathrm{M} \mathrm{NaCl}, \mathrm{pH} 2.7$ ). 


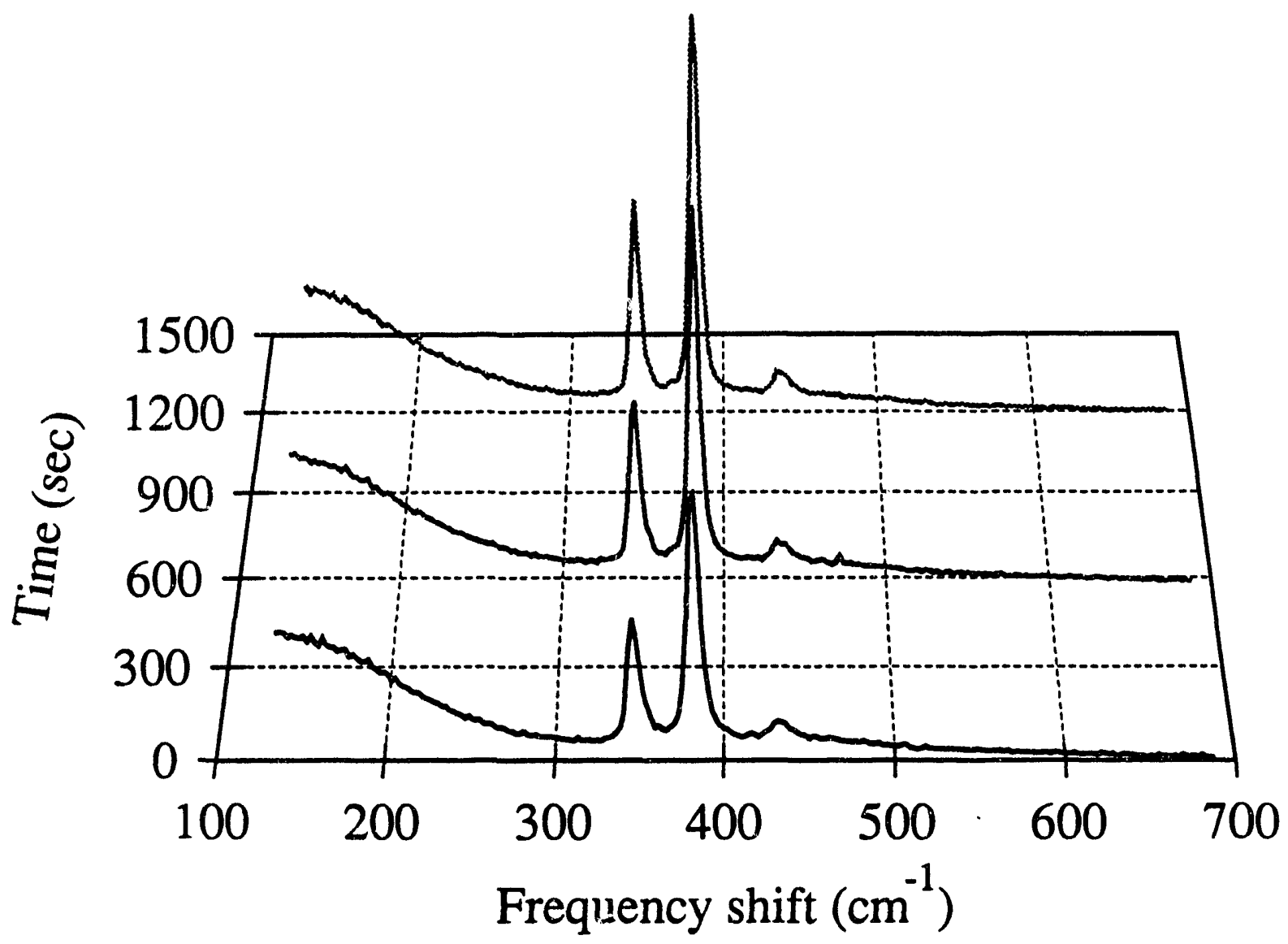

Figure 3.19. Raman spectra of electrochemically oxidized pyrite at $0.57 \mathrm{~V}$ (solution: $0.5 \mathrm{M} \mathrm{NaCl}, \mathrm{pH} 2.7$ ). 


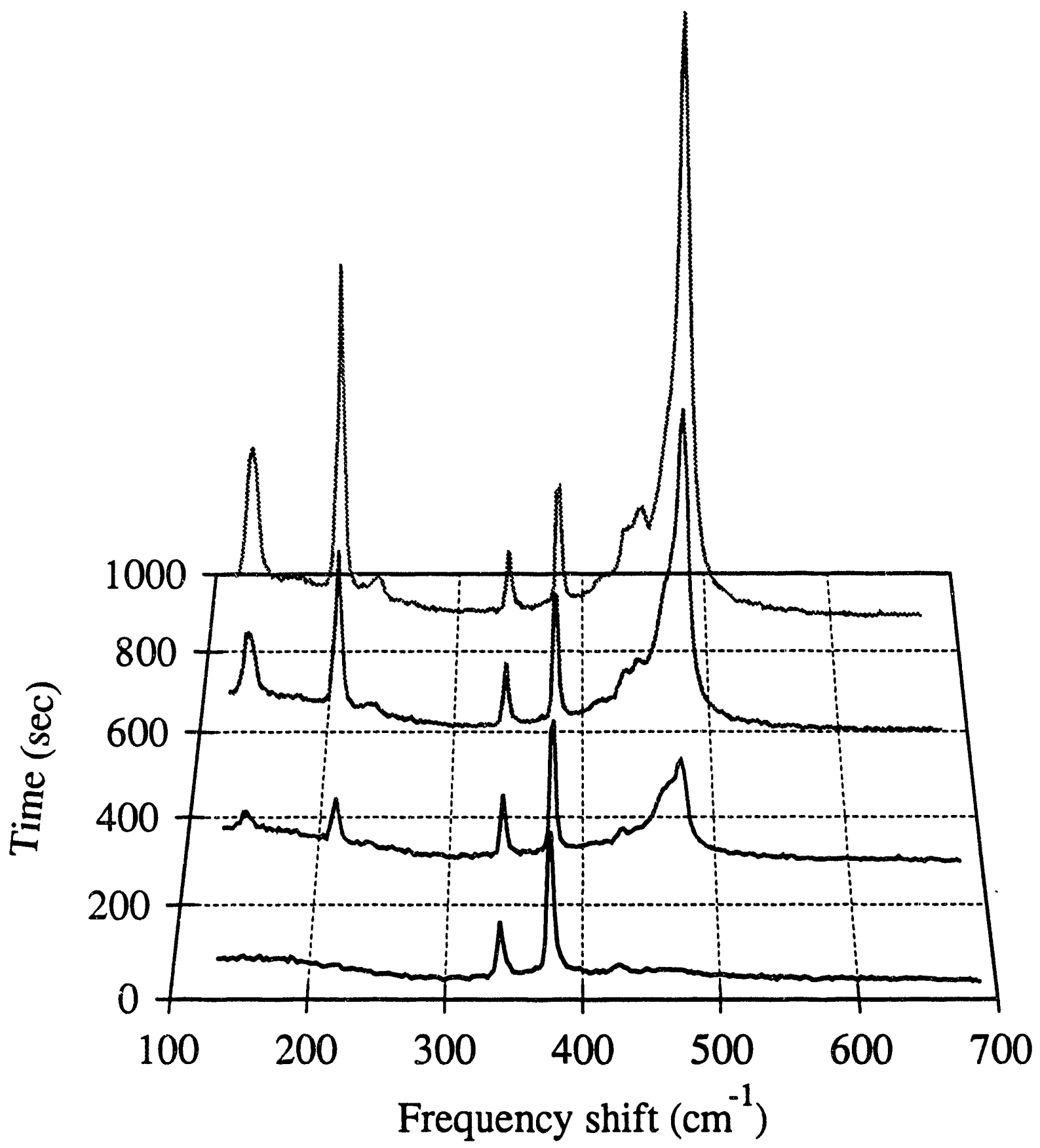

Figure 3.20. Raman spectra of electrochemically oxidized pyrite at $0.80 \mathrm{~V}$ (solution: $0.5 \mathrm{M} \mathrm{NaCl}, \mathrm{pH} 2.7$ ). 


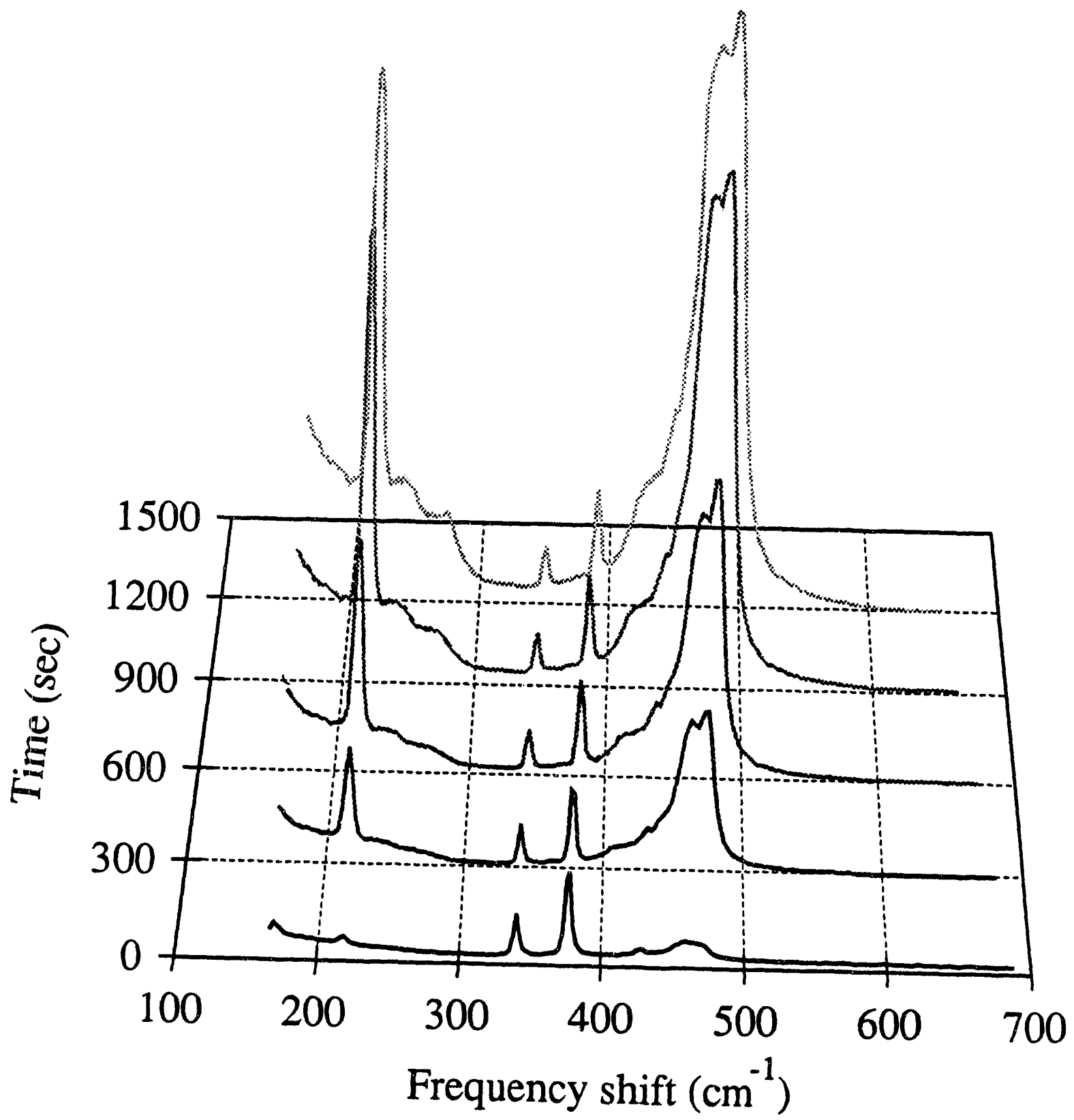

Figure 3.21. Raman spectra of electrochemically oxidized pyrite at $1.0 \mathrm{~V}$ (solution: $0.5 \mathrm{M} \mathrm{NaCl}, \mathrm{pH} 2.7$ ). 
is shown in Figure 3.22. Anodic peaks were identified at the following potentials: -0.76 , $-0.15,+0.06$ and $+0.60 \mathrm{~V} / \mathrm{SCE}$. Two large photocurrent peaks were observed at -0.40 and $+0.42 \mathrm{~V} / \mathrm{SCE}$ (see the section of photocurrent experiment). Raman spectra were taken at potentials coinciding with these photocurrent peaks, the four anodic peaks and +0.30 , +0.80 and $+1.0 \mathrm{~V} / \mathrm{SCE}$. The Raman spectra for pyrite held at the above potentials are shown in Figure 3.23-3.30. At or below +0.30 V/SCE no sulfur peaks were detected.

At a potential of $+0.42 \mathrm{~V}$, the sulfur peaks were observed after 5 minutes and the passage of charge of $3.3 \mathrm{mC}$ (Figure 3.27). The peaks were not very strong but are clearly present. The pyrite peaks were also present and were very strong. No spectral features were observed at higher frequency shift at this or any other potentials.

Weak Alkaline Conditions. The cyclic voltammogram of pyrite for weak alkaline conditions $(\mathrm{pH}$ 9.2) is shown in Figure 3.31. Anodic peaks were identified at the following potentials: $-0.78,-0.15,+0.15,+0.60$, and $+1.0 \mathrm{~V} / \mathrm{SCE}$. Raman spectra were taken at potentials $+0.60,+0.80,+1.0$ and $+1.2 \mathrm{~V} / \mathrm{SCE}$. The Raman spectra for mineral pyrite held at the above potentials are shown in Figure 3.32-3.35. Below $+0.60 \mathrm{~V} / \mathrm{SCE}$ no sulfur peaks were detected while, above $+0.80 \mathrm{~V} / \mathrm{SCE}$, sulfur and polysulfide Raman peaks were observed. These results confirm the fact that sulfur may be formed on pyrite surfaces by applying an appropriate potential even in weak alkaline solutions. Furthermore different forms of sulfur, other than $S_{8}$, are formed initially.

The results define potential and $\mathrm{pH}$ conditions for pyrite hydrophobicity, and provide new information regarding transient sulfur stability. According to thermodynamic calculations, elemental sulfur should not exist in solutions with a pH higher than 9 [3.28]. The electrochemically formed sulfur on the pyrite is thus transient and metastable. The decomposition rate of sulfur and its intermediates is an important factor in considering coal/pyrite separation processes.

Strong Alkaline Conditions. The cyclic voltammogram of pyrite for strong basic conditions ( $\mathrm{pH} \mathrm{12.5)}$ is shown in Figure 3.36. Raman spectra were taken at the following potentials: $-0.40,0.0,+0.35,+0.62$ and $+1.0 \mathrm{~V} / \mathrm{SCE}$ (Figures 3.37-3.41). There were 


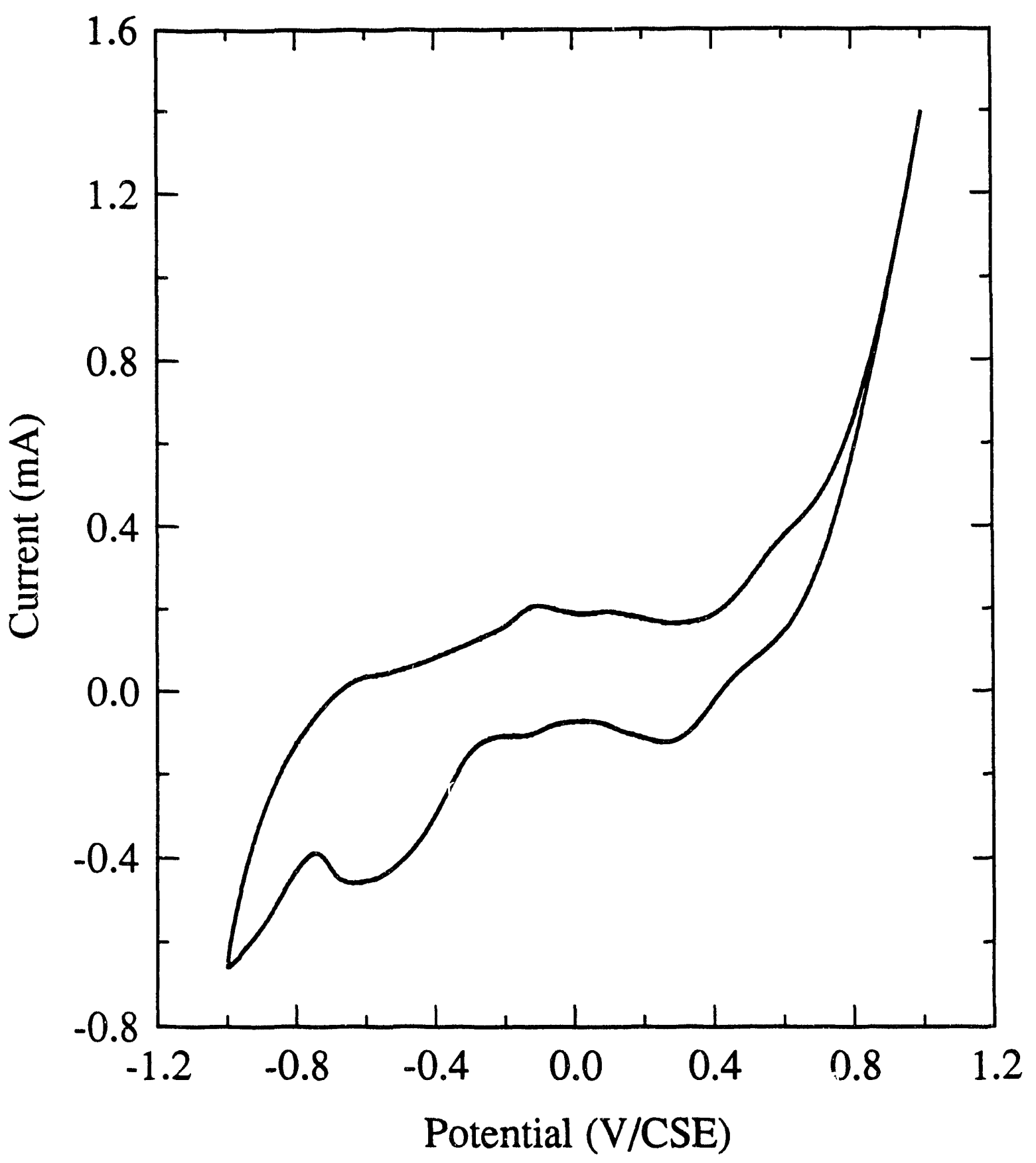

Figure 3.22. Voltammogram of mineral pyrite in a $0.5 \mathrm{M} \mathrm{NaCl}$ solution of $\mathrm{pH} 6.5$, scan rate $50 \mathrm{mV} / \mathrm{sec}$. 


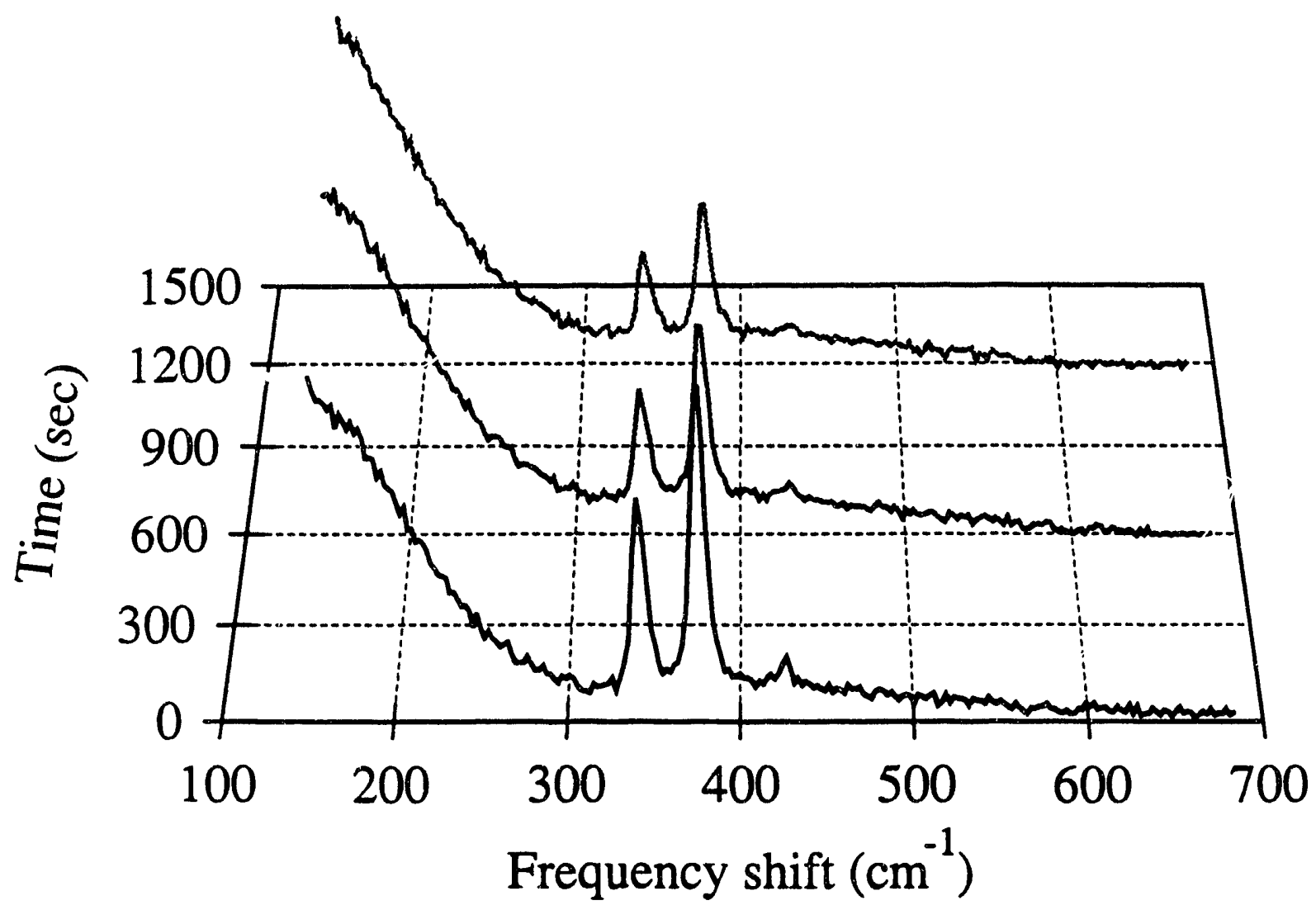

Figure 3.23. Raman spectra of electrochemically oxidized pyrite at $-0.76 \mathrm{~V}$ (solution: $0.5 \mathrm{M} \mathrm{NaCl}, \mathrm{pH} 6.5$ ). 


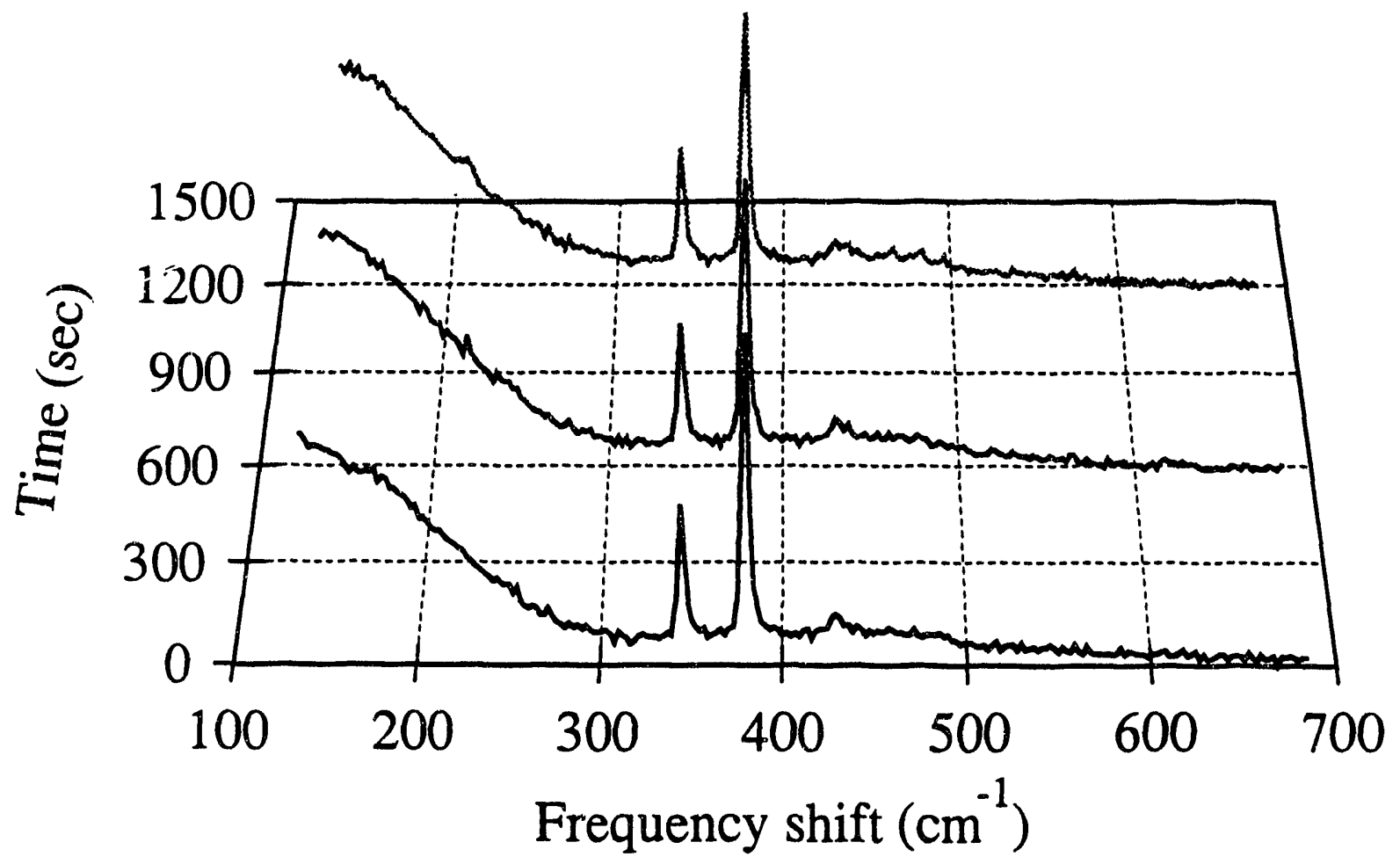

Figure 3.24. Raman spectra of electrochemically oxidized pyrite at $-0.40 \mathrm{~V}$ (solution: $0.5 \mathrm{M} \mathrm{NaCl}, \mathrm{pH} 6.5$ ). 


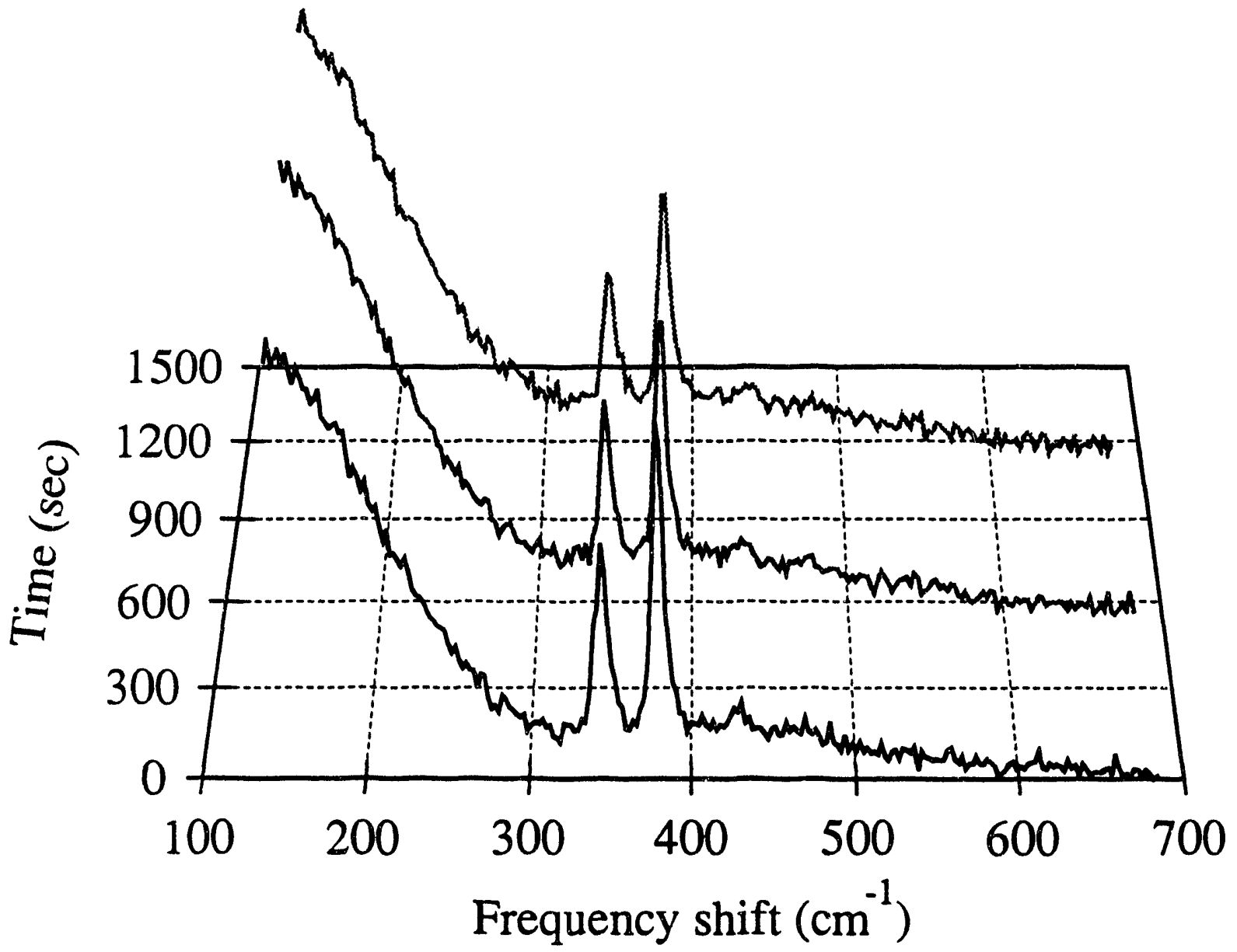

Figure 3.25. Raman spectra of electrochemically oxidized pyrite at $-0.15 \mathrm{~V}$ (solution: $0.5 \mathrm{M} \mathrm{NaCl}, \mathrm{pH} 6.5$ ). 


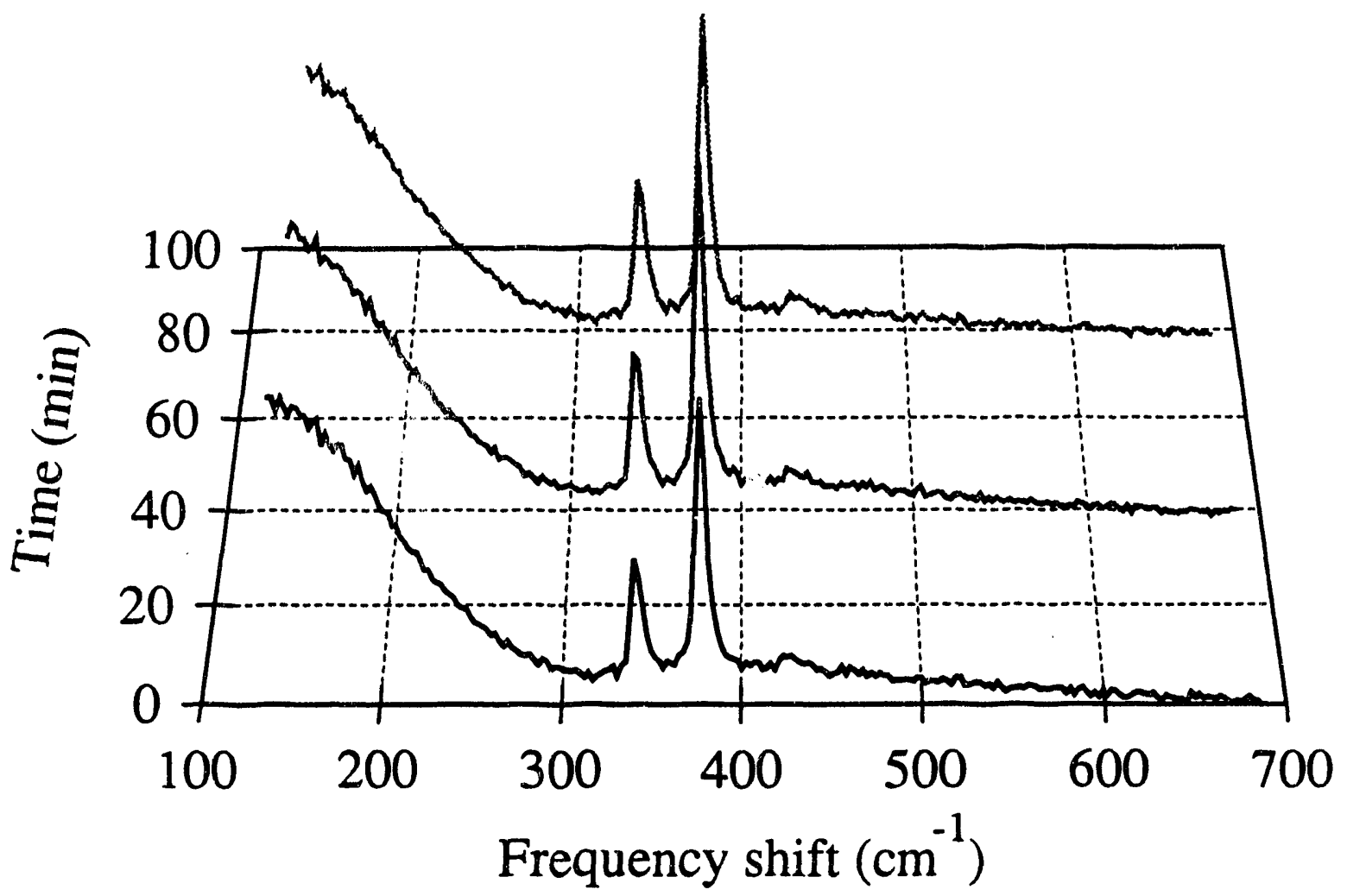

Figure 3.26. Raman spectra of electrochemically oxidized pyrite at $0.30 \mathrm{~V}$ (solution: $0.5 \mathrm{M} \mathrm{NaCl}, \mathrm{pH} 6.5$ ). 


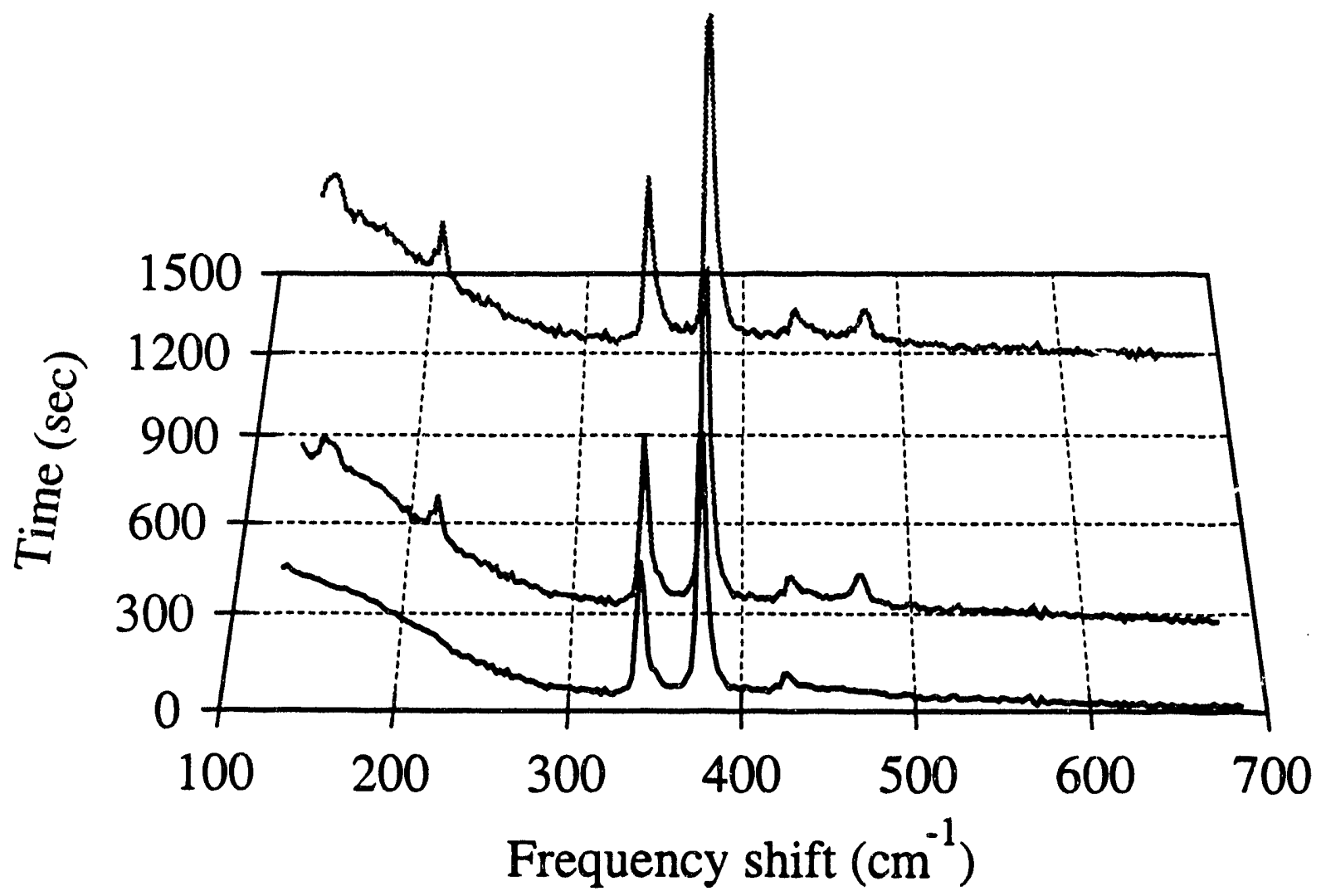

Figure 3.27. Raman spectra of electrochemically oxidized pyrite at $0.42 \mathrm{~V}$ (solution: $0.5 \mathrm{M} \mathrm{NaCl}, \mathrm{pH} 6.5$ ). 


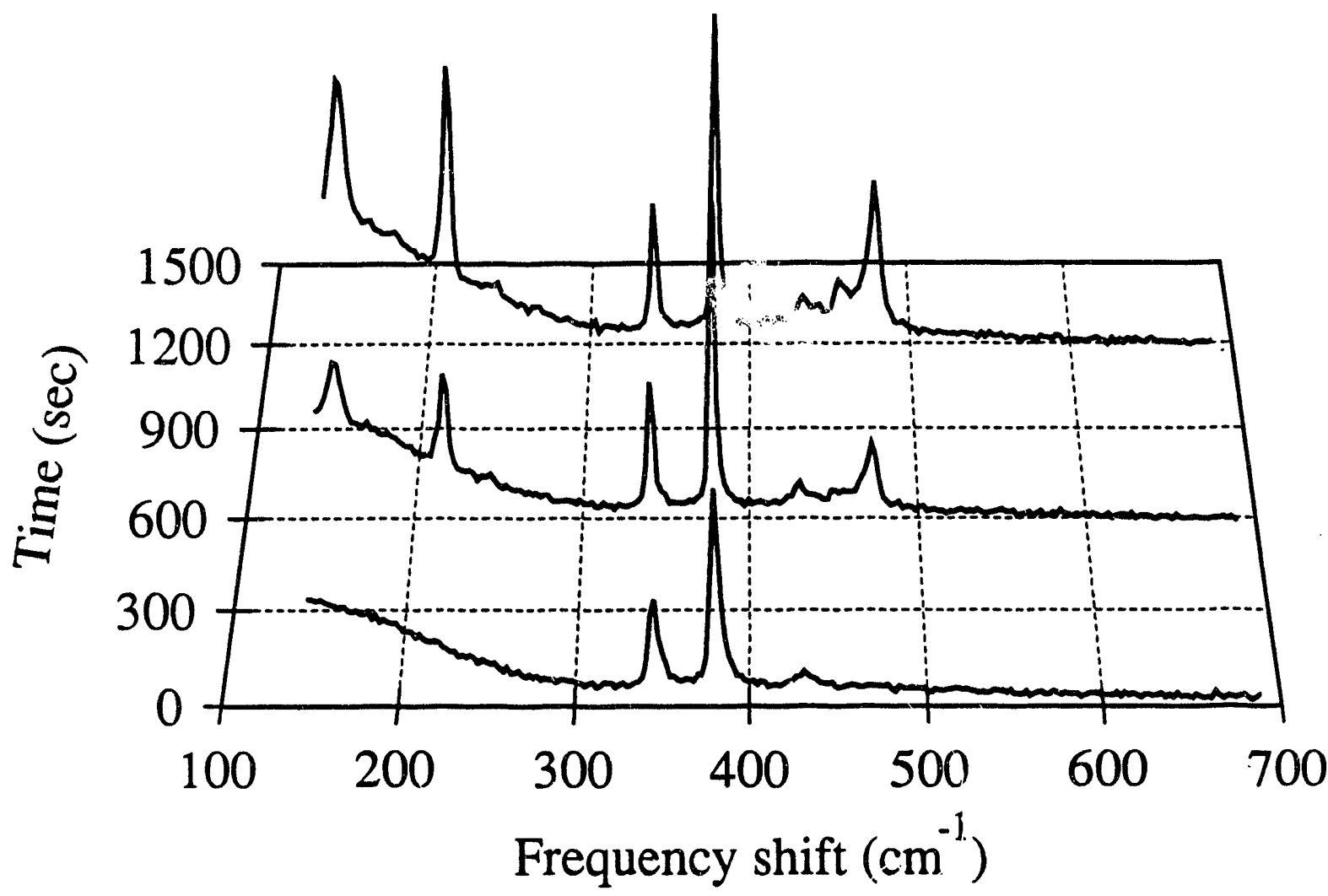

Figure 3.28. Raman spectra of electrochemically oxidized pyrite at $0.62 \mathrm{~V}$ (solution: $0.5 \mathrm{M} \mathrm{NaCl}, \mathrm{pH} 6.5$ ). 


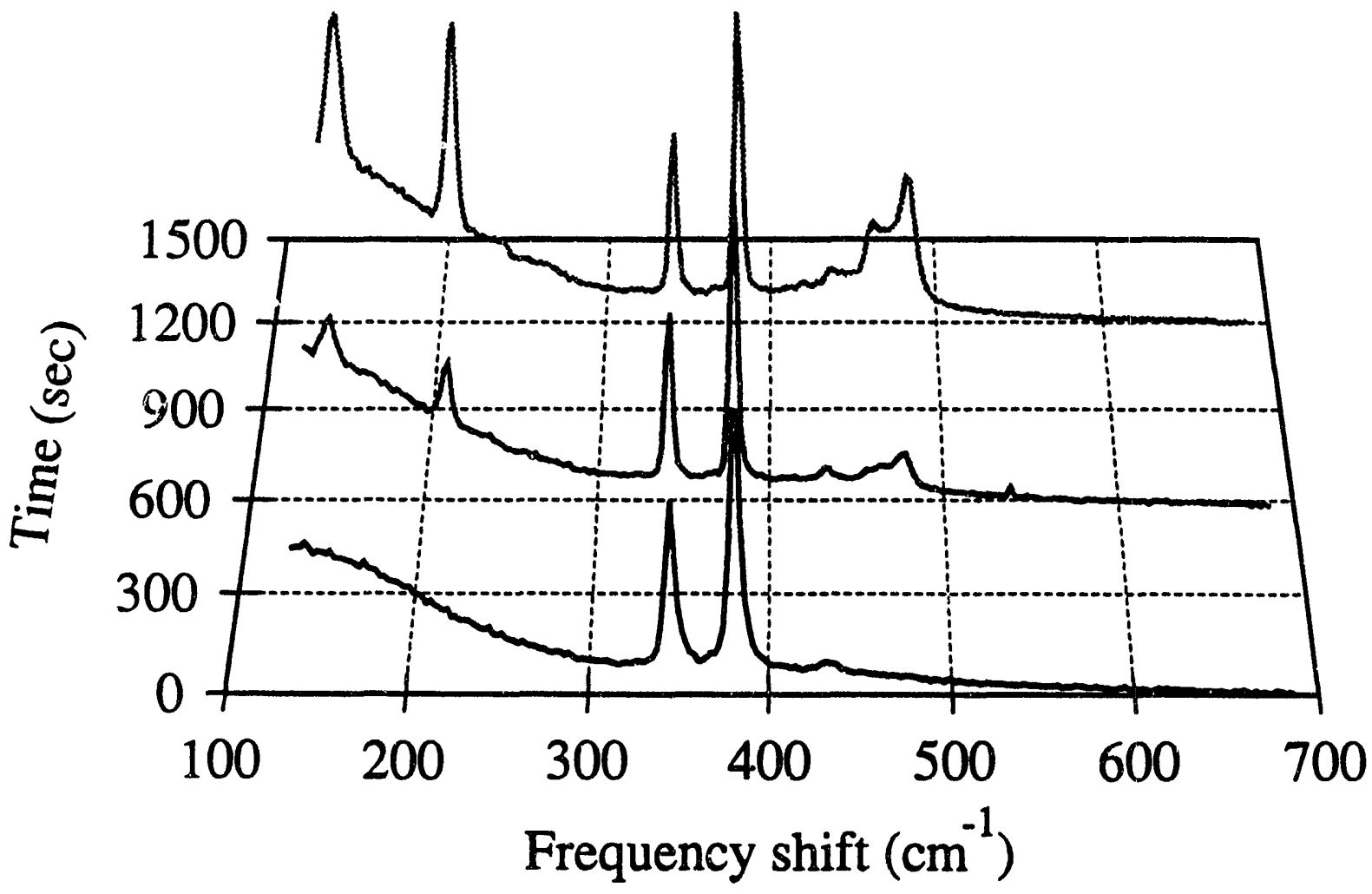

Figure 3.29. Raman spectra of electrochemically oxidized pyrite at $0.8 \mathrm{~V}$ (solution: $0.5 \mathrm{M} \mathrm{NaCl}, \mathrm{pH} 6.5$ ). 


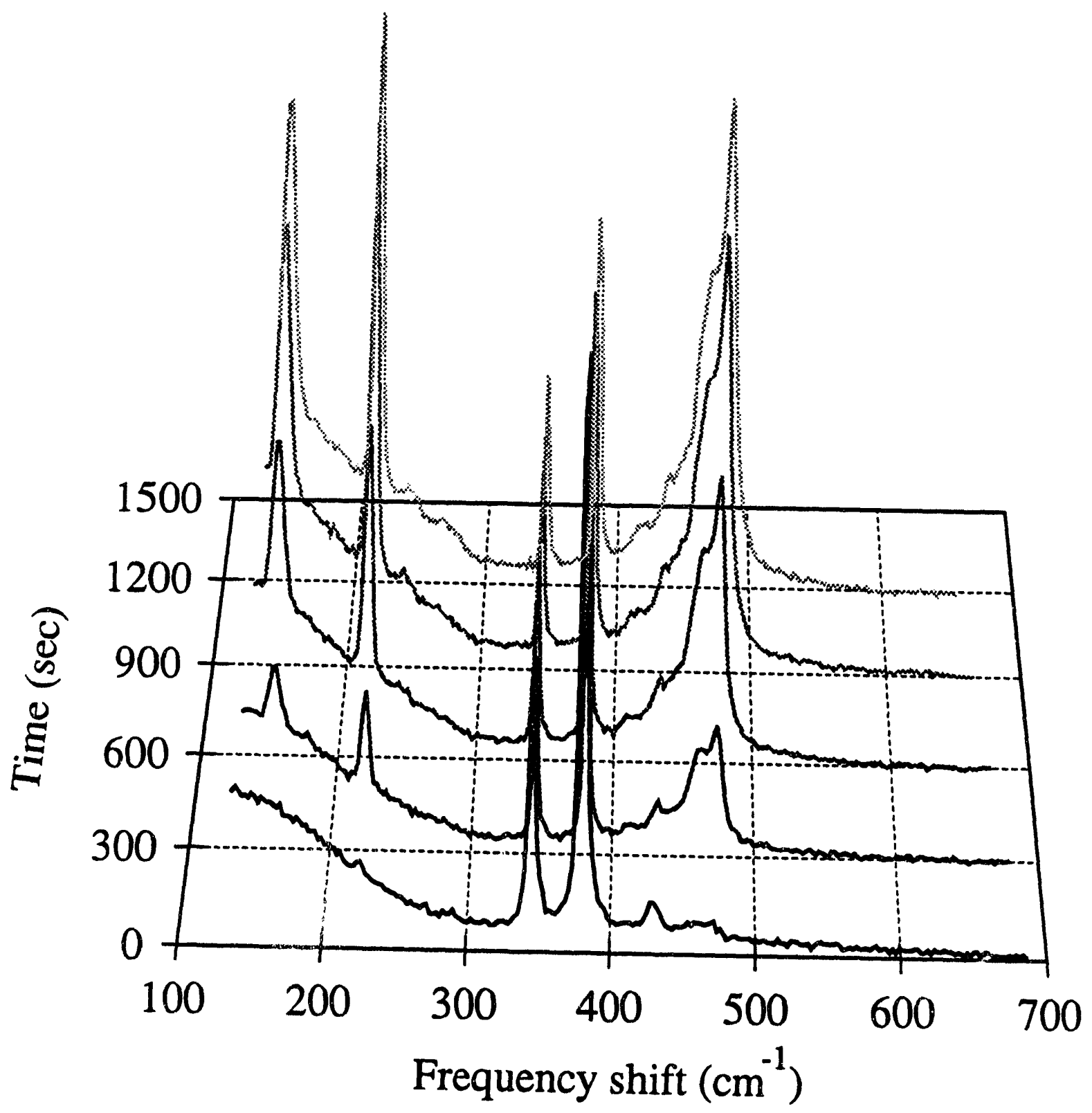

Figure 3.30. Raman spectra of electrochemically oxidized pyrite at $1.0 \mathrm{~V}$ (solution: $0.5 \mathrm{M} \mathrm{NaCl}, \mathrm{pH} 6.5$ ). 


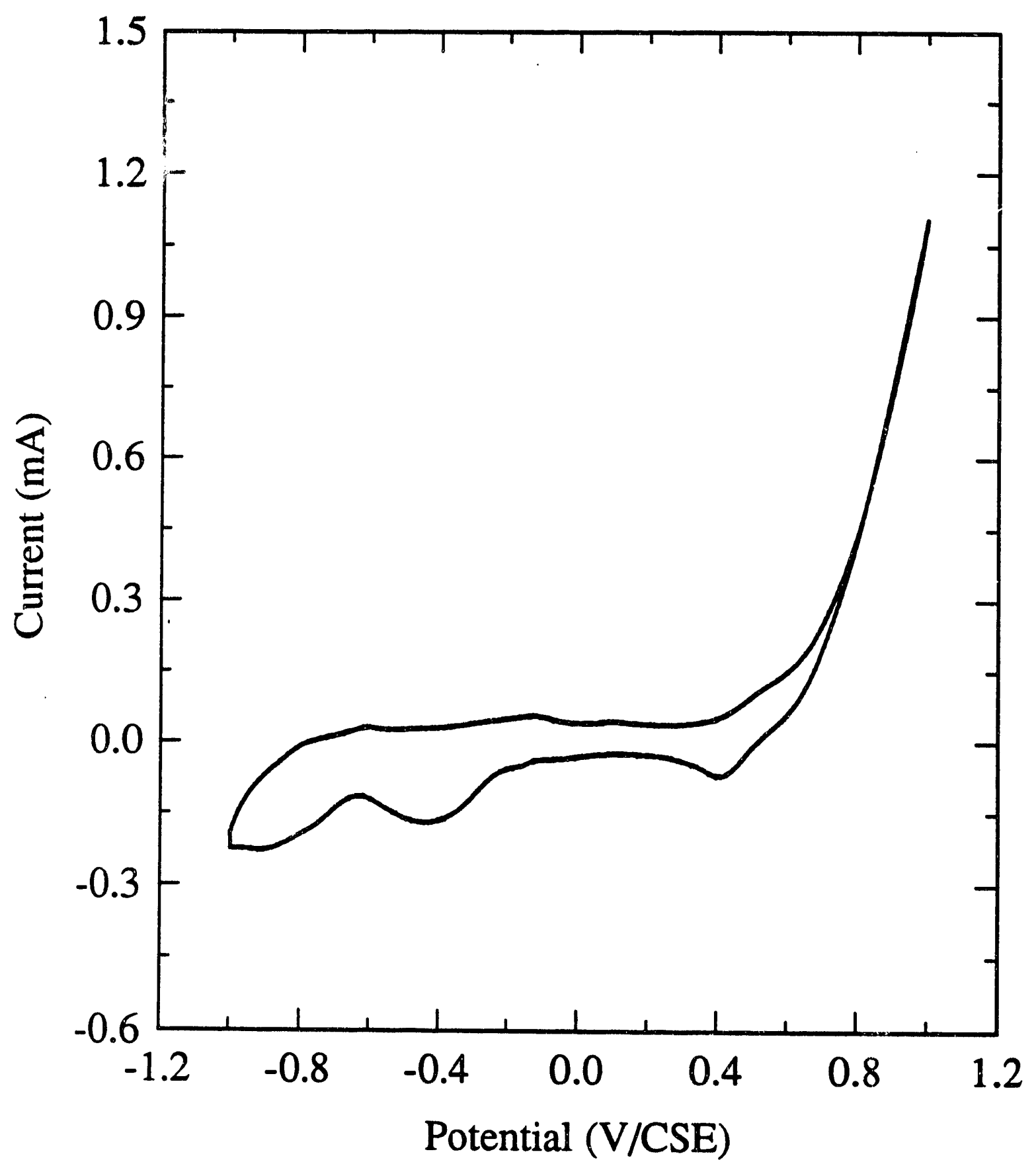

Figure 3.31. Voltammogram of mineral pyrite in a $0.5 \mathrm{M} \mathrm{NaCl}$ solution of $\mathrm{pH} 9.2$, scan rate $50 \mathrm{mV} / \mathrm{sec}$. 


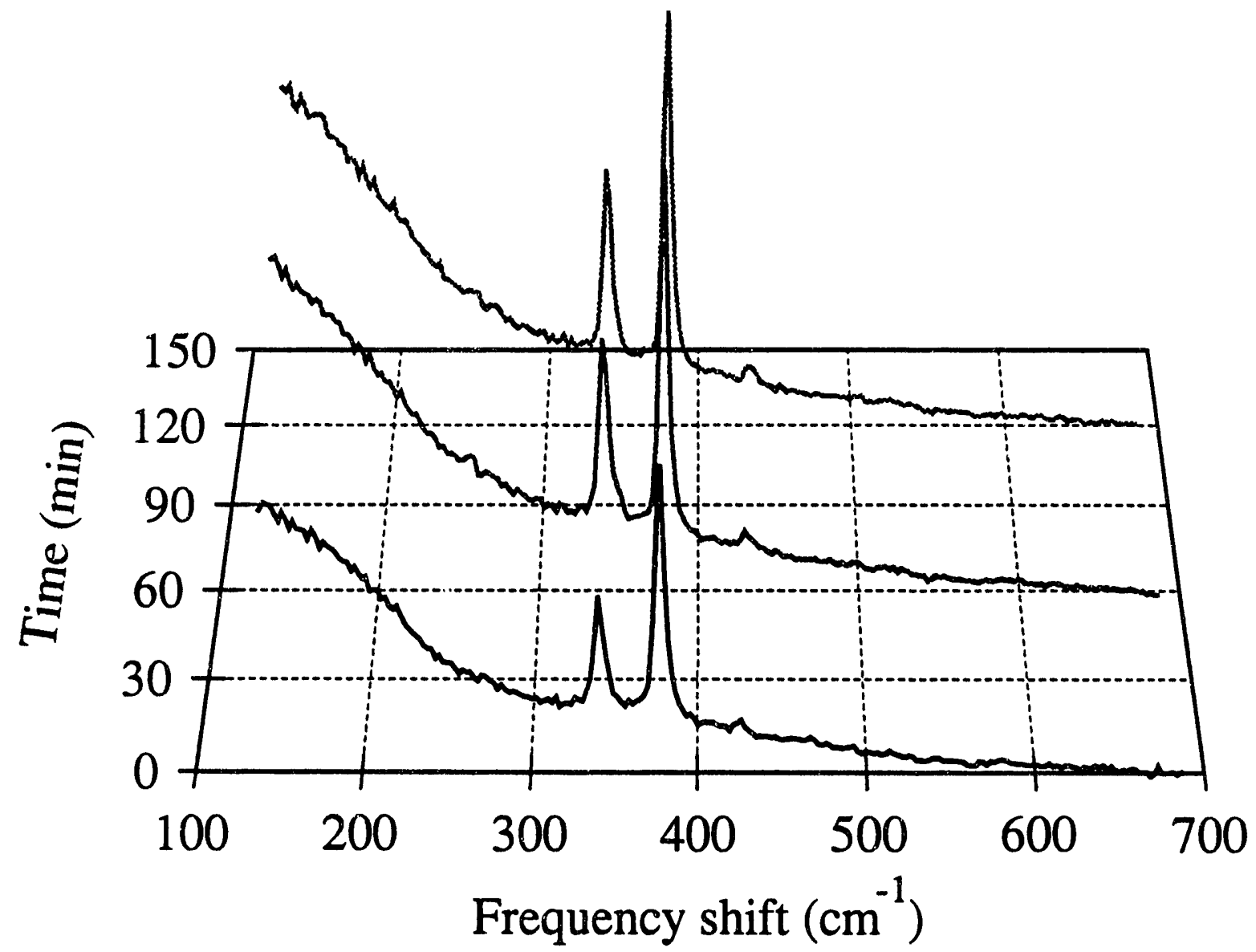

Figure 3.32. Raman spectra of electrochemically oxidized pyrite at $0.6 \mathrm{~V}$ (solution: $0.5 \mathrm{M} \mathrm{NaCl}, \mathrm{pH}$ 9.2). 


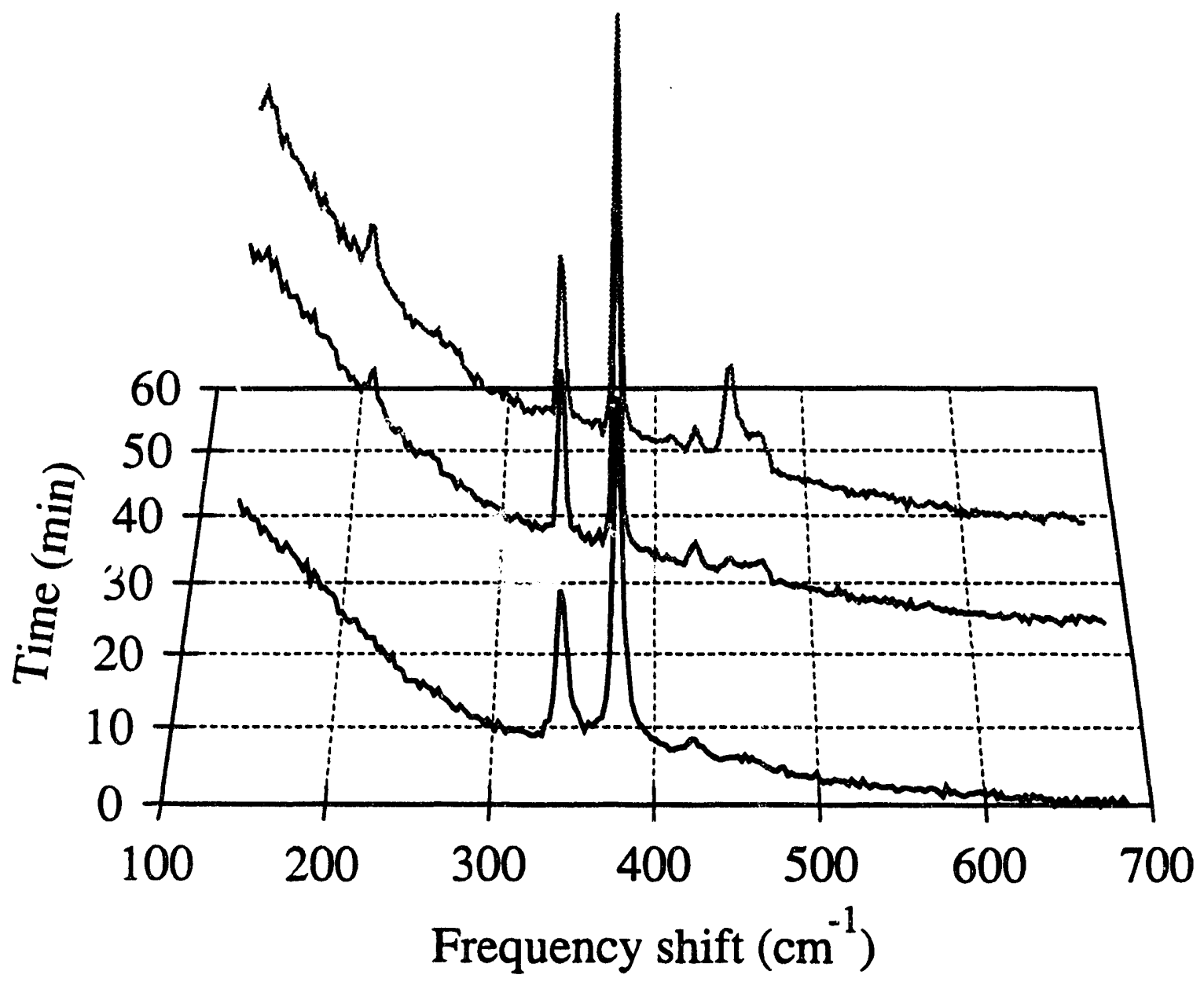

Figure 3.33. Raman spectra of electrochemically oxidized pyrite at $0.8 \mathrm{~V}$ (solution: $0.5 \mathrm{M} \mathrm{NaCl}, \mathrm{pH}$ 9.2). 


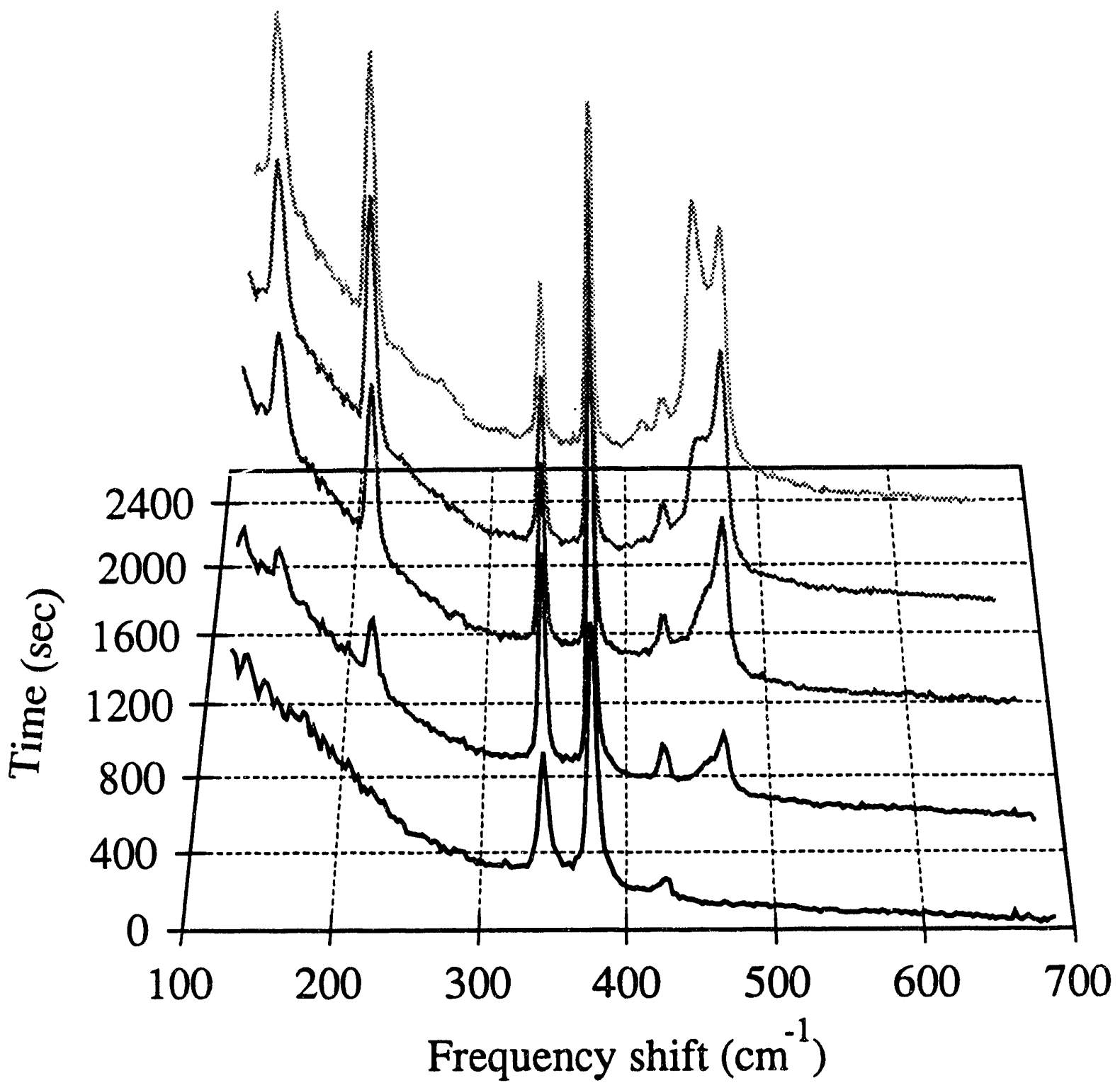

Figure 3.34. Raman spectra of electrochemically oxidized pyrite at $1.0 \mathrm{~V}$ (solution: $0.5 \mathrm{M} \mathrm{NaCl}, \mathrm{pH}$ 9.2). 


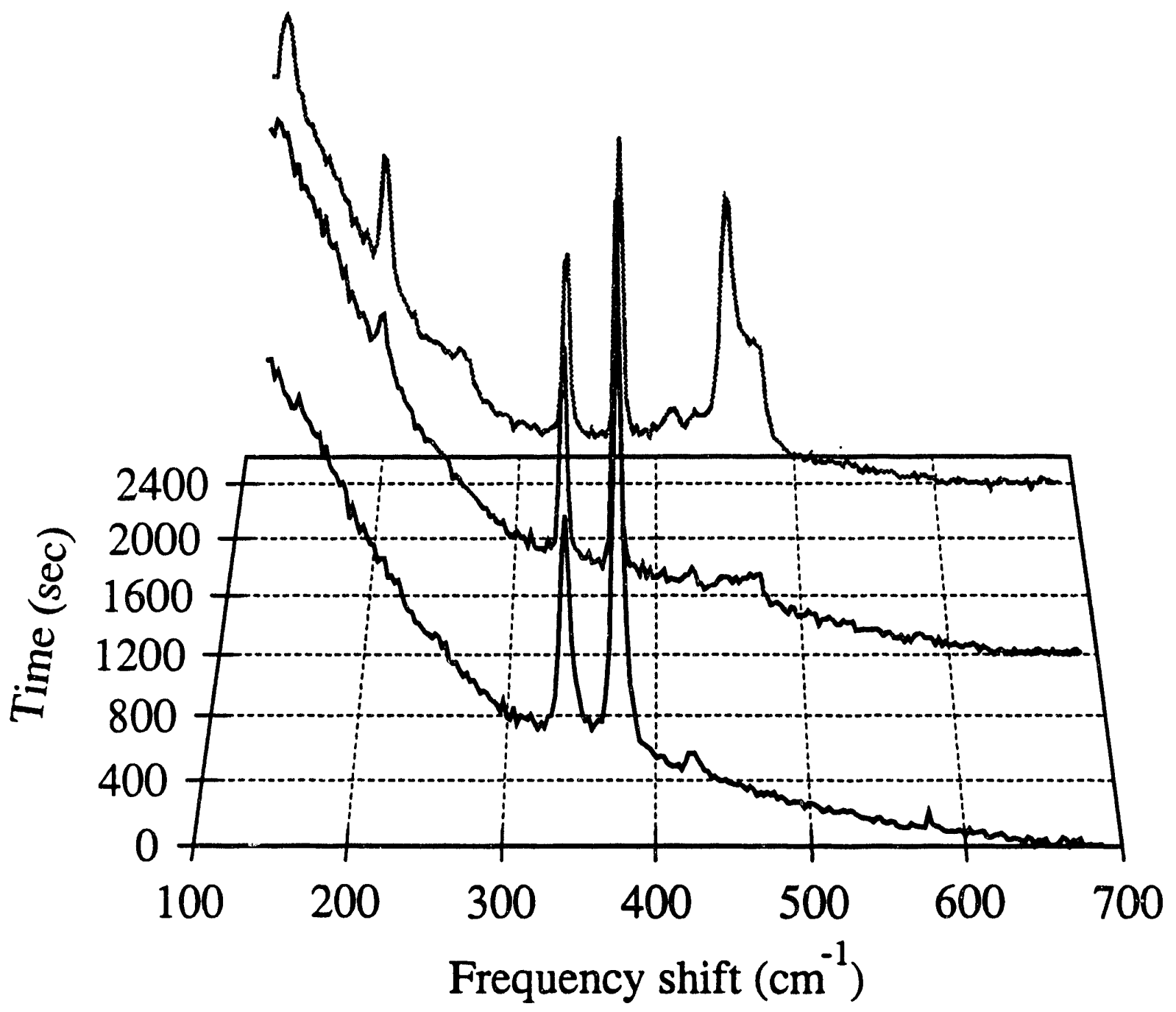

Figure 3.35. Raman spectra of electrochemically oxidized pyrite at $1.2 \mathrm{~V}$ (solution: $0.5 \mathrm{M} \mathrm{NaCl}, \mathrm{pH}$ 9.2). 


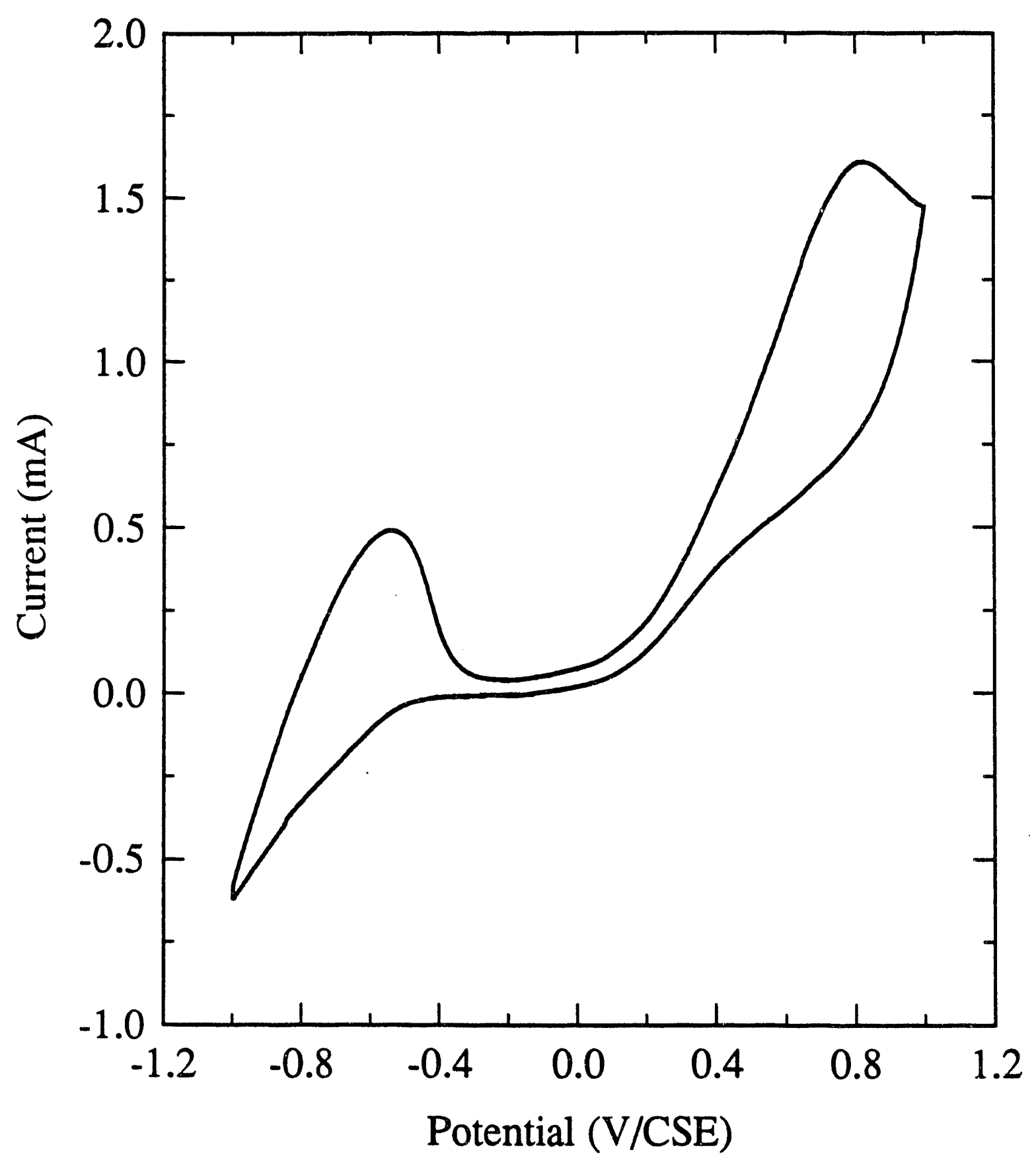

Figure 3.36. Voltammogram of mineral pyrite in a $0.5 \mathrm{M} \mathrm{NaCl}$ solution of $\mathrm{pH} 12.5$, scan rate $50 \mathrm{mV} / \mathrm{sec}$. 


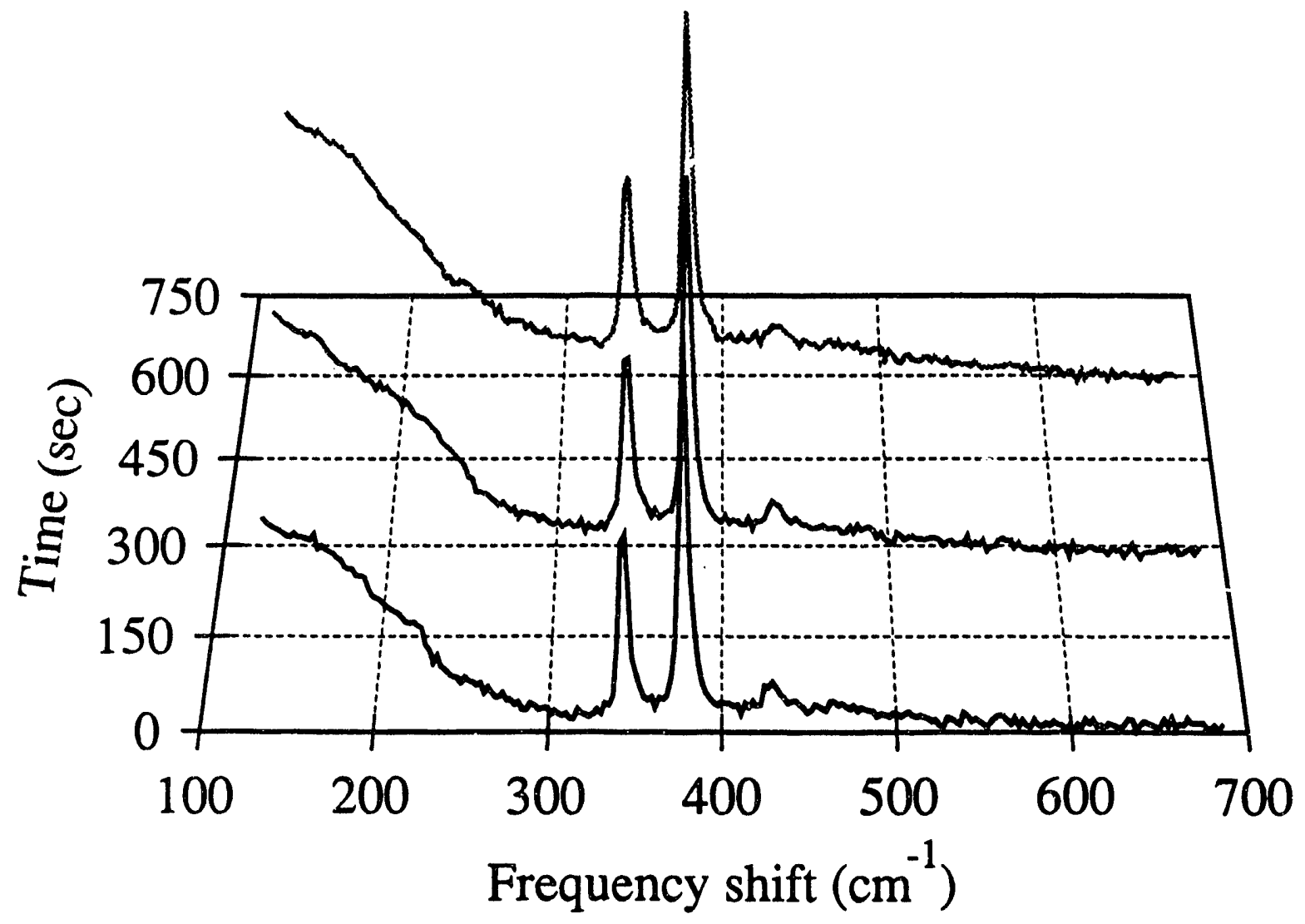

Figure 3.37. Raman spectra of electrochemically oxidized pyrite at $-0.4 \mathrm{~V}$ (solution: $0.5 \mathrm{M} \mathrm{NaCl}, \mathrm{pH} 12.5$ ). 


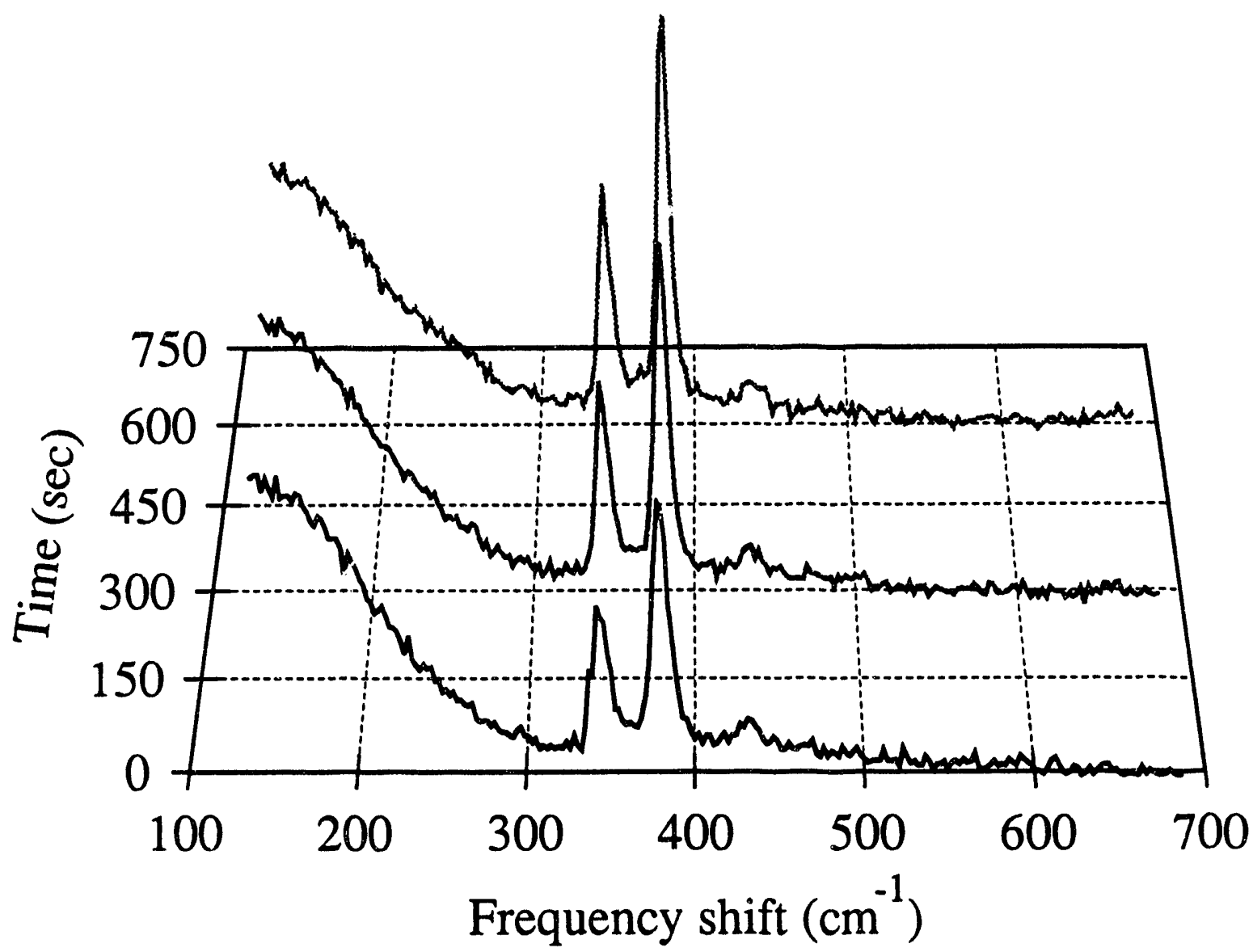

Figure 3.38. Raman spectra of electrochemically oxidized pyrite at $0.0 \mathrm{~V}$ (solution: $0.5 \mathrm{M} \mathrm{NaCl}, \mathrm{pH} 12.5$ ). 


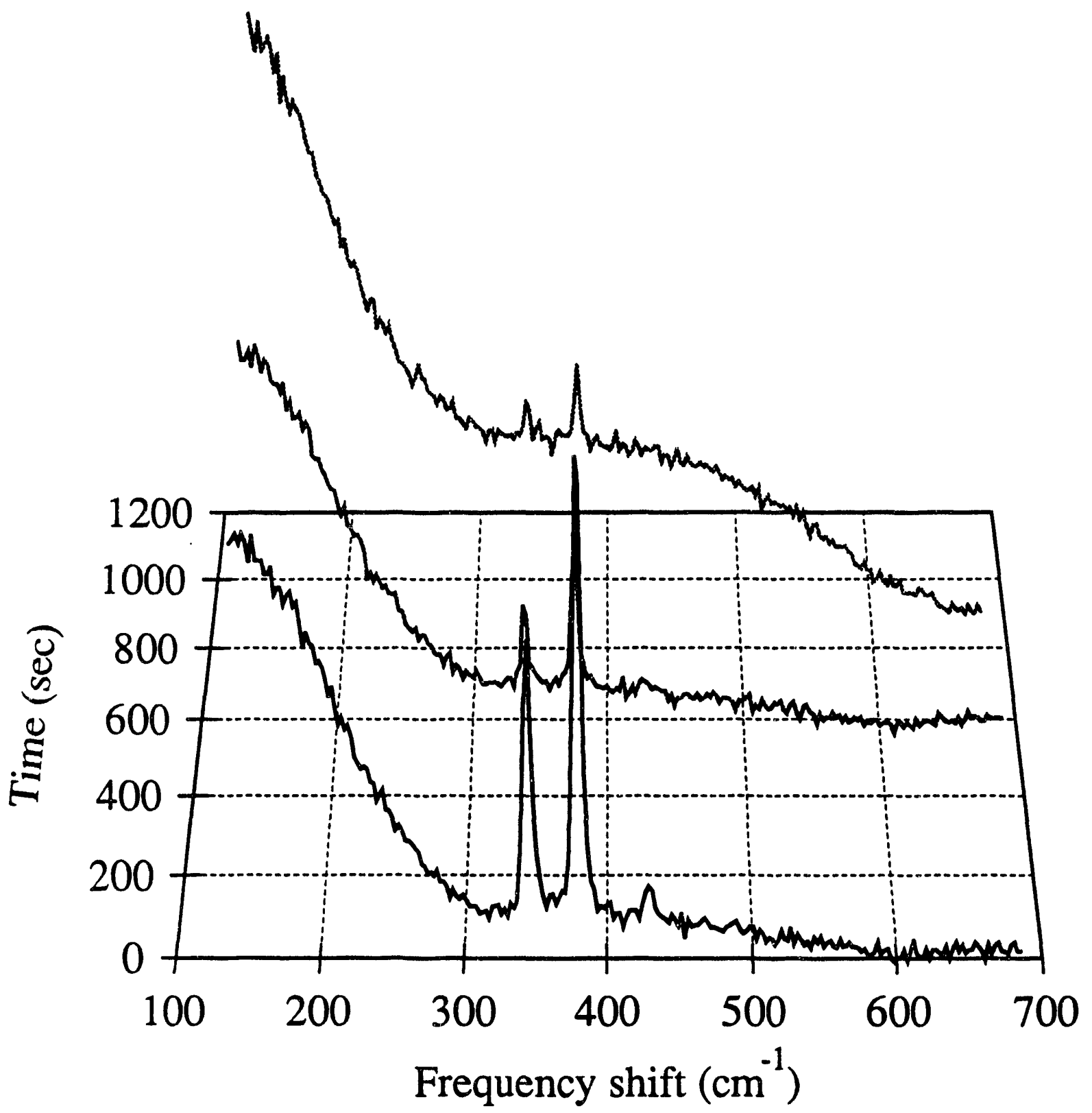

Figure 3.39. Raman spectra of electrochemically oxidized pyrite at $0.35 \mathrm{~V}$ (solution: $0.5 \mathrm{M} \mathrm{NaCl}, \mathrm{pH} 12.5$ ). 


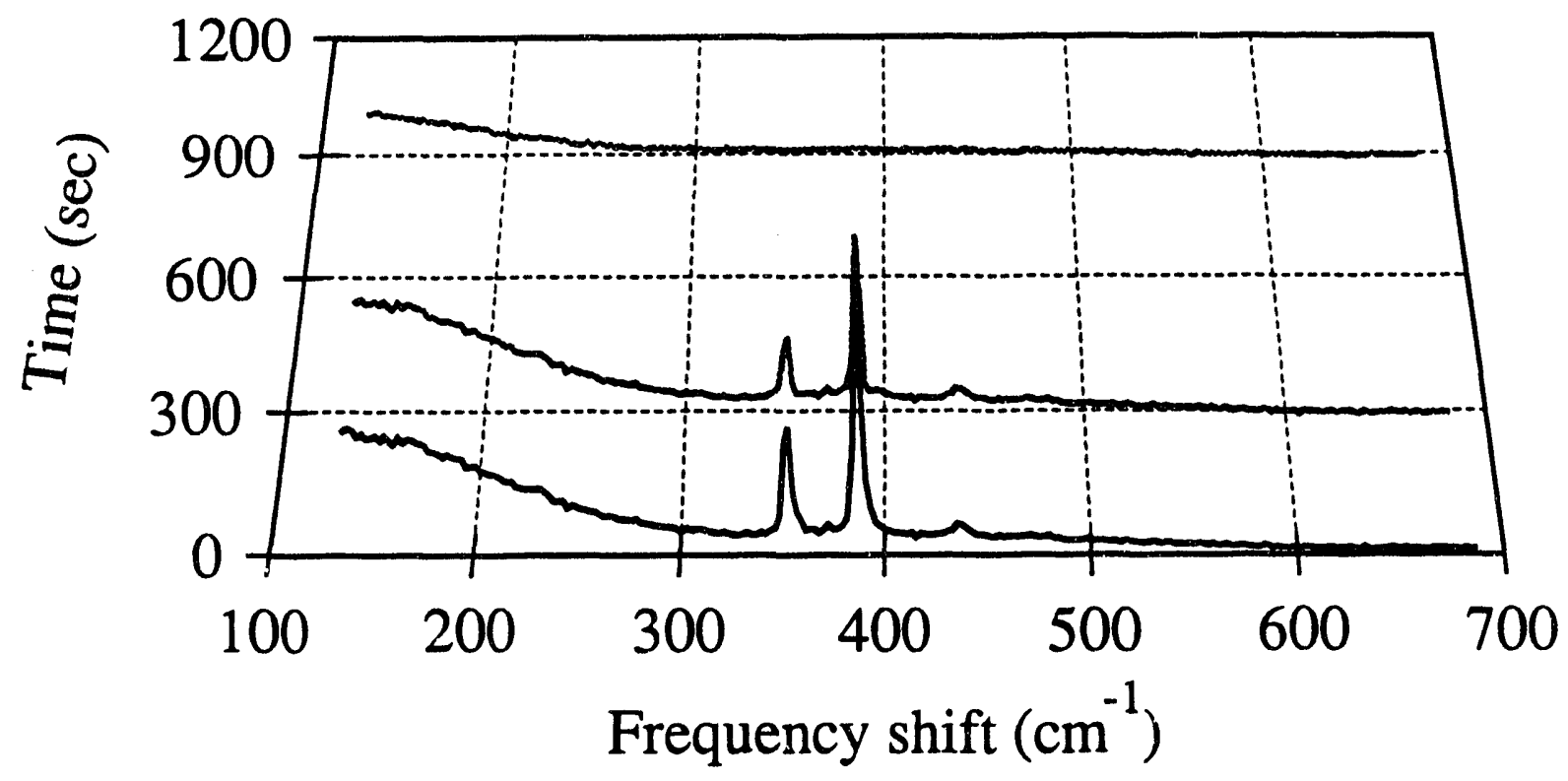

Figure 3.40. Raman spectra of electrochemically oxidized pyrite at $0.62 \mathrm{~V}$ (solution: $0.5 \mathrm{M} \mathrm{NaCl}, \mathrm{pH} 12.5$ ). 


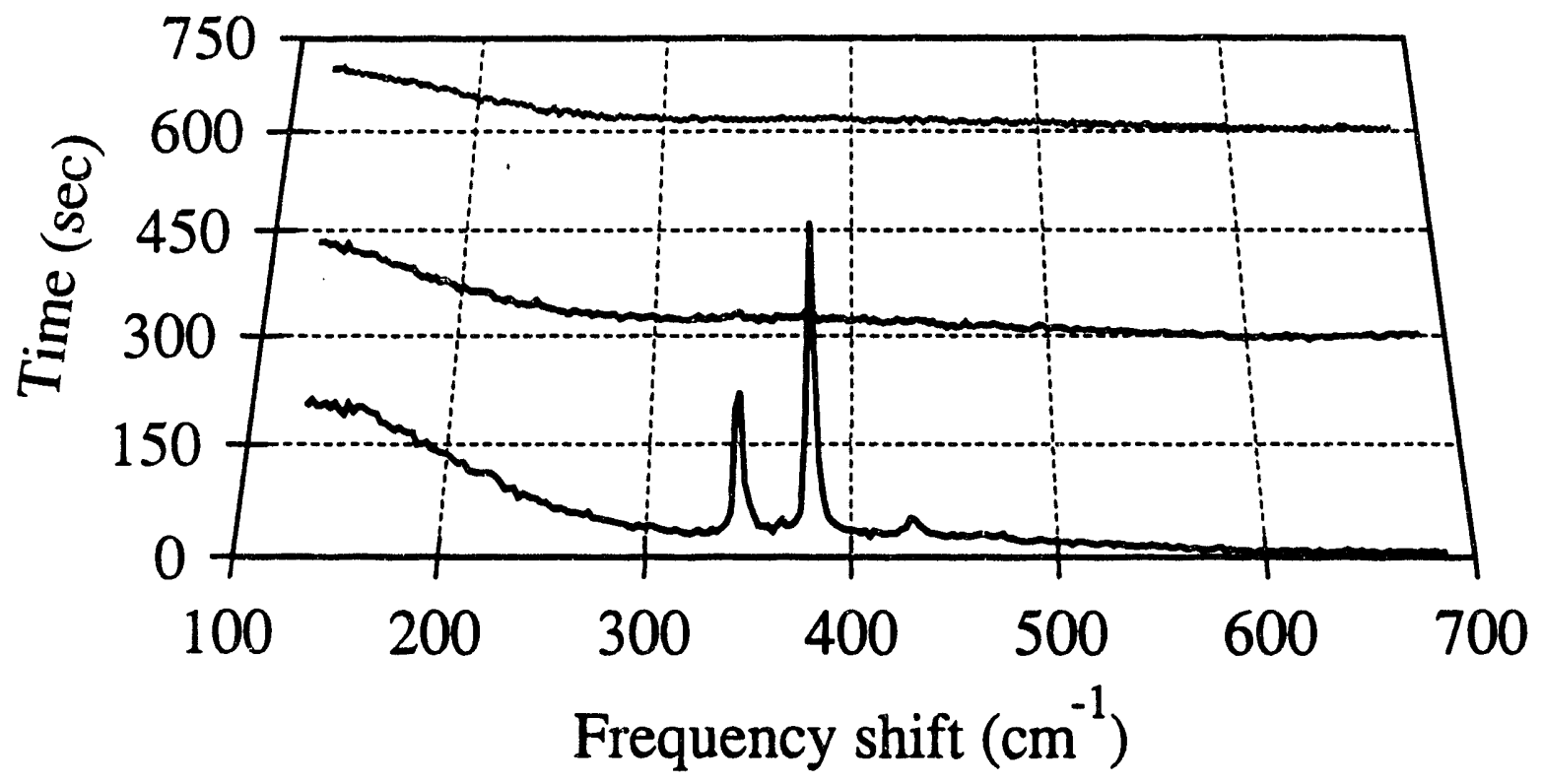

Figure 3.41. Raman spectra of electrochemically oxidized pyrite at $1.0 \mathrm{~V}$ (solution: $0.5 \mathrm{M} \mathrm{NaCl}, \mathrm{pH} 12.5$ ). 
distinct differences between the spectra taken at this $\mathrm{pH}$ and those below this $\mathrm{pH}$. Peaks associated with sulfur were not detected at any potential applied.

The pyrite peaks were clearly present and did not change with time to a significant extent at potentials below $0.0 \mathrm{~V} / \mathrm{SCE}$. At higher oxidation potentials (above $+0.35 \mathrm{~V} / \mathrm{SCE}$ ) the pyrite peaks decreased in magnitude throughout the course of the oxidation (Figures 3.39-3.41). At $+1.0 \mathrm{~V} / \mathrm{SCE}$ they were clearly present after the potential was applied for 20 seconds but after 10 minutes and the passage of $828 \mathrm{mC}$ they were no longer visible (Figure 3.41). This may be attributed to the formation of amorphous iron hydroxides, which covered the surface. Since amorphous iron hydroxides are poor Raman scatters, only blank background was present in the spectra.

Conditions of Potential and $\mathrm{pH}$ for Sulfur Formation. The conditions at which sulfur was observed by Raman spectroscopy from electrochemical oxidation of pyrite are shown in the S- $\mathrm{H}_{2} \mathrm{O}$ E-pH diagram (solid circles in Figure 3.42). For comparison, those experiments which did not produce sulfur signals are also marked in the figure with open circles. Potential and solution $\mathrm{pH}$ affected the electrochemical oxidation of pyrite and the threshold for sulfur formation. As may be seen from the spectra of the oxidized pyrite in different solutions and as depicted in Figure 3.42, a minimum potential was required to form sulfur on pyrite surfaces (except in strong alkaline solutions). The minimum potential for sulfur to be detected changed with the solution $\mathrm{pH}$ in the time period studied (about 2 hours). For both acid ( $\mathrm{pH} \mathrm{2.7)} \mathrm{and} \mathrm{weak} \mathrm{alkaline} \mathrm{(} \mathrm{pH} \mathrm{9.2)} \mathrm{solutions,} \mathrm{the}$ observed value was $+0.80 \mathrm{~V} / \mathrm{SCE}$, whereas for neutral solutions the value lowered to $+0.40 \mathrm{~V} / \mathrm{SCE}$. The solid circles of Figure 3.46 define a metastable region for the formation of sulfur intermediates and sulfur and thus define of region for pyrite hydrophobicity. In strong alkaline solutions ( $\mathrm{pH} 12.5$ ) sulfur could not be detected at any potential. The pyrite peaks also disappeared at high applied potentials and high $\mathrm{pH}$ because of the formation of surface amorphous iron hydroxides.

\section{Intermediates of Pyrite Oxidation: Polysulfides}

The sulfur formed by oxidation of pyrite has sufficient interatomic bonding with 


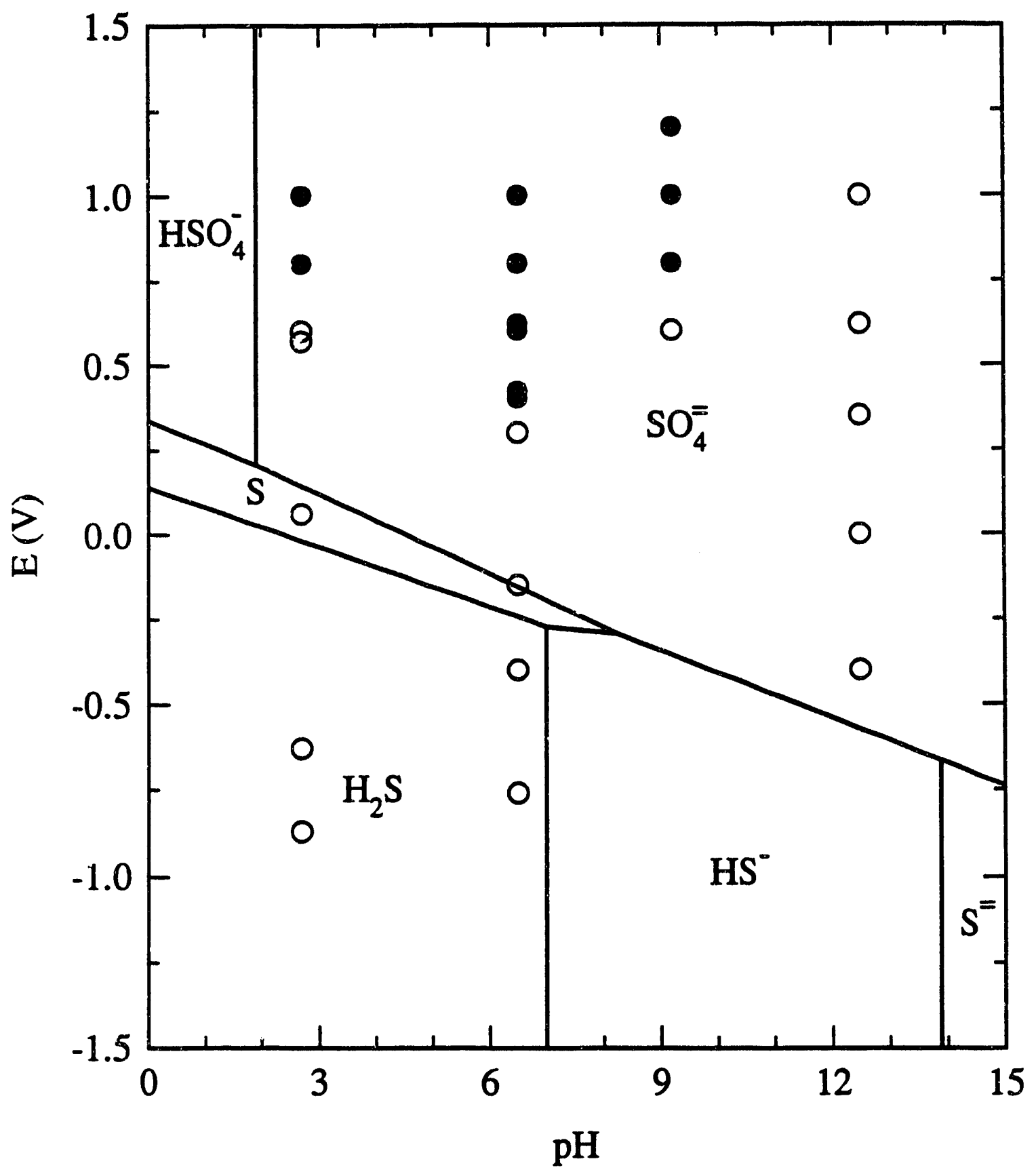

Figure 3.42. Conditions for sulfur detection from oxidation of pyrite with Raman spectroscopy: 0 unobserved; observed. 
other sulfur atoms to be able to generate the simplest forms of vibrations, namely the S-S stretching and S-S-S bending modes. However, the broad peak between 440 and $480 \mathrm{~cm}^{-1}$ is not characteristic of elemental sulfur. In Figures 3.43-3.45 the frequency shift axes of Figures $3.21,3.30$, and 3.34 are expanded to show more detail of this peak as a function of time. It is seen that the peak is the sum of a number of separate peaks. These peaks are attributed to the S-S stretching mode of various polysulfide species.

The separate peaks change in size relative to each other with time. As shown in Figure 3.45, for example, after 30 minutes a large peak at $455 \mathrm{~cm}^{-1}$ appeared. Eventually this peak disappeared again. At the end of the experiment it was visually observed that the pyrite electrode surface was slightly blackened. These peaks develop with time indicating that the relative distribution of polysulfide species is changing. This result is different from what Mycroft et al. has reported [3.8]. They found only a single polysulfide species instead of a mixture. The difference could be due to the fact that they did not take enough spectra, especially during the early stage of the experiment.

It is known that the Raman shift is a strong function of the S-S bond length. Comparison with other work on inorganic polysulfides illustrates results in agreement with this interpretation [3.29, 3.30]. Janz et al. have measured the Raman spectra of various potassium and sodium polysulfides. They show that there exist many Raman peaks for S-S stretching modes from the polysulfide species $S_{3}{ }^{2}(458,466,472$, and 476 $\left.\mathrm{cm}^{-1}\right), \mathrm{S}_{4}=\left(468,478,482\right.$ and $\left.485 \mathrm{~cm}^{-1}\right), \mathrm{S}_{5}{ }^{2}\left(479,485\right.$ and $\left.488 \mathrm{~cm}^{-1}\right)$ and $\mathrm{S}_{6}{ }^{2}(455$ and 495 $\mathrm{cm}^{-1}$ ) [3.31, 3.32]. Also Lenain et al. have published Raman spectra of sulfur vapor [3.33]. Unfortunately, there were no published iron polysulfide data for reference purposes.

Polysulfides formation during pyrite oxidation may occur according to the following mechanism in a series of steps:

$$
\begin{array}{ccc}
3 F e S_{2}(\text { lattice })=2 F e S_{3}(\text { lattice })+F e^{3+}+3 e^{-} \\
\cdot & \cdot & \cdot
\end{array}
$$




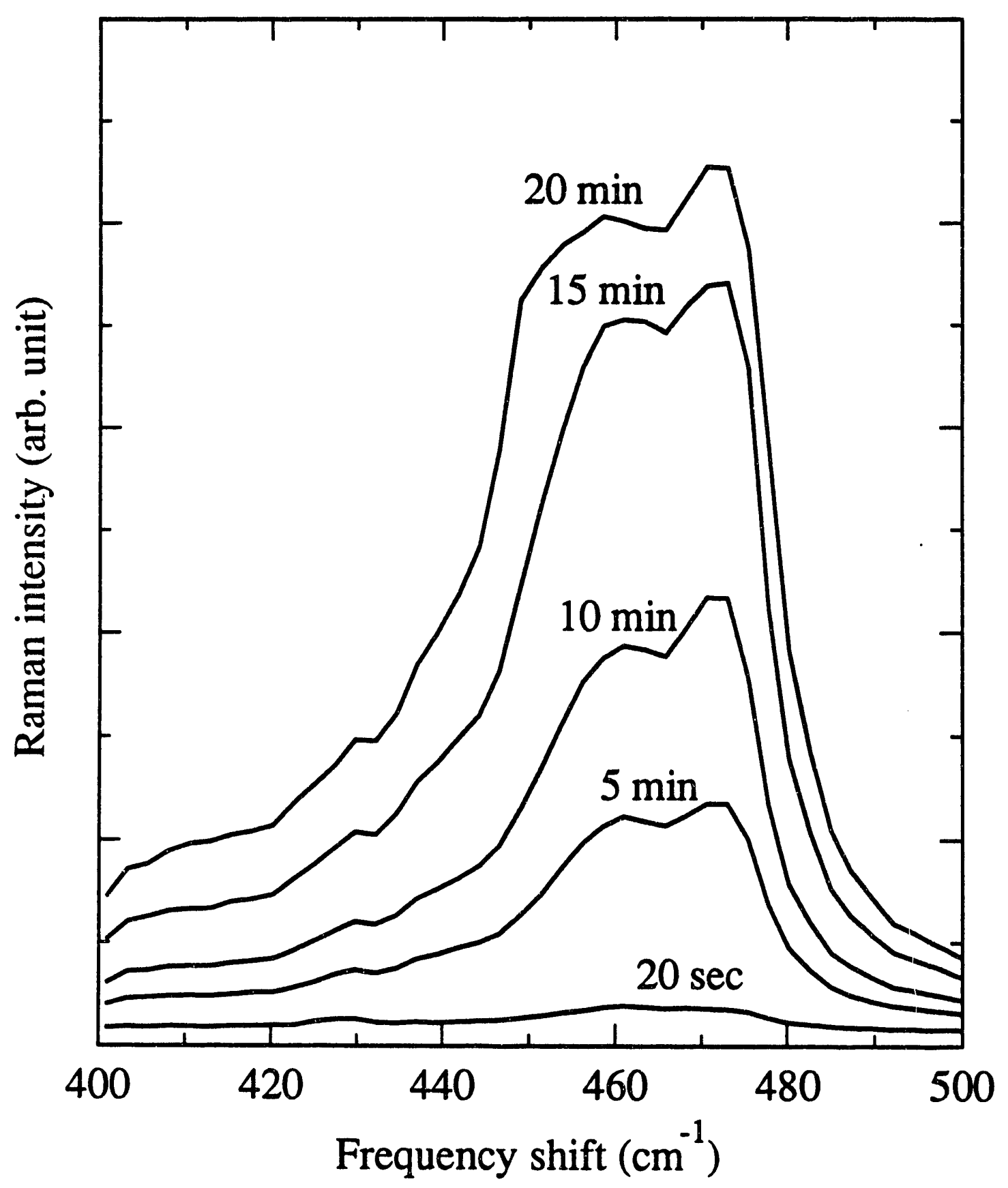

Figure 3.43. Expanded frequency shift scale for Figure 3.21 (pH 2.7). 


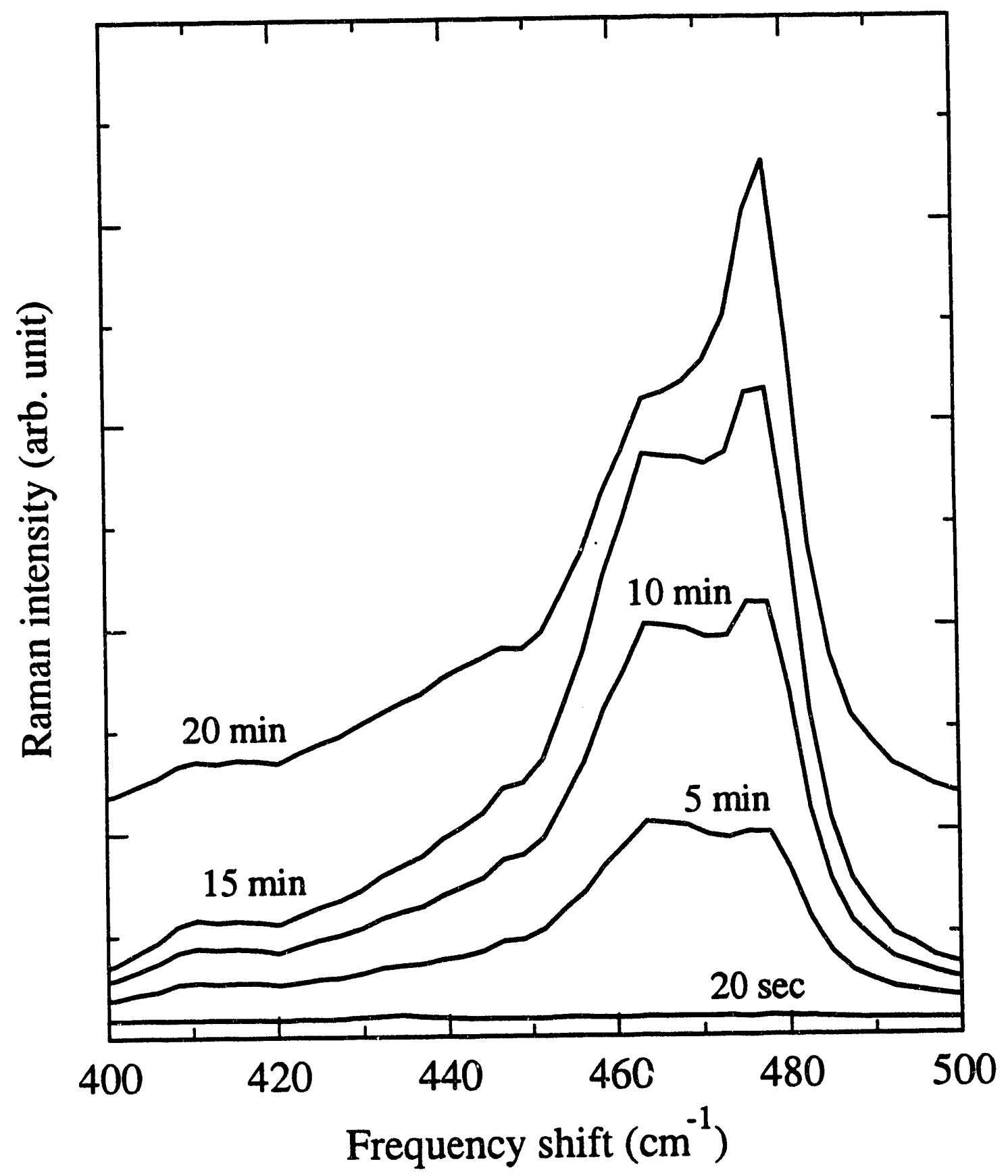

Figure 3.44. Expanded frequency shift scale for Figure 3.30 (pH 6.5). 


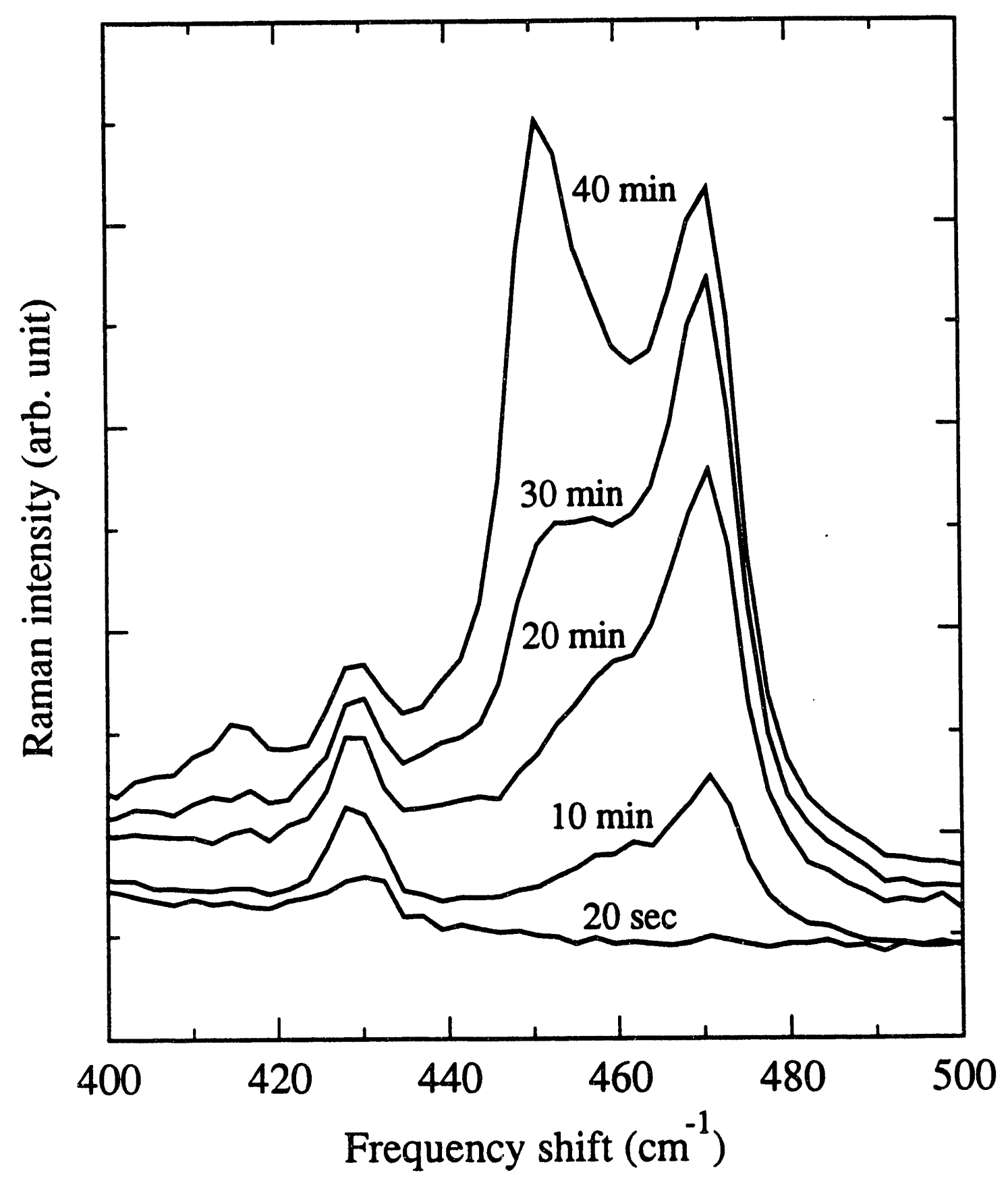

Figure 3.45. Expanded frequency shift scale for Figure 3.34 (pH 9.2). 
According to thermodynamic analysis, polysulfides are not stable under these experimental conditions. Given time, they convert to elemental sulfur as shown from the Raman spectra. This is shown in Figure 3.46. The Raman spectrum of the pyrite electrode in a neutral solution was taken every half hour during a potentiodynamic experiment. The scan started from $0.0 \mathrm{~V} / \mathrm{SCE}$ and ended at $+1.0 \mathrm{~V} / \mathrm{SCE}$ with a very slow scan rate of 0.02 $\mathrm{mV} / \mathrm{sec}$. The whole experiment lasted about 14 hours. At the end of the experiment, the sulfur peaks obtained from the oxidation of pyrite completely resembled those of elemental sulfur. Mycroft et al. reported the similar results [3.8]: after 23 hours of oxidation at $+0.70 \mathrm{~V} / \mathrm{SCE}$ elemental sulfur became the predominant surface component.

\section{Detection of Oxy-Sulfur Compounds}

It has been suggested that oxy-sulfur compounds may be produced during the oxidation of pyrite [3.2]. However, ring-disc studies of the oxidation of sulfide ion on gold did not provide any evidence for the formation of oxy-sulfur species [3.3].

Sulfate is a known product of $\mathrm{S}_{2}{ }^{2-}$ oxidation and has been measured as a function of oxidation potentials [3.35]. Woods, Constable and Hamilton have also looked for other oxy-sulfur species using a ring-disc electrode at $\mathrm{pH} \mathrm{6,9}$ and 13 [3.36]. On the basis of the coulometric analysis they concluded that none were produced and the oxidation products were entirely sulfur and sulfate. An attempt was made in these studies to observe the presence of sulfate ions which are indicated by a Raman peak at approximately 985 $\mathrm{cm}^{-1}$ (Figure 3.47b). However, it was generally unsuccessful even though large quantities of charge (several dozens of Coulombs) were passed during electrochemical oxidation. After prolonged oxidation (1 hour) at $+1.0 \mathrm{~V} / \mathrm{SCE}$ in a neutral solution ( $\mathrm{pH} 6.5$ ), a very small peak at $985 \mathrm{~cm}^{-1}$ was observed (Figure $3.47 \mathrm{c}$ ). The addition of sodium sulfate to the solution caused a large increase in the intensity of the peak confirming its identification with the sulfate breathing mode (Figure 3.47d). The obstacle to the detection of sulfate in these studies is its considerable solubility. The sulfate dissolves immediately upon formation and is transported by diffusion away form the pyrite surface and out of the probe volume.

There are a large number of oxy-sulfur species whose Raman spectra have been 


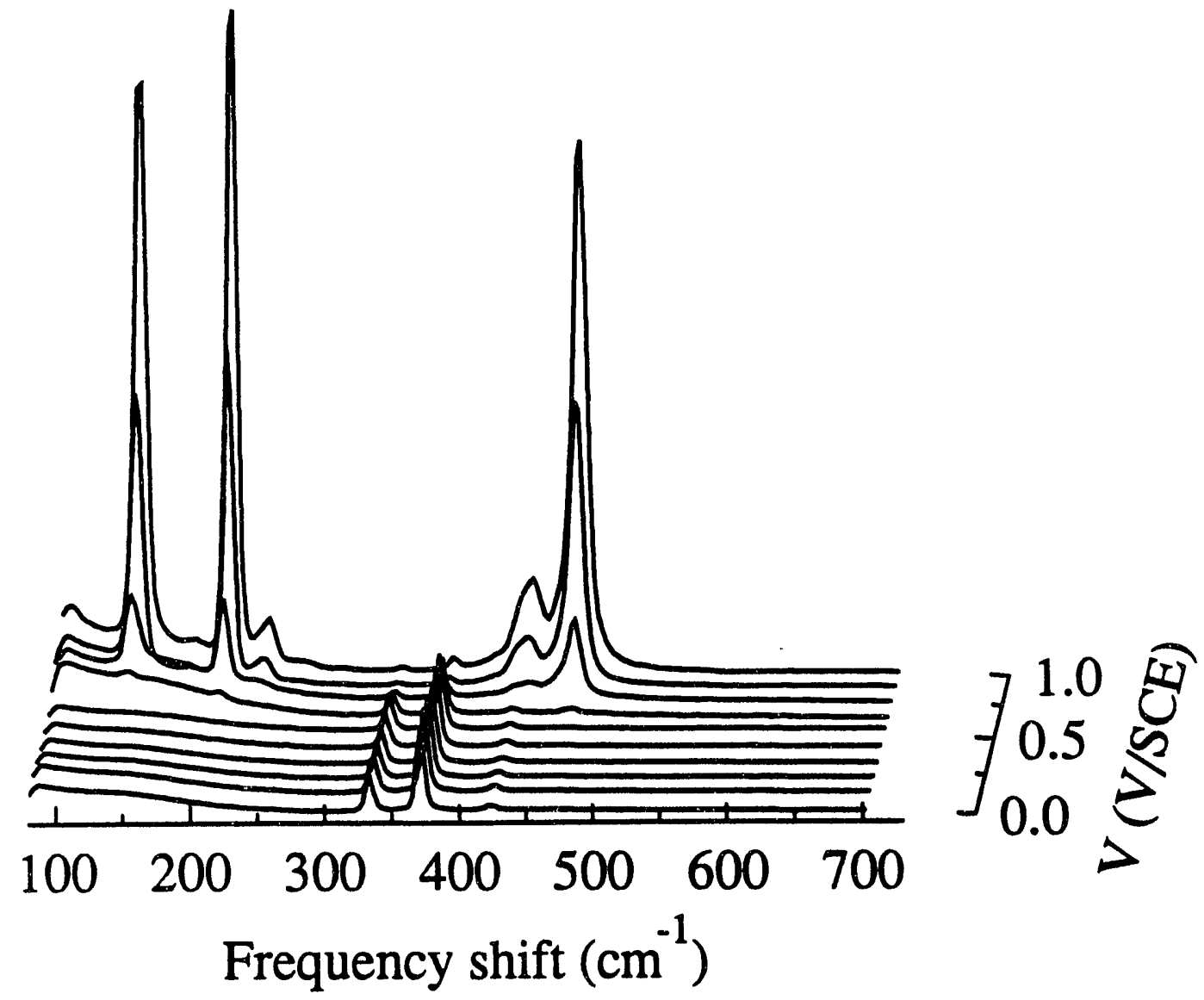

Figure 3.46. Raman spectra of pyrite during a cyclic voltammetry experiment (solution: $0.5 \mathrm{M} \mathrm{NaCl}, \mathrm{pH} 6.5$; scan rate: $0.02 \mathrm{mV} / \mathrm{sec}$ ). 


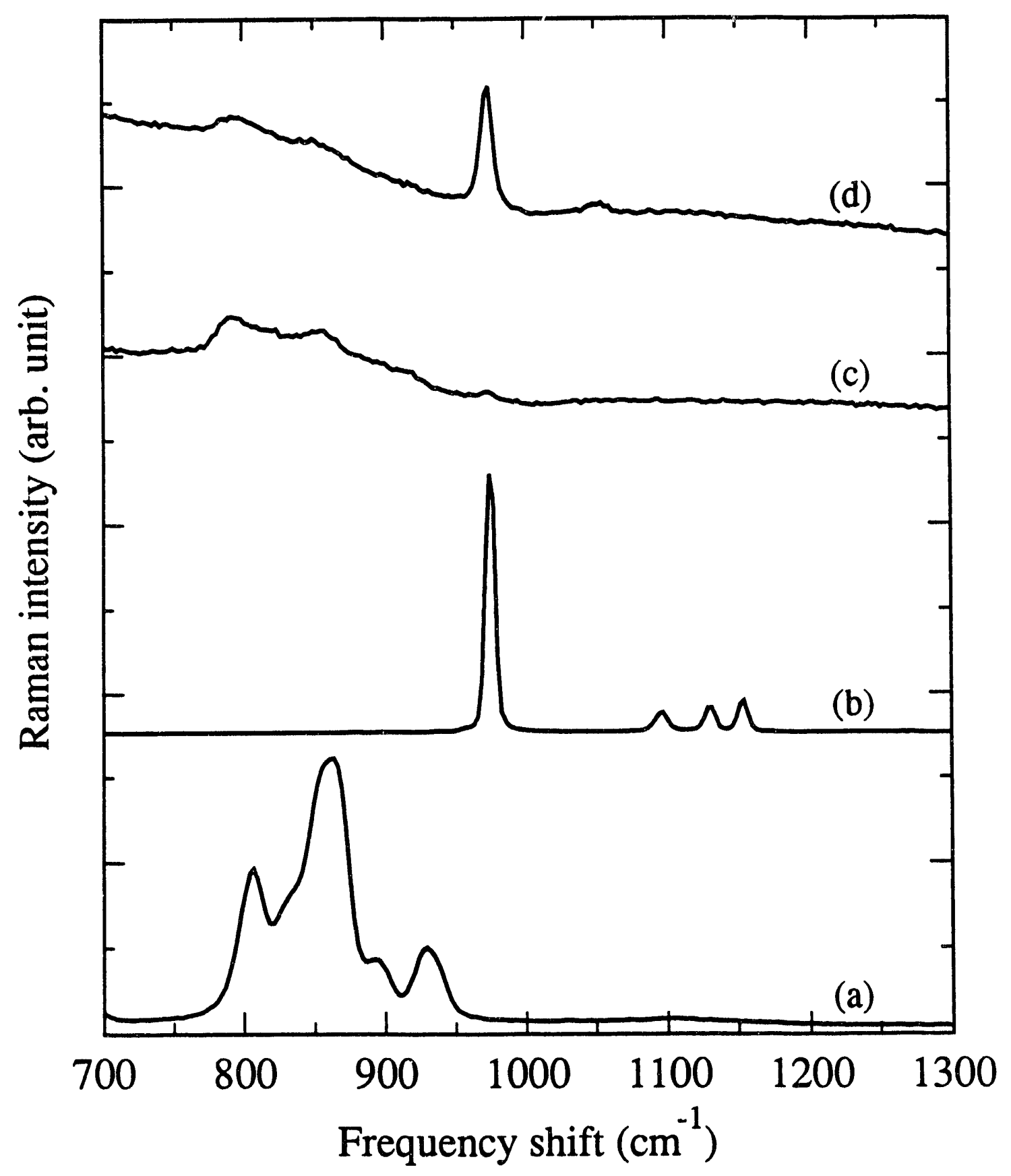

Figure 3.47. Detection of sulfate with Raman spectroscopy (a) sulfur in air; (b) $\mathrm{Na}_{2} \mathrm{SO}_{4}$ in air; (c) mineral pyrite oxidized at $+1.0 \mathrm{~V} / \mathrm{SCE}$ for 1 hour (pH 6.5); (d) adding $\mathrm{Na}_{2} \mathrm{SO}_{4}$ to solution after (c). 
characterized [3.37]. However, to date, none have been identified in these in-situ experiments.

\section{Optimum Potential for Sulfur Formation}

There exists a minimum or threshold potential for sulfur to form and be detected by Raman spectroscopy for solutions of different $\mathrm{pH}$ values. Raman results suggested that higher potentials produced stronger sulfur peaks, as shown in previous figures. Naturally this raised the question whether a higher potential in fact produced more sulfur or whether kinetic factors give an appearance of greater amounts of sulfur. To answer this question, total charge passed must be compared to the Raman spectra observed for a given $\mathrm{pH}$. Data were collected under identical Raman experimental conditions for a solution containing $0.5 \mathrm{M} \mathrm{NaCl}$ at a $\mathrm{pH}$ of 9.2. Raman spectra were obtained for pyrite oxidized at potentials $+0.80,+1.0$ and $+1.20 \mathrm{~V} / \mathrm{SCE}$ respectively. Sulfur spectra were detected at all three potentials and were similar to those shown in Figures 3.33-3.35.

The intensity of the sulfur spectra is defined here arbitrarily as the integration of the broad peak at about $470 \mathrm{~cm}^{-1}$ with respect to the frequency shift. The intensity, thus defined can be plotted against the charge passed to the pyrite electrode to deniriastrate the effectiveness of sulfur formation at each applied potential. The results are illustrated in Figure 3.48. From Figure 3.48 it may be seen that for potentials above $+0.80 \mathrm{~V} / \mathrm{SCE}$ the amount of sulfur formed diminishes compared to total charge passed. The observed steady-state currents were about $2.5,1$, and $0.4 \mathrm{~mA}$ respectively for potentials of +1.20 , +1.0 and $+0.80 \mathrm{~V} / \mathrm{SCE}$. These results are in good agreement with the sulfur-deposition experiment. Whell sulfur was precipitated from a sulfide solution onto the platinum electrode, an optimum potential was observed for maximum sulfur formation (Figure 3.13).

Diminishing sulfur production at potentials higher than $+0.80 \mathrm{~V} / \mathrm{SCE}$ was also reported in the electrochemical studies under this project [3.38]. The optimum potential for making sulfur, according to the electrochemical research, is between $0.75 \sim 0.80$ V/SCE. The results from Raman spectroscopic study agree well with those from electrochemical measurements. 


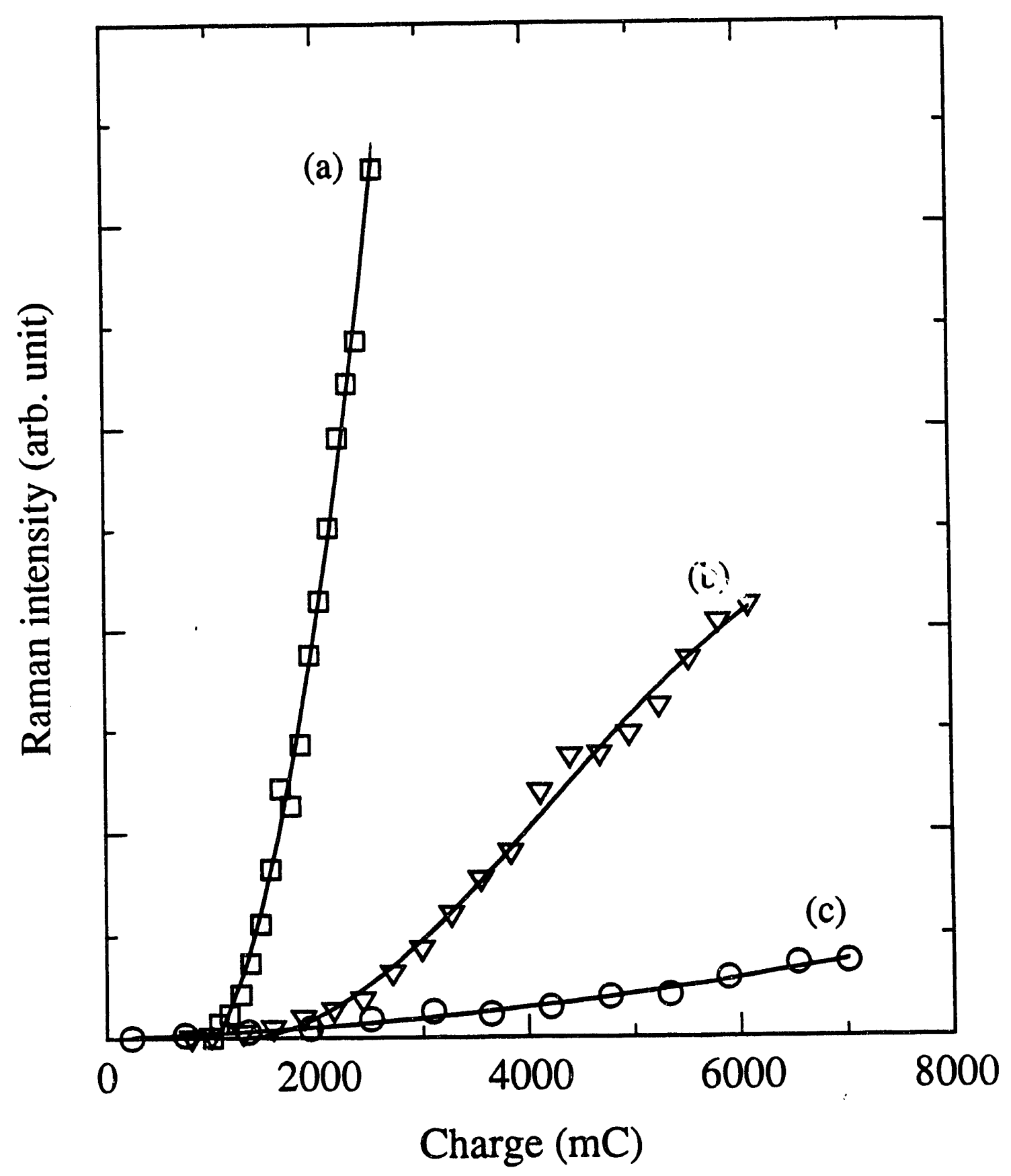

Figure 3.48. Effect of charge on sulfur formation by mineral pyrite oxidation at different potentials: (a) 0.80 , (b) 1.0 , and (c) $1.20 \mathrm{~V} / \mathrm{SCE}$ (solution: $0.5 \mathrm{M} \mathrm{NaCl}, \mathrm{pH}$ 9.2). 
204

\section{Rate of Sulfur Formation and Sensitivity Analysis}

Kinetic information for sulphur formation can be estimated from the Raman spectra data. One example is shown in Figure 3.49. The integrated intensity of the sulfur peak at about $470 \mathrm{~cm}^{-1}$ is plotted against time and fitted to an exponential equation. Initially, the equation deviates from the observed data. An "induction" period is present, probably caused in part by the detection limit of the Raman instrumentation. The electrochemical processes observed in previous studies [3.4] provide a more sensitive means to observe the kinetics. The Raman technique, though less sensitive, is a direct method for following the rate of sulfur formation.

An estimate of the sensitivity of this technique can be obtained by a measure of the charge passed during the electrochemical oxidation. The Raman spectrum taken at 5 minutes in Figure 3.27 was after the passage of less than $3.3 \mathrm{mC}$ of charge which corresponded to $3.3 \times 10^{-3} / 96500=3.42 \times 10^{-8}$ moles of sulfur assuming $100 \%$ efficiency. The area occupied by each sulfur atom may be estimated by using the density ( 2.07 $\mathrm{g} / \mathrm{cm}^{3}$ ) and molecule weight $(32 \mathrm{~g} / \mathrm{mole})$ of sulfur and it is $8.70 \AA^{2} /$ atom. This number agrees with that described by Ralston et al. [3.39]. According to this approximation, there are $1.15 \times 10^{15}$ sulfur atoms per squared centimeter, or $1.15 \times 10^{15} / 6.02 \times 10^{23}=1.91 \times 10^{-9}$ moles $/ \mathrm{cm}^{2}$ for a monolayer. Given the area of the electrode being about $0.2 \mathrm{~cm}^{2}$, the number of sulfur layers detected is $3.42 \times 10^{-8}$ moles $/\left(0.2 \mathrm{~cm}^{2} \times 3.42 \times 10^{-8}\right.$ moles $\left./ \mathrm{cm}^{2}\right)=$ 89. The number of sulfur layers detected by electrochemical measurements is about 27 (see Chapter II), almost three times as sensitive as this technique. It should be noted, however, that the area probed by the laser beam $\left(1.77 \times 10^{-4} \mathrm{~cm}^{2}\right)$ is much smaller than the area of the electrode $\left(0.2 \mathrm{~cm}^{2}\right)$. Hence the detected Raman signal is from a much smaller quantity of sulfur (approximately $3 \times 10^{-11}$ moles). This is a very poor estimate of the sensitivity as no allowance is made for the production of soluble polysulfide or oxy-sulfur complexes. These are known to occur during the oxidation of sulfides to sulfur and the coulombic efficiency may be much less than $100 \%$ as assumed in this calculation [3.36].

\section{Cathodic Reduction of Electrochemically Formed Sulfur}

Mineral pyrite was treated potentiostatically at $+1.0 \mathrm{~V} / \mathrm{SCE}$ for 10 minutes. The 


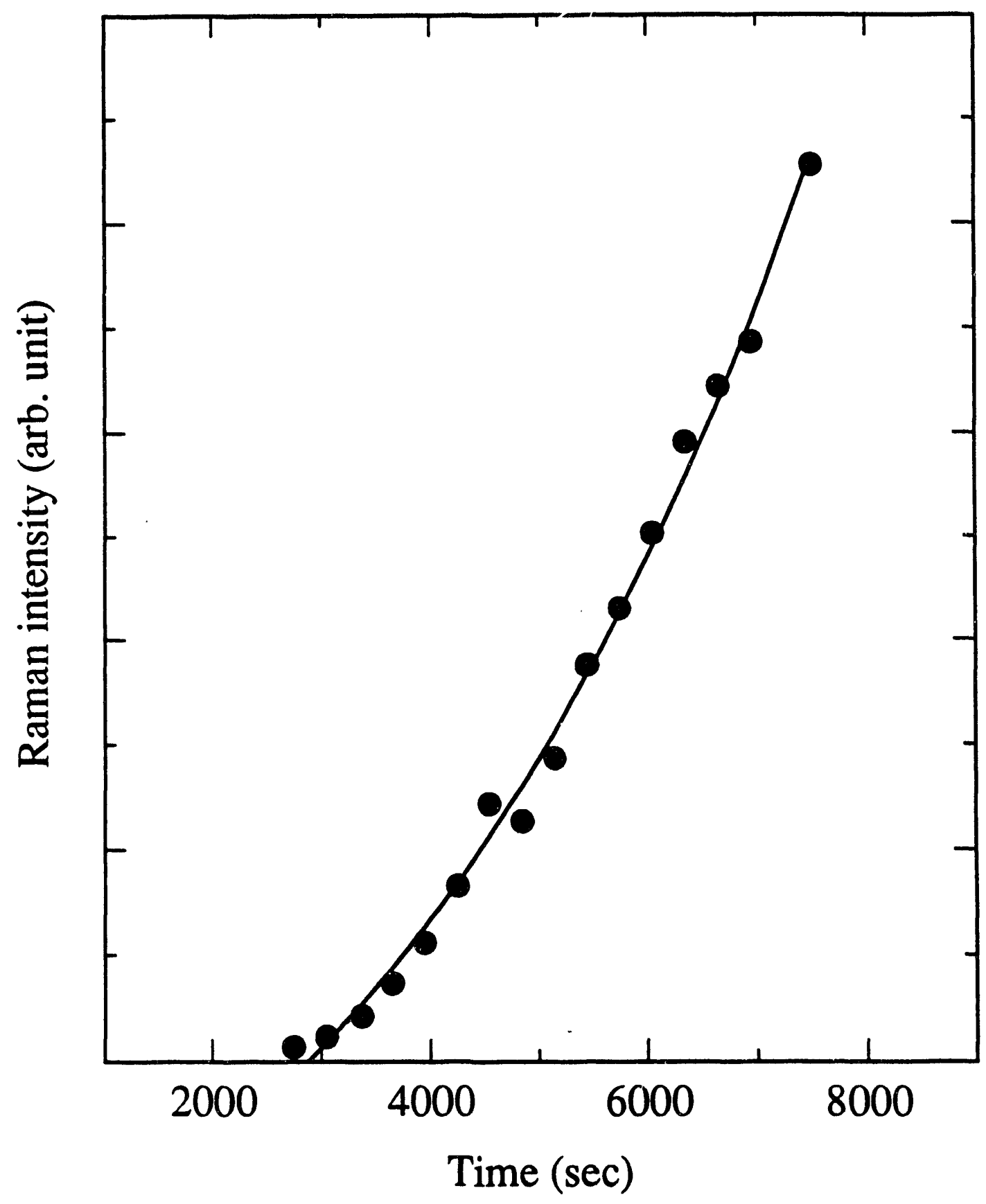

Figure 3.49. Raman intensity of sulfur peak at $470 \mathrm{~cm}^{-1}$ as a function of time: data fit with exponential equation (data from Figure 3.48 for the potential of $0.80 \mathrm{~V} / \mathrm{SCE}$, mineral pyrite, $0.5 \mathrm{M} \mathrm{NaCl}, \mathrm{pH} 9.2$ ). 
Raman spectrum was taken and is shown in Figure 3.50a. The sulfur peaks can be seen clearly from the figure. Then the potential was immediately reversed to $-1.0 \mathrm{~V} / \mathrm{SCE}$. The object was to determine the reducibility of the surface films that had formed during the conditioning at $+1.0 \mathrm{~V} / \mathrm{SCE}$. The middle three Raman spectra in Figure 3.50 were taken at 20 seconds, 3 minutes and 8 minutes respectively. The three sulfur peaks that appeared at $+1.0 \mathrm{~V} / \mathrm{SCE}$ have now been greatly diminished and the spectrum is almost identical to that at the beginning of the experiment. The sulfur-rich surface layers are readily reducible. After three minutes, the sulfur peaks completely disappeared. At the end of the experiment, the potential was reversed again to $+1.0 \mathrm{~V} / \mathrm{SCE}$. The top spectrum (Figure $3.50 \mathrm{e})$ shows the reappearance of sulfur peaks after two minutes of oxidation.

Sulfur produced by electrochemical deposition from sulfide solutions at a platinum electrode can also be reduced. Sulfur was deposited at a potential of $+1.0 \mathrm{~V} / \mathrm{SCE}$ from a solution containing $0.002 \mathrm{M} \mathrm{Na}_{2} \mathrm{~S}, 0.5 \mathrm{M} \mathrm{NaCl}$ and $\mathrm{pH}$ 6.5. The Raman spectrum of the platinum surface at $+1.0 \mathrm{~V} / \mathrm{SCE}$ after 25 minutes is shown in Figure 3.51a. The voltage was then adjusted to a potential of $-0.93 \mathrm{~V} / \mathrm{SCE}$. Figures $3.51 \mathrm{~b}$ and $3.51 \mathrm{c}$ were the spectra taken at 30 seconds and 2 minutes later, respectively. The absence of the sulfur peaks indicates that the sulfur has been removed from the surface.

The ability to reduce the electrodeposited sulfur electrochemically suggests that, at least for these thin films, the sulfur does not behave as an electrical insulator as does bulk elemental sulfur in its orthorhombic state. The ability of the material to support a photocurrent (discussed later) also suggests that the sulfurous film has unusual electronic properties more akin to a semiconductor than to an insulator.

\section{Detection of Iron Hydroxides}

According to thermodynamics, iron oxide (hematite) should be formed on the pyrite surface during electrochemical oxidation. Experience shows that metastable hydrated oxides precede hematite formation at low temperatures. It was very difficult to detect hydroxides in-situ. Although no signal from iron hydroxides was detected in-situ in the oxidation experiments, the oxidized pyrite did produce some weak peaks after being left in air for a few weeks. 


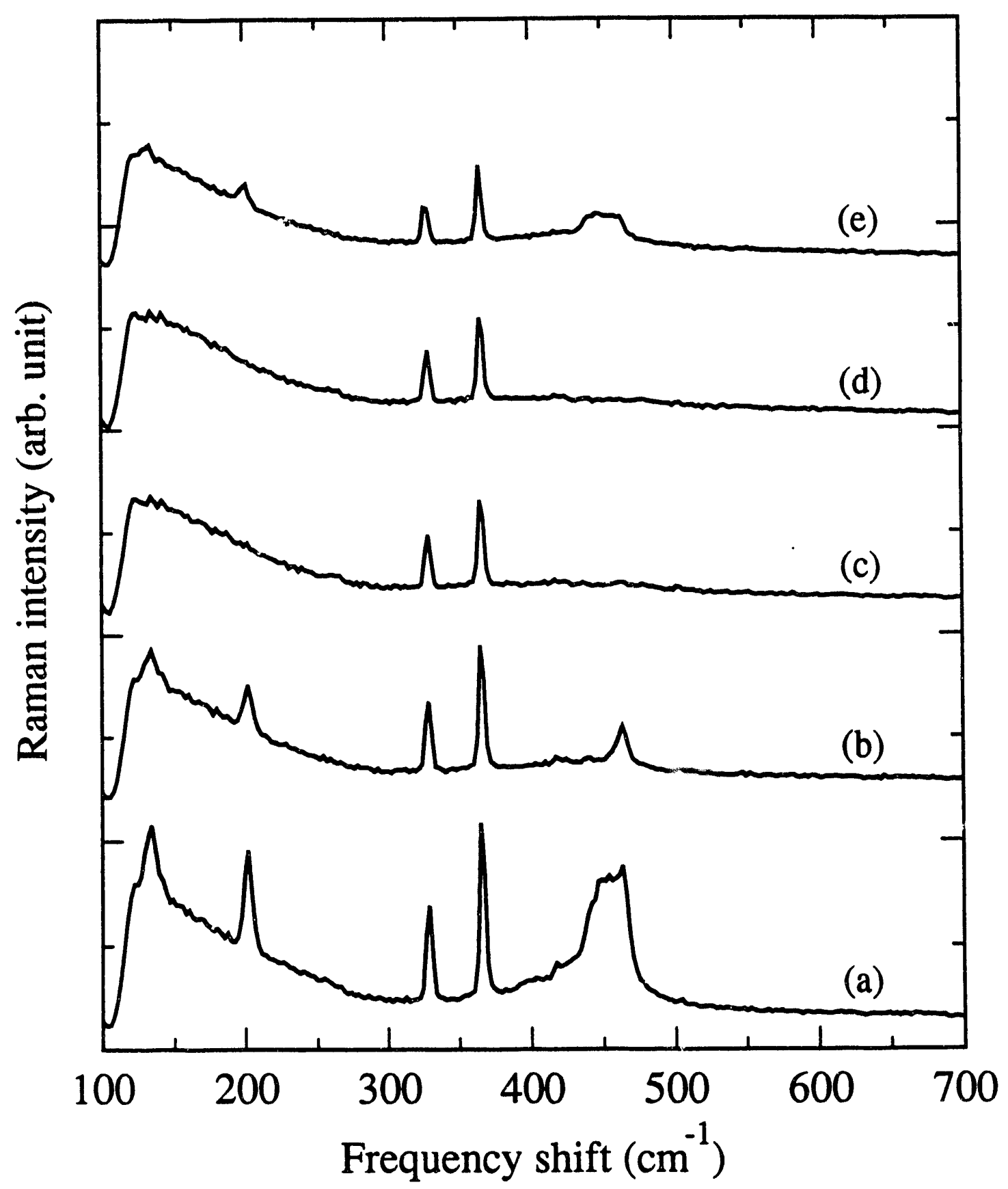

Figure 3.50. Raman spectra of mineral pyrite in $0.5 \mathrm{M} \mathrm{NaCl}$ solution (pH 9.2) Experimental sequence: (a) $10 \mathrm{~min}$ at +1.0 ; (b) $20 \mathrm{sec}$ at -1.0 ; (c) $3 \mathrm{~min}$ at -1.0 ; (d) $8 \mathrm{~min}$ at -1.0 ; and (e) $2 \mathrm{~min}$ at $+1.0 \mathrm{~V} / \mathrm{SCE}$. 


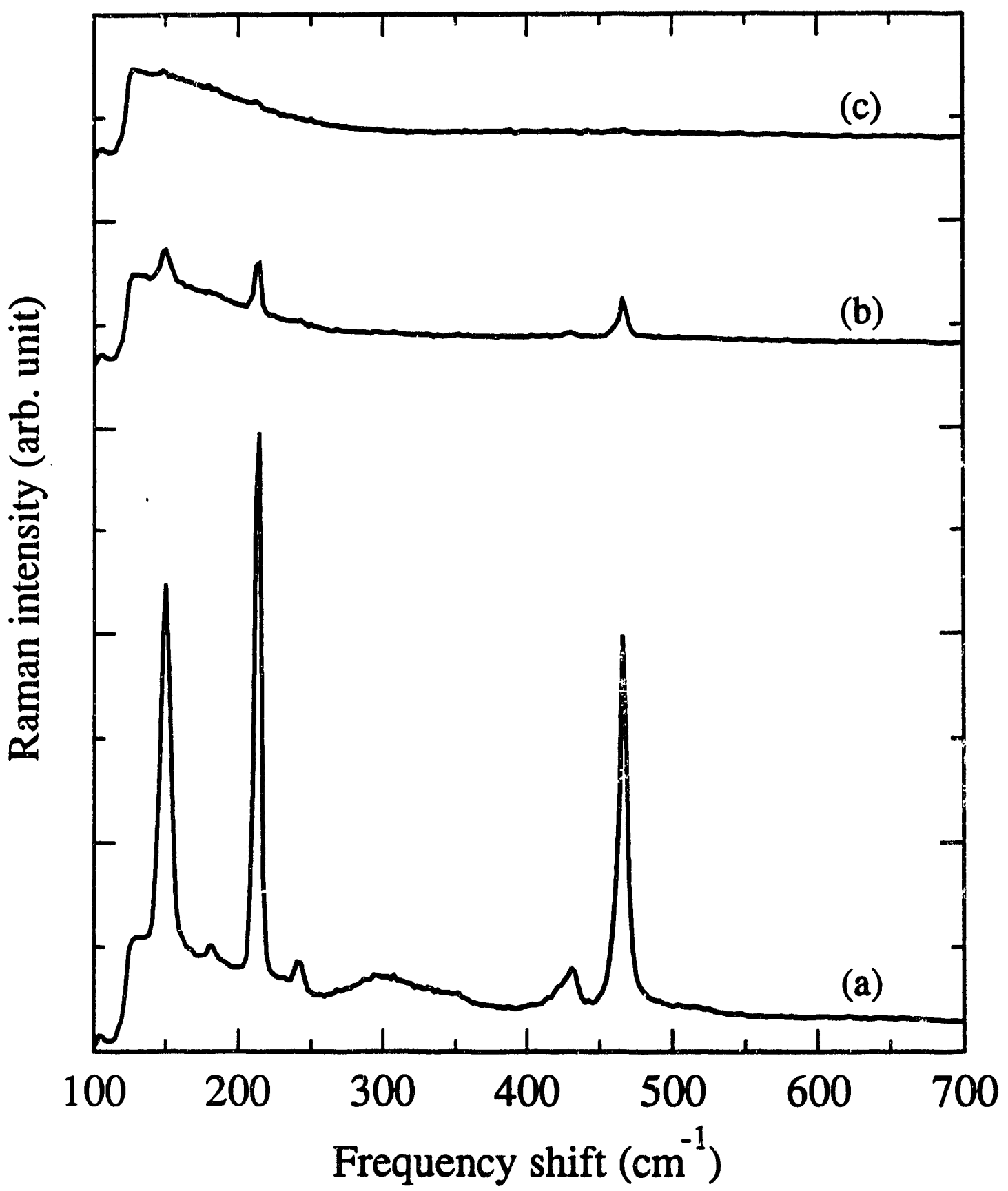

Figure 3.51. Raman spectra of electrodeposited sulfur on platinum. Experimental sequence: (a) $25 \mathrm{~min}$ at +1.0; (b) $30 \mathrm{sec}$ at -0.93 ; (c) $2 \mathrm{~min}$ at -0.93 V/SCE (solution: $0.002 \mathrm{M} \mathrm{Na}_{2} \mathrm{~S}, 0.5 \mathrm{M} \mathrm{NaCl}, \mathrm{pH} 6.5$ ). 
Surface Enhanced Raman Scattering (SERS) spectroscopy technique was employed to confirm the presence of iron hydroxides. The pyrite electrode was first polarized at $+1.0 \mathrm{~V} / \mathrm{SCE}$ in a $0.5 \mathrm{M} \mathrm{NaCl}$ solution of $\mathrm{pH} 6.5$ for one hour. The sulfur peaks could be seen clearly in the Raman spectrum. The electrode was then transferred to a $0.001 \mathrm{M}$ $\mathrm{AgNO}_{3}$ and $0.5 \mathrm{M} \mathrm{KNO}_{3}$ solution and polarized at $-0.6 \mathrm{~V} / \mathrm{SCE}$. After a charge of $5 \mathrm{mC}$ was passed, the electrode was taken out of the solution and thoroughly washed. A Raman spectrum was recorded and shown in Figure 3.52. A new peak at $696 \mathrm{~cm}^{-1}$ appeared in the spectrum. According to a published reference standard [3.12], this peak corresponded to $\mathrm{Fe}(\mathrm{OH})_{3}$.

A series of Raman spectra were recorded after the above electrode was transferred back to the $0.5 \mathrm{M} \mathrm{NaCl}$ solution of $\mathrm{pH} 6.5$ and a negative potential applied. The results are given in Figure 3.53. The ferric hydroxide peak disappeared after a potential of -0.8 V/SCE was applied for about 30 minutes.

\section{Raman Spectra of Coal Pyrite}

Figures 3.54-3.56 shows the Raman spectra of Illinois, Uppsi Freeport, and Pittsburgh coal pyrites, obtained in-situ during their respective electrochemical oxidation. The oxidation currett densities for coal pyrite electrodes were much higher than that for the mineral pyrite electrode at the same overpotentials. Except for this difference, oxidation produced the same general results.

As can seen from Figures 3.54-3.56, the sulfur peaks are clearly present in the spectra. However, the optimum conditions of sulfur formation for coal pyrites may not be the same as those for mineral pyrite. More detailed experiments are needed to find the proper oxidation potential in specific solutions of different $\mathrm{pH}$ values.

\section{Electrochemical Oxidation of Galena}

Thiosulfate has been identified as a product of the anodic oxidation of galena [3.40]. Some preliminary Raman work was carried out at $\mathrm{pH} 6.5$ to ascertain the existence of oxy-sulfur species (Figures 3.57-3.61). None have so far been detected. This probably is due to the poor detection limit of Raman spectrometry under these experimental 


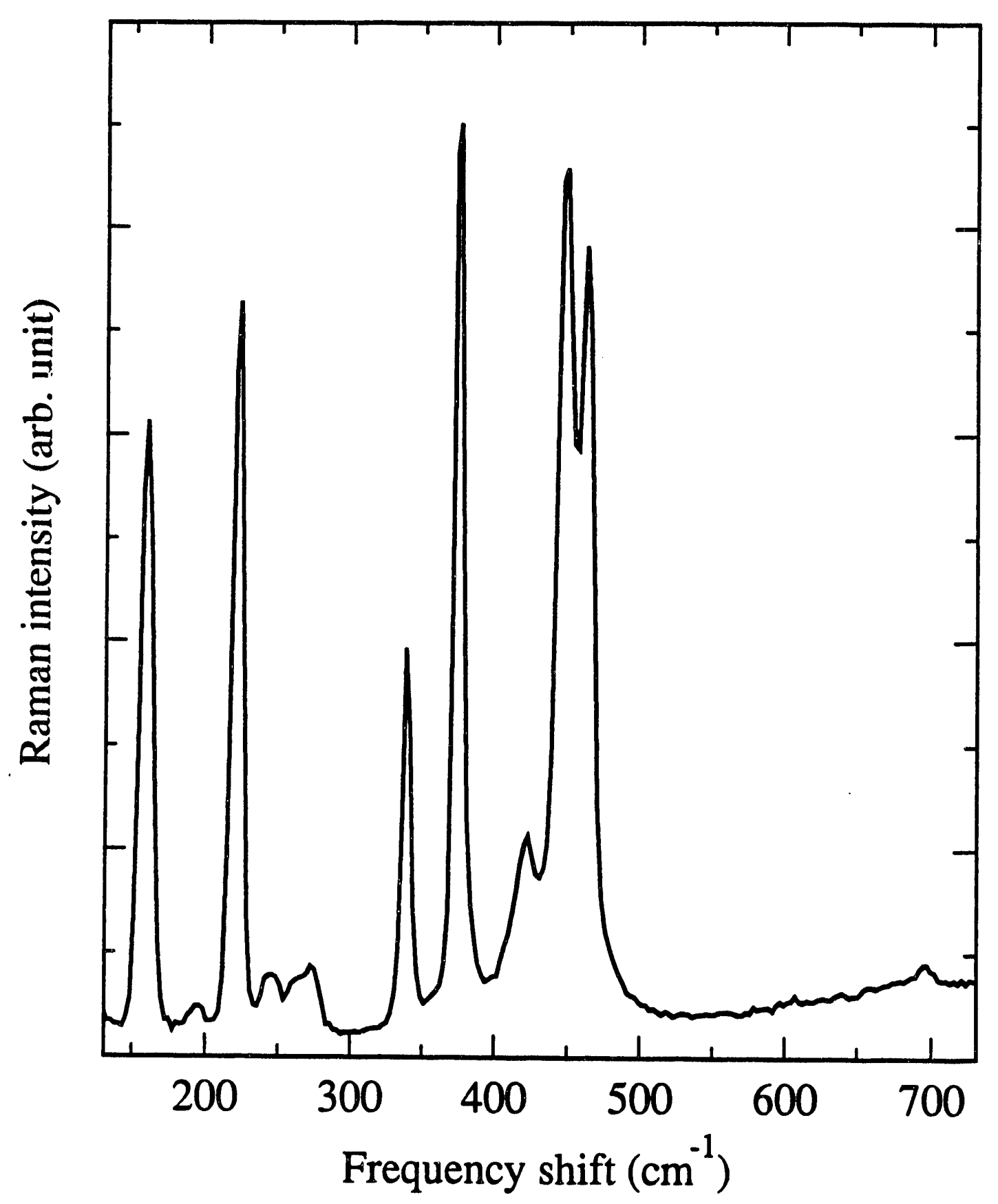

Figure 3.52. Raman spectrum of pyrite in air after being oxidized at $1.0 \mathrm{~V} / \mathrm{SCE}$ for one hour in $0.5 \mathrm{M} \mathrm{NaCl}(\mathrm{pH} 6.5)$ and polarized at $-0.6 \mathrm{~V} / \mathrm{SCE}$ in $0.001 \mathrm{M} \mathrm{AgNO}_{3}$ and $0.5 \mathrm{M} \mathrm{KNO}_{3}$ for passage of $5 \mathrm{mC}$. 


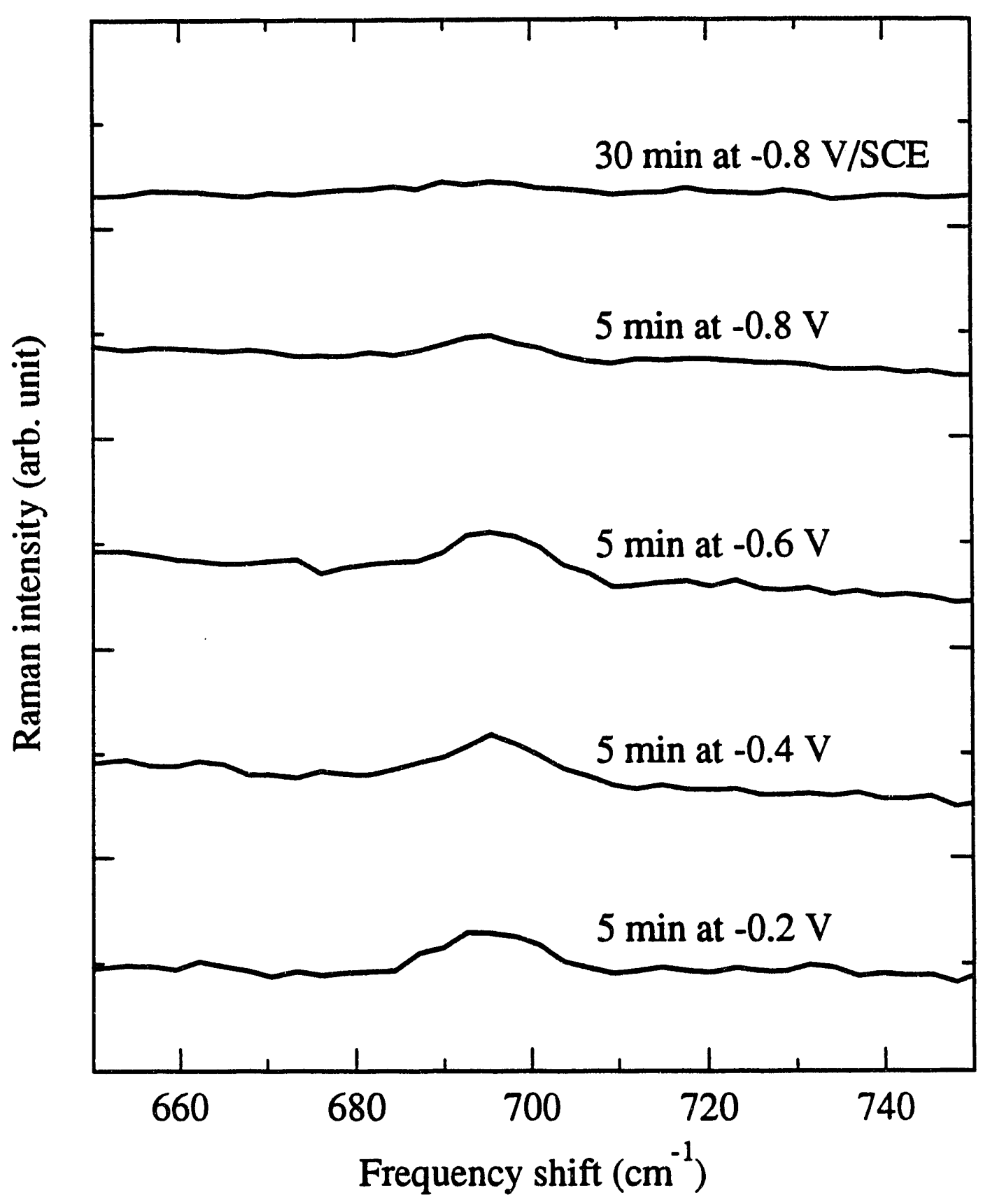

Figure 3.53. Reduction of ferric hydroxide in $0.5 \mathrm{M} \mathrm{NaCl}$ solution of $\mathrm{pH}$ 6.5. 


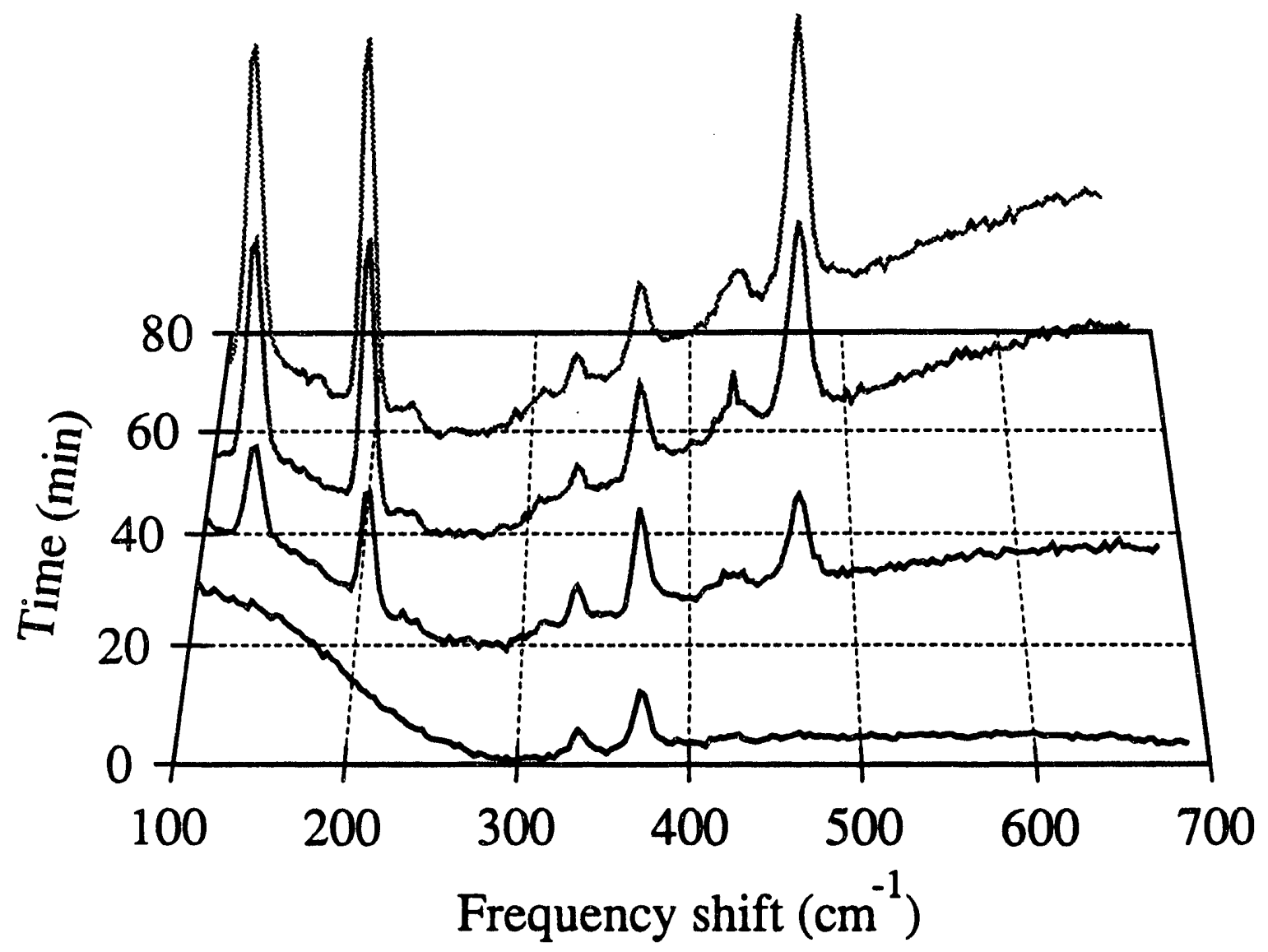

Figure 3.54. Raman spectra of electrochemically oxidized Illinois coal pyrite at +1.0 V/SCE (solution: $0.5 \mathrm{M} \mathrm{NaCl}, \mathrm{pH} 6.5$ ). 


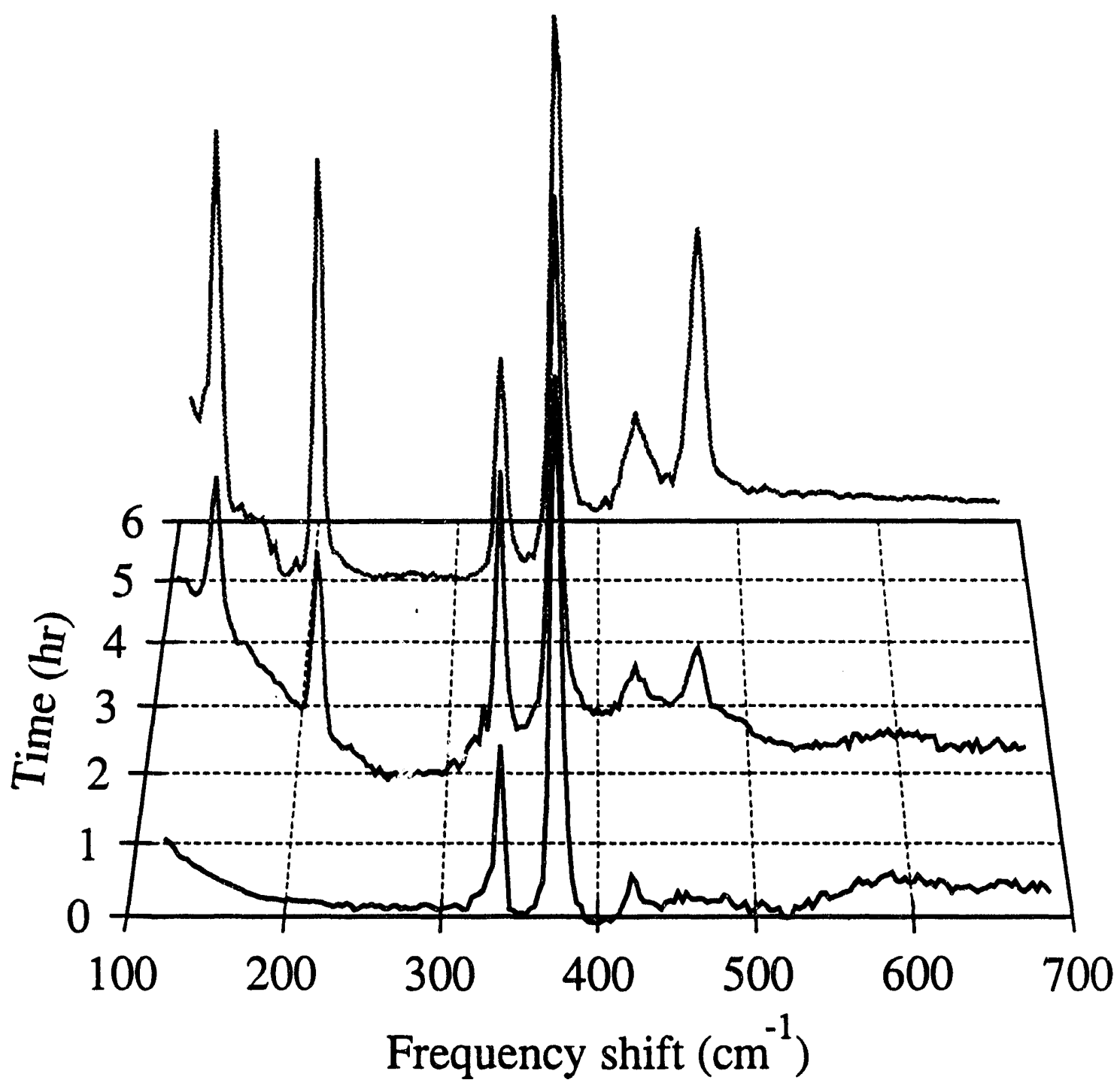

Figure 3.55. Raman spectra of electrochemically oxidized Upper Freeport coal pyrite at $+0.8 \mathrm{~V} / \mathrm{SCE}$ (solution: $0.5 \mathrm{M} \mathrm{NaCl}, \mathrm{pH} \mathrm{6.5)}$ ). 


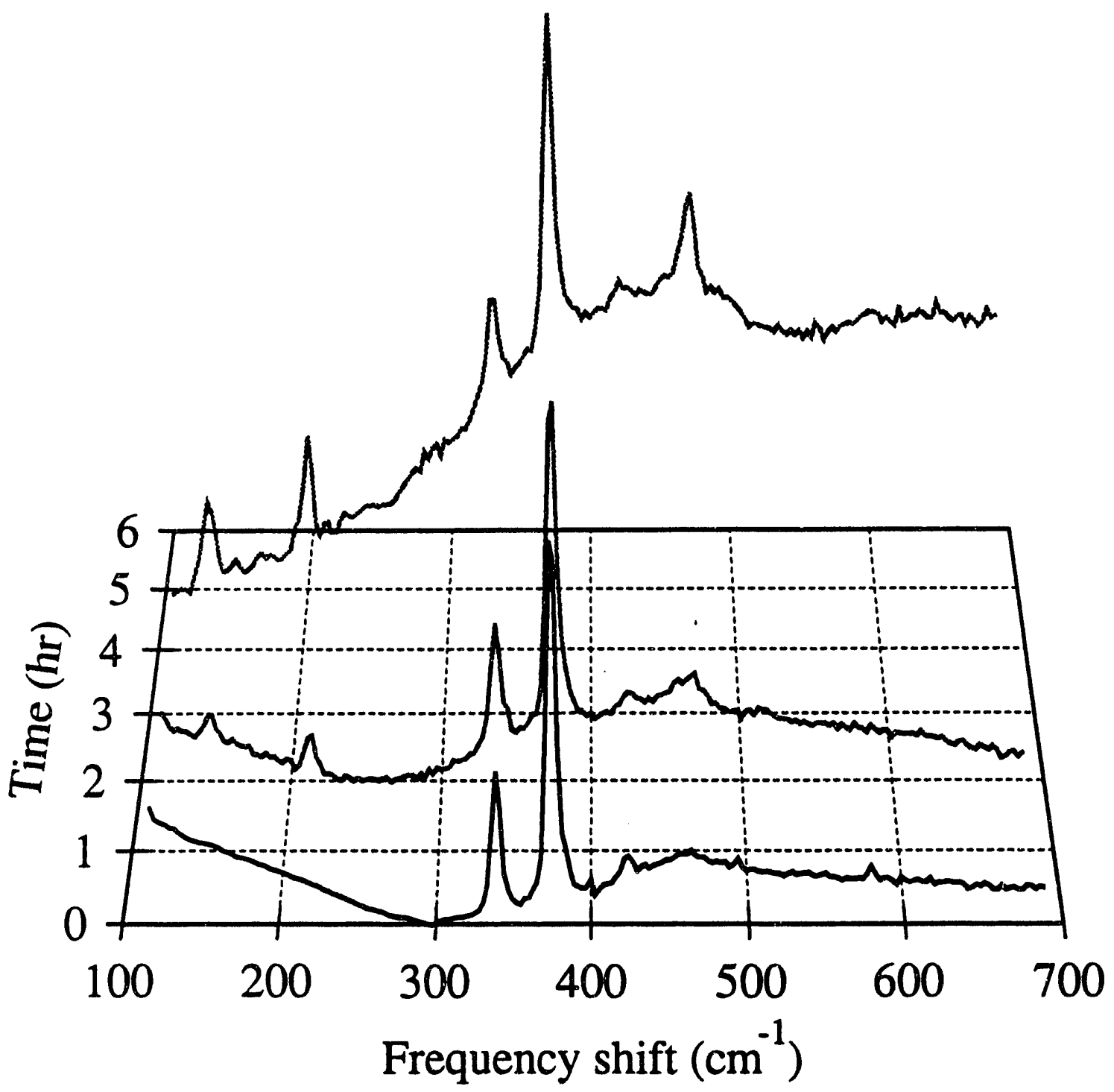

Figure 3.56. Raman spectra of electrochemically oxidized Pittsburgh coal pyrite at $0.7 \mathrm{~V} / \mathrm{SCE}$ (solution: $0.5 \mathrm{M} \mathrm{NaCl}, \mathrm{pH} 6.5$ ). 


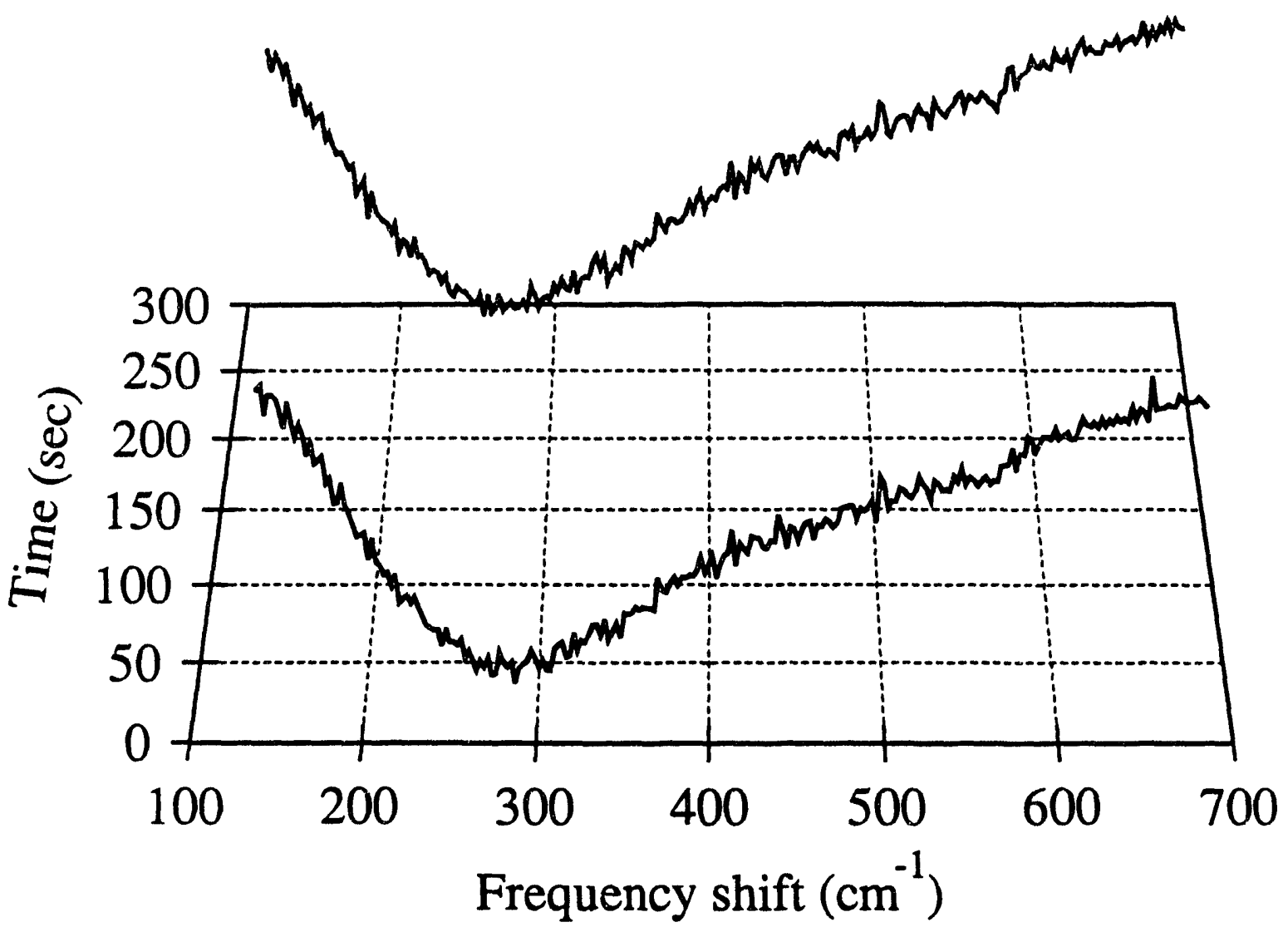

Figure 3.57. Raman spectra of electrochemically oxidized galen $\lambda$ at $-0.32 \mathrm{~V}$ (solution: $0.5 \mathrm{M} \mathrm{NaCl}, \mathrm{pH} 6.5$ ). 


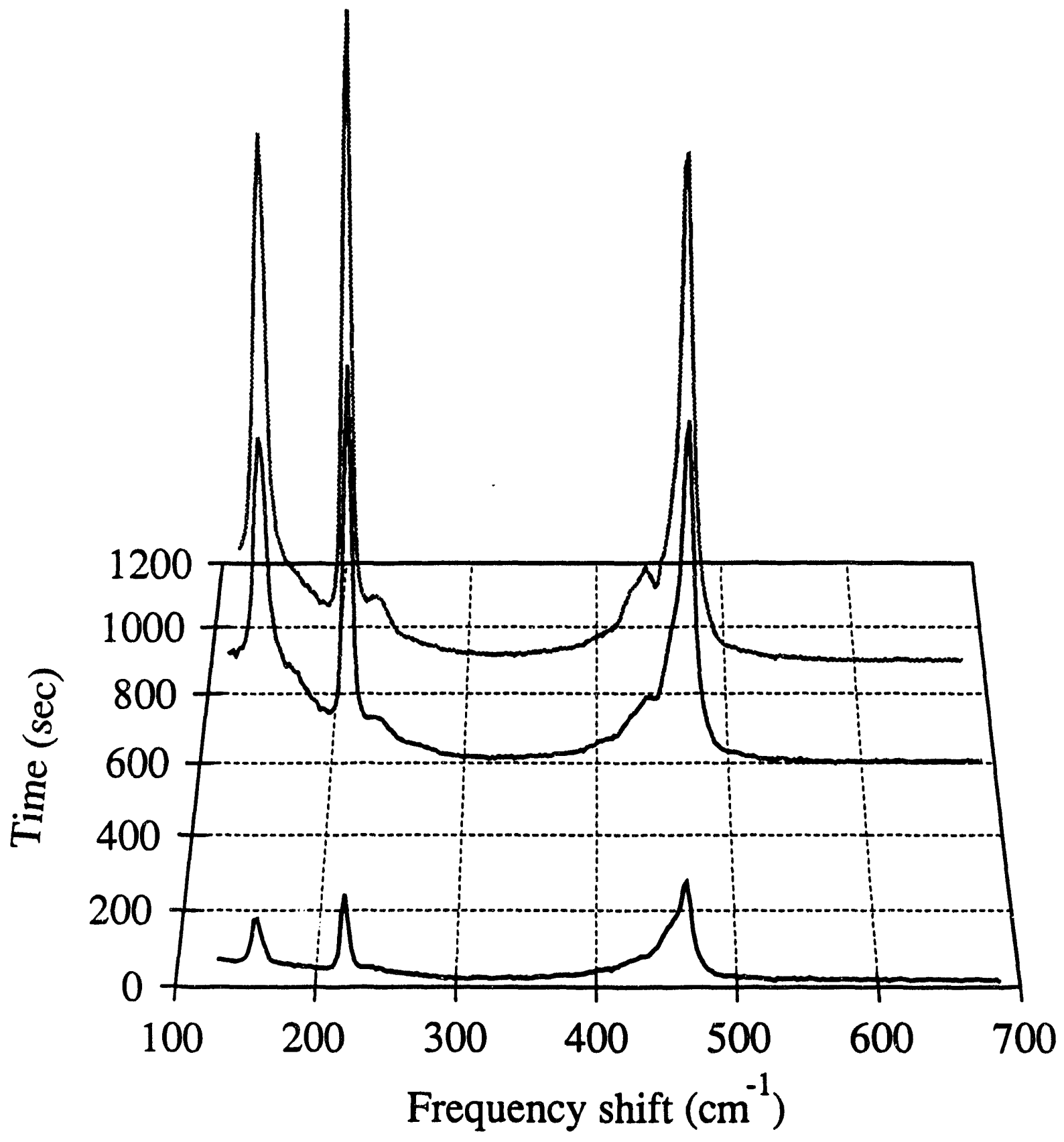

Figure 3.58. Raman spectra of electrochemically oxidized galena at $0.13 \mathrm{~V}$ (solution: $0.5 \mathrm{M} \mathrm{NaCl}, \mathrm{pH} 6.5$ ). 


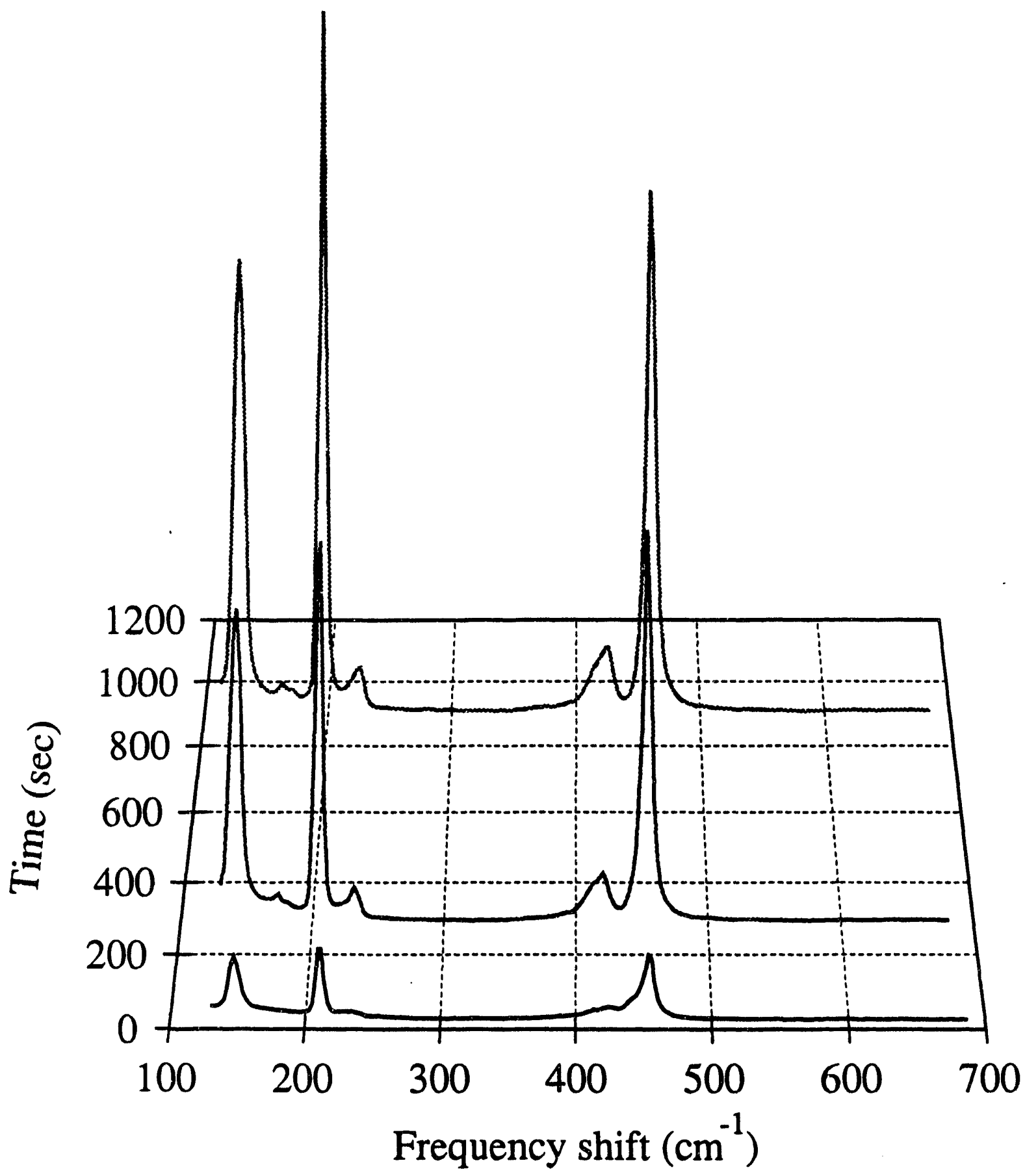

Figure 3.59. Raman spectra of electrochemically oxidized galena at $0.32 \mathrm{~V}$ (solution: $0.5 \mathrm{M} \mathrm{NaCl}, \mathrm{pH} 6.5$ ). 


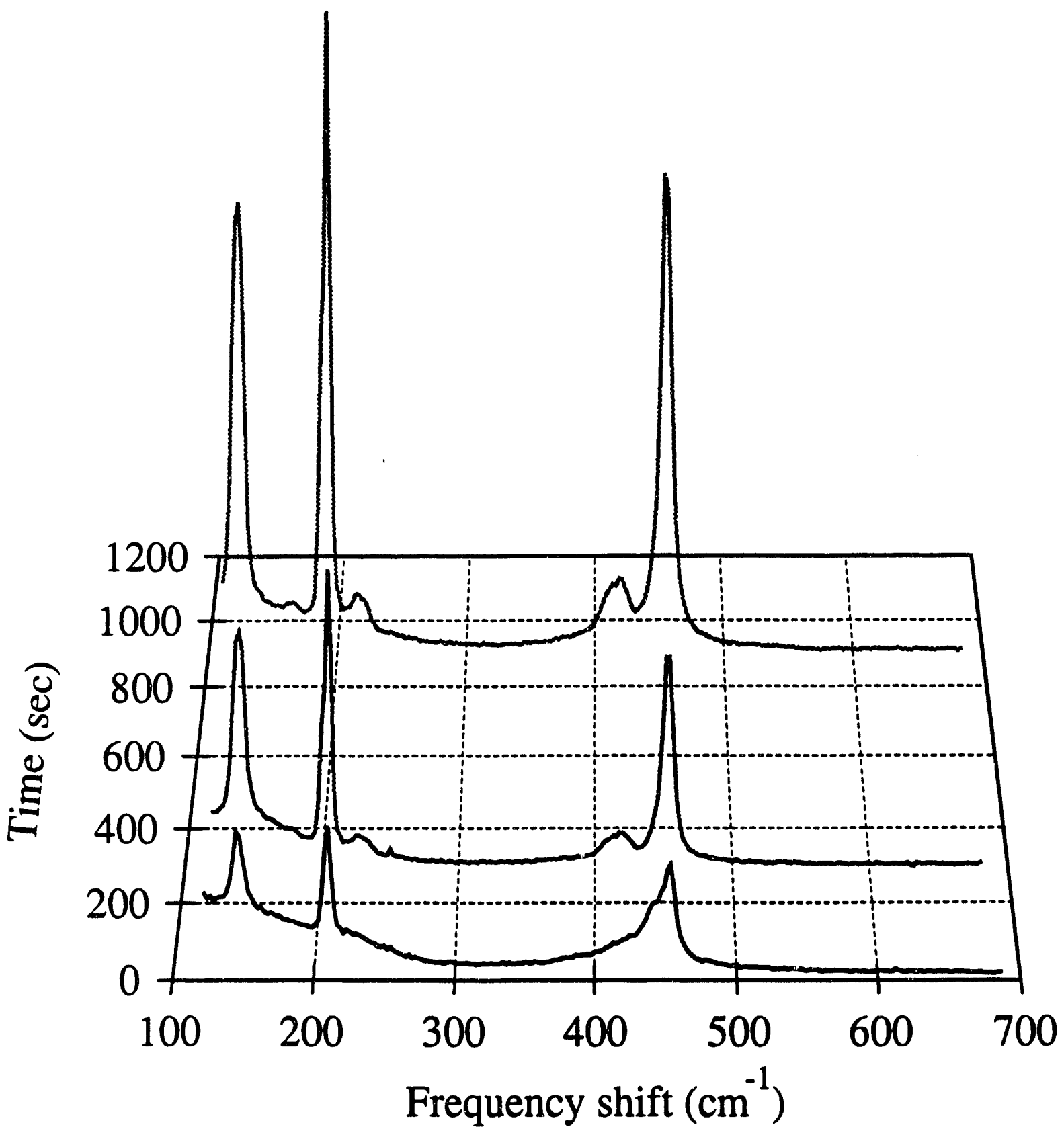

Figure 3.60. Raman spectra of electrochemically oxidized galena at $0.57 \mathrm{~V}$ (solution: $0.5 \mathrm{M} \mathrm{NaCl}, \mathrm{pH} 6.5$ ). 


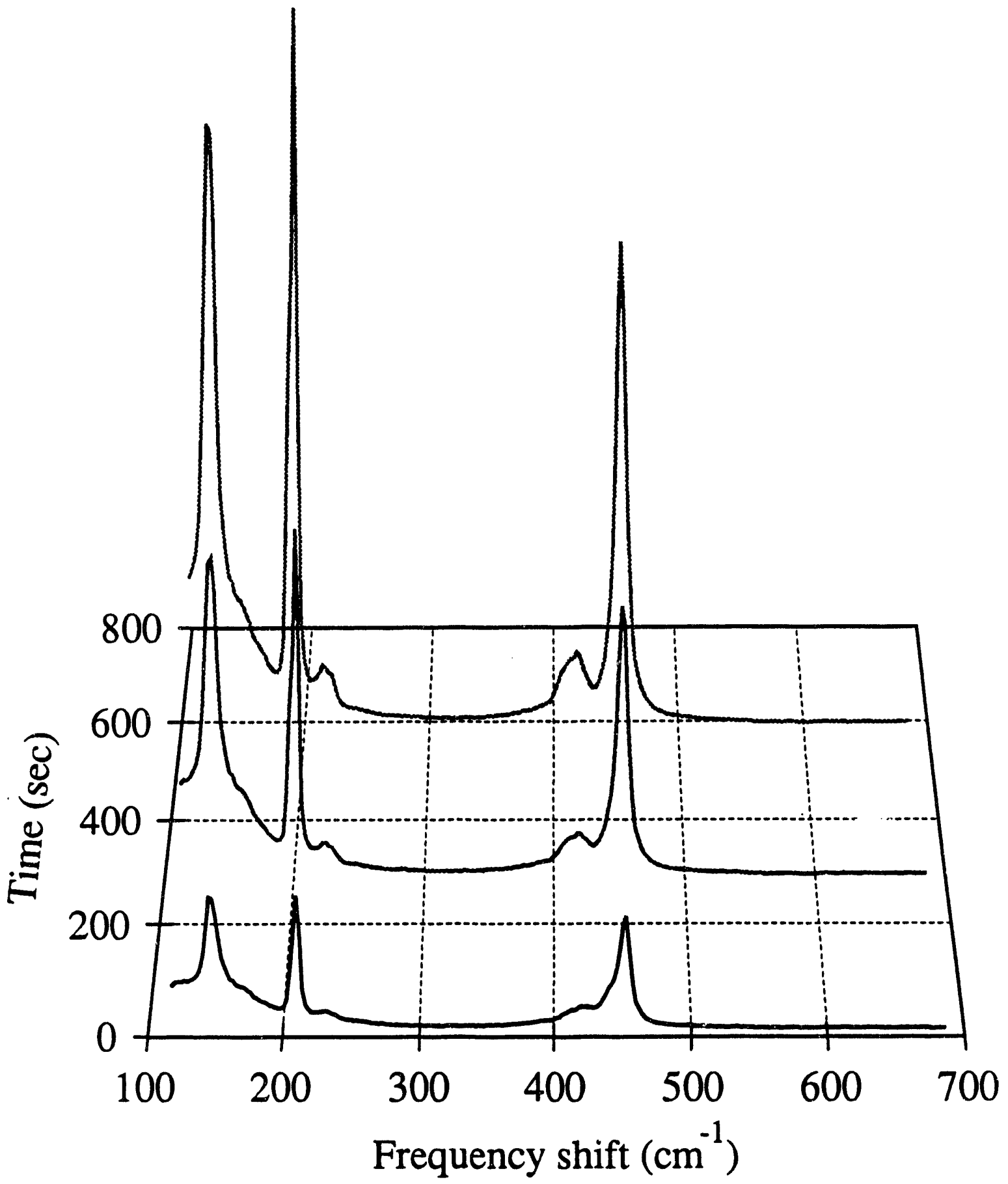

Figure 3.61. Raman spectra of electrochemically oxidized galena at $1.0 \mathrm{~V}$ (solution: $0.5 \mathrm{M} \mathrm{NaCl}, \mathrm{pH} 6.5$ ). 
conditions. Products a few atomic diameters thick may not be detected. Strong Raman peaks, similar to those observed on pyrite, have been observed at potentials of +0.13 $\mathrm{V} / \mathrm{SCE}$ and above (Figures 3.58-3.61). In particular, the sulfur peak in the range 400-500 $\mathrm{cm}^{-1}$ is broad initially suggesting some polysulfides formation. This initially broad peak changes rapidly with time (Figure 3.58 ) and quickly becomes indistinguishable from elemental sulfur (Figure 3.5). It suggests that the initial products of the oxidation are short chain polysulfides. As more charge passes, more sulfur is produced and the chains become longer. The Raman peaks of these S-S bonds will be shifted due to the different bond lengths. The longer chains will also have a tendency to arrange themselves into rings of different size. The final product is likely to be $S_{8}$ rings as it is the thermodynamically stable product at this temperature. Buckley et al. [3.3] and Woods et al. [3.36] have discussed the production of polysulfide chains in the context of their ringdisc electrode studies.

\section{Raman Spectra of Other Mineral Sulfides}

It has been suggested by Hamilton and Woods that one of the products of the oxidation of pyrite may be a non-stoichiometric compound of FeS [3.2]. The structural and chemical rearrangement of the substrate may lead to the alteration of the pyrite spectrum (peak position) or the creation of new peaks. Hence, samples of various types of mineral iron sulfides were obtained from Wards Scientific. For reference purposes Raman spectra were also obtained for samples of chalcopyrite, chalcocite, covellite, and galena (see the section "Electrochemical Oxidation of Galena").

The spectra for pyrrhotite $(\mathrm{FeS})$, marcasite $\left(\mathrm{FeS}_{2}\right)$, chalcopyrite $\left(\mathrm{CuFeS}_{2}\right)$, chalcocite $\left(\mathrm{Cu}_{2} \mathrm{~S}\right)$ and covellite (CuS) are shown in Figures 3.62-3.66. As there are no $\mathrm{S}_{2}{ }^{*}$ groups in pyrrhotite, chalcopyrite, and chalcocite, no Raman peaks were expected. This, in fact, was the case for pyrrhotite, chalcopyrite, and chalcocite, where only fluorescence background was observed.

Marcasite has the same chemical formula as pyrite but has a slightly different crystal structure. It also consists of $\mathrm{S}_{2}{ }^{-}$dumbbells. In pyrite the disulfide atoms lie at the center of a cube and the cube edges. The mid-point of the $\mathrm{S}_{2}{ }^{*}$ group occupies the $\mathrm{Cl}$ sites 


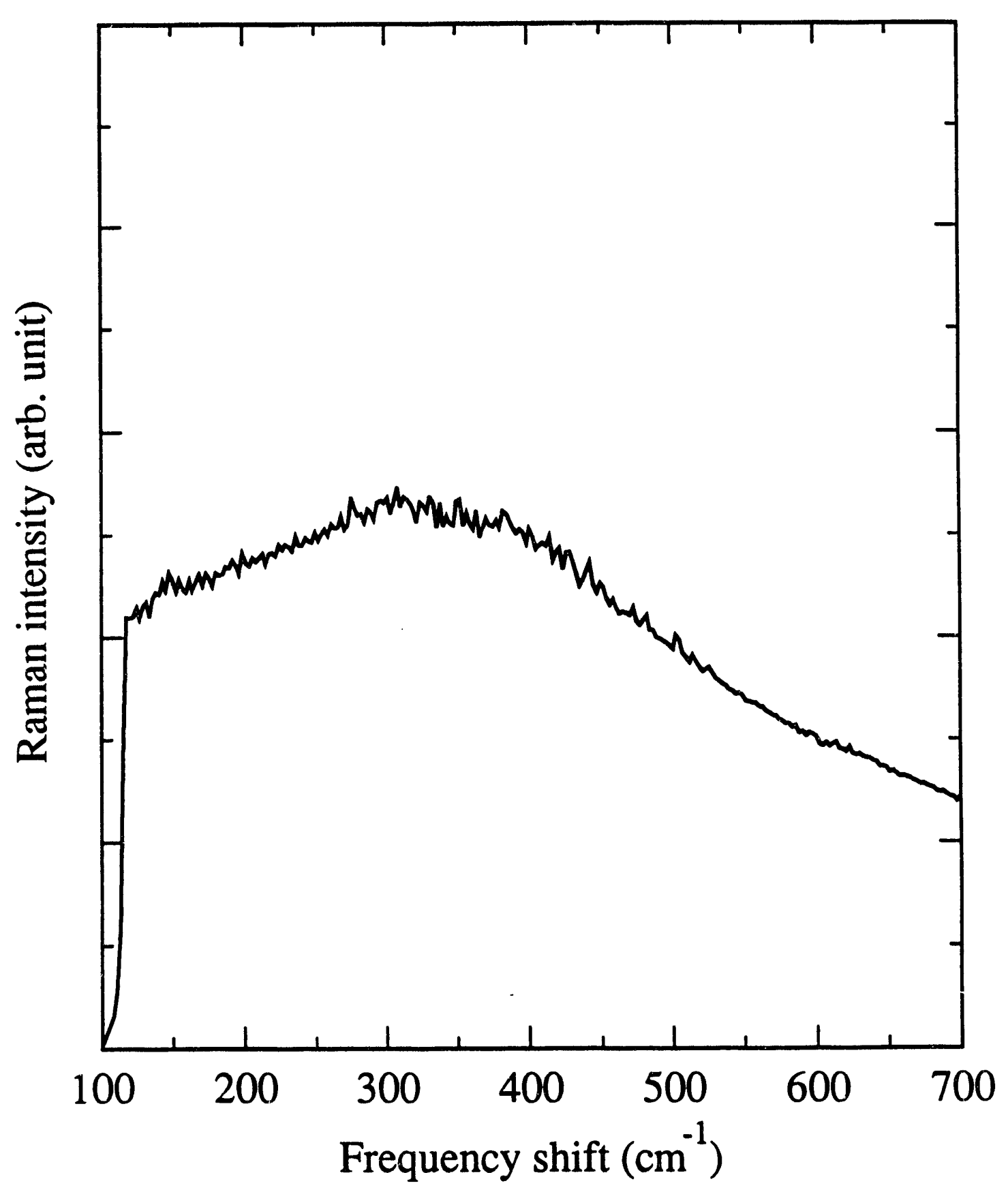

Figure 3.62. Raman spectrum of pyrrhotite in air. 


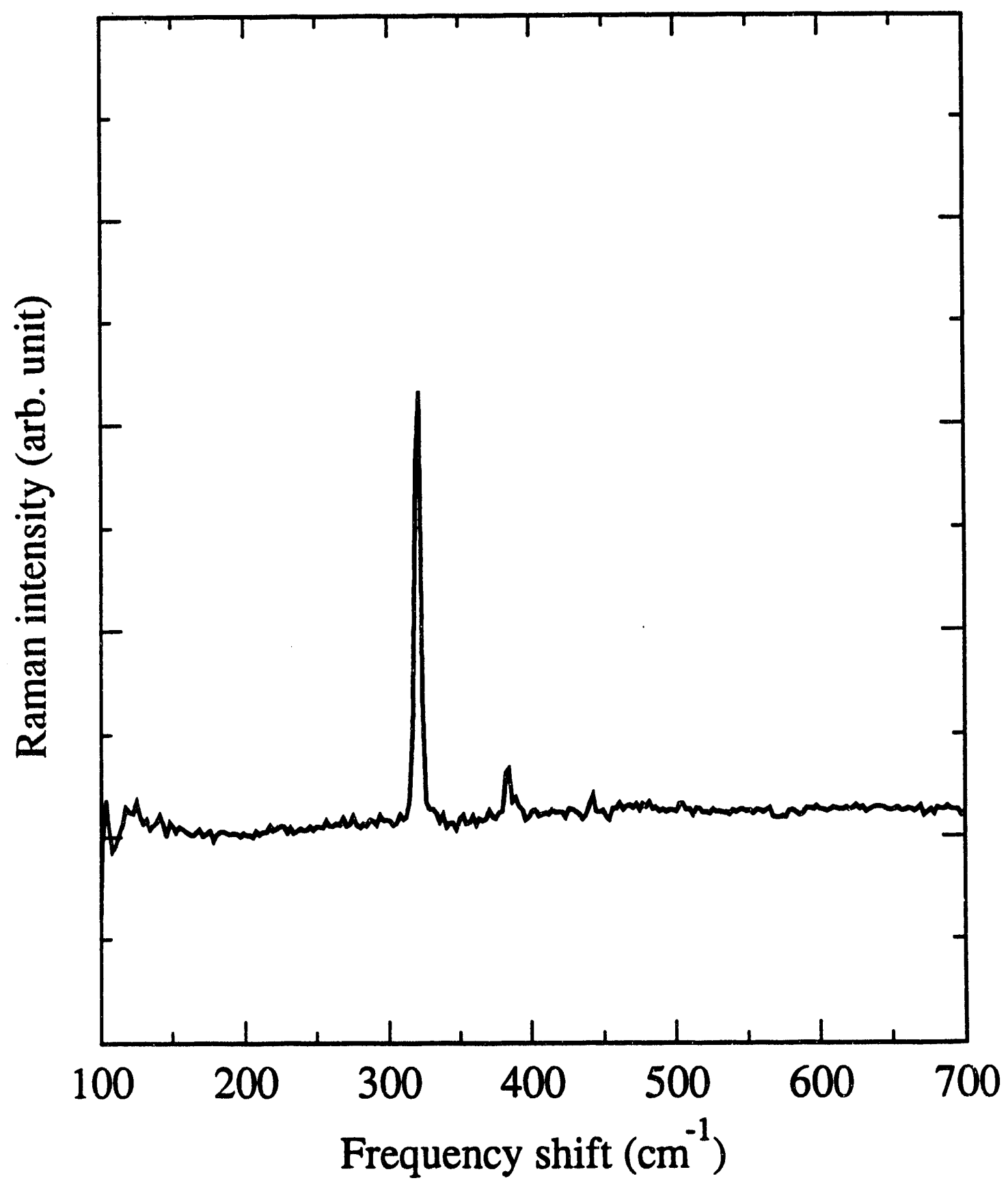

Figure 3.63. Raman spectrum of marcasite in air. 


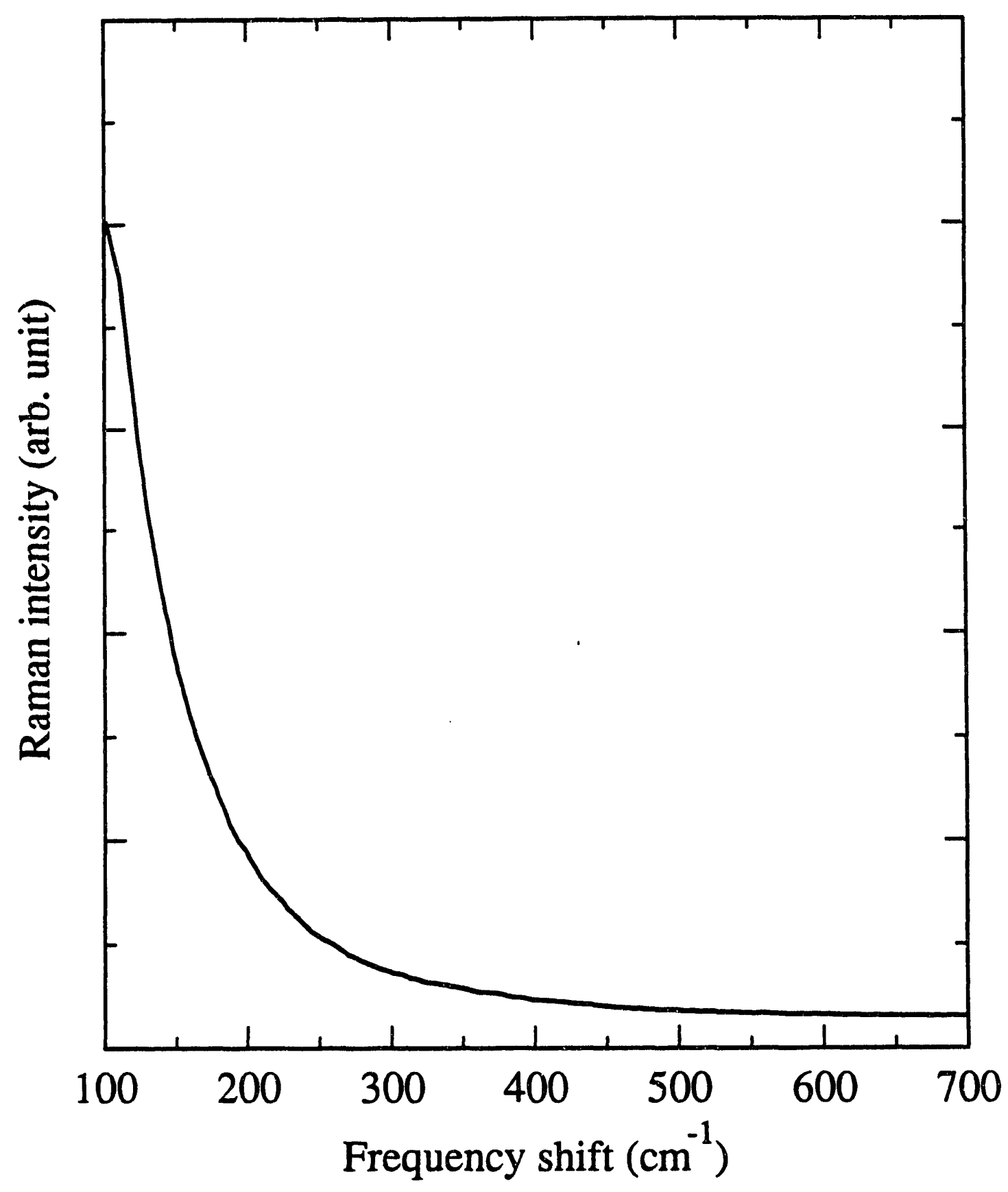

Figure 3.64. Raman spectrum of chalcopyrite in air. 


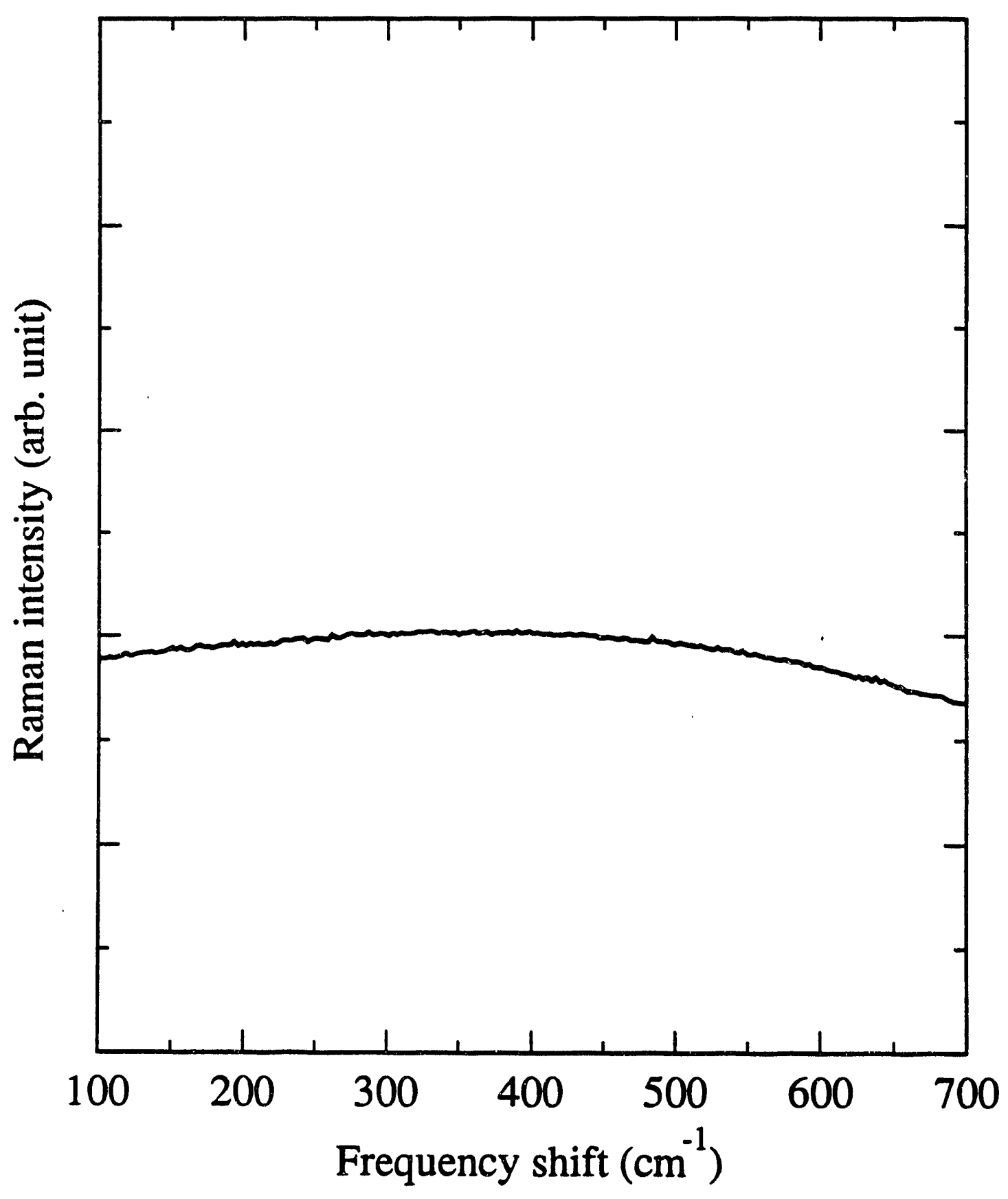

Figure 3.65. Raman spectrum of chalcocite in air. 


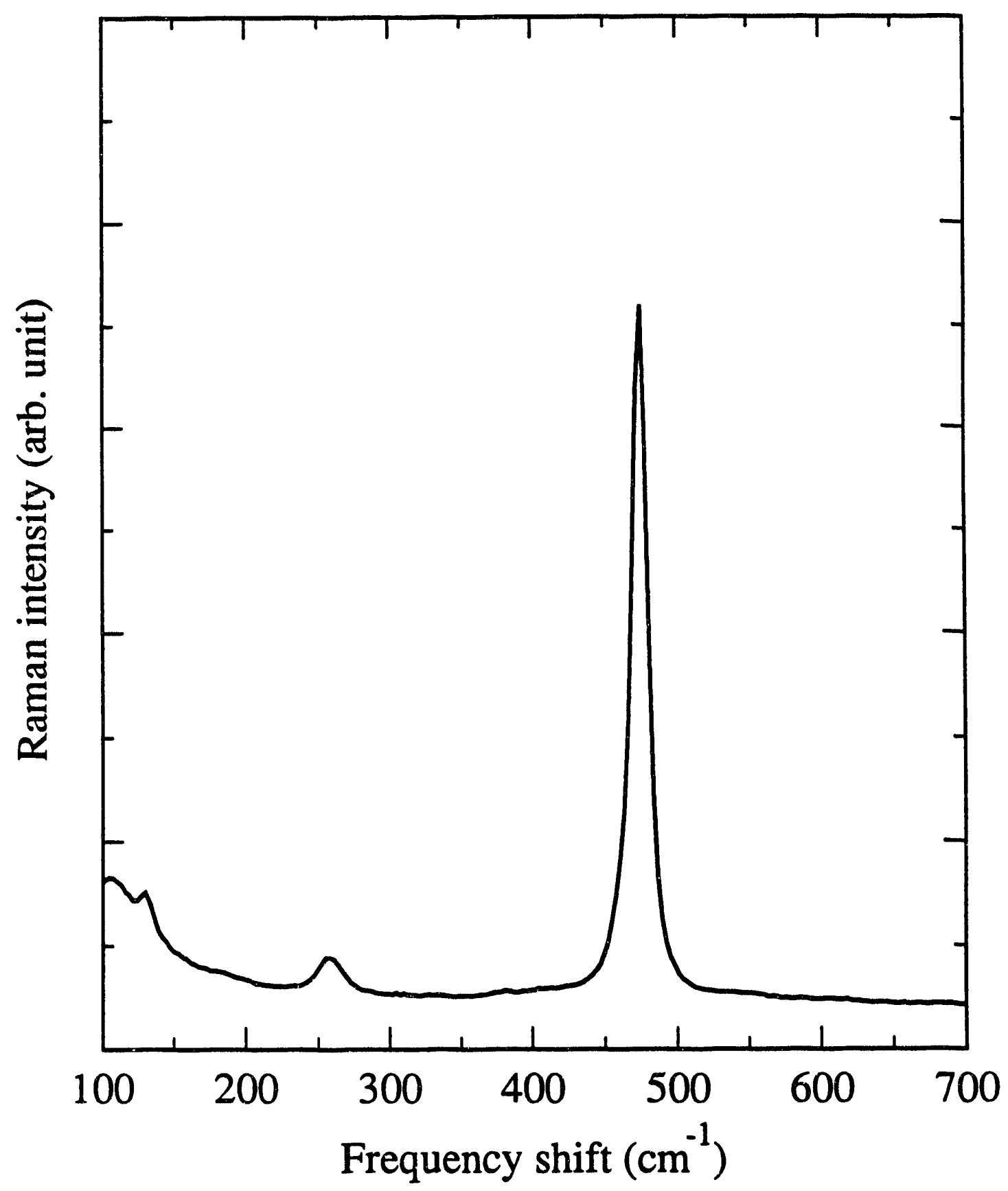

Figure 3.66. Raman spectrum of covellite in air. 
of an $\mathrm{NaCl}$ structure, the $\mathrm{Fe}$ atoms occupy the $\mathrm{Na}$ positions. The $\mathrm{S}_{2}{ }^{*}$ pairs are oriented such that their axes are parallel to 4 non-intersecting body diagonals of the cubic lattice. If the $S_{2}$ is replaced by $X$ then the structure can be seen to be made of $M X_{6}$ octahedra. In pyrite the $\mathrm{MX}_{6}$ octahedra share corners while in marcasite they share edges and form chains of linked octahedra. The structure of metal sulfides is discussed in detail by Vaughan and Craig [3.41]. In marcasite the intensity ratio of the peak at $379 \mathrm{~cm}^{-1}$ to the peak at $343 \mathrm{~cm}^{-1}$ is smaller than in pyrite. It is possible that the smaller size of the peak at $379 \mathrm{~cm}^{-1}$ is because the crystal structure of marcasite disrupts the in-phase motion of the S-S stretching mode.

Figure 3.66 shows the Raman spectrum of natural covellite. The peak in the spectrum can be attributed to the presence of $\mathrm{S}_{2}{ }^{2}$ groups in the structure. According to Vaughan and Craig [3.41], covellite is more correctly expressed as $\mathrm{Cu}_{2} \mathrm{~S} \cdot \mathrm{CuS}_{2}$ containing both $S^{=}$and $S_{2}{ }^{2}$. Raman experiments in this study confirmed the presence of $S_{2}{ }^{2}$ in the covellite lattice.

The oxidation products of pyrrhotite, chalcopyrite, covellite, and chalcocite were monitored by Raman spectroscopy. The Raman spectra are shown in Figures 3.67-3.70 for various time intervals during electrochemical oxidation. The oxidation product of pyrrhotite at $+1.0 \mathrm{~V} / \mathrm{SCE}$ in neutral solutions is shown in Figure 3.67 as a function of time. Like pyrite, pyrrhotite oxidized readily. However, only elemental sulfur peaks were in evidence for short as well as long experimental times. The expected oxidation reaction at $\mathrm{pH} 6.5$ is:

$$
\mathrm{FeS}+3 \mathrm{H}_{2} \mathrm{O} \rightarrow \mathrm{Fe}(\mathrm{OH})_{3}+\mathrm{S}^{\circ}+3 \mathrm{H}^{+}+3 e^{-}
$$

The oxidation of chalcopyrite was conducted electrochemically at $+1.0 \mathrm{~V} / \mathrm{SCE}$ in acid ( $\mathrm{pH}$ 2.7), neutral ( $\mathrm{pH}$ 6.5), and weak alkaline ( $\mathrm{pH}$ 9.2) solutions. The Raman spectra were taken at various time intervals in-situ. Figure 3.68 shows the time function of Raman spectra obtained in weak alkaline solutions. Sulfur peaks were clearly present in the spectra after a short time. The peak at about $470 \mathrm{~cm}^{-1}$ was broaden initially but the spectra taken at long times closely resembled elemental sulfur. No peaks of $\mathrm{Cu}_{2} \mathrm{O}, \mathrm{CuO}$ or $\mathrm{Cu}(\mathrm{OH})_{2}$ were detected. According to an electrochemical study [3.42], it was proposed 


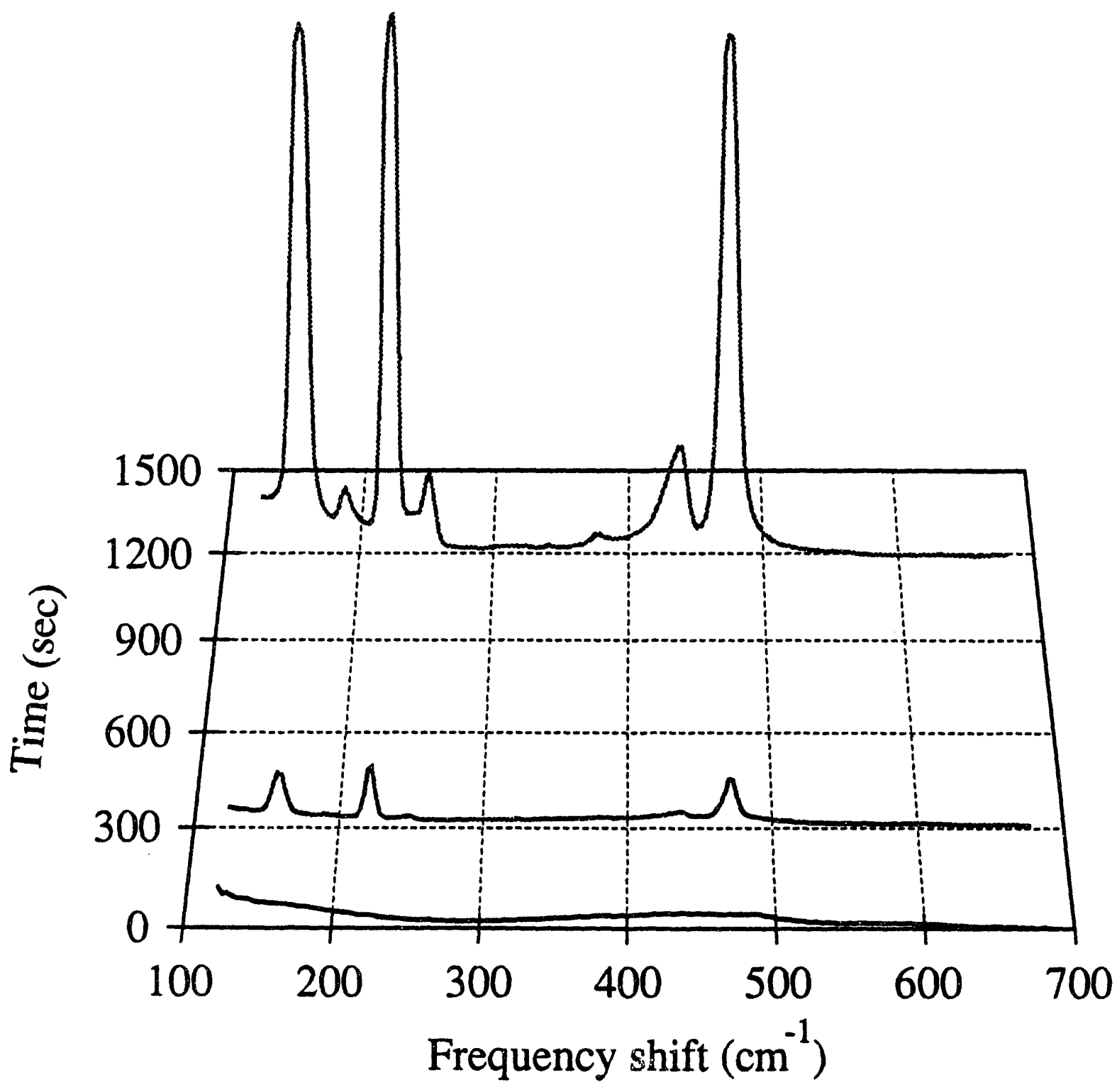

Figure 3.67. Raman spectra of electrochemically oxidized pyrrhotite at $1.0 \mathrm{~V}$ (solution: $0.5 \mathrm{M} \mathrm{NaCl}, \mathrm{pH} 6.5$ ). 


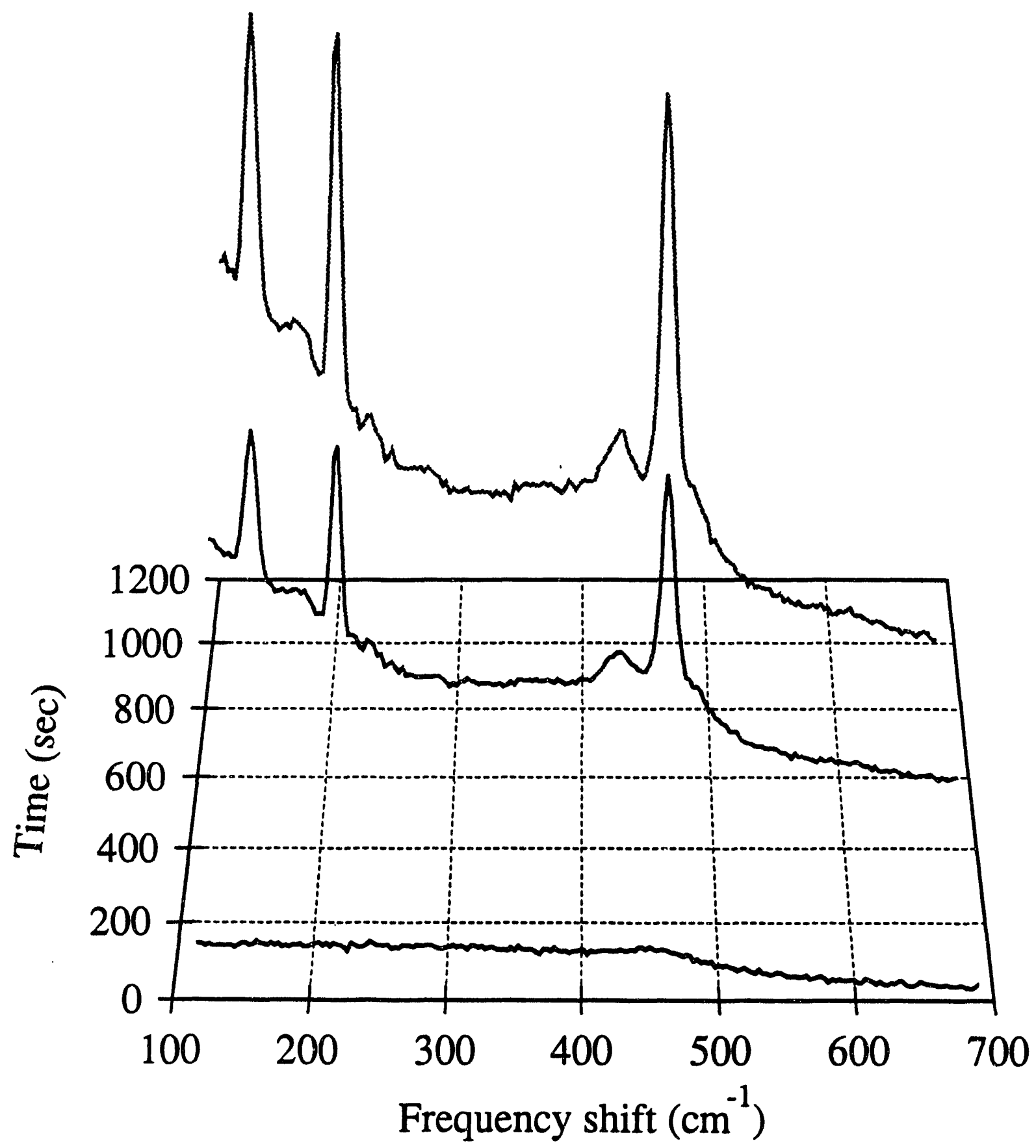

Figure 3.68. Raman spectra of electrochemically oxidized chalcopyrite at $1.0 \mathrm{~V}$ (solution: $0.5 \mathrm{M} \mathrm{NaCl}, \mathrm{pH}$ 9.2). 


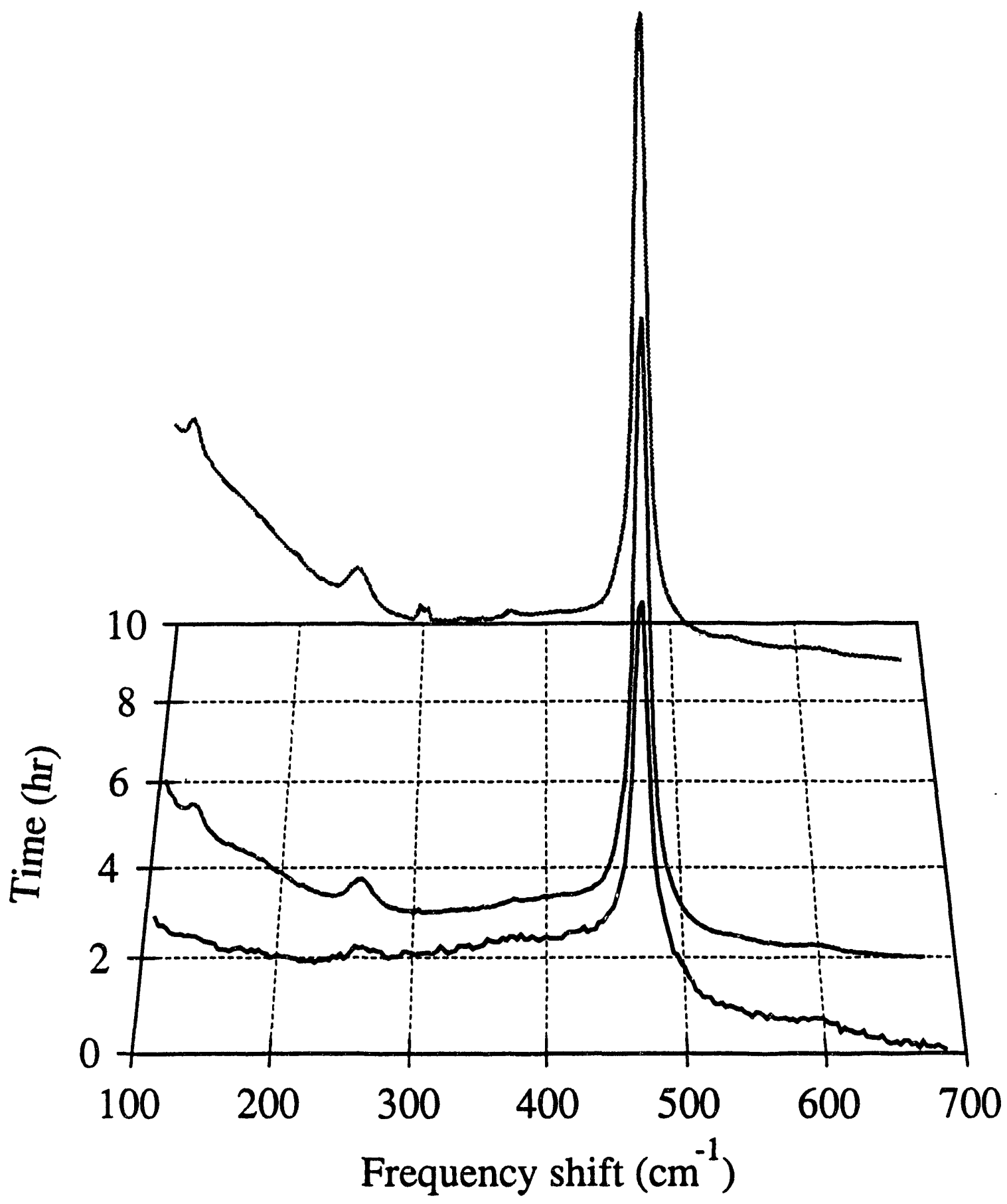

Figure 3.69. Raman spectra of electrochemically oxidized covellite at $0.4 \mathrm{~V}$ (solution: $0.5 \mathrm{M} \mathrm{NaCl}, \mathrm{pH} 2.7$ ). 


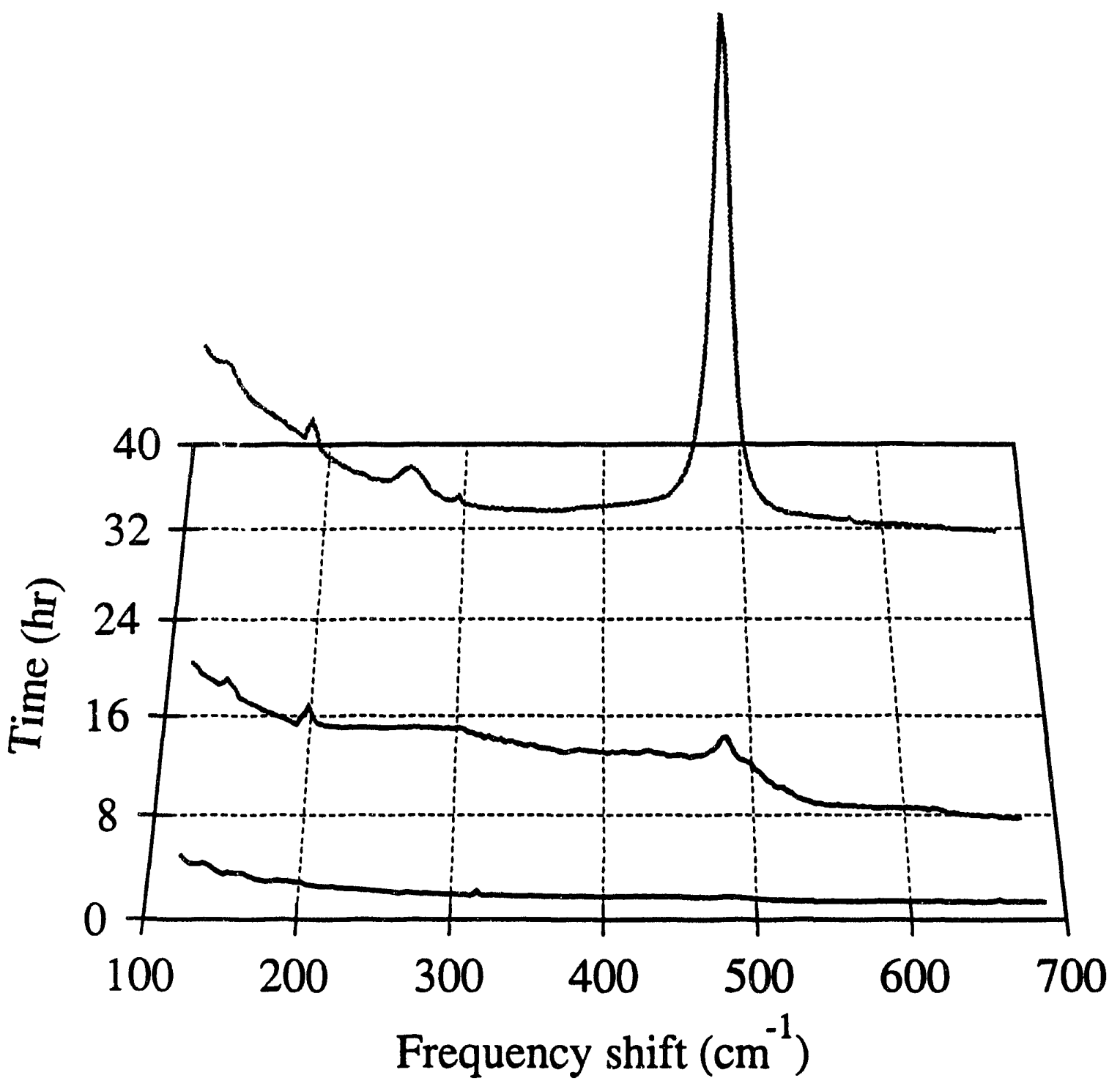

Figure 3.70. Raman spectra of electrochemically oxidized chalcocite at $0.3 \mathrm{~V}$ (solution: $0.5 \mathrm{M} \mathrm{NaCl}, \mathrm{pH} 2.7$ ). 
chalcopyrite, oxidized in a solution of $\mathrm{pH} 9.2$, would form iron oxide and a copper sulfide of $\mathrm{CuS}_{2}$ stoichiometry at potentials above 0 V/SCE. No $\mathrm{CuS}_{2}$ peaks were detected in these experiments. For these conditions, the reaction more likely is:

$$
\mathrm{CuFeS}_{2}+3 \mathrm{H}_{2} \mathrm{O}-\mathrm{Cu}^{2+}+\mathrm{Fe}(\mathrm{OH})_{3}+2 \mathrm{~S}^{\circ}+3 \mathrm{H}^{+}+5 e^{-} .
$$

The oxidation of covellite is presented in Figure 3.69. As the figure shows, sulfur was produced at the mineral surface when the covellite electrode was polarized at +0.4 V/SCE for a long enough time. The Raman spectra of oxidized covellite, however, was different from those of oxidized pyrite, pyrrhotite, chalcopyrite, and galena. Much less sulfur was produced on covellite as can be seen from the very low characteristic sulfur peaks ( 150 and $\left.215 \mathrm{~cm}^{-1}\right)$. The increase in polysulfide intensity may be explained by the following reaction:

$$
2 \mathrm{Cu}_{2} \mathrm{~S} \cdot \mathrm{CuS} \mathrm{S}_{2}-3 \mathrm{CuS_{2 }}+3 \mathrm{Cu}^{2+}+6 e^{-}
$$

Weak elemental sulfur peaks (equation 3.8) were apparent in the Raman spectra after extended periods of time. Since a very large quantity of charge was passed to the covellite electrode, the formation of sulfate must be more favorable, under these conditions, as shown in reaction (3.9):

$$
\begin{gathered}
\mathrm{Cu}_{2} \mathrm{~S} \cdot \mathrm{CuS} \mathrm{S}_{2} \rightarrow 3 \mathrm{Cu}^{2+}+3 \mathrm{~S}^{\circ}+6 e^{-} \\
\mathrm{Cu}_{2} \mathrm{~S} \cdot \mathrm{CuS}_{2}+12 \mathrm{H}_{2} \mathrm{O}-3 \mathrm{Cu}^{2+}+3 \mathrm{SO}_{4}^{-}+24 \mathrm{H}^{+}+24 e^{-}
\end{gathered}
$$

Figure 3.70 shows the Raman spectra of oxidized chalcocite at $+0.3 \mathrm{~V} / \mathrm{SCE}$ in acid (pH 2.7) solutions. The Raman spectra of oxidation products had $\mathrm{S}_{2}{ }{ }$ peaks as well as peaks of elemental sulfur. The in-situ observation confirmed that covellite, evidenced by the growing presence of $S_{2}{ }^{=}$ions in the lattice, was the intermediate of the oxidation of chalcocite under this condition. The reaction may be expressed as

$$
2 S^{*} \rightarrow S_{2}^{*}+2 e^{-}
$$

During the above reaction, a series of $\mathrm{Cu}_{2-\mathrm{x}} \mathrm{S}$ phases form. The peaks of $\mathrm{S}_{2}{ }^{2}$, which formed during the reaction, increased much faster than those of elemental sulfur, as can 
be seen from Figure 3.70. At higher potentials, the current passing through the chalcocite electrode was very high and no specific Raman peaks resulted. Like the oxidation of covellite, the formation of sulfate appears more favorable during the latter stages of oxidation of chalcocite.

\section{Particle Bed Experiments}

A solution of $\mathrm{pH} 6.5$ was used in these preliminary experiments. The Raman spectrum of particulate pyrite is shown in Figure 3.71a. The bed was polarized at +1.0 V/SCE where previous experiments demonstrated that sulfur was readily produced and detectable by Raman spectroscopy. However, after prolonged oxidation at this potential no evidence of sulfur was obtained; but, the pyrite peaks were clearly present. When the potential was increased up to $+1.5 \mathrm{~V} / \mathrm{SCE}$ sulfur peaks became apparent in the Raman spectrum (Figure 3.71b). The higher potential required to form sulfur is attributed to the large interparticle potential drop. The presence of such a large ohmic resistance may preclude the formation of sulfur since poor interparticle contact may limit electrochemical interaction. Thus, the use of electrode grids to activate pyrite particle by surface sulfur formation may be limited. The high resistance and short contact times mitigate against effective activation. This suggests surface cleaning by acid washing or reduction at a sufficiently negative potential may enhance electrochemical activation prior to flotation. Also strong agitation and fluidization by impellers or gas injection, or both, may assist.

The most convenient method for surface activation is perhaps to employ a solution with adequate oxidizing capability. This kind of solution is in direct contact with the particles and therefore overcomes the problem of ohmic potential drop. Figure 3.72 shows an example of pyrite particles oxidized in a potassium chlorate solution. Without application of any potential from a potentiostat, sulfur formed on the particle surfaces as the spectrum exhibited clearly. In this case the solution potential was about $+0.61 \mathrm{~V} / \mathrm{SCE}$.

\section{Photocurrent Experiments}

Pyrite. Photocurrent measurements were made for mineral pyrite in $0.5 \mathrm{M} \mathrm{NaCl}$ solutions of $\mathrm{pH} 2.7,6.5$ and 12.5. Only qualitative comparisons for acid and alkaline solutions were 


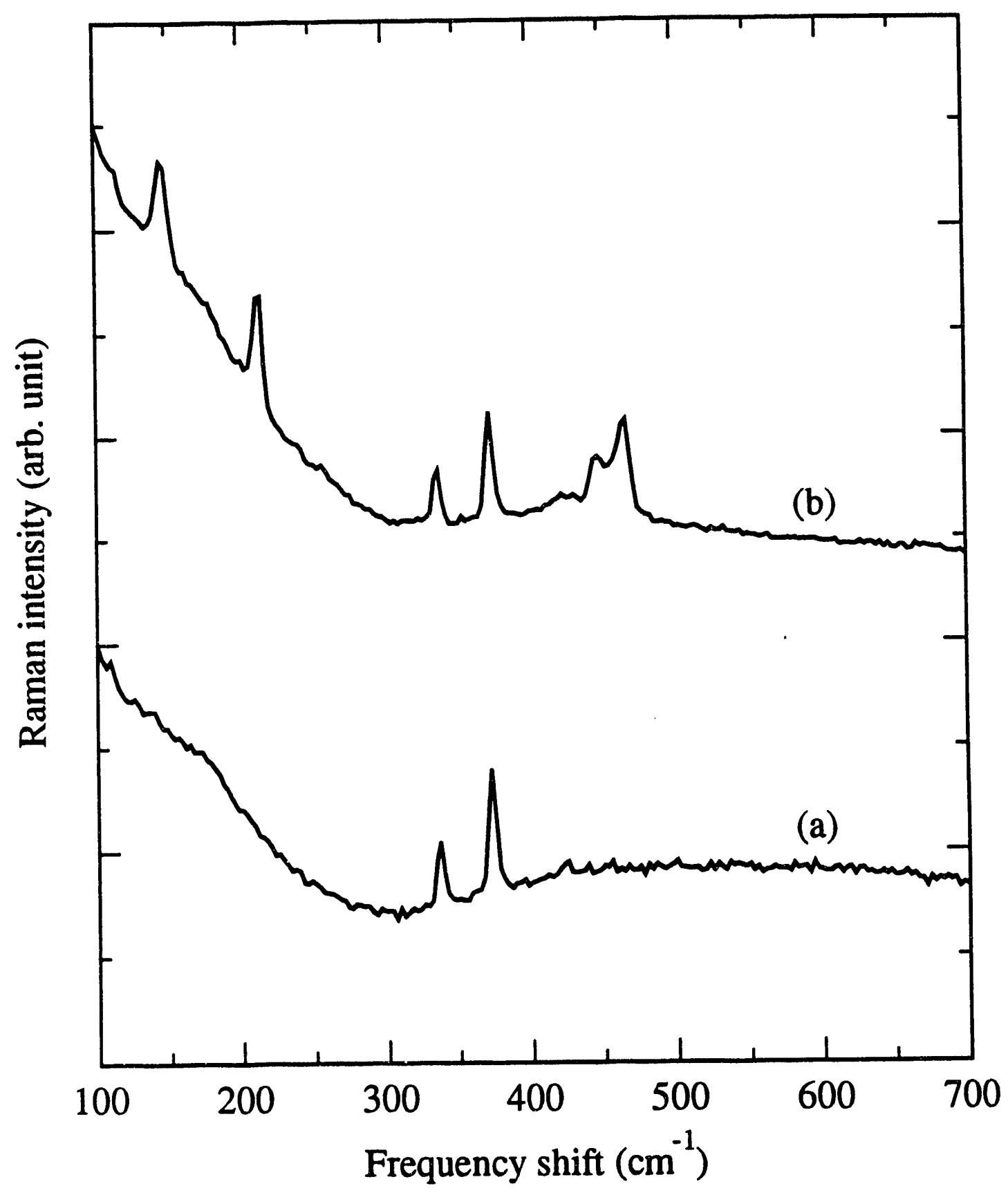

Figure 3.71. Raman spectrum of mineral pyrite particles (a) at rest potential; (b) at 1.5 V/SCE (solution: $0.5 \mathrm{M} \mathrm{NaCl}, \mathrm{pH} 6.5$ ). 


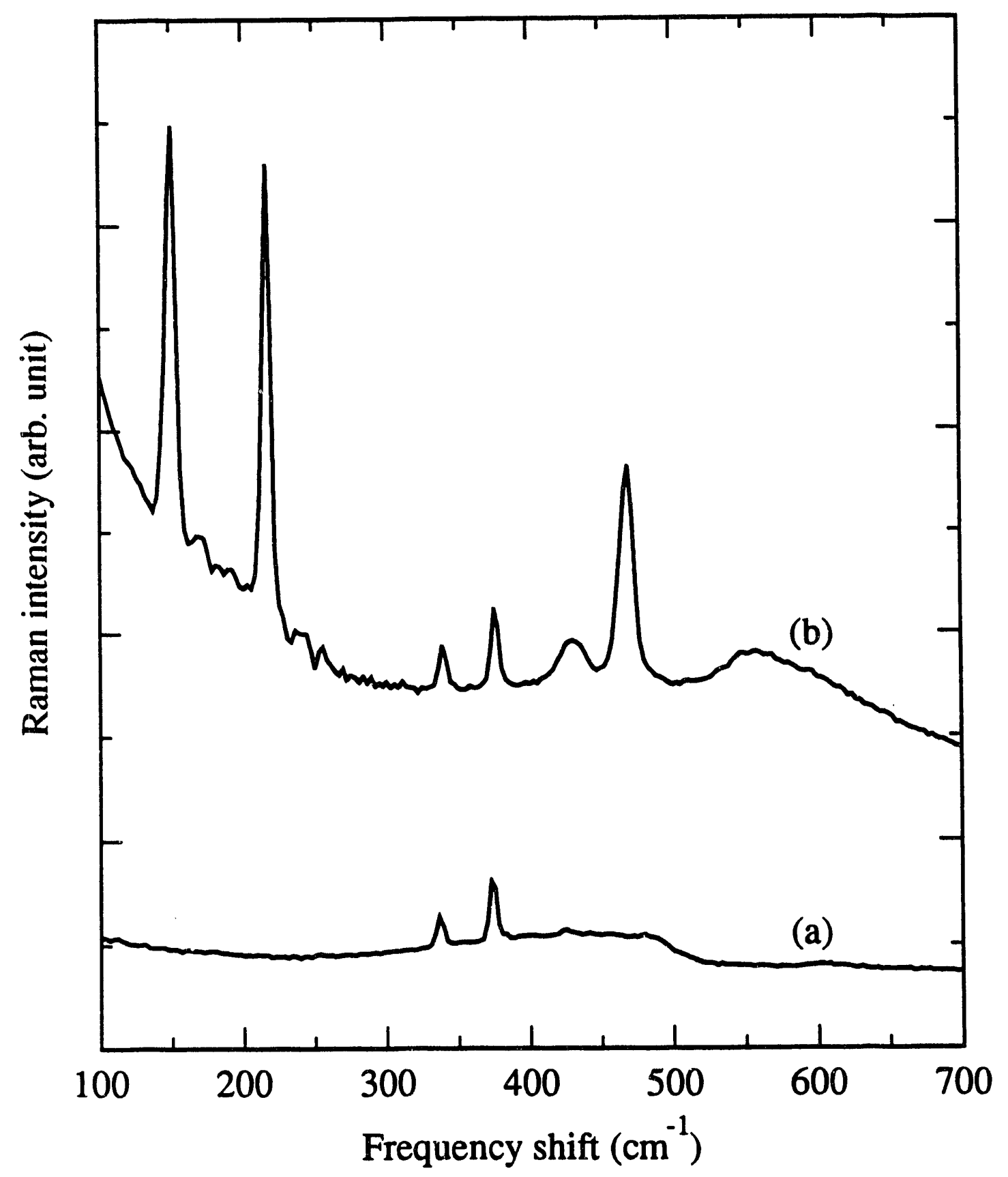

Figure 3.72. Raman spectrum of mineral pyrite particles (a) at the beginning; (b) at the end in $\mathrm{KClO}$ solution (sulotion potential: $0.6 \mathrm{~V} / \mathrm{SCE}$ ). 
attempted in this preliminary study. Considerable differences were observed for photocurrent behavior of pyrite at different $\mathrm{pH}$ values. No photocurrent was detected under acid conditions. In basic solutions, a strong photocurrent was observed only at anodic potentials above $0.0 \mathrm{~V} / \mathrm{SCE}$. The photocurrent response in neutral solutions was complex, with a large number of features, both anodic and cathodic. The in-phase and out-of-phase components of the photocurrent for a neutral solution are shown in Figures 3.73 and 3.74 .

The photocurrent behavior in acid and alkaline solutions may be explained by the absence and presence of a ferric hydroxide film. One of the oxidation products of pyrite is ferric hydroxide which is soluble in acid but insoluble under alkaline conditions. Photoelectrochemical studies of the corrosion of iron have shown that ferric films can produce a strong photocurrent response [3.16, 3.43]. In acid conditions the ferric hydroxide dissolves leaving no film capable of producing photocurrent. Conversely, the ferric hydroxide is very insoluble in basic conditions and a thick film exists on the electrode which produces a strong photocurrent response. The size of the photocurrent has been related to the oxidation state of the film, i.e., the $\mathrm{Fe}(\mathrm{II}) / \mathrm{Fe}$ (III) ratio [3.44].

The complex nature of the photocurrent at neutral pH suggests that many films of different electronic properties are present at different stages during the cyclic voltammogram.

Electrodeposited Sulfur. Sulfur was deposited and reduced during a cyclic voltammetry experiment from a solution of $0.001 \mathrm{M} \mathrm{Na} \mathrm{S}_{2}$ and $0.5 \mathrm{M} \mathrm{NaCl}$ with a $\mathrm{pH}$ of 6.5 . The photocurrent-potential curve was measured concurrently. No attempt has been made in this study to analyze the photocurrent spectra in detail. However, the film of electrodeposited sulfur is capable of producing a measurable photocurrent during both oxidation and reduction cycles. There is clearly a relationship between peaks on the cyclic voltammogram and photocurrent. Additional research is required to develop detailed explanation for these preliminary results. 


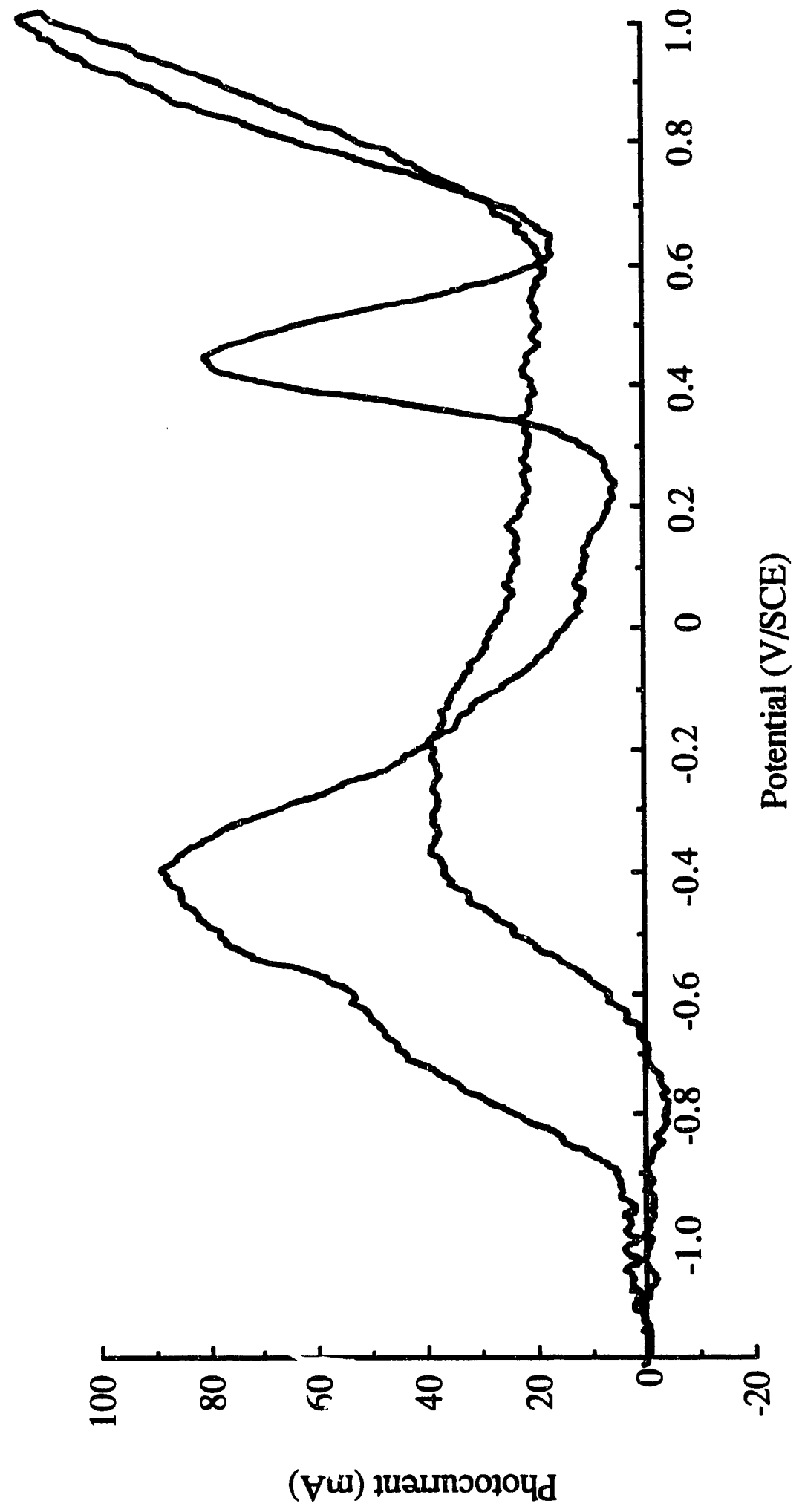

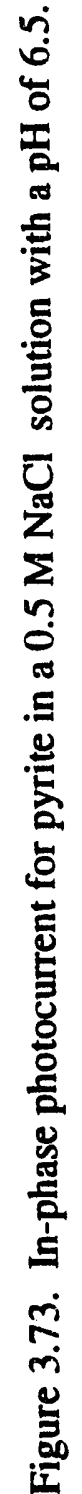




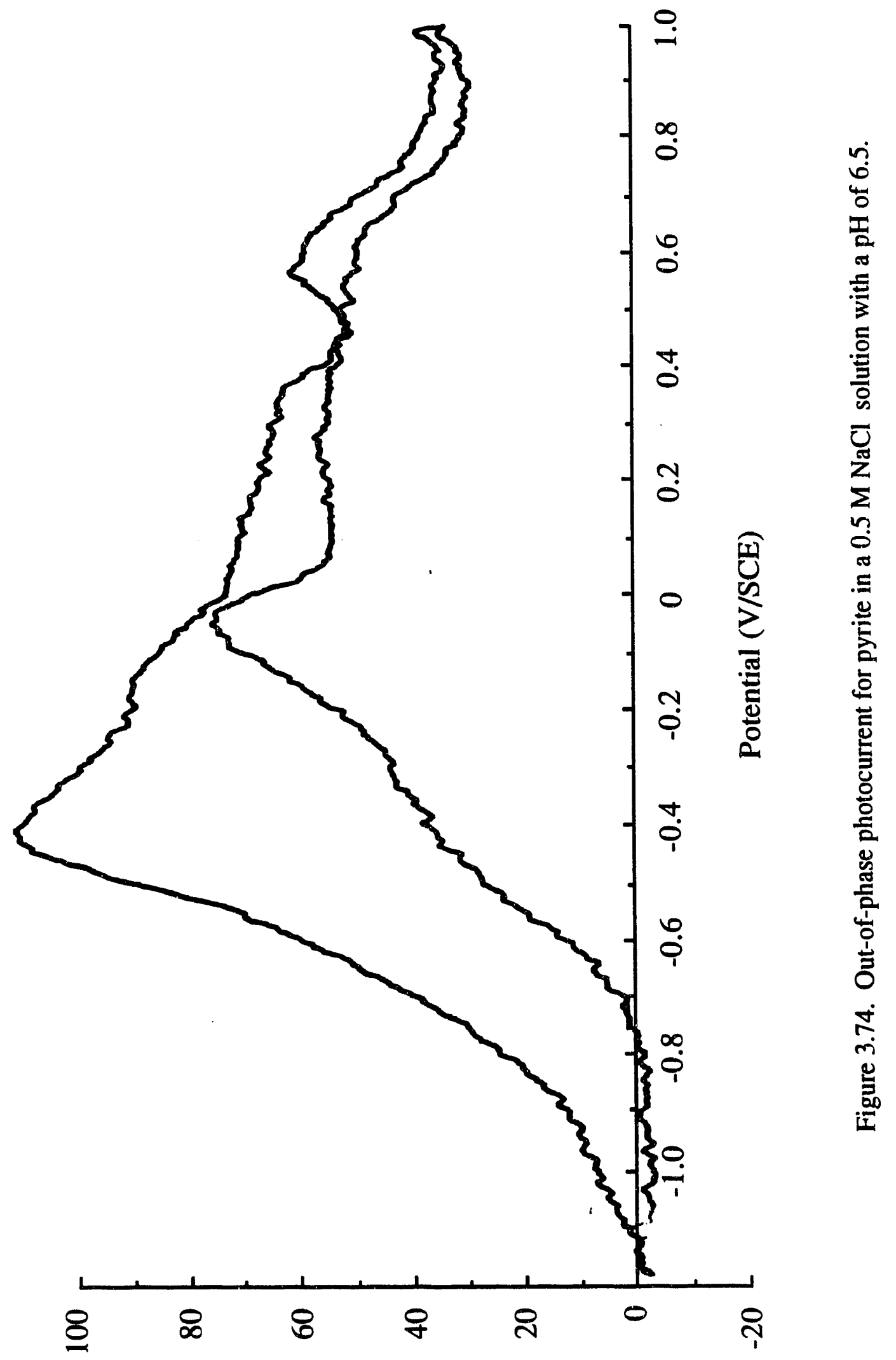

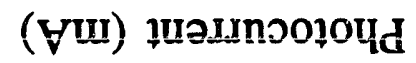




\section{CONCLUSION}

1. Raman spectroscopy has been applied successfully to characterize a pyrite surface in-situ during electrochemical anodic and cathodic surface reactions. Strong spectra were observed in relatively short times providing the possibility of being able to follow surface chemistry in real time without long integration periods to accumulate sufficient counts.

2. At appropriate potentials and solution $\mathrm{pH}$, sulfur was formed on pyrite surfaces via electrochemical oxidation. The initial surface products include both elemental sulfur and polysulfides. There is an optimum potential for sulfur formation. A proper solution with oxidizing capability may be used instead of external potential forces to produce hydrophobic sulfur films on pyrite surfaces.

3. The ability to be able to reduce the sulfur, formed by the oxidation of pyrite, indicates that the sulfur species must possess some degree of clectrical conductivity. The existence of a photocurrent from electrodeposited sulfur provides further evidence for its semiconducting nature.

4. Coulombic analysis shows that sulfur represents only a small fraction of the total coulombic production. While polysulfides and sulfur were observed, no oxy-sulfur species were detected by Raman spectroscopy. An exception was an occasional small peak attributed to sulfate. This is not surprising in view of the high solubility of these species. Its detection would depend upon it being trapped within the surface films on the pyrite.

5. The spectrum of the ferric hydroxide does not contain many distinct features and has a very weak Raman signal compared to pyrite and sulfur. SERS spectroscopy has been successful in detecting the Raman peaks. The ferric hydroxide films gave strong photocurrent response and can be best examined with this technique in addition to SERS.

\section{ACKNOWLEDGEMENT}

The financial assistance from the U.S. Department of Energy under project No. 
DE-AC22-89PC-89758 and the support of the John A. Dixon Laser Institute at the University of Utah are greatly acknowledged.

\section{REFERENCES}

[3.1] S. A. Allison and N. P. Finkelstein, "A method for the determination of elemental sulfur on the surface of sulfide minerals," (NIM report No 1495, Johannesburg, South Africa, 1972).

[3.2] I. C. Hamilton and R. Woods, "An investigation of surface oxidation of pyrite and pyrrhotite by linear sweep voltammetry," J. Electroanal. Chem., 118 (1981), 327.

[3.3] A. N. Buckley, I. C. Hamilton and R. Woods, "An investigation of the sulfur (-II)/sulfur(0) system on gold electrodes," J. Electroanal. Chem., 216 (1987), 213.

[3.4] J. R. Gardner and R. Woods, "The use of a particulate bed electrode for the electrochemical investigation of metal and sulfide floatation," Aust. J. Chem., 26 (1973), 1635.

[3.5] D. M. Bodily and M. E. Wadsworth, "Surface Electrochemical control for the fine coal and pyrite separation," (Jan. 1 to Mar. 31 Technical Progress Report, DOE Project No. DE-AC22-89PC89758).

[3.6] C. A. Murray and S. B. Dierker, "Use of an unintensified charge coupled detector for low light raman spectroscopy," J. Opt. Soc. Am. A, 3 (1986), 2151.

[3.7] P. M. Epperson, J. V. Sweedler, R. B. Bilhom, G. R. Sims and M.BonnerDenton, "Applications of charge transfer devices in spectroscopy," Anal. Chem., 60 (1988), 327.

[3.8] J. R. Mycroft, G. M. Bancroft, N. S. McIntyre, J. W. Lorimer and I.R. Hill, "Detection of sulfur and polysulfides on electrochemically oxidised pyrite surfaces by X-ray photoelectron spectroscopy and Raman spectroscopy," $J$. Electroanal. Chem., 292 (1990), 139.

[3.9] A. Campion, "Raman Spectroscopy" in Vibrational spectroscopy of molecules on surfaces, eds. J. T. Yates and T. E. Madey (Plenum, N.Y., 1987), 345.

[3.10] R. L. Garrell, "Surface enhanced raman spectroscopy," Anal. Chem., 61 (1989), $401 \mathrm{~A}$. 
[3.11] R. L. McCreery and R. T. Packard, "Raman monitoring of dynamic electrochemical events," Anal. Chem., 61 (1989), 775A.

[3.12] J. Dünnwald and A. Otto, "An investigation of phase transitions in rust layers using raman spectroscopy," Corr. Sci., 29 (1989), 1167.

[3.13] H. Gerischer, "Models for the discussion of the photo-electrochemical response of oxide layers on metals," Corr. Sci., 29 (1989), 257.

[3.14] H. Gerischer, "The impact of semiconductors on the concepts of electrochemistry," Elect. Acta., 35 (1990), 1677.

[3.15] U. Stimming, "Photoelectrochemical studies of passive films," Elect. Acta., 31 (1986), 415.

[3.16] C. Sunseri, S. Piazza, A. Di Paola and F. Di Quarto, "A photocurrent spectroscopic investigation of passive films on ferritic stainless steels," $J$. Electrochem. Soc., 134 (1987), 2410.

[3.17] A. Ennaoui, S. Fiechter, W. Jaegermann and H. Tributsch, "Photoelectrochemistry of highly quantum efficient single crystalline n-FeS (pyrite)," J. Electrochem. Soc., 133 (1986), 97.

[3.18] K. K. Mishra and Asseo-Asare "Photo-dissolution of coal pyrite," Fuel, 66 (1987), 1161.

[3.19] K. K. Mishra and Asseo-Asare, "Aspects of the interfacial electrochemistry of semiconductor pyrite $\left(\mathrm{FeS}_{2}\right)$," J. Electrochem. Soc., 135 (1988), 2502.

[3.20] T. Biegler, "Oxygen reduction on sulfide minerals," J. Electroanal. Chem., 70 (1976), 265.

[3.21] A. L. Echarri and C. Sanchez "N type semiconductivity in natural single crystals of $\mathrm{FeS}_{2}$ (pyrite)" Solid State Comm., 15 (1974), 827.

[3.22] H. Vogt, T. Chattopadhyay and H. J. Stolz, "Complete first order raman spectra of the pyrite structure compounds $\mathrm{FeS}_{2}, \mathrm{MnS}_{2}$ and $\mathrm{SiP}_{2}, " J$. Phys. Chem. Solids, 44 (1983), 869.

[3.23] P. D. Harvey and I. S. Butler, "Raman Spectra of Orthorhombic sulfur," J. of Raman Spectroscopy, 17 (1986), 329.

[3.24] S. Ushioda, "Raman scattering from phonons in iron pyrite $\left(\mathrm{FeS}_{2}\right)$," Solid Comm., 10 (1972), 307. 
[3.25] J. C. Rubim, "In-situ spectroelectrochemical study of the passivation of iron in alkaline solutions" J. Chem. Soc. Farad. Trans. 1, 85 (1989), 4247.

[3.26] J. C. Rubim and J. Dünnwald, "Enhanced raman scattering from passive films on silver coated iron electrodes," J. Electroanal. Chem., 258 (1989), 327.

[3.27] D. Thierry, D. Perrson, C. Leygraf, N. Boucherit and A. Hugot-Le Goff "Raman spectroscopy and XPS investigations of anodic corrosion films formed on Fe-Mo alloys in alkaline solutions," Corr. Sci., 32 (1991), 273.

[3.28] J. B. Hiskey and W. J. Schlitt, "Aqueous Oxidation of Pyrite," in Interfacing Technologies in Solution Mining, ed. W. J. Schlitt, (1982), 55.

[3.29] W. Giggenbach, "Optical spectra and equilibrium distribution of polysulfide ions in aqueous solution at $20^{\circ} \mathrm{C}$," Inorg. Chem., 11 (1972), 1201.

[3.30] R. Steudel, "Homocyclic sulfur molecules," in Inorganic ring systems ed. T. Chivers et al., Springer Verlag, (1982), 149.

[3.31] G. J. Janz, J. W. Coutts, J. R. Downey and E. Roduner, "Raman studies of sulfur containing anions in inorganic polysulfides. Potassium polysulfides," Inorg. Chem., 15 (1976), 1755.

[3.32] G. J. Janz, J. W. Coutts, J. R. Downey and E. Roduner, "Raman studies of sulfur containing anions in inorganic polysulfides. Sodium polysulfides," Inorg. Chem., 15 (1976), 1759.

[3.33] P. Lenain, E. Picquenard, J. Corset, D. Jensen and R. Steudel, "Raman spectrometric studies of the composition of sulfur vapor at temperature up to $700{ }^{\circ} \mathrm{C}^{\prime \prime}$, Ber. Bunsenges. Phys. Chem., 92 (1988), 859.

[3.34] I. C. Hamilton and R. Woods, in Proc. Int. Symp. Electrochemistry in mineral and metal Processing, eds. P. E. Richardson, S. Srinivasan and R. Woods (Pennington, NJ: The Electrochemical Society, 1984), 259.

[3.35] S. I. Zhdanov, "Sulfur," Encyclopedia of the electrochemistry of the elements, Vol. 4, ed. A. Bard, (Marcel Dekker, New York, 1974), 273.

[3.36] R. Woods, D. C. Constable and I. C. Hamilton, "A rotating ring disc electrode study of the oxidation of sulfur (-II) species on gold and sulfide minerals," Int. J. Min. Proc., 27 (1989), 309. 
[3.37] S. Sato, S. Higuichi and S. Tanaka, "Identification and determination of oxygen containing inorganosulfur compounds by laser raman spectrometry," Appl. Spect., 39 (1985), 822.

[3.38] X. Zhu, J. Li, D. M. Bodily and M. E. Wadsworth, "Transpassive oxidation of pyrite," Proc. Int. Symp. Electrochemistry in Mineral and Metals Processing, Vol. 3, eds. P. E. Richardson and R. Woods (Pennington, NJ: The Electrochemical Society, 1992), 391.

[3.39] J. Ralston, P. Alabaster and T. W. Healy "Activation of zinc sulfide with $\mathrm{Cu}(\mathrm{II}), \mathrm{Cd}(\mathrm{II})$ and $\mathrm{Pb}(\mathrm{II})$. The mass spectroscopic determination of elemental sulfur." Int. J. Min. Proc., 7 (1981), 279.

[3.40] R. L. Paul, M. J. Nicol, J. W. Diggle and A. P.Saunders, "The electrochemical behaviour of galena (lead sulfide)- 1. anodic dissolution," Elect. Acta., 23 (1978), 625.

[3.41] D. J. Vaughan and J. R. Craig, "Mineral Chemistry of Metal Sulfides," (Cambridge University Press, 1978).

[3.42] R. Woods, D. C. Constable, and I. C. Hamilton, "A rotating ring disc electrode study of the oxidation of sulfur (II) on gold and sulfide minerals," Proc. Int. Symp. Electrochemistry in Mineral and Metal Processing, Vol. 2, eds. P. E. Richardson and R. Woods (Pennington, NJ: The Electrochemical Society, 1988), 113.

[3.43] E. Ahlberg, K. S. E. Forssberg and X. Wang, "The surface oxidation of pyrite in alkaline solution," J. Appl. Electrochem., 20 (1990), 1033.

[3.44] M. P. Dare-Edwards, J. B. Goodenough, A. Hamnett and P. Trevellick, J. Chem. Soc. Farad. Trans. I, 79 (1983), 2027. 


\section{FLOATABILITY OF COAL AND COAL PYRITE}

\section{INTRODUCTION}

Flotation and oil agglomeration are two major important physical processes for depyritization based on economical and technological criteria. Conceivably, the separation of coal pyrite from coal by flotation can occur in two ways: (1) by selective, conventional, flotation of coal from pyrite using frothers, collectors of coal and depressants of pyrite; and, (2) by selective (reverse) flotation of pyrite from the depressed coal. Frothers, conventionally used, are MIBC, pine oil or cresylic acid in amounts of the order of $0.2 \mathrm{lb} /$ ton. Fuel oil is commonly used as a collector for coal and many chemicals have been investigated as pyrite depressants.

The flotation mechanism of mineral pyrite is perhaps the best understood of all sulfide minerals. The surface active collector in xanthate flotation of pyrite is dixanthogen, formed by the oxidation of xanthate. Pyrite depression is thus made possible by using various chemical reductants to lower the oxidation potential of the of the pyrite below the threshold potential for dixanthogen formation. There have been few studies of the relative floatability of coal pyrite and coal. The mechanism is not well understood, and processes for separating coal and coal pyrite are still not satisfactory. It has been found that the flotation behavior of coal pyrite is quite different from that of mineral pyrite. Coal pyrite represents a minor component in coal, and flotation of the minor part (pyrite) with suppression of the major part (coal), reverse flotation, has not been achieved satisfactorily. Compared to mineral pyrite, coal pyrite has a lower floatability [4.2]. Esposito et al. [4.3] studied seven pyrite samples from coal sources and mineral pyrite. Some of the coal pyrites were nonfloatable. Lai et al. [4.4] reported a very different dependence for mineral pyrite and coal pyrite in the presence of sodium hydrosulfide and an anionic fluorosurfactant. Maximum recovery of mineral pyrite and coal pyrite was at $\mathrm{pH} 5$ and $\mathrm{pH} \mathrm{8,} \mathrm{respectively.} \mathrm{Maximum} \mathrm{flotation} \mathrm{at} \mathrm{pH} 8$ was attributed to the activation influence of ferrous ion or other multivalent cations in the solution.

There are a number of different approaches to investigate floatability. These 
include contact angle measurements, bubble pickup tests, reagent adsorption measurements, zeta potential measurements, critical surface tension for floatability [4.5], the film flotation technique [4.6], Hallimond tube flotation tests, and laboratory flotation cell tests. In considering the various merits of these methods, the Hallimond tube and laboratory flotation cell tests were selected for use in this study. These methods measure flotation response directly and the Hallimond tube was adaptable to provide electrochemical pretreatment.

This study focused on the following three methods and procedures for measuring coal and coal pyrite floatability:

(1) Floatability Based on Hallimond Tube Flotation Tests,

* Floatability of coal and pyrite with xanthate as a collector

* Activation of pyrite

* Depression of pyrite

(2) Floatability Based on Laboratory Flotation Cell Flotation Tests,

* Flotation with distilled water. (This was considered as a measure of the coal's natural propensity for flotation)

* Flotation with frother only. (This was taken as a measure of the coal's floatability and selectivity under conventional froth flotation conditions)

* Salt flotation. (Salt flotation of coal has been used in China, the USSR and recently in the U.S.A. to evaluate the relative floatability and selectivity of coal and pyrite in an indifferent environment)

(3) Electrochemical Flotation in an Electrochemical Flotation Mini-cell

* The effects of electrolyte on floatability

* Electrochemical pretreatment of coal pyrite

\section{EXPERIMENTAL}

\section{Sample Characteristics}

Three coal samples which cover a range of sulfur and pyrite content and rank were selected for this investigation:

(1) Upper Freeport Medium Volatile bituminous Coal (MVb) 
(2) Pittsburgh High Volatile A bituminous coal (HVab)

(3) Illinois High Volatile C bituminous coal (HVCb)

Proximate and ultimate analyses of the three coal samples are shown at Tables 4.1 and 4.2.

Table 4.1 Proximate analysis of three coal samples

\begin{tabular}{lcccc}
\hline \multirow{2}{*}{ Coal Sample } & Moisture & \multicolumn{3}{c}{ Proximate Analysis (Dry Basis) } \\
\cline { 3 - 5 } & $\%$ & V.M.(\%) & F.C.(\%) & Ash (\%) \\
\hline Illinois HVCb & 11.05 & 36.43 & 47.38 & 16.19 \\
Pittsburgh HVAb & 3.63 & 35.63 & 52.31 & 12.06 \\
Freeport HVb & 2.23 & 25.60 & 62.26 & 12.14 \\
\hline
\end{tabular}

Table 4.2 Ultimate analysis and heat value of three coal samples

\begin{tabular}{lcccccc}
\hline Coal Sample & C\% & H\% & N\% & S\% & O\% & $\begin{array}{c}\text { Heating Value } \\
\text { Btu/Lb }\end{array}$ \\
\hline Illinois HVCb & 66.48 & 4.56 & 1.12 & 5.19 & 6.46 & 11,814 \\
Pittsburgh HVCb & 72.06 & 4.85 & 1.32 & 3.95 & 5.76 & 12,815 \\
Freeport MVb & 77.25 & 4.64 & 1.32 & 2.24 & 2.41 & 13,601 \\
\hline
\end{tabular}

The mineral pyrite used in this study was obtained from Wards's National Science Establishment while the coal pyrite was from lumps of massive sulfur refuse obtained from Pittsburgh No 8 Seam of the Cumberland Mine, Green County, Pennsylvania. The assay of samples is listed at Table 4.3.

Table 4.3 Assay of pyrites

\begin{tabular}{cccc}
\hline Sample & Mineral Pyrite & Coal Pyrite & Coal \\
\hline FeS $_{2}$ & 91.93 & 78.64 & 4.99 \\
Ash & & & 12.29 \\
\hline
\end{tabular}




\section{Hallimond Tube Floatability Tests}

Sample Preparation. Feed coal was dry-ground in a laboratory rod mill, then sieved to recover a size fraction of $-100+325$ mesh. The mineral and coal pyrite were mechanically crushed with a steel pestle, dry ground in a ceramic ball mill, and then sieved to size $-100+325$ mesh.

Equipment and Experimental Procedures. The floatability of the coals and coal pyrites was measured using a Hallimond flotation tube. One gram of pyrite or coal and about 30 $\mathrm{ml}$ of water or solution, with desired $\mathrm{pH}$ and electrolyte, were first placed in the tube. Collectors such as xanthate, dodecane and butyl alcohol are then added to the tube. The suspension was stirred and conditioned at a moderated stirring rate with a set argon flow rate for 5 minutes. Flotation was initiated by introducing more water or solution to the cells to increase the volume of the suspension to $120 \mathrm{ml}$. The argon flow rate and the stirring speed were kept constant during the course of conditioning and flotation. The concentrate and tail were filtered, dried and weighed.

\section{Floatability Measurements Using a Laboratory Flotation Cell}

Sample Preparation. The feed for each flotation test was wet-ground in a laboratory rod mill (8-in diameter $\times 10$-in length) to obtain a product of $95 \%$ finer than 200 mesh.

Equipment and Experimental Procedures. An automated flotation cell was used for the tests. Flotation test feed weight for each test was 125 grams. Conditioning time for pulping was 4 minutes, for pulp level adjustment and $\mathrm{pH}$ measurement 1 minute, and for frother conditioning 3 minutes. Flotation time required to attain a steady state was 5 minutes. For the kinetic study, froth removal intervals were: 15 seconds, 30 seconds, 60 seconds, and 150 seconds, and the accumulated time was 300 seconds.

In the assessment of flotation test results, the Yield\% and Ash\% of cleaned coal are generally determined in conventional practice. Since the yield was only a weight measurement, and the ash itself was not the main separation goal in coal desulfurization research, additional evaluation criteria of floatability and selectivity were defined and used 
as follows [4.7]:

AC Ash (\%) in the cleaned coal or concentrate

AF Ash (\%) in the feed

AR Ash rejection; (\%) of total ash in the tailings

BTUR Recovery of BTU (\%); [BTU (Conc) /BTU (feed)] $\times 100$

C Concentrate, (wt) cleaned coal or float product

CMR Combustible material recovery (\%)

EI Index for pyrite separation efficiency

F Feed (wt)

PSC Pyritic sulfur (\%) in concentrate or cleaned coal

PSR Pyritic sulfur (P.S.) rejection; (\%) of total P.S. in tailings

PST Pyritic sulfur in tailings

y Yield $(\%)$ of cleaned coal or float product

$$
\begin{aligned}
& C M R=y\left[\frac{100-A C}{100-A F}\right] \\
& P S R=(100-y)\left[\frac{P S T}{P S F}\right]
\end{aligned}
$$

EI includes a matrix made up of matrix elements Eij, where i refers to specific component and $\mathrm{j}$ to products. The two components in this analysis refer to combustible material (i $=1)$ and pyritic sulfur $(i=2)$. The two $j$ th products are concentrate $(j=I)$ and tailings $(j=I I)$. From the definitions listed above, it is apparent that $E_{11}=C M R$ and $E_{2 n}=P S R$. Since the matrix elements of EI are measured in \%, the Efficiency Index is represented by the matrix:

$$
E I=\frac{1}{100}\left[\begin{array}{ll}
E_{11} & E_{1 I} \\
E_{2 I} & E_{2 \pi}
\end{array}\right]=C M R+P S R-100
$$

\section{Electrochemical Hallimond Mini-flotation Cell Test}

Sample Preparation. Mineral and coal pyrite were mechanically crushed with a steel 
pestle, dry ground in a ceramic ball mill, and then sieved tc get samples with the desired particle size. A $-100+325$ mesh fraction was coliected for microflotation and electrochemical pretreatment tests. The sized fraction was used to minimize mechanical carry over or entrainment. The coal sample from Pittsburgh No 8 seam was prepared with the same procedure.

Solutions. The solutions were prepared from reagent grade chemicals and deionized water. Sodium sulfate and sodium borate were added to the solution as supporting electrolyte. A buffer solution having a pH of 9.2 with $0.125 \mathrm{M} \mathrm{Na}_{2} \mathrm{SO}_{4}$ and $0.005 \mathrm{Na}_{2} \mathrm{~B}_{4} \mathrm{O}_{7}$ was prepared for most electrochemical measurements. Concentrated $\mathrm{HCl}$ and $\mathrm{NaOH}$ were used to adjust the $\mathrm{pH}$ of solution for some tests.

Equipment and Experimental Procedures. Conventional flotation tests and electrochemical pretreatment flotation experiments were carried out in a modified Hallimond tube (Figure 4.1). A platinum plate electrode was used as the working electrode to electrically contact a bed of particulate pyrite and was placed in the bottom of the glass cell. Additionally, a platinum counter electrode was separated from the cell by a medium porosity glass frit in the base of the cell. The argon flow rate was set with a rotameter at $14 \mathrm{mil} / \mathrm{min}$. A saturated calomel reference electrode was placed in a separated compartment to measure the potential near the top of the pyrite bed by means of a Luggin capillary tube.

In a typical electrochemical pretreatment flotation experiment, sufficient pyrite of a known particle size and weight was added to cover the platinum plate and $30 \mathrm{ml}$ of electrolyte solution was introduced to the cell. Electrochemical pretreatment, at a set potential, was conducted for twenty minutes under quiescent conditions followed by collector addition and reagent conditioning for five minutes. Flotation was carried out for an additional five minutes with the combined action of a teflon stirring bar and an argon gas stream. After flotation, the floated fraction and the sink fraction were filtered, dried and weighed separately. For some tests, evaluating the separation of pyrite from coal, the DCP technique was used to analyze for pyrite content in the cleaned coal for the calculation of pyrite rejection. 


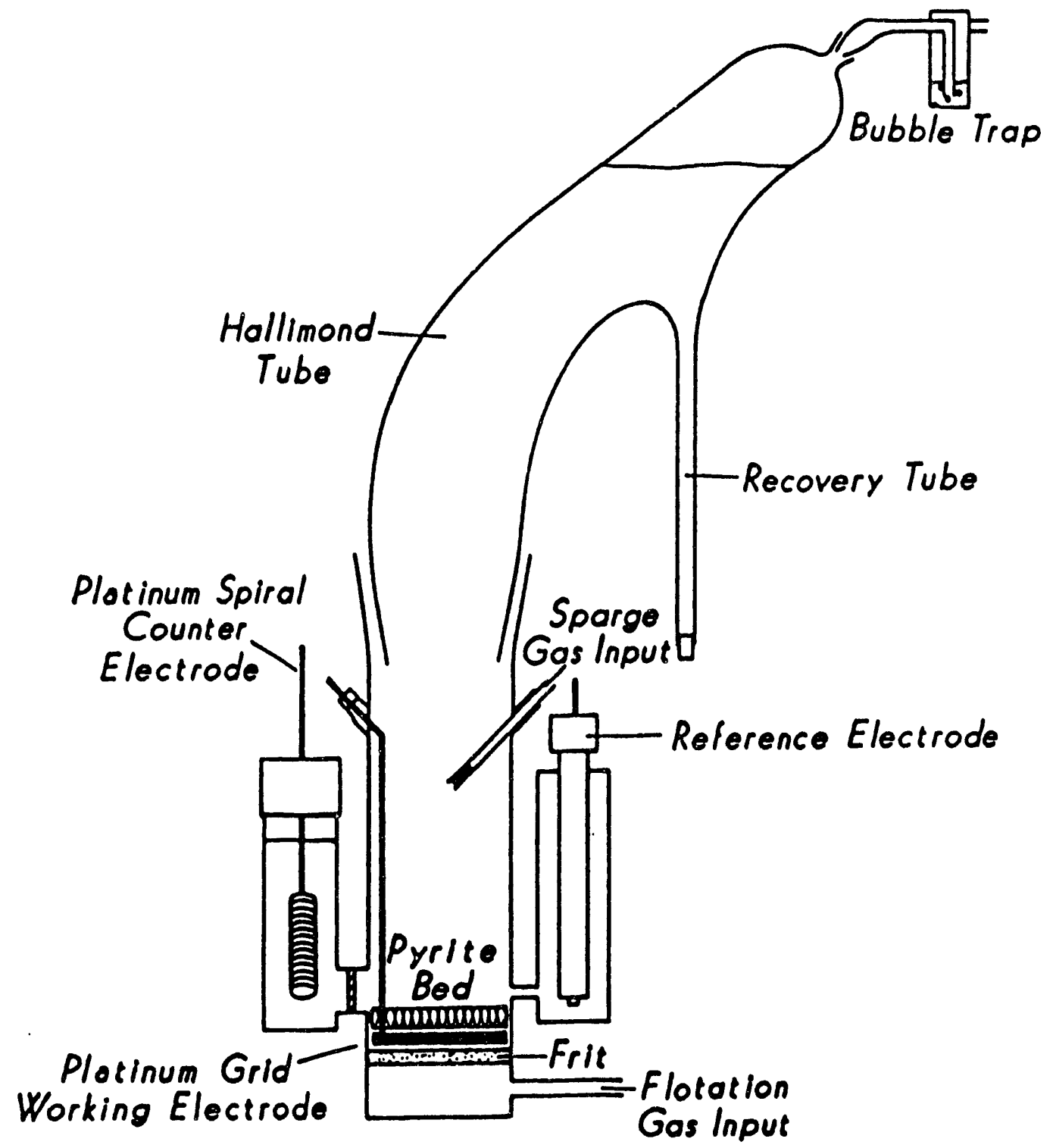

Figure 4.1 Electrochemical Flotation Mini-cell 


\section{RESULTS AND DISCUSSION}

\section{Floatability Measurements Using the Hallimond Tube}

Flotation Using Amyl Xanthate as Collector. Figures 4.2 and 4.3 illustrate the floatability of mineral and coal pyrite as a function of xanthate concentration. The floatability of mineral pyrite was close to its natural floatability when the concentration of xanthate was less than $0.25 \times 10^{-5} \mathrm{M}$. At higher xanthate concentrations, the recovery of mineral pyrite increased significantly as the concentration of xanthate was increased. Mineral pyrite was almost 100 percent floated when the xanthate concentration was increased to $1.25 \times 10^{-5} \mathrm{M}$. In contrast with mineral pyrite, coal pyrite showed a continuous increase in floatability with increasing xanthate concentration. From Figure 4.2 and 4.3, it can be seen that the floatability of mineral pyrite was always much higher than that of coal pyrite. For the same recovery, the amount of xanthate required for coal pyrite was about 50 times that required for mineral pyrite. The mineral pyrite reached its maximum floatability at $1.25 \times 10^{-5} \mathrm{M}$ xanthate concentration while for coal pyrite, the floatability remained unchanged from its natural floatability at this level of xanthate.

It was observed that the mineral pyrite sample was bright in color, while the coal pyrite was dark. As mentioned early in this report, the $\mathrm{FeS}_{2}$ content of mineral pyrite and coal pyrite was $91.93 \%$ and $78.64 \%$ respectively. Characterization of mineral and coal pyrite by SEM showed that the surfaces of the mineral pyrite tended to be smoother than those for coal pyrite; and, more fine material adhered to the surfaces of coal p;rite than to mineral pyrite [4.8]. Mineral pyrite had a comparatively clean surface, while the surface of the coal pyrite was contaminated by carbonaceous and gangue materials. This is a major reason for the difference between mineral and coal pyrite flotation behavior.

In order to determine the floatability of coal pyrite and coal with xanthate as the collector, flotation tests at different xanthate concentrations and $\mathrm{pH}$ were performed. Figure 4.4 illustrates the floatability of Pittsburgh coal and coal pyrite for various concentrations of xanthate at it's natural $\mathrm{pH}$. For the entire range of experiments, coal exhibited higher floatability than coal pyrite. At natural $\mathrm{pH}$ and $1.3 \times 10^{-4} \mathrm{M}$ xanthate, the floatability of Pittsburgh coal pyrite was nearly $100 \%$. Figure 4.5 shows the floatability at different $\mathrm{pH}$ values. The trend with $\mathrm{pH}$ was the same for coal and coal pyrite, but coal 


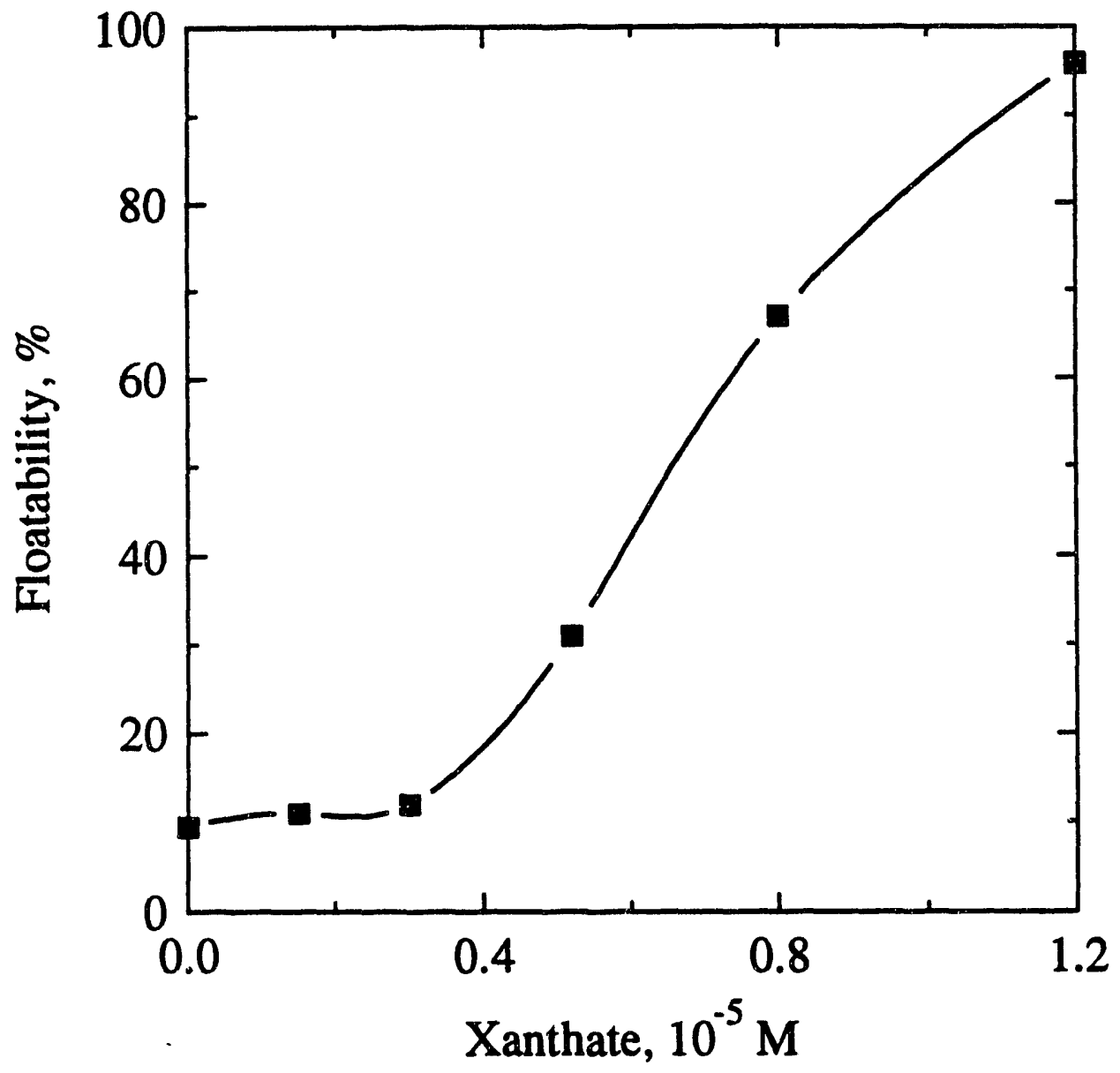

Figure 4.2 Floatability of Mineral Pyrite for Various Xanthate Concentrations 


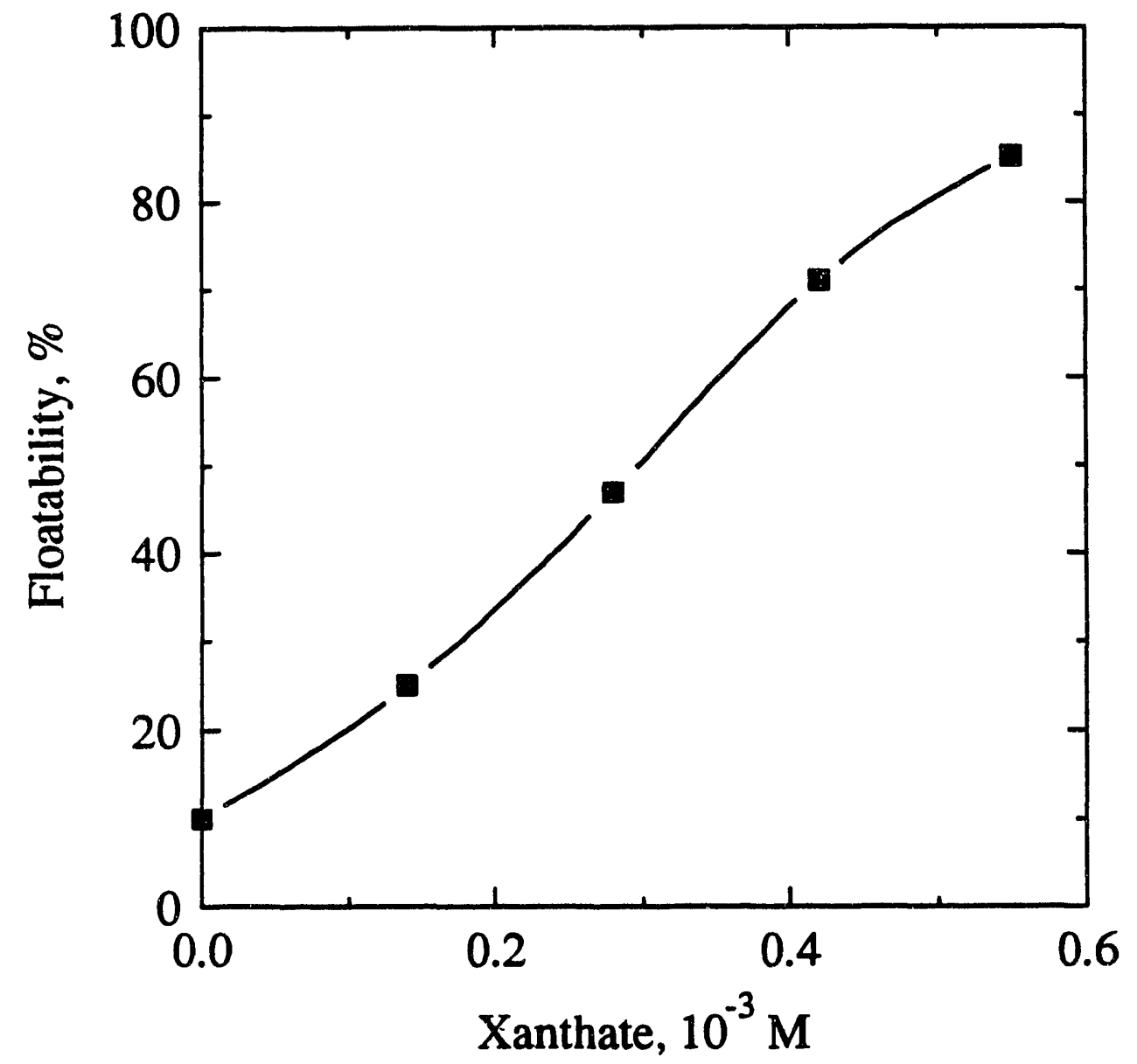

Figure 4.3 Floatability of Coal Pyrite for Various Xanthate Concentrations 


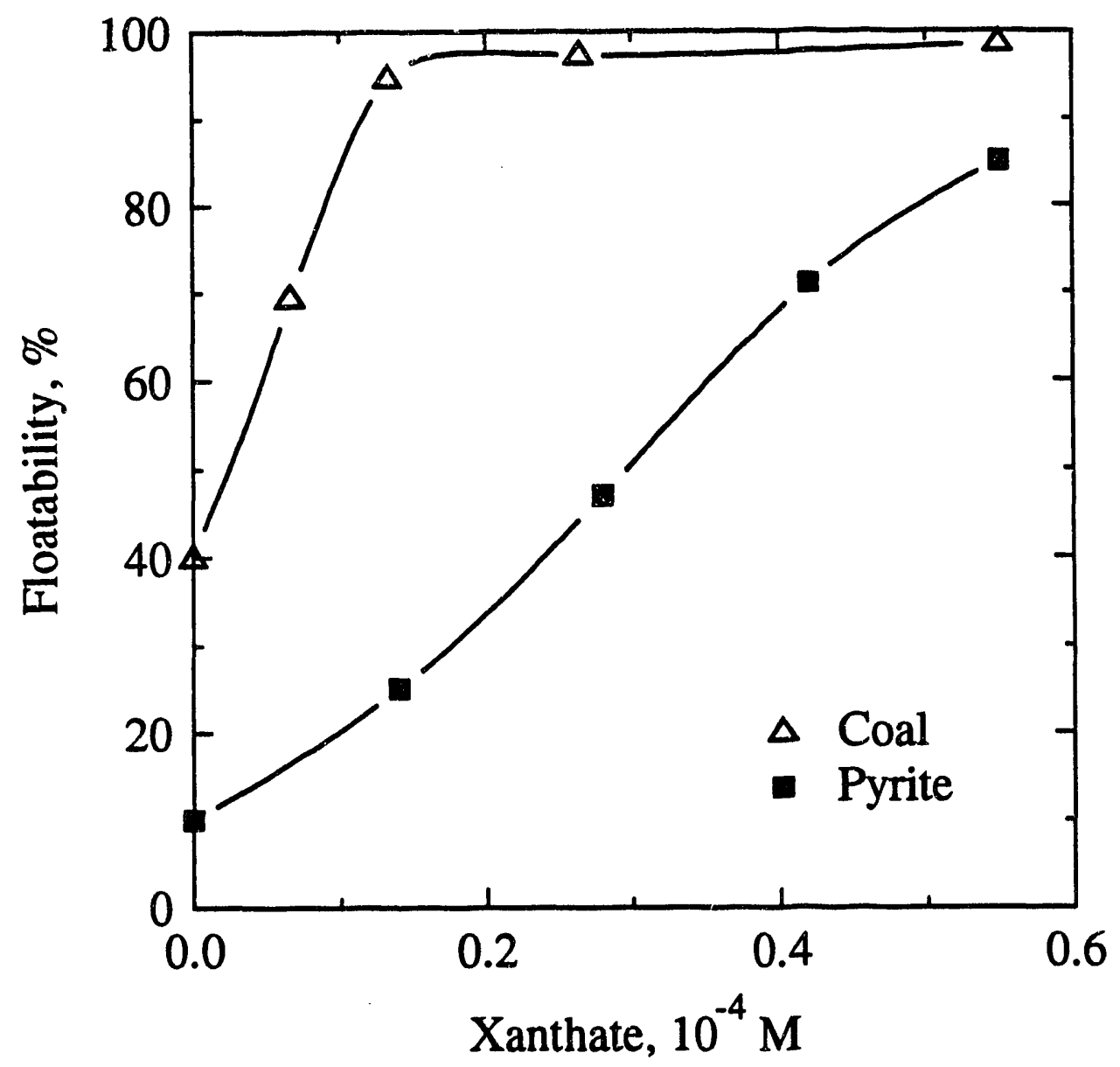

Figure 4.4 Floatability of Pittsburgh Coal and Coal Pyrite with Xanthate as a Collector 


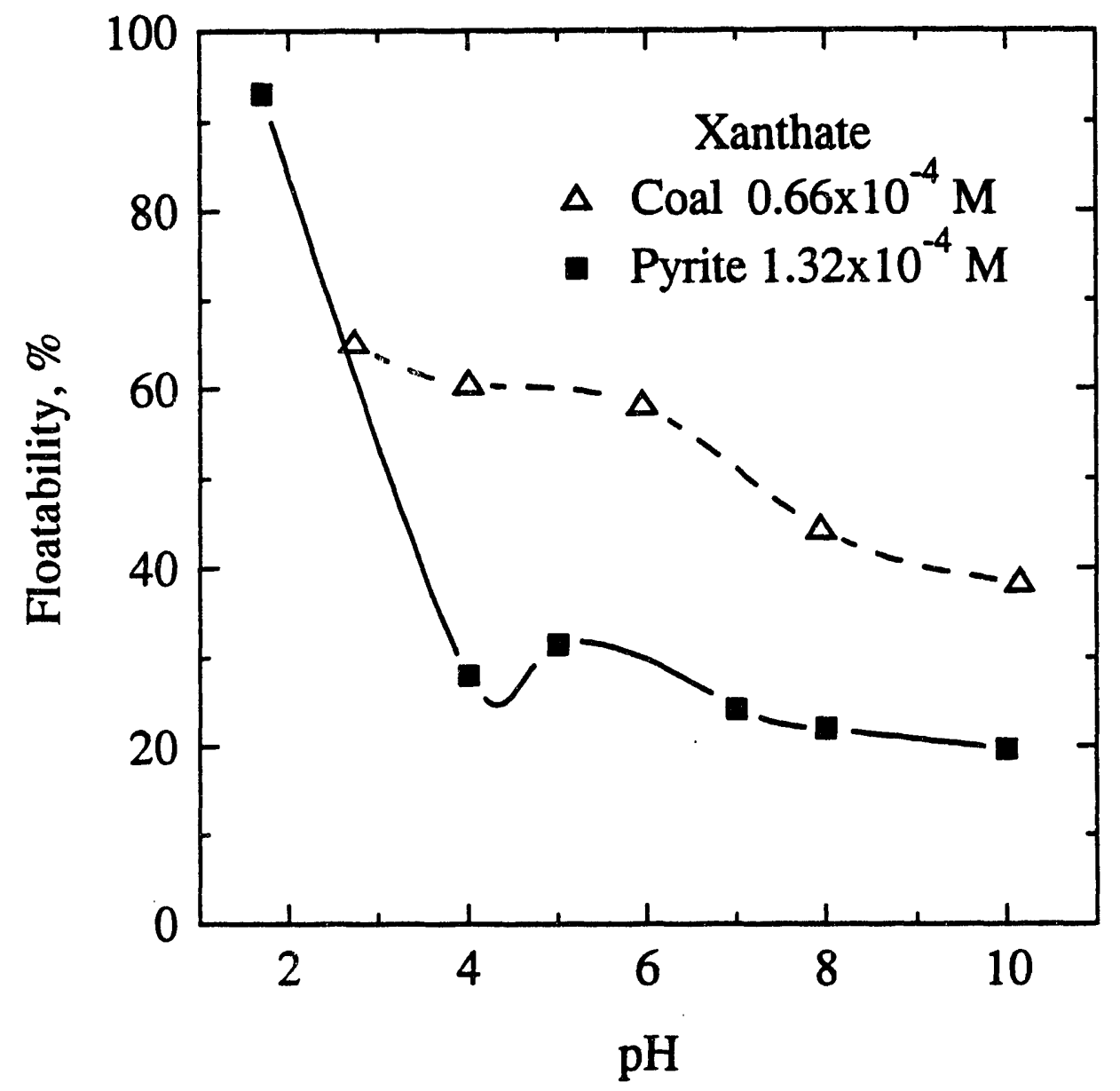

Figure 4.5 Floatability of Pittsburgh Coal and Coal Pyrite as a Function of $\mathrm{pH}$ 
had better floatability. The flotation yield for coal was much greater than that of pyrite at one half the xanthate concentration.

Flotation Using Dodecane as a Collector. Figure 4.6 shows the floatability of Pittsburgh No. 8 coal and coal pyrite as a function of $\mathrm{pH}$ in an electrolyte containing dodecane. $\mathrm{HCl}$ and $\mathrm{NaOH}$ were used to adjust $\mathrm{pH}$. The floatability of coal decreased with increased $\mathrm{pH}$. The floatability of Pittsburgh coal pyrite was low and essentially independent of $\mathrm{pH}$.

Figures 4.7 and 4.8 illustrate the effect of dodecane concentration on the floatability of coal and coal pyrite at pH 6 and 9.2. The floatability of coal and coal pyrite increased with increased dodecane concentration at $\mathrm{pH} 6.0$. At $\mathrm{pH} 9.2$, the floatability of the coal was much less than at $\mathrm{pH}$ 6.0, but increased regularly with dodecane concentration. In the solution containing $0.125 \mathrm{M} \mathrm{Na}_{2} \mathrm{SO}_{4}$ and $0.005 \mathrm{M} \mathrm{Na}_{2} \mathrm{~B}_{4} \mathrm{O}_{7}$ and 0.24 $\mathrm{ml} / \mathrm{l}$ of dodecane, and a $\mathrm{pH}$ value of 6.0 , the floatability of coal and coal pyrite were $32.28 \%$ and $3.78 \%$ respectively.

Flotation Using Butyl Alcohol as a Collector. Figure 4.9 illustrates the floatability of coal and coal pyrite as a function of $\mathrm{pH}$ using butyl alcohol as the collector. The floatability of coal pyrite was almost independent of $\mathrm{pH}$. Coal flotation with butyl alcohol was similar to that observed for xanthate or dodecane as far as the flotation behavior is concerned, that is, decreased floatability occurred with increased pH. Figures 4.10 and 4.11 show the variation of floatability of coal with butyl alcohol concentration for solutions at pH 4.0 and 9.2. As for the case of coal in xanthate and dodecane flotation, its floatability increased with increased butyl alcohol concentration; but, flotation with butyl alcohol displayed lower floatability for the same condicions even on the acid side.

Pretreatment of the Pyrite Surface. Surface cleaning of coal pyrite can be done chemically or mechanically or preferably by a combination of the two. For the chemical treatment, the coal pyrite sample was placed in an acid solution to dissolve surface carbonaceous matter, oxides or hydroxides, and gangue materials from the surfaces. Mechanical cleaning can be done by scrubbing with intense agitation at high pulp density. In these 


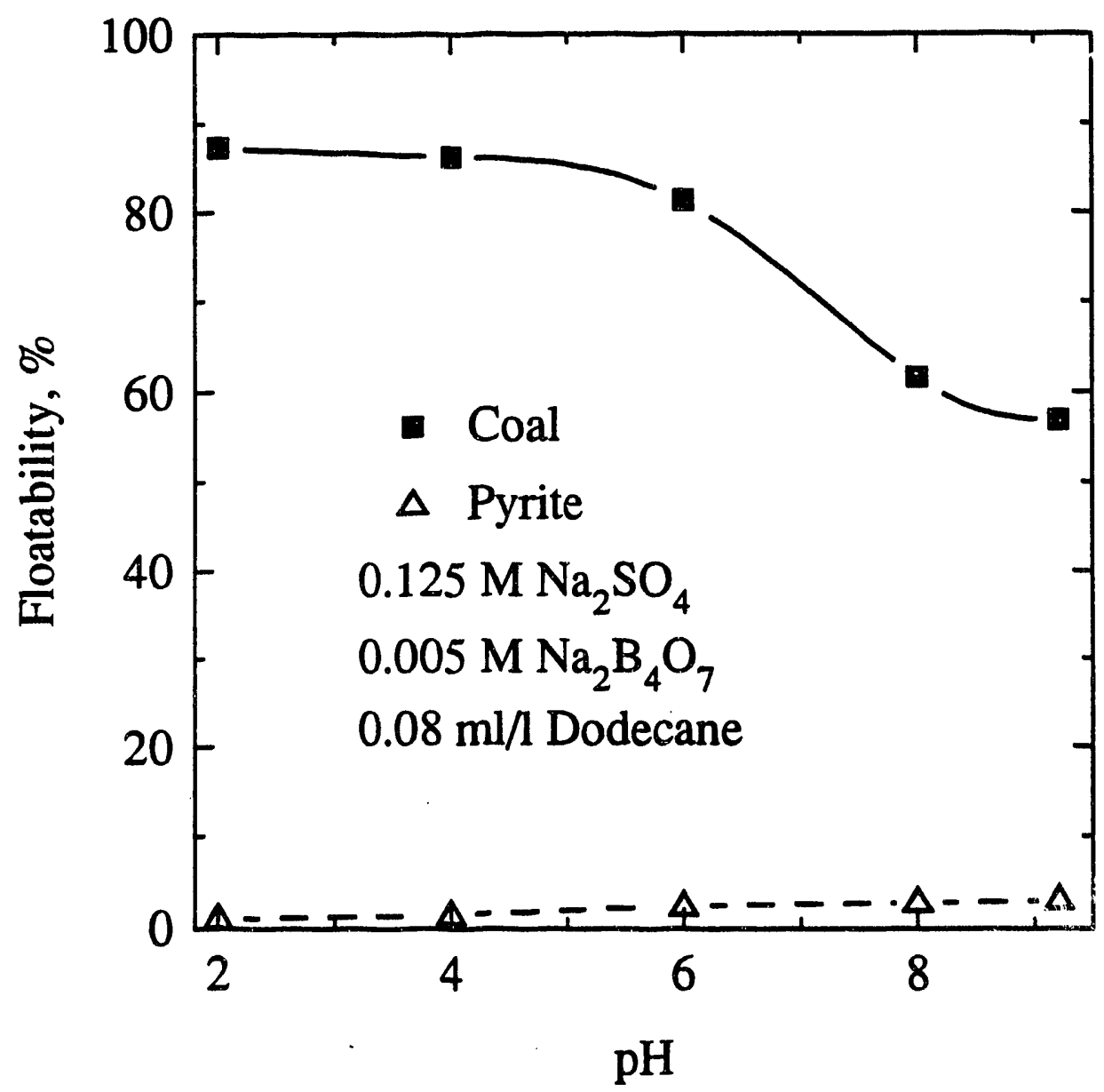

Figure 4.6 Floatability of Pittsburgh Coal and Coal Pyrite as a Function of $\mathrm{pH}$ in Dodecanc- Slestrolyts 


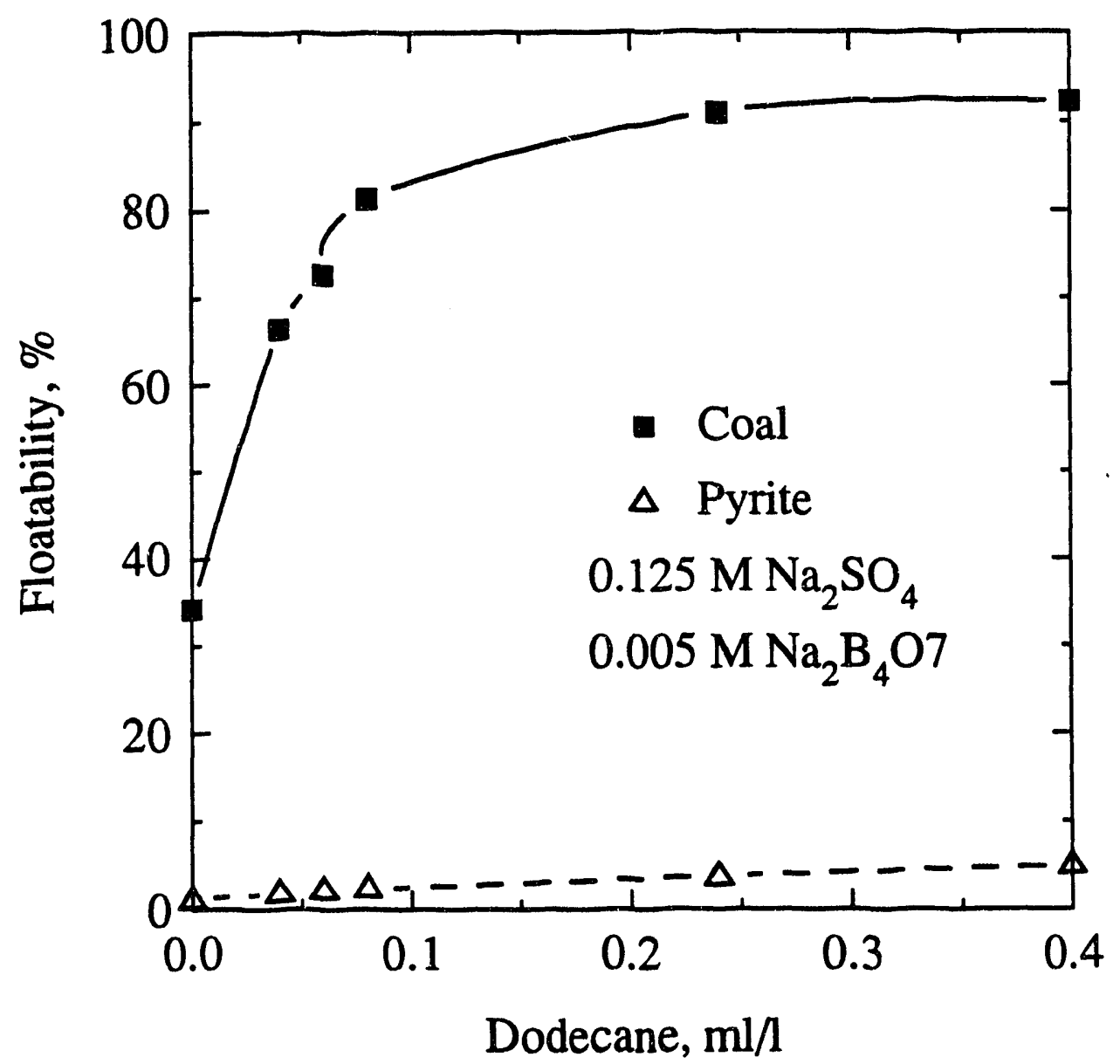

Figure 4.7 Floatability of Pittsburgh Coal and Coal Pyrite in Dodecane-electrolyte $(\mathrm{pH}=6)$ 


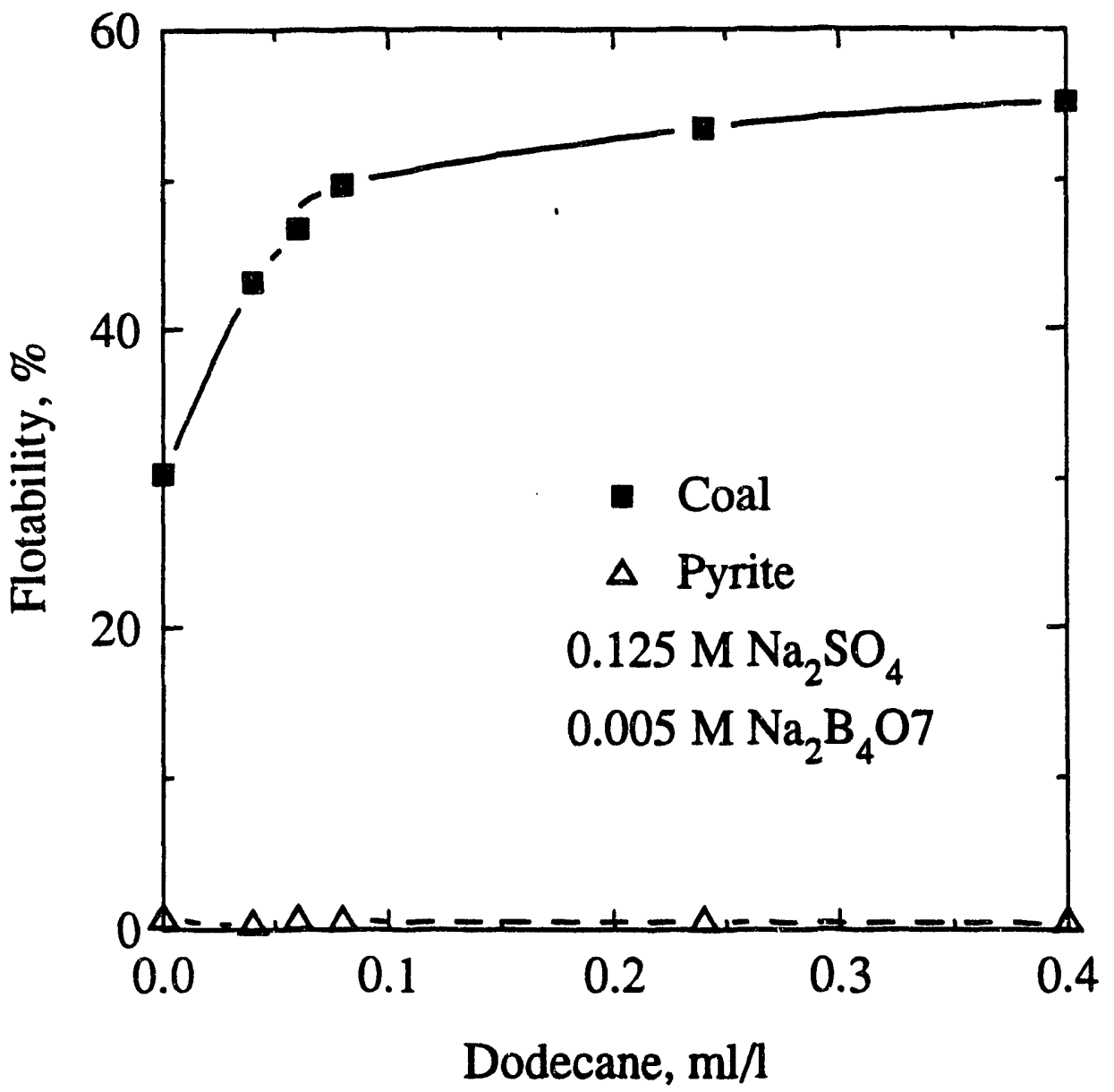

Figure 4.8 Floatability of Pittsburgh Coal and Coal Pyrite in Dodecane-electrolyte $(\mathrm{pH}=9.21)$ 


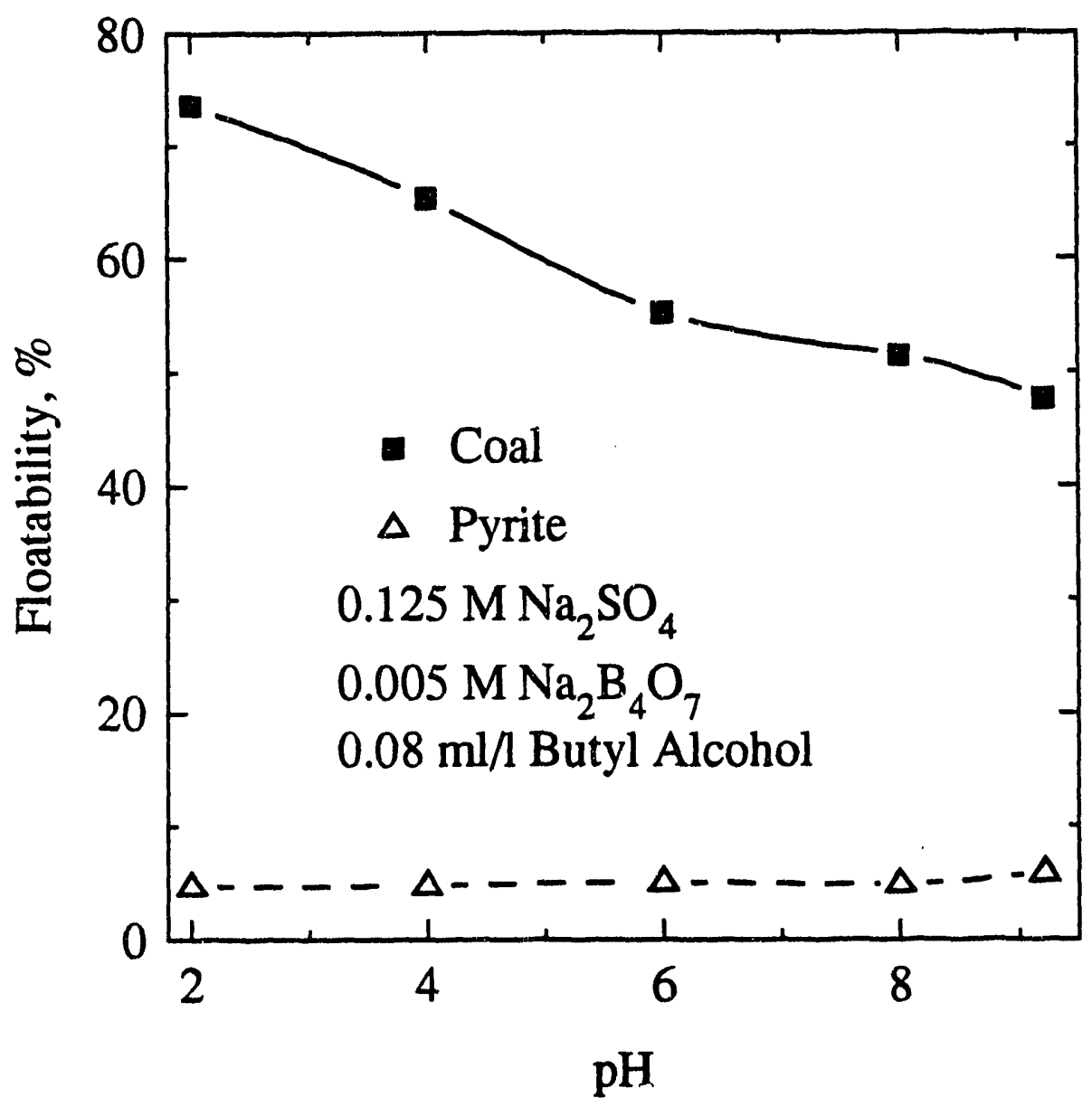

Figure 4.9 Floatability of Pittsburgh Coal and Coai Pyrite as a Function of $\mathrm{pH}$ in Butyl Alcohol-electrolyte Solvtion 


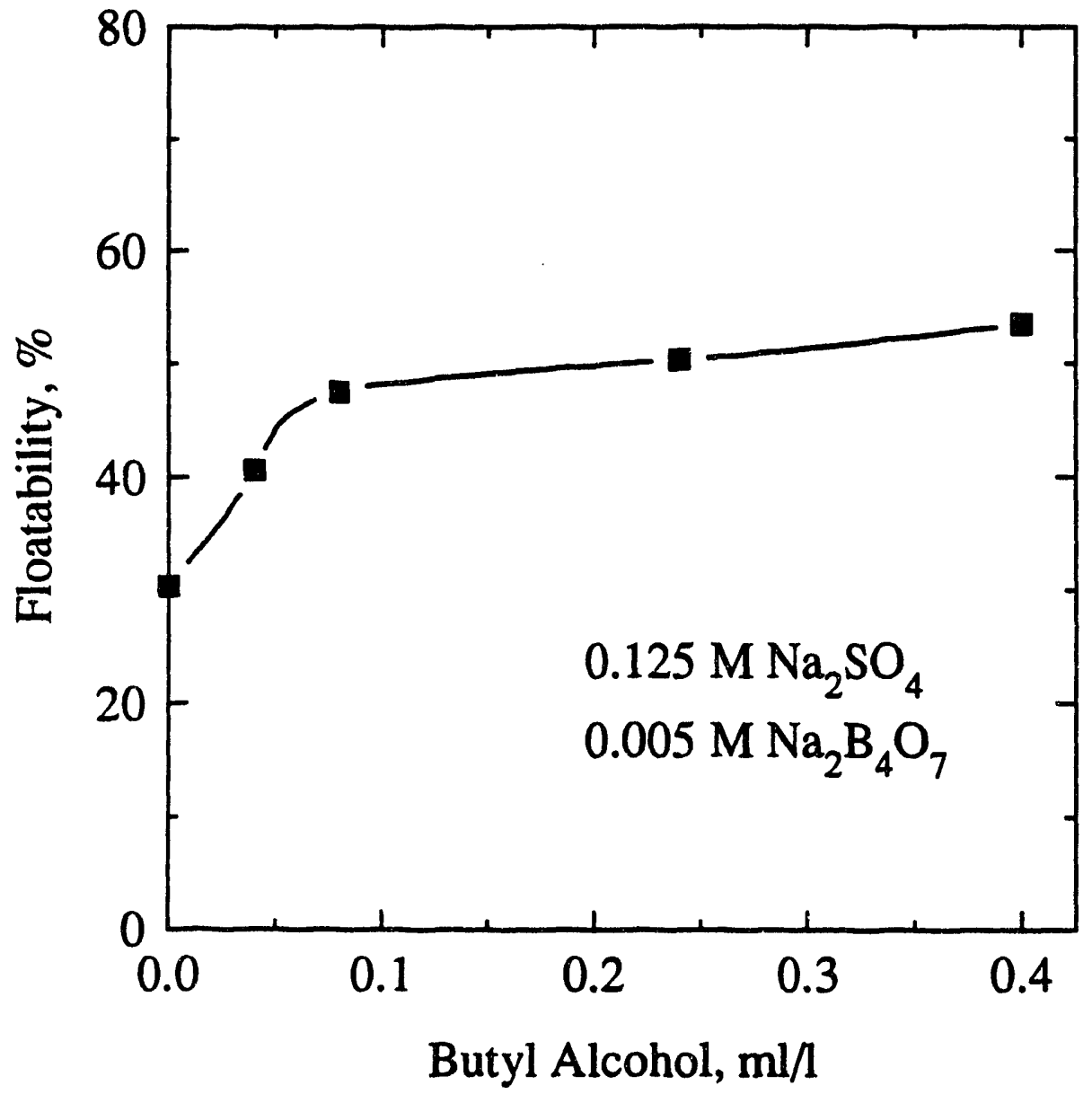

Figure 4.10 Floatability of Pittsburgh Coal in Butyl Alcohol-electrolyte $(\mathrm{pH}=4.0)$ 


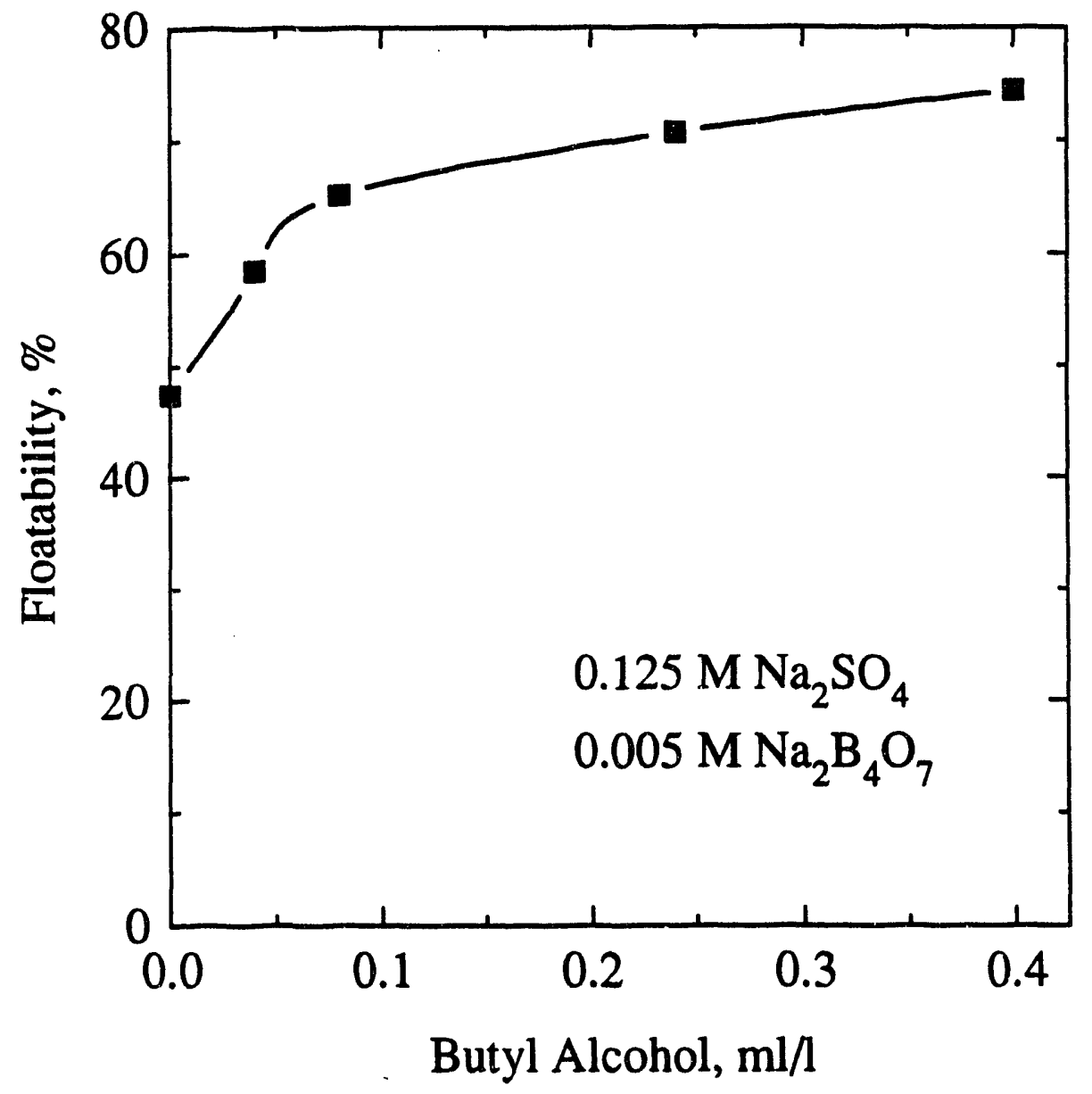

Figure 4.11 Floatability of Pittsburgh Coal in Butyl Alcohol-electrolyte $(\mathrm{pH}=9.21)$ 
tests the two methods were combined. Figures 4.12 and Figure 4.13 illustrate the floatability of coal pyrite pretreated with sulfuric acid and hydrochloric acid respectively. The floatability of coal pyrite increased with the increasing concentrations of acid. Sulfuric acid was more effective for this purpose than was hydrochloric acid. The recovery of coal pyrite was $91.39 \%$ and $83.40 \%$ respectively after pretreatment with $1.48 \times 10^{-2} \mathrm{M} \mathrm{H}_{2} \mathrm{SO}_{4}$ and $2.63 \times 10^{-2} \mathrm{M} \mathrm{HCl}$. For untreated coal, recovery was only about $26 \%$.

To better understand the effects of pretreatment, the following experiments were conducted:

1. Pretreatment of coal pyrite in acid solution followed directly by dilution and flotation.

2. Pretreatment of coal pyrite in acid solution, dilution and washing to $\mathrm{pH} 5.8$, followed by flotation.

3. Flotation tests at selected $\mathrm{pH}$ values without acid pretreatment.

The floatability of coal pyrite, after pretreatment with acid solution and dilution ( 1 above), is compared with that for pretreatment with water only in Figure 4.14. The floatability was clearly increased by acid washing. Flotation behavior for acid treatment and dilution ( 1 above), is compared with acid treatment and washing to pH 5.8 ( 2 above) in Figure 4.15 for various acid concentrations. Washing at $\mathrm{pH} 5.8$ degraded the pyrite for flotation for all acid concentrations. Degradation of the pyrite surface for flotation at $\mathrm{pH}$ 5.8 may be attributed to the formation of iron nxides on the surface at this $\mathrm{pH}$.

$\mathrm{CuSO}_{4}$ and $\mathrm{NaS}_{2}$ as Modifiers. In mineral flotation, $\mathrm{CuSO}_{4}$ and $\mathrm{Na}_{2} \mathrm{~S}$ are used to activate oxidized pyrite. Floatability tests of Colorado mineral pyrite and Pittsburgh coal pyrite were conducted using these reagents. The results are shown in Figures 4.16, 4.17, 4.18. As shown in Figure 4.16, the floatability of Pittsburgh coal pyrite increased from $26 \%$ to $74 \%$ in $2.0 \times 10^{-6} \mathrm{M} \mathrm{CuSO}_{4}$ and $1.32 \times 10^{-4} \mathrm{M}$ xanthate. The floatability decreased at higher $\mathrm{CuSO}_{4}$ concentrations. The floatability of Colorado mineral pyrite in the presence of $\mathrm{Na}_{2} \mathrm{~S}$ is shown at Figure 4.17 for a xanthate concentration of $6.6 \times 10^{-6} \mathrm{M}$. The floatability increased from $39 \%$ to $62 \%$ for an optimum concentration of $2.0 \times 10^{-6} \mathrm{M} \mathrm{Na} \mathrm{Na}_{2} \mathrm{~S}$. The 


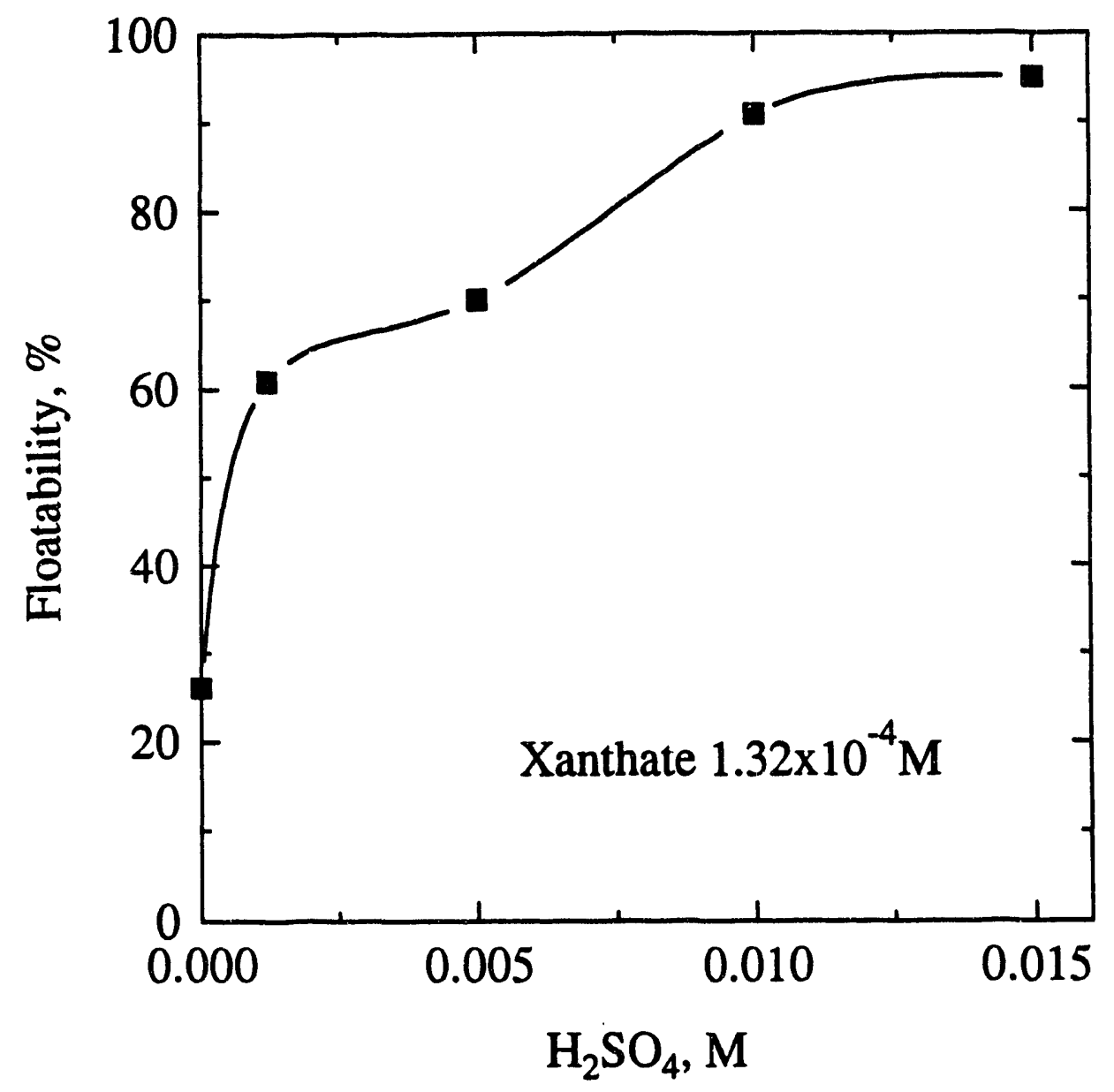

Figure 4.12 Floatability of Pittsburgh Coal Pyrite after Pretreatment With $\mathrm{H}_{2} \mathrm{SO}_{4}$ 


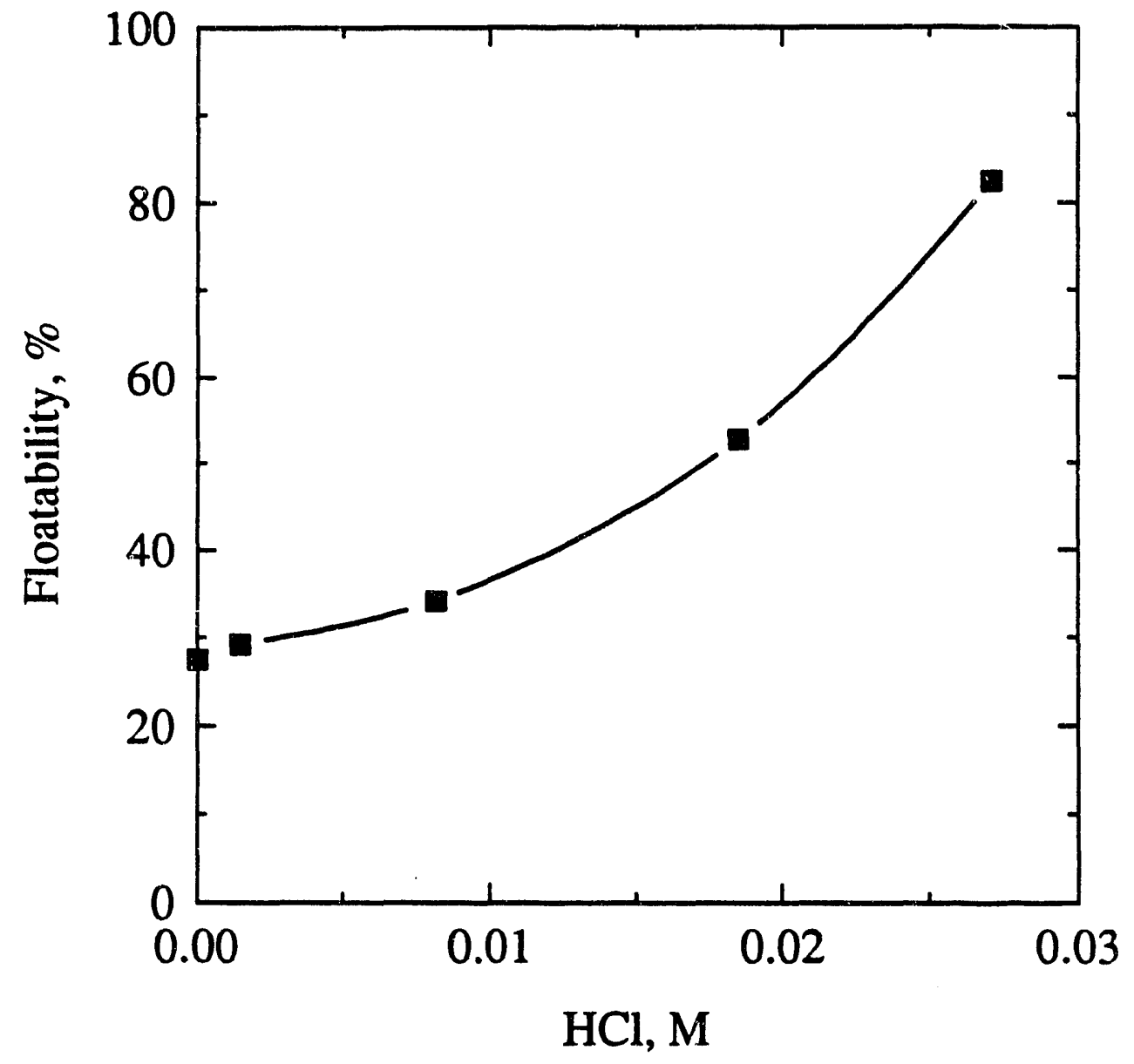

Figure 4.13 Floatability of Pittsbugh Coal Pyrite after Pretreatment with $\mathrm{HCl}$ 


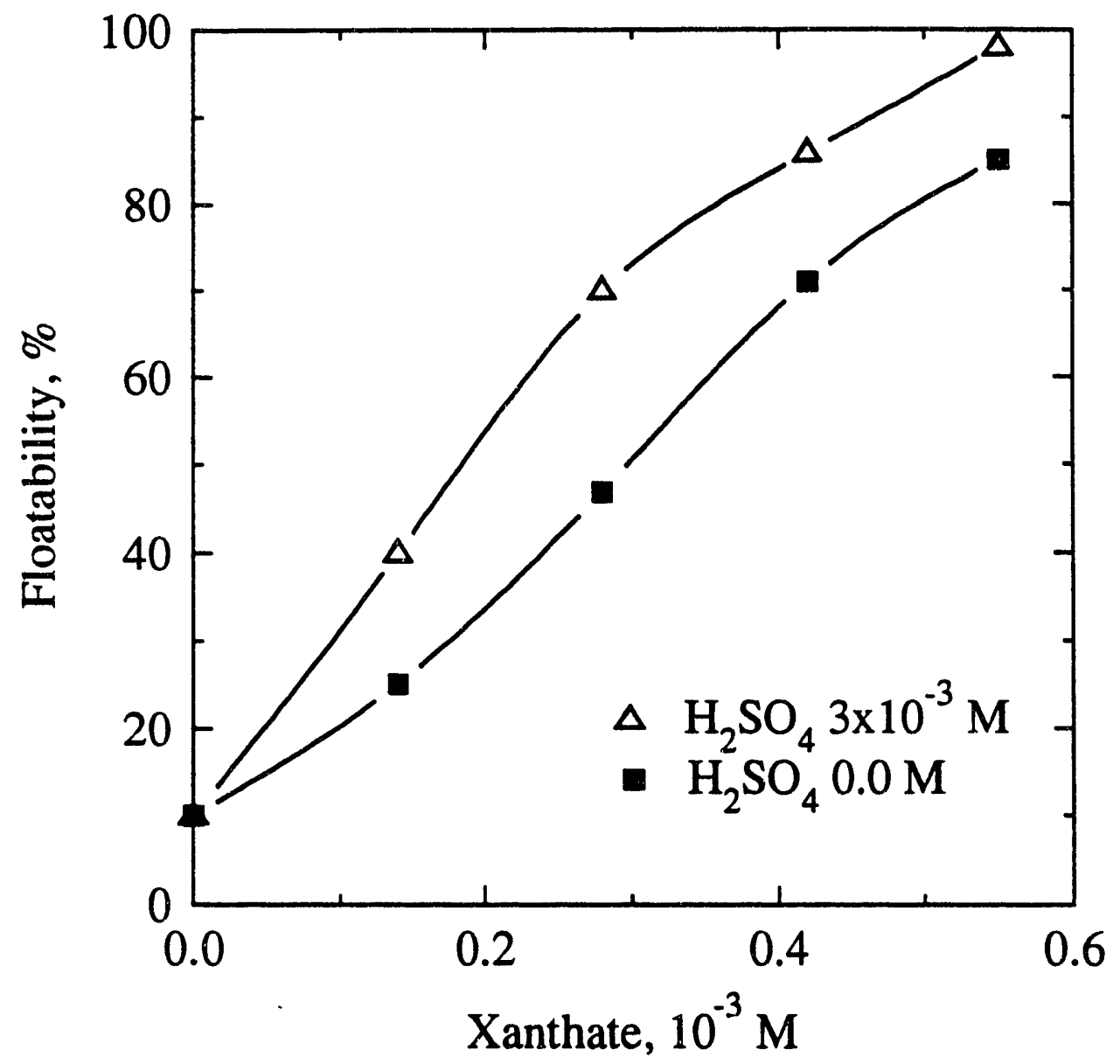

Figure 4.14 Floatability of Pittsburgh Coal Pyrite after Pretreatment with $\mathrm{H}_{2} \mathrm{SO}_{4}$ 


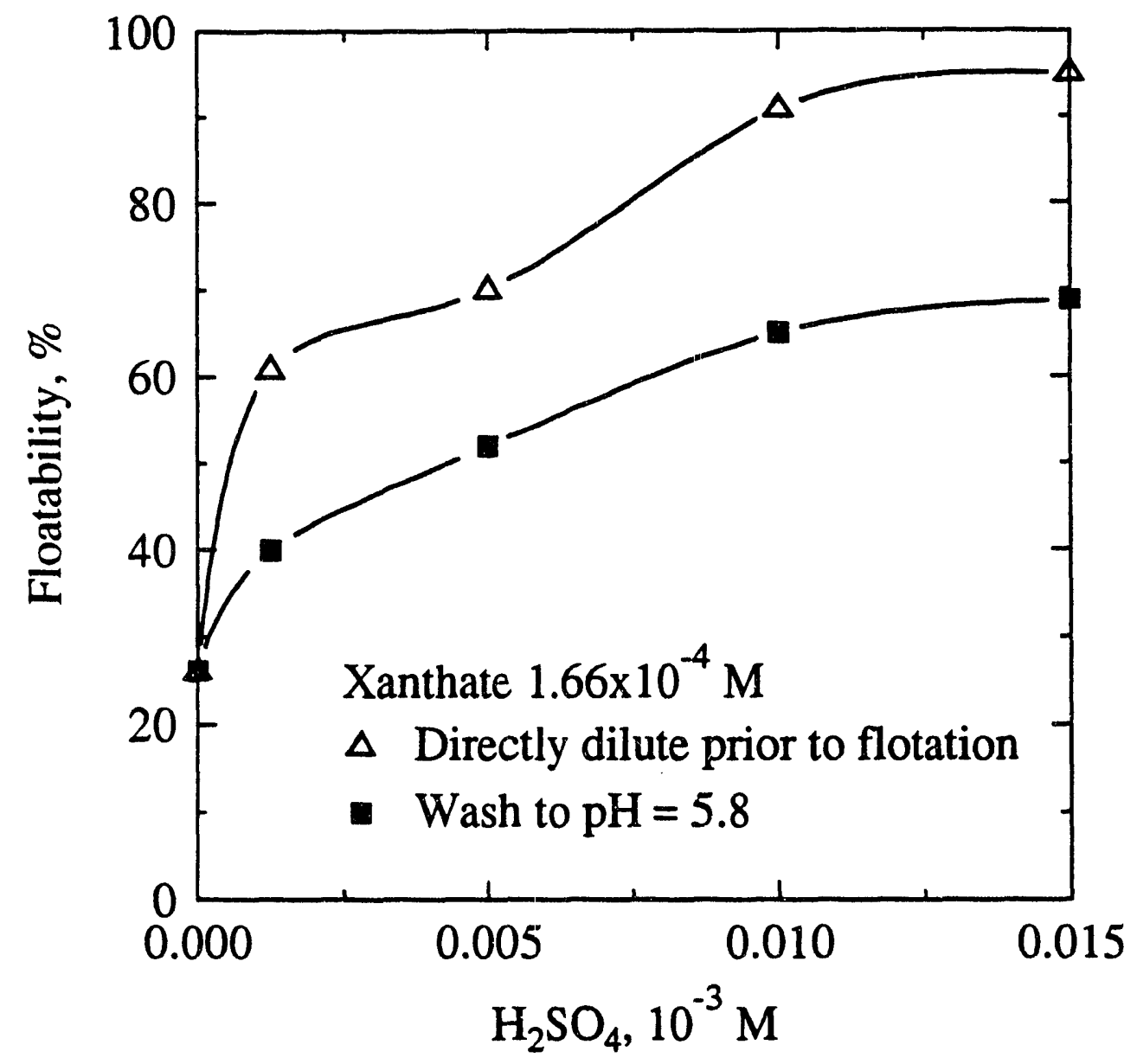

Figure 4.15 Floatability of Pittsburgh Coal Purite after Pretreatment with $\mathrm{H}_{2} \mathrm{SO}_{4}$ 


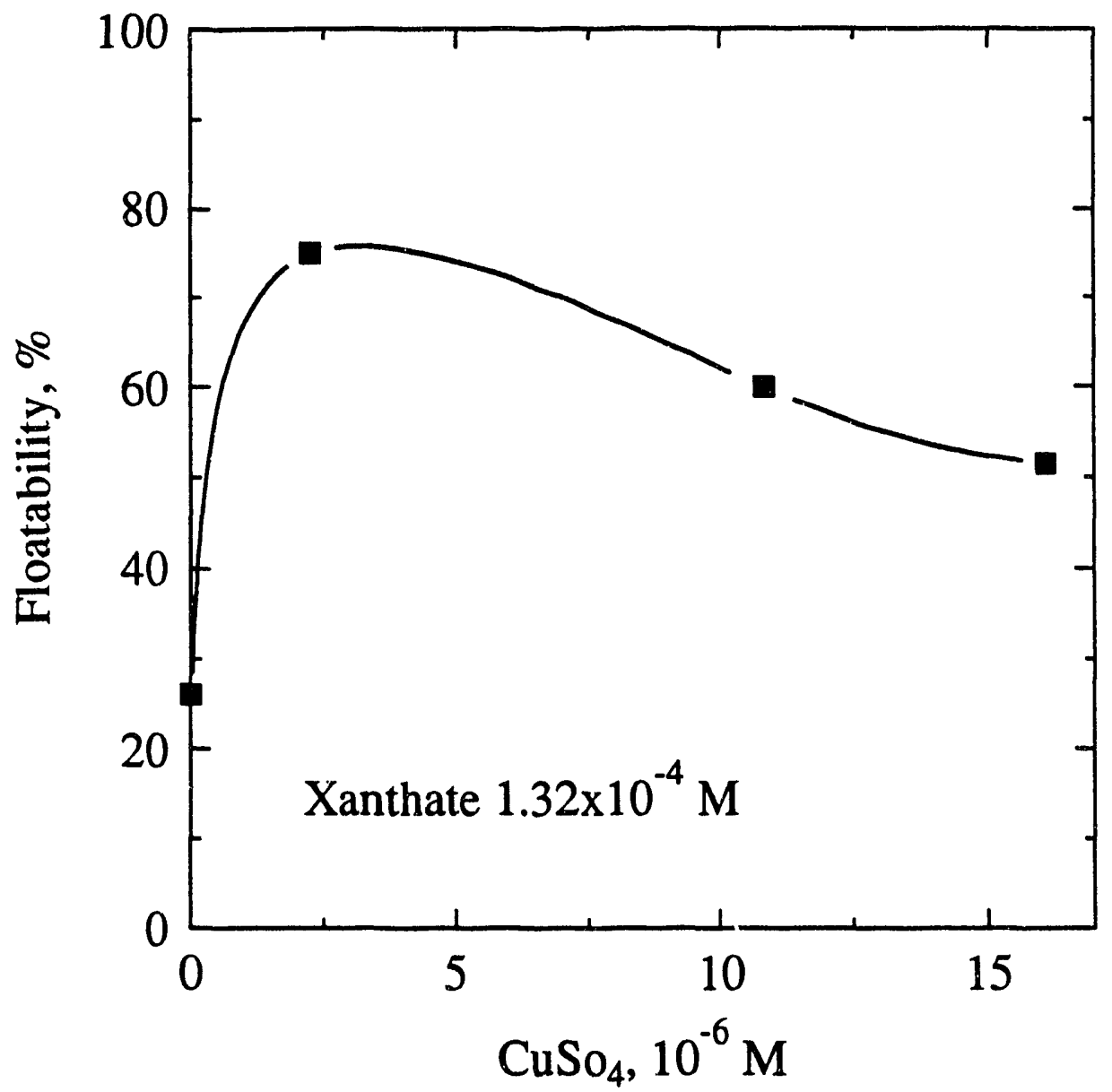

Figure 4.16 Floatability of Pittsburgh Coal Pyrite activated by $\mathrm{CuSO}_{4}$ 


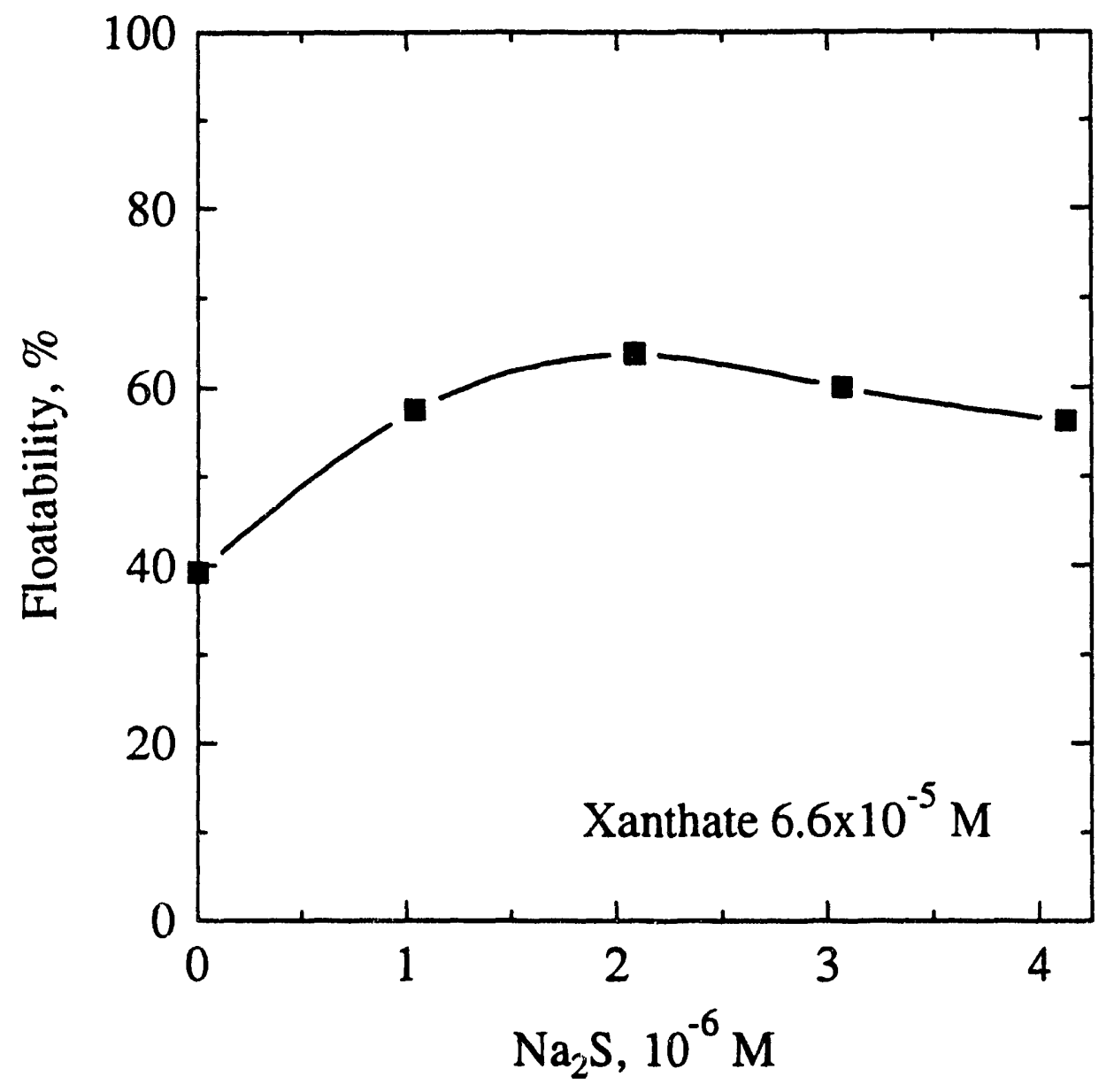

Figure 4.17 Floatability of Colorado Mineral Pyrite Activated by $\mathrm{Na}_{2} \mathrm{~S}$ 


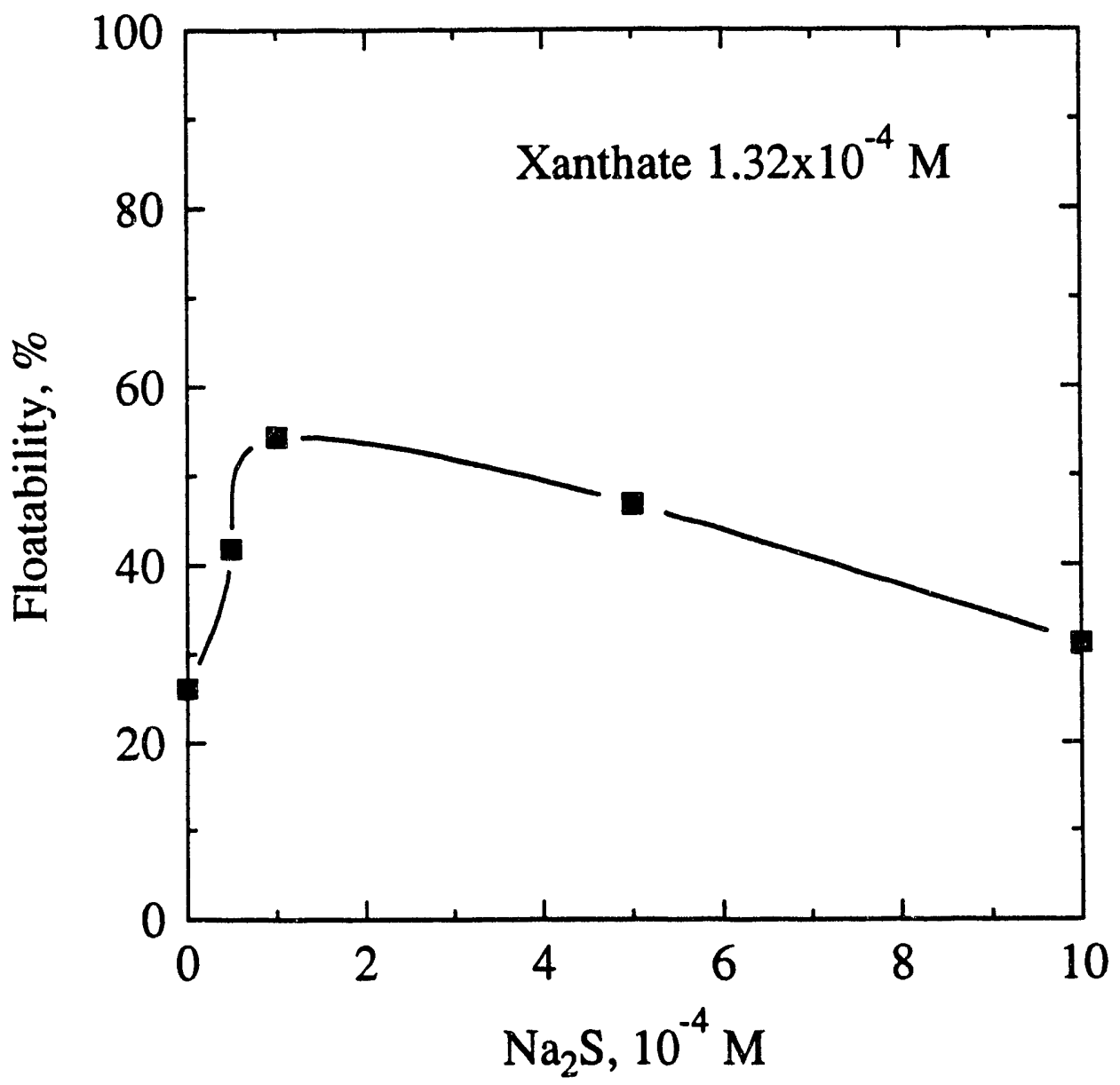

Figure 4.18 Floatability of Pittsburgh Coal Pyrite Activated by $\mathrm{Na}_{2} \mathrm{~S}$ 
floatability decreased at higher $\mathrm{Na}_{2} \mathrm{~S}$ concentrations. Pittsburgh coal pyrite floatability increased in the presence of $\mathrm{Na}_{2} \mathrm{~S}$ as shown in Figure 4.18 . For $1.32 \times 10^{-4} \mathrm{M}$ xanthate, maximum floatability occurred at a $\mathrm{Na}_{2} \mathrm{~S}$ concentration of $1.0 \times 10^{-4} \mathrm{M}$. The floatability decreased at higher $\mathrm{Na}_{2} \mathrm{~S}$ concentrations. Proper control of the ratio of activation reagent to xanthate is required for optimum floatability.

$\mathrm{CO}_{2}$ as a Modifier. Flotation tests of Colorado mineral pyrite and Pittsburgh coal pyrite were performed using $\mathrm{CO}_{2}$ aerated solutions. Both samples showed increased floatability (Figures 4.19 and Figure 4.20). The effect was greatest for coal pyrite, Figure 4.19. Jin [4.10] reported that $\mathrm{CO}_{2}$ also enhances the hydrophobicity of coal. Therefore $\mathrm{CO}_{2}$ is not expected to improve the selective separation of coal and pyrite.

EDTA as a Modifiers. The combined effect of EDTA and xanthate on the floatability of Pittshurgh coal pyrite is shown in Figure 4.21. The flotation yield increased from $16 \%$ to $80 \%$ as the EDTA concentration increased to $1.5 \times 10^{-4} \mathrm{M}$. It then decreased with higher concentrations of EDTA. It is clear that EDTA can increase the floatability of coal pyrite in the presence of xanthate.

Flotation Using Lime as a Modifier. The rejection of pyritic sulfur and ash forming minerals from coal is one of the most important tasks for coal processing, mainly due to its environmental consequences. The separation of coal and pyrite by froth flotation has been a difficult problem for a long time. Xanthate, as an effective collector, has been frequently used in mineral sulfide flotation processes. In the case of coal flotation, it was observed that the floatability of both coal pyrite and coal increased with xanthate concentration. In order to enhance the selectivity of coal flotation, some modifiers, either activator or depressant, may be used to increase the hydrophobicity of coal and decrease the hydrophobicity of the mineral fraction or vice versa. Calcium cyanide and lime have served as depressants for mineral sulfides in flotation procēsses. In this study, lime was used to depress coal pyrite. Figures 4.22 and 4.23 show the influence of lime addition on the floatability of coal pyrite and coal. The floatability of coal and coal pyrite decreased 


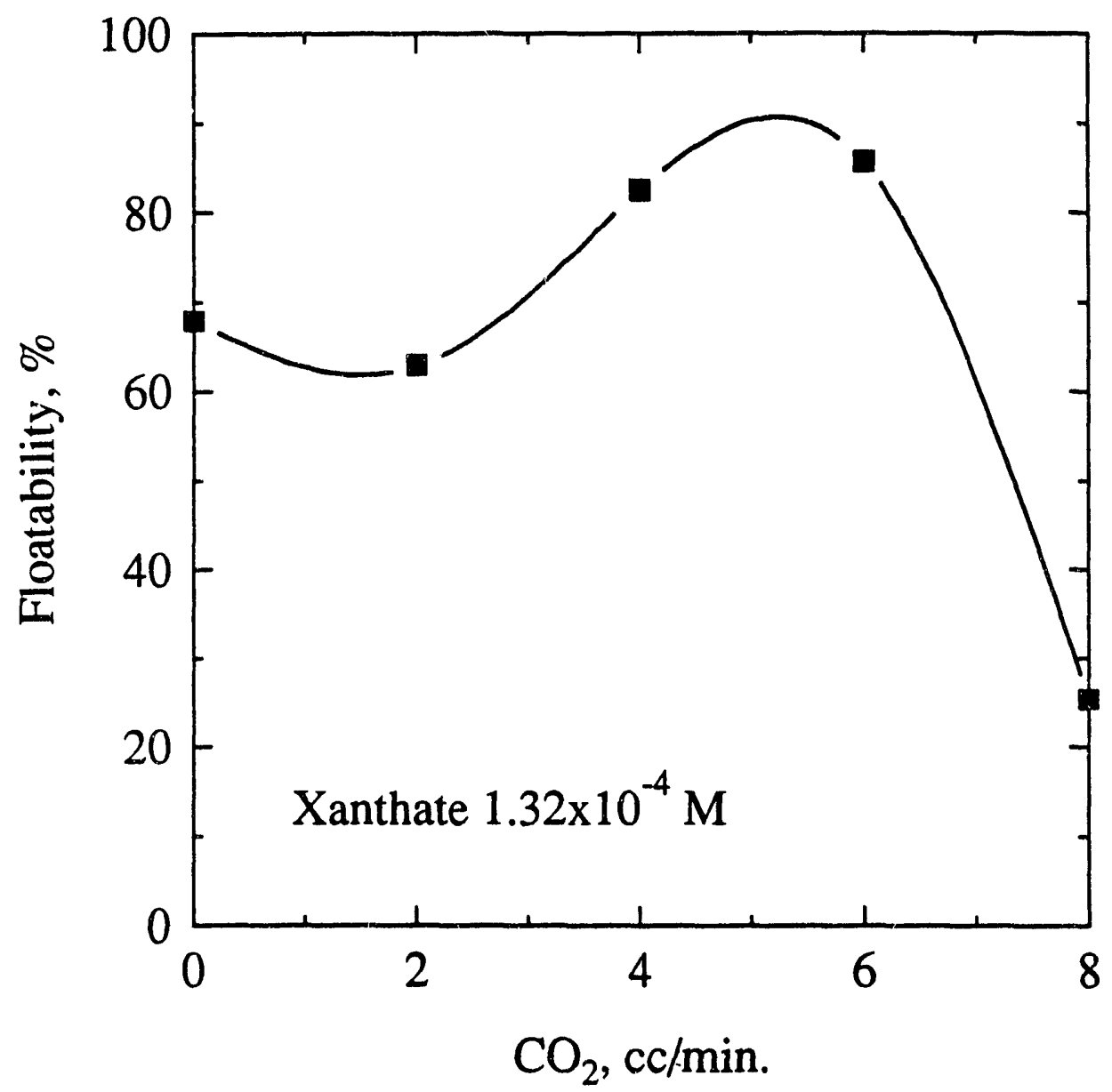

Figure 4.19 Floatability of Colorado Mineral Pyrite in $\mathrm{CO}_{2}$ Aerated Solutions 


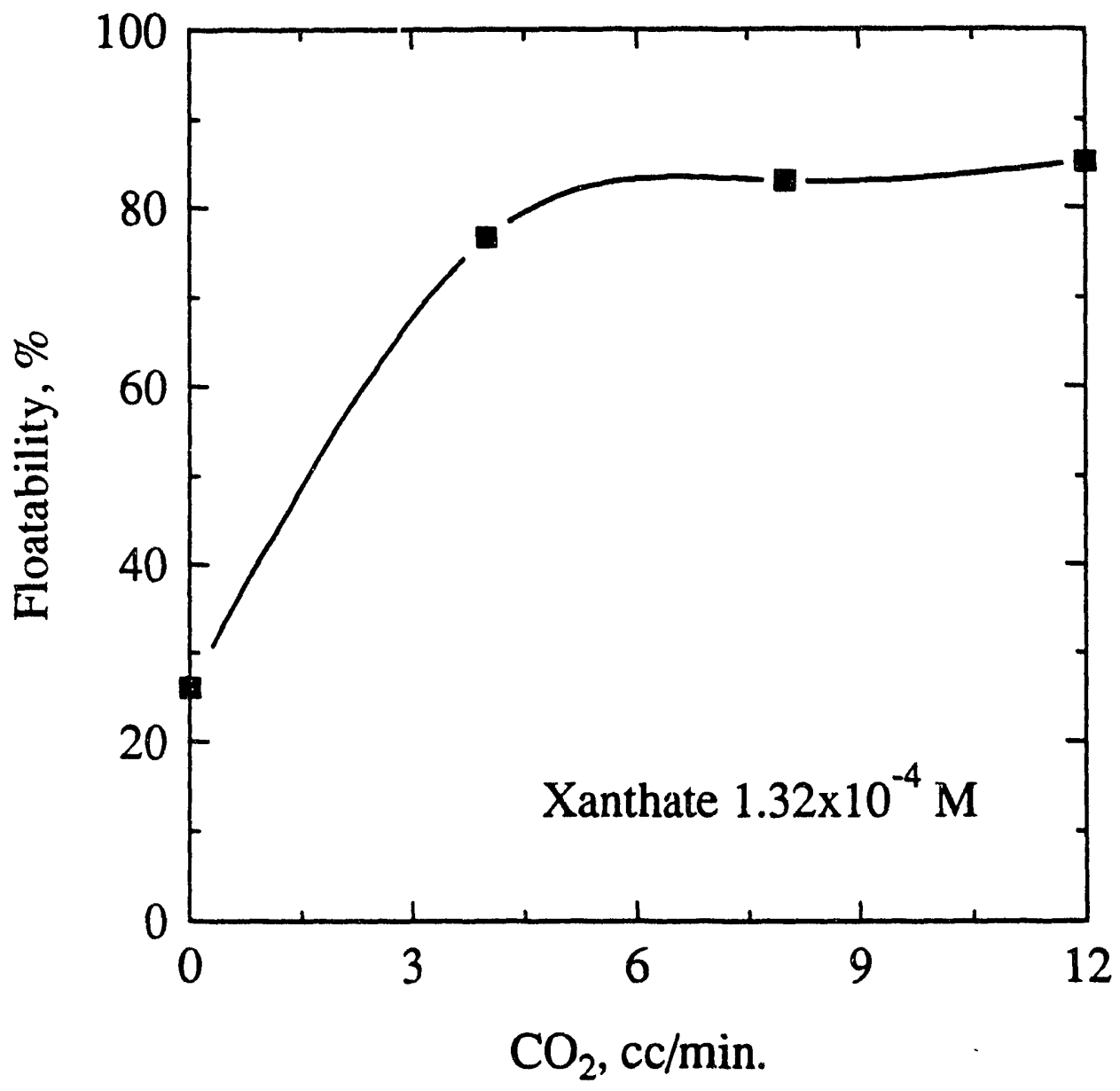

Figure 4.20 Floatability of Pittsburgh Coal Pyrite in $\mathrm{CO}_{2}$ Aerated Solutions 


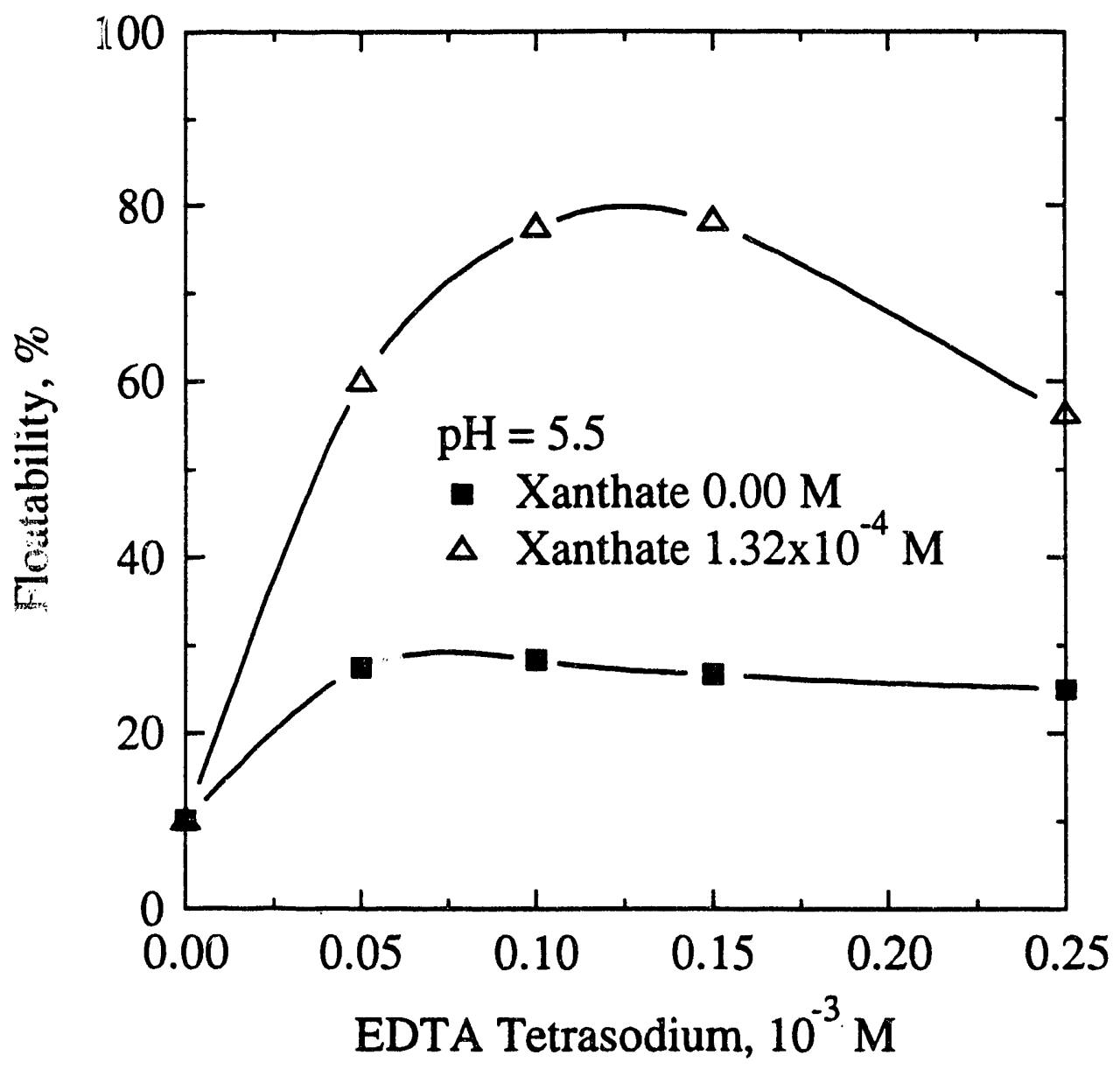

Figure 4.21 Floatability of Pittsburgh Coal Pyrite in EDTA Tetrasodium Solution 


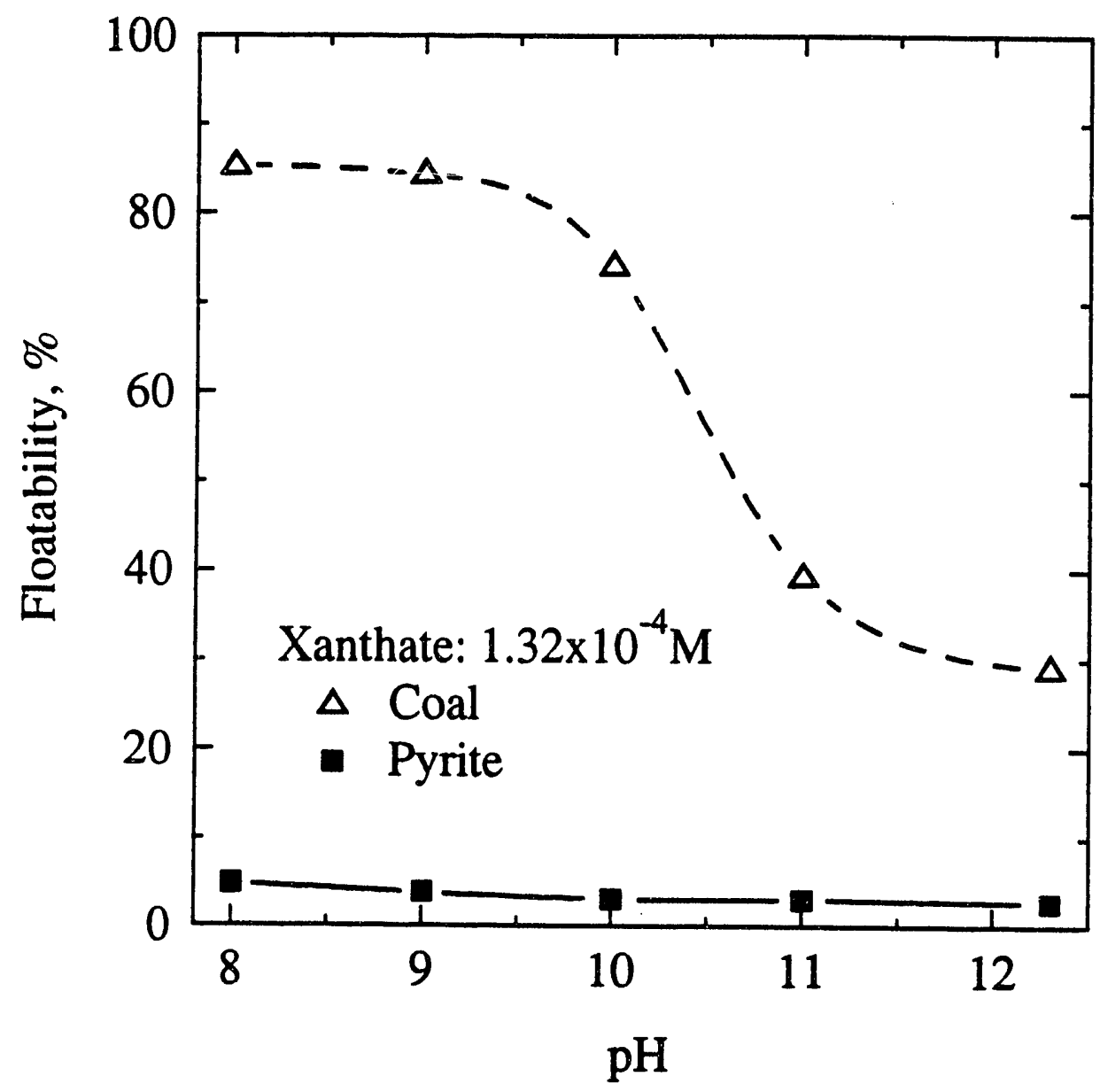

Figure 4.22 Floatability of Pittsburgh Coal and Coal Pyrite as a Function of $\mathrm{pH}$ with Lime as a Modifier 


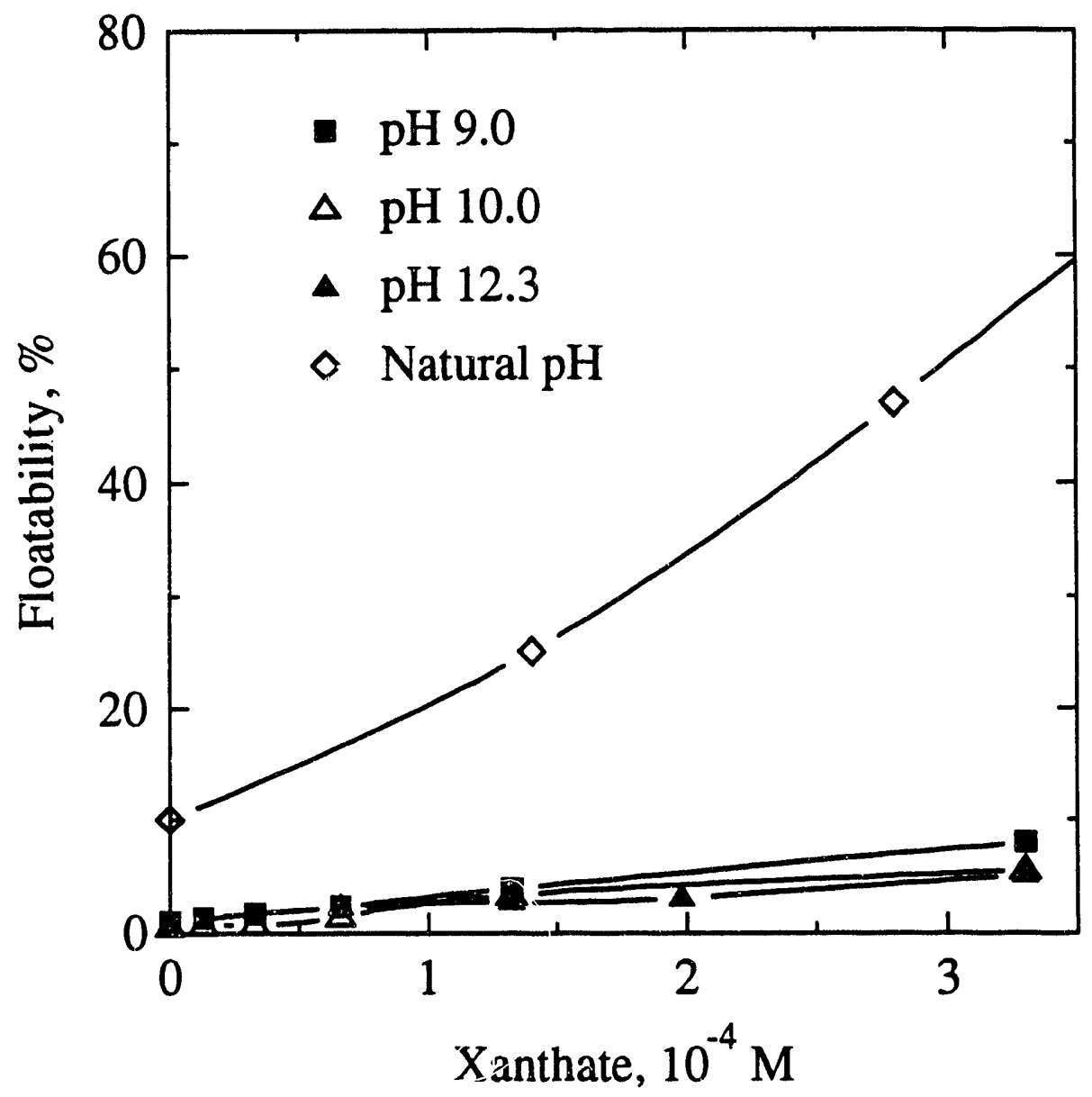

Figure 4.23 Floatability of Pittsburgh Coal Pyrite in Xanthate with and without Lime as a Modifier 
with increasing concentrations of lime (indicated by the increase in $\mathrm{pH}$ values, Figure 4.22). In comparison with xanth flotation of coal pyrite without lime (Figure 4.4), coal pyrite flotation in the lime-xanthate medium was depressed significantly. In contrast, the coal maintained its higher floatability until the $\mathrm{pH}$ of the lime solution reached 10 , after which the coal was depressed significantly. This situation is also shown in Figure 4.24. The largest difference of floatability between coal and coal pyrite was about $80 \%$ at $\mathrm{pH}$ 9.0 (Figure 4.25). Therefore, it is expected that the maximum separability of pyrite from coal for Pittsburgh coal should be obtained at a $\mathrm{pH}$ less than 10 with lime used for $\mathrm{pH}$ control and xanthate as the collestor.

Pyrite Rejection From Raw Coal. Based on the experimental results obtained for separate samples of coal and coal pyrite, two sets of tests on pyrite and ash rejection from raw coal in xanthate-lime and dodecane-electrolyte solutions were performed. Figure 4.26 and 4.27 illustrate the results of pyrite and ash rejection as a function of yield in a xanthate medium. Lime was used for $\mathrm{pH}$ control. Figure 4.28 presents the results of pyrite rejection from coal in dodecane-eiectrolyte for two $\mathrm{pH}$ values. As evidenced in Figures 4.26, 4.27, and 4.28 , rejection of pyrite and ash decreased with increasing yield. While the addition of lime improves pyrite separation efficiency, these results only quantify the ever-present problem of increased loss of pyrite separation efficiency with increased yield.

There was an impressive difference in floatability of separate coal and coal pyrite samples in xanthate-lime and dodecane-electrolyte. The experimental results obtained for raw coal, as noted above, were very different. For the same recovery of coal, pyrite rejection from raw coal was always lower than the floatability difference between separate coal and coal pyrite samples, differing by as much as 30 percentage points. The lower pyrite rejection for raw coal illustrates the negative effects of poor liberation and entrainment of fine pyrite during flotation.

\section{Floatability Measured in a Laboratory Flotation Cell}

Natural Floatability and Selectivity. The three coal samples were conditioned with distilled water, in the absence of added reagents. Flotation test results show that only 


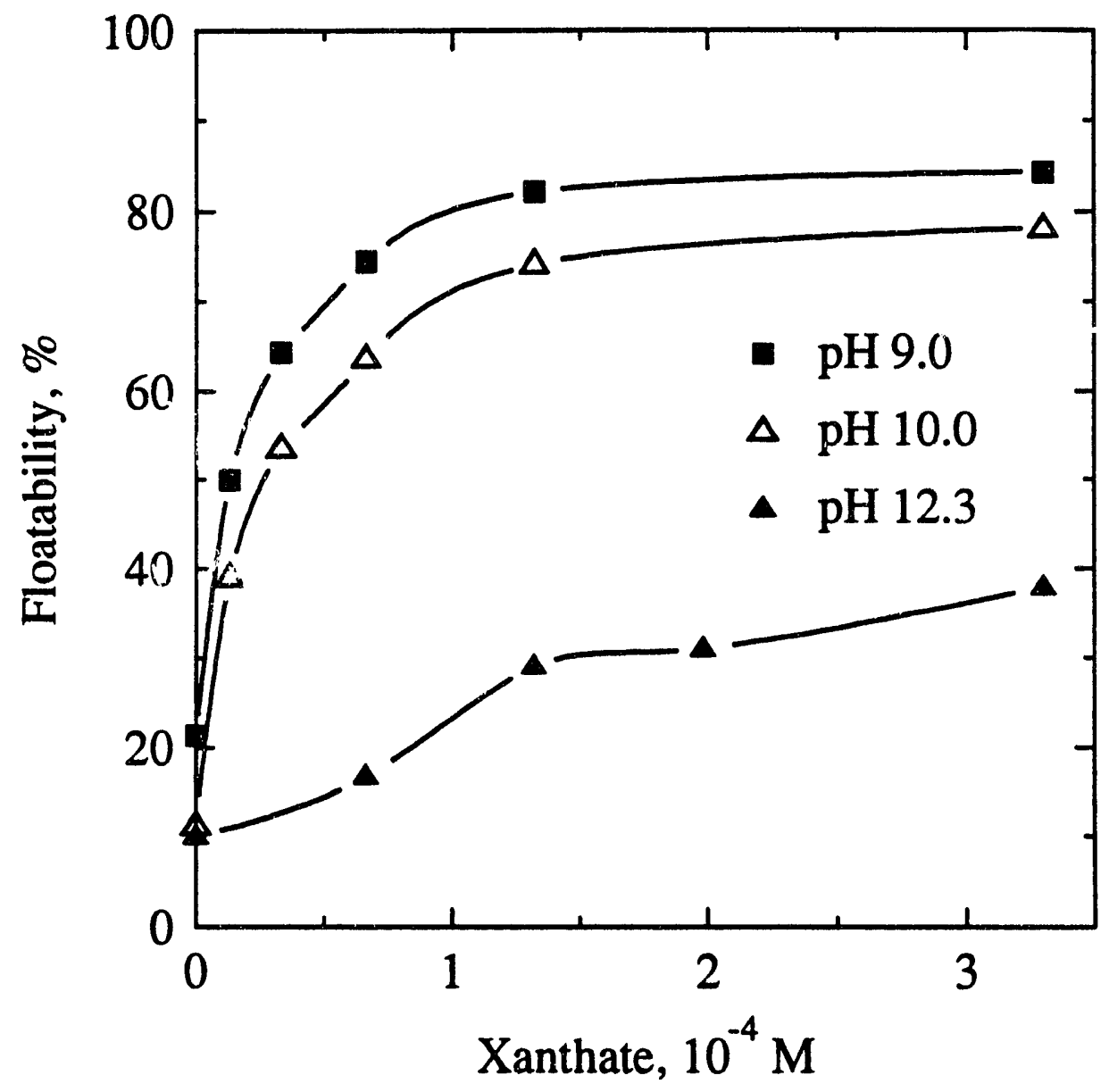

Figure 4.24 Floatability of Pittsburgh Coal in Xanthate-lime Solution 


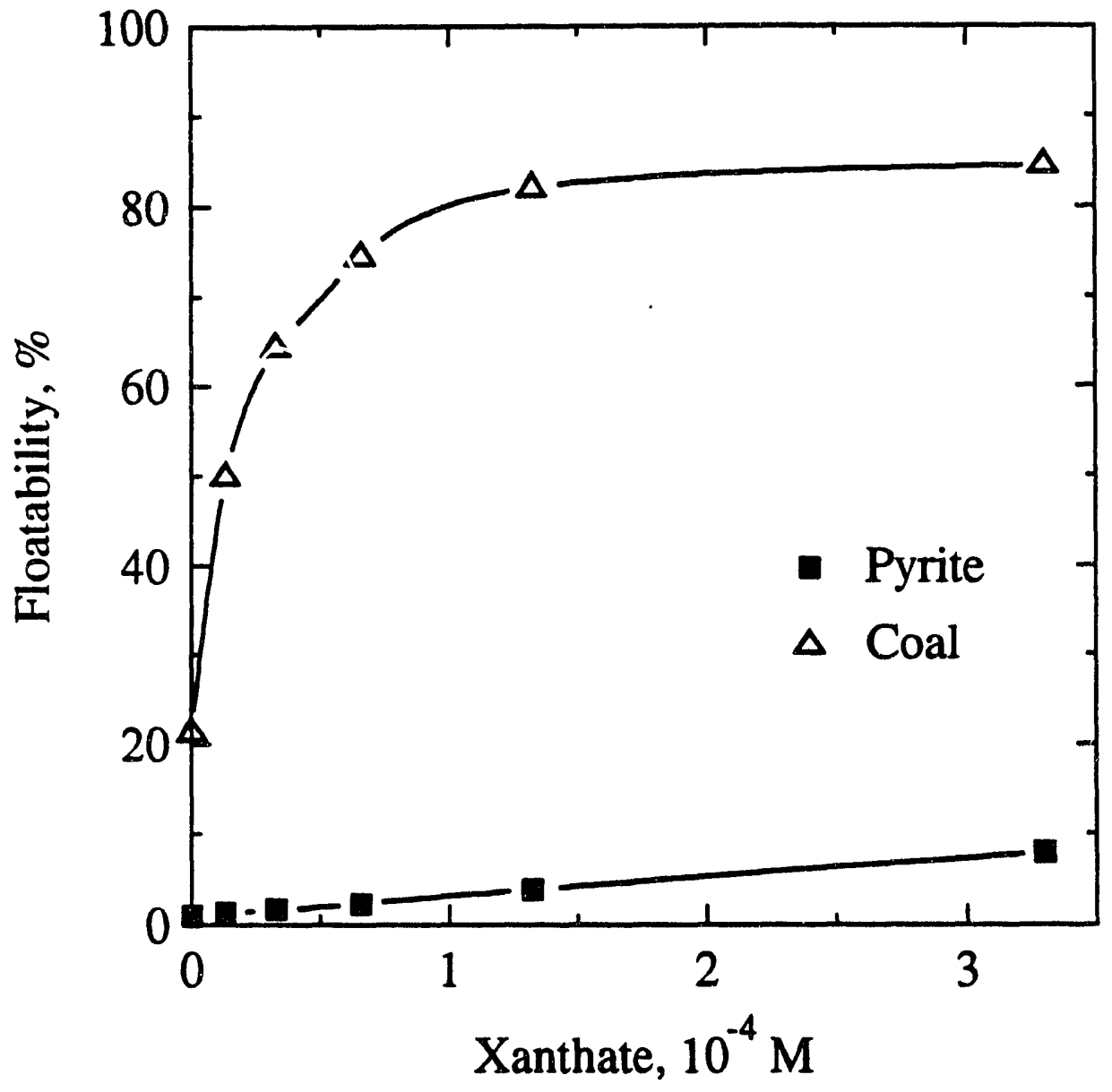

Figure 4.25 Floatability of Pittsburgh Coal and Coal Pyrite in Xanthate-Lime Solution $(\mathrm{pH}=9)$ 


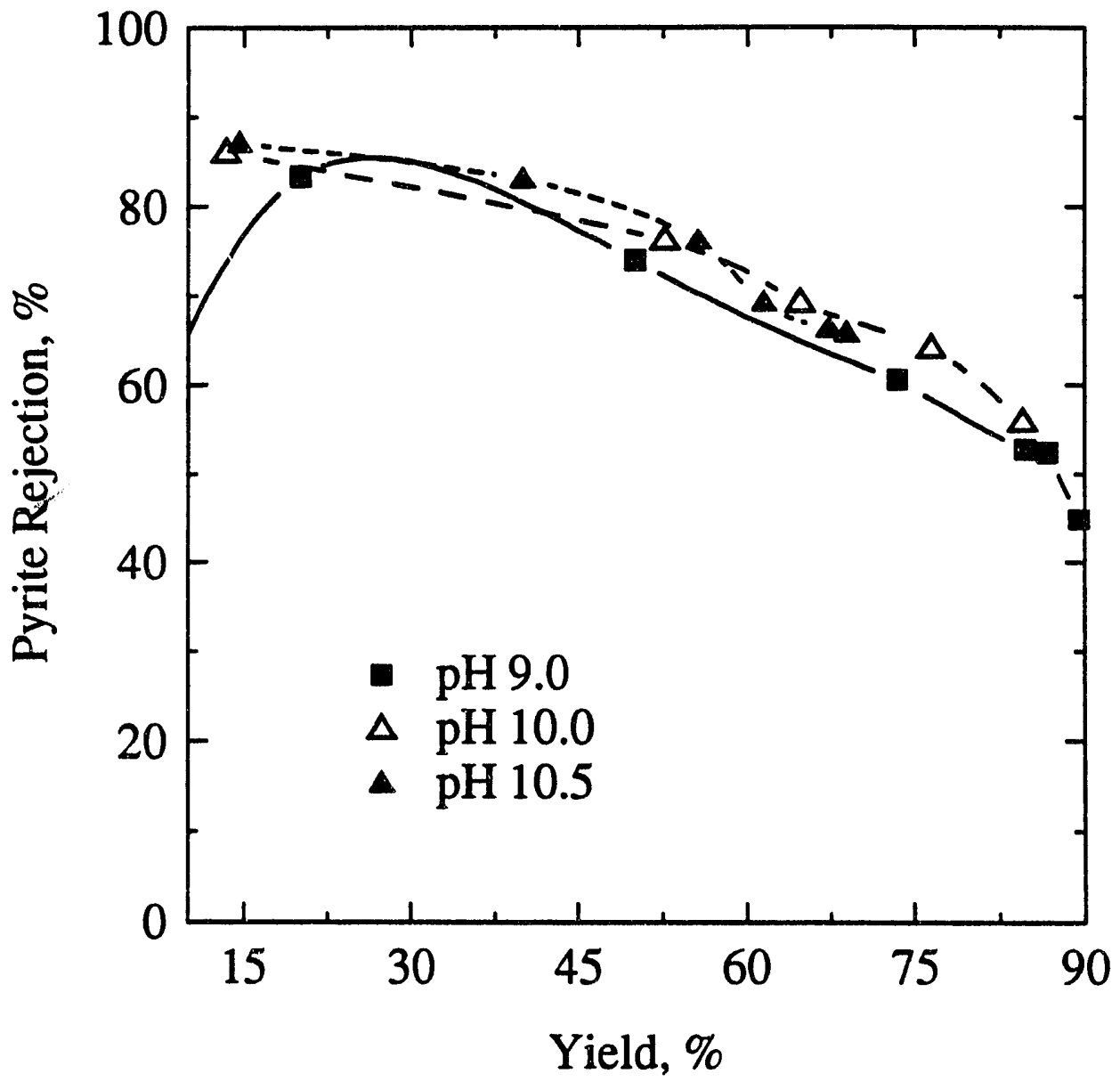

Figure 4.26 Pyrite Rejection as a Function of Yield for Pittsburgh Coal in Xanthate-lime Solution 


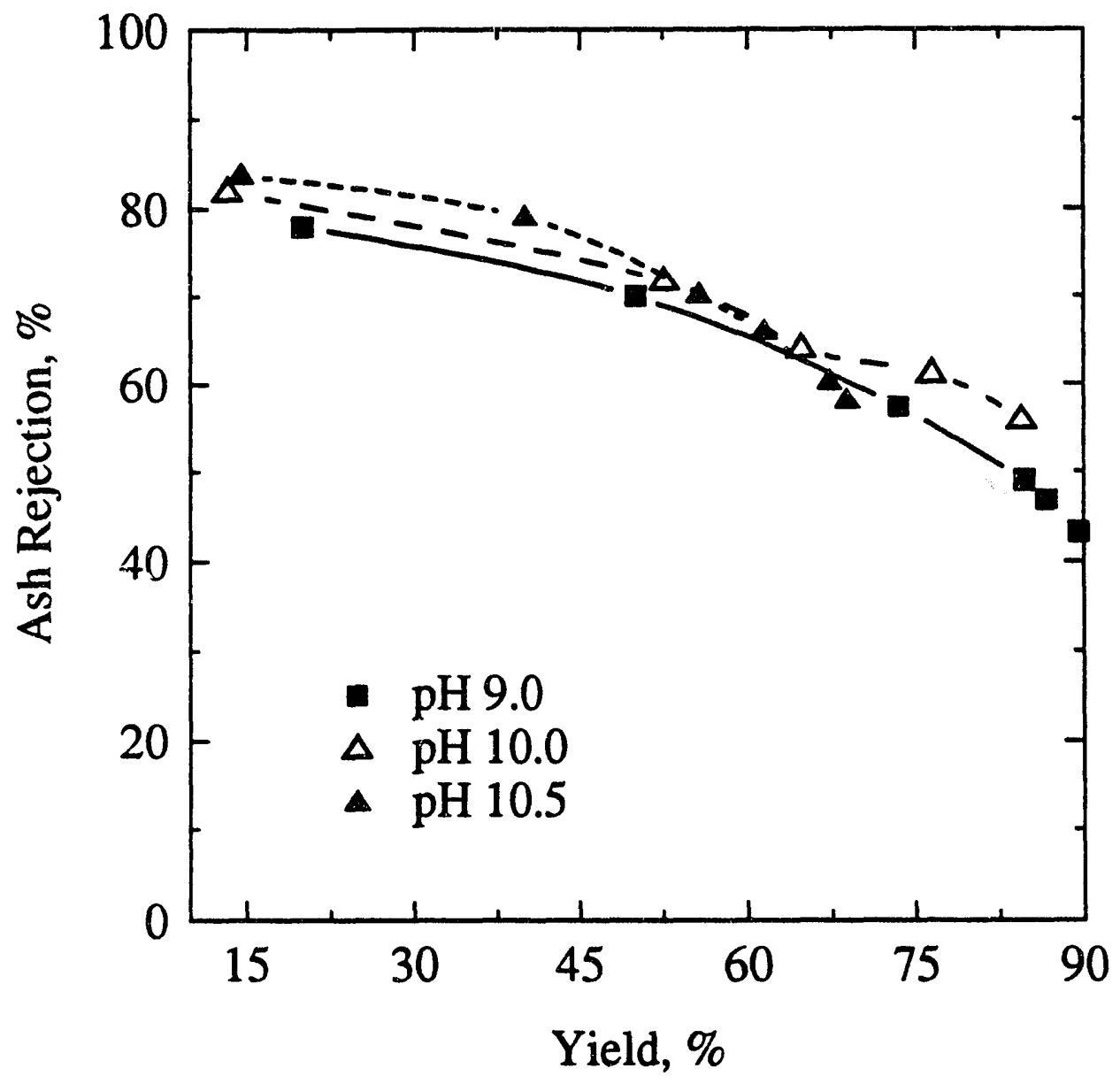

Figure 4.27 Ash Rejection as a Function of Yield for Pittsburgh Coal in Xanthate-lime Solution 


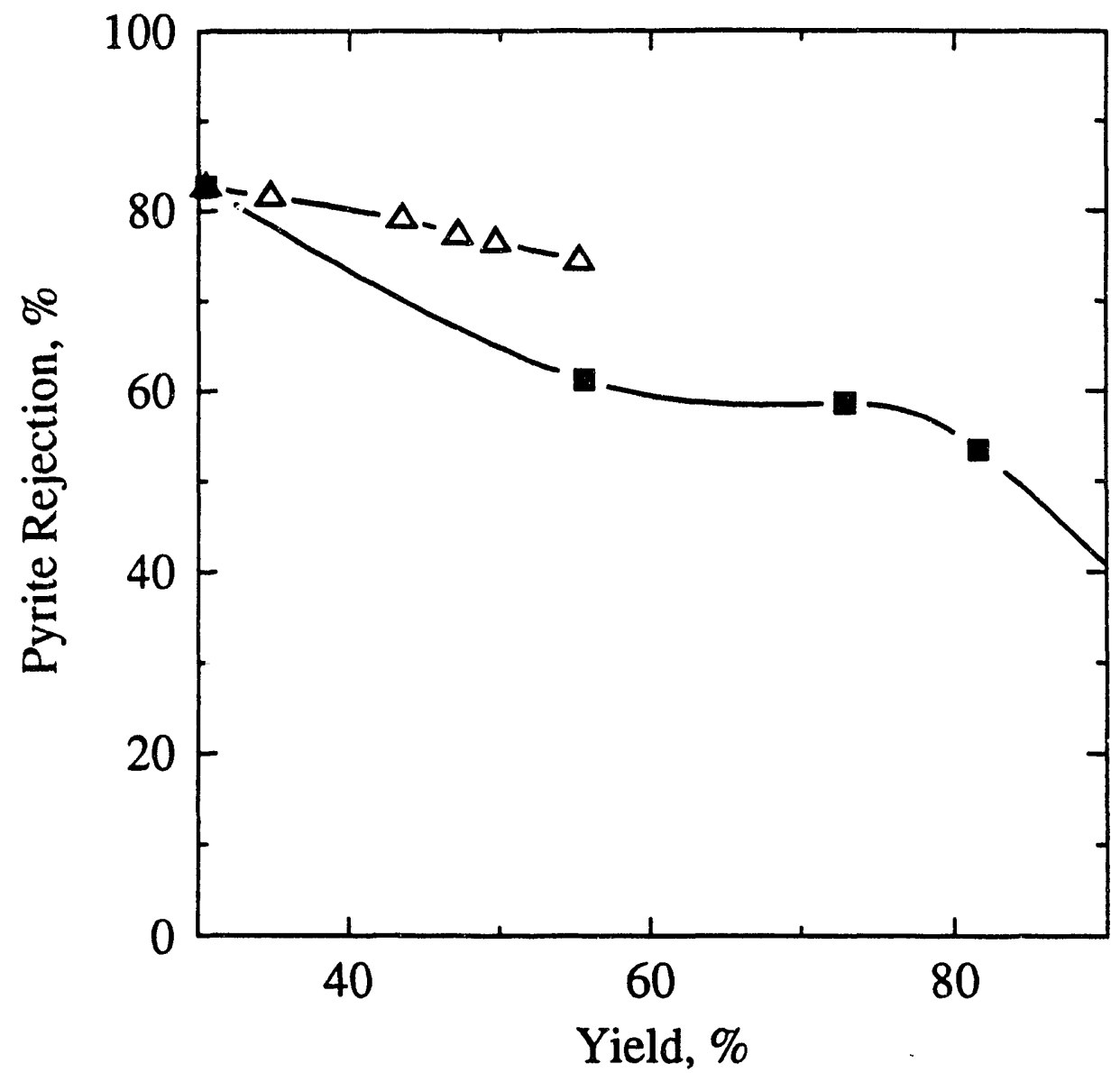

Figure 4.28 Pyrite Rejection as a Function of Yield for Pittsburgh Coal in Dodecane-electrolyte 
Upper Freeport coal has natural floatability; but, the combustible material recovery was only $26 \%$. It displayed good pyritic sulfur rejection of $96.0 \%$; but, the separation efficiency was only $22 \%$ because of the low yield. Neither Illinois nor Pittsburgh coal samples displayed natural floatability.

Floatability with Frother Only. Test results for flotation in the presence of MIBC only are illustrated in Figures 4.29, 4.30, 4.31, showing respectively, yield, combustable material recovery (CMR) and separation efficiency (EI). It is evident that the yield, CMR and separation efficiency increased markedly with increased frother (MIBC) concentration for thie Upper Freeport (MVb) and Pittsburgh (HVAb), while the Illinois (HVCb) showed much lower response to all three measures.

Flotation kinetics of the three coals, using MIBC, are presented in Figures 4.32, 4.33 and 4.34 for yield, CMR and separation efficiency. The results show that the Upper Freeport coal has a rapid flotation rate, Pittsburgh coal a medium rate, and Illinois coal a very slow rate of flotation.

Salt Flotation Test. Salt flotation test results are presented in Figures 4.35, 4.36 and 4.37, showing yield, $\mathrm{CMR}$ and separation efficiency for increasing $\mathrm{NaCl}$ concentration. It is apparent that salt has a significant effect on coal flotation. Kinetic results are illustrated in Figures $4.38,4.39$, and 4.40 . The relative rank of floatability (evaluated by yield and combustibie material recovery) and selectivity (evaluated by pyritic sulfur rejection and separation efficiency) was:

Upper Freeport MVb > Pittsburgh HVAb > Illinois HVCb.

\section{Flotation in an Electrochemical Mini-cell}

The Effects of Electrolyte on Floatability. Figure 4.41 illustrates the floatability of mineral and coal pyrite as a function of $\mathrm{pH}$ with xanthate as collector with and without $\mathrm{Na}_{2} \mathrm{SO}_{4}$ and $\mathrm{Na}_{2} \mathrm{~B}_{4} \mathrm{O}_{7}$ electrolyte. It was observed that mineral and coal pyrite floated very well in acid medium with amyl xanthate as the collector, but were depressed in alkaline solutions. For both mineral and coal pyrite in the absence of electrolyte, there was low 


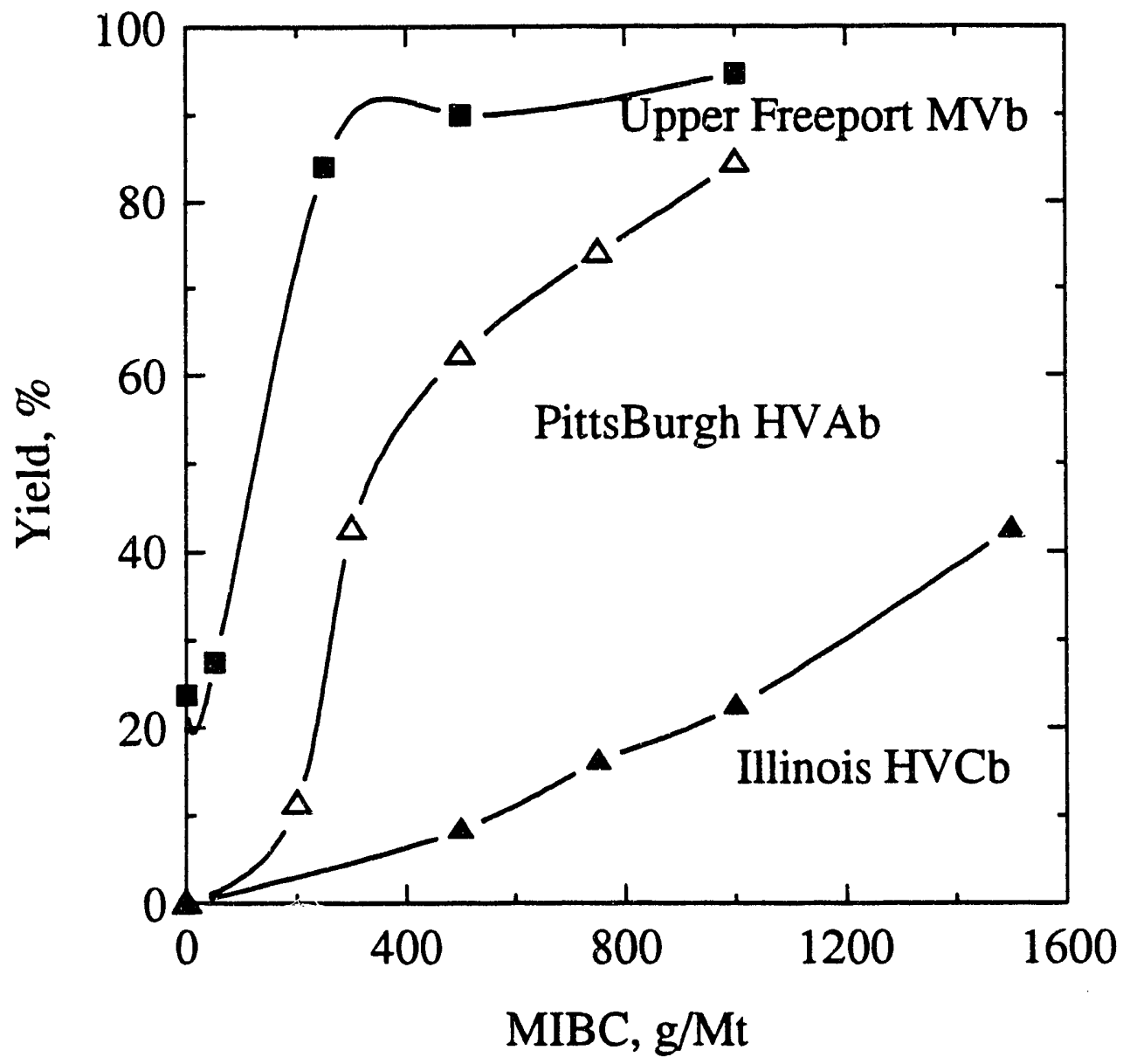

Figure 4.29 Natural Floatability of Coal Samples and Effect of MIBC on Flotation 


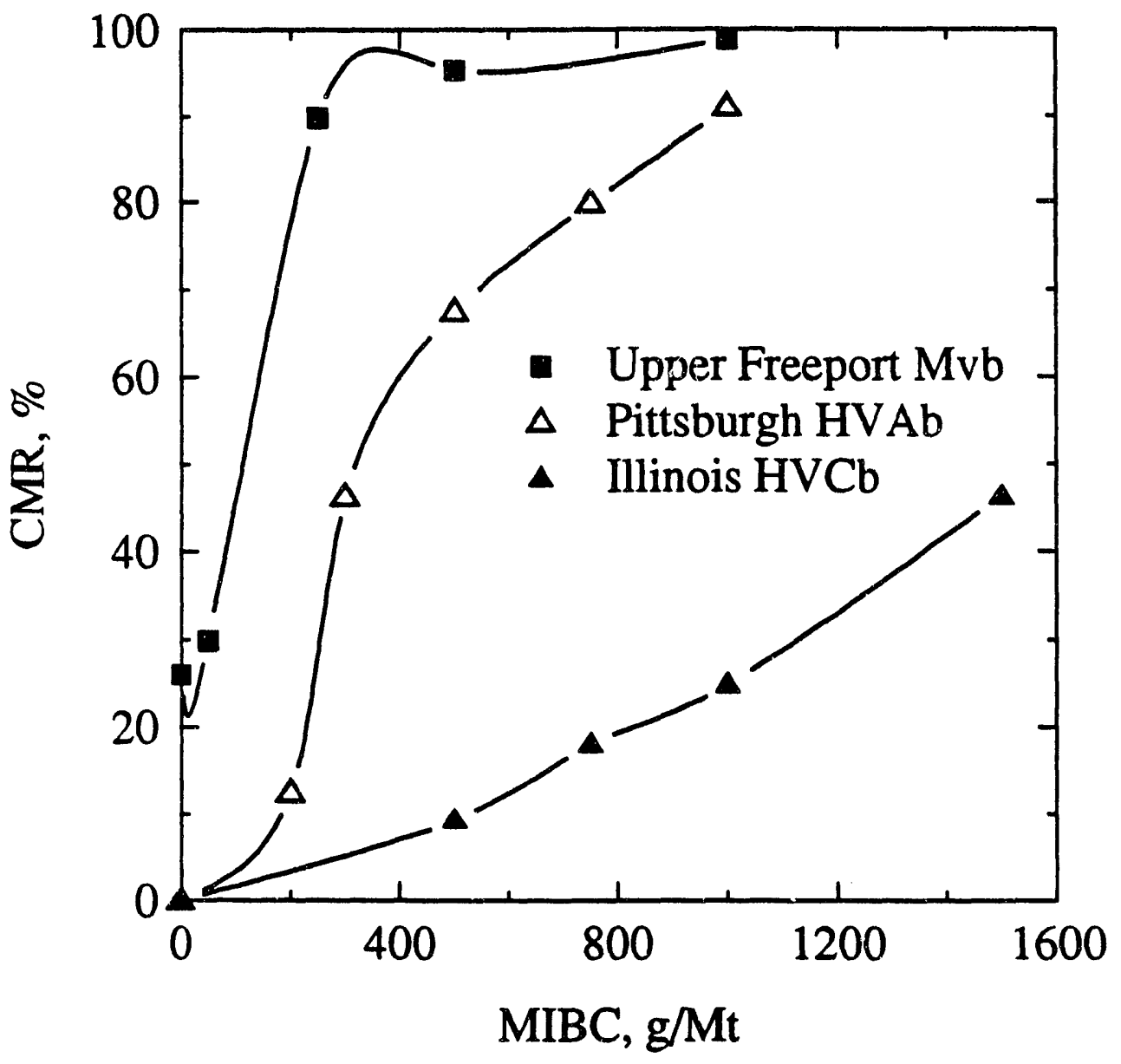

Figure 4.30 Natural Floatability of Coal Samples and Effect of MIBC on Flotation 


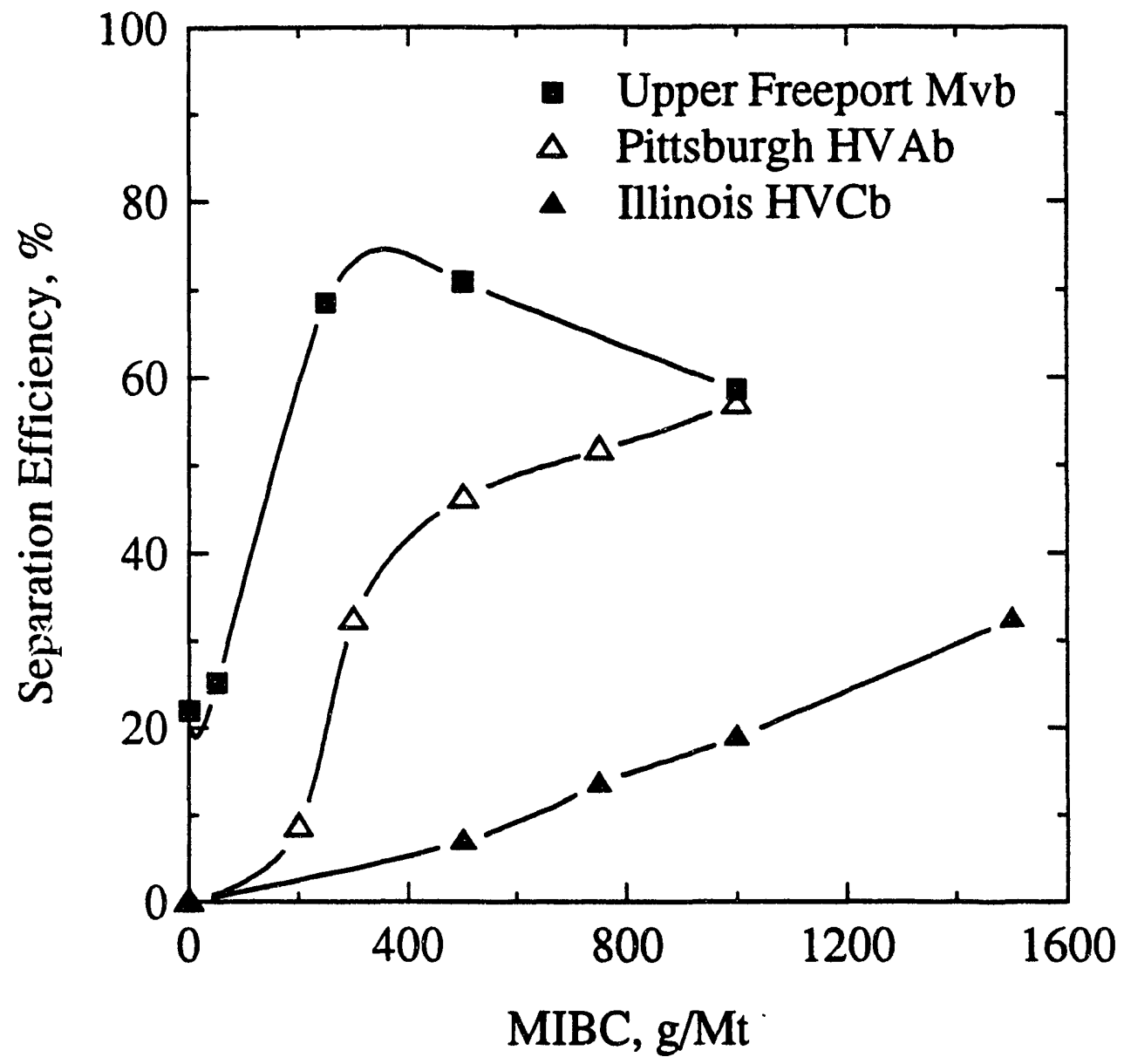

Figure 4.31 Natural Floatability of Coal Samples and Effect of MIBC on Flotation 


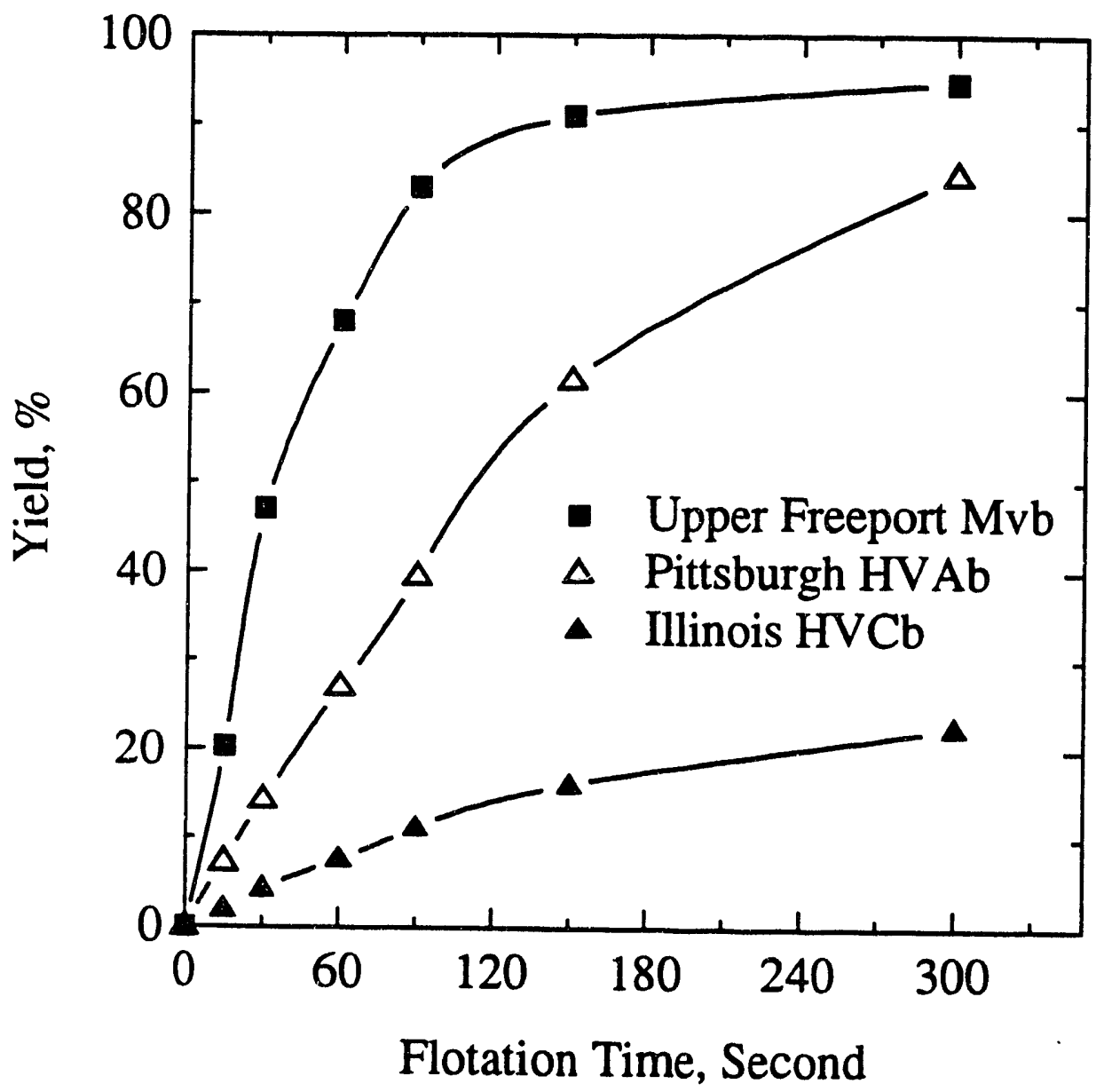

Figure 4.32 Flotation Kinetics Using MIBC Only (MIBC $1000 \mathrm{~g} / \mathrm{Mt}$ ) 


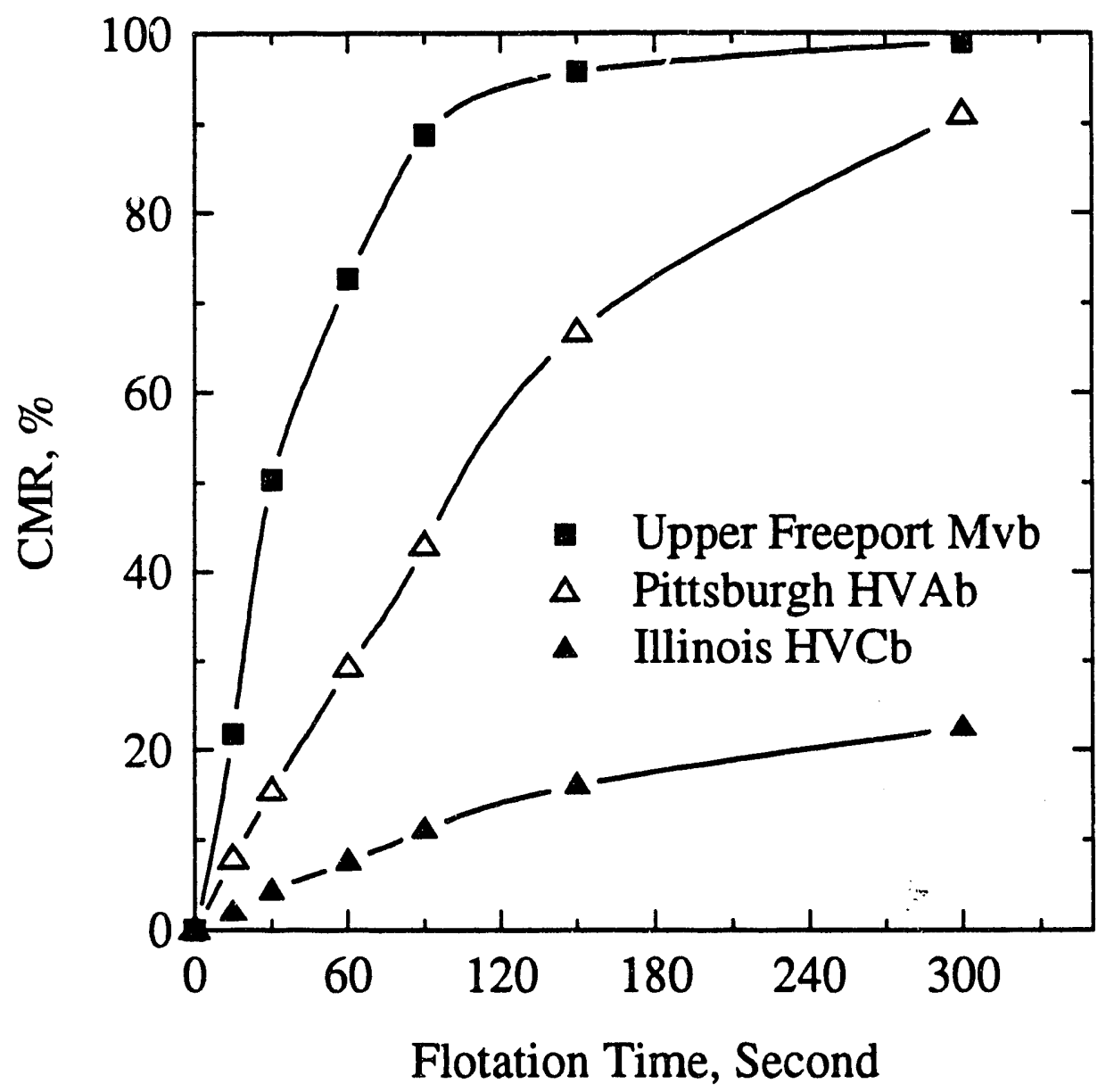

Figure 4.33 Flotation Kinetics Using MIBC Only (MIBC $1000 \mathrm{~g} / \mathrm{Mt}$ ) 


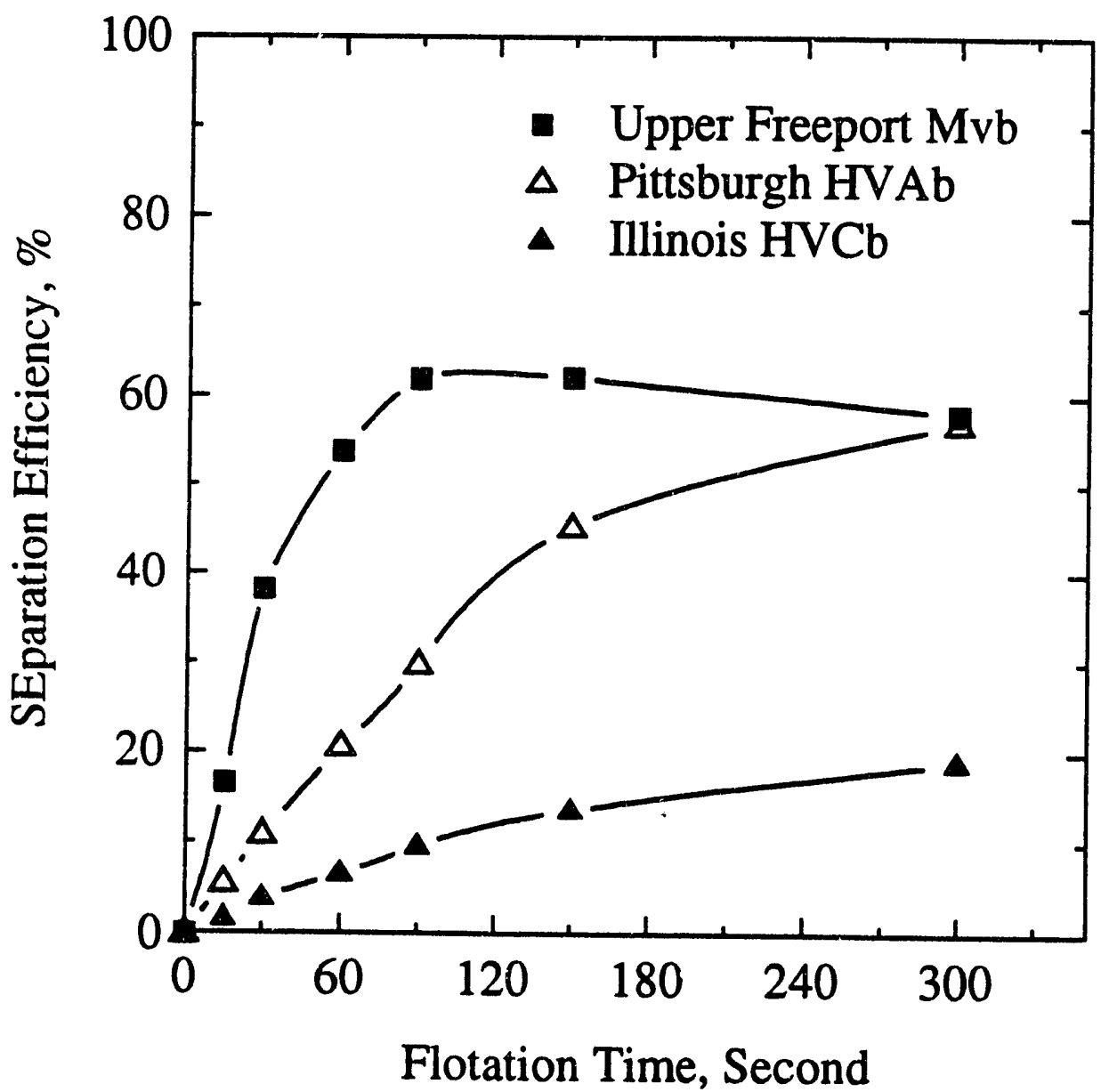

Figure 4.34 Flotation Kinetics Using MIBC Only (MIBC 1000 g/Mt) 


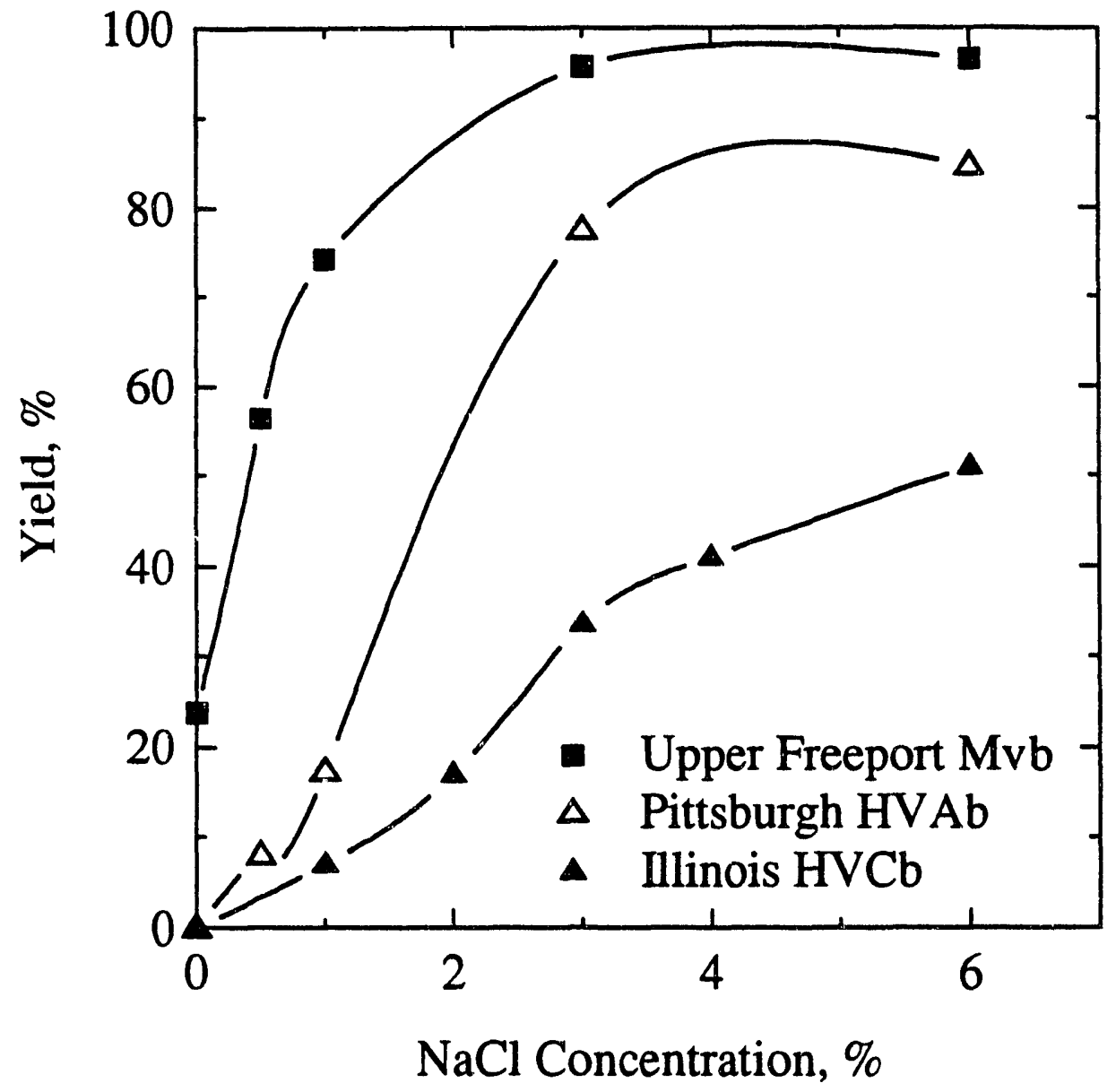

Figure 4.35 The Effect of Salt $(\mathrm{NaCl})$ on Floatability of Coal (no Frother or Collector) 


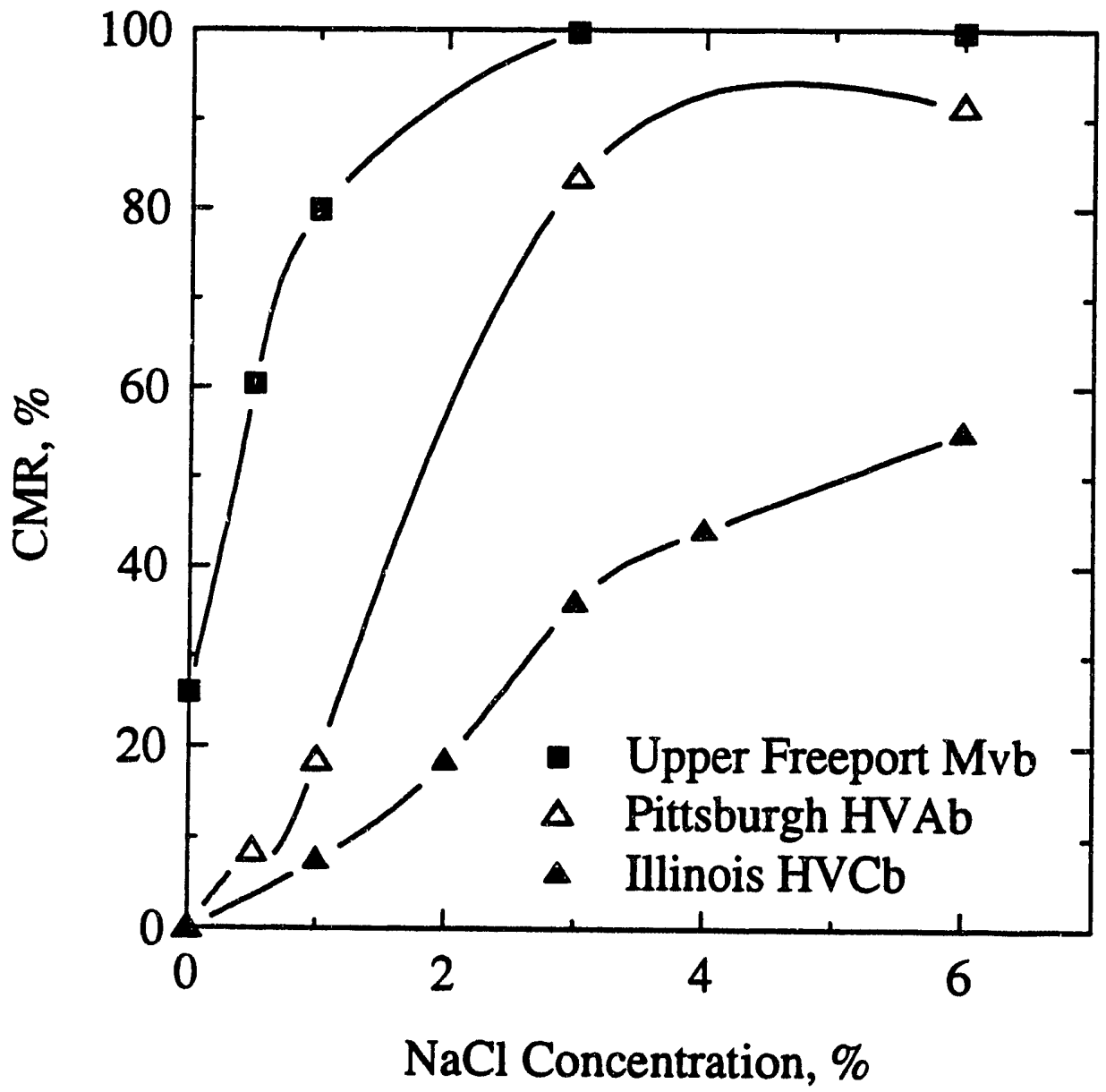

Figure 4.36 The Effect of Salt $(\mathrm{NaCl})$ on the Combustible Material Recovery(No Frother or Collector) 


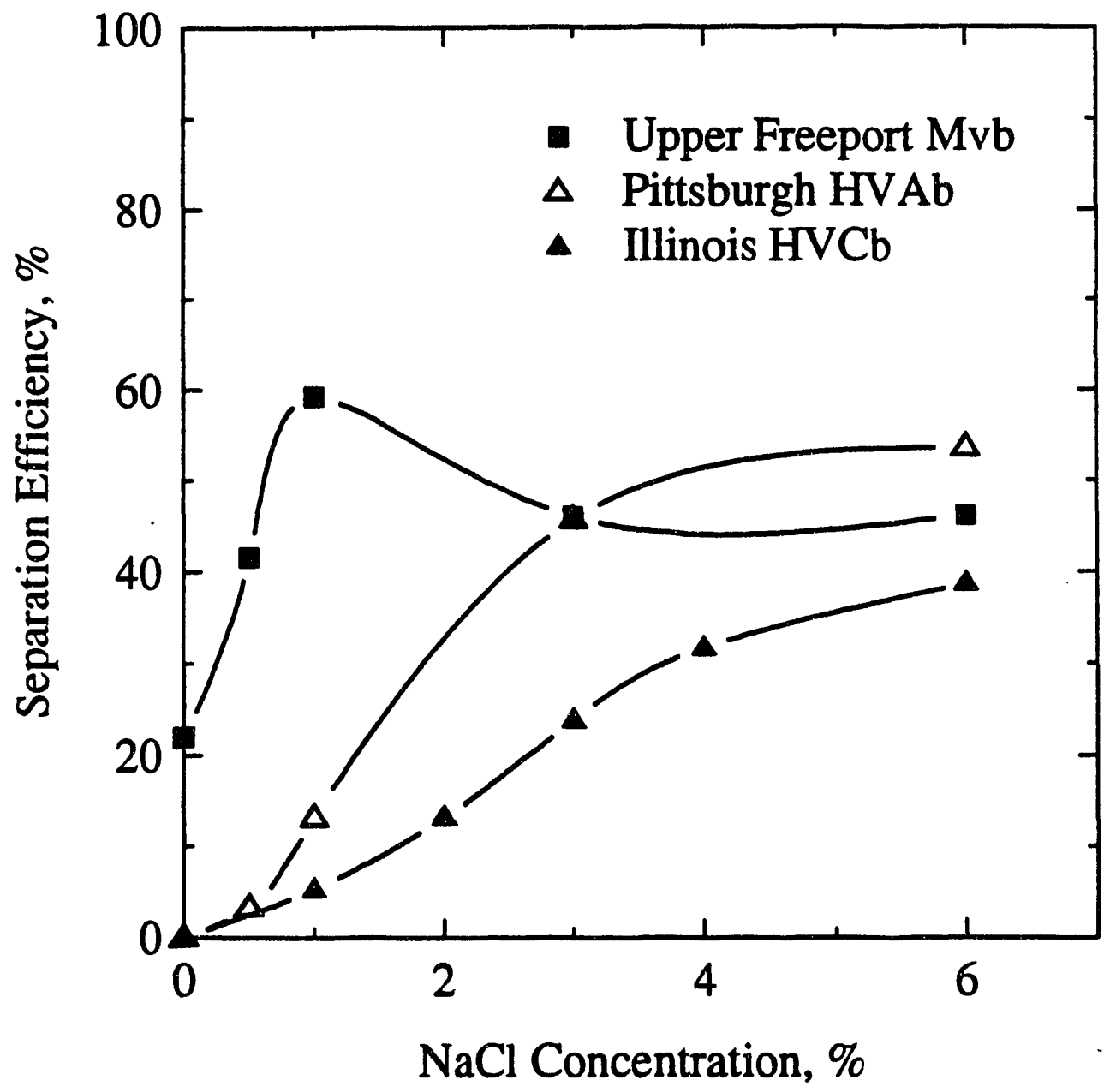

Figure 4.37 The Effect of Salt $(\mathrm{NaCl})$ on the Efficiency of Pyritic Sulfur (No Frother \& Collector) 


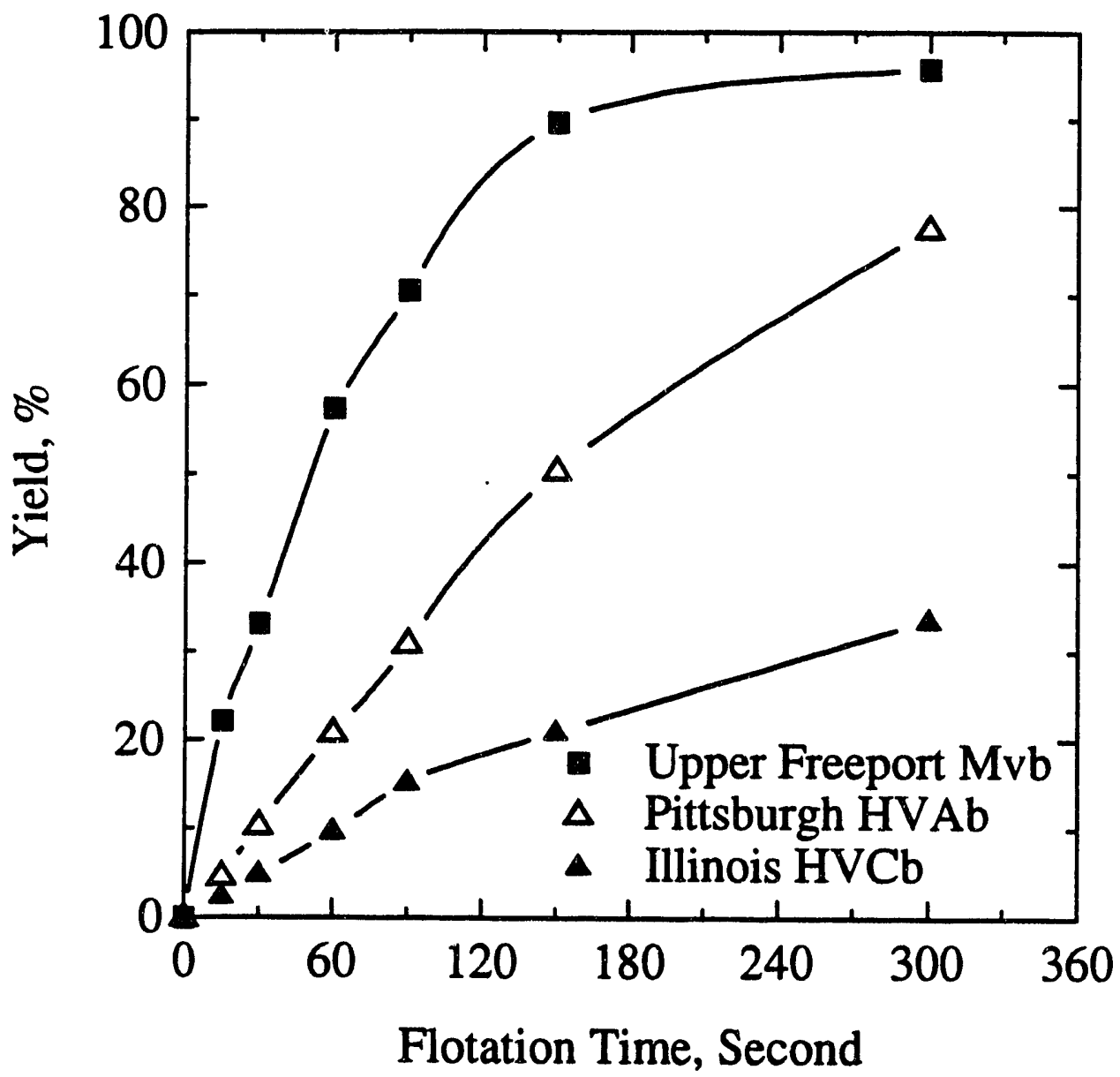

Figure 4.38 Relation Between the Yield of Salt Flotation and the Flotation Time (Salt Concentration: 3\%, No Frother or Collector) 


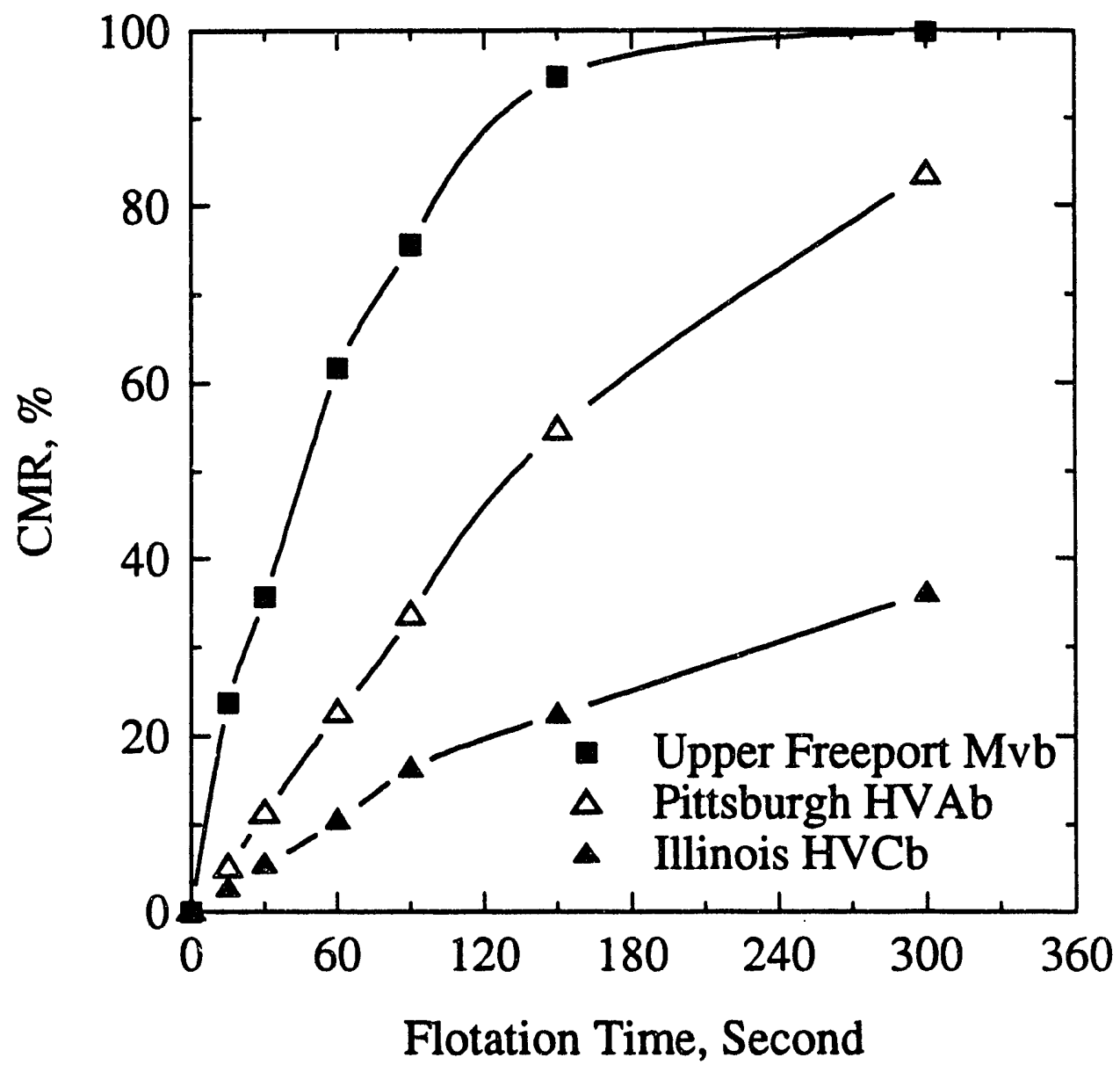

Figure 4.39 Relation Between the Combustible Material Recovery and the Flotation Time (Salt Concentration: 3\% and No Frother or Collector) 


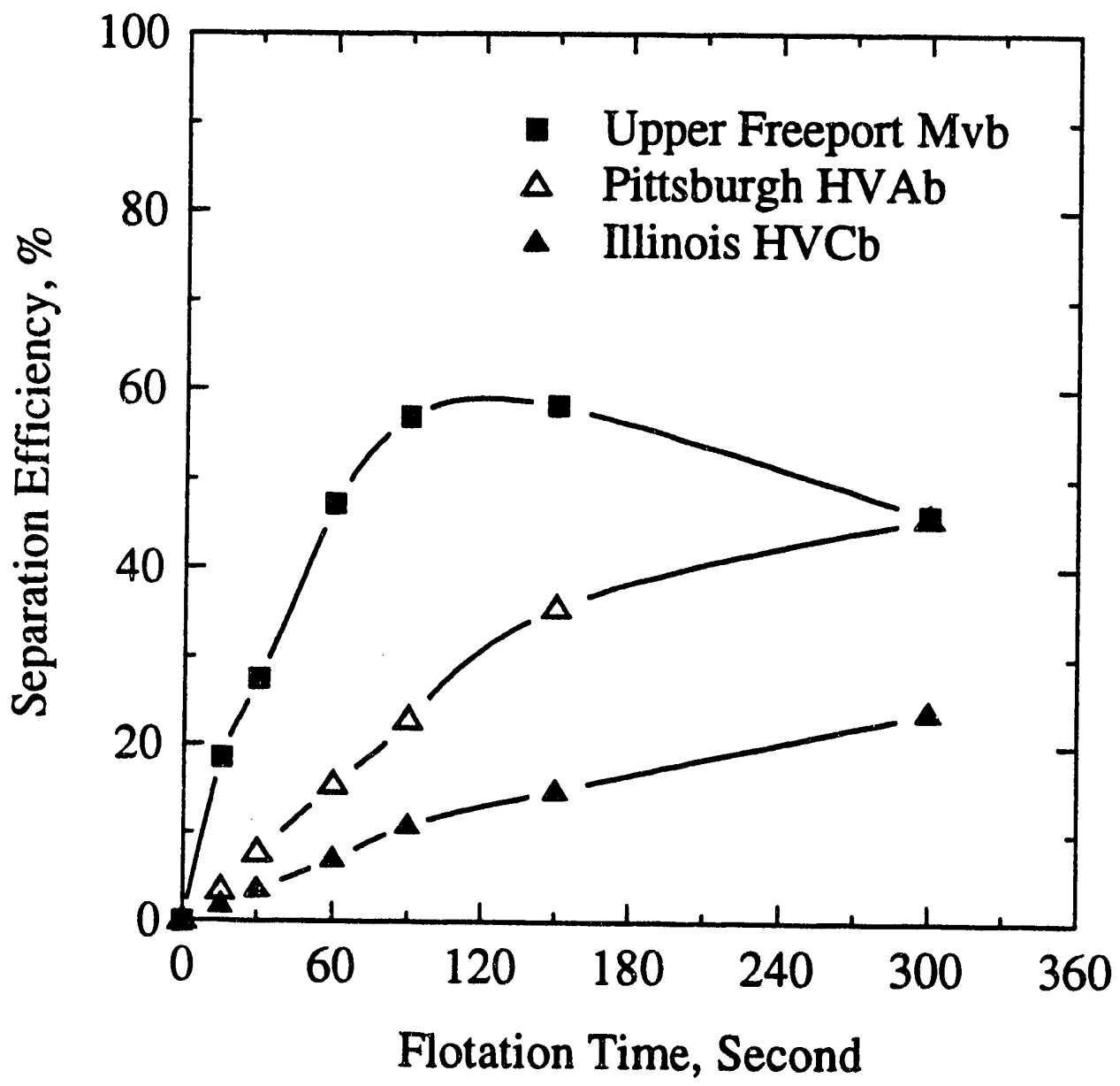

Figure 4.40 Relation Between the Separation Efficiency and the Flotation Time(Salt Concentration: 3\%, No Frother or Collector) 
Sample

Solution(M)

Xanthate $\mathrm{Na}_{2} \mathrm{SO}_{4} \mathrm{Na}_{2} \mathrm{~B}_{4} \mathrm{O}_{7}$

1 Mineral Pyrite $0.66 \times 10^{-5} \quad 0.00 \quad 0.00$

2 Mineral Pyrite $0.66 \times 10^{-4} \quad 0.49 \quad 0.01$

3 Coal Pyrite $\quad 1.32 \times 10^{-4} \quad 0.00 \quad 0.00$

$\begin{array}{llll}4 \text { Coal Pyrite } & 1.32 \times 10^{-4} & 0.49 & 0.01\end{array}$

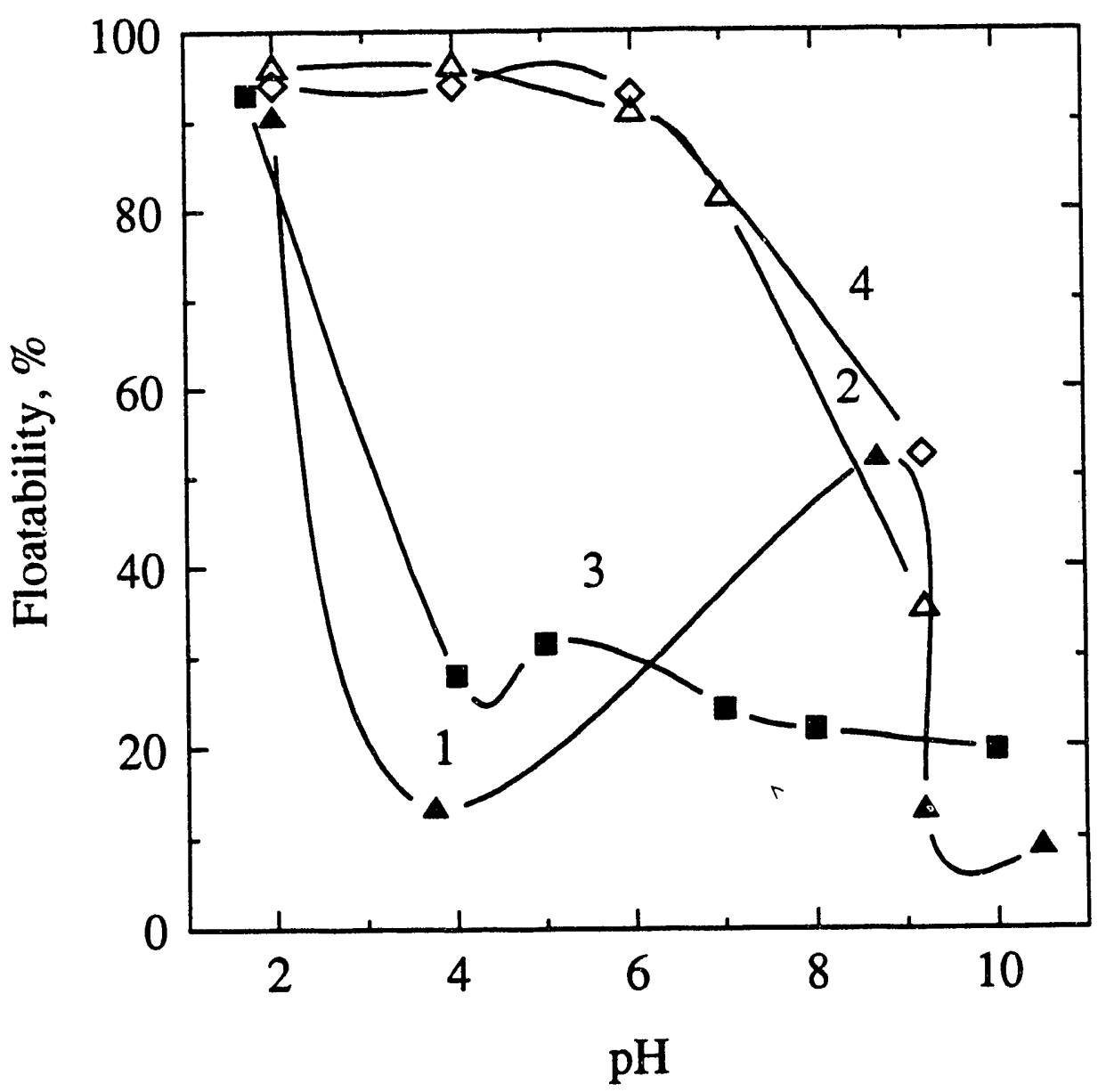

Figure 4.41 Floatability of Mineral and Coal Pyrite as a Function of $\mathrm{pH}$ 
floatability at $\mathrm{pH}$ values around 4, which are close to the natural $\mathrm{pH}$ of the coal pyrite. These results are consistent with the findings of Fuerstenau et al. [4.9]. In contrast, in the presence of electrolyte, the floatability of mineral and coal pyrite was enhanced and the depressed floatability around their natural $\mathrm{pH}$ disappeared. It may be concluded that sodium sulfate and sodium borate are effective activators for mineral and coal pyrite in the xanthate system in the $\mathrm{pH}$ range of 2 to 8. For comparison, a set of experiments on the flotation of coal and coal pyrite were carried out in water without frother or collector. The results are shown in Figure 4.42. The natural floatability of both coal and coal pyrite was much lower than that in xanthate (Figure 4.41) and xanthate-electrolyte (Figure 4.43) solutions.

Electrochemical Pretreatment of Coal Pyrite. In the cyclic voltammetry and Raman spectroscopy studies, shown earlier, it was observed that hydrophobic elemental sulfur and polysulfides and hydrophilic iron oxides and hydroxides can be formed under certain electrochemical conditions. The formation of sulfur and polysulfide on the pyrite surface enhances floatability, while the formation of metallic oxides and hydroxides depresses floatability.

Figure 4.44 illustrate the effect of applied potential on floatability of coal pyrite. $\mathrm{Na}_{2} \mathrm{SO}_{4}$ and $\mathrm{Na}_{2} \mathrm{~B}_{4} \mathrm{O}_{7}$ were added to the solution as supporting electrolyte. The highest floatability of coal pyrite occurred in the potential range from +0.8 to $1.0 \mathrm{~V}$. Considering the higher resistance of the particle bed compared to solid bed, these results fit well with those from electrochemical studies and Raman spectroscopy.

Figure 4.45 illustrates the effects of xanthate concentration and electrochemical pretreatment on the floatability of coal pyrite at $\mathrm{pH}$ 7.0. Coal pyrite, electrochemically pretreated at a potential $+0.8 \mathrm{~V}$, showed much higher floatability due to the formation of elemental sulfur and polysulfides. Figure 4.46 and 4.47 illustrate the effect of electrochemical pretreatment on the floatability of coal pyrite in xanthate-lime medium, without electrolyte, at $\mathrm{pH} 10$ and 12.3. The positive influence of electrochemical treatment on the floatability of coal pyrite was significantly depressed by the addition of lime. For example, the floatability of coal pyrite pretreated at $+0.8 \mathrm{~V}$ in $\mathrm{Na}_{2} \mathrm{SO}_{4}$ and $\mathrm{Na}_{2} \mathrm{~B}_{4} \mathrm{O}_{7}$ 


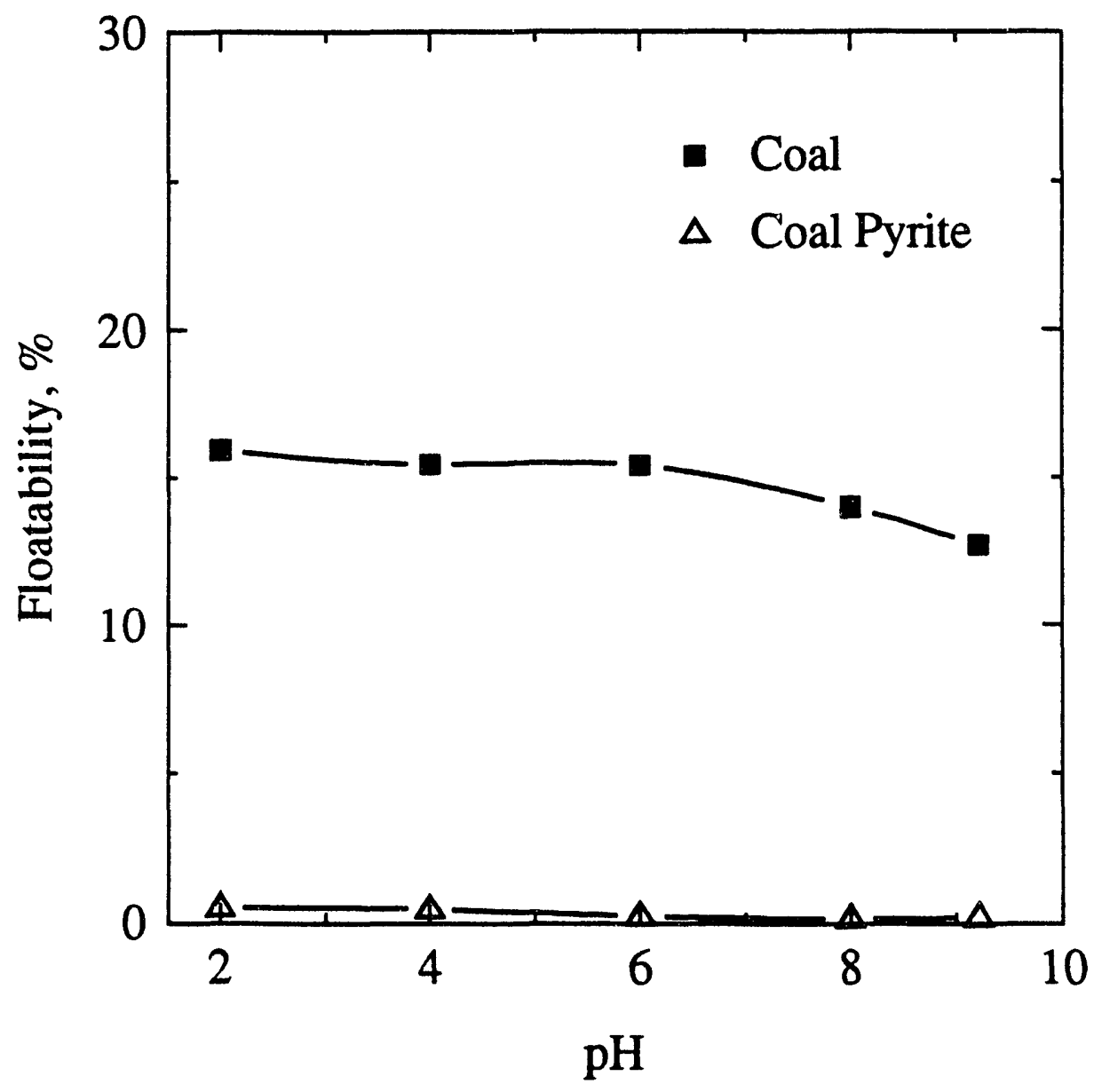

Figure 4.42 Floatability of Pittsburgh Coal and Coal Pyrite as a Function of $\mathrm{pH}$ 


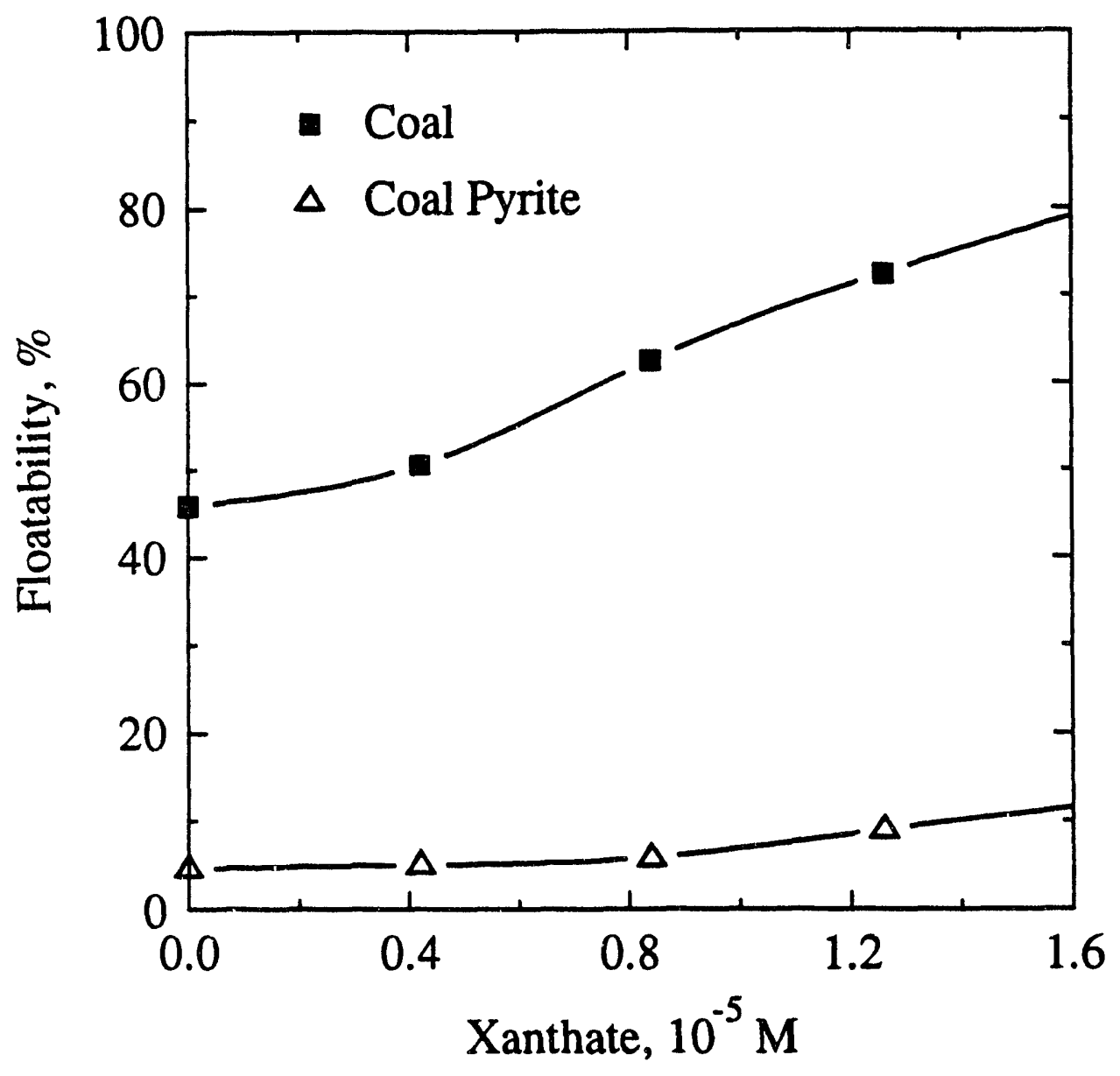

Figure 4.43 Floatability of Pittsburgh Coal and Coal Pyrite in Xanthate-electrolyte 


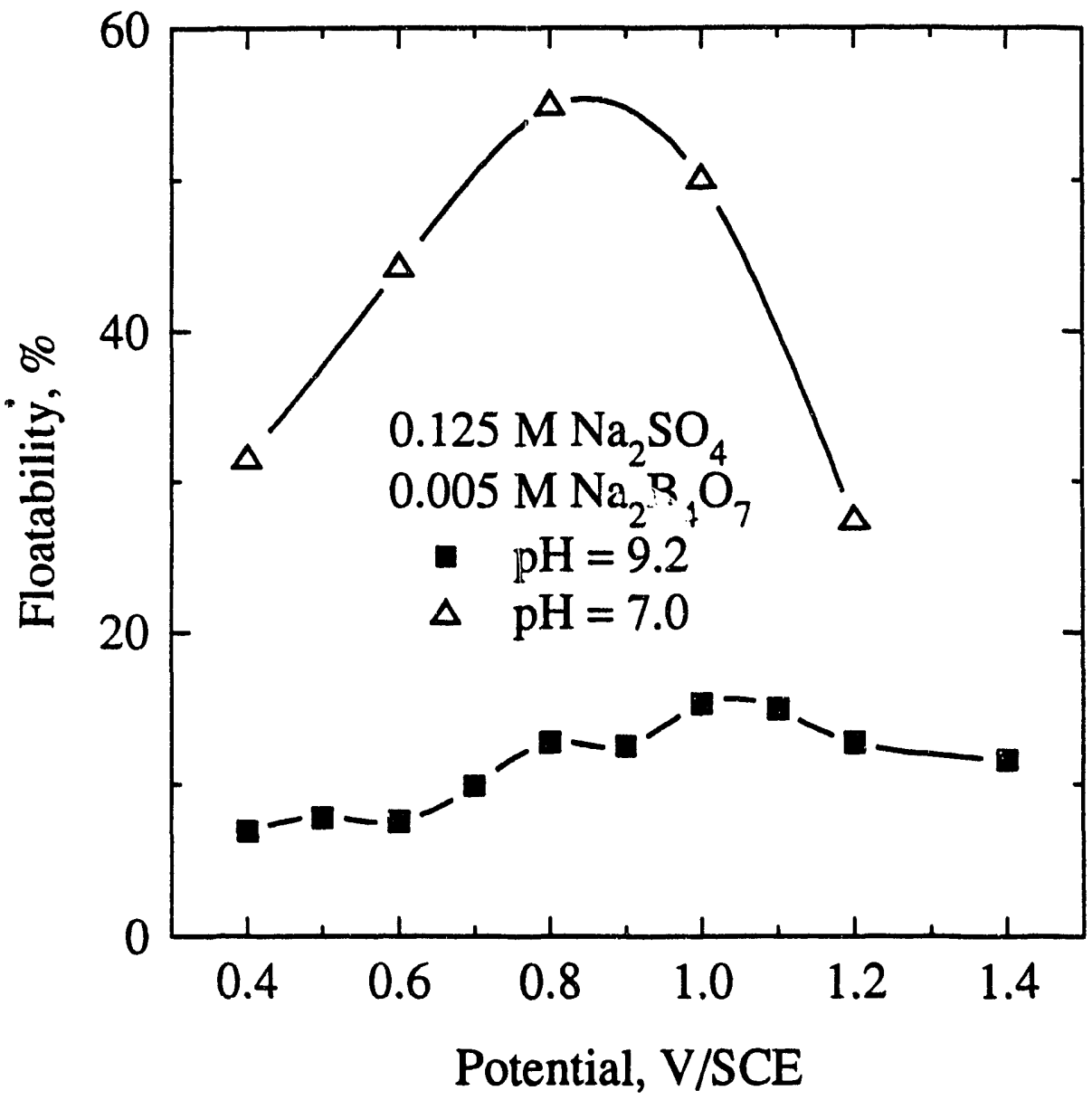

Figure 4.44 The Effect of Potential on Flotability of Coal Pyrite 


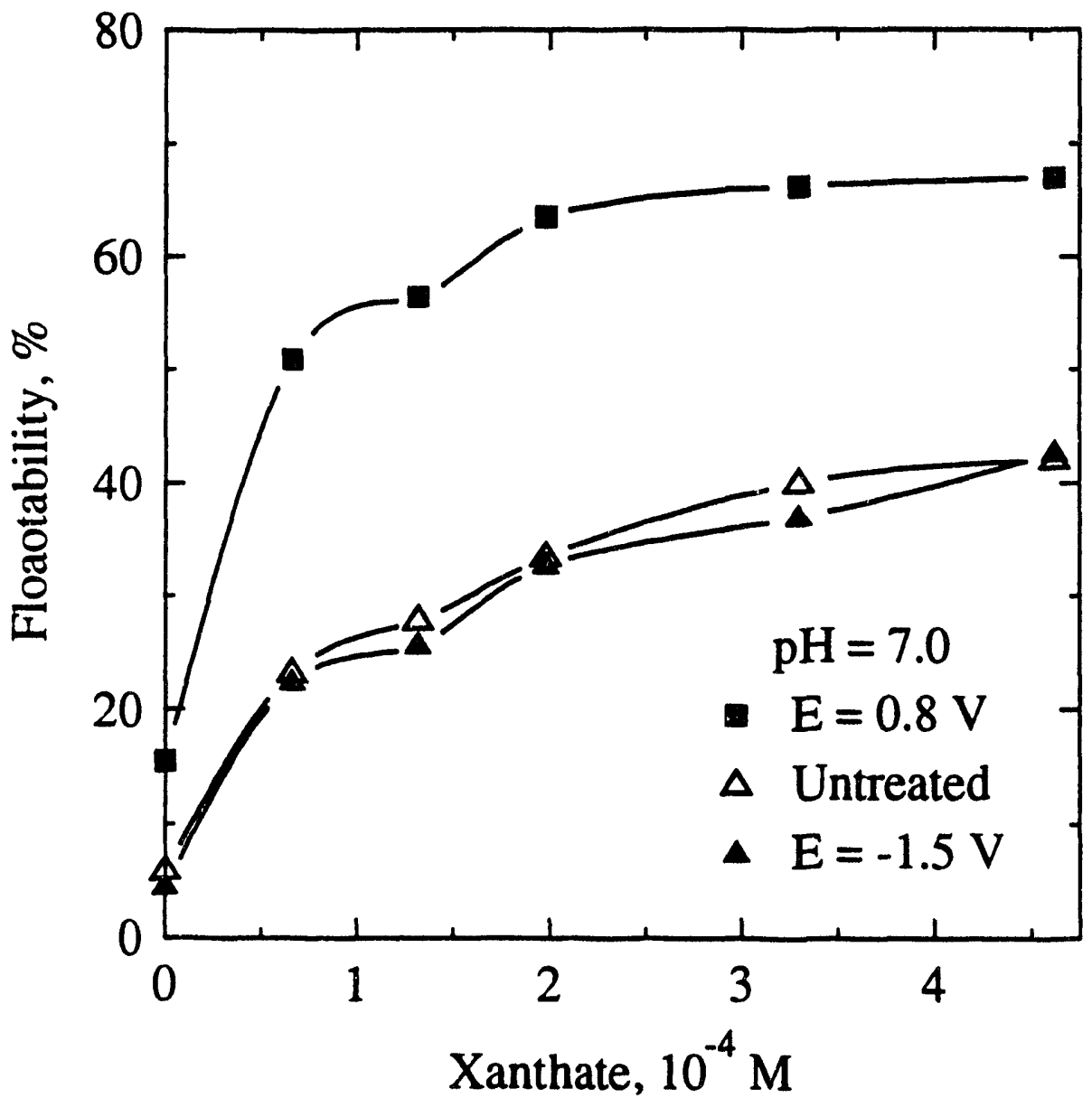

Figure 4.45 The Effect of Electroshemical Pretreatment on Floatability of Coal Pyrite 


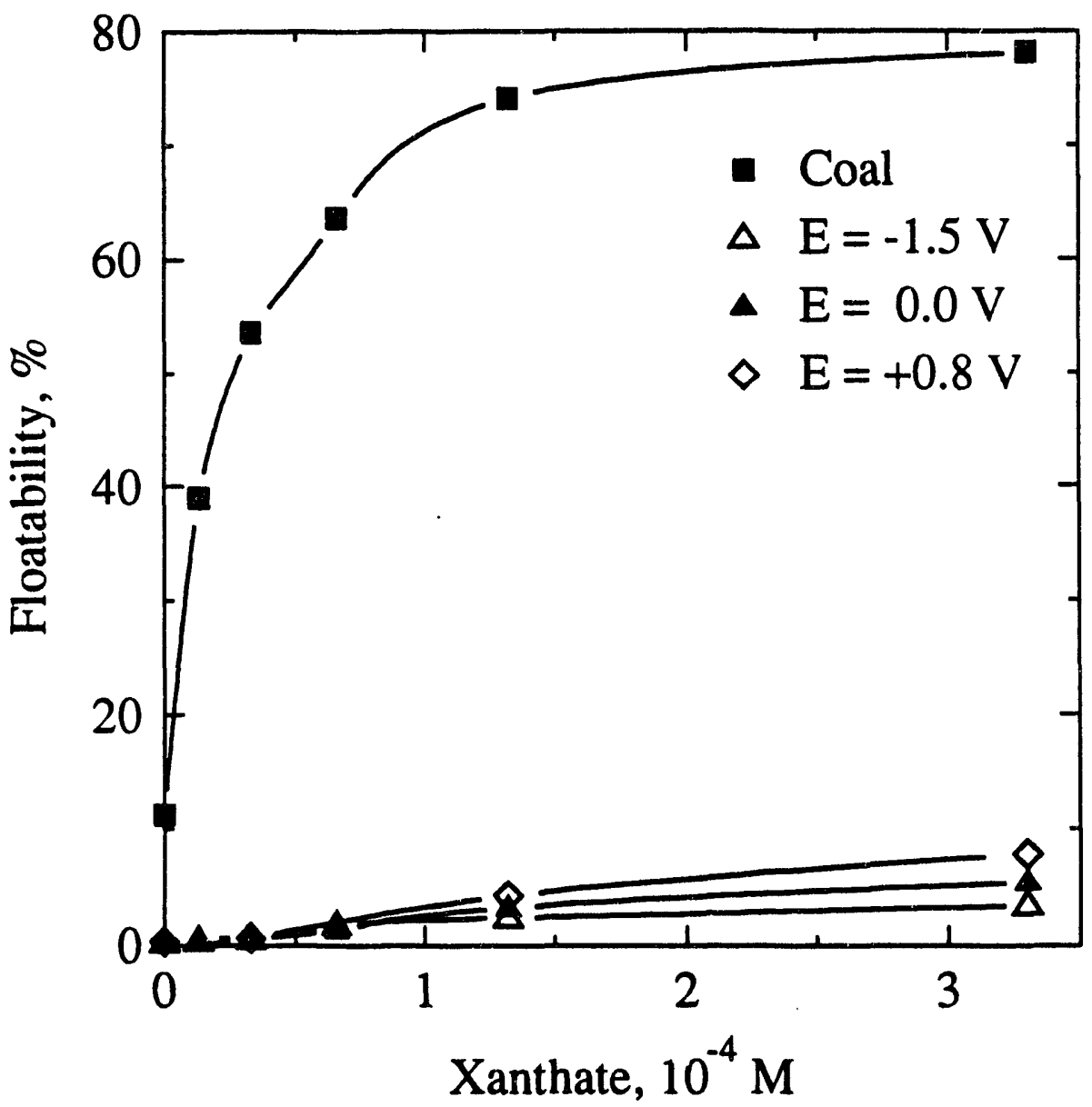

Figure 4.46 The Effect of Electrochemical Pretreatment on Floatability of Coal Pyrite in Xanthate-lime Solution $(\mathrm{pH}=10.0)$ 


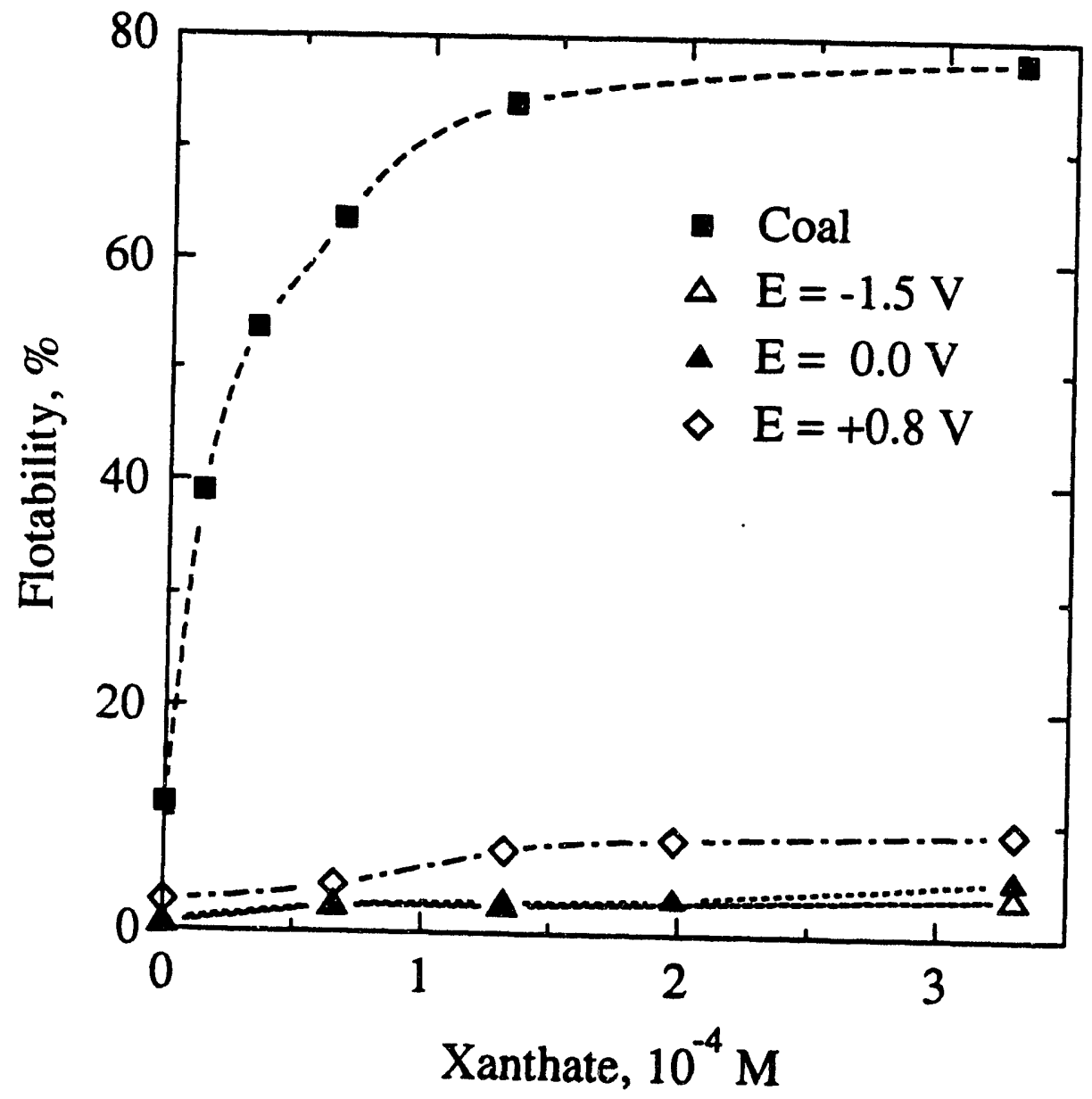

Figure 4.47 The Effect of Electrochemical Pretreatment on Floatability of Coal Pyrite in Xanthate Solution $(\mathrm{pH}=12.3)$ 
electrolyte with $3.3 \times 10^{-4} \mathrm{M}$ xanthate was $66.3 \%$. Under similar conditions, except $\mathrm{Na}_{2} \mathrm{SO}_{4}$ and $\mathrm{Na}_{2} \mathrm{~B}_{4} \mathrm{O}_{7}$ were replaced by lime to adjust the $\mathrm{pH}$ of solutions to 10.0 and 12.3 , the floatabilities of pretreated coal pyrite were $9.3 \%$ and $5.1 \%$ respectively.

\section{CONCLUSIONS}

Based upon the results obtained for the three coals considered in these studies, the following was concluded:

1. The ranking of floatability of the three coals including natural floatability, floatability with xanthate and salt flotation was: Upper Freeport > Pittsburgh $>$ Illinois.

2. The floatability of mineral and coal pyrite increases markedly with concentration of xanthate and exhibits a negative effect with increasing $\mathrm{pH}$.

3. Coal pyrite is much more difficult to float than mineral pyrite due to the contamination of coal pyrite surfaces by the carbonaceous and gangue materials.

4. Acid pretreatment significantly improves the floatability of coal pyrite, and involves three aspects: (1) removal of the carbonaceous matter from the surface, (2) the intrinsic $\mathrm{pH}$ effect, and (3) dissolution of oxidized passivation layers.

5. For both mineral and coal pyrite in solutions without electrolyte, there is low floatability around their natural $\mathrm{pH}$. The floatability of mineral pyrite and coal pyrite is enhanced in the presence of an electrolyte. The low floatability at the natural $\mathrm{pH}$ disappears in xanthate-electrolyte solutions.

6. The floatability of coal pyrite is significantly reduced by small additions of lime for $\mathrm{pH}$ control.

7. Modifiers $\mathrm{CuSO}_{4}, \mathrm{Na}_{2} \mathrm{~S}, \mathrm{CO}_{2}$, and EDTA enhance the floatability of coal pyrite.

8. Enhanced floatability of coal pyrite occurs when electrolyte is present and the pyrite is exposed to certain applied potentials. These potentials fall in a range where elemental sulfur and polysulfides form. These results are consistent with electrochemical and Raman spectroscopy findings reported earlier in this study. 
9. While interesting trends and influences of chemistry and chemical and electrochemical pretreatment on coal pyrite floatability were observed in this study, none of these findings provide much hope for reverse flotation as an effective coal/coal-pyrite separation technology. The effects of inadequate liberation and entrainment appear overriding.

\section{REFERENCES}

[4.1] K.J. Miller, Trans. AIME, 258 (1975), 30.

[4.2] F.J. Chernowsky and M. Lyon, Trans. AIME, 252 (1972), 11.

[4.3] M.C. Esposito, S. Chander, and F.F. Aplan, "Characterization of Pyrite from Coal Sources", Process Mineralogy VII, ed. A.H. Vassiliou, (TMS/AIME, IS82), 55.

[4.4] R.W. Lai et al., "Comparative Study of Surface Properties and Keactivity of Coal Pyrite and Mineral Pyrite", (Preprini, SME Annual Meeting, Las Vegas, NV, Preprint Number 86, 1989).

[4.5] Hornsby, D.T., and Leja, J., Coal Preparation, Vol. 1, (1984), 1.

[4.6] Fuerstenau, D.W., Williams, M.C., and Urbina, R.H., Proceedings, International Conference on Coal Science, (Sydney, Australia, October 1985).

[4.7] W. Hu, R. Jin and D.M. Bodily, "Floatability Evaluation of Fine Coal," SMEAIME Transaction 282, 1910.

[4.8] D.M. Bodily, J.P Wan, W. Chen, X. Zhu, W. Hu and M.E. Wadsworth, "Characterization of Mineral and Coal Pyrite", to be published.

[4.9] M.C. Fuerstenau et al., Trans. AIME, 241 (1968), 148. 


\section{FLOTATION KINETICS}

\section{INTRODUCTION}

Froth flotation is a major process for producing clean coal. Although flotation is a rate process, flotation kinetic data are rarely collected or analyzed for commercial application. The analysis of flotation kinetics is useful in providing engineering design criteria, process scale-up information and a process control strategy. Understanding fine coal flotation kinetics may also prove important for improving flotation processes and understanding important flotation parameters. Coal and pyrite have not only different floaiabilities but also different flotation rates. These differences may be utilized in the separation of coal and coal pyrite [5.1]. In the literature, many kinetic studies of the flotation of mineral and coal have been presented. But there are few studies of fine coal kinetics. It has been reported [5.2] that fine coal flotation kinetics are different from conventional coal and mineral flotation kinetics. This study presents kinetic results of fine coal flotation for three typical U.S.A. coals: Upper Freeport, Pittsburgh No 8 and Illinois No 6 coals.

The early application of kinetics to flotation was bastd on the analogy between a chemical reaction (collision theory of molecules) and the underlying flotation mechanism; namely, collision of hydrophobic particles and air bubbles generated in the pulp volume. The simplest and most basic model is the first order rate equation, in which the rate of flotation recovery is directly proportional to the material remaining to be floated, given in equations (5.1) and (5.2).

$$
\frac{d R}{d t}=k\left(R_{1}-R\right)
$$

where: $\quad R_{i}$ is the ultimate yield,

$t$ is the flotation time (minutes),

$\mathrm{k}$ is the flotation first order rate constant,

$\mathrm{R}$ is the yield at time $\mathrm{t}$.

or in integrated form, 


$$
R=R_{l}(1-\exp (-k * t))
$$

First order kinetics, which applies for many chemical reactions, has been assumed to apply to flotation kinetics. Since some flotation process might not be first order rate processes, several modified flotation rate laws have also been proposed [5.3-5.7].

In this study, it was observed that about 80 percent of the coal was floated during the first few minutes. When the process approached completion, flotation was very slow. Actually, coal appears to consist of fractions with differing flotation rates.

For a flotation process constituting $n$ species, where $n=1,2, \ldots n$, each having a different rate constant, equation (5.2) becomes in general form,

$$
R=R_{i}-\sum_{i}^{n}\left[\phi_{i} * \exp \left(-k_{i} * t\right)\right]
$$

Initially, it seemed adequate to consider the feed coal simply as consisting of two types of coal: the fast floating fraction and the slow floating fraction. The corresponding modified first order kinetic expression for fine coal flotation consisting simply of fast and slow floating components, both following the first order kinetics, would be,

$$
\left.R=R_{i}-\left[\phi * \exp \left(-k_{s} * 1\right)+(1-\phi) * \exp -k_{f} * t\right)\right]
$$

where: $\phi$ is the fraction of the slow floated materials,

$k_{i}$ is the flotation rate constant of the fast floated materials,

$k_{s}$ is the flotation rate constant of the slow floated materials.

The parameters in the above equation may be determined out by a non-linear curve fitting technique.

A proportional law of kinetics was proposed by Lai $[5.3,5.7,5.8]$ and used to analyze and interpret a multitude of kinetic phenomena. Examples of this equation's application have been given in fields as diverse as chemical kinetics, extractive metallurgy and froth flotation [5.3]. The proportional law states that the rate of flotation recovery is proportional to the material remaining to be floated, and is inversely proportional to flotation time. The mathematical form is, 


$$
\frac{d R}{d t}=K \frac{\left(R_{t}-R\right)}{t}
$$

Equation (5.5) assumes $\mathrm{k}$ of equation (5.1) varies inversely with time, or $\mathrm{k}=\mathrm{K} / \mathrm{t}$. The proportional law, while not based upon a clear mechanistic model, can serve to correlate kinetic data. In integrated form, equation (5.5) is

$$
\ln \left[\frac{1}{\left(R_{l}-R\right)}\right]=K \ln (t)+\ln (c)
$$

where $c$ is a constant of integration and it is an anchor point which gives the value of $1 /\left(R_{i}-R\right)$ at a time unit of 1 . The above equation should yield a linear log-log plot of $1 /\left(R_{i}-R\right)$ versus $t$ with a slope of $K$, when the process is in conformity with the proportional law. For valid experimental application of the proportional law, the data set must be complete, including points for short process times and for extended times. The objective of this study was to collect flotation kinetic data for fine coal and coal pyrite and find appropriate kinetics equations to quantify the results.

\section{MATERIALS AND EXPERIMENTAL PROCEDURES}

Three typical U.S.A. coals was selected for this kinetics study:

(1) Upper Freeport Medium Volatile bituminous Coal (MVb),

(2) Pittsburgh High Volatile A bituminous Coal,

(3) Illinois High Volatile $\mathrm{C}$ bituminous coal ( $\mathrm{HVCb}$ ).

Coal pyrite came from lumps of massive sulfur refuses obtained from Pittsburgh No 8 Seam from the Cumberland Mine, Green County, Pennsylvania. The analyses of these samples were presented at CHAPTER IV.

Flotation experiments were conducted in a laboratory batch flotation cell for the pyrite and three coals. The collectors were xanthate and dodecane. The particle size of each sample was $-100+325$ mesh. The concentrates were collected from 0.5 to 96 minutes. After each test, the froths were dried, weighed and cumulative recoveries calculated. In order to determine the constants in the kinetic equations, a numerical fitting 
method (NLF program) and graphic method were used. NLF basically is a computer program which automatically finds the parameters in the equation using a non-linear fitting technique. The graphic method plots yield versus time using different transformations.

\section{EXPERIMENTAL RESULTS AND DISCUSSION}

Flotation kinetics for Pittsburgh No. 8 coal and coal pyrite, with xanthate as collector, are presented in Figures 1 and 2. The coal has higher floatability and higher flotation rate than coal pyrite.

Flotation kinetic data for the three coals, using dodecane as collector are given at Table 5.1. The three kinetics equation evaluated by computer program in this study were: first order rate law, Lai's proportional law and the modified first order rate law. The kinetics parameters for the three coals are listed at Table 5.2.

\section{First Order Kinetic Equation}

First order kinetics parameters were found out by using computer program NLF. Comparison of the observed and calculated yields using first order kinetics are given in Figures 5.3 and 5.4. The first order kinetics equation always underestimates flotation yields at longer times and was concluded to be unsatisfactory.

\section{Proportional Law}

Figures 5.5, 5.6, and 5.7 present $\log -\log$ plots of $1 /\left(R_{i}-R\right)$ versus $t$ for Upper Freeport, Pittsburgh No 8 and Illinois No 6 coals. In all these cases the plots are straight lines. It shows that the completed fine coal flotation kinetics follow the proportional law very well for these test conditions. Observed and calculated yields are shown in Figures 5.8 and 5.9, showing good agreement. The proportional law of flotation kinetics was applicable over a very long time range.

\section{Modified First Order Kinetics Equation}

The results of the evaluation of the two component kinetics equation are shown 


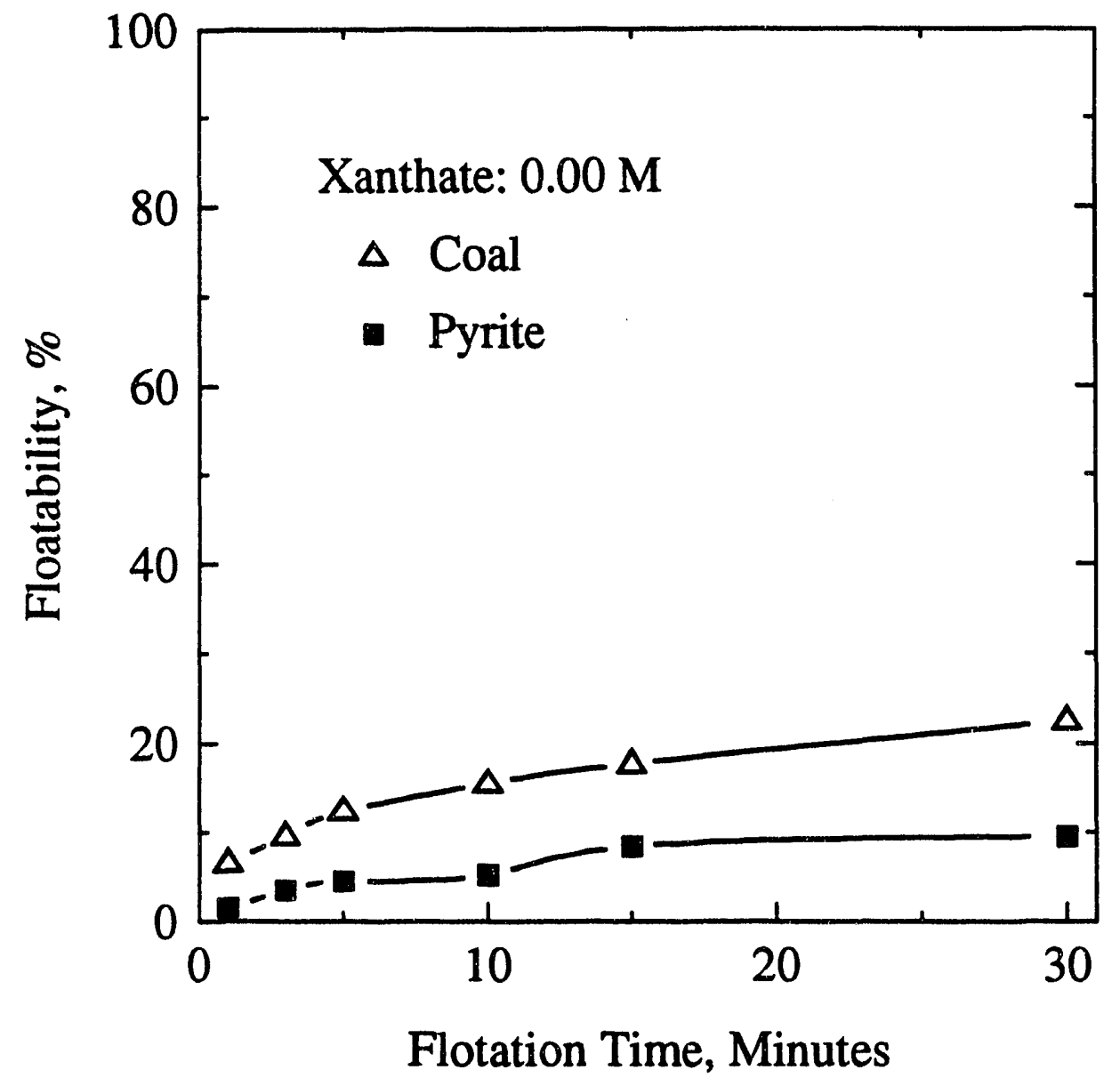

Figure 5.1 Flotation Kinetics of Pittsburgh No 8 Coal and Coal Pyrite Without Frother or Collector 


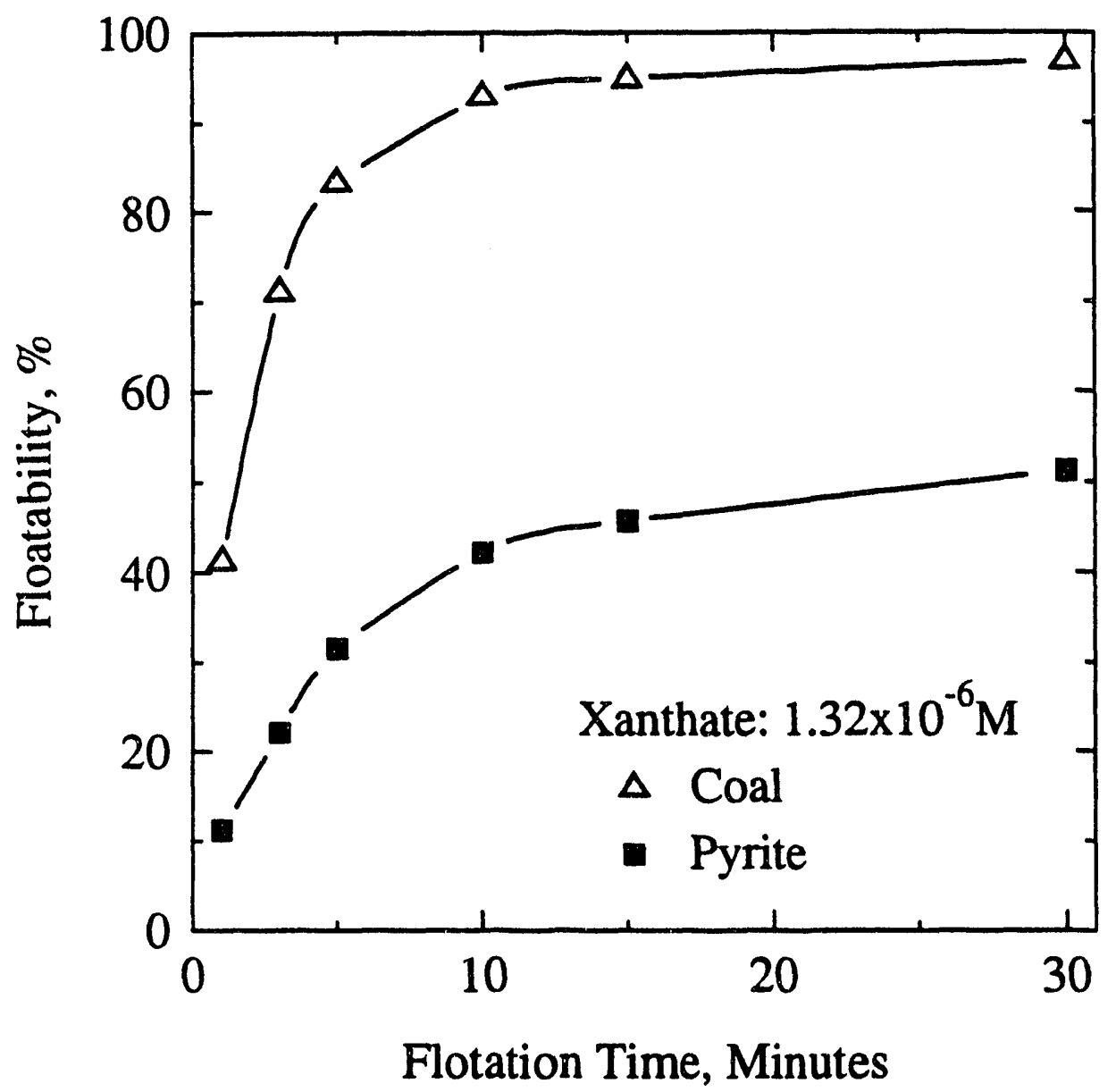

Figure 5.2 Flotation Kinetics of Pittsburgh No 8 Coal and Coal Pyrite With Xanthate as Collector 


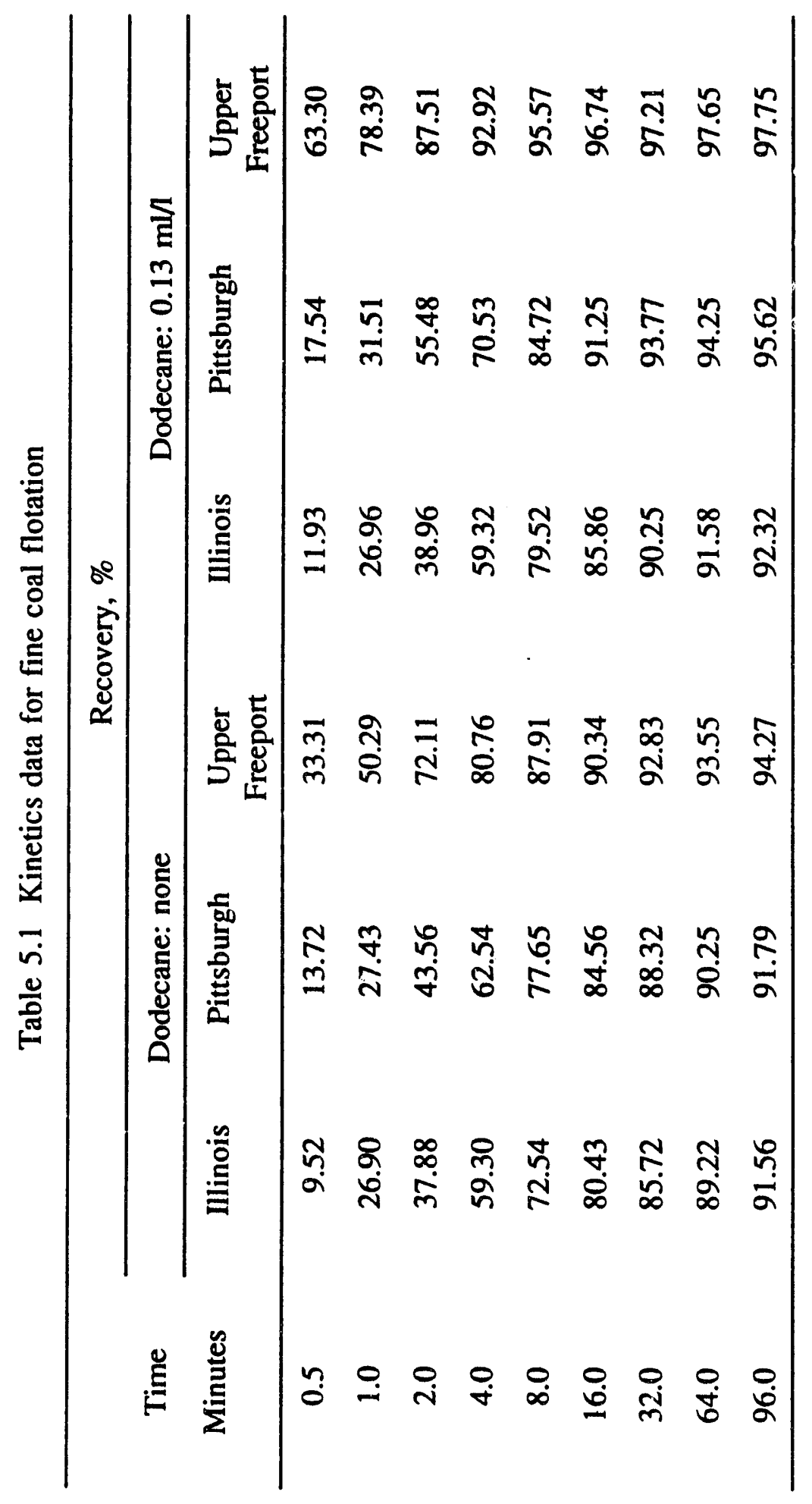




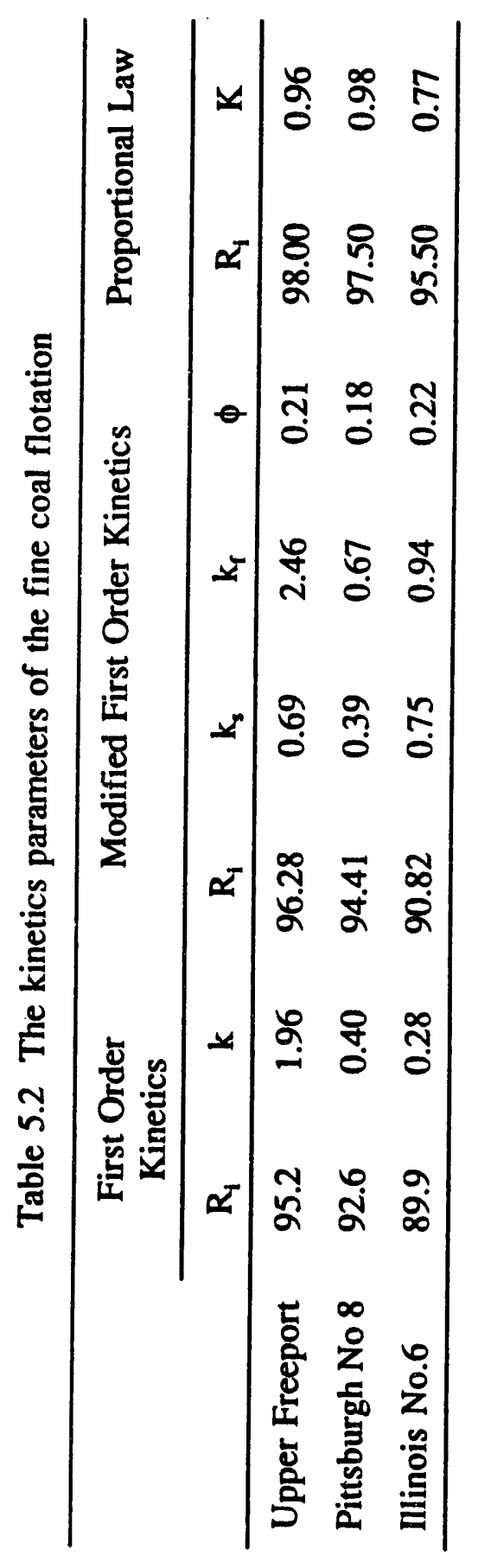




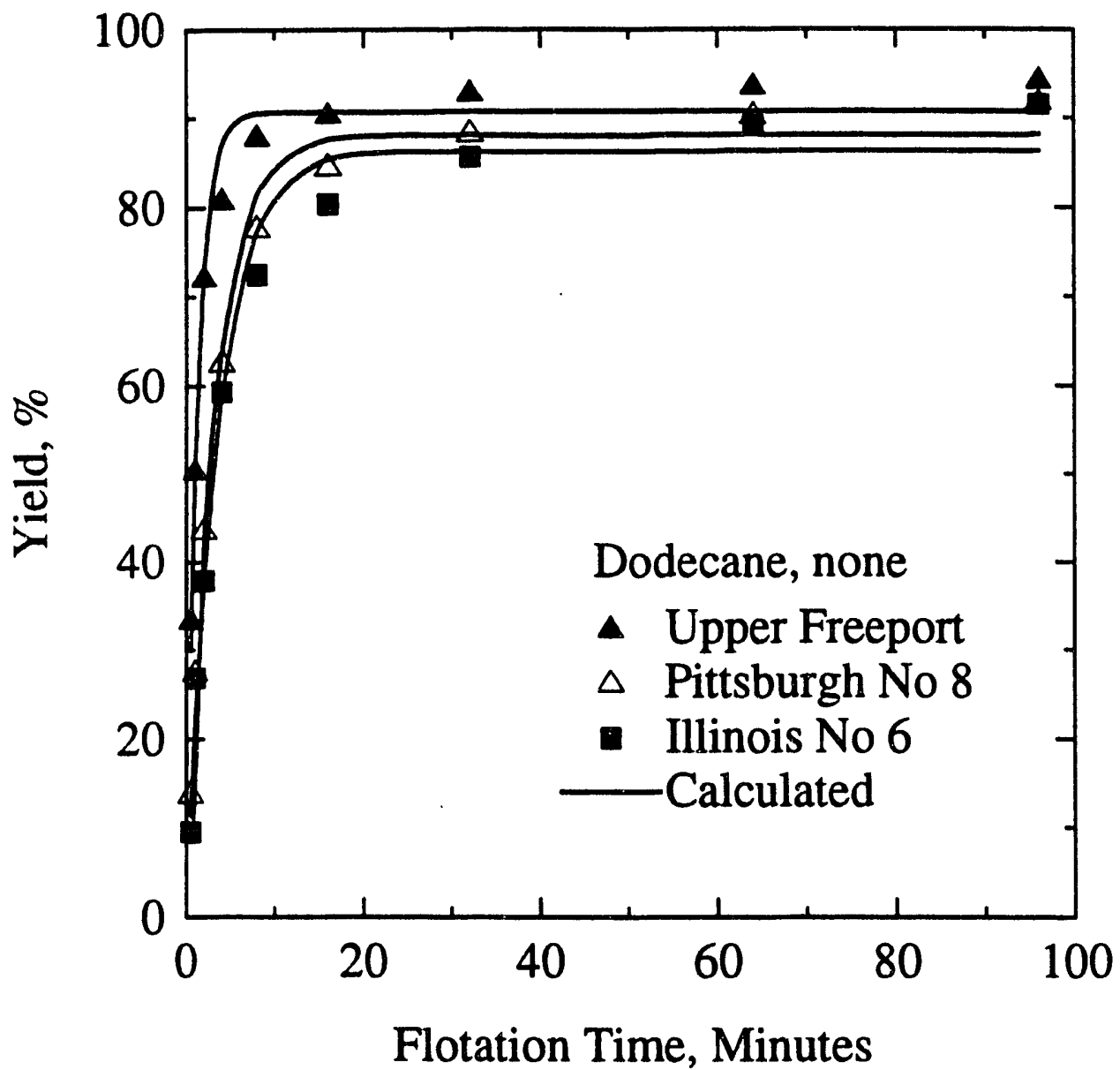

Figure 5.3 The Kinetics Evaluation Using the First Order Kinetics And without Dodecane 


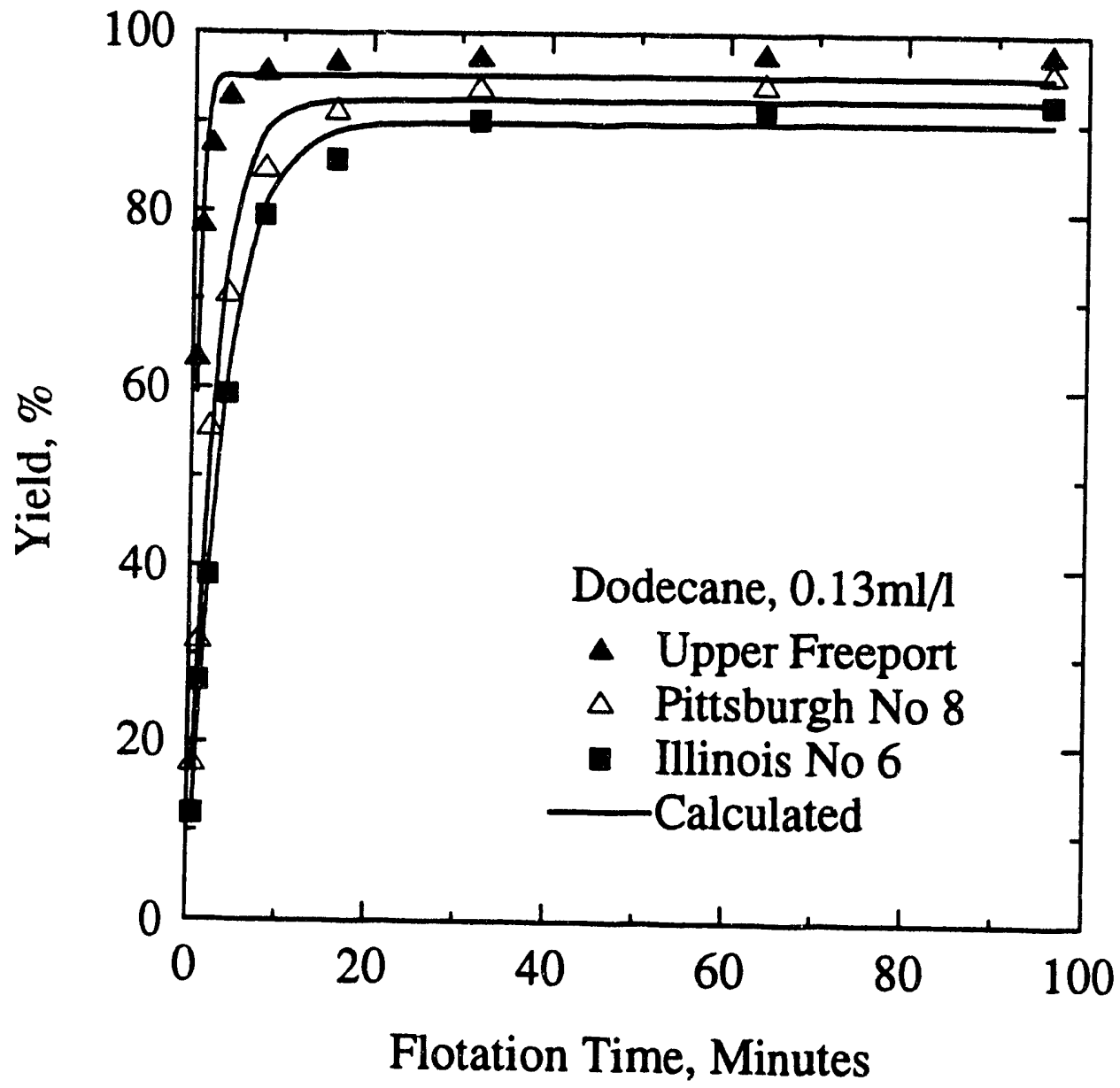

Figure 5.4 The Kinetics Evaluation Using the First Order Kinetics And With Dodecane 


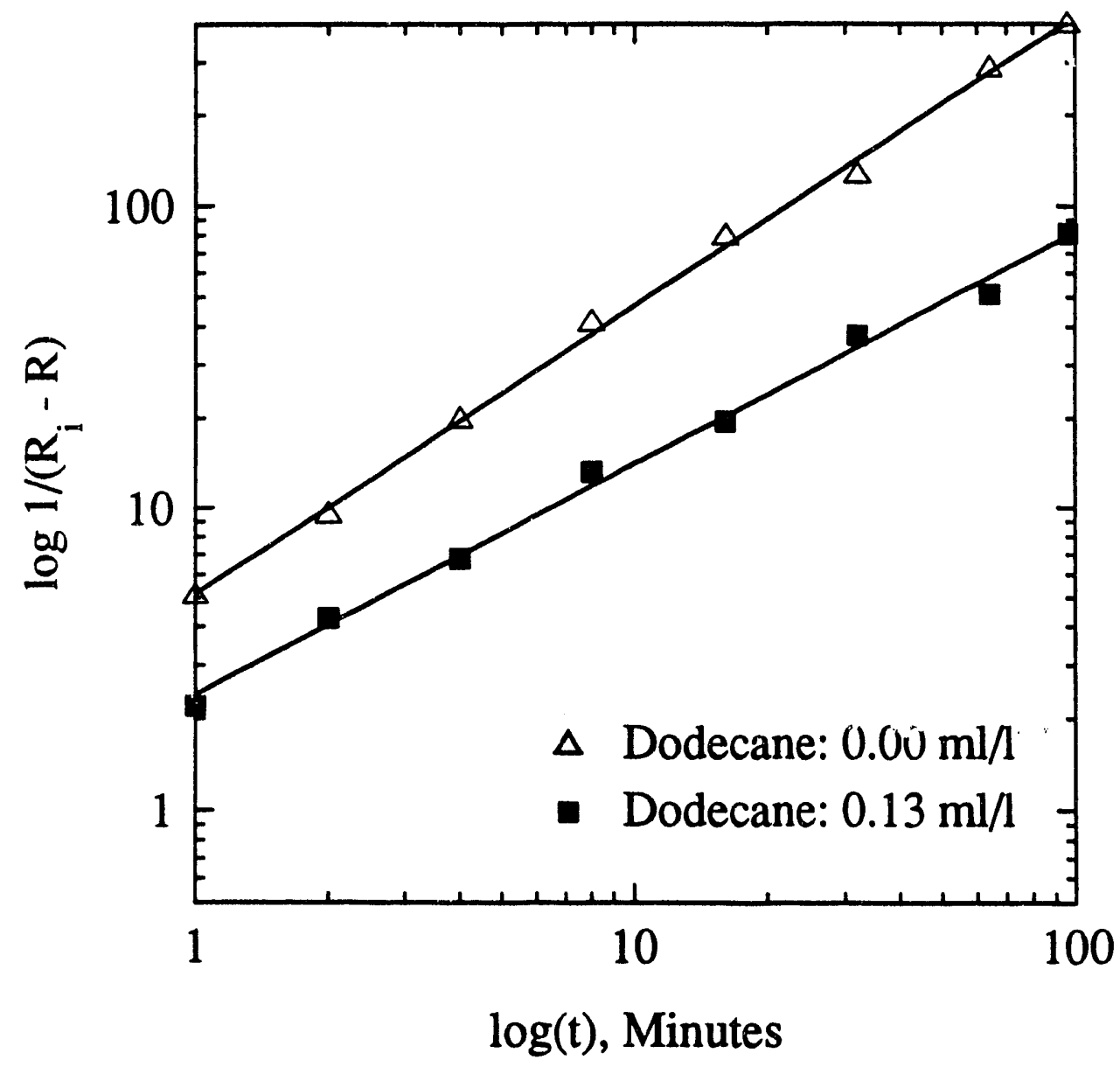

Figure 5.5 The log-log Plot of Flotation Kinetics of Upper Freeport Coal According to the Proportional Law 


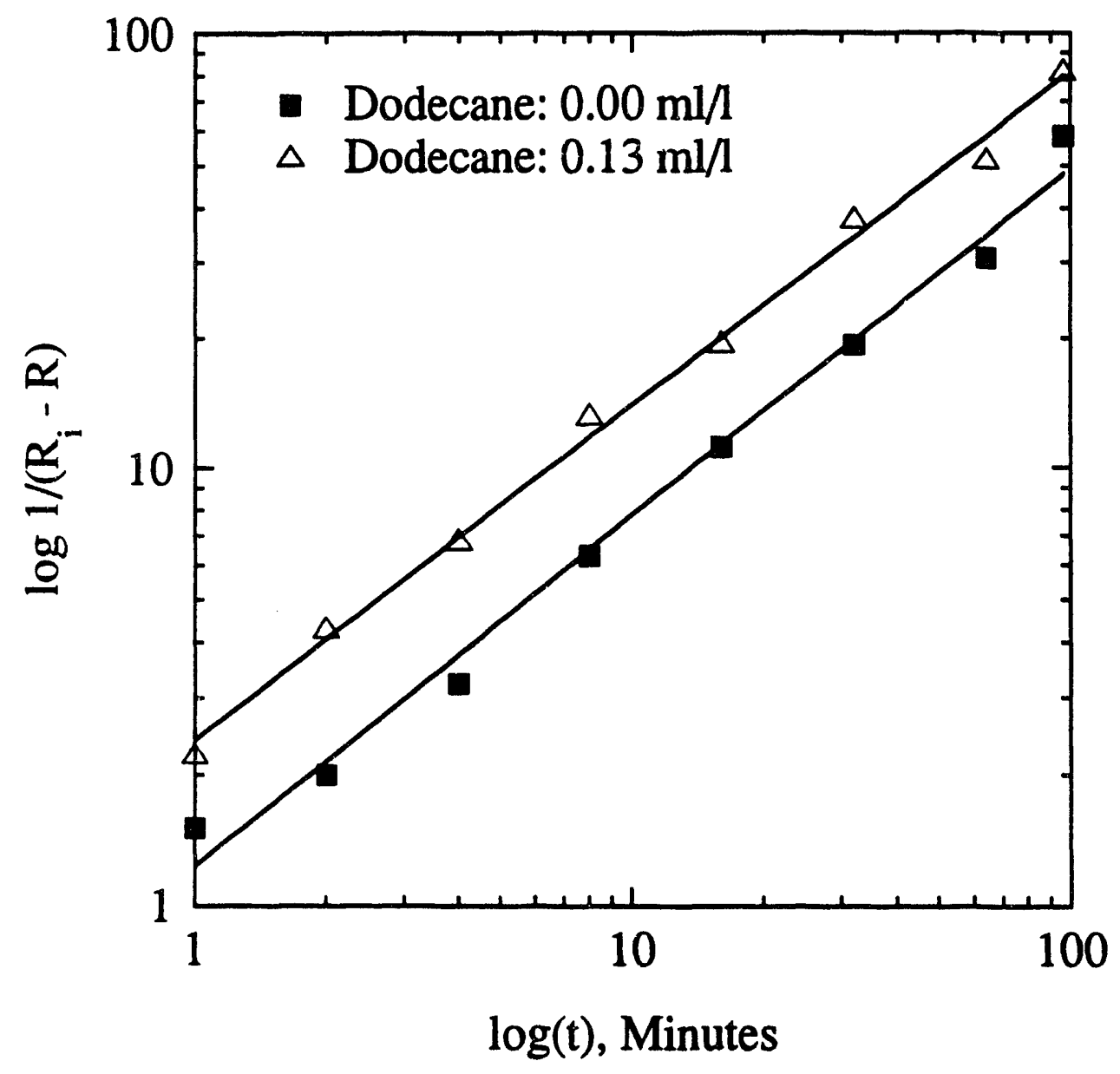

Figure 5.6 The log-log plot of Flotation Kinetics of Pittsburgh No 8 Coal According to the Proportional Law 


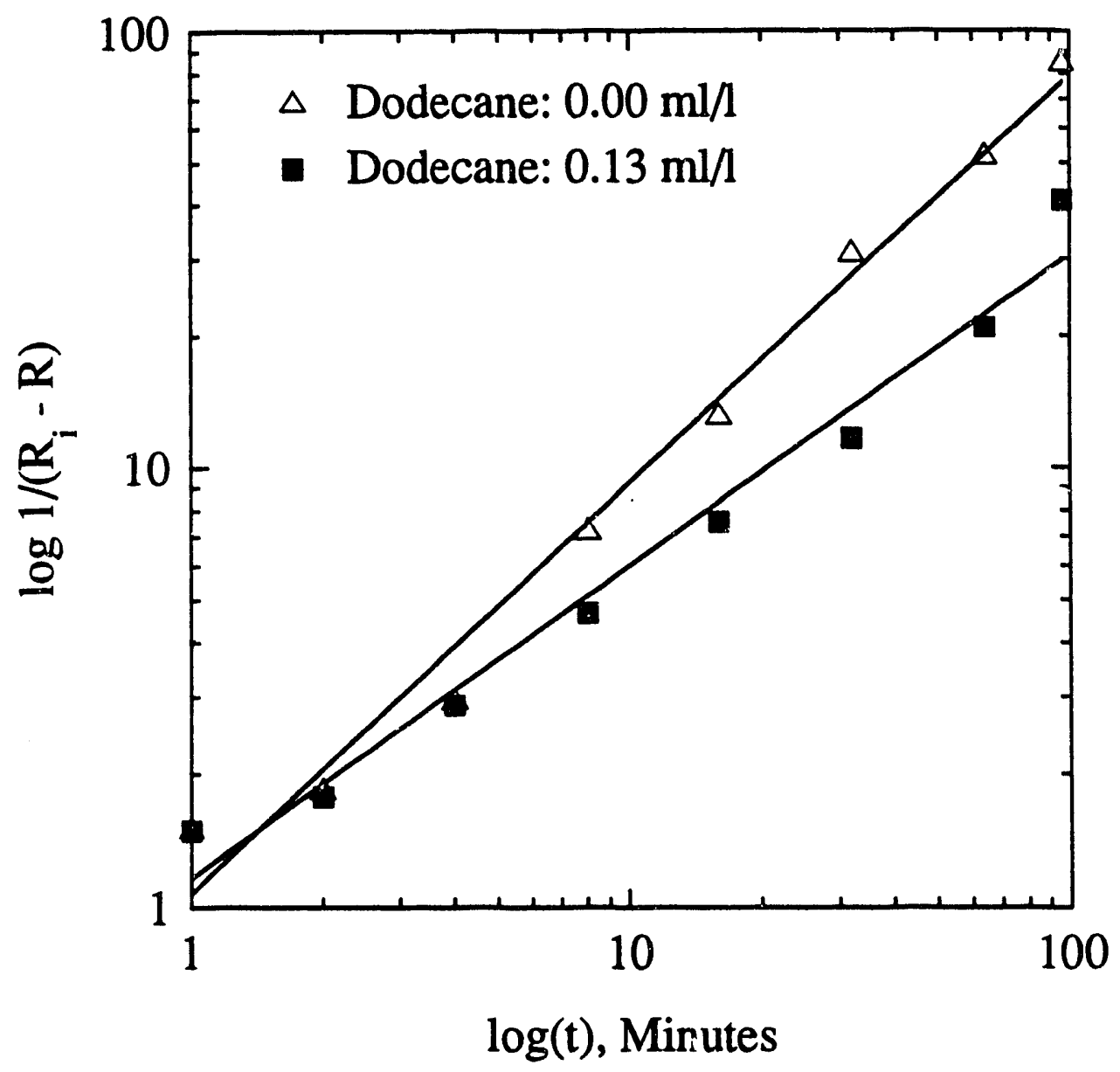

Figure 5.7 The log-log plot of Flotation Kinetics of Illinois No 6 Coal According to the Proportional Law 


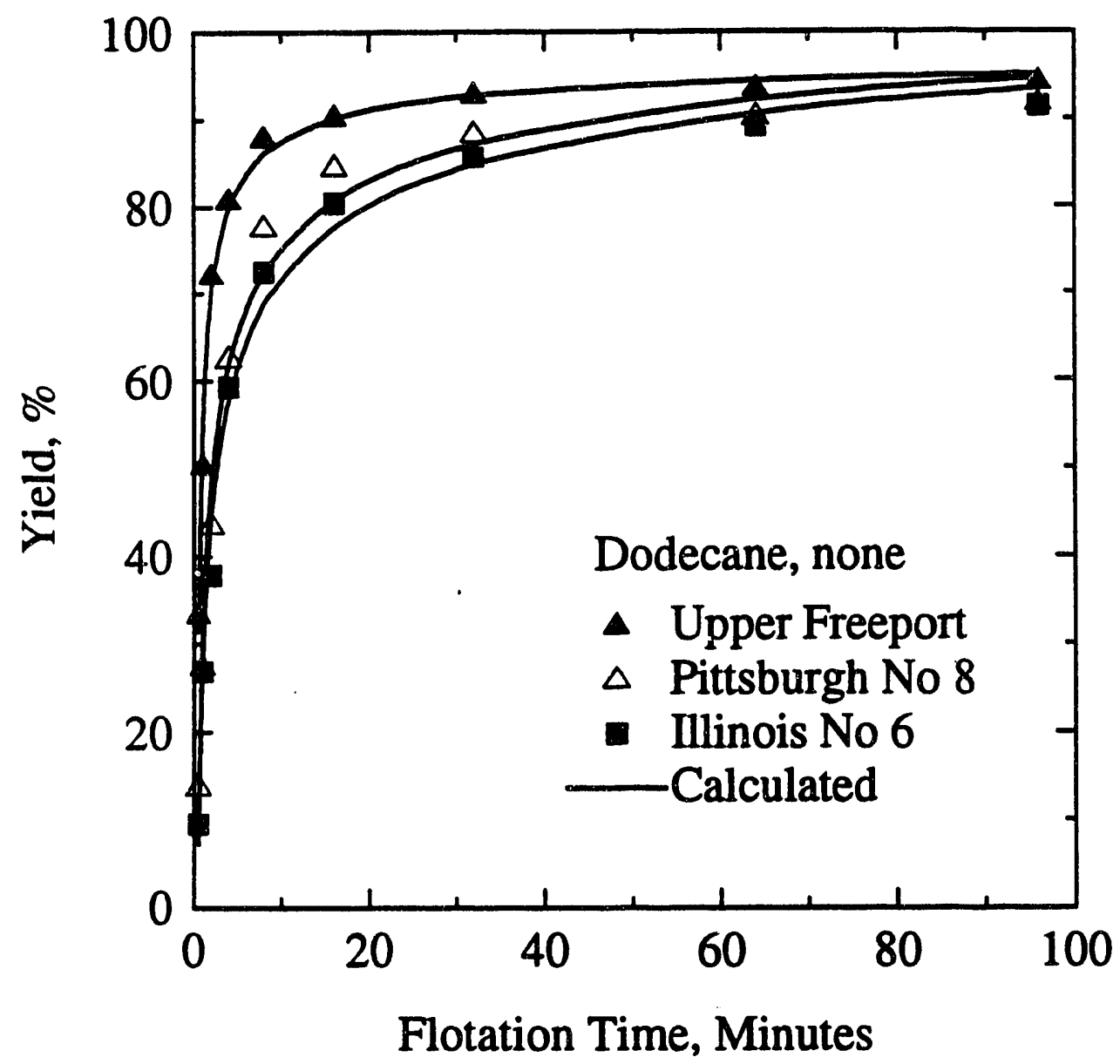

Figure 5.8 The Kinetics Evaluation Using the Proportional Law and Without Dodecane 


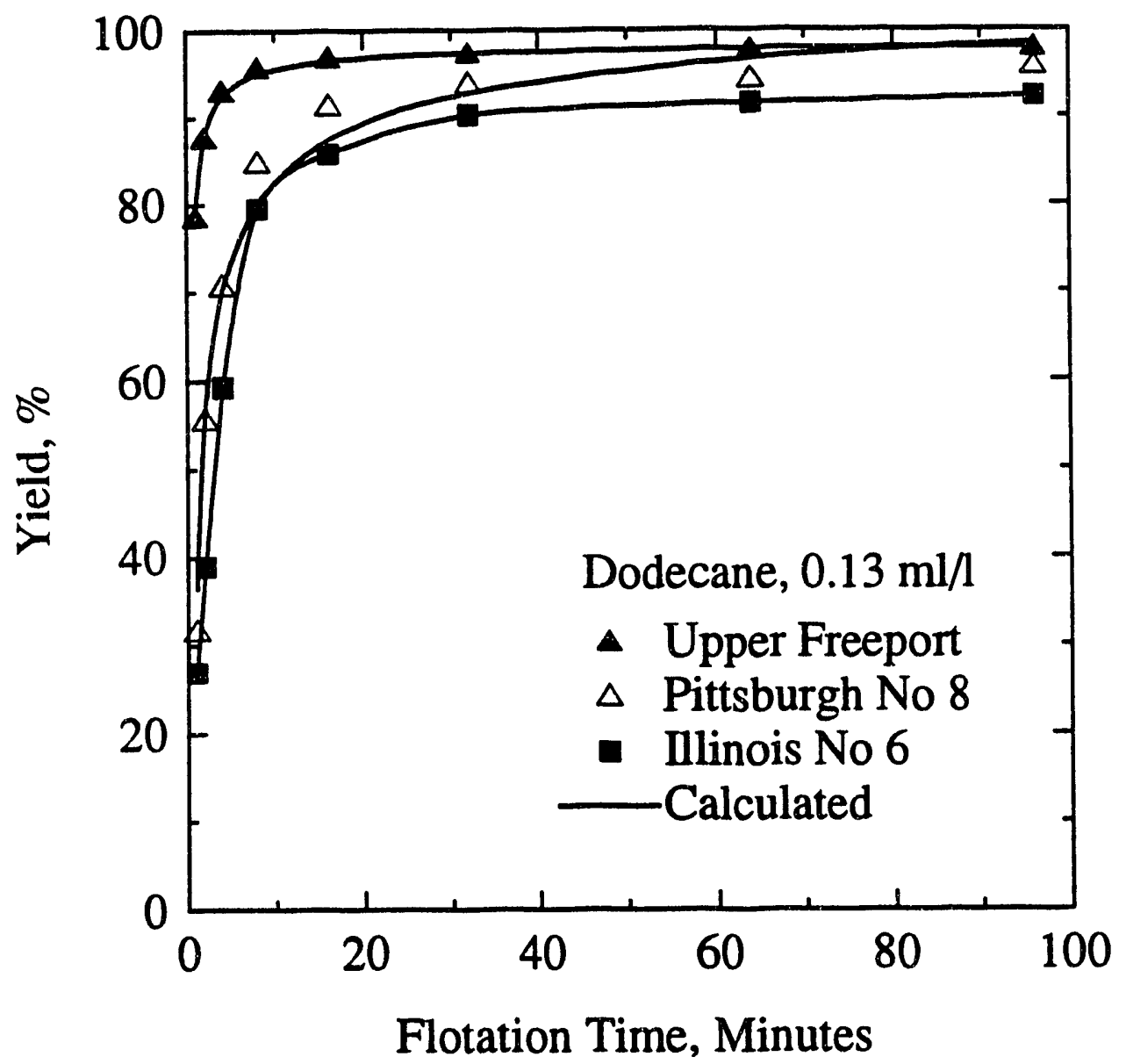

Figure 5.9 The Kinetics Evaluation Using the Proportional Law and With Dodecane 
in Figures 5.10 and 5.11. Observed and calculated yields were very close. This is an indication that the modified first order equation is a good approximation for fine coal flotation kinetics.

\section{CONCLUSION}

Pittsburgh No 8 coal has higher floatability than coal pyrite. The ranking of flotation rate constants for the three coals is: Upper Freeport > Pittsburgh No $8>$ Illinois No 6. The proportional law and modified first order kinetics equations were suitable for analyzing fine coal flotation kinetics. Simple The first order kinetic equations were unsatisfactory. 


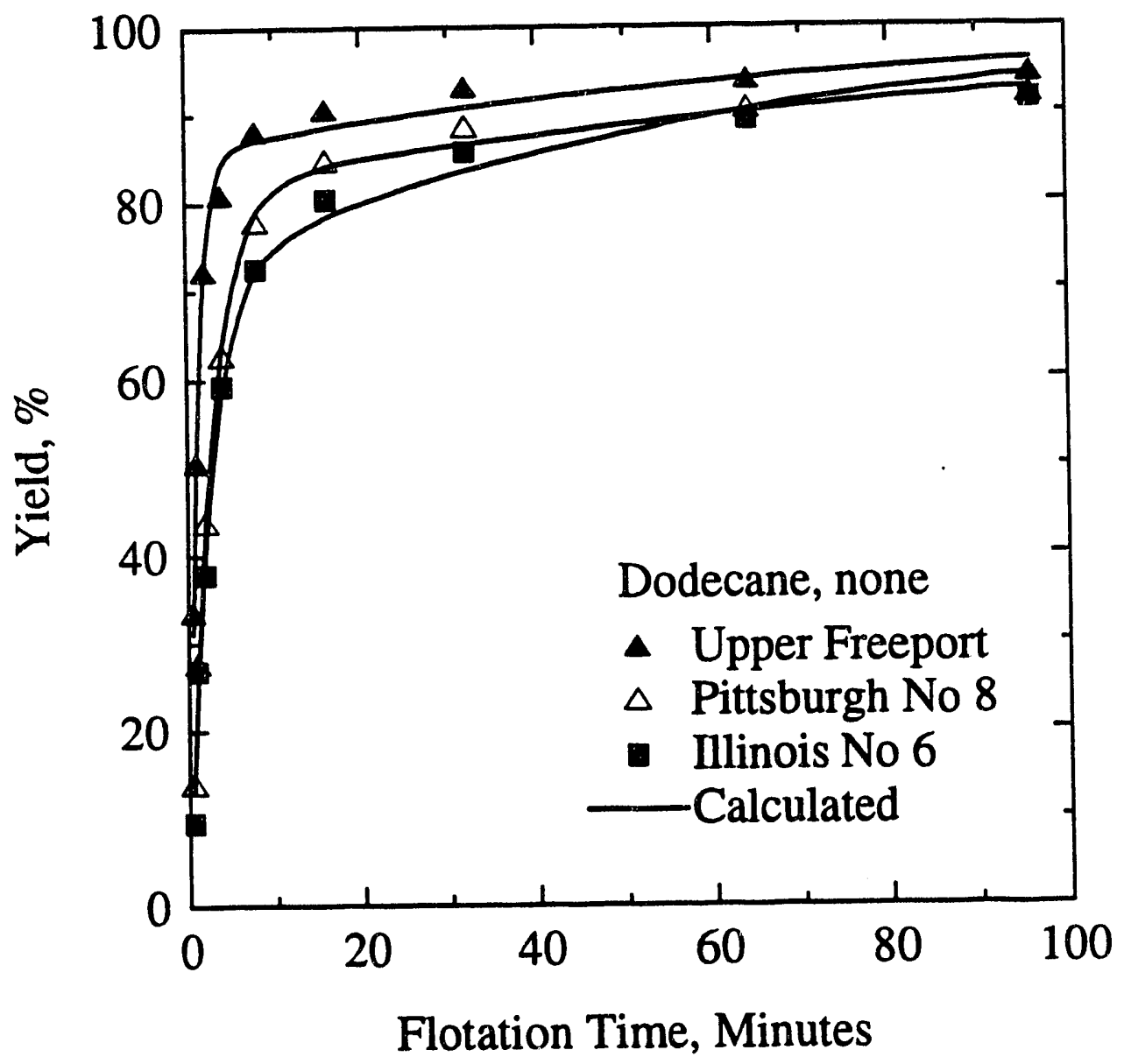

Figure 5.10 The Kinetics Evaluation Using the Modified First Order Kinetic Equation and without Dodecane 


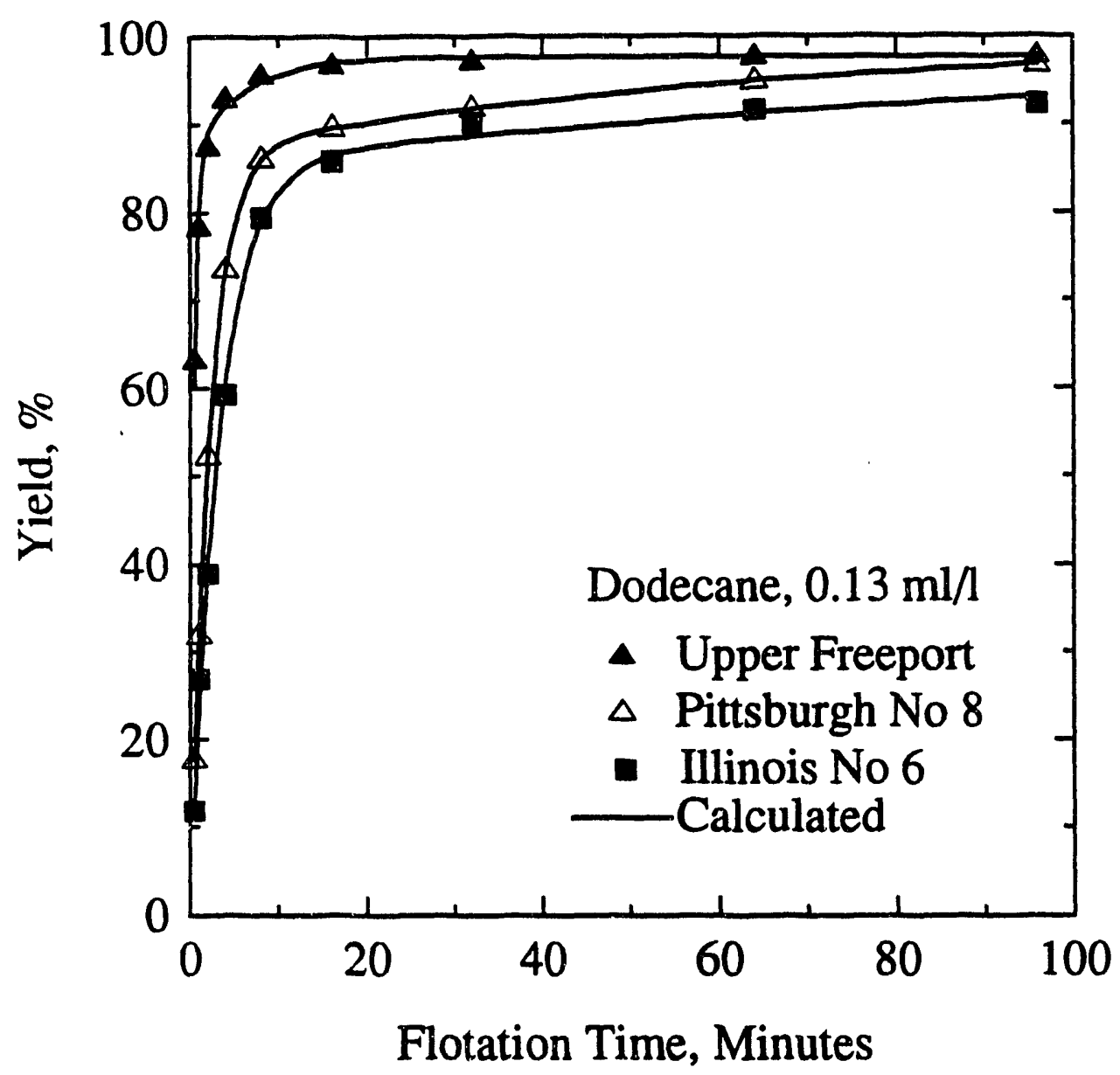

Figure 5.11 The Kinetics Evaluation Using the Modified First Order Kinetic Equation and with Dodecane 


\section{REFERENCES}

[5.1] T. K. Zhong, Q. P. Huang et al., "Flotation Behavior of Mineral and Coal Pyrite," Proceedings of Eighth Pittsburgh Coal Conference, (1991), 282.

[5.2] Annual Report No 2, (Project No DOE AC22-88pc88578, January 11990 to September 30 1990, presented by University of California, Berkeley, Columbia University and University of Utah to Department of Energy).

[5.3] R. W. Lai, The overlooked Law of Nature, (Toshi Company, Pittsburgh, Pennsylvania, 1990).

[5.4] R. P. King, "The Use of Simulation in the Design and Modification of Flotation Plant," (Gaudian Flotation Symposium, Annual Meeting of AIME, Las Vegas, February, 1976), 937.

[5.5] Huber-Panu, et al., "Mathematical Models of Batch and Continuous Flotation," (Gaudian Flotation Symposium, Annual Meeting of AIME, As Vegas, February, 1976), 87.

[5.6] E. C. Dowling, R. R. Klimpel, and F. F. Aplan, "Model Discrimination in the Flotation of a Porphyry Copper Ore," Mineral and Metallurgical Processing, (5) (1985), 87.

[5.7] D. F. Kesall, "Application of Probability in the Assessment of Flotation Systems," Trans Inst. Min. Met., 70 (1961), 191.

[5.8] R. W. Lai, "How to Obtain More Information Out of Flotation Data," Trans. AIME, 272 (1982), 1989.

[5.9] R. W. Lai, "Get More Information from Flotation Data," Chem. Eng., (10) (1981), 181. 

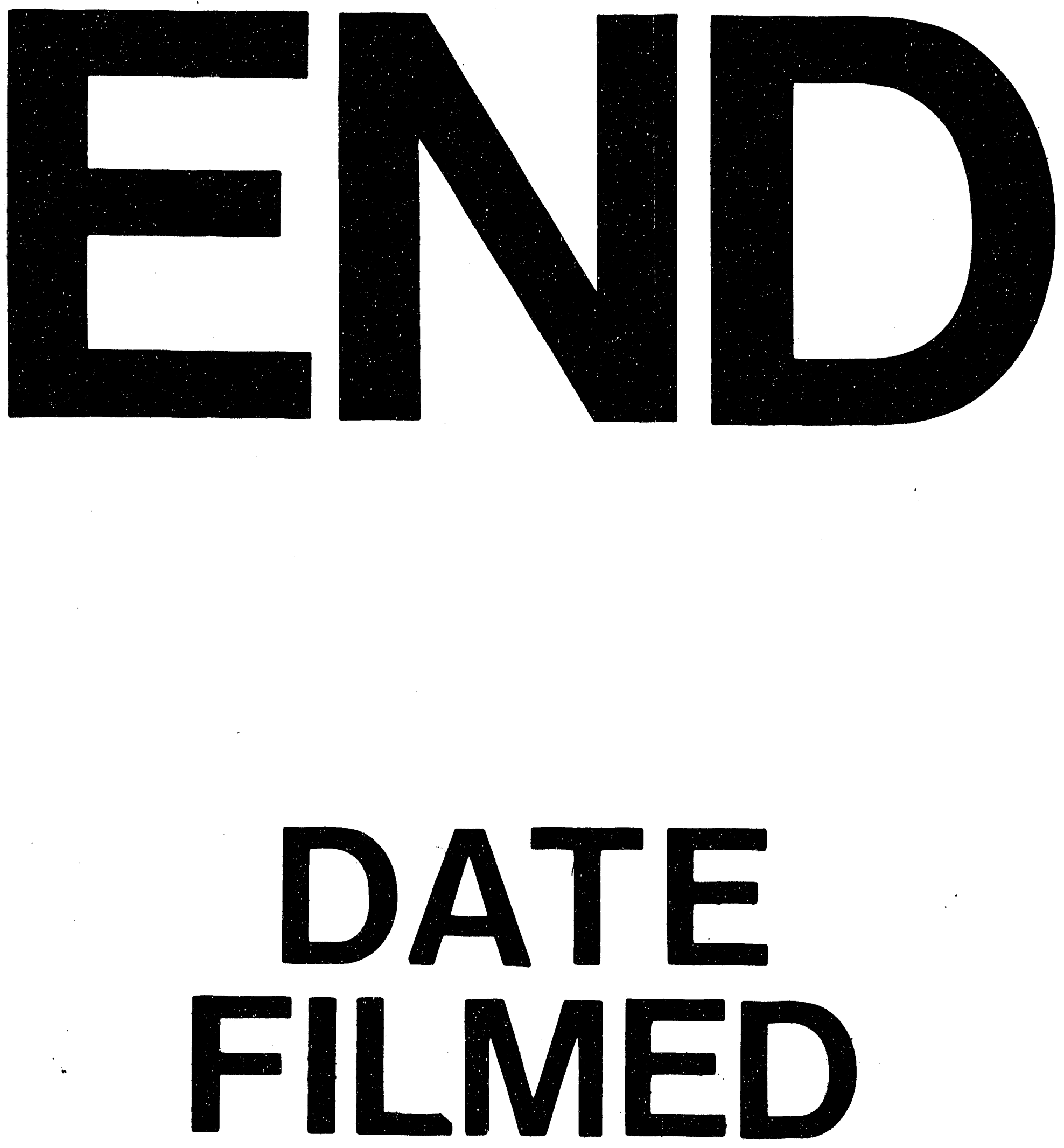

1

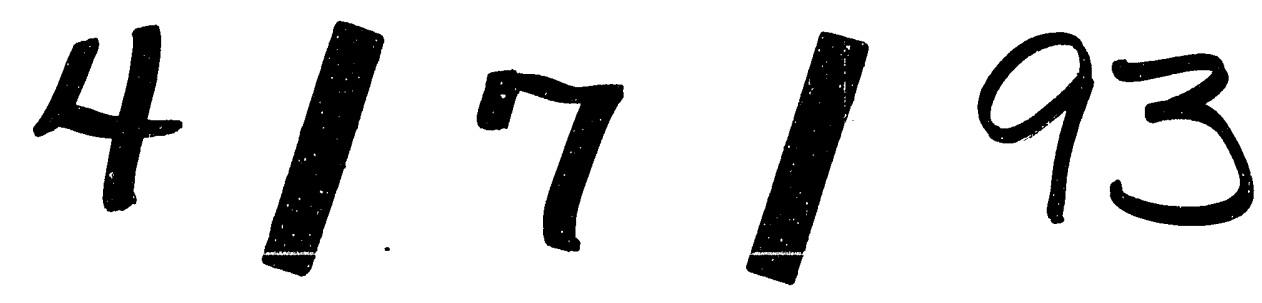


